


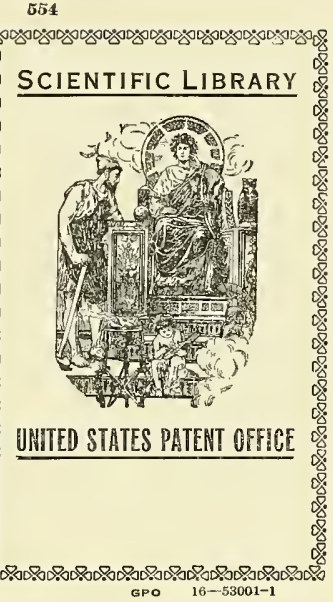





$$
\begin{aligned}
& -5 K \\
& 14
\end{aligned}
$$




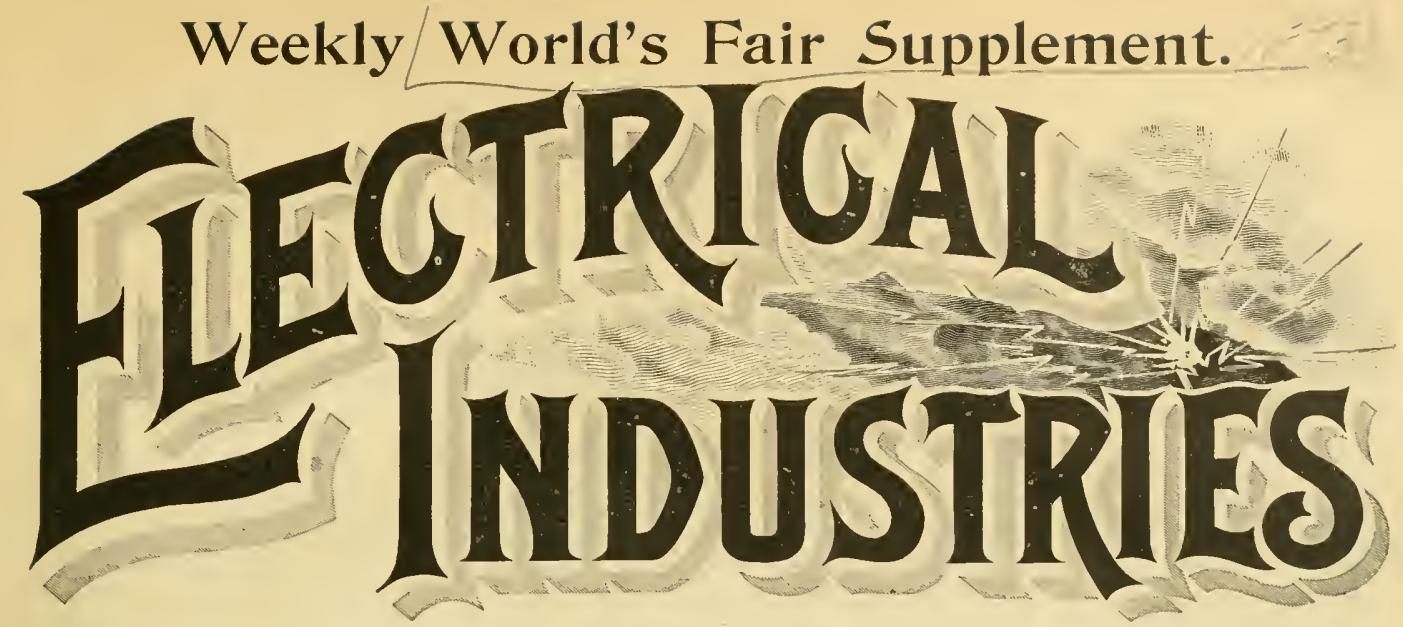

DEVOTED TO THE ELECTRICAL AND ALLIED INTERESTS OF THE WORLD'S FAIR, ITS VISITORS AND EXHIBITORS.

Vol. I, No, I. CHICAGO, JUNE 15, 1893.

TEN CENTS A COPY
FIVE MONTHS $\$ 1.00$

The Western Electric Company's Exhibit in the hind glass of rare color and design,together with the rapid Electricity Building. and mysterious changes in form and color has faseinated the beholder. The large column covered with hundreds Among the large number of exhibits in the Electricity of incandescent lamps of red, white and blue from the top

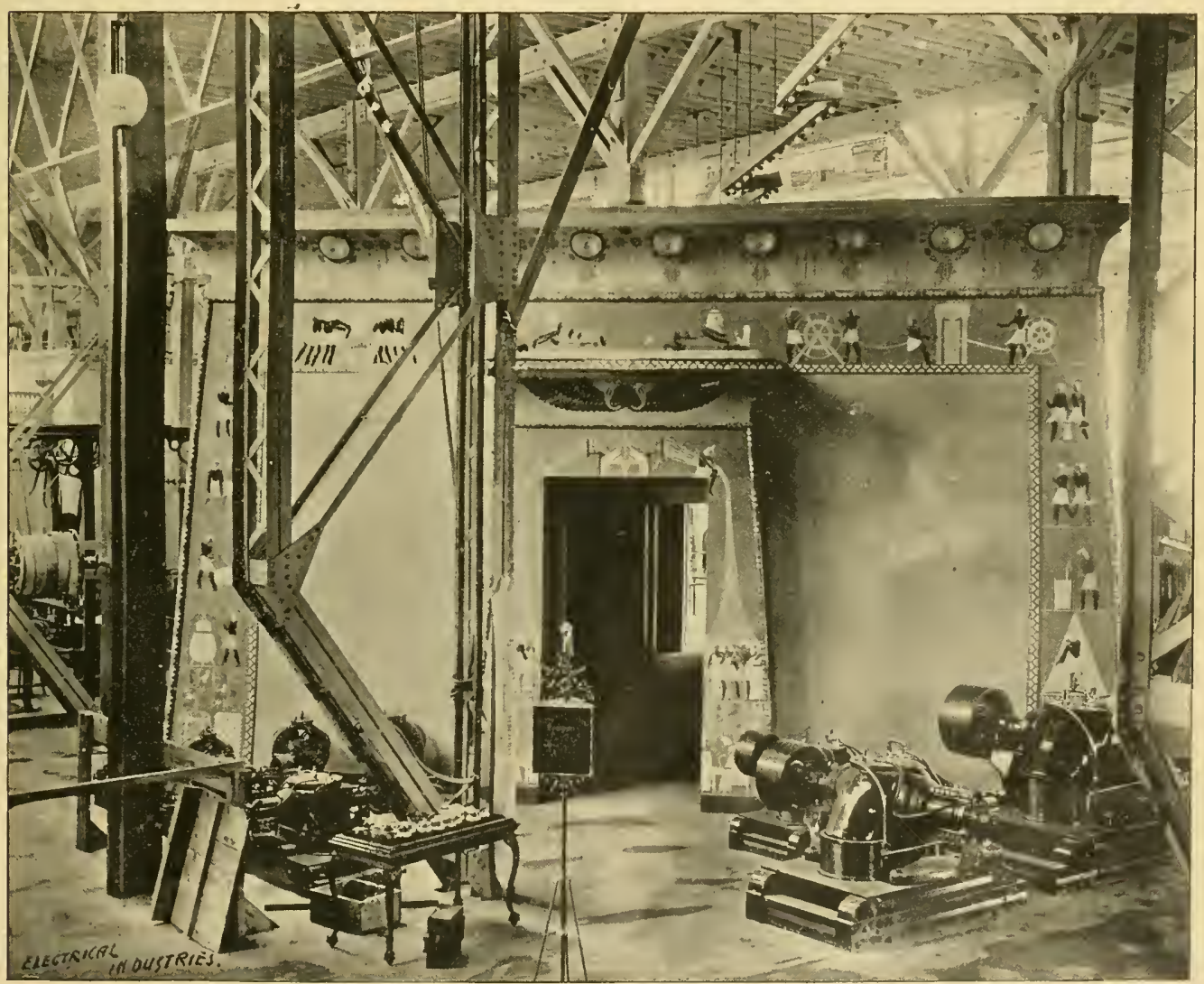

WERTLRN ELECTRIC COMPANY'S EXIHBIT-TIL EGYTTIAN TEMPLF,

building none has attracted more attention from all classes of which reach out four zig zag arms of colored lamps with of visitors than that of the Western Electric Company. globes at their ends also covered with colored lights, and The arrangements of lights, many of them concealed be constantly revolving, attracts constantly a crowd of visit- 
ors who watch the band of light rise from the bottom of the column to the top and then spread out over the arms to the globes turning first red, then white, then blue. The large automatic switch or commutator in the basement is especially of interest to those engaged in electrical pursuits. Its construction, the manner of making and breaking the contacts, the arrangement of the air blast which extinguishes the sparks, etc., are all very ingenious reaches it. This effect is produced by two cams at right angles and of suitable shape for producing the motion through racks and gears. Another ingenious device operated on the same principle is that in which an incandescent lamp on the end of a pointer is made to spell out the words Western Electric Co.

The Egyptian temple which has been erected for the display of telegraph, testing, and other small instruments

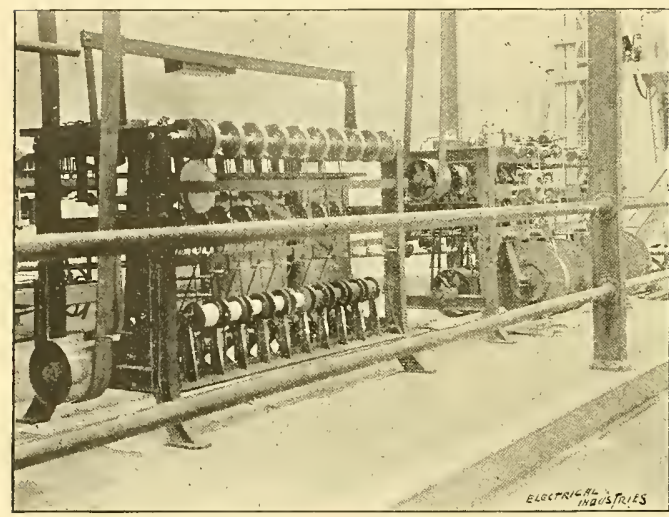

WESTERN ELECTRIC CO.'S EXHIBIT-COMBINATION COVERING AND SILK MAOIINES.

and interesting. A window has been placed in the floor orer this machine, and it is always surrounded by a crowd of curious people trying to understand its operation.

The large illuminated sign on which is the name of the company, and the eities at which are located its different factories is another attractive object. The letters are conposed of bits of colored glass set in the darker stained glass background, and the lourteen are lamps whichl are

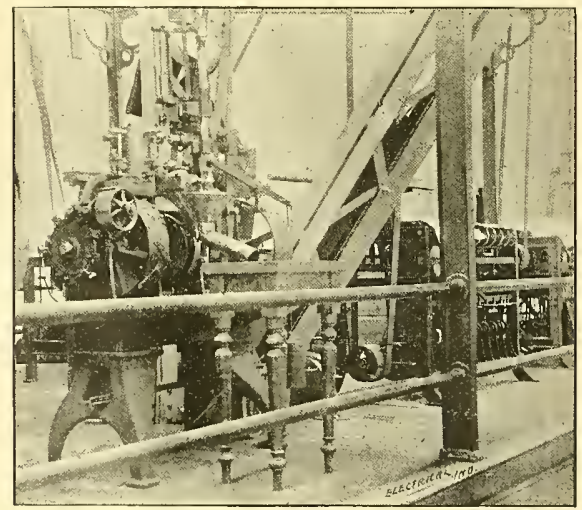

WESTERN ELECTRICAL CO.'S EXIIIBIT-AUTOMATIC SCREW MACIINE.

concealed within the sign are so morted by means of a motor that the letters on the sign have a spark!ing appearance which seems mysterious until explained. This sign is especially noticeable at night. Some unique features have been devised by the use of cams and gears in connection with electric lights. A cabinet surmounted with the large letters W. E. Co. in incandescent lamps of red, white and blue is made especially attractive by the lamps being lighted in rotation commencing with W. and a pointer on the top of the box at the back of the letters follows their outline and seemingly lights ench lamp as it

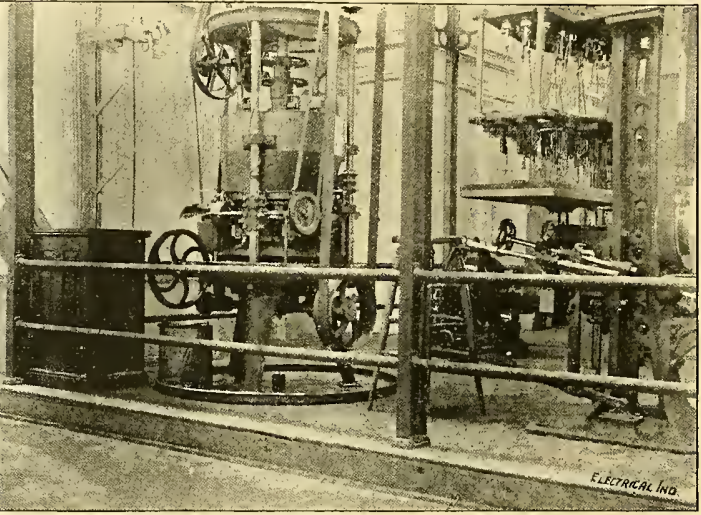

WESTERN ELECTRICAL CO.'S EXHIBIT-NUT AND MULTIPLE DRILL MACHINES.

and brass work is lighted entirely by lights concealed behind translucent glass of many colors. A large number of lights are arranged above the false ceiling of colored glass, and are somanipulated as to vary the light and render it mild and more pleasing to the eye. Columns of heavy green

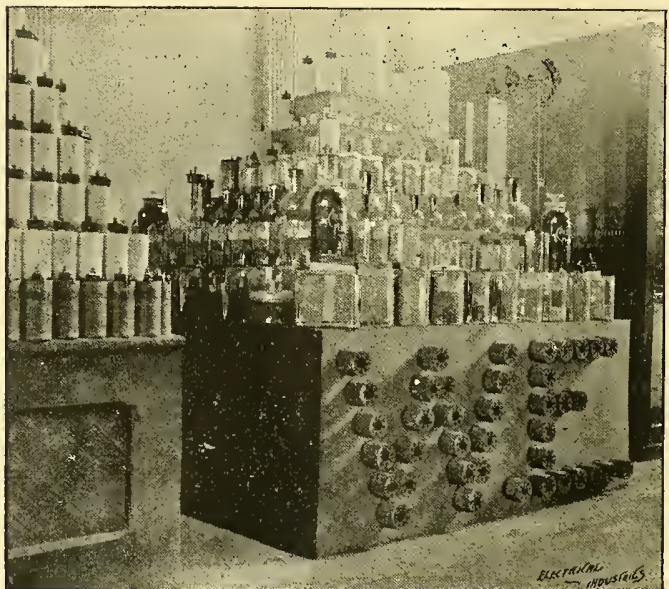

WESTERN ELECTRIC CO.'S EXHIBIT-RATTERIFS,

glass illuminated by incandescent lamps placed within them add to the effect produced by the other lamps. Plush lined cases sunk in the walls and lighted by incandescent lamps concealed above are filled with the various articles displayed. For the lighting of this temple between 1,100 and 1,200 incandescent lamps are used,700 of which are constantly burning.

An examination of the interior and exterior frescoing of the temple show forms and figures of Egyptian design illustrating the various departments of electricity. The lineman and wiremen are shown at work, the operation of 
the fire and police patrol systems as well as the operation of the telephone and telegraph are illustrated in these interesting decorations. The combination of the ancient figures with the various applications of electricity, the most modern force, is certainly unique. From the upper part of the walls light is thrown out through ground glass globes which add to the striking appearance of this tem ple. The wire for this building is laticl in interior conduit tubing and is easily accessible througl suitable traps in the upper part of the structure, and a switehloard is placed in the top for controlling the different eirenits of with no extra foundation ahove or below the floor boards and they are so well balanced that there is no vibration whatever.

Back of the motor-generator exhibit toward the main aisle is another enclosure with some representative machines designed and in use by this company to save labor. Among them is an antomatic nut-making machine, which from strijs of brass focl into it, cuts out a blank, stamps the comprany's name on it, faces it "u) on both sides, threads it and casts it out for inspection. Next comes a multiple drill press so arranged that any number of small holes up
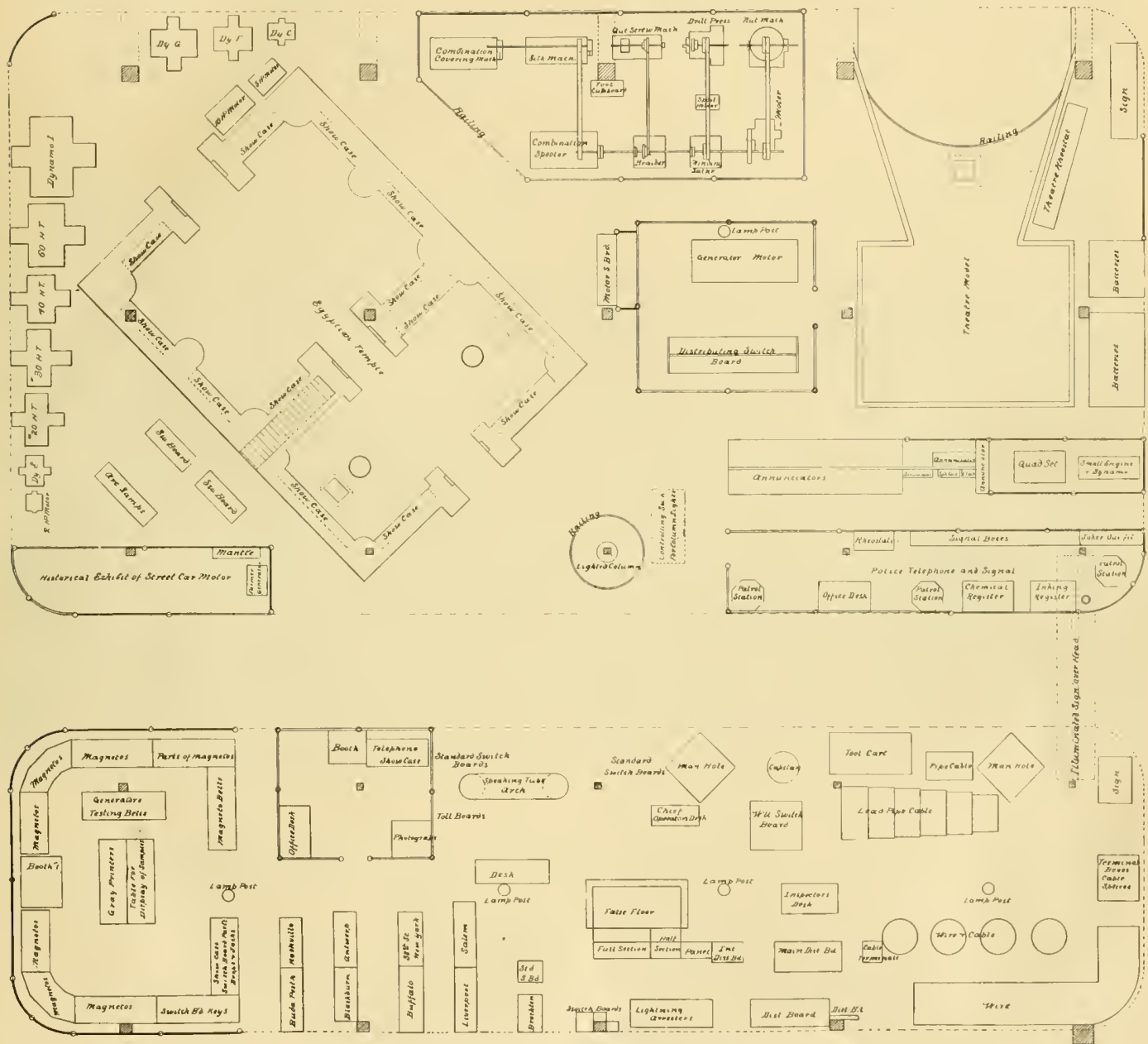

$s i d$
$s \& d$

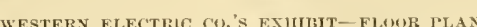

lamps. Leaving the temple by a northerly doorway the combination switchboarl of marble attracts the attention of the isitor. This board is equipped with the necessary switches and apparatus for controlling are lamps, incandescent lamps, and power or motor circuits and is a finely finished piece of work; in fact, the back of the hoard containing all the electrical connections is, contrary to the usual case, fully as well finished as the front side. In the same enclosure with the switchboard is one of the company's 120 ampere 220 volt motors directly connected hy a shaft coupling to a 240 ampere 110 rolt generator of the same type. The two machines are set on a common floor, to 32 in any position may he drilled all at one motion, by setting the drills once by jig. Another is a rery ingenions screw machine for turning smal] brass work. It is almost luman in its actions, anc is completely antomatic going through the various motions, cutting and even transferring a partly finished piece from one set of jaws to the other with an acenrtey which defies criticism.

Other machines are for insulating small wires with silk, paper ind cotton, and for twisting and forming different flexible cords. A machine for winding the armature for magneto bells is also shown. A miniature theatre has been built to the north of the machinery exhibit in which are 
shown in connection with a standing scene, the various effects of lights, changing from daylight to night and moonlight, making the complete cycle of the day. The operation of an electric lighting plant is neatly illustrated in miniature. On a stand of polished wood and enclosed in a glass case is shown a fine model of a three-cylinder engine complete with steam pipes, etc. Belted to this is a small motor, and on a bracket in the center is a group of six incandescent lamps, giving the appearance of a dynamo run by an engine and lamps burning from the current generated. The deception is quite complete as no wires leading to or from this stand are seen. The various dry and wet batteries made by this company are shown with all the parts going to make up the completed cells, carbons, zincs, porous cups, etc.

A large number of samples are shown of the hotel calls and annumeiators with all the accompanying equipment. A complete system of police patrol booths with eall boxes of various descriptions is also shown. Reels of wire large and small, for all classes and kinds of work, from the finest green silk covered magnet wire up to the many circuit lead to today. Statistical tables showing the growth of various exchanges and multiple switchboards are submitted for inspection. Samples of telephones made abroad at the Antwerp factory of the company are shown also, while magneto bells and telephones unassembled with all parts laid ont for inspection make a fine exhibit with reference to the amount of detail necessary for such construction.

A Hollerith electrical tabulating machine, as used by the United States and other governments, is exhibited, and it is expected that a sample of Lientenant Bradley Fiske's range finders will soon be; both of these machines being made for the inventors by this company. Among the historical exhibits is a sample set of the Gray printing telegraph which was just coming into use when the telephone came out and supplanted it. A model of an electric street car designed by the late Prof. Moses G. Farmer, in 1847, is also shown. It has batteries under the seat and is equip ped with proper levers for controlling the motor. There is also one of the original bi-polar motors, built at a very early date by Prof. Farmer. In a conspicuous place over this exhibit is a very handsome portrait in oils of the Pro-
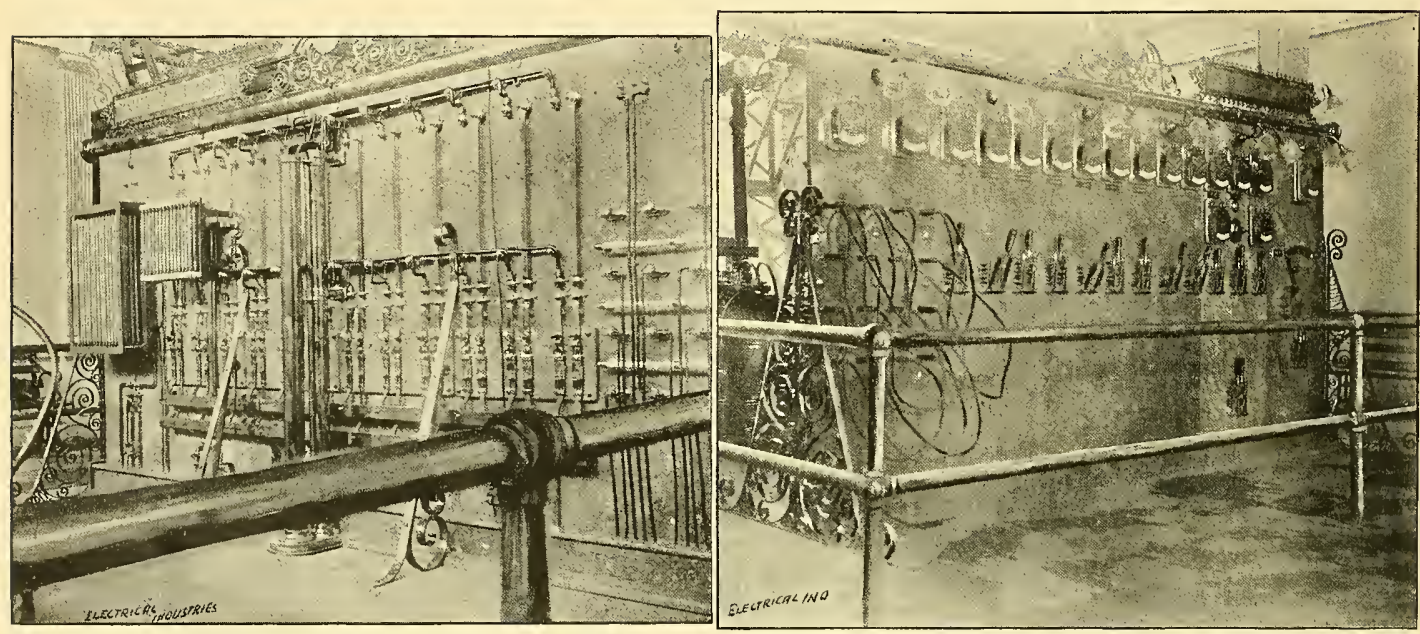

WESTERN ELECTRIC CO.'S EXHIBIT-COMBINATION SWITCH BOARD, BACK AND FRONT VIEW.

covered underground cable, are on exhibition. Two brick manholes for subways are shown with cables placed as in actual use, and the methods of drawing in and splicing are indicated in an excellent manner. The Western Electric Company, it may be said in passing, was the first to adopt the underground system and to develop it in proper form. Various types of telephone transmitters and receirers as made for the American Bell Telephone Company are shown, including the regular instruments, long distance sets and the various forms of desk sets now coming largely into use in large office buildings.

There is a fine historical exhibit of telephone switchboards, commeneing with one made in 1884 and taking in all the improvements, up to and including a section of the latest board now made for and used by nearly all the local telephone exchanges in the country. These boards are all connected up just as they would be in use, and where improvements have been made in the connections which were not radical enough to require a new board to demonstrate it, the diagram is on the back of the board showing the circuits in ontline. This permits of following each and every step of this branch of the business from the beginning up fessor made in recent years. One unique feature is a portal over the entrance of one section constructed wholly of speaking tube, showing the straight tubing and various curves; another is a coil of coppered iron rheostat wire spirally coiled and the spiral, over 200 feet in length, is festooned from post to post.

In the are lighting exhibit is shown a case containing the various small supplies used for that work, such as side brackets, insulators, switches, hanger-boards, etc.; an ornamented rack suspended from which are the various styles of are lamps made by the company; one of its standard are switchboards with marble face, and samples of each of the company's high tension are dynamos of $20,30,40,50$ and 60-light capacity. In connection with the large service plant of are dynamos in Machinery Hall is shown the Rudd ground alarm, used for detecting grounds in are circuits while the current is on. All the dynamos shown are set up on the regular wooden base and show fine workmanship in all parts. Samples of the Chicago City lamp post as designed and constructed by this company are on exhibition in its section, but are also to be found in actual use abont the galleries of the Electricity building. In the line of in- 
candescent dynamos, are samples of 110 -rolt machines of

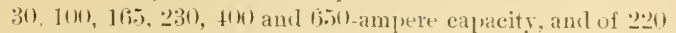
rolt motors, aside from the 10-horse power four pole motor used for driving the machinery exhibit, the company has samples of seren, 17 and 35-aupere four pole slow speed motors and the previously mentioned bi-polar nutor directly connected to the lighting generator.

Taken altogether this exhibit covers more ground in detail and classes of work shown than any other in the department. Comment on the nature of the work is unnecensary in connection with the well-known rejputation of this company and it only need be said that it is finished up to the high standard set by it. The comprehemsireness of the exhibit can be judged by the fact that outside of the time taken in designing and building the apparatus it has taken six months to complete its erection and installation. Hard and jersistent work has heen required by all hands

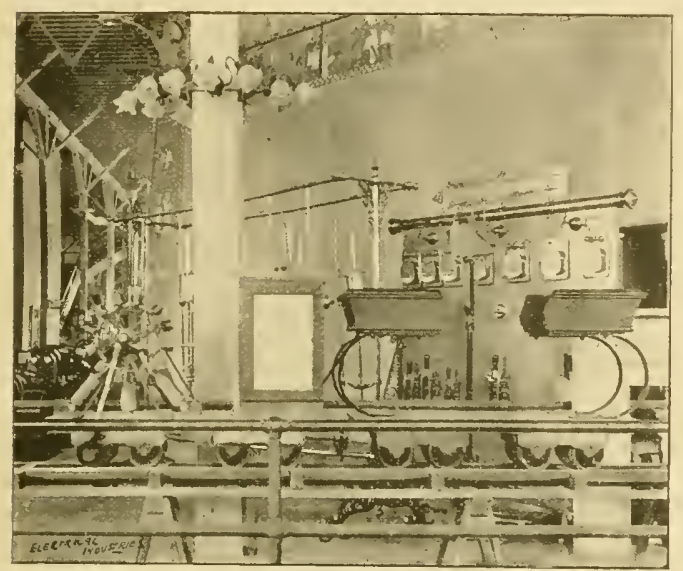

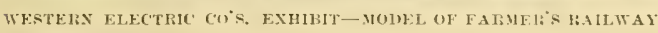
MOT, IR.

to overeone the difficulties that have beset work at the Fair during the winter, the elements and all else seeming to combine to prevent any hut the very slowest jogress.

\section{Search Lights at the Fair.}

The field in which the search light is used being limited but few manufacturers of electrical good- have grisen any attention to itsconstruction. At the present time the principal use to which it has been put is on river and excursion steamers, on the large ocean steamers and in the narr, and in at few cases large business and oftice buildings have been furnished with them for advertising jurposes. Of the three exhibitors of search lights but one is American, the General Electric Co., the others are schuchert a Co., of Nurmberg, and Santer-Harle d Co., of Parim.

Messrs. Schuckert id Co. exhibit four search lights with lenses respectively fire, four, three and two feet in diameter. These are placed at the four corners of the main roof of the Manufacturers and Liberal Arts building. ()nly two of them have been used so far, but the wiring is nearly completed for the other two, then all four of them will be seen the three nights of each week, on which the Fair is open. The largest of these lamps uses a carbon one and one-half inches in diameter for the positive and one incli for the negative. In the center of the positive carlon is a glass core, three-sixteenths of an inch in diameter for the better focusing of the arc. This light refuires $150 \mathrm{am}$. peres of current at $b(0)$ volti, and represents the lights designed for coast defense. In the manufacture of these lights great precision and exactness is required as well as excellence in the guality of the material uset. The reflector mut be of a certain shape and finely finished. The lense must be of a particularly elear glass earefully ground to the required shime to give the rays of Jight a parallel or slightly direrging direction. This company also exhibits in the Electricity Building a three-foot marine search light, a stanlard search light intended for wse in war on land. AH the lamjs maufactured by Schuckert of Co, areautomatically adjusted and controlled. Its lamps are all designed for war purposes. The beam from the largest lamp is estimated at 194 million candle power and has betn seen in Milwankere

The General Electric Company shows a rariety of search lights, some controllecl antomatically, others by hand. the arljustment bing automatic in all. The lights controlles automatically ean by setting suitable stops on the frame, be marle to swing automatically through any desirecl are without any attention. On the roof of Music hall is a light with a 30 -inch lens. In the equipment of the model battle ship Illinois, which was done by the General Electric Company are two 30-inch antomatically eontrolled lanpm. There are also two lamps of this type but smaller in the galleries of the Electricity Building for lighting the torer. An interesting part of the exhibit is a search light recotered from the $[$.S. S. Trenton that was sunk in the harbor at Samoa and was the first L. S. Man-of- War to be (cfripled with an clectrical plant. The company also shows a 1,000 canclle power focusing lamp for making b]ue prints or photographic printing.

Sautter-Harle d Co. show a „4-inch Nangin projector automatically adjusted and controlled electrically. The controlling apparatus is rery simple and ingenions. Near. ly all the naval search lights are provided with a double lens, the outer one being movable so that the direction of the rays of light may be changed so as to corer a small or large area as desired.

\section{Models from the Patent Office.}

The Goverument Building eontains a large number of articles from the patent office including a number of models of early electrical inrentions, among which is a model of a magnetic machine invented by Pixii in 1432 , an engine by M. H. Jacuhis in 1\$34, maguetic motor by Joseph Henry, an electric motor by Thos. Darenjort in 1 1337 , etc.; then the more modern models of Gramme. Sims. Farmer, Fuller, Weston, Brush, Eclison, Thompson-Houston and others. Besides these models of motors and dymamos there are also models of arc lamps, meters, welding machines, converters, telephone and telegraph apparatus. There is also shown in this building samples of the apparatus used by the [. S. Signal Corps, both the stationary and portable sets. Anong them is a light iron wagon holding all the ap paratus used in the field, with the wire wound on reels so that it may be quickly rum ont, all the batteries, instruments, ete., placed where they can he gut hold of to enable the complete line to be quickly put in working order.

The Standard Electric Company has at present twenty , o) light dynamos in operation daily in Machinery Hall. The company is also putting in two additional machines for the exclusive purpose of lighting the power plant. 


\title{
ELECTRICAL INDUSTRIES.
}

Entered at Chicago Postottice as second-class mail nuatter.

\section{ELECTRICAL INDUSTRIES PUBLISHING GOMPANY, INCORPORATEO 1839 . \\ MONADNOCK BLOCK, CHICAGO. \\ Teletrone Hartisox 159}

E. L. POWERS, Pres. axd Treas.

E. E. WOOD, SEcLETART.

\author{
E. L. POWERS, \\ H. A. FOSTER \\ W. A. REMINGTON, \\ E. F. TOOD.
}

EDIToN

- Assoctate Emitors.

FLOYDT. SHORT,

EAstern MaNager.

EASTERN OFFICE, WORLD BUILDING, NEW YORK. World's Fair Headquarters, Y 27 Electricity Building.

FIVE MONTHS, SINGLE COPY,

SUBSCEITTION

Àdvertising Rates Ūpon Application.

News items, notes or communications of interest to World's Fair Visitors are earnestly desired for publication in these columns and will be heartilr appreciated. Ite especiall $\mathrm{r}^{\circ}$ in rite all risitors to call upon u or send address at once upon their arrival in city or at the grounds.

Ionadnock Block, Chicago.

\section{Salutatory.}

The World's Cohumbian Exposition is recognized thronghont the world as the most important event of the day. Tol umes have already been written upon the beauty of itsarchitecture and its educational advantages to erery one interested in the progress of the times and still the Fair is anly now just fairly begun. Visitors are filled with wonder at what they see and go away satisfied that they have beheld the most marrelous exhibition of the lind erer held or is likely to be held for many years to come. The electrical and mechanical features of the Exposition, it is agreed, however, are among the most attractive and important of all, and the field of research for the electrician. electrical engineer and manufacturer is almost beyond comprehen sion. The growth, extent, and importance of the electrical industries is here fully shown and the phenominal development of these interests is a matter of which we may well be proud. Indeed without electricity the Exposition would fall far short of being the great success that it is. To gather in a comprehensive manner and put in acceptable form for the reader the vast amount of data here found is the function of the trade journal, and the task to say the least is not an easy one. The pressure upon the reading columns of our regular monthly issue has become so great that we have found it necessary to publish this weekly supplemental sheet of modest proportions. The mission of this paper will be to advance the electrical and allied mechanical interests of the Fair and at the same time be of interest and value to the visitor. With this object in view we present on another page a map of the city of Chicago, giving the name and location of the electrica] interests in the city. This map is to be in each issue, thus making it a permanent feature. On another page will also be found diagrams of the Electricity Building, giving the name and location of each exhibitor. This map likervise is to be a permanent feature and will, we helieve, be invaluable to every one visiting that building. The paper, in fact, is to cover an important field now existing and we have every assurance that our enterprise in thus serring our readers will be appreciated.

\section{WORLD'S FAIR NOTES.}

The electric pianos in the west gallery of the Electricity building furnish very enjoyable musie.

In the Freuch section of the Electricity buitling there is shorn a model of the Letrange process for the reduction of zinc by electricity.

On the evenings of August 24,25 and 26 , during the International Electrical Congress, public lectures of a popular character will be given by eminent electricians.

A. Groetzinger \& Sons, of Allegheny, Pa., show samples of gears and pinions for street car work of dermaghutine. This process of preparing raw hide for this work has been very successful.

The exhibit of the Excelsior Electric Company was nearly completed when Mr. Fuller decided to send a large amount of additional material whicln would make the exhibit better represent the factory.

Prof. Barrett is now preparing some very attractive electrical features which will be placed in the galleries of the Electricity building, which will, without cloubt, draw a crowd to those parts of the building.

The basins of the electric fountains are being boarded over on a level with the bottom of the spray eaps. This covering will conceal the pipes and other material, giving the fountains a more finished appearance.

The entire south wall of the Electricity building above the gallery has been for some days in the hands of the clecorators, who are preparing some very fine decorations under the direction of the Westinghouse company.

Both the General Electric and Westinghouse companies have made elaborate preparations for exhibiting the triphase systems and also the Allgemeine Electricitats Gesellschaft have several machines installed for that purpose.

The Page Belting Company, of Concord, $\mathrm{x}$. H., has a rery neat and appropriate booth erected on the main floor of the Electricity building. It is made up entirely of the well known link belting and makes a very attractiva display.

A number of changes are being made in the Bell Telephone Company's building, which will cause the building to be partly closed to risitors for a number of days, but when it is again opened the change will undonbtedly be appreciated.

Lieut. Spencer reports that when the exhibit of the General Electric Company is completed, there will be exhihits of Prof. Thomson's experiments with currents of very high tension. A regular program will be issued so people may know when the experiments are to take place.

The General Electric Company has just issued for the World's Fair a very handsome folder describing and illustrating its works and the most noteworthy central stations furnished with its system. The application of electricity to its many uses is also shown by numerous cuts, and the company's exhibits at various expositions are clescribed. It is a rery neat and interesting sourenir of the company.

When completed, the Tesla Multiphase exhibit of the Testinghouse Electric and Manufacturing Co., will be one of the handsomest on the grounds. The structure in the center of the space, painted cream color, tonched out with gold leaf and lighted brilliantly with incandescent bulbs and short ormamental are lamps is one of the finest yet built. Many of the features in this exhibit are entirely 
new and will prove of very great interest to electrical en gineers.

Although some of the exhibits in the various buildings are covered at night, and almost all the exhibitors leave the grounds at $60^{\circ}$ clock, enongh remains open for inspection to consume much time. It is a mistake that people are apt to assume, that little is to be seen at night. Many of the exhibits are seen to atvantage only at night, and this is especially true of many of those in the Electricity Building, the tower, the various illuminated signs and other curious features being well worth a special visit.

It is reported that Nikola Tesla will show some entirely new experiments in high tension currents in a room provided for the purpose in the Westinghouse section. The Westinghouse company are prejaring to exhibit various phenomena produced by currents of this nature. They will also show the working of the Wurtz non-areing lightning arrester for various voltages and will endeavor to produce by means of a Holtz machine all the phrenomena and eflects aceompanying lightning on alternating eurrents.

In the southwestern part of the Transportation Buihling, there is being installed a portable electric lighting plant, which is designed for use in war or for temporary lighting for any other purpose away from a central station. It consists of a heary wagon enclosing a gasoline engine with tanks holding a supply of fuel, a dynamo of the Manchester type, and ten are lamps hung on a portable frame with a spool of well insulated flexible conduit for each lamp. When completed this exhibit will undoubtedly be very interesting.

The cable for feeding the lights on the buoys for marking a safe way between Van Buren street pier and the pier at the Worll's Fair grounds for boats will be laid this week. The course is now marked out with white spar buoys, where the lamp buoys will be located. Commander J.J. Brice is pushing the work as fast as circumstances will permit. Mr. Ira W. Henry, the electrical eugineer, and Capt. Marks, superintendent of the Bishop Gutta Percha Co., are to lay the cable. Mr. Frank Marks will make the comnections and look after the details.

A large and very comprehensive exhibit of the University of Illinois in the Illinois Building at the Fair includes many excellent and interesting features, especially from the department of electrical engineering and physics, in which are shown apparatus and instruments with photographs of the machinery used in its lahoratories. The exhibit is in charge of Prof. Crawford who invites inspection of the school's work and facilities. It is his intention at the close of the school year to have stuclents clo practical test. ing with the apparatus during the day to more fully illustrate the instruction given in the University.

\section{PERSONAL.}

Mr. Gisbert Kapparrived in Chicago June 1st.

Mr. Waddell, of the Waddell. Entz company, is in the city.

Prof. Elihu Thompson registered at the Hyde Park Hotel last week.

Mr. E. Wilbur Rice of the General Electric Company was in Chicago visiting the Fair last week.

Mr. H. D. Fuller, president of the Excelsior Electric Com pany, was registered at the Auditorium last week.

Mr. W. II. Knight, superintendent of the railway department of the Lynn factories was in Chicago last week.

Mr. J. R. Lovejoy of the Boston office of the General Electric
Company has just returned home after a hasty trip to the Fair. He will make a more extended visit later in the season.

Mr. 11. MeL. Marding lately with the Westinghouse Company, is registered at the Auditorium, and visiting the Fair.

Mr. George Cutter has gone east for a brief trip in the interest of some of his specialties which he is exhibiting at the Fair.

Captain IV. L. Candee of the Okonite Company, Ltd, is spending a few days at the Fair looking after his exhibit which has been delayed by the press of work at the factory.

\section{BUSINESS NOTES.}

The Mather Electric Company is enlarging its factory at Manchester, Conn., by the addition of a new $100 \mathrm{ft}$. building.

Tile Cilcago Insulated Wrre Co., Chicago, has recently added to its power plant in the factory at sycamore, Ill., a 100horse power engine and boilers. The factory is now in shape to fill all orders promptly.

THF: WARIUX STREET RAIITAY COMPANY has commenced work on the line from Marion, Ind., to Gas City, via the Soldiers Home. The overhead fixtures and attachments are being fur. nished by the Ansonia Electric Company.

THE J, Il. \& D LAKE CUNIPAY, manufacturer of all kinds of friction clutch pulleys, has just removed from its old quarters at Hornellsville, N. Y., to new and larger shops and foundry just completed at Massillion, Ohio, where the company will have better facilities for handling its increasing trade.

Tue Great Western Mantfacturing Company, 201-30" South Canal St., in its monthly bulletin for June gives lists with prices of the standard supplies and specialties, for which this company is so well known. The new fixture catalogne will be ready for distribution within a very few days.

Bartnolomew, STow \& Co., Chicago, selling agents for the $11 \mathrm{cNutt}$ Incandescent Lamp have had some difficulty in getting a sufficient number of lamps from the factory to fill orders promptly, but they now state that arrangements have been perfected so that all orders will receive immediate attention.

Mr. J. H. CrATES is now manager of the western department of the Waddelt-Entz Company, of Bridgeport, Conn, with a temporary office at 1122 , until the offices 1139 and 1140 are ready for occupancy, Monadnock building, Chicago. Direct coupled lighting and railway generators are made a specialty of by this company.

The Buckere Exgine Compant, Salem, Ohio, has a very fine exhibit in the large 1,500-horse power engine in Machinery hall running one of the 10,000-light Westinghouse dynamos. This engine has run very smoothly since it was started, and has given good satisfaction. There are also five other smaller Buckeye engines exhibited ruming dynamos.

The Ansonia Electric Companx, Chicago, reports that the old Nunbeam incandescent lamp finds a ready sale, as the former buyers gave it the preference as soon as they learned it was in the market; that favorable reports are coming in from the users of tho IV-IV lightning arrester, and that it has just shipped a large order of shield brand wire to Iowa.

The Cential Elecitilc Company, 115 Franklin St., Chicago, is furnishing the Sentinel building, Milwaukee, Wis., with conduit and fittings, manufactured by the Interior Conduit \& Insulation Company, New York. The Lundell fan motors, manufactured by the same company, for whom the Central Company is western agent, are being placed in a number of places. The demand for Okonite wires and tapes continues as lively as ever.

The Ansonia Electric Company, Chicago, has just completed the elegant club rooms, it has had the enternrise to fit up for the special accommodation of its friends and World's Fair visiturs. These rooms are handsomely furnished throughout and will be formally opened this week. Great credit is due Mr. George B. shaw, who has charge of the World's Fair Bureau of the com. pany and under whose personal supervision the fitting up of the rooms has been.

Tue Electric Appliaxce Company has made some novel ad. ditions in its incandescent lamp department. The first is a six candle power lamp made to fit any regular socket and burn on regular circuits. In the direction of large lamps the stock includes lamps up to 1,000-candle power and of a high efficiency. One of these lamps will soon be placed on exhibition at the One of these lamps will soon be placed on exhibition at the
World's Fair. These lamps are the Packard lamp manufactured by the well known New York \& Ohio Company for whom the Electric Appliance Company is western agent.

The Detroit Dyxamo Company, Detroit, Mich., has been very successful in its construction work which was started less than a year ago. The new hotel Ste. Claire, Detroit, opened to the public on June sth was equipped by it with motors for ventilation and power, the Herzog telesame system, fire alarms, bells, annunciators, speaking tubes, etc., and it shows the excellent quality of the work done by this company. A large number of orders has been received for dynamos among which was one for the yacht of Mr. Cudahy of Chicago. 


\section{ELECTRICITY BUILDING.}

DIAGRAMS OF FLOOR SPACE GIVING EXHIBITORS AND THEIR LOCATION.
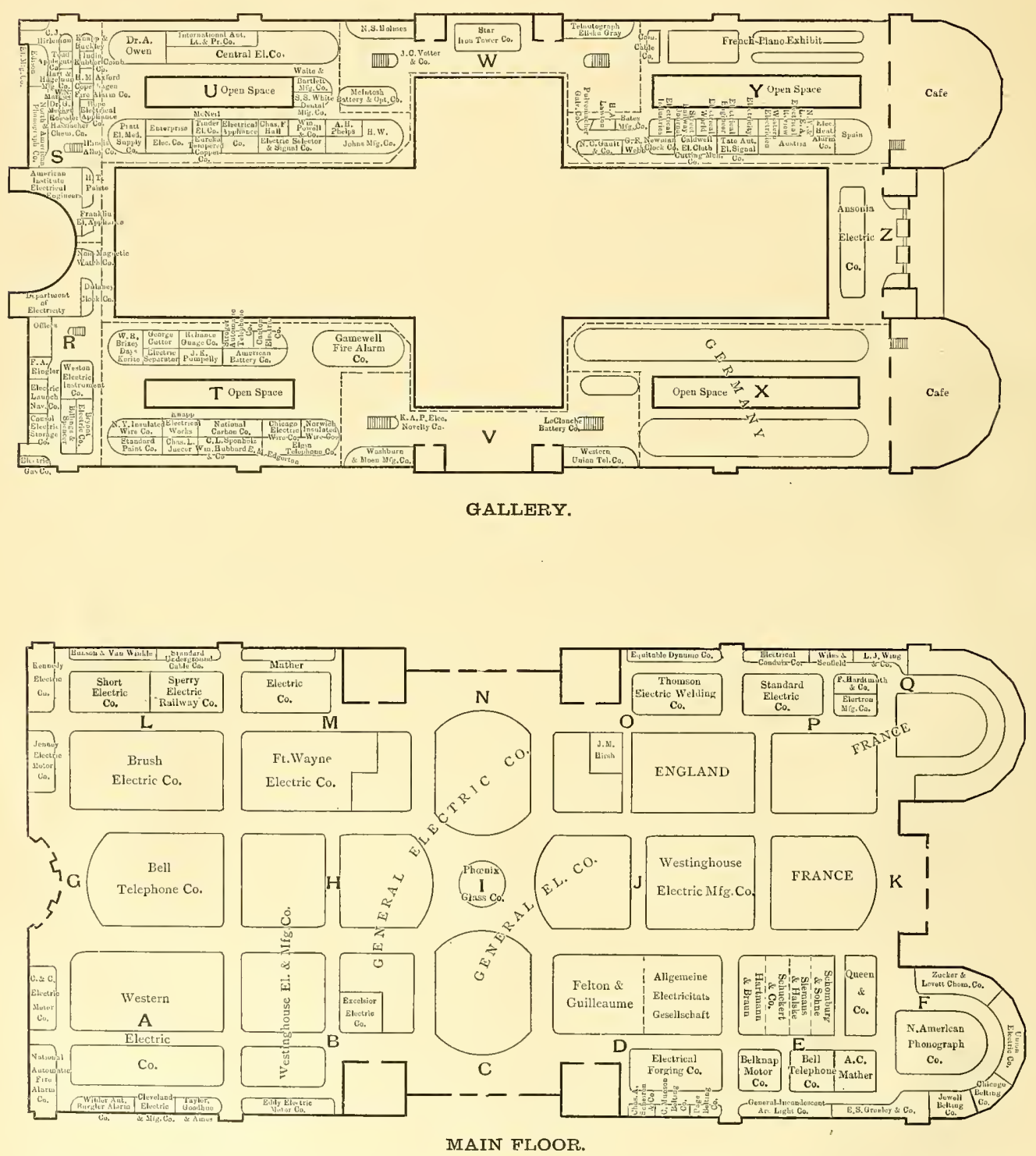
WE ARE PLEASED TO EXTEND A HEARTY

\section{WELCOME}

to our customers and the trade in general to visit us at our World's Fair headquarters

\section{ELECTRICITY GE $6^{\text {"N }}$ BUILDING}

in the Southwestern part of gallery. Make our space your headquarters-you will find a place to rest yourself and

MESTON FAN MOTORS...to keep you cool.

ELECTRIC APPLIANCE COMPANY,

ELECTRICAL SUPPLIES.

242 Madison Street,

CHICAGO.

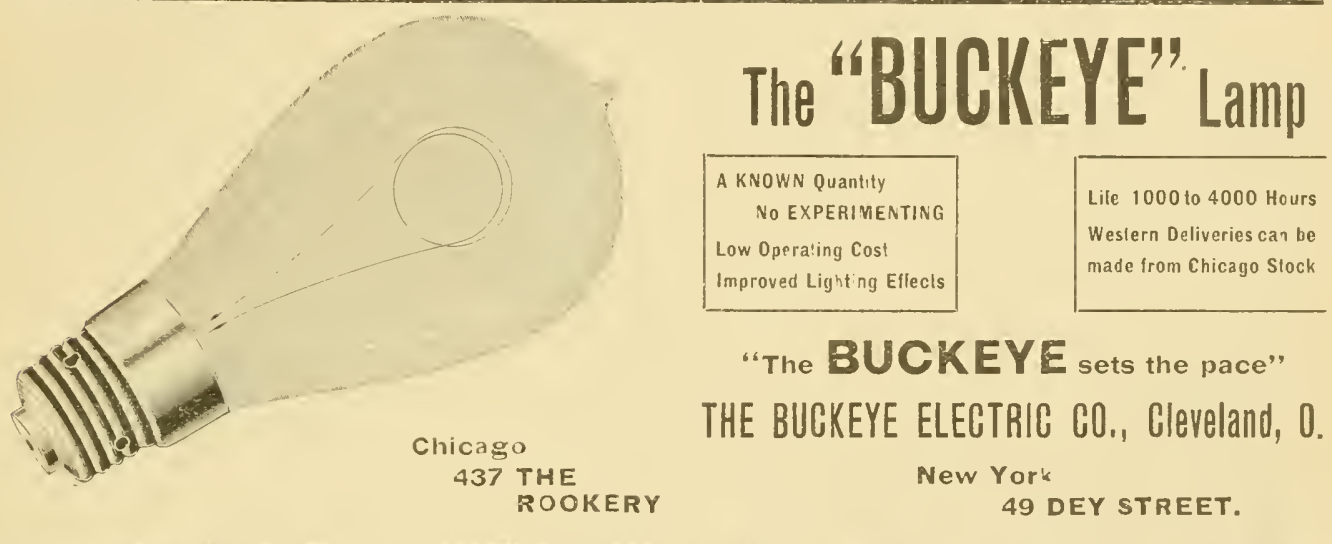

\section{THE MATHER ELECTRIC CO, \\ THE "NOVAK" LAMP.}

MANCHESTER, CONN.

Dynamos, Motors, Gennerators,

Offices, $1 / 6$ Bedford St., BOSTON.

$\longrightarrow$ IND

1002 Chamber of Commerce Bldg., CHICAGO. IOC2 Chamber of Commerce Bldg., CHIGAGO.

Ceneral Selling Agents.

116 Bedford Streel, BOSTON.

\section{CLAFLIN \& KIMBALL (Inc.)}

Mariufacturers' Agents and Mill Reprosentatives for

Electric Railway,

Telegraph, Telephone and Electric Light.

$$
\begin{aligned}
& \text { Agents for Cedar Poles, } \\
& \text { Cypress Poles, Oak Pins, }
\end{aligned}
$$

Locust Pins, Cruss Arms, Class

Feeder Wire,

Insulators,

WIRES, CABLES, TAPE and TUBING 
Map of Chicago.

Showing Location of its Electrical and Allied Business Interests, Principal Hotels, Theatres, Deputs and Transportation Lines to the World's Fair Grounds. (Index numbers refer to the black squares.)
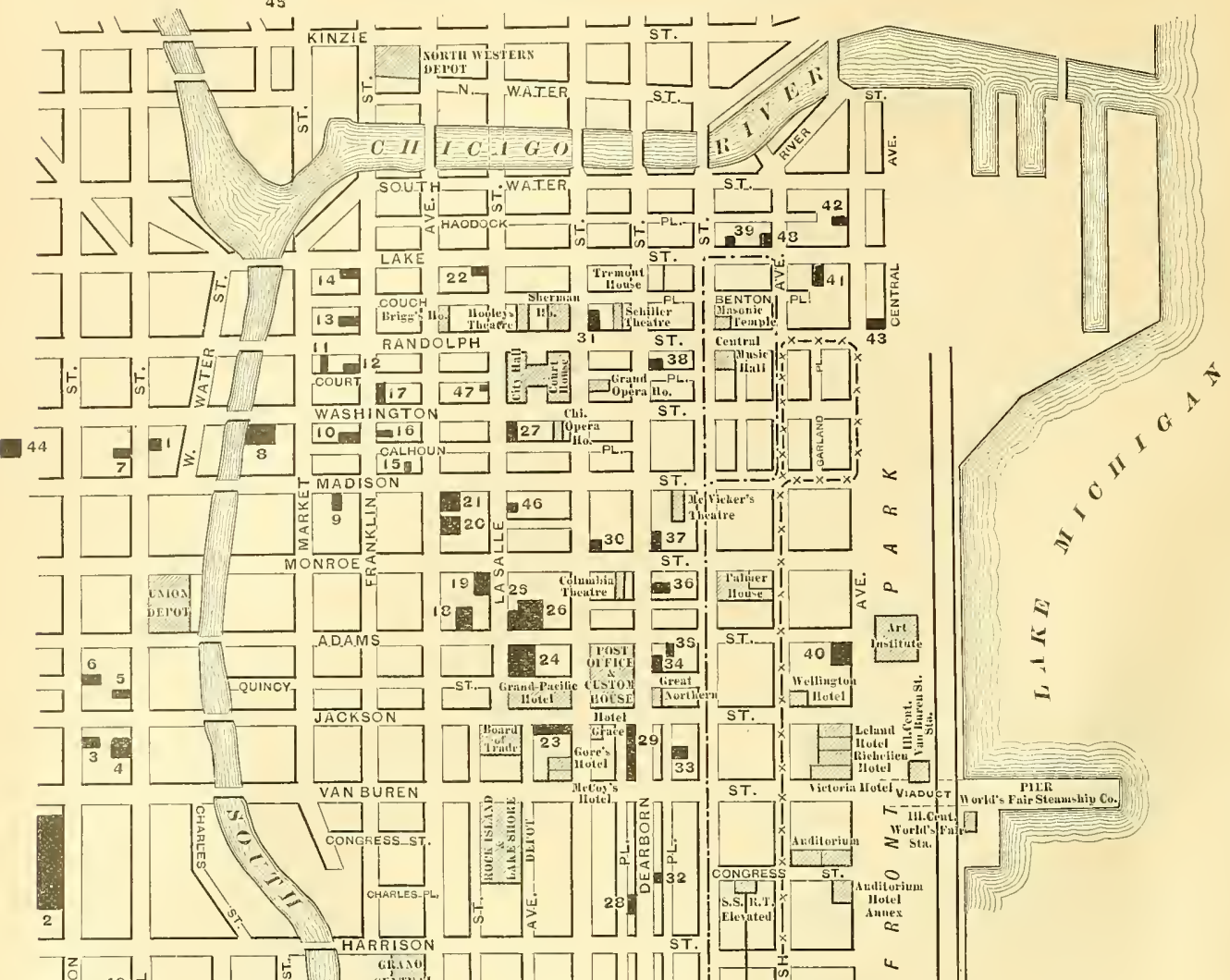

]$_{4}^{39}+\frac{42}{48}$
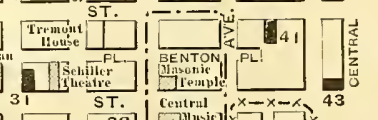

$\int$ in
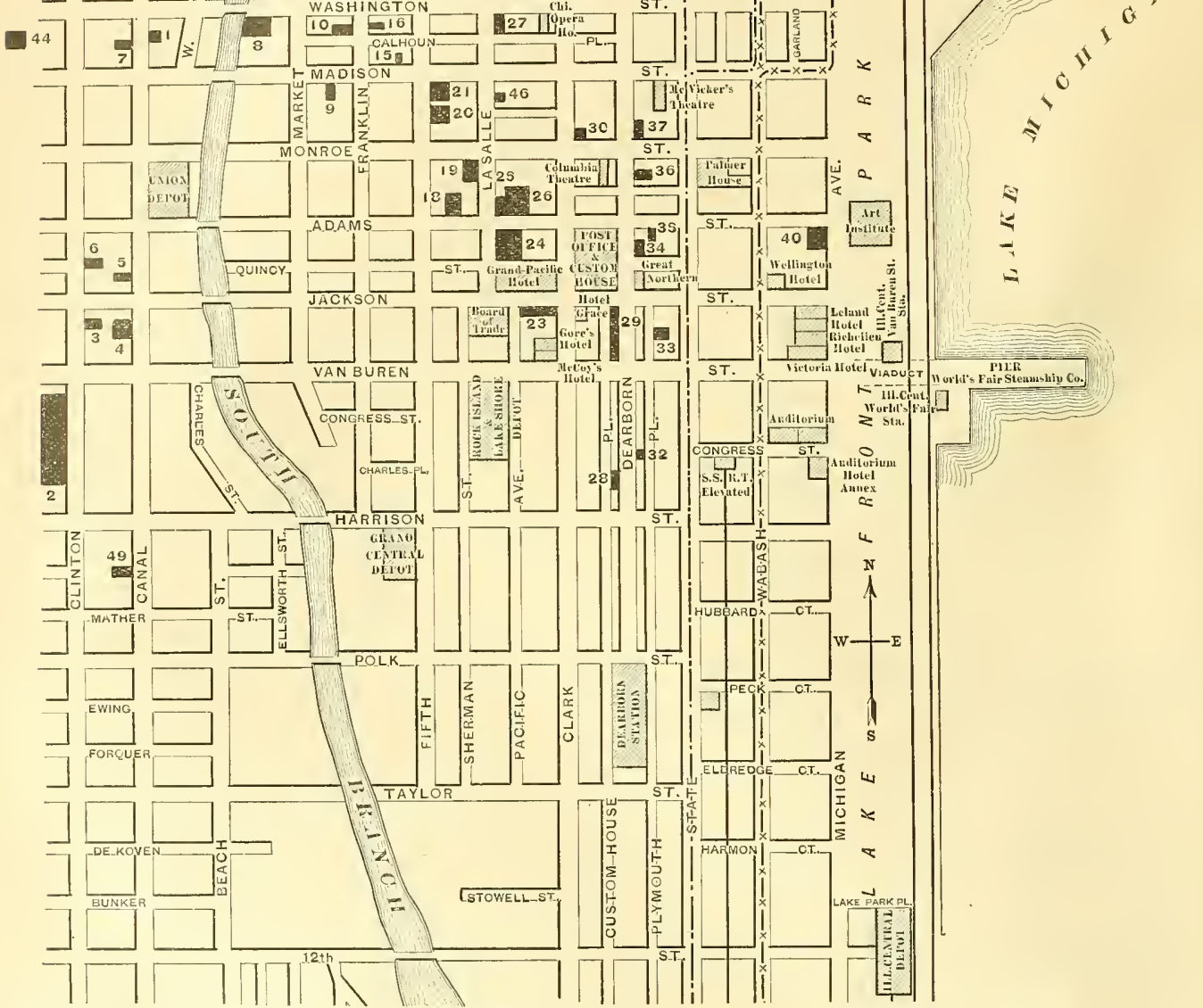

Ansonia El c Co., Michigan Ave, \& Randolph St...43 Commercisl Elec Co.. Monadnock Block......

American Battery Co., 188 Nadison

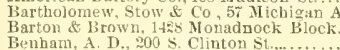

Brush Ejectric Co., Monadopek Block.

Buckeye Electric Co. $43 \pi$ liookery Bldg.

42 Contolidaled Electric Co.... El Electric Motor Co., Nadi on S 29 U Unger El. Telephone Co., Stock Exchange B]dg 3 Detroit Electrical Works, 917 Monadnock Block...

Eddy Electric M Irg. Co. 1417 Monadnock Biock Eleciric Construction \& Supply Co., T nity Bldg. 6 Electric Appliance Co., 242. Madicon St................. 36 Enterprise Eleetric Co. 30; Dearboru St... Ft. Wayue Elec. Co., 185 Demboro 10 .

Central Tele
Chicago Are Light \& Power Co, Washington St.. Pjymouth P1.................................. \& 33 Greit Western Mifg. Co.. 203 S. Cannl St...

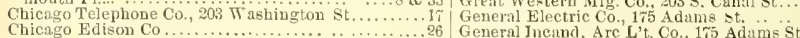
Chicago Edison Co Chicago Electric Motor Co., $313 \mathrm{~s}$. Canal st................ 31 Hood, Wm..239 Lasalle St.................. 49 IIo el Cadillac, State St. \& Peck Ct..... Chicago Insnlated $W$ ire Co., 2It The Nortbern............

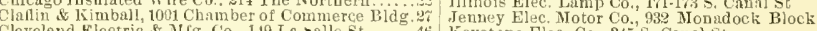
Cleveland Eleetric \& Mig. Co., 149 La salle St...... 40 Keystone Elec. Co., 345 S. Canal st

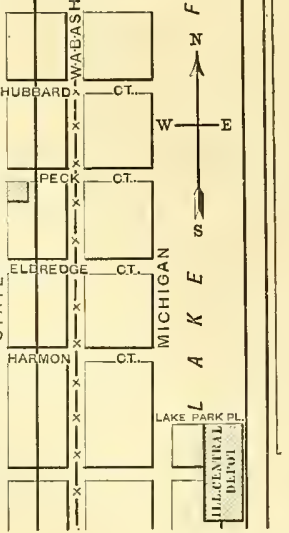

89. Mr. Dougall a Cammings, Tnity Bldg Mc Lean if Schnitt 195 S. Canal St...................... New York Insulated Wire Co., 80 Frankln St. National Elec. Mrg. Co., Pnllman Bldg.......

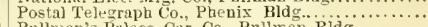
Phoenix Glass Co. Wrabash ATe and Lake St....... Railway Equipment Co.. Pullman Bldg...........40 Rockford Elec. \& Mfg. Co., 94 La Salle St.............47 Standard Elec. Co., 625 Home Ins. Bldg..........25

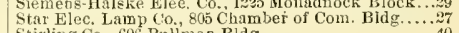
Stiding C 0.606 Pullman Bldg.......... Schiereu, Chns. A., \& Co., 46 S. Canal St.... .... I Sbort Elec. Railway Co. Monadnock Block ........29 Taylor, Goodhue \& Ames. 318 Dearborn St..........28 Todd. Applegate Co.. The, 310 Dearborn st...........29 5 Westingbouse Eleetric \& Mff. Co, Pullman Bldg...4 19 Wollensak, J, F ., Lake and Franklin St................ 13 Western Union Telegraph Co., Phenix Bldg.........23 
(C)

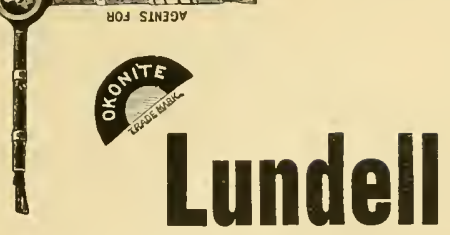

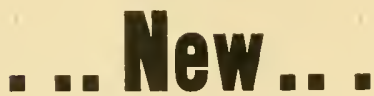
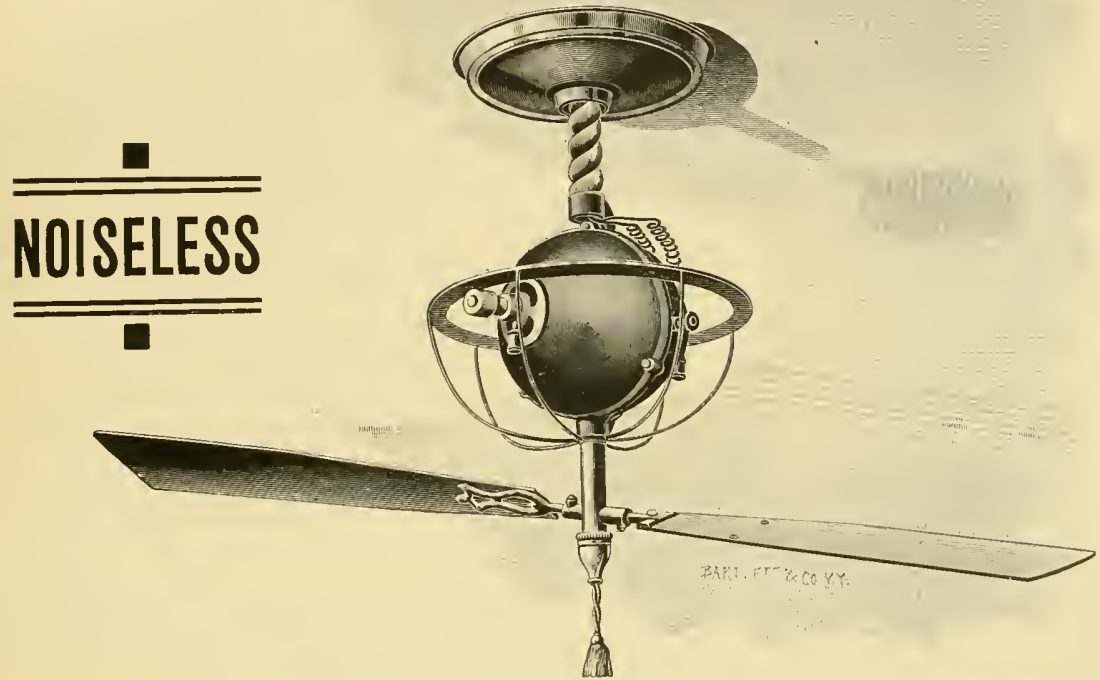

-

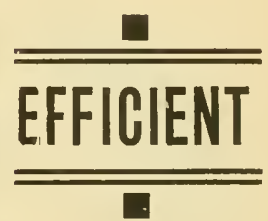

FINISHED IN BLACK JAPAN AND ANTIQUE POLISHED BRASS FAN BLADES BLACK WALNUT-PENDANT SWITCH

Okonite Wires and Gables

Okonite and Manson Tapes

Interior Conduit Lundell Power and Exhaust Fan Motors.

GENERAL SUPPLIES OF ALL KINDS

SEND IN YOUR ORDFRS
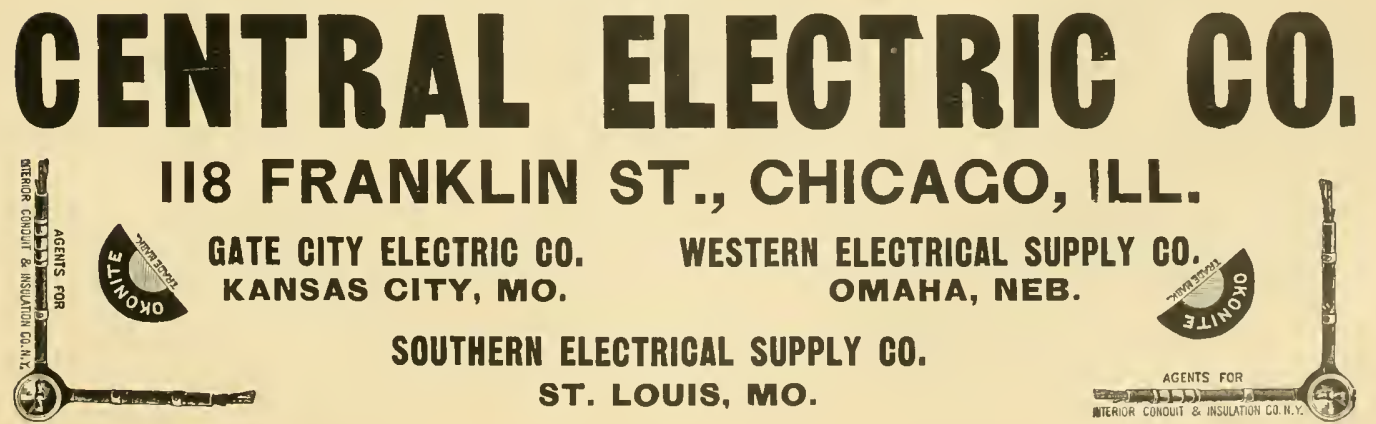

GATE CITY ELECTRIC CO.

KANSAS CITY, MO.

SOUTHERN ELECTRIGAL SUPPLY CO.

ST. LouIs, Mo.

WESTERN ELECTRICAL SUPPLY CO. OMAHA, NEB. 


\section{COMPANY, NEW YORK.}

192 Broadway and II John Street.

MANUFACTURERS OF ARC LIGHTING APPARATUS FOR EVERY PURPOSE A SPECIALTY. The CLARK ARL LAMPS for use on EVERY CURRENT, have the reputation of being the best and most durable of any ever made in the United States.

Consolidated Elpctric 6.

Manulacturers and Dealers in all kinds of

ELECTRICAL . SUPPLIES,

115 Franklin Street, CHICACO.

\section{BEAR IN MIND}

that the regular monthly issue of ELECTRICAL INDUSTR1ES contains the most complete and correct directories published of the electric light central stations and the electric railways in North America.

World's Fair Headquartors $Y 27$ Electricity Building. CITY OFFICES, Monadnock Block.

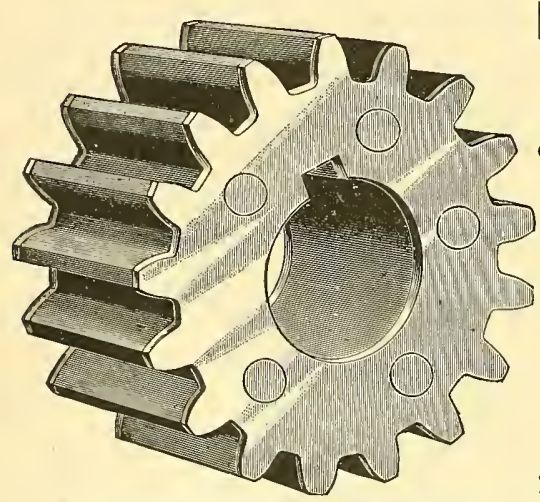

RAWHIDE PINIONS FOR ELECTRIC MOTORS

A SPECIALTY.

RAWHIDE DYNAMO BELTING

Greatest Adhesive Qualities.

Causes Less Friction than any other Belt.

THE GHIGAGO RAWHIDE MANUFACTURING CO. THE ONLY MANUFACTURERS IN THE COUNTRY.

LACE LEATHER ROPE AND OTHER RAWHIDE

GOODS

OF ALL KINDS

BY KRUEGER'S PATENT
This Belting and Lace Leather is not affected by steam or dampness; more durable and thic most economcal Belting made. The Rawhide Rope for Round Belting Transmlssion is superior to all 


\section{Western Electric Company, CHICAGO. NEW YORK.}

Arc Lighting Apparatus

High and Low Tensiori,

Double and Single Service Lamps,

All Night Single Lamps,

Theater and Focusing Lamps.

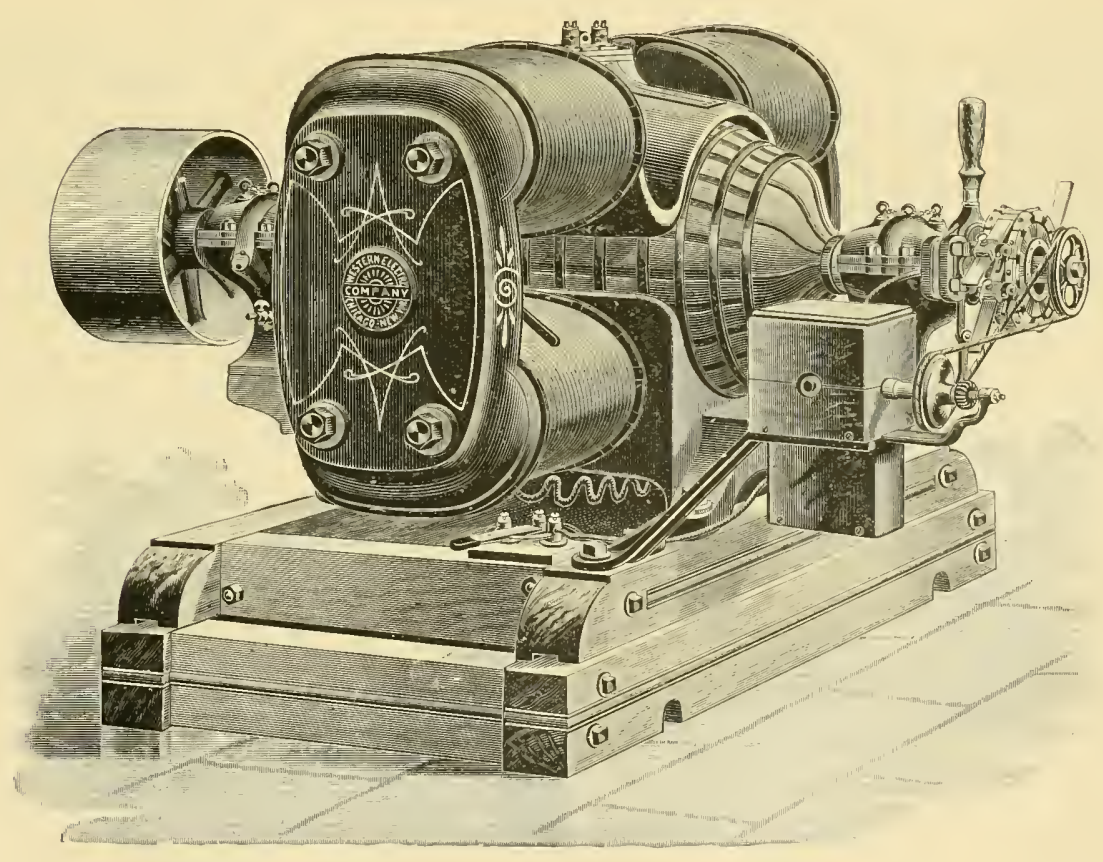

SLOW SPEED

INGANDESGENT DYNAMOS AND POWER GENERATORS. SLOW SPEED MOTORS. 


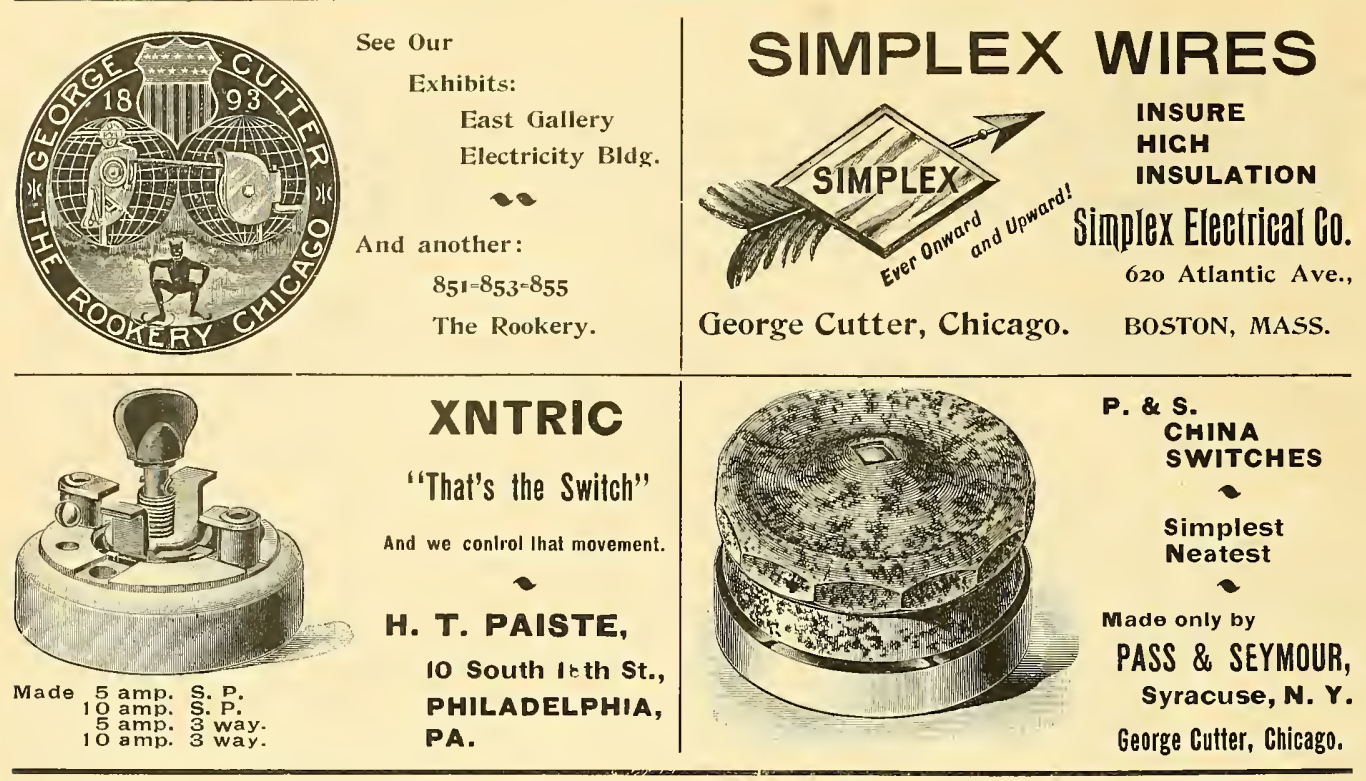

See Our Exhibit of ELECTRICAL FIXTURES

IN SECTION "N", BETWEEN COLUMNS 62 AND 64, MANUFACTURES BUILDING,

GLOBE LIGHT \& HEAT CO., 52 \& 54 Lake St., CHICAGO. ... SEE AD . .

Western Electric Co., PAGE 13.

\section{CHAS. A. SCHIEREN \& CO,}

MANUFACTURERS OF

\section{Genuine Perforated Electric Leather Belting.}

46 So. Canal Street, - CHICACO.

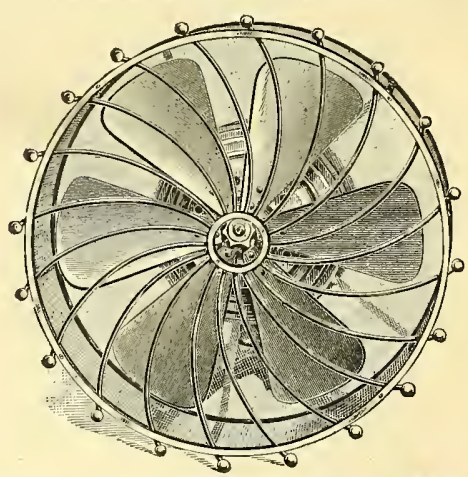

WAGNER ELECTRIC FAN MOTORS

For Direct on Alterwating Curreuts.

These motors give a stronger breeze with less consumption of cnrrent than any other fan motor on the market. They are full 1-8 horke power, Six bladed 2-inch fan. Self-oiling. Furnished with or without guarde.

IT WILL PAY YOU TO SEE THE WAGNER BEFORE BUYING ELSEWHERE.

TAYLOR, GOODHUE \& AMES, 348 Dearborn Street, CHICACO.

See Map of Chiceggo, page 10, showing location of Electrical Business Housess. 


\section{Weekly World's Fair Supplement.}

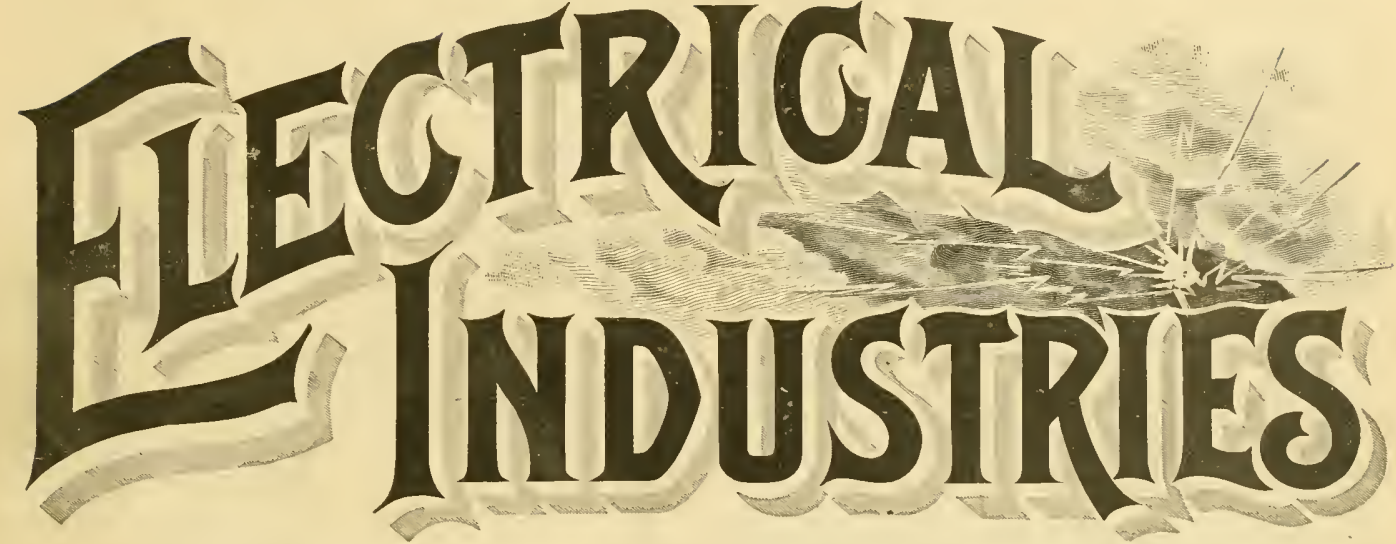

DEVOTED TO THE ELECTRICAL AND ALLIED INTERESTS OF THE WORLD'S FAIR, ITS VISITOLS AND EXHIBITORS.

Vリ, I, No, 2. CHICAGO, JUNE $22,1893$. FIVE MONTHS \$1.00.
TEN CENTS A COPY.

The Exhibit of the Ft. Wayne Electric Company.

It is now nearly 1 i) years since the first Wood dynamo was placed on the market, and since then these machines have been installed all over the country, especially through the south and west. The exhibit of the Ft. Wayne some entirely new ideas. These dynamos and generators are fully up with the times and the alternators shown are especially interesting.

The exhibit is on the left main aisle as one faces north just beyoud the Bell Telephone building. In connection with the display of machines there has been fitted up a very

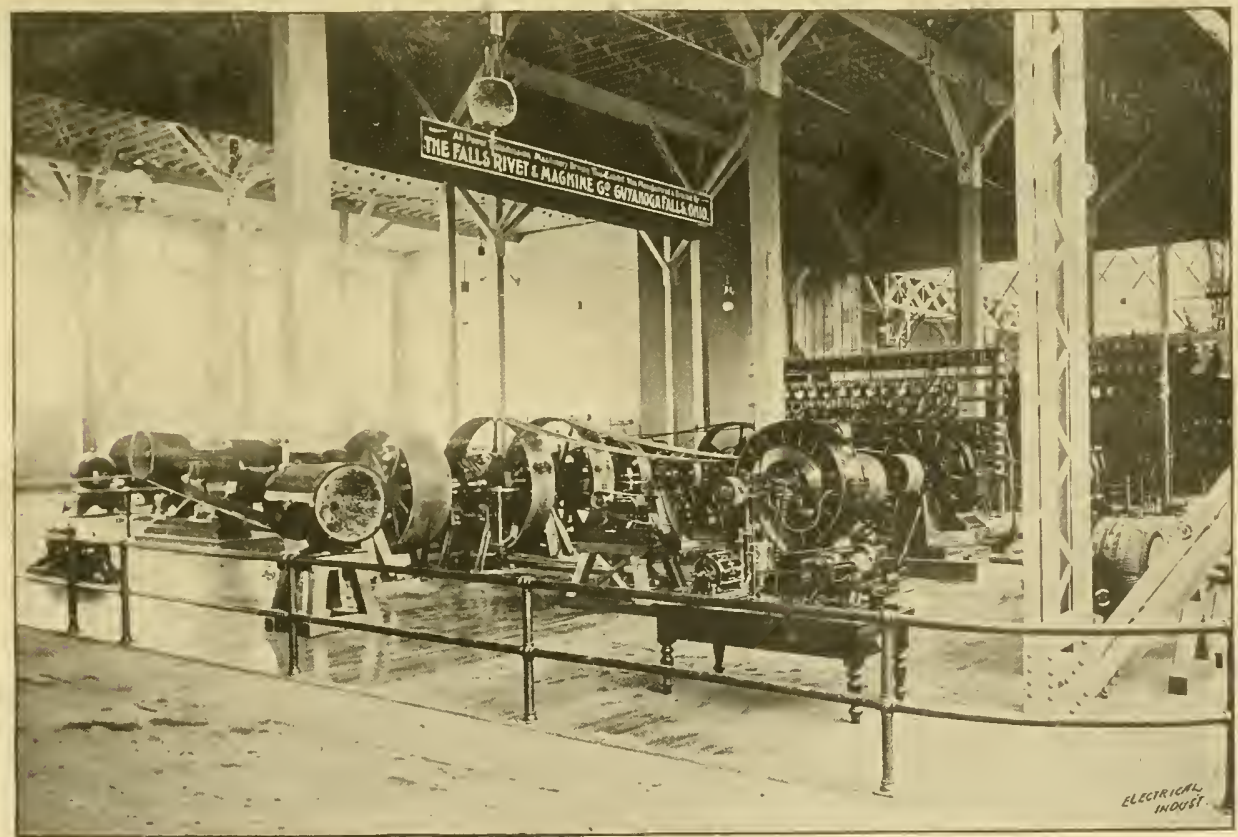

TIE EXHIBIT OF THE FT. WAYNE ELECTRIC COMPANY.

Electric Company, the manufacturers of the Wood machines, has received a large number of visitors which is undoubtedly due to these machines being so well known. This exhibit was one of the first arranged. It is confined almost entirely to the standard machines for commercial use. It also contains a vumber of machines embodying elaborate office, furnished with everything necessary to make it a comfortable resting place. The carpets, rugs, portierres and polished oak furniture tastily arranged are an exhibit in themselves. Next to the office, an ample storeroom las been erected for keeping supplies, etc.

For the converient distribution of power a shaft was 
placed, rumuing the length of the space equipped with suffieient friction elutch pulleys so that the power may be distributed to the different machines as desired. Two Wood constant potential motors one of 120 -horse power, and the other of 80 -horse power are belted to the pulley shaft and furnish power for the different machines. The current for the motors is furnished from the Machinery Hall plant. The motors and incandescent lighting dynamos are placed on the west side of the shaft, while the arc dynamos are on the east side. Among the machines shown are a 30 and a 15 K.W. incandescent 110 volt Wood machine, while near the office are placed $20,40,65$ and 125 light Wood dynamos, and near them a 1,200 light Slattery alternating current dynamo, and a 25 light, 6.8 amperes Wood arc. On the opposite side are a 75 K.W. Wood alternator and exciter, a 1,200 light eomposite Slattery alternator with exciter, a 40 light nine and a half ampere Wood arc, and also Wood are dynamos of 60,80 , and 120 light capacity. A 3,000 light alternator is on the way and will soon be in place in the exhibit. This dynamo is a new departure in armature construction, it being made up of sheet iron links put together like a link belt. It is said to make a very efficient machine producing one volt for each 3.6 inches of conductor. A one-light are machine, coupled direct to a

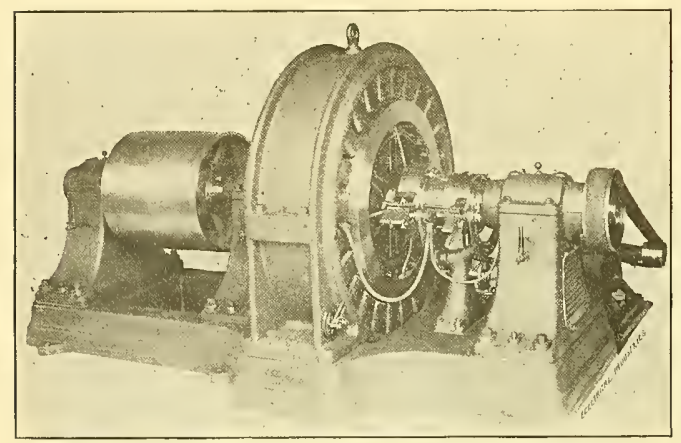

EXHIBT OF THE PT WAYNE EIECTRIC CO-ALTERNATOR

Wood motor is nsed to run a large locomotive head light which oceasions considerable comment when running. There is also the historical dynamo and lamp described and illustrated in our June issue. A simple of a plain marine projector is also shown. Various sizes and styles of armatures are on exhibition; samples of the Fort Wayne record. ing meter and a lamp bank for testing them, a hanging rack with 80 are lamps comprising 26 different styles and supplied with the different currents in order to test them; a bank of transformers of all the styles made by the company and of a capacity for 1,500 lights, samples of various forms and sizes of bearings, commutators and a new style hangerboard rheostat, are all arranged in good shape for close inspection. The hangerboard rheostat deserves more than passing mention as it apparently solves a problem heretofore often very awkwardly handled. A skeleton iron frame no larger than the ordinary wooden hangerboard, has a coiled iron wire rheostat corered with insulating material located on the back side, and when secured against a ceiling notbing shows but the ornamental front, and it also allows sufficient space for thorough ventilation. The new alternating are lamp shown is remarkable in its simplicity, there being nothing but a couple of coarse wire magnet spools, and a few gear wheels for the whole mechanism; it is of the constant potential type, and run two in series from a 100 volt converter with the above described hangerboard for a resistance. Samples of the regular standard rack lamp both single and double, and of the newer single and double clutch lamps are shown.

In switeh boards there is a combination arc and alternating board with marble face, on a wooden framework, the are board being on the front and the alternating instruments and devices on the back; it is very compact and exceedingly simple. A large Iow tension switch board made of old Tennessee marble, and provided with all the necessary ammeters, volt meter, switches and fuse cut-outs is shown. Two large rheostats are placed on the floor beneath it. The alternating eurrent switch board is after plans by Mr. A. E. Barnes, who has charge of the exhibit and is very complete in all details. It is of the skeleton wooden frame type, and has a capacity for six dynamos and 12 circuits, the necessary ammeters, volt meters, pilot lamps, and fuse blocks being also provided for. The dynamo switches are located at either end of the board, and the circuit switches

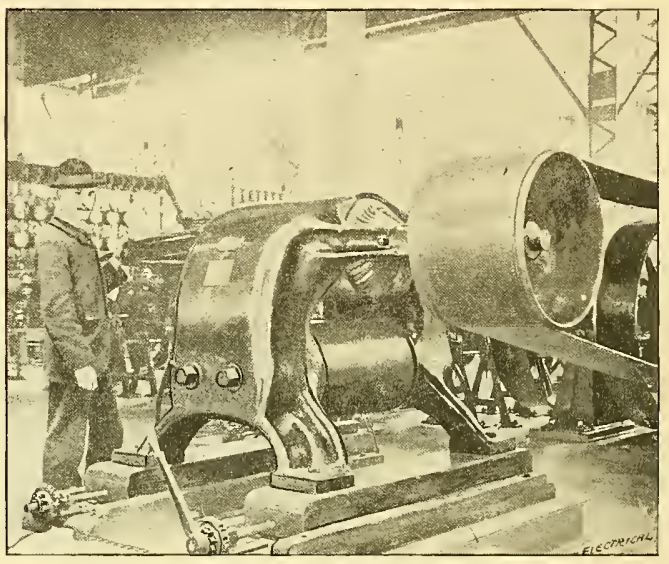

EXIIBIT OF THE FT. WAYNE ELECTRIC CO.-MOTOR.

in the center space. The dynamo switches are so arranged that circuits can be changed from one medium or source of current to another without change of light and without danger of coupling two dynamos together. The whole scheme has been very e'everly worked out, and Mr Barnes states that he has installed a number of them about the country that are reported as giving excellent satisfaction.

This plant furnishes current for lighting part of the building with are lamps and supplies incandescent current for the lamps in the booths in newspaper row.

The Fort Wayne are dynamos are carefully examined by all comers. It is a common test to drop a pair of pliers across the two binding posts thus shorteircuiting the dynamo; the regulator takes care of the armature perfectly, and will immediately return to place on removal of the pliers. This was recently done for an eminent English electrician, and he was loath to believe it until the action of the regula. tor was explained to him.

The exhibit of H. T. Paiste together with the other exhibits in the center of the south gallery have been practic ally closed since the erection of the scaffolding by the decorators at the south end of the building. 
The Brixey Exhibit of Day's Kerite Wires.

This exhibit oecupies a prominent position in the gallery fronting the main eastern stairway of the Electricity Building. The whole end of the section is occupied, a sprace over 1,000 square feet in area. The center is taken up by it very handsome pavilion, serving as an oflice and assembling place for the company's numerous visitors. This parilion is 10 by 12 feet, finished outside in white, touched out with gold leaf, while the interior is prettily finished in sycamore with a number of incandescent lamps for light and ornamentation. Desks, chairs, a comfortable lounge and a well stocked look case furnish comfort for the friends of the company.

A handsome sign is suspended above the roof of the of fice calling attention to the exhibit. Numerous portraits of the proprietors and managers and several fine photographs of cable laying and different samples of cable are hung on the outside of the pavilion. The diplomas received by the firm in commendation of its wires are also suspended on the office walls. Coils of wire for interior use and with

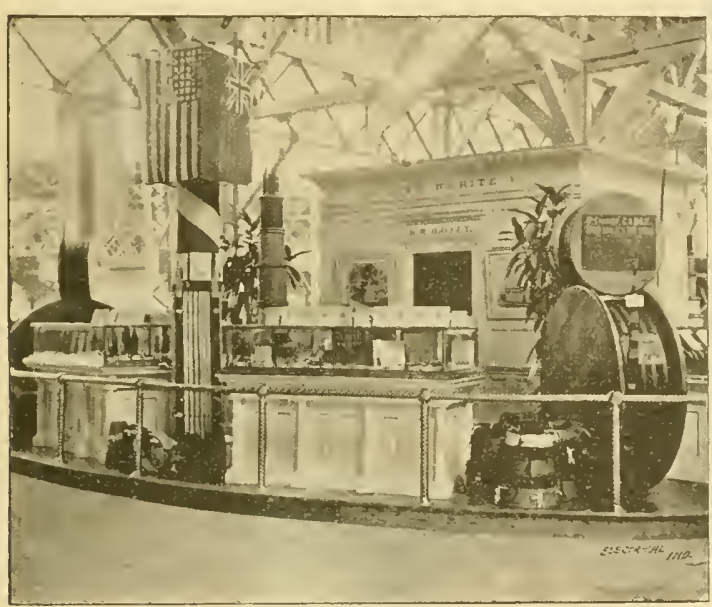

EXIIIBIT OF DAY'S KERITE WITES.

eovering of different colors are displityed on a table in front of the office; a pyramid of wire on reels, and short lengths of 15 t conductor cable on the top add to the finish of the figure.

The column in front of the building is draped in the nat tional colors, combined with those of several foreign na tions. Show cases surround the space and contain sanples of cables, the Kerite tape, feeder wires, medals and other smaller products of the company.

The nuture of the insulating naterial used is shown from its very origin up throngh the various stages of manufacture. The kierite compound is a combination of pure para rubber and erucle kerite, the nature of the latter being a secret known only to Mr. W. R. Brixey, the proprietor of the business. A rubber plant, blocks of pure para rubber as gathered for shipment, blocks of crude kerite and samples of the kerite componnd are shown, illustrating the various stages in the development of the material. The compound here exhibited has the appearance of long skins of black yarn matted together.

Reels of wire of various sizes and kinds are shown, wire for electric lighting, numerous samples of telegraph and telephone cables, both underground and submarine of vari- ous sizes from the two wire submarine to the 100 conductor underground cable.

This comprany received medals of the highest award from the Centennial exhibition and has been doing business for a quarter of a century, being among the oldest in sulaterl wire companies in America. Its display is large, complete and very comprehensive, and is a credit to the owner, Mr. W. li. Brixey.

Mr. Eckert in charge gladly shows the wares of the company, explains their uses and is untiring in his entertain. ment of visitor's.

\section{J. C. Vetter \& Company's Exhibit.}

This company exhilits in the west gallery of the Electricity building the various batteries and apparatus for physician's use, it mannfactures. They are displayed in a finely designed and constructed eabinet of cherry, ornamented by numerous miniature ineandescent lamps. It is

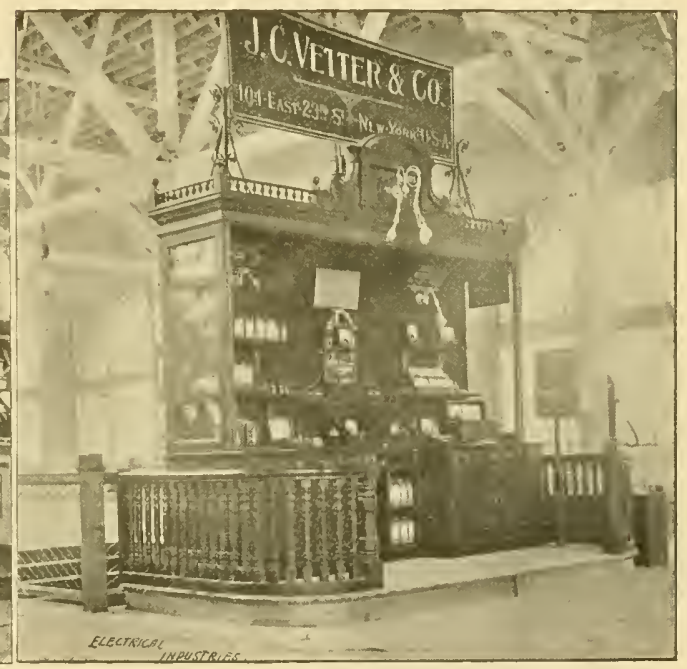

J. c. VETTER \& $\mathrm{CO}^{\circ} \mathrm{S}$ EXHIBIT.

near one of the central stairways on the west gallery of the Electricity builling.

The exhibit consists more particularly of the Vetter moist and dry Leclanche disque batteries, several styles of an improved form of portable dry Leclanche faradic batteries for physicians' use, and numerous pieces of appart us for use in electro-therapeutics, among which are switches, standard milliampermeters, carbon current controllers, and the Vetter current adapter. Cases of apparatus combining almost everything required by the physician are also slown. constructed and finished with the finest of workmanship.

The eurrent adapter accomprnying these ontfits is an ingenions device consisting of a receptacle plug with three binding posts. Where a physician has incandescent lighting current handy he can unserew a lamp and insert this adapter in its place, replace the lamp in the receptacle and turn on the light again. When a slight current is clesired, flexible terminals from the medical apparatus are attached to the first two binding posts. This cuts the lamp and the apparatus in series and therefore furnishes a very small amount of current which can be varied by changing lamps. In case a current of the full potential is required the terminals are attached to the two outer loinding posts and 
the current is governed by the carbon current controller. This controller is manufactured on the principle that the resistance of earbon increases as it is eompressed. The exhibit although not large is nicely arranged, and makes an attractive object in that part of the gallery.

\section{A Large Holtz Machine.}

The Waite \& Bartlett Manufacturing Company, has on exhibition among several important features, a Holtz induction machine which Dr. Waite says, as far as he is able to learn, is the largest one in existence, the next largest being one constructed by Wimshurst and but 36 inches in diameter. This machine has six revolving plates of plate glass, one-quarter inch thick and 10 inches in diameter; they are covered with a lacquer which was discovered by the makers. The shaft of the machine is of two inch steel, covered with a hard rubber bushing, four inches in diameter. The plates are secured on this bushing, separated

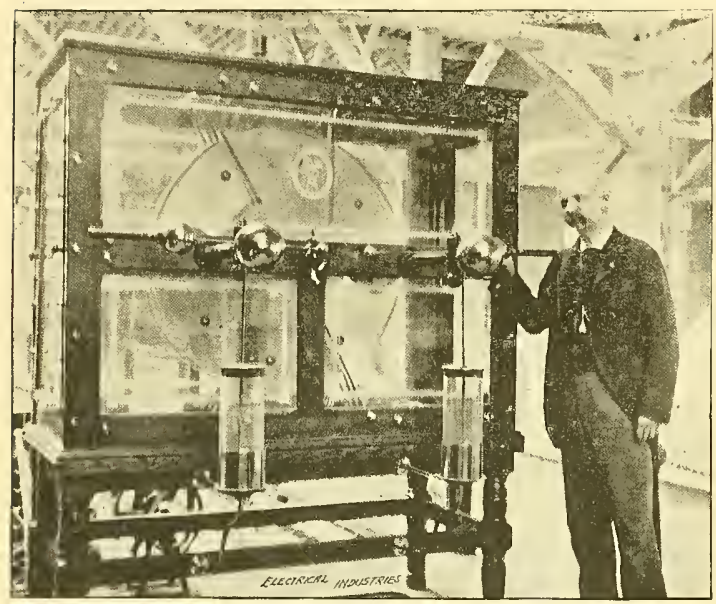

WAITE AND BARTLETT HOLTZ MACHINE.

by hard rubber collars, drawn into place and fastened by a large brass nut on the outside.

The stationary plates are common glass of the ordinary thickness and are in halves, one part being supported on hard rubber insulators from below, and the other half from above. The stationary plates have the usual paper covering and a small piece of tinsel on the edges. As the machine receives its initial charge from a 16 -inch Wimshurst machine the cat-skin and other similar apparatus are not used. The combs are of one-half inch brass rod with numerous small points. These combs and the stationary plates are all easily adjustable, all parts of the machine being easily and quickly reached for adjustment. The pole pieces project two feet from the combs and the balis of the prime conductors are of hollow brass, six inch:s in diameter. These pole pieces are insulated for 19 inches by fine hard rubber made by the Butler Hard Rubber Co., two and one-quarter inches diameter. Two leyden jars are used with this machine, 14 inches high by six inches in diameter of glass, one-quarter inch thick.

The case is of old oak and glass finished with brass ornaments and bolts. It is four and a half feet high, six feet long and 30 inches wide, setting on a table of the same wood, two and one-half feet high. All joints being packed the case is air tight and by the use of lime kept dry so that no trouble is found in starting. Various electrodes, chains and chain holders are provided, also an insulated table for seating or for patients to stand on for treatment or experiment.

The machine is run by a Perret motor of one-half horse power and in dry cold weather will produce a 20 -inch spark. Owing to the state of the atmosphere at the Fair it has been impossible to get a spark of over 12 inches. With the leyden jars in contact and short-circuited terminals this spark is quite heavy and makes a noise like the sharp crack of a whip. For such people as think they are helped by electrical treatment the Doctor places them on the insulated stool, gives them an electrode chain and with rubber holders passes the other electrode over the surface of the body or affected parts at a distance of three or four inches; bright sparks are seen and the sensation is not exactly pleasant. One very queer effect is that made by seating a person on the insulated stool, with one electrode and with the other attached to a light brass frame suspended orer the head at a distance of a foot or more, the hair rises and a sensation as of a cool breeze seems to sweep up all around the head towards the terminal. The feeling is entirely novel and pleasant and is said to be of use in insomnia and some other nervous diseases.

\section{The Exhibit of Hardtnuth Carbons.}

In connection with their American representative, the International Thomson-Houston Company, Messrs. F. Hardtmuth \& Company of Vienna have made a very creditable exhibit of carbons. The demand for a high grade of earbon has gradually inereased, and although more expen-

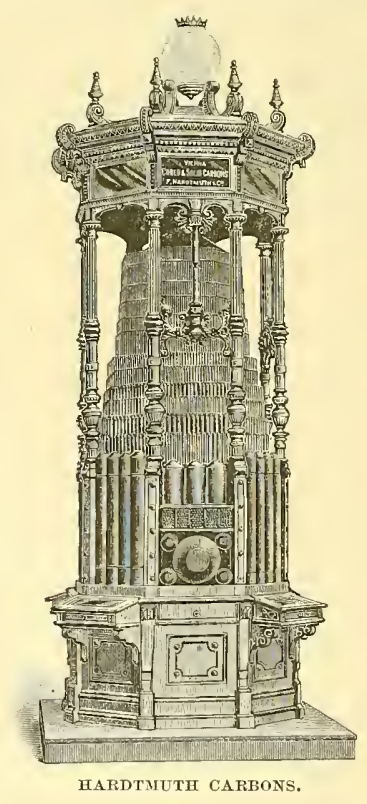

sive, large sales are reported in this country. In the exhibit a general view of which is given in the accompanying cut earbons of from an eighth of an inch to 12 inches are shown, of different shapes aecording to the various uses for which they are intended.

The display is arranged in a rery tasty open booth of 
ebonized wood. It is located in section P at the right of the north entrance of Electricity Building near the French exhibit. The mamufacture of earbons is an industry that has grown up with that of electrie lighting and the improvement in the quality and grade of carbons manufactured has kept pace with the general advancement. The Exposition company has purchased $100,(1)(1)$ of these earbons for nse on the grounds so that they may be seen in use.

\section{Cutter's Boulevard Streethood.}

Among the novelties exhibited by (reorge Cutter is the handsome form of outdoor incandescent reflector which has been nicknamed Cutter's Bonlevard Streethood. In designing it the many little improventents which are found only in Mr. Cutter's streethoods have been retained, the

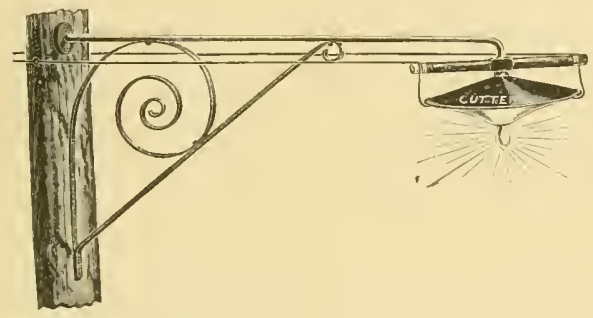

(ITTER'S HOULEYARIY STHELTH(OO).

departure lying in the special bracket arm which takes the place of the ordinary gooseneck. This is as strong and well hraced as it is neat, and holls the lamp five or six feet from the pole so as to give a good effect on thickly shaded streets. The appearance of these houds when seen on well kept streets is said to be unusually fine; and the maker is already pleased with the calls for them.

\section{The Lake Cable Laid.}

For some two weeks past the [.S. Light House tender, Dahlia, commander J. J. Brice with Mr. Ira W. Henry, the electric engineer of the Bishop (nutta Percha Co., and a party of assistants, has be'n 'ngaged in the laying of the cable and the anchoring of the light buoys between the I an Buren St. pier and the pier at the Fair grounds. The ends of the cables were brought up and tied to the pier on Tuesday night, and as soon as the tests are completed, the current will be turned on.

The work bas been done without accident or trouble except on the occasion when the new whaleback steamer Christopher Columbus backed into the end of the cable at the pier. One of the propellors canght the cable and after twisting it up bally one of the blarles broke and it was thus released. Thus about $I(1)$ feet of the cable was torm off, but the end was easily recorered by the grapple and the cable carefully spliced out to the required length and the end again made last, but in a permanent manner to prevent a repetition of the wishap.

The ends of the cable are connected with the switch board in the house erected on the end of the pier, which is surmounted by a flag staff and peunant. The use of this system of lighting for this purpose is entirely new and as swon as completed and in working orler a careful examination will be made of it by Capt. W. S. Schley of the United States Light House Establishment at New York. It will also be inspected by other officers of the Light House Establishment and harbor masters from different points. Great credit is due Commander J. J. Brice for his persistence in carrying out the scheme and to Mr. Henry for this application of the system and his boldness in carrying it out.

\section{De Laval's Turbine-Dynamo.}

In a very neatly arranged space on one of the main aisles of Machinery Hall, is a dynamo which is decidedly novel in having two armatures in the place of one. The machine is of the bi-polar type of the direct current dynamos, and in appearance resembles very much some of the ordinary dynamos with the exception of the double armatures. The armatures are placed close together, and revolve in the same direction, being geared direct to the shaft of the steam turbine. The whole combination takes up but little room. The motor dynamo and all attachments and connections are placed on one foundation. It is fitter with modern oil cups, ete. The connections and general work manship seems to be of an excellent kind.

It is supplied with a governor, and the necessary regulating apparatus, and is said to be entirely sate. The coverings and boxes are so constructed as to be easily opened permitting the inspection of any and all parts.

These machines are manufactured at the G. de Laral's Steam Turbine Works, Stockholm, Sweden.

\section{Exhibit of the Williams Engines.}

The Williams engines are being shown in Machinery Hall in various uses and types. Two are used for driving line shafts and one for driving a $200 \mathrm{~K}$. W. Siemens Brothers' direct current inverted field type of dynamo. This engine made and used so largely in England is about to be built in Chicago by the M. C. Bulloch M'f'g. Comprany. Whi? they are somewhat after the Westinghouse type, being wholly inclosed, and single acting, they are compound, have a central valve and in place of cushioning on a back pressure of steam are supplied with an air chamber which takes its place and saves that amount of power. The engines are comparatively high speed, the 500 -horse power machines ruming 3201 revolutions per minute. The governor is the old form of weights in a horizontal position on the end of the main shaft which extends out through the engine casing into a box provided for the purpose. A bell crank lever changes the motion of theaxis of the balls from a horizontal to a perpendicular position and through a long rod connects directly with a throttling valve in the steam pipe controlling the admission of steam to the high pressure cylinders. About half way un this rod is a lever the fulerum of which may be changed at any time, thus controlling the throw of the throttle valve in eomparison with the action of the gorernor balls in order to vary the speed of the engine. The balls are held together by a very light spring and are apparently very sensitive to any ehange. A steam separator is used in connection with the main supply pipe to prerent as far as possible the entrance of water to the cylinders.

The agents and engineers claim to be able to compete in economy of steam consumption with any of the Corliss type of engines. The machine requires very little space, runs remarkably free from jar and noise and is of fine desigu and appearance. 


\title{
ELECTRICAL INDUSTRIES.
}

Entered at Chicago Postoflice as second-class mail matter.

\section{ELEGTRICAL INDUSTRIES PUBLISHING COMPANY, INCORPORATED 1889 \\ MONADNOCK BLOCK, CHICAGO. \\ TELEPHONE HARRISON 159.}

E. L, POWERs, Pres, and Treas.

E. E. WOOD, SECRETARI.

\author{
E. L. POW ERS \\ H. A. FOSTER, \\ W. A. REMINGTON, \\ E. E. WOOD, \\ FLOYD T. SHORT,
}

EDrtor.

$=$

EASTERN OFFISE, WORLD BUILDING, NEW YORK. World's Fair Headquarters, $Y 27$ Electricity Building.

FIVE MONTHS,

SINGLE CUPY,

Àdvertising Rates Ūpon Application.
$\$ 1.00$

10

News items. notes or communications of interest to World's Fair Visitors are earnestly desired for publication in these columns and will
be heartily appreciated. We especiall invite all visitors to call upon us

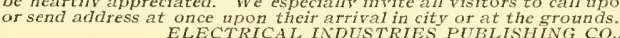

ELECTRICAL INDUSTRIES PUBLISHING CO.,
Monadnock Block, Chicago.

On a number of oceasions the crowd has been so great at the north and sonth entrances of the Electricity Building as to cause a dangerous jam at these places. Cannot the crowds be directed so as to go in at one entrace and out at another or be separated so as to use the side entrances more? A number of complaints have come to our notice of this fact.

A few chairs or settees might be placed in the gallery of the Electricity building in some of the open space along the railing on which persons fatigued by walking might rest. It is not an uncommon sight to see large numbers resting on the stairs or on the platforms among the exhibits. The chairs or settees so placed would not be in the way and would be greatly appreciated by the visitors.

That the World's Columbian Exposition is an assured success there can now be no doubt. The attendance has increased gradually but steadily each week since the Fair was opened, and as the season advances when schools are closed, the increase will unquestionably continue. The attendance the first week was large on account of the opening exercises. Since the second week in May between the 7 th and $13 \mathrm{th}$, when the number of paid almissions was 134,000 , the attendance has increased to 724,000 for the week ending Jume 17. The Department of Electricity certainly has no reason to complain with regard to the number of its visitors. No building on the grounds shows the crowds present that are to be found in the Electricity Building and great interest is shown by the visitors in the various exhibits. Later in the season as the time approaches for the assembling of the Congress of Electricians, the prominent electricians from all parts of the world will be found among the visitors to this building.

The historical features of the exhibits in the Electricity Building are worthy of especial attention. A number of the older companies have gone to a considerable expense and trouble to collect instruments and apparatus which are of historical interest. In nearly all the fields of electricity are shown the apparatus used in its earlier applicacation to commercial use. The first instrument with the subsequent ones arranged as one succeeded another, ar shown in a number of eases. Where it was impossible to secure the original instruments, models have been constructed from diagrams or memory to make the list complete. A number of articles are also shown interesting from their association with important events. The gradual advancement of the Mechanical Art, the drawing togethe of the scientist and the mechanic, or rather the growth of a highly intelligent class of mechanies and the utilization in every day life of what was only a chemist's toy, were never exemplified as in the exhibits in theElectricity Building.

Some of our foreign friends have had many troublesome and rexing delays in the receipt of their exhibits. Mr. J. G. Lorrain, of London, England, reports that some of his exhibits are still on the way and what he has received are in rery bad shape. He hopes to receire it all soon and will then have his display arranged for exhibition.

The Government exhibit from the naval observatory occupies a position near the lake just east of the Government building and the camp of the U.S. regulars. The various instruments, transits, chronographs,etc., used for ascertaining and signalling the correct time to all parts of the United States by means of the telegraph are exhibited.

The British Government Postal Telegraph exhibit has just arrived and is being rapidly arranged under the direction of Mr. Chapman. It includes a number of instruments of great historical value. The first telegraph instruments made by Cooke and Wheatstone, a very cumbersome affair, having five needles and requiring five wires between each instrument. A relic of the line between Euston and Camden Town is shown in the shape of a short piece of wood into which the five bare copper wires were sunk separately and covered with strips of wood. Instruments are displayed showing the gradual improvement and perfection of the instruments, and the system from the first instrument requiring five wires to send one message to the latest Dulaney multiplex system, by which six messages are sent over one wire at the same time. A sample of the first submarine cable laid is shown, having been laid between Dover and Calais in 1850. It was insulated with gutta percha with no protection against mechanical injury, consequently its useful life was short. It was recovered in 1875. The instrument used in the House of Commons, a two needle machine with case finished in the same style as the interior is shown, with many other interesting articles. Most of the historical part of this exhibit is from the British Post Office section of the South Kensington Museum and is worthy of a careful inspection.

\section{THE OPENING OF THE FAIR EVENINGS}

On Monday of this week the council of Administration decided to open the Fair evenings, commeneing with Thursday night. This deeision has given universal satisfaction, especially to those interested in the Electricity Building. Many of the exhibits in this building are seen to advantage only during the evening, and under the new arrangement every visitor will have an opportunity of seeing them. The exhibitors will undoubtedly give more attention to the lighting of their exhibits, and should, as far as possible, have a representative in eharge of their display at night as well as during the day. The buildings will be closed at 10 o'clock, and it is expected that all visitors will leave the grounds by 11 o'clock. The work of completing the lighting of the grounds is being pushed as rapidly as possible. 


\section{WORLD'S FAIR NOTES.}

The changes in the electric fountains are nearly completed, and great improvement has been noticed when in operation.

The exhibit of L. J. Wing \& Company has been increased by the addition of several electrically driven exhaust fans and other apparatus.

The efficiency of the electric launch was shown in rather a clisastrous manner a few evenings since in the collision between a launch and a gondolı.

The Western Electric Company's miniature theatre is practically finished and the apparatus is being adjusted. It will be opened to the public in a few days.

The Jewell Belting Company, of Hartford, have an exhibit of thrir well-known oak tanned leather belting in the northeastern alcove of the Electricity building.

The Brush Electric Company are expecting to open their exhibit to the public this week. The temple erected in the center of the exhibit is very artistic and is much admired.

The General Electric Company started last week several electric percussion drills in which a considerable interest has been aroused. Huge blocks of stone have been placed for the purpose of testing them.

Some very beautiful negatives of lightuing flashes are shown in the case exhibited hy E. Ducretet and L. Lejeme, of To Rue Claude Bernard, Paris. They also exhihit many fine electrical testing instruments.

The Electricity huilding is the great evening attraction; when no special feature is to be seen elsewhere the building is crowded. As soon as the fire works cease, or the play of of the electric fountains, the crowd moves back to the build ing. The crowd is especially noticeable at the times set for the illumination of the tower.

The Otto Gas Engine Company of Cologne have in their exhibit in Machinery Hall a vertical high speed gas encrine coupled direct by shaft comection to a Schukert dynamo. A combination is thus presented that has been successfully used in a number of places in Europe, lunt which has not been nsed to any great extent in America, probably on account of the greater cost of gas.

One of the most valued historical relies at the Fair is a magnetic electric machine loaned to the Hanson \& Van Winkle Company by the corporation of Birmingham, England. It is said to have been built by Woolrych in $154 t$ for Thos. Prince \& Son and was the first machine success. fully used. It was in constant use until 1877 when it was superceded by a more modern machine.

On the 1eith inst. Mr. George Ferris, the engineer and designer of the Ferris wheel, with a party of friends and stockholders of the comprany made a trial trip around the great wheel. When completed it is to be lighted by electric lights and will be undoubtedly a very attractive object at night. The current is to be conveyed to the lights through slicling contacts on the axis of the wheel.

The Conz electric night signal apparatus recently installed in one corner of the German exhibit and near the central tower, is not large, but deserves attention. It seems remarkably simple, but is said to have been adopted by the German and Duteh navies. It consists of three double lanterns, one half the globes of which are colored red and the other half white. Two incandescent lamps corresponding to the colors are placed in the lantern. The lanterus are suspended by eables about seven feet apart. Each light is controlled from a controlling box, which is about eight inches square. This box has 14 points on the top, repres enting different combinations of the lights. A central handle with pointer is the arrangement by which the combinations are made. Mr. Chas. H. S. Schultz is the Chi eago representative.

Tests were made on Saturday night of the high tension apparatus of Prof. Thomson in the General Eleetric Company's exhibit. The apparatus is capable of producing a spark 64 inches in length with a potential estimated at $2,000,000$ volts. Some little difficulty was experienced in manipulating the apparatus and the full capacity of the machine was not showr. With some adjustments it will undoubtedly work better at the next test.

F. A. Ringler \& Company, 21 Barclay St., New York, have a beautiful exhibit of electroplated material and electrotypes in their space just east of the departneut offices in the gallery of the Electricity building. The electrotypes of engraved steel plates are especially fine. A unique feature is the plating of any article which one desires to preserve of any material. They are first corered with copper and then plated with any metal desired.

It is expected that the headquarters of the American Institute of Electrical Engineers will be an exhibit in themselves. Mr. Hammer has shipped six large frames of photograjhs, Mr. William Wallace contributes some interesting apparatus, Prof. Feraris, of Turin, Italy, has shipped the experimental apparatus used in his discovery of the principle of the rotating field and Van Nostrand has promised a complete library of electrical books.

The Charles Munson Belting Company, of 22-36 Canal St., Chicago, have a unique exhiloit, not only of their wellknown leather belting, lut also of leather ornaments and furniture, leather chairs, tables, carpet, feuce and railing, gate posts, etc. A sample of an $\$ t$-inch double leather belt shows the eapacity of their hydraulic press and the method of jointing. Mr. H. B. Morgan is in charge and will be found a genial companion for a talk on belting.

Advisory Council, Chicago World's Congress of Elec. tricians.

l'resident, Dr. Elısila GRAY, Highland lark, 11 . EXECUTIVE COMMITTEE.

Prof, Elihu Thomson, Chairman, Lynn, Mass. F. S. Terry, Chicago.

George M. Phelps, New York City.

Prof. B. F. Thomas, Columbus, O. E. M. Barton, Chicago. COMMITTEE ON INVITATTON:

T. C. Martin, Chairman, New York. Dr. Louis Dnnean, Baitimore. Prof. C. R. Cross, Boston. T. D. Lockwood, Boston. C. H. Wilmerding, Chicago. COMMTTEE ON PROGRAMME:

Prof. T. ( Mendenhall, Chairman, Washington, I. C. Carl Hering, Philadelphia, Pa.

Prof. W. A. Anthony, Manehester, Conn. Prof. H A. Rowland, Baltimore, Nld. A. E. Kennelly, Orange, N. J.

Prof. F. B. Crocker, New York City.

Prof. E L. Nichols, Ithaca, N. Y, FINANCE COMMTTEE:

B. E. Sunny, Chairman, Chicago.

Prof. E. J. Houston, Philadelphia.

W. A. lireidler, Chicago.

ILon Sec : Prof, U. S. CArHart, Ann Arbor, Mich. (Member Prog'me Com.) 


\section{PERSONAL.}

Mr. Frank B. Rae, of Detroit, made a hasty visit to Chicago on the 15 th.

Thos. D. Lackwood, of the American Bell Telepbone Co., Boston, is in the eity.

Mr. Chas. B. Fairchilds, editor of the Street Railway Journal, was in the eity on the 16 th.

Mr. W. F. Richardson, of the Enterprise Electric Company, returned a few days ago from a ten days' tr ip in the east.

Mr. Ludwig Gutmann, of Pitsburgh, lately with the Westinghouse Electric \& Manufacturing Co., is in town for a few days.

Mr. W. H. Preece, chief of the British Postal Telegraph service, sails for America August 5 th on the Paris, and will pay quite an extended visit to the Fair.

Hon. Jacob Hess, commissioner of the New York Board of Electrical Control, was in town for a few days last week at the Auditorium. The commissioner will return later and make an extensive examination of the electrical features of the Fair.

\section{The Cummings \& Engelman Conduit Company.}

The Cummings \& Engelman Conduit Company has just been organized in Detroit, with a paid up capital stock of $\$ 300,000$. The president of the new company is Mr. James F. Cummings, the treasurer and general manager being Mr. E. M. Engelman. Mr. Cummings is well known to the electrical fraternity from his former connection with the Edison company whose interests he served for several years in the laying of underground conduit. As a result of his former experience he has brought out a new conduit system which will be known as the Cummings and Engelman system, recently illustrated in these columns. Mr. Engelman is a thorough mechanical engineer, havin $€$ had a practical experience covering the past five years. The new company has patents for the United States, Canada, England, Germany, France and Austria for high and low tension long distance transmissions of power, and for electric railways.

The low tension system which it will promote, will, it is claimed, take eare of as high as 5,000 volts, using bare copper wires, while the high tension system will take care of 100,000 volts using bare copper wires. The company is at present putting in a conduit for the Co-operative Electric Light \& Power Company, of Chicago, which is to use the Siemens \& Halske system of lighting. In this plant bare copper wires will be used to carry a 2,000-volt alternating current. In addition to this large contract the company is also putting in a low tension system for the Edison Company, of St. Paul, the Edison Company, of Detroit, and a number of others. The company has established an extensive plant to manufacture its patents in Detroit, at the corner of Fourth and West Congress sts., with main offices in the new telephone building of that eity. The new company invites all interested in electrical work to call and visit them. At present Messrs. Cummings and Engelman are in Chicago overseeing the putting in of their system for the Co-operative company, and besides are just now establishing a company in Canada for the manufacture of their patents.

\section{BUSINESS NOTES.}

The souvenir of the World's Fair issued by the Eureka Tempered Copper Company, of North East, Pa., is very tastily gotten up.

The Stow Manufacturing Company, Binghamton, N. Y., has recently placed on the market a portable electric motor for driving the well-known Stow flexible shaft.

The Enterprise Electric Company, Chicago, reports very brisk trade in fan and power motors. N. I. R. wire, which the company is agent for, is in good demand, and the capacity of the factory is now being doubled in order to take care of its rapidly increasing business.

The Hoppes Manufacturing Company, Springfield, Ohio, have recently made a number of large sales of live steam feed water heaters to street railway companies. This company is able, with its excellent shop facilities, to manufacture feed water heaters of any size and eapacity.

The Tice-Lintner Electric Company, Minneapolis, Minn., are among the pushing electrical houses of the northwest. The new potential indicator recently placed on the market by this company has received many favorable comments from the trade and will no doubt find a ready sale.

QUEEN \& Co., incorporated, Philädelphia, Pa., carry a large stock of magnetic vane ammeters and voltmeters, which they ean ship promptly. These instruments are specially valuable for isolated plants, combining qualities essential for switch board work. A number are in use by various exhibitors at the World's Fair.

Chas. A. Schieren \& Co., 46 Canal St., Chicago, make a specialty of perforated leather belting for central stations and power plants. Their exhibits in Machinery Hall and the Electricity Building show the goods for which they are well known and will well repay a visit.

Chas. Mundt \& Sons, 88, 90 Walker St., New York, report large sales of perforated metal to makers of motors and dynamos. The kind and quality of work done by this firm is well known to all branches of the electrical trade. All kinds of perforated metal are made by them, but a specialty is made of perforated lead for street railway work.

The Ansonia Electric Co., Michigan Ave. and Randolph St., Chicago, have recently issued a circular descriptive of the Wirt dimming switch, which is a great convenience and luxury in sick rooms. This company has recently closed a contract for upwards of 40 miles of shield brand wires, and during the past month has sold large quantities of Habirshaw wire. The sale of Stanley transformers is active, largely due to the good grade of the goods.

R. Thomas \& Sons Company, East Liverpool, Ohio, has established western headquarters at 115 Dearborn St., Chicago, with Mr. J. E. May, manager. A full stock of porcelain electrical supplies will be kept there which will enable it to supply its western customers promptly. The company has made a number of improvements recently at its factories, including new buildings and new machinery.

The Electric Appliance Co., Chicago, promises some marked improvements in the Elkhart transformers in the way of a new fusing arrangement, particularly adapted for eircuits of 2,000 volts primary. It is also improved by the introduction of a system of removable coils, making it a very simple matter to repair an occasional burn out. Since the Electric Appliance Co. took the western agency, the sales of the Elkhart converters have been very large, and are now used in all parts of the country.

General Manager Echert, of the Telautograph, reports considerable progress in the business, and is expecting to fit out a number of central stations, now under eontract, as soon as the material can be gotten under way. Prof. Gray is constantly improving the apparatus as well as getting out new material. The exhibit at the Fair will be connected this week with the city of Chicago, so that a practical demonstration of its usefulness can be had by all. Prospects in this field promise very well.

The managers of the Columbian Intramural Railway treated the denizens of Midway Plaisance to an excursion around the grounds of the Exposition recently. Representatives from the different nations exhibited turned out for the ride. A brass band from the Indian school furnished the music for the party. Numerous photographs of the novel sight were taken and will be used to advertise the company. The sight of representatives from the older nations in their odd costumes riding on one of the most modern roads was certainly unique.

The Western Electric Compant, Chicago, has just closed a contract for putting in an are and incandescent central station plant at St. Clair, Mich. The eompany has also received a contract for lighting the new Hanneman Hospital, Chicago, with incandescent lights, including the complete electric equipment throughout of annunciators, call bells, etc. The new St. Nicholas Hotel of St. Louis which is to be one of the finest in the country is to be lighted by the Western Electric Company's system of incandescent lighting, the contract for which was closed recently. 
Electrical heating apparatus is receiving considerable attention of late, but we are conceited enough to think that we have something more to the point and appropriate to the season in our

apparatus. We are having a great run on
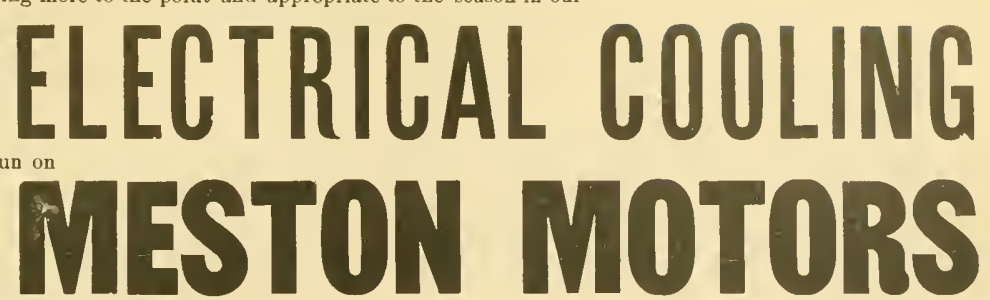

which have undisputed control of the alternating current fan motor field.

Are you pushiug them and getting your share of the profits that are to be made out of the fan motor business this year?

ELECTRIC APPLIANCE COMPANY,

ELECTRICAL SUPPLIES,

CHIOAGO.

e4e Madison Street, The "BUCKEYE" Lamp

A KNOWN Quantity
No EXPERIMENTING
Low Operating Cost
Improved Lighting Effects

"The BUCKEYE sets the pace"

THE BUGKEYE ELECTRIC CO., Cleveland, 0.

Chicago 437 THE ROOKERY
New York

49 DEY STREET.

\section{THE MATHER ELECTRIC CO,} MANCHESTER, CONN.

Dynamos, Motors, Benereators,

Offices, II6 Bedford St., BOSTON.

$$
\text { AND- }
$$

1002 Chamber of Commerce BIdg,, CHIGAGO.

\section{THE "NOVAK" LAMP.}

\section{CLAFLIN \& KIMBALL (Inc.)}

Ceneral Selling Agents.

II6 Bedford Street, BOSTON.

1002 Chamber of Commerce Bldg., CHICAGO.

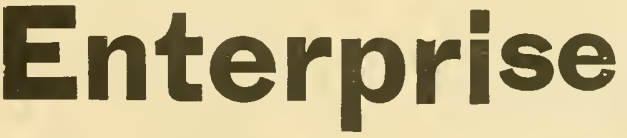

Electric Company

307 Dearborn Street, Chicago ....
Manufacturers' Agents and MIII Repre* sentatlves for

Electric Railway,

Telegraph, Telephone and Electric Light

SUPPLIES

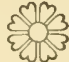

Agents for Cedar Poles,

Cypress Poles, Oak Pins,

Locust Pins, Cross Arms, Class

- Feeder Wire,

Insulators,

WIRES, CABLES, TAPE and TUBING 


\section{ELECTRICITY BUILDING-EXHIBITORS AND THEIR LOCATION.}

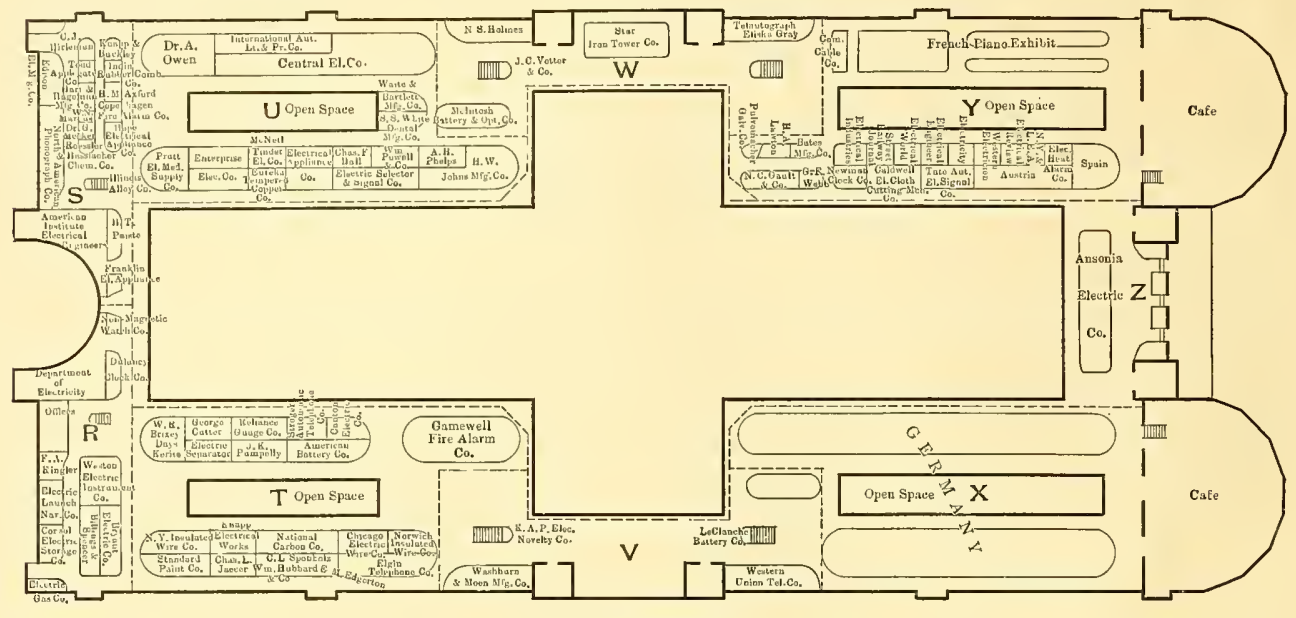

GALLERY.

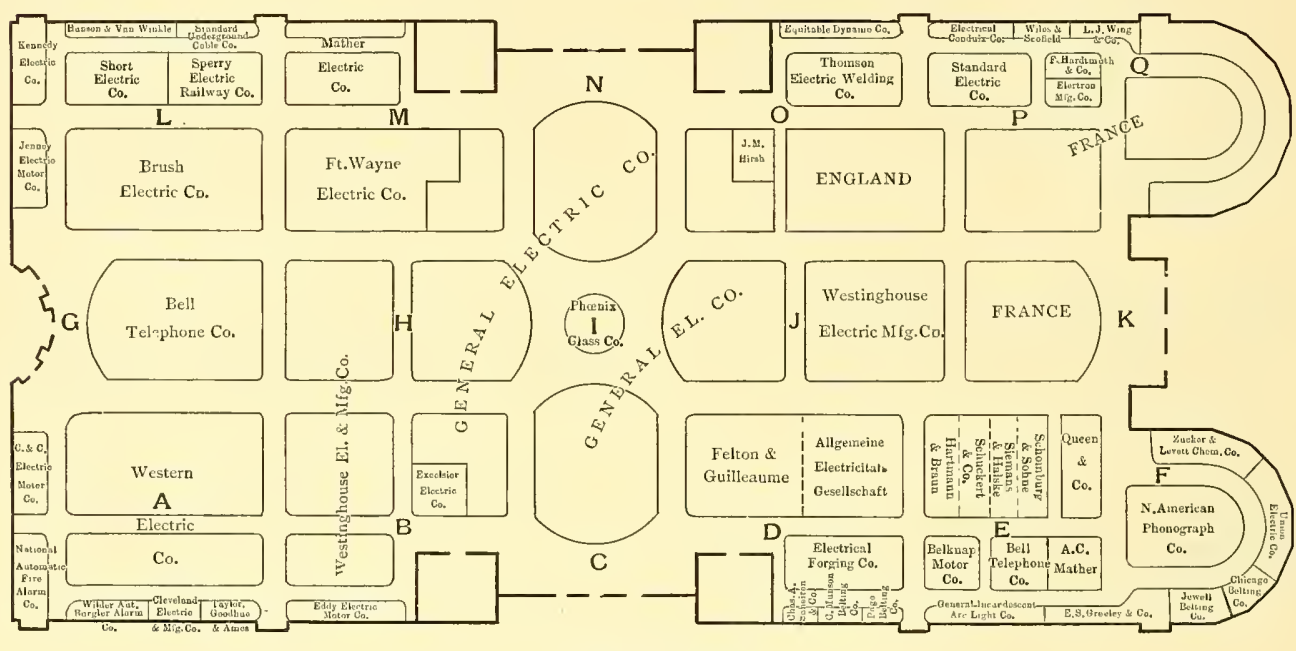

\section{MAIN FLOOR.}

Exhibitor.

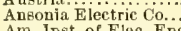

Am. Inst. of Elec. Eng

American Battery

Allg. Elec. Gresellschät.

Bates Mfg. Co..............

Billings \& Spencer.

B-lknap Motor Co.

Bell Telephone Co

Brash Electric Co ................

Caldwell El. Cloth Cut. Mich. Co...

Consol. Elec. Storage Co

natter, George

Chicago Elec. Wire Co.

Copenhagen kire Alarm Co.....

Central Electric Co

C. \& C. E ec. Motor Co

Clevelaud Eirc. \& Mfg. Co

Chicago Belting $\mathrm{Co}$

Department of Electricity.

ELECTRTCAI INDESTRIES

Elec. Launch \& Nay. Co.

Electric Separato

Elgin Telephone Co.

Elgin Telephone Co
Edison Elec. Mfg. Co

Enterprise Elec. Co.

Eureka Temp. Copper

Electric A ppliance Co

Electric Heat Alarm Co.
Section. Exhibitor.

Electrical Revi

Electricity ..............

Eleetrical Enginee

Electrical World..................

Excelstor Electric Co.

Electrical Forging $\mathrm{C}$

Equitable Dynamo

Electrical Conduit Co

England

Empire China Wor

Franklin Elec. Appliances

French P Lado Exhibit

Felton $\&$ Gnlleaume

Ft. Wayne Elec. Co

Gault \& Co., N. C .................. Y

Gamewell Fire Alarm Co...... \& T

General In and's't Arc L't Co.

Greeley, E. S., \& Co

Hubbard, wm.. \& Co.

Hirleman, C. J..................

Hope Elee. Applince Co.

Hall, Chas.

Holmes, $N$.

Hantman \& Van Winki

Hirsh, $\mathrm{N}$.

Illinois Alloy Co.................
Internat. Ant. L't \& P
India Rubber Comb Co....
Sectiun. Exhibitor:

Jaeger, Chas. L....... Section.

Jewell Belting Co. $\mathrm{H}$.

J. nney Elec. M otnr Co.

Koapp Electricat Worki...

Knapp \& Buckley

Kenpedy Electric Co.............

Lawton, II. A

LeClanche Battery Co. ...

MeNeil-Tinder Elec. Co.

$H \operatorname{arcus}, \pi . N$

Meeker, Dr. G..................

Mnn on, C. Belting Co

Muther, A.

Wather Electric Co

Non-II cotic Watch

$\mathrm{N}$. Y. Insulated Wire Co.

National Carbon Co....

North Am. Phonngraph

N. Y.\& L. E. A

Nat, Ant Fire Alarm Co.

Nat. Engraving Nachine Co

Owen, Dr. A

Phoenix Glas.

Paiste, H. 'T..............

Pumpelly. J.

Pratt El. Nied. Sup. Co

Powell, $W \mathrm{~m}$. \& $\mathrm{Co}$.

Page Belting Co.

Qneen \& $\mathrm{Co}$
Exhibitor.

Reliance Guage Co........... Section.

Roeseler \& Hasblacher Chem. Co.....

Street Railway Jonrnal............. Y

Strowger Ant Telph, Co..

Standurd Paint $\mathrm{C}$

sponbolz, $\mathrm{C}, \mathrm{L}$...

Sphin.........................

Schombure \& Sohne

Siemene \& Halske.

Schuekert \& Co

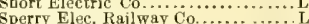

Standard Underg. Cuble Co

Standard ectric Co.

Tate Ant, El. Sigual

Todd Applegate co

Taylor, Goodhne Ac Ames............. A

Thomson Elec. Welding Co .........

Webb, $G$. Washbnrn \& Noen Mfg. Co........

Western Inion Tel. Co........... .

Waite \& Bartlett Mfg, Co............ U

Western Electrician ................. Y

Wilder Ant. Burglar Al. Co. .......... A

Westinghonge El. \& Nifg. Co _...........J

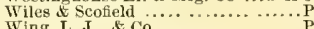

Wing, L. J, \& Co................ 


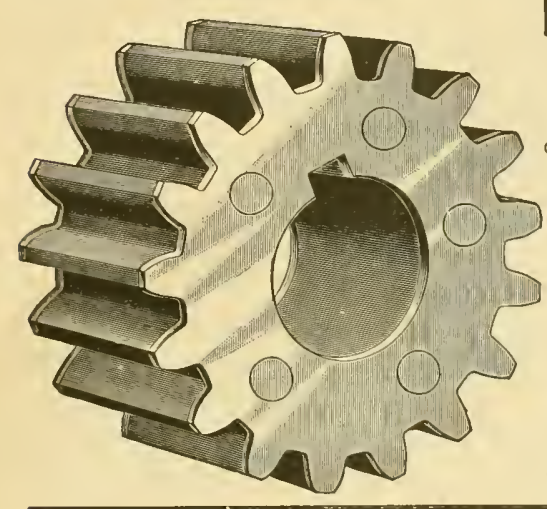

RAWHIDE PINIONS FOR ELEGTRIC MOTORS A SPECIALTY.

RAWHIDE DYNAMO BELTING

Greatest Adhesive Qualities. A Non-Conductor of Electrlcity. Causes Less Friction than any other Belt.

THE GHICAGO RAWHIDE MANUFACTURING CO.

THE ONLY MANUFACTURERS IN THE COUNTRY.

\begin{tabular}{|c|c|}
\hline $\begin{array}{l}\text { LACE LEATHER ROPE } \\
\text { OTHER RAWHIDE }\end{array}$ & $\begin{array}{l}\text { This Belting and Lace Leather is } \\
\text { not affected by steam or dampness; } \\
\text { never becomes hard; is stronger }\end{array}$ \\
\hline $\begin{array}{l}\text { GOODS } \\
\text { OF ALL KINDS } \\
\text { BY KRUEGER'S PATENT }\end{array}$ & $\begin{array}{l}\text { ical Pelting made The Raw- } \\
\text { hide Rope for Round Belting } \\
\text { Transmission is superior to all } \\
\text { others }\end{array}$ \\
\hline
\end{tabular}

75 Ohio Street,

CHICACO, UL

\section{THE REGULAR MONTHLY EDITION}

\section{....OF ... \\ Electrical Industries}

Is read more widely and used more constantly for reference by actual buyers in the electrical field than any other similar publication. WHY? Because it has in every issue handsomely illustrated special articles and descriptions of everything of interest in the electrical world besides a complete

BUYERS DIRECTORY giving the names of all the manufacturers and dealers in the trade; a complete directory of

ELECTRIC LIGHTING CENTRAL STATIONS and a complete directory of the

ELECTRIC RAILWAYS of North America corrected to the date of going to press, features found in no other electrical journal in the world.

The Weekly World's Fair issue contains the most novel and unique features yet undertaken by an electrical Journal.

Sample copies free on application. Every electric lighting company should write for our special terms. IVe are now making the most liberal offer to subscribers for both publications during the next few months ever made by an electrical paper.

\section{ELECTRICAL INDUSTRIES PUB. CO.}

Monadnock Block, CHICAGO. 

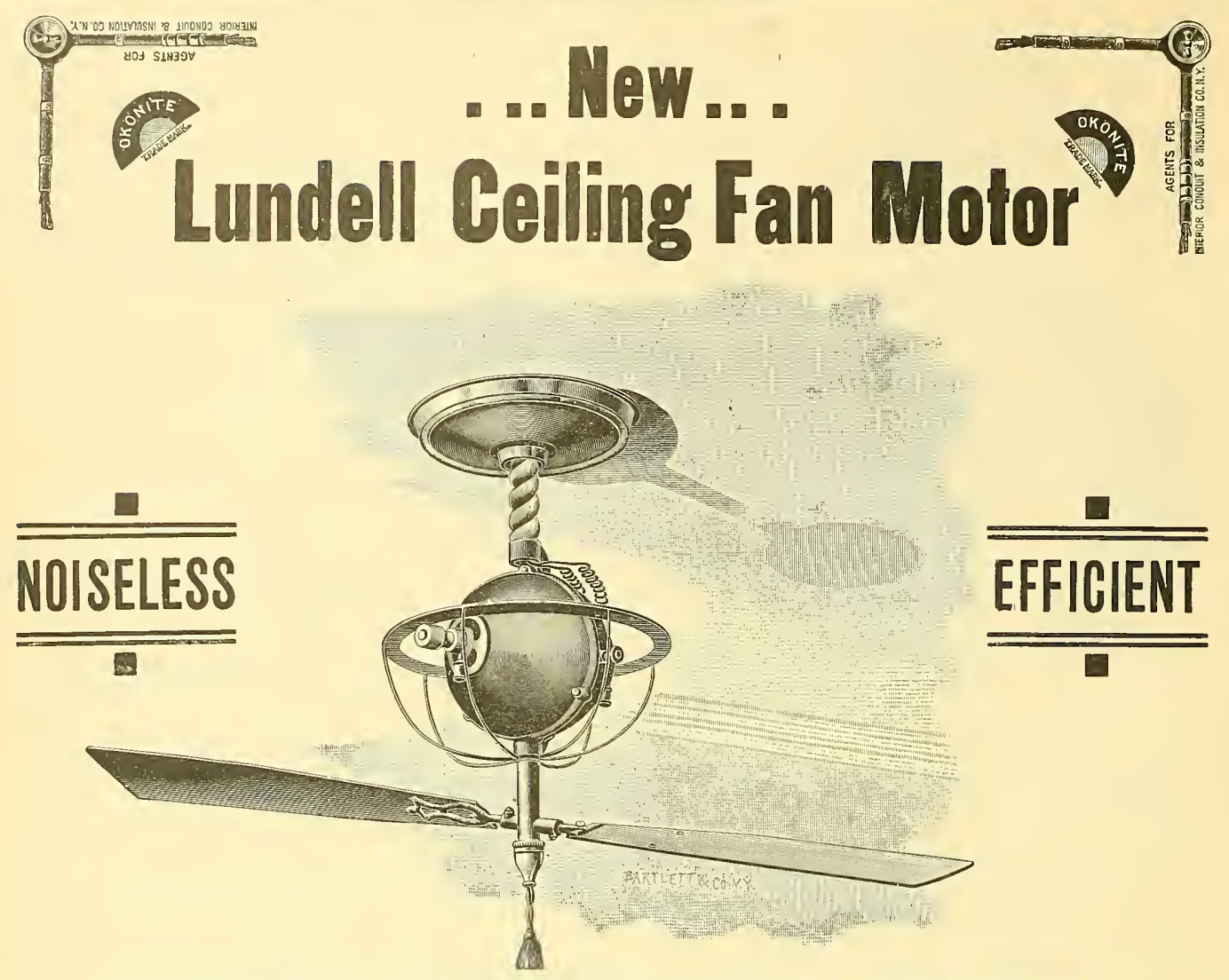

FINISHED IN BLACK JAPAN AND ANTIQUE POLISHED BRASS FAN BLADES BLACK WALNUT-PENDANT SWITCH

Okonite Wires and Gables Okonite and Manson Tapes Interior Conduit Lundell Power and Exhaust Fan Motors.

\section{GENERAL SUPPLIES OF ALL KINDS}

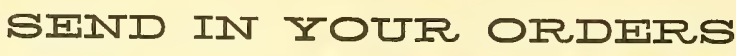
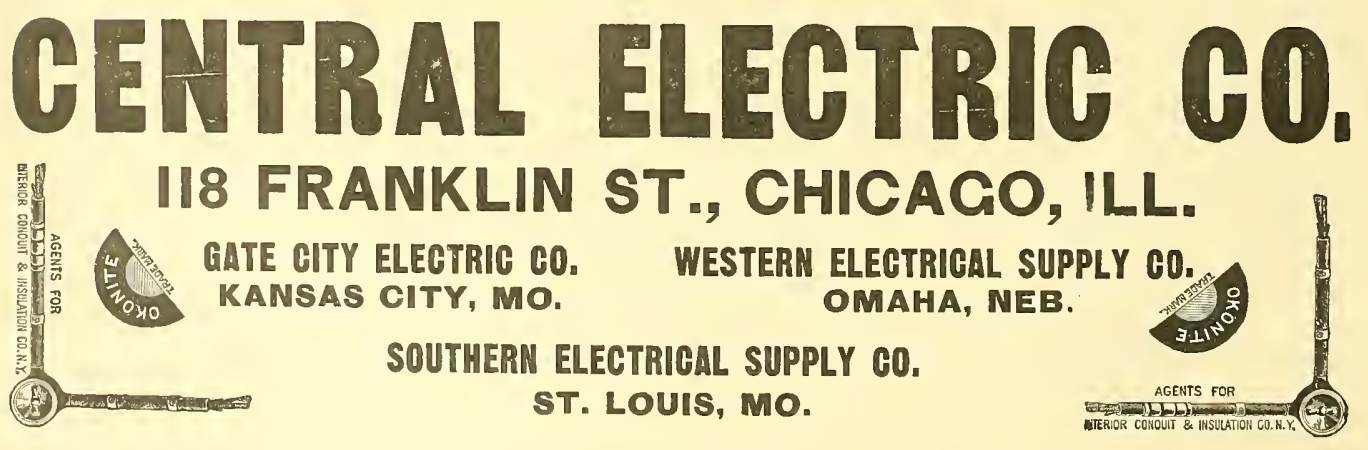
Map of Chicago.

Showing Location of its Electrical and Allied Business Interests, PrineipaI Hotels, Theatres, Ilepots and Transportation Lines to the World's Fair Grounds. (Index numbers refer to the black squares.)

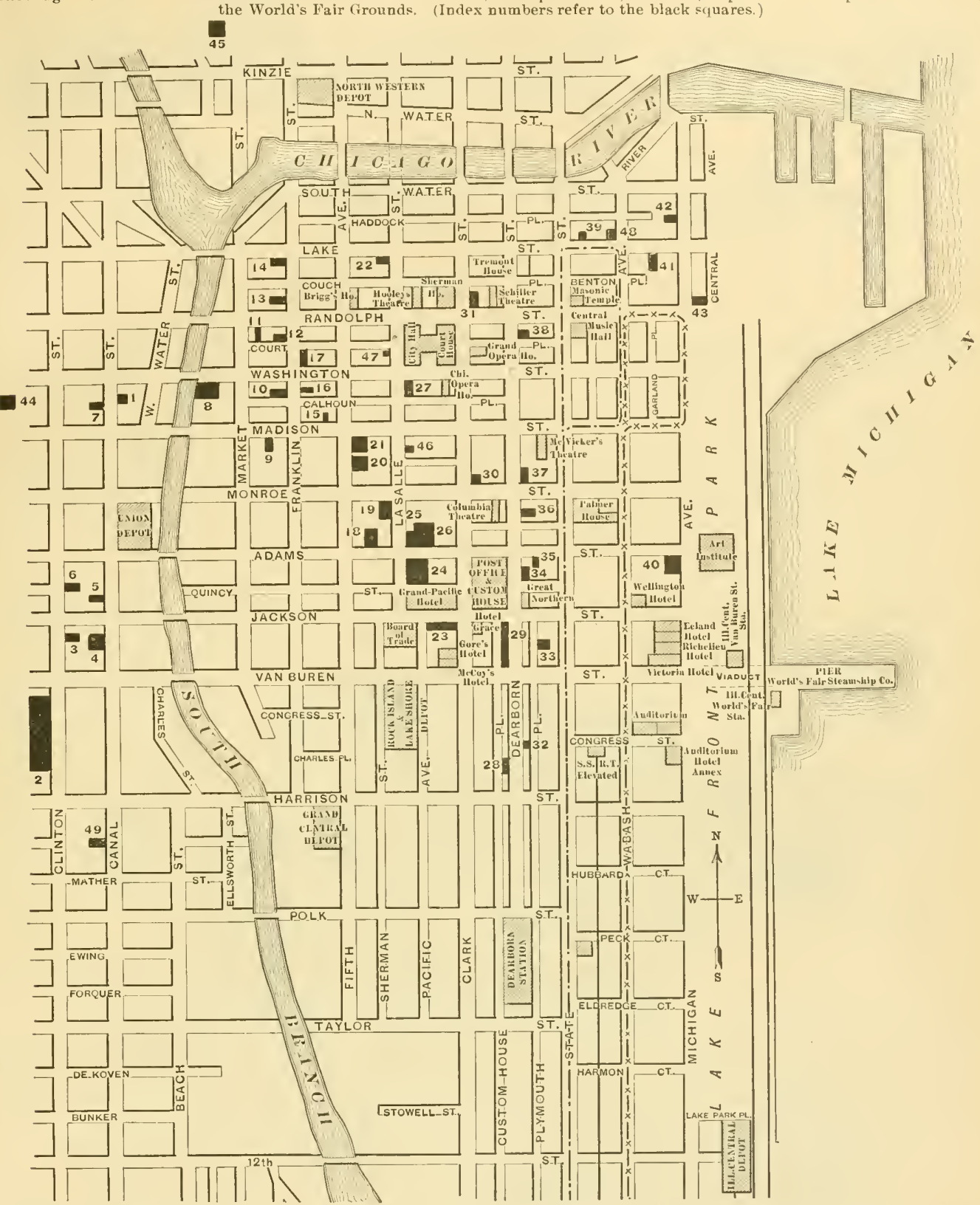

Ansunia El-c Co., Micbigan Are. \& Raulo ph st .. 4.3 Commereial Elec Co.. Monadnock lBlock. American Battery ('o., 18* vadi-on st. Bartholomew, Stow \& Co, si Michigith Ave. Barton a brow, ltin alonadnock Block. Benbam, A. O., wo s. Clinton st

Brngh Electric Co vlonaduet Block

Buckeye Electric Co 137 Rookery 1 .

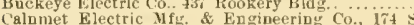

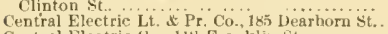

Central lilectric en..

3 Commercial Elec Co.. :

42 C. \& C. Electric Motor ("o., 201 3iadi on

29 ULgir El. Trieplione Co, stork Exchange Bid

23 Edwarda. W s. Mfg. Co at Lake St

Eddy Electric Vifu. Co. 141 . Monadaock Block.

Electric Coustruction \& Supply Co., Unity Bldg

Electric Appliance Co., 212 Madieon St.............

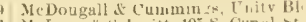

6 Me Lean d Schmitt, 195 S. Cun 4 ! ot ........ Bid

Mlather Blec. Co., Chamber of ('ommetce Bid

Nationil Elfe. Ml fg. Co.. Pullman lildg.

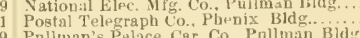

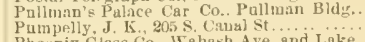

Phornix Glass Co., Wahash Ave. and Lake

Railway Eqnipment Co. Pullmu Bldg...

Rockford Elec. \& MPg. Co., 94 La salle st.

10. Ft. Wryoe Electric Co,

Chical Wight \& I Eeat Co.. 52 Like St ....

The

Cbicago Telepbone Co., 203 W ashington St.........17 General Electric Co., 175 Adams ot.....

26 General Incand. Arc L't. Co., 175 Adems st....

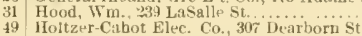

Chicaro Electric Motor Co., 313s. Canal St.........

Chicago Insulated Wire Co..214 The Nortbern ............. Jenney Elec. Motor Co. 932 Monadock Block.

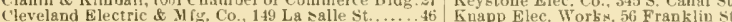

(Eutter, Geo 851 The Rookery

Gusbing \& Hilorae, 225 Dearborn St.

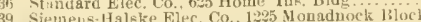
star Elec Lamp co 805 Chamber of Com. Bldte Stirling Co 006 Pullmg Blidg 18 Sehieren, Chas. A., E Co., 45 S. Canal st....

aylor, Goodhye A Ames, 348 Dearhorn

Todd. Applegate Co. The, 310 Dearborn

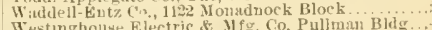

4!) Wretern Electric Co.,227 S. Cliuton St.

Wentern Lnion Telegraph Co., Phenix Bldg........ 


\section{Western Electríc Company, CHICACO. NEW YORK.}

Arc Lighting Apparatus

High and Low Tension,

Double and Single Service Lamps,

All Night Single Lamps,

Theater and Focusing Lamps.

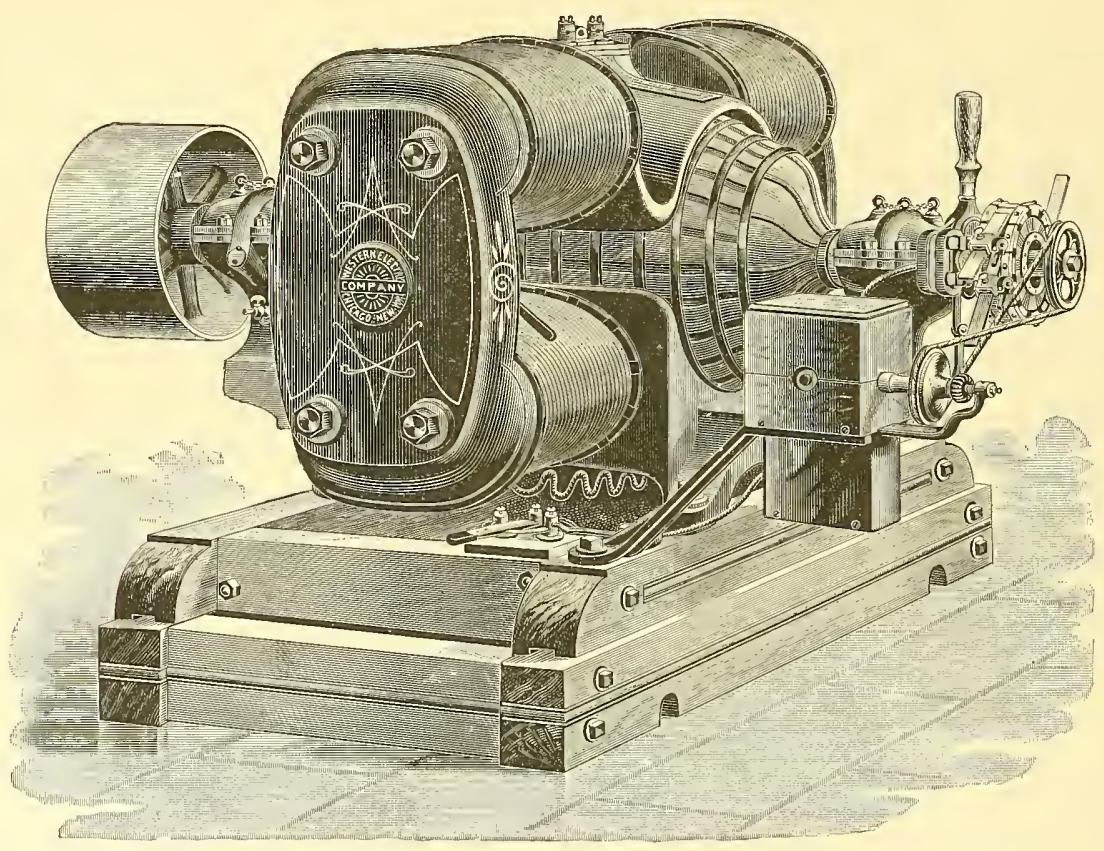

SLOW SPEED

INGANDESGENT DYNAMOS AND POWER GENERATORS.

SLOW SPEED MOTORS. 


\section{Fort Wayne Electric Co. \\ FORT WAYNE, IND.}

Manufacturers of Apparatus for Arc Lighting; Alternating Current Lighting; Direct Current Incandescent Lighting; Generators for Railway and other Motor Circuits; Accurate Measuring Instruments, Meters and General Supplies. This Apparatus possesses the highest Electrical Efficiency, best Mechanical Construction and the most Artistic Design.

The Armature of the new "Wood" Iron Clad Slow Speed Alternator is indestructible. These dynamos are being manufactured in the following sizes, 750 light, 1500 light, 3000 light and 6000 light capacity.

Twenty-six styles "Wood" Arc Lamps for Constant Current Circuits, Constant Potential Circuits and Alternating Circuits. Noiseless, no extra Rheostat.

The largest stations in existence are of the Fort Wayne Company's System.

\section{SEE OUR APPARATUS IN OPERATION AT OUR WORLD'S FAIR EXHIBIT.}

\section{BRANOFI OFFIOFS:}

New York, 42 \& 44 Broad St.

Chicago, 185 Dearborn St.

Philadelphia, 907 Filbert St.

Pittsburgh, 405 Times Building.

Syracuse, Kirk Building.
Columbus, Ohio, 67 East State St.

San Francisco, 35 New Montgomery St.

City of Mexico.

Dallas, Tex.

New Orleans, 52 Union St. 


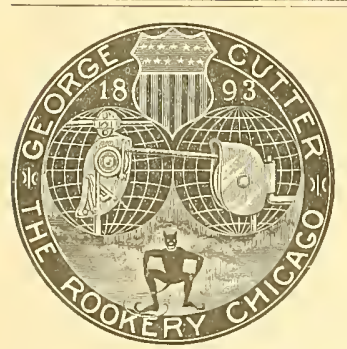

See Our

Exhibits:

East Gallery

Electricity Bldg.

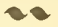

And another:

$85 I=853-855$

The Rookery.

\section{XNTRIC}

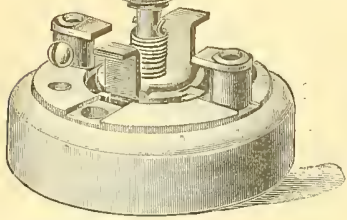

Made 5 amp. S. P.

10 amp. 3 way.

"That's the Switch"

And we control that movement.

H. T. PAISTE,

10 South 18 th St., PHILADELPHIA, PA.

Consolidated Elpctric 6.

Manutacturers and Dealers in all kinds ol

\section{ELECTRICAL . SUPPLIES,}

115 Franklin Street, CHICACO.

. . SEE AD ...

Western Electric Co.,

PACE 14

\section{CHAS. A. SCHIEREN \& CO.}

MANUFACTURERS OF

\section{Genuine Perforated Electric Leather Belting.}

4.6 So. Canal Street, -. CHICACO.

Section 15, Dpt. F. Clm. 27.

Section D, Space 3.

MACHINERY HALL. ELECTRICITY BUILDING.

\section{SIMPLEX WIRES}

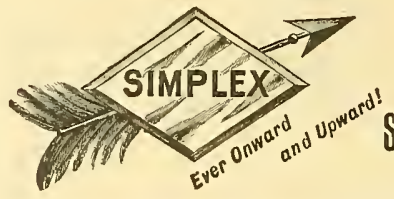

INSURE

HIGH INSULATION

George Cutter, Chicago. BOSTON, MAss. 620 Atlantic Ave.

2.1 P. \& S

CHINA SWITCHES

Simplest Neatest -

Made only by

PASS \& SEYMOUR, Syracuse, N. Y. George Cutter, Chicago.

\section{BEAR IN MIND}

that the regular monthly issue of ELECTRICAL INDUSTRIES contains the most complete and correct directories published of the electric light central stations and the electric railways in North America.

World's Fair Headquarters Y 27 Electricity Building. CITY OFFICES, Monadnock Block.

\section{WAGNER ELECTRIC FAN ROTORS}

For Direct or Alteruating Curent:

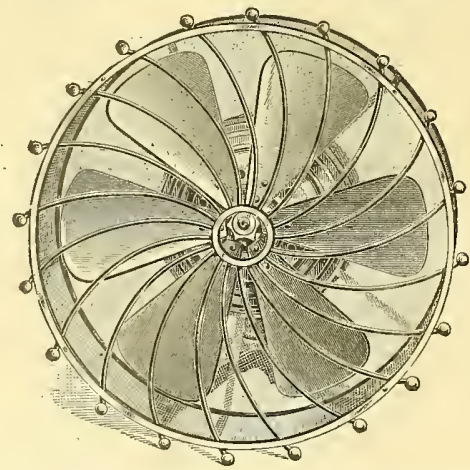

These motors give a stronger breezit with less consumptinn of eurrent than any other fan motor on the miarket. They are fall $1-8$ horge power. Six bladed 12-inch fan. Self-oiling. Fnrnished with or withont guards.

IT WILL PAY YOU TO SEE THE WAGNER BEFORE BUYING ELSEWHERE

TAYLOR, GOODHUE \& ARF ES, 348 Dearborn street, CHICACO.

IN SECTION "N", BETWEen COLUMNS 62 AND" 64, Manufactures BUILDING, 


\section{Weekly World's Fair Supplement.}

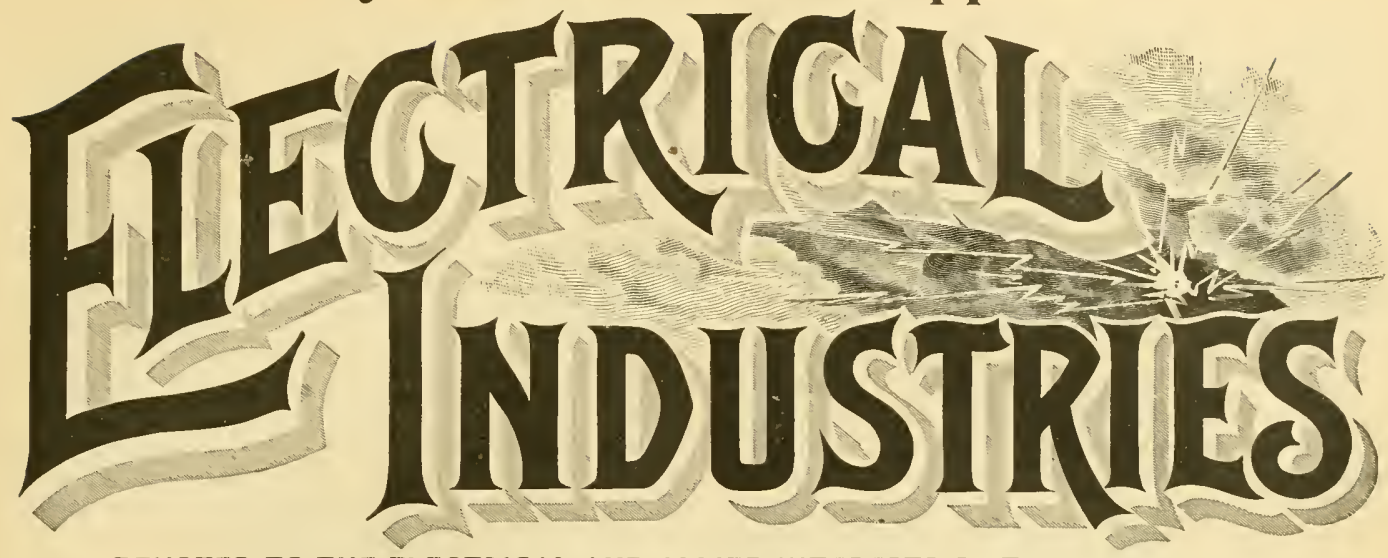

DEVOTED TO THE ELECTRICAL AND ALLIED INTERESTS OF THE WORLD'S FAIR, ITS VISITORS AND EXHIBITORS.

Vil, I, No, 3, CHICAGO, JUNE $29,1893$.

The Ferris Wheel.

W'hat the Eiffel Tower was to the Paris Exposition the modern feat of engineering skill rises far above the different villages in Midway Plaisance in marked contrast to the simple structures of the natives from the eastern hemisphere.

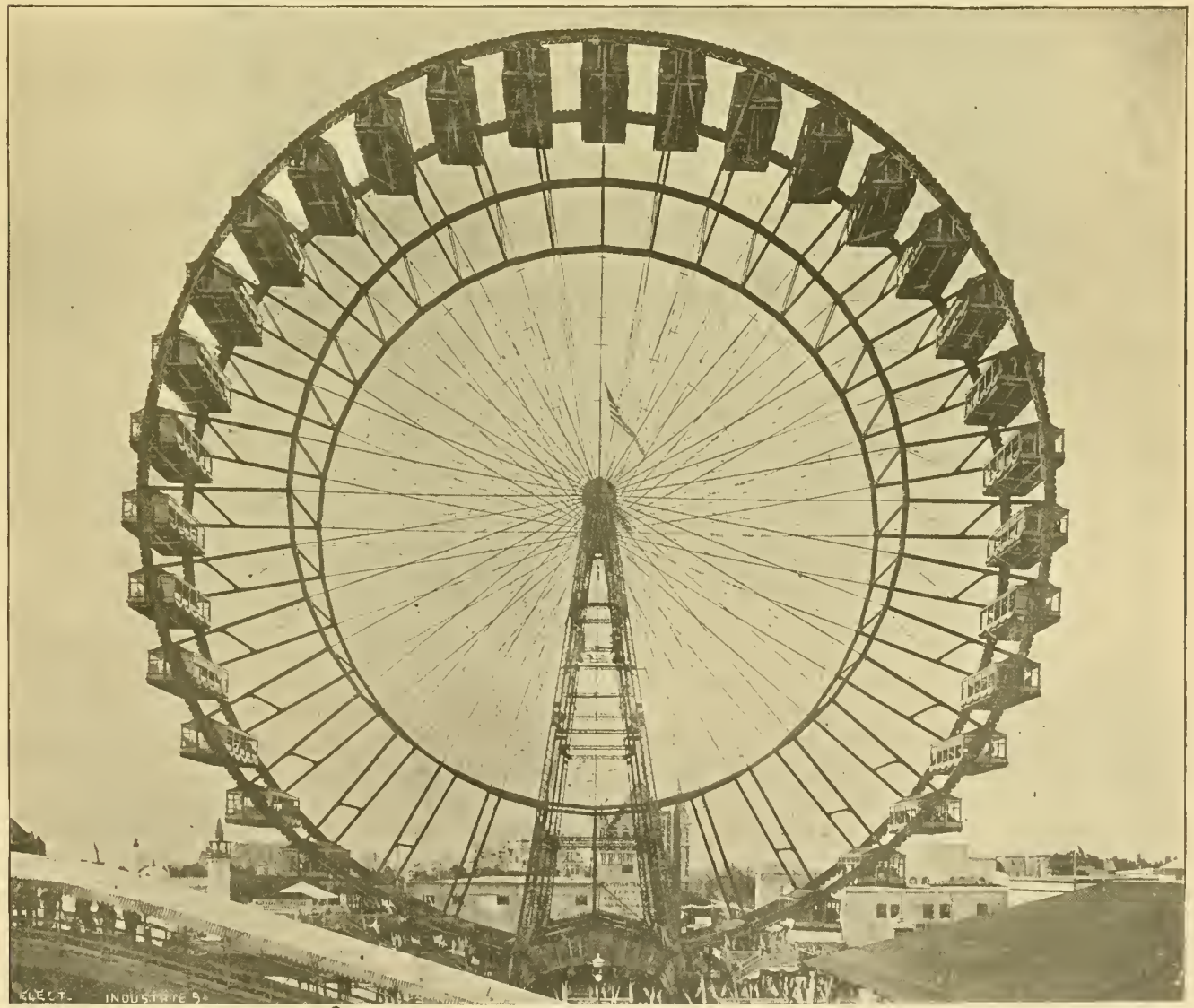

THE FERRIS WHEEL.

Ferris Wheel is to the World's Columbian Exposition. It is one of the most prominent objects and is seen by the visitor a long time before he reaches the entrance to the grounds. This
Although the idea of carrying people in seats attached to the circumference of a wheel is not new the construction of a wheel of such mammoth size and the manner of erecting 
it is decidedly novel. The engineering problems involved demanded the best of engineering skill and the workmen and material employed were necessarily of the best. As it is the most prominent object during the day it will also be one of the most prominent at night when it is lighted as it is now intended. Although the plans are not yet fully completed, the cars and offices as well as the framework of the wheel itself will be lighted by thousauds of incandescent lamps, and also numerous arc lamps.

The wheel was designed by Mr. George WT. G. Ferris, of G. W. G. Ferris \& Co., the well known engineers of Pittsburgh. It is built entirely of steel. The wheel is of the bicycle pattern 250 feet in diameter and 28 feet wide. The two outer bands are 40 feet apart. The total height of the wheel is 264 feet while the weight is three million pounds. It is built on a sub-foundation made of 30 to 40 foot piles
Steam, for motor power, is furnished, at 125 pounds pressure, by three Heine safety boilers of 400 -horse power each located 700 feet from the structure. The main steam supply pipe is of wrought iron with serew joints and 10 inches in diameter.

The engines built by Wm. Tod \& Co., of Youngstown, Ohio, are double, reversible and have piston valves. The cylinder dimensions are 36 -inch diameter by 48 -inch stroke rumning at 48 revolutions per minute. They have, in all, 1,000 nominal horse power. The gear on the engine shaft is about three feet in diameter with 14 -inch face, the teeth being $\mathrm{V}$ shaped across the face. The transmission shaft 12 inches in diameter is geared into the engine gear and extends each way to the nests of gears running to the sprocket wheels. There is a counter shaft gearing into the transmission on one hand and into the sprocket shaft on

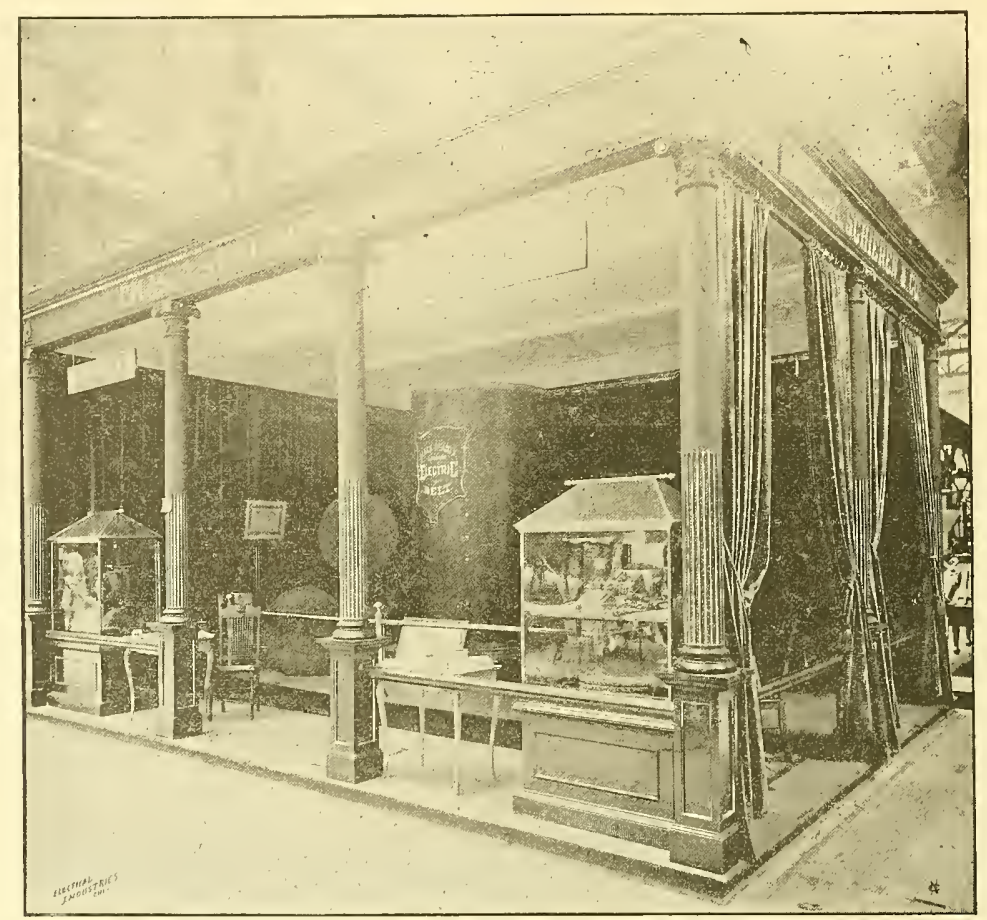

THE EXHIBIT OF CHAS. A. SCHIEREN \& CO. IN MACHINER MALI,

above which is a second foundation of conerete. The towers that support the wheel are pyramidal in form 135 feet high to the center of the shaft with a base 40 by 50 feet. The tops of the towers are six feet square and support the bearings which are of east iron lined with earbon bronze bushings. The four main legs of the towers are made of $24 \frac{1}{2}$ inch channel beams with latticed bracings. The shaft is of forged steel 45 feet long, 32 inches in diameter and weighs, with the hubs, 60 tons. This shaft was raised to its place by four engines, each with a four sheave block and falls. The piece was raised, resting against the west side of the towers, until it reached the top when it swung over and dropped into place. There are 36 cars, 26 feet long, 13 feet wide over all and seven feet bigh in the clear inside, which will seat 38 persons each. They are suspended from the periphery of the double wheel by heary steel pins in the top of the car so that the weight of the car always keeps its floor very nearly level. the other. The ratio of sprocket to engine revolutions is about one to 16 . The gears are very heavy, being made of east iron, and having a flange on each face rising as high as one-half the depth of tooth.

The two sprocket wheels on each side are nine feet in diameter and are placed 22 feet apart center to center. There are seren teeth on each wheel and on the face of the wheels are raised studs which catch the pin as the chain drops off the large wheels. The shaft of these wheels is 18 inches in diameter.

On the periphery of the two sides of the wheel are cast iron lugs having gear spaces sunk in them 24 inches apart the pitch diameter of which is 126 feet and the depth six inches.

The chain is formed like a huge bicycle chain of double iron links, 24.08 inches long from center to center of pins. The eyes are 10 inches in diameter outside, a five-inch pin being used, secured in place by a nut and cotter pin. The 
web of the links is five inches in width by one inch in thickness. In order that the links may wear as little as possible rolls are provided on the pins with the eyes and adjustable platforms under both upper and lower sides of the chain are provided for keeping the weight of the chain from the sprocket wheels.

To stop the motion of the wheel a band brake wheel nine feet in diameter, with a wood-lined sheet iron band, eight inches wide, is used on the counter shaft. This band is tightened from the engine by a common 12-inch air cylinder attached to a lever on the land. A fire-eighths inch pipe supplies air pressure, which is under the control of the engineer. Each loading gate, of whieh there are six, is provided with a push button connecting with an anmunei-
Mr. Ferris is quite a poung man, but 36 years of age, a graduate of the Rensselier Polytechnie lnstitute, Troy, N. Y.

The fact that the steel work was not commenced until Mareh, 1893, spealks well for the plant and ability of the Detroit Bridge Company, which built all the steel work. The steel was furnished by Jones it Laughlin, the Carbon Iron Company and Oliver of Pittsburgh. The castings for gears were furnished by the (iriffin Car Wheel Company, and the sprockets were made by the Walker Manufacturing Company, of Cleveland, O.

A large force is necessary for operating the wheel. Three shifts of engineers and firemen are required, a guard in each ear and one on each platform, a total of 42 , being re-

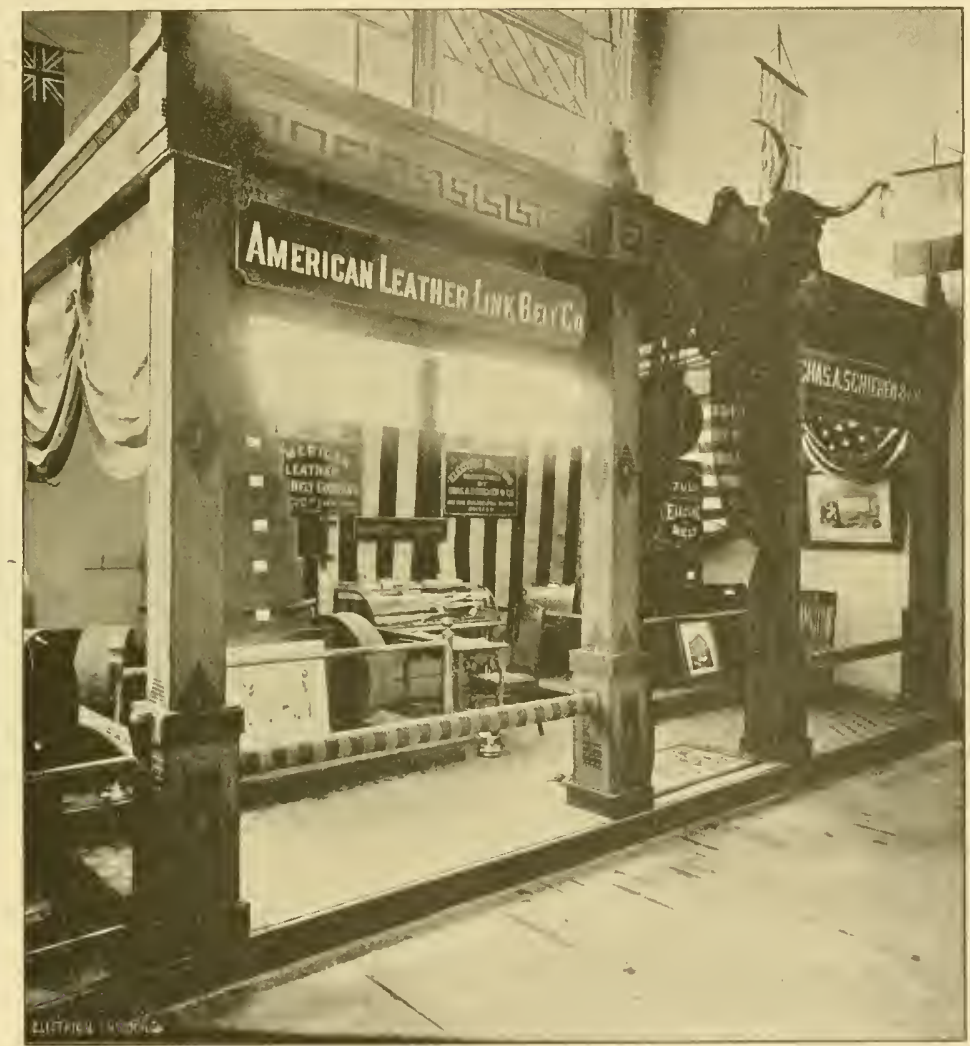

EXHIBIT OF CHAS. A. SCIEREN \& CO IN EAECTICITY BHLDING.

ator placed direetly in front of the engineer so that he may know when to start up.

Six cars are loaded at eaeh stop, from the six platforms provided. It takes about 15 minutes to load all the ears and ten minutes to go around and unload.

The huge structure is owned by the Pittslumrgh Construction Co., which is incorporated under the laws of the State of Illinois. The oflicers are: Rolst. WV. Hunt, president; George W. G. Ferris, engineer; L. V. Rice, general manager; H. R. Thornton, seeretary. The contractors were McCain Bros., the Rookery, Chieago; the inspector of eonstruetion being Geo. R. Buchan.

The wheel was designed by Mr. Ferris, the calculations made by $\mathrm{Wm}$. F. Gronau and the draughting done by Paul Laur, both the latter being with Mr. Ferris in Pittsburgh. quired for the wher l itself, together with six ticket sellers and six turnstile guards stationed at the entrances.

\section{Exhibits of Chas. A. Schieren \& Co.}

To visitors to the Centennial and Paris Expositions the name of Chas. A. Schieren \& Company must be familiar. Their exhibits at the various expositions have attracted the attention of visitors and have been apyreciated by the juries of award as shown by the various diplomas and medals received

Their exhibits at the World's Columbian Exposition are unique in clesign and the construction of the booth is worthy of a careful insprection. The method of construeting booths and pavilions of link belting has been studied with care and some very artistic combinations have been pro- 
duced in these exhibits which display to good advantage the construction and general qualities of the leather and the finished belts. The firm has quite outdone itself in this respect in the booth on the east side of the Electricity Building. A classic structure has been erected with four square supporting colums made of the link belt, using black links for the ornamental figures and the Greek scroll around the cornice. The columns are surmounted by small pyramids of belting and adorned with the Spanish colors and American flags. The huge bull's head with graceful and wide spreading horns, which serves also as a trade mark, is erected directly over the entrance to the pavilion and as the horns are each tipped with an incandescent bulb, the effect, joined with that of the light from the other lamps in each panel is pleasing in the extreme.

The interior of the booth is provided with chairs, tables, and a show ease containing numerous curiosities in belting, among which might be mentioned several old styles of belt joints; one made in $\mathbf{1 8 3 0}$ is laced and riveted without cement, another of 1840 riveted and sewed, and various old style English joints both sewed and riveted. Several pieces of belting are shown constructed of narrow strips of leather laid side by side on edge and fastened together by steel bolts. Other styles of joints are exhibited, the old laced joint, the joint made by fine wire lacing and the cement. Over this case hangs a frame constructed of link belting in which are contained the various medals received by them for the superiority of their product.

At the left surrounded by a brass rail is the exhibit of link belts by the American Leather Link Belt Company. It contains the diploma and bronze medal received at the Paris Exposition of 1889, also various coils of the belt. One large roll contains 100 feet of 36 -inch belt one-inch thick and others of $12,11,10$ and 9 -inch belt, all being eleven sixteenths of an inch thick and used for dynamo work are shown. Other coils fill out the geometric figures formed by those mentioned.

On the opposite side of the pavilion is the exhibit of perforated and electric belt the several smaller rolls being grouped tastefully about one large roll consisting of a "Zulu" electric belt, 72 inches wide. A roll of 14 -inch perforated electric, one of 18-inch and another of 16-inch are also shown. A photograph of the New York factory at 41-51 Ferry street rests against this exhibit.

In section F, block 27, Machinery Hall, Schieren \& Company have another very fine display. A large square pavilion of ebonized wood, touched out with gold leaf and gracefully bung with linen velour curtains of old rose color contains among others a roll so large that one doubts if the wheel has yet been built that will support it. This is a three-ply belt, 200 feet long and 96 inches wide and required the hides of 450 large steers for its construction. Grouped about it in graceful figures are rolls of the electric and perforated belt similar to those described in the exbibit in the Electricity Building. In a show case at the left are samples of the company's patent round and twisted belting, and in another case at the right are ex. hibited belt lacings both in rolls and in bunches tipped and plain. Belt dressing and coils of raw hide rope are also shown in the latter case. The names of the four principal offices of the company at New York, Chicago, Boston and Philadelphia are displayed on tasty signs on the front and back of this pavilion. Two diplomas received by the company at the Centennial and at Paris in 1889 adorn the walls. While the exhibit of belting at the Fair is large, Messrs. Chas. A. Schieren \& Co. can be said to have held their own in all ways and may well be proud of the display.

These pavilions do not contain all the belts of the firm at the Exposition. In Machinery Hall and the Electricity Building may be seen the Schieren belts in use on many of the various machines. Nearly all of the all-black belts in use at the Fair are of their make. The contracts from the Columbian Exposition Company amounting to nearly $\$ 8,000$ are shown at the Chicago office of the company. Visitors at the Fair interested in belts and belting will find pleasure in examining these exhibits.

\section{The Exhibit of the Belknap Motor Co.}

One hardly looks to Maine for mechanical industries except shipbuilding, yet the exhibit of the Belknap Motor Company shows what Portland can do in the way of dynamo and motor construction. The Belknap Water Motor Company originally commenced the manufacture of water motors, cyclone coffee grinders and pulverizers.

The inability of the water motor to eompete in many places with the electric motor was soon apparent, and the construction of electric motors was undertaken. The facilities have been greatly increased and the various sizes and styles of machines as shown in the exhibit are now manufactured.

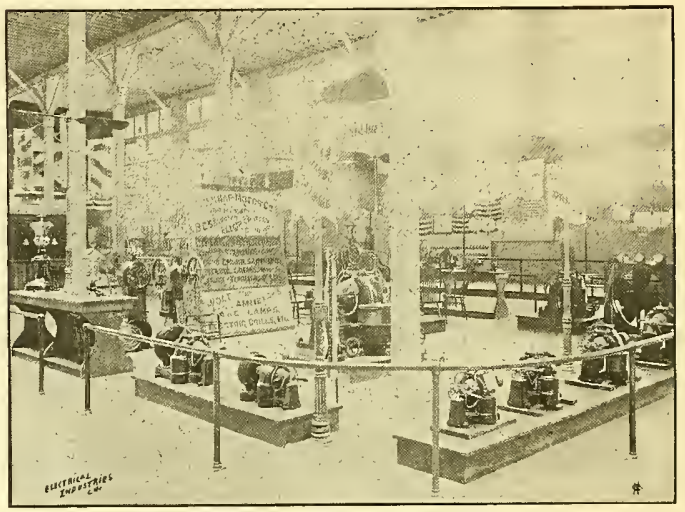

THE EXFIBIT OF THE BELKNAP MOTOR CO.

Mr. George W. Brown is in charge of the exhibit, and takes especial pains to explain the different apparatus to visitors. The display is decorated by numerous signs and banners, fancy arrangement of colored lamps, etc. A large illuminated sign in the center of the exhibit has attracted a good deal of attention. A curtain constantly moved by a motor lets the lights concealed behind it flash out through openings, thus lighting up the glass sign, and as the opening in the curtain passes up to the top of the sign they give the appearance of waves of light passing over the sign.

The display includes various sizes of dynamos and motors, mills and pulverizers, water motors, fans, etc., in different combinations. A large exhanst fan and an electric drill that holds the piece of iron to be drilled by a magnet are shown. Among the exhibit of motors are motors of three and five horse power for a 220 -volt circuits, a one horse power for a 110 -volt circuit, a one-quarter horse power, a one and one-half horse power running a large exhaust fan. This motor is of the four pole type. In dynamos the company has on exhibition 25, 60, 100 and 250-light capacity, at 110 volts. A combined dyuamo and water motor 
of 10 -lights capacity, and a similar one of 25 -light capacity. These are very eompact and efficient, and where water rates are not tou high ean be used to advantage.

The electric and water motors are shown in combination with fans, coffee mills and other small machines. A very convenient style of coffee mill and motor is one shown with the motor beneath the table. There is also shown six are lawp on the constant potential 1111-volt current. The various ammeters and roltmeters manufactured by the company are shown in use. The current for the different lights and motors in the exhibit is generated by $6.4 \mathrm{~K}$. W. generator run by a 10 -horse power 220 volt motor.

All the electrical devices shown are well designed, substantially built, ancl finely finished. Carbon brushes are used, and no sprarking at the brushes is seen. The commutators are of tempered copper. The bearings are selfoiling. The dynamos are all compound wound. These machines have been designed by Mr. W. H. Chapman, the electrical engineer of the company.

\section{The World's Congress of Electricians.}

The World's Congress of Electricians that meets in Chicago in August, promises to be an interesting event. The response to the invitation for papers on appropriate subjects has been generous. It is desired that all papers be sent to Prof. T. C. Mendenhall, W' ashington, D. C., as early as the first of August to allow time for printing. Prof. H. S. Carhart, Ann Arbor, secretary of the Advisory Council, reports the following list of prominent electricians who have consented to read papers.

Mr. W. H. Preece, F.R.S., engineer in chief of the Post Oflice, London, "Signalling through space by means of the elcetromagnetic vibrations."

Prof. W. E. Ayrton, F.R.S., City and Guilds of London, Central Institute, London. "Variations of P.D. of the electric are with current, thickness of carbons and distance apart."

Dr. Stephen Lincleck, Physikalisch-Technische Reichs. austalt, Berlin. "On materials for standards of electrical resistance and their construction."

Prof. S. P. Thompson, F.R.S. Finsbury Technical college, London. "Ocean Telephony."

Prof. Elihu Thomson has accepted the invitation of the committee to deliver one of the evening lectures which will be profusely illustrated.

\section{An Exhibit of Incandescent Lamp Decorating.}

One of the most ornamental features of the exhibit of the General Electric Company is the room in which are shown the meters, switches, instruments and other smaller products. The ceiling is ornamented and illuminated by pretty figures marked by minature electric incandescent lamps of various colors. The frieze is also constructed of lamps set back in the wall making the entire effect very pleasing. In all 725 miniature lamps are used in the room, 398 of $j$ candle power in the frieze; 60 of ten-candle power in the cornice; and 277 of $1,5,8$ and 32 -candle power in the ceiling, making in all 3,892-candle power, equal to 243 gas jets of 16-candle power each. While this exhibit shows what can be done in the way of decorating and fancy work the switchboard in Machinery Hall for the 125-volt circuits of the General Company's plant shows what can be done in a mechanical way. The instruments are all of the latest pattern mounted on white marble. The connections are of massive copper bars and large cables.
A model of the tree system of wiring very accurately worked ont and constructed is shown in one corner of the company's exhibit. The varions sizes of wire and quantity of wire needed for a stated output are shown. Next to it is a model of the feeler system showing the same quantities as required by this system. Square blocks are shown that give the comparative quantities of copper needed for a given load and distance by each of the different systems used with the direct current. The old long magnet type of the Edison dynamo is shown and is quite a curiosity to some although there are a number of them still in use.

In looking over the exhibits of this company one sees nearly everything to which electricity could be applied; while it is doubtless a fact that some of the machinery designed has had little practical use it shows what can be done and in what direction inventive genius has workerl. The alplications are now becoming so numerous that it will not be long before the dynamo factories will be confined to the building of special apparatus and the smaller shops will take up electrical machine construction from special plans aud specifications prepared by electrical engineers as is already done to some extent in Europe.

\section{Coming Events at the Fair.}

To-day is Millers' Day, and the flour makers are given the privileges of the grounds.

For Saturday evening a special program is being prepared, including music and fireworks.

On Tuesday, the Fourth of July, preparations are being made for a grand old-time celebration. The event will undoubtedly be a memorable one to all who attend, as the committee on ceremonies is arranging a suitable program to commemorate America's greatest day. The exercises will commence with the national salute at sunrise.

At 11 o'clock A.x.-The international procession of the peoples on Midway Plaisance.

At 3 o'clock P.M. - The reading of the Declaration of Independence. Speeches by distinguished men to be given in front of the Administration and Government Buildings, and in the Stock Pavilion.

At 8 o'clock P.x.-The illumination of the grounds, the Grand Basin and buildings.

At S:30 o'clock P.x.-Fireworks in the Court of Honor, and at the Government Pier.

Theodore Thomas and Prof. Tomlins will give musical entertainments at Music and Festival Halls, and there will also be music at the band stands.

The Central Electric Company is completing its exhibit in the gallery of the Electricity Building as fast as possible. The main part of this exhibit consists of nine very haudsone reels of Okonite submarine lead cased and aerial cables, for which the company is the western agent. Several photographs of the Okonite Company's factories are shown. The Central Company is also including in its exhibit two large boards containing samples of conduit in all the various forms made by the Interior Conduit and Insulation Company, for which it is the western agent. The boards contain all the necessary tools and fittings. Besiles the exhibits mentioned the company is also making a handsome display of the Washington Carbon Company's product consisting of samples of pure carbon, battery carbons, light and brush carbons. When complete the Central company's display will certainly be very creditable and well worth seeing. Mr. H. H. Small is in charge. 


\section{ELECTRICAL INDUSTRIES.}

Entered at Chicago Postoffice us second-class mail matter.

\section{ELECTRICAL INDUSTRIES PUBLISHING COMPANY, INCORPORATEO 18R9. \\ MONADNOCK BLOCK, CHICAGO. \\ TELEPHONZ HARRISON 159.}

PUBLAGHED EVERT THURSDAY BY THE

E. L. PoWERs, Pres. and Treas.

E. E. WOOD, Srcretary.

\section{E. L. POWERS, \\ H. A. FOSTER, \\ W. A. REMINGTON, $\}$ \\ E. E. WOOD,}

FLOYDT. SHORT,
Eistor.

Associate Enitors.

Eastern ilanager. AdVertising Department.
EASTERN OFFICE, WORLD BUILDING, NEW YORK. World's Fair Headquarters, Y 27 Electricity Building.

\begin{tabular}{l}
\hline FIVE MONTHS, \\
SINGLE CUPY, - \\
\hline
\end{tabular}

The attendance at the Fair was not as large last week as during the previous week, being but 704,000. The special outside attractions undoubtedly limited the attendance, so that the large attendance on Thursday and Saturday of the previous week more than equalled the increased attendance of the other days. Next week the Fair will have the greatest crowls yet seen. The special attractions on the 4 th of July and the inducements in the excursion rates offered by the railroads will bring large crowds to the city.

Although the buildings at the Exposition are large and well lighted, they seem to lack one very important feature, that of ventilation. The main floors are cool and comfortable, but it is a general complaint that the galleries are almost unbearable on warm days. As the days are all warm now and will continue so until toward the close of the Fair, steps cannot be taken too soon to remedy this defect. By a combined effort of the exhibitors in the Electricity Building and the Department some means can undoubtedly be found to effect a change. In some of the other buildings steps have already been taken.

THE appointment of the jury of awards and the method to be employed in making the awards in the Department of Electricity is at present of the greatest interest to exhibitors. It is stated that the selection of the jury is now being made, the appointments to take place July 3rd, while the work of making awards will begin July 15th, and continue for two months. In the regulations gorerning the awards it is understood that sections 3 and 5 will be slightly modified, a matter whlch will be decided upon at once. From the great number of practical and theoretical electricians of the country we are sure that Chief Barrett and his department will succeed in selecting the best men avail able.

SinOe the initial number of our weekly World's Fair issue many compliments together with warm words of approval for our enterprise have poured in upon us from all parts of the country. It is, to say the least, very gratifying to us to know that our efforts to give our readers the freshest and most timely news connected with the great Exposition, are thus appreciated. We feel that our object has been fully attained in giving visitors to the Fair information not otherwise available. The illustrated articles and news items already published we have the satisfaction of knowing have been read far and wide and that the diagrams giving the names and locations of the exhibitors in Electricity Building are used universally as an official directory. We have also the satisfaction of knowing that strangers in the eity use and appreciate the map showing the location of the electrical and allied business interests of Chicago. All we can say to our readers is that we thank them one and all for their kind words of approval, their subseriptions and good wishes, and hope they will be even better pleased with our subsequent issues.

\section{Dynamos run by Gas and Oil Engines.}

As yet very little has been done in the United States in the way of running dynamos by gas or oil engines. Many types, however, of both of theseare shown in Machinery Hall. Among those deserving special mention is the safety oil engine, a three and a half horse power machine after the Hornsby-Akroyd patent, and made by R. Hornsby and Sons, Limited, of Grantham, England.

This engine using crude petroleum of 300 degrees flash test is said to consume but three-quarters of a pint of oil per hour per horse power, and as run at this exhibition fuel for it is said to cost less than a cent per hour. The supply of oil is carried in a tank forming a part of the foundation box, and is automatically pumped into the combus tion chambers as needed after the machine is started.

The engine is somewhat like the Otto gas engine, and works on the Otto-cycle principle. A hot combustion chamber at the rear end of the cylinder receives oil and air, vaporizes the former, and after mixing it with the air the gas thus formed is exploded by the compression of the piston foreing it into and against the hot combustion chamber. To start the machine, a lamp underneath this combustion ehamber is lighted, and a blower provided for the purpose is turned by hand to heat the chamber up to a cherry red. When this is accomplished, which takes but three or four minutes, the light is extinguished and the chamber is kept hot by the compression and explosion of the oil gas, an explosion taking place once during each two revolutions of the $\mathrm{fly}$-wheel.

This particular engine is belted to a Castle dynamo of 24 lamp capacity, and the regulation of speed is very perfect, no variation being noticeable when the load is all cut off or all thrown on. The dynamo was built by J. H. Holmes \& Co. of Newcastle-on-Tyne, England, and is of much the same type as the Crocker-IVheeler dynamo of this country. It is very slow speed for the size, running at not over a thousand turns per minute. There is a large field here for engines of this type as the Americans have scarcely become aware of the fact that oil engines are very useful as well as inexpensive for producing electric currents. The foreign firms at the Fair have already noticed this fact and are preparing to supply the demand.

The Westinghouse Company is daily experimenting in alternating currents of very high potential in the room provided by it for the purpose. Some of the effects as now shown are grand and startling in the extreme. One needs his ears covered while sitting in the room, and the smell of ozone is strongly apparent. The advance made since the commencement of the exhibit has been very great, and new effects have been designed which will be ready for display very soon. 


\section{WORLD'S FAIR NOTES.}

Numerous inquiries are made as to the whereabouts of the Edison Kinetograph. It is said to be advertised in the official catalogue, but has not been seen in the Electricity Building.

The Jeuny Motor Co. has in operation two generators this week, current for which has beeu supplied by another exhibitor. The engine plant for supplying the regular power is not yet installed.

The large railway signaling exhibit of Siemens \& Halske in the southeast end of the Transportation Building seems to be making progress. It is very nearly finished, but hardly attracts the atteution it really deserves.

Mr. H. T. Paiste, Philadelphia, is just completing his exhij)it in the gallery at the south end of the Electricity Building. Mr. Paiste is giving away a neat lead pencil to electricians, wiremen, and, in fact, to all who apply.

The numerous streams of water being pumped into the receiving basin in the annex to Machinery Hall from the various pump exhibits are continuous sources of amusement and wonder to the crowds of visitors in that part of the building.

Mr. Prentiss expects to have the large exhibit of the Brush Electric Company completed so as to have the formal opening on Saturday next. The parilion is finished and all the heary work clone, and ouly a few details now need attention.

The current for charging the storage batteries in the electric launches is furnished by the two bipolar dynamos at the west eud of the row of Edison dyuamos in the Machinery Hall. For a time six boats were charged in series from the 500. rolt power current.

The Electrical Engineering Dejartment is at work placing 20-candle power series incandescent lamps under all the bridges crossing the lagoon. They are cut in on the regular are lightning circuits and will make those spots decicledly more cheerful than at present.

The Ide and Icleal engines made by the Harrisburg Foundry and Machine Works of Harrisburg, Penn., attract much attention by their silent and smooth running. They are tandem compound, occupy little space and are in most most respects self oiling. The location is blocks $1 \tilde{j}$ and 16 , Sec. F

The Briggs' Antomatic Screw Machine, in the exhibit of the Western Electric Co., is ove of the permanent attractions and bids fair to hold its favor with the public to the close of the Exposition, if one may judge by the number of people standing in line waiting the souvenirs it turns out with measured regularity.

A rery handsome and smooth running engive is show by the Siemens \& Halske Company in their exhibit in Machinery Hall. It is vertical, triple compound condensing and drives their main lines of shafting by a peculiar arrangement of ropes. The engine was built by F. Schichan of Elbing Preussen, and is well designed.

The Walworth Maunfacturing Company of Boston, Seetion O, No. 27, Machinery Hall, show samples of the several types of street railway poles, also a large assortment of steam valves in all sizes, A handsome ebonized wood glass paneled cabinet occupies the center of the space in which are shown the large number of smaller proclucts of the factories, such as the Stillsou wrenches, die plates and clies and a great many other specialties. A rery large proportion of the iron poles used by the electric street railways of the country has been supplied by this establishment.

The electric fountains are now in working order after various vexing delays. They are played three nights a week and have proved a drawing card. It must be admitted that they suffer somewhat from being placed so far below the level of the court and the best of the effect is thus lost to people who cannot get close to the railing.

The Vacuum Oil Company of Rochester and Olean, New Fork, exhibits in section K, No. 23, Machinery Hall, complete models of the manufacturing plants at both these places. They are complete in all detail and very instructive. This company maunfactures the celebrated $600 \mathrm{w}$. cylinder oil, so long and favorably known to the trade.

The Exposition might well be called an electrical exposition since, with the exception of Machinery Hall where steam is used, all the power for every kind of apparatus is supplied by the electric current. The plan is carried out of driving each line of shafting by a separate electric motor; a more convenient method it would be difficult to find.

Taylor, Goodhue \& Ames, have ready for their exhibit in Electricity Building a 10-horse power alternating current motor but are delayed in showing it in operation owing to their not being able to get alternating current in the space assigned them. This motor will, it is elaimed, enjoy the distinction of being the only large alternating motor in operation on the grounds.

The Newark factory of the Westinghouse company has just contributed its quota of exhibits, and although long delayed, every one will be pleased to see the machines from this old established factory. All the new types and designs will be shown and when completed this exhibit will add one more to the numerous excellent displays of the Westing. house Electric and Manufacturing Company.

The exhibit of the Phoenix Glass Company in the Electricity Building has usurpet the place occupied by the Corliss engine at the Centennial Exposition as a meeting place. The tower has become one of the best known features of the Exposition, and Mr. Fox, the genial representative of the Phoenix Glass Company is daily the temporary guardian of lost children, packages, etc., and the custodian of various articles and messages.

Randolph \& Clowes have an exceedingly appropriate booth in the Mining Bnilding, made of different sizes and shapes of drawu brass and eopper tubing. The general offices and factory of this company are in Waterbury, Conn., while the gools of Randolph \& Clowes are not "quickwiuling" they quite eridently possess all the other points of merit that are indelibly impressed on the public mind as synonymous with the word "Waterbury!"

One ean get some idea of where the copler comes from what is now so extensively used in the electric trades by a thorough examination of the fine large exhibit of the Calumet and Hecla Compray in the Mines and Mining Building. Huge square cakes aud ingots of solid copper are pilerl up on the Hoor and large cones of sheet copper and wire confront one on the west side of the exhibit. Models of some of its shafts and rock houses are shown and many fine pictures in colors adorn the walls of the section. The native ore is piled up about the space, and from the large majs and pictures one is able to get something of an idea of the size of the works. 


\section{Amusements.}

Hooley's Theater-Mr. E. S. Willard, in "The Professor's Love Story." 149 Randolph street.

Colombia Theater - Miss Lillian Russell, in "GirofleGirofla." Sixth week. 108 Monroe street.

Grand Opera House-Sol Smith Russell, in "April Weather." 87 Clark street.

Acdroniom-Imre Kiralfy's Spectical "America." Congress street and Wabash arenue.

McVicker's Theater- "The Black Crook;" next week Denman Thomson, in "The Old Homestead." 82 Madison street.

Chioago Opera Hodse-American Extravaganza Company, in "Ali Baba," or "Morgiana and the Forty Thieves." Fifth week. Washington and Clark streets.

Sohiller Theater-Chas. Frohman's Stock Company, in "The Girl I Left Behind Me." Fifth week. Randolph, near Dearborn.

Haverly's Casino-Haverly's United Minstrels. Wabash avenue, near Jackson street.

Havlix's Theater-“"The Cracker Jacks." Wabash avenue, near Eighteenth street.

Haymarket Theater-James J. Corbett, in "Gentleman Jack." Madison, near Halstead.

Windsor Theater-Rider Haggard's "She." 468 Clark street.

Tattersall's-Military Tournament, 16th and Statestreets. Buffalo Bill's "Wild West." 63d street.

Pain's "Seige of Sebastopol," 60th street and Cottage Grove avenue. Opens Saturday, July 1.

\section{PERSONAL.}

Prof. W. E. Ayrton sails for New York early in July.

Prof. S. P. Thompson sails for New York on the Etruria July 15 th.

Mr. Luke Lilly returned to Cincinnati Sunday night after a short visit to the Fair.

Mr. C. A. Coolige, of Centralia, Washington, is a visitor to the Fair, Chicago and vicinity.

Mr. Henry Villard, of the New York Financier, was a visitor at the Electricity Building last week.

Prof. George D. Shephardson, of the University of Minnesota with his wife is spending a week at the Fair.

Mr. L. B. Stillwell, of the Westinghouse Electric \& Manufacturing Company was in the city June 21st.

Prof. Dugald C. Jackson, of the University of Wisconsin was at the Fair Saturday, accompanied by several of his pupils.

Jas. H. Mason of the Simplex Electrical Co., was in the eity this week looking after the company's exhibit in George Cutter's space.

Prof. B. F. Thomas, of the Ohio State University, is paying a short visit to the Fair, expecting to return for the Electrical Congress.

Mr. Franklin Phillips, of the well-known firm of engine builders, the Hewes \& Phillips iron works, is visiting the Fair with his wife.

Mr. G. E. Emmons, auditor of the Lynn factories of the General Electric Company, with his wife, has been visiting the Fair during the past week.

Mr. H. T. Paiste of Philadelphia is at the Fair looking after his exhibit that has been elosed for a few days on account of the decorators working above it.

Mr. Ralph W. Pope, secretary of the American Institute of Electrical Engineers, arrived in Chicago last Friday and will make his home here until the elose of the Fair.

Col. Geo. L. Beetle, the popular veteran in the electrical business, and in the service of the Western Electric Company, is confined to his house for a few days with a slight illness, due to over exertion during the recent warm weather.

Mr. John Kreusi, superintendent of the Schenectady works of the General Electric Company, was in the city for a few days early this week, making a short visit to the Fair.

Mr. Frank B. Rae of Detroit, was in Chicago last week. He has been retained as consulting engineer by a number of towns that contemplate putting in electric lighting plants.

Mr. W. J. Hammer, chairman of the committee on headquarters for the A.I.E.E. at the Fair, arrived last week, and is arranging the rooms of the Institute in the Electricity Building.

Mr. W. W. Primm, the electrical engineer of the Department of Electricity, and Miss Adilena M. Stark were recently married. The many friends of $\mathrm{Mr}$. Primm at the Fair extend their congratulations and good wishes.

\section{TRADE PUBLICATIONS.}

The Charles E. Gregory Company, Chicago, has just issued a very neat and convenient pocket memorandum book containing a valuable telephone directory of the electrical interests in Chieago, and at the World's Fair grounds. Its value will be greatly appreciated by all who are so fortunate as to secure a copy.

The Ansonia Elefotrio Compant has just issued a very handy and neat edition of its house goods catalogue which will be known as B. 44. It is only issued temporarily for use until the larger and more complete catalogue comes out on which the company is now at work. A number of new goods are shown in this catalogue and also some changes in price. It may be had on application.

One of the many valuable and improved features in the catalogue just issued by Taylor, Goodhue \& Ames is the manner of indexing. 'The index is placed in a convenient part of the book and includes a general index, an index of trade members and an index of all the numerous articles and supplies handled by this firm. The book is substantially bound with eloth covers, well printed, neatly and intelligently arranged. The house goods, central station supplies, line and general supply goods are all very finely illustrated on good paper and make the catalogue a valuable reference book for every user of electrical supplies.

\section{BUSINESS NOTES.}

MCLEAN \& SchмітT, Chicago, are keeping an increased force of men at work in their shop, doing general repair work, and a considerable of extra work for the World's Columbian Exposition.

Mr. Geo. W. Brown, general manager of the Belknap Notor Company, has a puzzle for his visitors when they attempt to tell which of his motors are running and which are not. The motors run so silently and even that it is almost a puzzle for an motors

The Brush Electric Co., Cleveland, Ohio, are putting in a $\$ 100,000$ plant at Hontgomery, Ala. Mr. Ira J. Britton, for many years chief expert for the company, is in charge of the work. Over 300 men are engaged in the construction. The plant, when completed, will supply hoth light and power to the city of Montgomery.

THE INTERIOR CONDUIT AND INSULATION CoMPANY are distributing at the Fair very neat and useful souvenirs in the shape of pocket screw drivers. They are nickel-plated and close up in very convenient shape to carry in the pocket. The company's very convenient shape to carry in the
name is neatly etched on the handle.

THE Electrio Appirance COMPANx's exhibit of Meston alternat ing current motor applied to the operation of a sewing machine continues to attract considerable attention and keep a crowd around their World's Fair space. The outfit is certainly a very complete and compact affair and the ease with which it can be controlled leaves nothing to be desired. The outfit is certainly one that will find a very large field.

The Telegraph \& Telempone Construdtion Co., Detroit, Mich, has just removed to its new building containing the new exchange to which it has transferred all its old subscribers. This exchange is a model in every way, being equipped with a new multiple switch board made by the Western Electric Company, Chicago. All of the wires are run underground, and the building and its equipment constitute one of the most modern and hest equipped telephone exchanges in the world. 


\section{STANDARD ELECTRIC CO.}

General Offices, Suite 625 Home Ins. Bldg.,
Works. 313-317 South Canal Street,

BUILDERS OF TFE

\section{STANDARD SYSTEM OF ARC LLGHTING.}

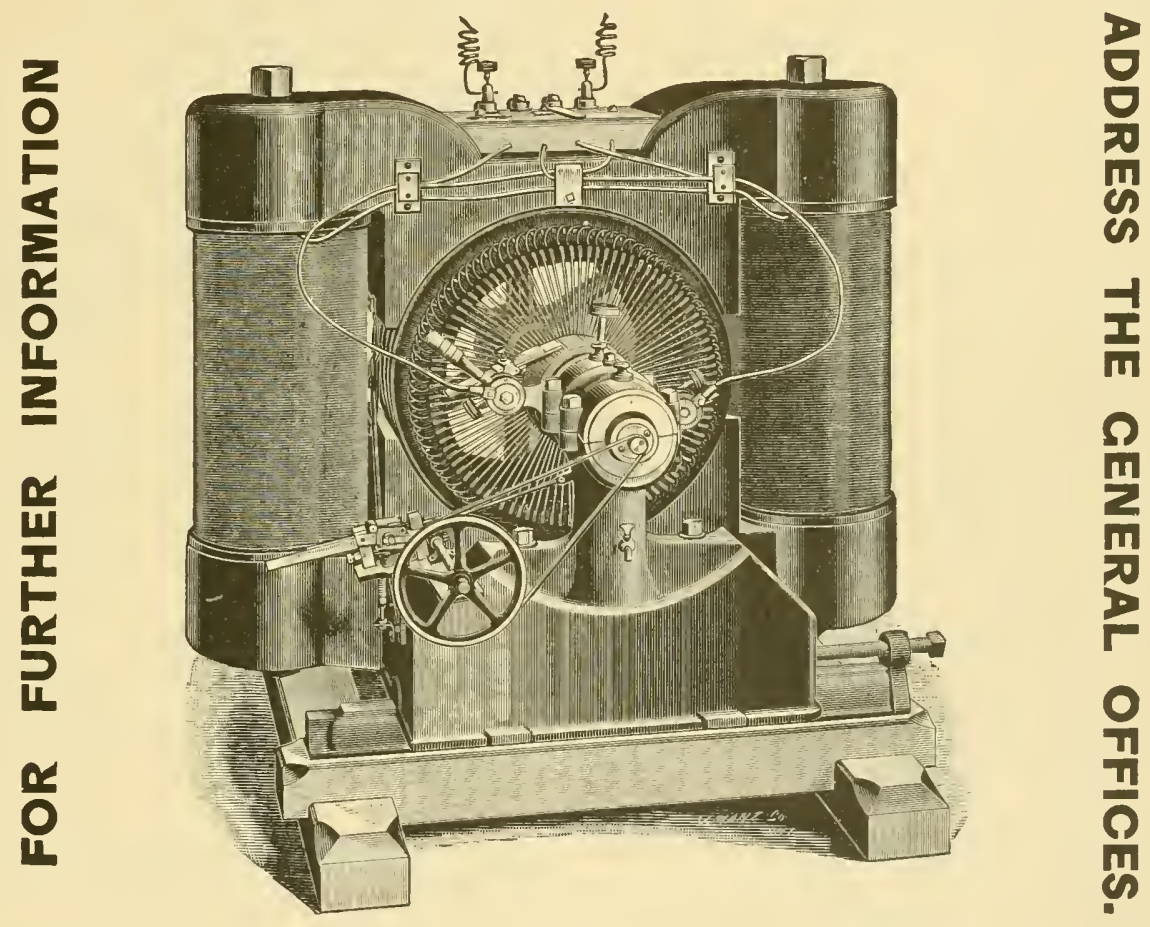

NTAE. Central Station Managers, Municipal Officers, Owners of Isolated Lighting Plants and Prospective Purchasers everywhere are invited to inspect and investigate the STANDARD SYSTEM before contracting for apparatus.

For lighting stores, foundries, factories, or the streets of a city, this system has no equal.

OUR CONTRACT does not obligate the purchaser to buy apparatus or supplies exclusively of us for a term of years, but courts open competition and encourages fair tests for merit between any and all existing arc lighting systems and the STANDARD. 
ELECTRICITY BUILDING-EXHIBITORS AND THEIR LOCATION.
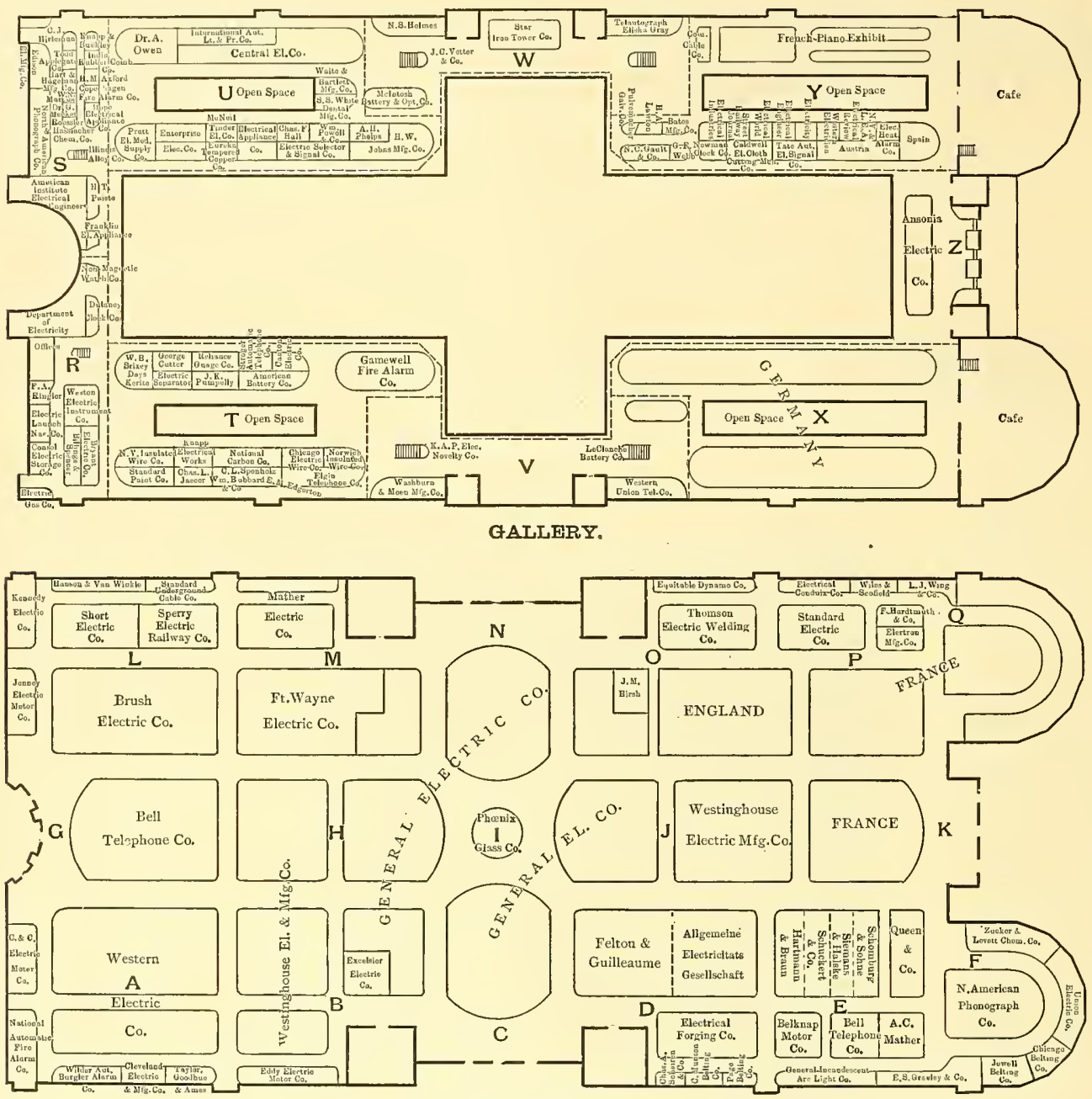

MAIN FLOOR.

\begin{tabular}{|c|c|}
\hline $\begin{array}{l}\text { Exhihitor. } \\
\text { Austria...................... Section, }\end{array}$ & Exhibitor. \\
\hline Ansonia Electric Co.... & $\begin{array}{l}\text { Electrical Review...... } \\
\text { Electricity............... }\end{array}$ \\
\hline m. IDst. of Elec. Eng.. . & Electric Gas Co. \\
\hline mericad Battery Co... & Electrical Engineer \\
\hline xpord, H. М............... & Electrical world............ \\
\hline Allg. Elec. Gesellschaft.... & Eddy Electric Motor Co \\
\hline Bates Mfg. Co............ & Excelsior Electric Co.. \\
\hline Bryant Electric Co.. & Electrical Forging Co \\
\hline & Eqnitable Dyuamo C \\
\hline & GEle \\
\hline p Mlotor Co....... & cal Conduit Co.. \\
\hline Il Telephone Co....... & Eoglaud ................ \\
\hline etric co $\ldots . . . .$. & Empire China Works. \\
\hline El. Cloth Cnt. M & Franklin Elec. Appliance \\
\hline Storage Co & French Piano Exl \\
\hline orge $\ldots . . . . . . .$. & Felton \& Guilleaume. \\
\hline & France ................ \\
\hline Chic & Gt. Wayne Elec, Co \\
\hline & Ganlt d Co., N. C... \\
\hline & Gamewell Fire Alarn \\
\hline Co......... & General Electric Co .... B-H-N-C- \\
\hline $\mathrm{Co} \ldots .$. & 1 Incand's't Arc L't Co. \\
\hline $\begin{array}{ll}\text { Cle } \\
\text { Chi }\end{array}$ & E. S \& $_{1} \&$ Co \\
\hline & Ger \\
\hline & Hn \\
\hline $\begin{array}{l}\text { Department of Electricity } \ldots \ldots \ldots \\
\text { ELECTRICAt INDUSTRIEs } \ldots . . . \cdots\end{array}$ & Hirleman, C. J............. \\
\hline Elec. Launch \& Nav, Co.............. & Hope Elec. Appliauce Co.. \\
\hline & Hall, Chas . F ….... \\
\hline 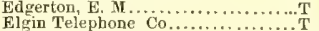 & Holmes, N. S.......... \\
\hline Elec. Mfg. Co... & on \& Van Winkle.. \\
\hline & , J. MI , ............. \\
\hline & Hardtmath, F.. \& Co... \\
\hline & Illinois Alloy $\mathrm{Co} \ldots \ldots . . . . . .$. \\
\hline & \\
\hline
\end{tabular}

Exhibitor.

Jaeger, Chas. L......

Jewell Belting Co...

Jenuey Elec. Motor Co...

Kuapp Electrical Works....

Knapp \& Backley....

Law ton, H. A

LeClanche Battery Co.

MeNeil-Tinder Elec. Co...

Mareus, W. N

IreIntosh But. \& Opt. Co

Munson, C., Belting Co

Mather Electric Co.

Newman Clock Co.

Non-Magnetic Watch Co.

N. Y. Insulated Wire Co...

National Carhon Co.

North Am. Phouograph Co.

Nat.

Nat. Engraving Machine Co.

Owen, Dr, $A$...

Phoenix Glas
Paiste, H. T.

Pulvermacher Galv. Co

Pumpelly, J. K .........

Powell, Wm. \& Co.

Phelps, A. H

Page Belting $\mathrm{Co}$

Queen \& Co .
Ringler, F, A.
Section.

Exhibito

Section Roessler \& Hasslacber Chem. Co...... Street Railway Jonrnal............. Y Strowger Ant. Telph. Co.......... T

Sponbolz, C. L.................. Star Iron Tow

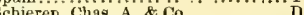
( jiemeus \& Ilalske.

Schuckert \& Co.

. serry elec. Railway Co.............. Standard Electric Co Samson Battery Co ..................

Taylor, Goodhoe \& Ames.............. Thomson Elec. Welding Co ......... o Telaatograph, Elisha Gray ........... Vetter J C \& Co ........................ Webh, G. F .................... Weston El. Justrument Co............. Washhnrn \& Moen Mrg. Co......... V Western Union Tel. Co .............. White, S. S., Dental M ig. Co...........

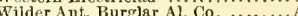
Western Electric Co $\ldots \ldots \ldots \ldots . . . . . . .$. Westinghouse El. \& Mirg. Co .... B-H Wiles $\&$ Scofield ..................... Zucker \& Levett Chem. Co............. 


\section{HAVE YOU EXAMINED}

the new 6 C. P. PACKARD lamps made to burn on regular voltages and to fit ordinary sockets.

SEE THEM .in our worrds's Fair Exhiblt.

\section{ELECTRIGITY "U 16" BUILDING}

and place your orders with our representative there or send them to

242 Madison Street, CHICACO.

\section{ELECTRIC APPLIANCE COMPANY.}

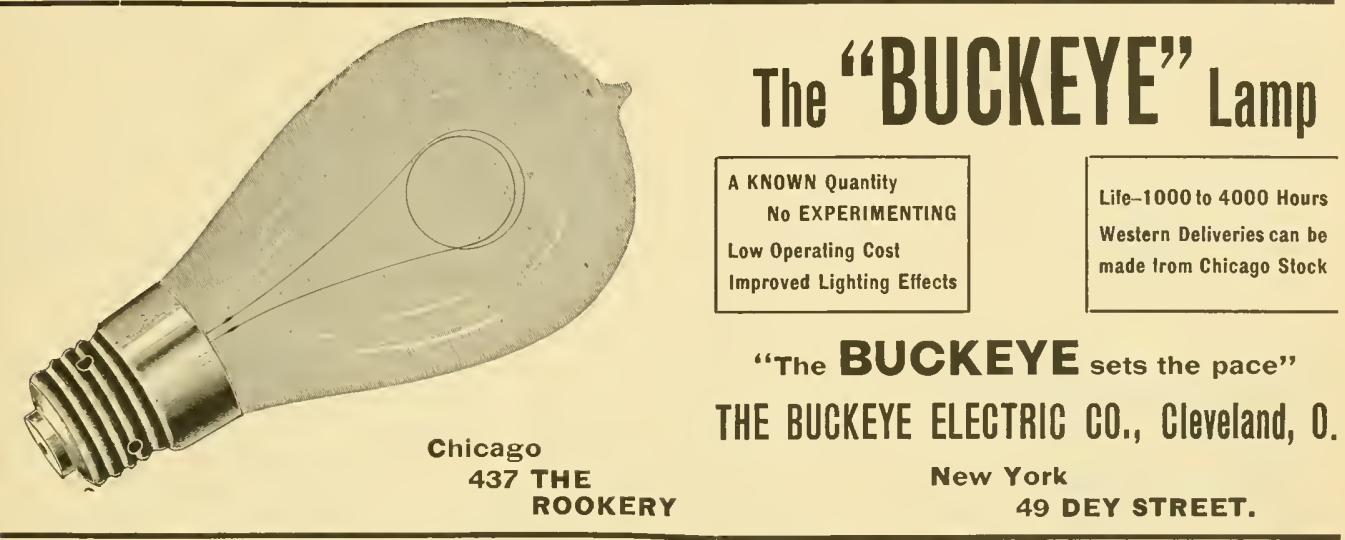

THE MATHER ELECTRIC CO,

MANCHESTER, CONN.

Dynamos, Motoors, Genereatorss,

Offices, 116 Bedford St., BOSTON. -AND-

1002 Chamber of Commerce Bldg., CHICAGO.

\section{THE “NOVAK” LAMP.}

\section{CLAFLIN \& KIMBALL (Inc.)}

Ceneral Selling Agents.

116 Bedford Street, BOSTON.

1002 Chamber of Commerce Bldg., CHICAGO.

\section{Enterprise}

Electric company

307 Dearborn Street, Chicago ....
Manufaoturers' Agents and MIII Representatives for

Electric Railway,

Telegraph, Telephone and Electric Light

$$
\begin{gathered}
\text { SUPPLIES OF EVERy } \\
\text { Agents for Cedar Poles, } \\
\text { cypress Poles, Oak Pins, } \\
\text { Locust Pins, Cruss Arms, Glass } \\
\text { Insulators, }
\end{gathered}
$$

WIRES, CABLES, TAPE and TUBING 


\section{Map of Chicago.}

Showing Location of its Electrical and Allied Business Interests, Principal Hotels, Theatres, Depots and Transportation Lines to 45

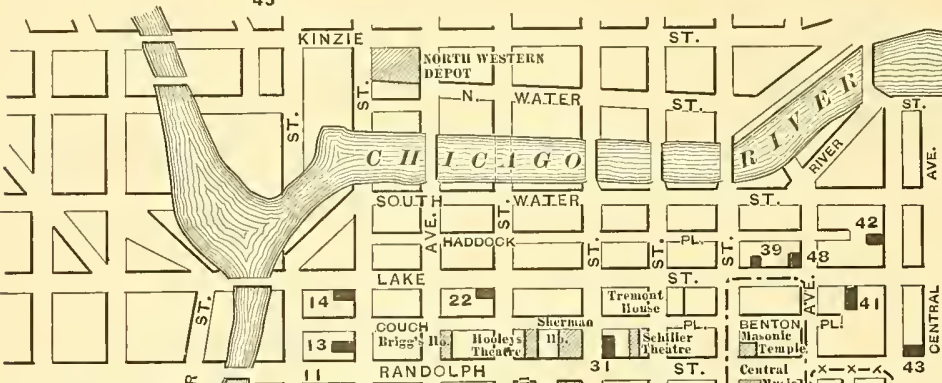

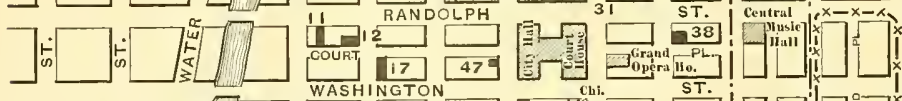
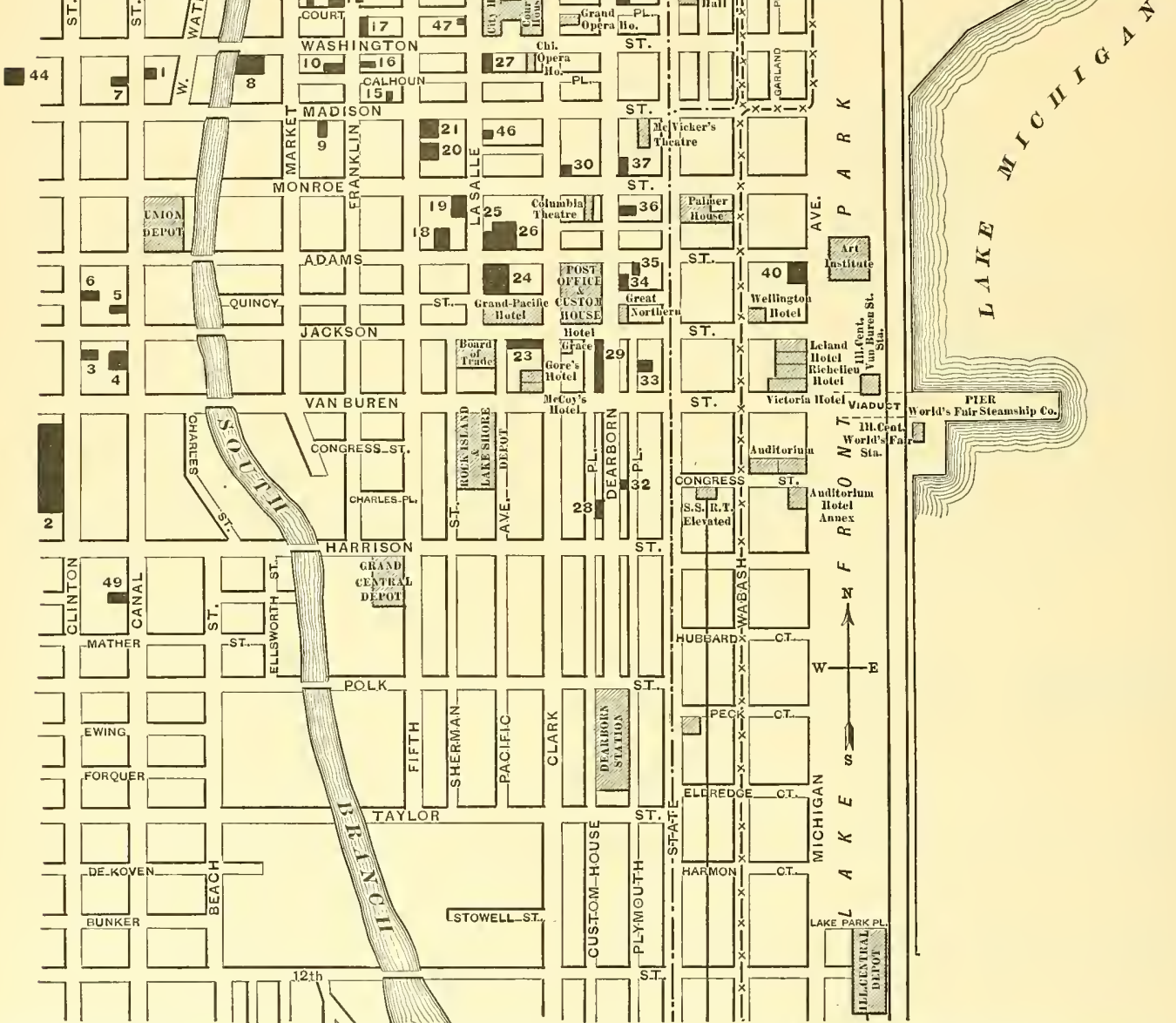

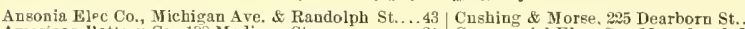

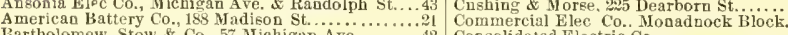
Bartholomew, Stow $\&$ Co, 5 ; Michigatn A

Benham, A. D., :00 S. Clinton St.
Brill Co.,J. G., Phenix Bldg............

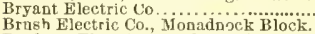

Brush Electric Co., Monadnock Block...............29
Bnckeye Flectric Co.. 437 Rookery Bldg. C.... ini S.
Calnmet Electric Mfg. \& Engineering Co.,

Clinton St. . . . . . . . .

Central Electric Con, 118 Franklin St.

Central Telephone $\mathrm{Co}$

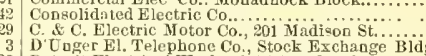
Detroit Electrical Works, 917 Monadn

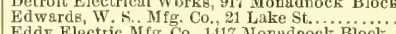

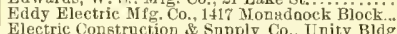
Electric Construction \& Supply Co., Unity Bldg... Electric Appliance Co., 242 M adison S

Eaterprise Electric Co., 30 i Dearbora St....

mouth PI...
mot

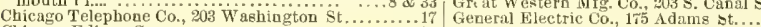

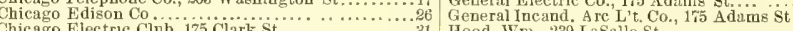

lub, 175 Clark St

c llotor Co, $313 \mathrm{~s}$. Canal St.

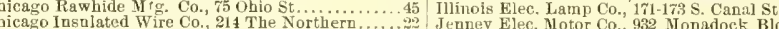

.

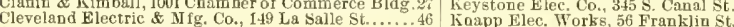

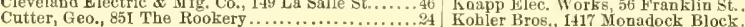

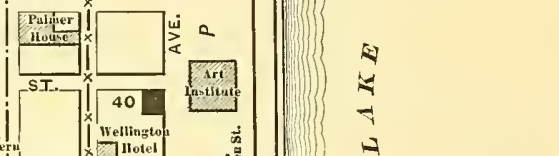




\section{(1).

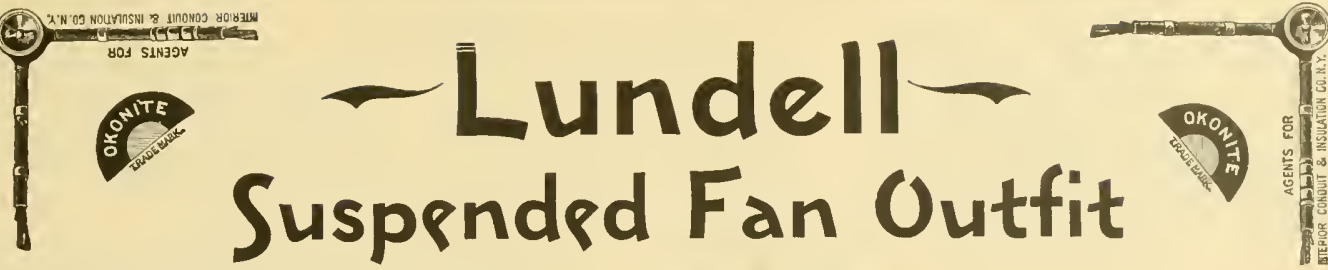

\section{0 \\ Black \\ Japan \\ Finish

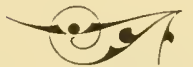

Electric Fans
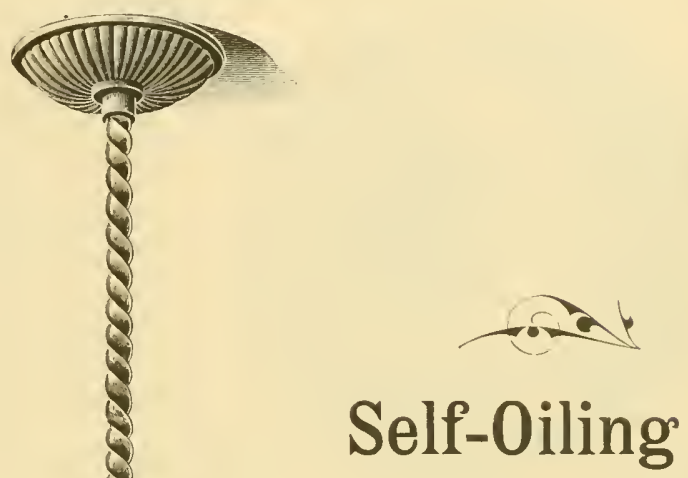
....and

Self-Aligning Bearings

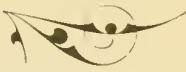

Electric Fans

OKONITE WIRES

OKONITE $=$ TAPES $=$ MANSON INTERIOR CONDUIT.

Batteries, Bells, Push Buttons, Annunciators, Volt Meters, Ammeters, Wheatstone Bridges, Line Wire Cross Arms, Brackets, Pins, Insulators, Tools.
GENERAL
SUP
PLIES. 
COMPANY, NEW YORK.

192 Broadway and II John Street.

MANUFACTURERS OF ARC LIGHTING APPARATUS FOR EVERY PURPOSE A SPECIALTY. The CLARK ARC LAMPS for use on EVERY CURRENT, have the reputation of being the best and most durable of any ever made in the United States.

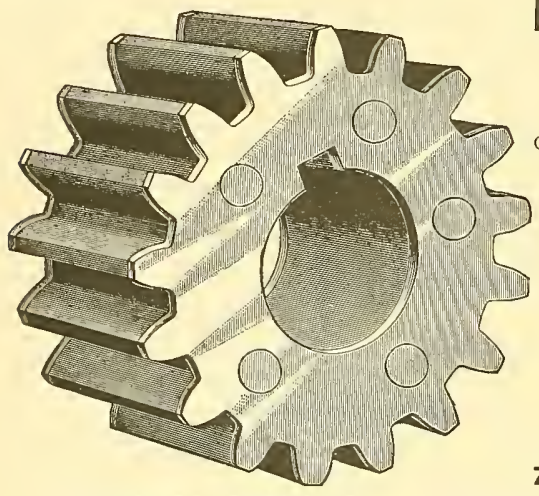

RAWHIDE PINIONS FOR ELEGTRIC MOTORS A SPECIALTY

RAWHIDE DYNAMO BELTING

Greatest Adhesive Qualities. Causes Less Friction than any other Belt.

\section{THE CHIGAGO RAWHIDE MANUFACTURING GO.}

THE ONLY MANUFACTURERS IN THE COUNTRY.

\begin{tabular}{|c|c|}
\hline $\begin{array}{l}\text { LACE LEATHER ROPE } \\
\text { AND OTHER RAWHIDE }\end{array}$ & $\begin{array}{l}\text { This Belting and Lace Leather is } \\
\text { not affected by steam or dampnes; } \\
\text { never becomes hard; is stronger, }\end{array}$ \\
\hline $\begin{array}{l}\text { GOODS } \\
\text { OF ALL KINDS } \\
\text { BY KRUEGER'S PATENT }\end{array}$ & $\begin{array}{l}\text { ical Belting made. The Raw- } \\
\text { hide Rope for Round Belting } \\
\text { Transmission is superior to all } \\
\text { others }\end{array}$ \\
\hline
\end{tabular}

75 Ohio Street,

CHICACO, ULL

\section{THE REGULAR MONTHLY EDITION}

\section{$\ldots$ OF $\ldots$ \\ Electrical Industries}

Is read more widely and used more constantly for reference by actual buyers in the electrical field than any other similar publication. WHY? Because it has in every issue handsomely illustrated special articles and descriptions of everything of interest in the electrical world besides a complete

BUYERS DIRECTORY giving the names of all the manufacturers and dealers in the trade; a complete directory of

ELECTRIC LIGHTING CENTRAL STATIONS and a complete directory of the

ELECTRIC RAILWAYS of North America corrected to the date of going to press, features found in no other electrical journal in the world.

The Weekly World's Fair issue contains the most novel and unique features yet undertaken by an electrical Journal.

Sample copies free on application. Every electric lighting company should write for our special terms. We are now making the most liberal offer to subscribers for both publications during the next few months ever made by an electrical paper.

\section{ELECTRICAL INDUSTRIES PUB. CO.}




\section{Western Electric Company, CHICAGO. NEW YORK.}

Arc Lighting Apparatus

High and Low Tension,

Double and Single Service Lamps, All Night Single Lamps,

Theater and Focusing Lamps.

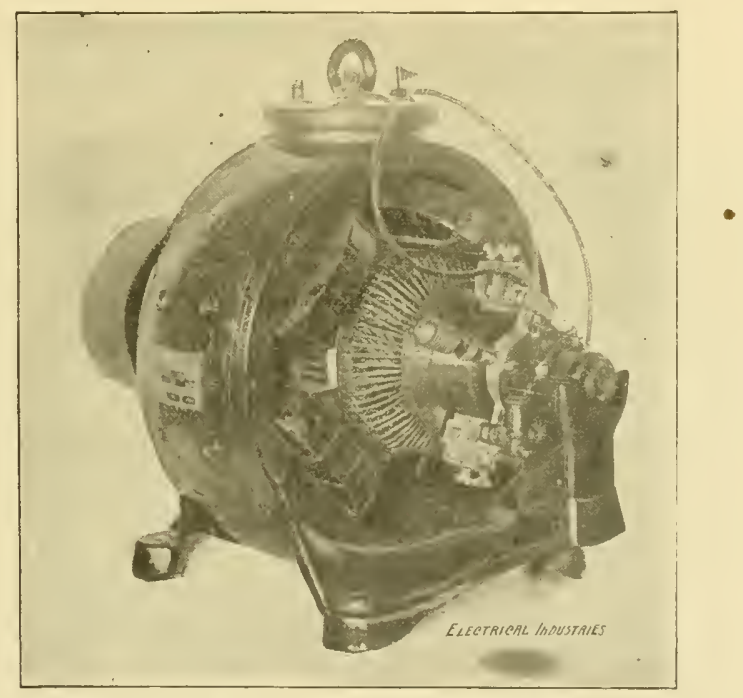

\section{ELECTRIC MOTORS}

FIGFI SPFED

VARIAB工E SPEFD

S工OW SPEFD.

BUILT FOR SEVERE AND CONTINUOUS SERVICE, SPECIAL TYPES FOR SPECIAL DUTY. 


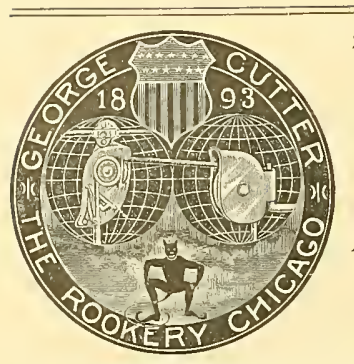

See Our

Exhibits:

East Gallery

Electricity Bldg.

?

And another:

$\mathbf{8 5}_{\mathbf{5}} \mathrm{I}=\mathbf{8 5 3}=\mathbf{8 5 5}$

The Rookery.

\section{SIMPLEX WIRES}

INSURE

HIGH

SIMPLEX INSULATION

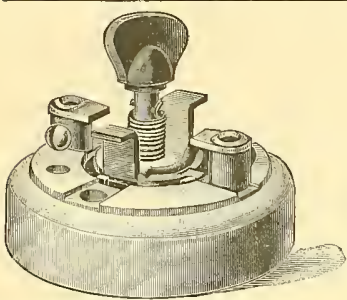

Made 5 amp. S. P.

I 5 amp. 3 way.

\section{XNTRIC}

"That's the Switch"

And we control that movement.

H. T. PAISTE,

10 South 18th St., PHILADELPHIA, PA.

Consolidated Elpctric 6.

Manutacturers and Dealers in all kinds of

\section{ELECTRICAL : SUPPLIES,}

115 Franklin Street,

CHICAGO.

... SEE AD ...

Western Electric Co.,

PACE 15.

\section{CHAS. A. SCHIEREN \& CO,}

MANUFACTURERS OF

Genuine Perforated Electric Leather Belting,

46 So. Canal Street, - CHICAGo.

Section 15, Dpt. F, CIm. 27.

Section D, Space 3.

MACHINERY HALL.

ELECTRICITY BUILDING

Do not fall to call and leave your name for our new catalogue of electric and gas globes and shades.

For Direct or Alternating Currents.

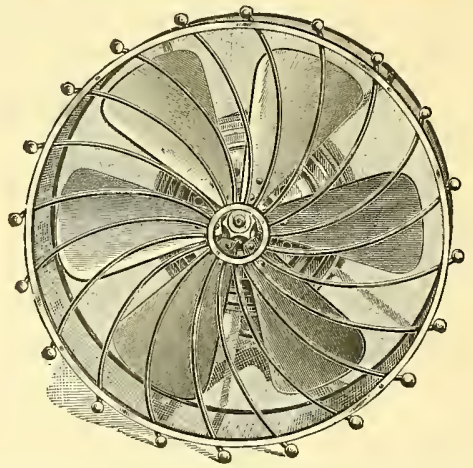

These motors give a stronger breeze with less consumption of enrrent that These motors give a stronger breeze with less consumption or cnrrent tha 12-inch frn. Self-oiling. Fnrnished with or withont gnards.

IT WILL PAY YOU TO SEE THE WAGNER BEFORE BUYING ELSEWHERE.

TAYLOR, GOODHUE \& AMES, 348 Dearborn Street, CHICACO.

See Our Exhibit of ELECTRICAL FIXTURES

IN SECTION "N", BETWEEN COLUMNS 62 AND 64, MANUFACTURES BUILDING,

GLOBE LIGHT \& HEAT CO.. 52 \& 54 Lake St., CHICAGO. 


\section{Weekly World's Fair Supplement.}
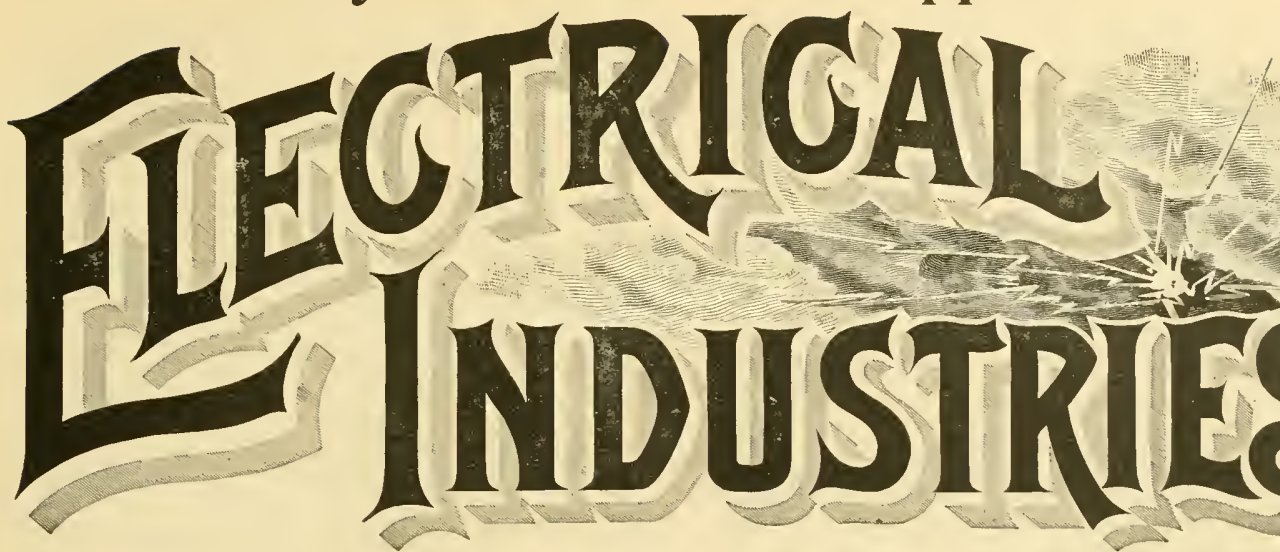

DEVOTED TO THE ELECTRICAL AND ALLIED INTERESTS OF THE WORLD'S FAIR, ITS VISITORS AND EXHIBITORS.

Vo, I, No, 4, CHICAGO, JULY 6, 1893. FIVE MONTHS S1.00
TEN CENTS A COPY

The Exhibit of the Weston Electrical Instrument Company.

The exhibit of the Weston Electrical Instrument Company is locater in the gallery of the Electricity Building, just east of the main stairway leading to the offices of the Department of Electricity. A square showease around a square upright glass faced cabinet occupies the center of the ments on the switchboard consist of one ammeter reading to 1,500 amperes, and four reading to 300 amperes, four roltmeters and one potential indicator. All are of the regular switchboard illuminated dial type now so extensively made by the Weston company. Ajax switehes are used on the switchboards and include six of 300 ampere and one of 1,000 ampere cupacity, the latter being double-throw and changing from a three-wire to a two-wire system.

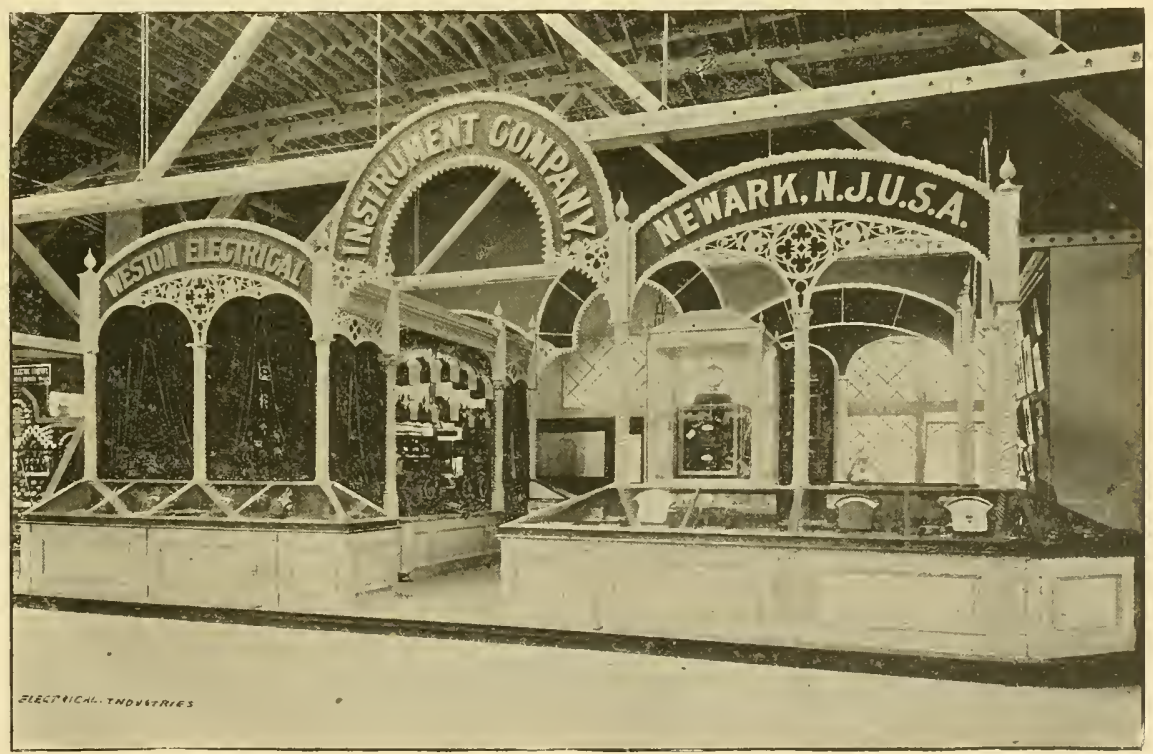

THE EXIIBTT OF THE WESTON ELECTRICAL INSTHUMENT COMPANY.

space in front of a comfortably equipped office. Arranged around the ontside are showcases in which are shown the various instruments and appartus made by the company. The office itself is provided with current, and various forms of instruments are shown in use.

The front sicle of the office is formed by a large enameled slate switch-board furnished by J. T. Murphy, of New York; the enameling on this board is an imitation of the grain of oak, and the effect is quite pleasing. The instru-
At the bottom of the board on a slab of onyx enameled slate is a voltmeter arranged as a ground detector. It has two keys for closing on either side of the circuit, the line potential being read on the indieator above, the resistance of the ground is calculated by the following formula. $R$ being the resistance of the voltmeter; $Y$, the total line voltage, and $v^{1}$ and $v^{2}$ being the readings on the positive and negative sides respectively; thus $\mathrm{S}$, the resistance of the ground $\left(\frac{r=\left(v^{1}+v^{2}\right)}{v^{1}}\right) R$ for the positiveside and $X^{1}=\left(\frac{V \cdot\left(v^{1}+v^{2}\right)}{v^{2}}\right) R$ 
for the negative side. Mr. R. O. Heinrich, who is in charge of the exhibit has made a very thorough study of the detection and measurement of grounds with the Weston instruments and has simplified many of the usual formulae. The company manufactures high grade, portable, and laboratory standard resistance boxes in sizes from 100,000 ohms up. The construction of these boxes is such that the hard rubber top may be removed withont disturbing the coils. The alloys used in these boxes which do not require a temperature co efficient are the invention of Mr. Weston and the fundamental patents were issued to him in 18S8, on nickel-copper and manganese nickel-copper alloys.

The central square cabinet contains samples of all the instruments made by the company separated into all the parts used in their construction, even to the smallest screw or jewel. Various samples of standard voltmeters,alternating current voltmeters, ammeters both for laboratory use, testing and switchboard work are shown. A variety of shunts for use with the switchboard ammeters are exhibited. It
Weston instruments may seem expensive to the ordinary central station superintendent, the saving in lamp breakages and other faults by knowing the actual condition of machines and circuits, more than compensates for this cost. For switchboard use in isolated plants and smaller stations they make instruments which, while not having the fine exterior finish found in the standard instruments, are made of exactly the same working parts and are in every way just as reliable as the standard instruments and at about one. half the price. Mr. Richard O. Heinnch, in charge, will be found willing to explain in a very concise and clear manner all the various exhibits, and a chat with him on the use of these instruments is sure to be of benefit to anyone interested.

\section{The Western Electric Company's Scenic Theater in the Electricity Building.}

While travelling abroad one of the officials of the Western Electric Company saw a small scenic theater in operation, all the different effects being produced by electric

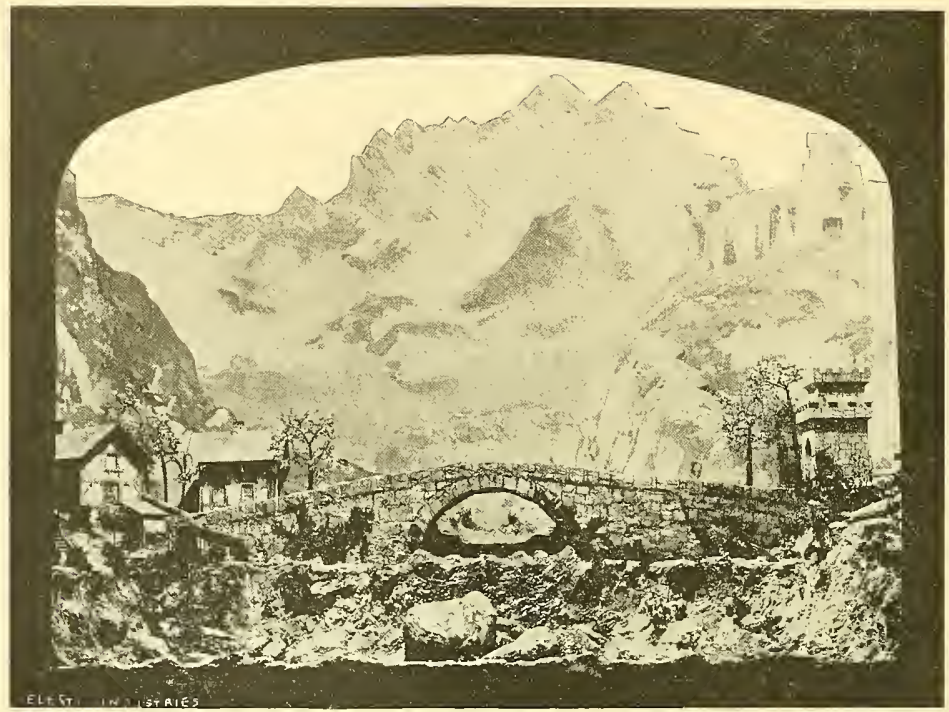

FIG. 1. - THE WESTERN EIECTRIC COMPANY'S SCENIC THEATER IN THE'ELECTRICITY BUILDING.

will be remembered that the Weston anmeter is simply a milli-voltmeter, reading the fall of potential around a shunt. Several samples of laboratory voltmeters and other instruments are shown. A new form of bridge for laboratory work is here exhibited for the first time. All contact blocks are placed underneath the hard rubber top, and the plugs are long and extend through holes in the same. This arrangement prevents dust settling between the blocks and facilitates cleaning to a great extent. All coils in this and the other instruments are wound with the patent composition wire made by this company and which has practically no temperature co-efficient. Various sizes of multiplying coils for use with the ordinary voltmeters for reading very high voltages are shown.

Of other instruments deserving special mention are various samples of the astatic ammeters for nse in places where there is a strong magnetic field; an inspector's set including voltmeter, and four adapted plugs for use with the Edison, T-H., Westinghouse, and the old U. S. sockets, together with flexible cord and plugs. While the higher grades of lighting. The result was so pleasing that when the company was searching for new features for showing the applications of electricity this gentleman expressed a desire that such a theater might be constructed for the company's exhibit at the World's Columbian Exposition, and the matter was placed in the hands of Mr. A. L. Tucker for execntion. Dr. Hornsby, the Assistant Chief of the Department of Electricity, had also seen the same thing and was able to add some information to that already obtained. Messrs. Sosman \& Landis of Chicago were given the order to make the scenery under the direction of $\mathbf{M r}$. Tucker, a small model eight or nine inches wide having been completed about February 14th. The scene is supposed to be Swiss, although no special location is given.

As shown in the engraving, a snow-capped mountain is in the rear of the scene repesenting foot hills, in front of which is a lake of real water overflowing into a brook that tumbles over several little falls and emerges under an old Roman bridge in the foreground. At the right is an abrupt crag or preeipice surmounted by a castle, with a road winding 
away from the bridge up the hillsicle. At the left on the road leading from the brilge and orershadowed by a rugged mountain is a church and sereral small houses and outbuildings nestling against the hillside. The object of the arrangement is to show by means of electric lighting the varied light of the complete cycle of a day.

Commencing in the evening with the lamps lighted in the houses, the church is illuminated, and the whole scene is enveloped in moonlight. As the moonlight dies out and dawn approaches, the soft grey light first appears and gradually turns to red, orange and yellow as the sun gets farther above the horizon. The lights first strike the mountain peaks and creep gradually down the sides into the valley until the full light of the gorgeous sun is spread over all, being tempered by a bluish light to give the proper atmospheric effect tothe scene. After the sun has passed the meridian a storm appears, the first indication being a dimming of the sunlight and a gradual darkening of the sky. As the storm arrives sheet and chain lightening fill the sky, after which
To the electrical engineer the method of accomplishing these wonderful lighting effects is full of interest, and we are pleased to be able to give a deseription of the apparatus used.

The amphitheatre is about 20 feet broad by 15 deep, the floor sloping toward the stage. Between the curve of the front of the amphitheatre and the procenium arch is a space of $\mathbf{1 0}$ feet in width in which are placed two miniature electric fountains which play constantly and by means of clockwork change colors from red to green, red, yellow, blue and white. A 10-horse power electric exhaust fan is placed under this floor and discharges upward into the room to cool the interior.

The stage is 20 feet wide by 15 feet deep, the procenium arch being 12 feet wide loy nine feet in height. The sky is represented by a painted canvas hung in a curve on the back wall and being perforated with holes, the 3016 -candle power lamps behind it gives all the appearance of stars in the sky. In front of this scene and in rear of the mountain

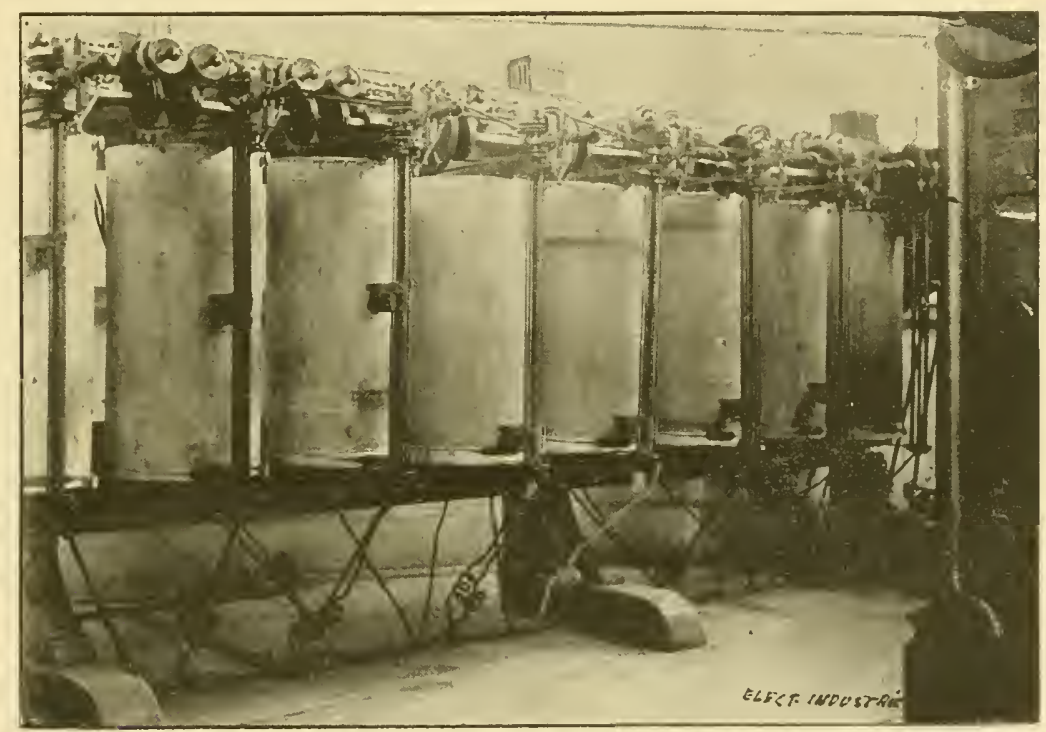

FIG, 2,-THE WESTERY ELECTRIC COMPAYY'S SCENIC THEATER IN THE FLECTRICITY BUILDING, THE RHEOSTATR.

the sunlight begins to emerge and a rainbow aprears. The ends of the bow are first seen at the sides of the mountain creeping up and finally arching over, becoming as vivid as in nature. The sun gradually increases in brilliancy and the bow disappears in the same mysterious manner in which it came, breaking first in the centre and gradually disappearing as if into the ground. By this time evening has arrived and the sun begins to set, the first evidence of which is a purple glow and the light slowly ereeps back up the mountains and changes through the yellows, oranges and reds glowing in the sky and over the mountains, lake and foot hills until it entirely disappears. As darkness approaches, the stars peep out in the sky, twinkling as in nature, the houses are lighted, shooting stars and a comet appear and the Aurora Borealis spreads its glow over all the scene. The cycle is thus completed, taking about 211 minutes. Visitors wait for a long time to get inside the amphitheatre, and this feature is in every way as well patronized as the others of this company's most attractive exhibits. scene are, first a tin reflector on each side sloping from a higher point in the center downward toward the sides, each containing 15, 16-canclle power lamps under a red glass screen. These lights are used to illuminate the sky during the rising and setting of the sun. Just forward of the red lights are two more tin reflectors slanting in the same way and containin 20, 32-candle power blue lamps used for making blue sky.

In front of the mountain and immediately back of the foot hills scene is one long tin reflector containing 24,32 . candle power blue lamps used for tinting the mountains and for producing atmospheric effects.

Placed in reflectors one on each side back of the foreground scene are 10, 32 -candle power blue lamps for lighting the sides and foot hills and for the general atmospheric effects. On each side of the procenium arch is a vertical row of 10, 16-candle power lamps behind red glass for rising and setting sun effects, with a row of 10,32 candle power blue lamps on either side for producing atmospheric effects on the frout scenes. The moon consists of a group 
of three 16 eandle power green lamps placed directly over the arch, over which is a drum about three feet long by about 12 inches in diameter with part of the surface covered with red and orange gelatine for running the sun light down or up the mountains at the proper time.

The sun is made up of a group of 15,32 -candle power lamps on a carriage which travels across the stage from right to left, the color effects being obtained by graduated glass screens on either side running from a deep red down through the lighter reds, oranges and yellows until the clear light appears on the scene, the same being repeated on the opposite side but in reverse order. The border lights are in the usual long inverted reflectors, the rear one having 26, 32-candle power blue lamps; the middle, 20, 16-candle power lamps behind a red glass sereen; while the front one for grey effects contains 20, 16-candle power lamps behind ground glass. An extra frout border is being put in place for lighting the front of the scenery more effectually. Of course the lamps would be of no effect
The mechanism is simple, very effective, and provided with cut onts which act automatically to stop the serew at any point desired. Drums with cords attached and revolved from the machine shaft work the sun and color drum by watching the progress of the scene the prompter is able to start up the lights at the proper time: The theatre runs very smoothly and requires but one man for its operation.

The company intends to move the theatre into the southeast corner of the Electricity Building early in July, and the present pavilion will then be used as an office by the representatives of the company located at the Fair.

\section{Exhibit of the General Incandescent Arc Light . Company.}

In contemplating the decorative lighting of interiors one cannot belp wondering why the use of the are lamp for that purpose has been so long neglected. The amonnt of illumination obtainable, the economy of production and the

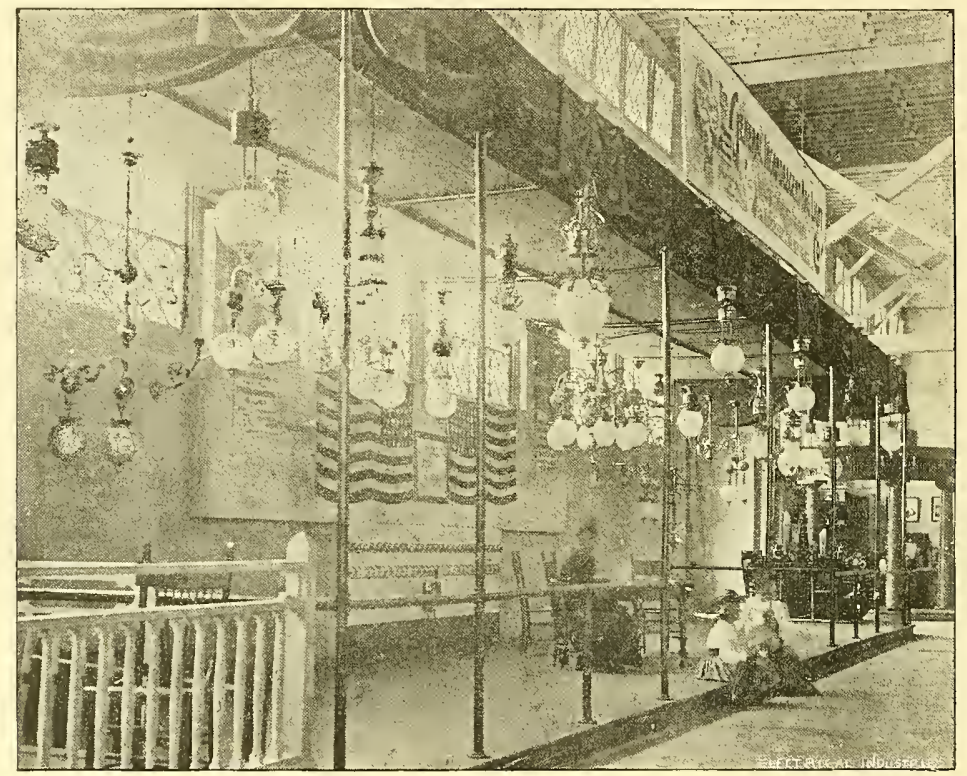

THE EXHIBIT OF THE GENERAL INCANDESCENT ARC LIGHT COMPANY.

unless means were provided for turning on the light gradually and at the proper time. For this purpose all eircuits from the lamps are led to a frame work placed just north of the theatre on the outside. On this are 11 rheostats, made of cylinders of sheet iron, about 20 inches long by 10 inches in diameter. These cylinders are wrapped with asbestos and wound with german silver wire of the proper size, the lower end being connected to one terminal of the bus bars the other being free. A slide which is made to travel up and down the side of the cylinder is attached to the wire leading to the lamps and cuts in more or less resistance according to its position on the cylinder. Switches and safety fuses are provided for cutting out any circuit.

The slide screws are revolved by means of round belts running over grooved pulleys on a shaft along the frame of the machine and as the belt doubles back to the screw, another grooved pulley above the first can be thrown in by a guide so as to turn the slide screw either up or down thus cutting the resistance in or out. large field for decorative lighting and effects which needed but a good lamp and experience, would seem to commend its use. In spite of this the same old time shapes of lamps are still in use and it is exceedingly difficult to convince central station managers that a lamp handsome in appearance and ornamental in desigu is desirable, and can be made financially successful.

The General Incandescent Arc Light Co. seems to have recognized this as shown by the interesting and attractive exhibit, located in section E, Electricity Building, a space 68 feet long by 13 feet wide. It is surrounded by a substantial railing with iron posts supporting a canopy of red and yellow, the Spanish colors, and tastefully draped from post to post. The rear wall is partially covered by a large American flag. A table and comfortable chairs are provided.

The specialty of the company is ornamental arc lamps for every service and any current for which the arc lamp is to-day adapted. The regular series are lamp with auto- 
matic ent-ont, lamps for low tension multiply cirenits either continuons or alfernating current; railway lamps used 10 in series on 5010 volt cireuits; long lamps with rack feed and short lamps with ribbon or chain feed are all shown in heatiful designs and suspended in many different ways.

The company's standard are lamp is of the rack feed type, plain in finish and when for use out of doors is provided with a very neat protecting hood inside of which the extra resistance is placed when used in multiple. The resistance is separate when the lamp is used for interior lighting and is placed in some convenient place. This resistance is of German silver wire wound on an iron frame having porcelain eovering where wires touch and a cover of shcet iron over all. These lamps are ornamented in many ditferent ways, by an extra finish of brass; in dead black or in a steel finish. Handsome designs in fancy brass and iron worli are shown, and also of designs suitable for any place. For places where it is not desirable or convenient to use the standard lamp, the bijou or short lamp is provided. This lamp has a so-called riblou feed, the ribbon being formed of fine brass or composition wires braided together thus forming a very strong and Hexible suspension as well as a good conductor to the positive carbon. The works are otherwise precisely the same as in the rack feed lamp with

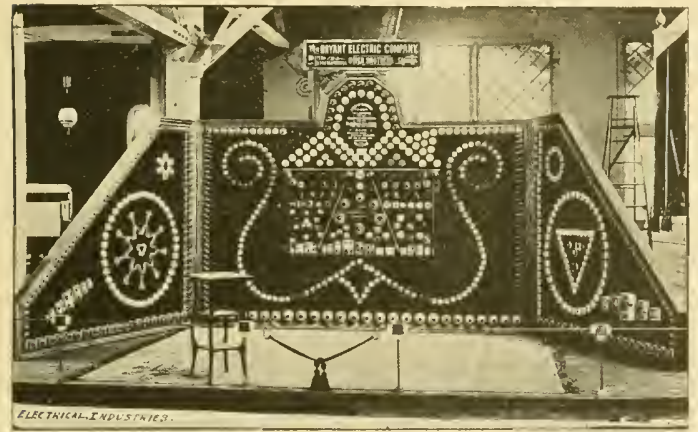

THE BRYANT COMPANY'S EXHHIT.

the exception of the drum which holds the cord. These lamps are only 30 inches long orer all, and are made in all the standard sizes of four, six, eight, ten and 20 ampere current capacity, and are subject to the same degree of ornamentation as the standard lamps. Another new feature is the use of side brackets and electroliers for the hanging of small lamps, samples of the latter for two lamps and six lamps being shown; by this means the small are lamp' should be not only very effective for illuminating purposes but ean be made highly decorative.

The lamp mechanism is very simple in construction, having but one electro magnet for feeding, the lifting of the upper carbon to draw the are being accomplished by means of a spring, which may be tightened or loosened to increase or decrease the length of arc. The side rods are of small brass tubing, the lower carbon holder being made of a small split tube with a conical screw on the end which enters the lower base framed from the bottom. It can thus be removed with the lower carhon attached without disturb. ing the globe, a small feature but one that will be much appreciated by the practical central station man. All parts of the lamp are thoronghly insulated from the circuit excepting those holding the carbon and electrical contacts.

This company is a special advocate of are lamps on the low teusion continuous currents now so largely supplied in onr large eities at from 110 to 220 volts. They state as reasons for it, the simplieity of installation, safety and reIiability of service, and great range of canelle power as intu. $700,1,0(10$ and 1,000 or 2,0100 candle power lamps can le taken from the same circuit, thus supplying any kind or quality of illumination that may he desired. It is said that many of the local Edison companies have some humblreals of the lamps already in use and are increasing their orders. The company's factory is at 33rd street and First ave., New York eity and its western office is 169 Adams street, Chicago. Mr. S. Bergmam being the Presirlent of the company is in itself an assurance that the ornamental features will receive the best of attention. Mr. Phillip Kleim is the Secretary.

\section{The Bryant Company's Exhibit.}

Every electrical man who attends the fair becomes fa miliar with the sight of the Bryant D. P. switch, as all the incantescent lights throughout the fair grounds are controlled by the Bryant switch. The company's exhibit, which is in the gallery of the Electricity Building in the sontheast corner, however, gives an iclea of the great va riety of specialties which are manufactured by this company.

Bug cutouts, horseshoe cutouts, of white porcelain, key and keyless soekets, polished yellow brass Paiste S. P. live and ten ampere and three way switehes, also the donble pole Bryant switch with shining nickel caps, together with brancly and main line cutonts of various kinds and a beantiful assortment of finely decoraterl china switehes, all gromped in a most artistic mamer on the black back ground forms a picture interesting and pleasing to the eye. The arrangement of these appliances in this manner is so striking that visitors panse to examine them. Eren the railing that surrounds the exhibit is constructed of the Bryant specialties.

The harmony of color and the beantiful arrangement of these useful devices show that artistic talent exists in a marked degree among some of our electrical fraternity. Mr. Edward R. Grier, who is associated with Mr. Thos. G. Grier in the management of the western office, personally arranged and erected the entire exhibit. The reputation of the Bryant company aud the merits of its goorls are both well establisherl and so well-known here to the electrical trade they need no comment. Their western office is located in the Monadnock Block.

A very pleasant event happened on June $2 t$ in the department offices of the Electricity Building. It was the birthday of the genial chief of the department, Prof. Barrett, and his friends, the press representatives from newspaper row presented him with a handsome floral emblem in the conventional shape of a magnet. Mr. M. J. Sullivan made the presentation speech in a very short aud aptropriate manner, but the Professor was too surprised to frame a reply.

Electrical Industries hais endeavored always to keep in the foremost rank in giving its readers the latest and best information on current subjects, but never has it received a more graceful compliment than it did the other day when a representative discovered one of its contemporaries using the map of Electricity building, published in the Weekly World's Fuir Supplement, as a guide in locating the different exhibitors. The compliment is a]preciated. 
ELECTRICAL INDUSTRIES.

Entered at Chicago Postofice us second-elass mail matter.

\section{ELECTRIGAL INDUSTRIES PUBLISHING COMPANY, INCORPORATED 1989. \\ MONADNOCK BLOCK, CHICAGO. \\ TELEPHONE HARRISON 159 \\ E. L. POWERS, Pres. AND TREAs. \\ E. E. WOOD, SECRETARY,}

E. L, POWERS,

EDITor.

H. A. FOSTER,

W. A. REMINGTON,

E. E. WOOD,

- Associate Editolis.

d. Eastern Manager

FLOTD T. SHORT,

A diertising Department.

EASTERN OFFICE, WORLD BUILDING, NEW YORK. World's Fair Headquarters, Y 27 Electricity Building.

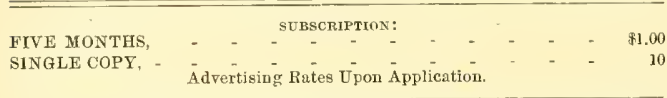

News items, notes or communications of interest to World's Fair Visitors are earnestly desired for publication in these columns and will be heartily appreciated. We especially invite all visitors to call upon u or send address at once upon their arrival in city or at the grounds.
ELECTRICAL INDUSTRIES PUBLISHING CO.

The Fourth of July was most fittingly celebrated at the Fair. Special efforts were made, especially in the Elcctricity building to make the exhibits look as attractive as possible. The grounds and buildings were most elaborately decorated, and everything had a holiday appearance. Although a program was prepared including speeches. parades and music, the electric fountains and fireworks were the great attraotions. The attendance exceeded 300,000 .

The presentation to Prof. J. P. Barrett, Chief of the Department of Electricity, a few days ago, of a handsome floral design by the electrical press, on the occasion of his birthday was a most pleasant occurrence. This compliment, however, only reflects the sentiment and high esteem in which be is held by the entire electrical fratemity. Prof. Barrett is without doubt one of the most popular chiefs of any department of the Fair, and his efforts in behalf of the electrical interests to act impartially and bring about a display of credit to these important interests are certainly appreciated. Electrical Industries most heartily unites with all his friends in wishing him many more and pleasant birthdays.

THE various outdoor attractions, the fountains, the bands, the boats and the attractions of Midway Plaisance seem to draw the evening crowds. With the exception of the Electricity building, the buildings have very few visitors during the evening, so few that the exhibitors do not consider it to their advantage to be with their exhibits nor to place attendants in charge. A program is being discussed by the chiefs of the departments, and the management for keeping open during the evening the Electricity building and one other building, taking the buildings in order. If this program is adopted, as it now has the appearance of being, the attendance at the Electricity building will be greatly increased, much to the advantage of the exhibitors.

The Jury of Awards in the Department of Electricity has not as yet been announced. It will include from 21 to 31 members, as the occasion and necessity of the situation demand. Of this number from 6 to 5 will be selected from the eminent foreign electricians. The jury will be divided into 9 committees, one for each section in the department. A meeting of the committee will be held to determine the method of conducting examinations and tests. The actual work in each section will be done by one or more members of the committee forming a sub-committee. The report will be made by the sub-committee to the committee of the section by whom it will be referred to the Department Jury of Awards for consideration. From the Department Jury of Awards a report will be referred to the Executive Jury of Awards, from whom it will pass to the National Commission, who will order the awards to be made by the secretary of the treasury. A bronze medal, accompanied by a diploma, stating the points of excellence and advancement, will be awarded to those selected by the Jury.

At noon, on July 1, and entirely without ceremony of any nature, the decorations by the Westinghouse company on the south end of the Electricity building were unveiled. Over the top, following the curve of the arches of the building, is the name of the company. Immediately underneath is a large painting of the head of Columbus, large handsome scrolls being painted on either side. Lower down are the dates, 1492 on the left, and 1892 on the right, with the name, Columbus, directly underneath the picture. All these letters and figures, which are painted on the wall with a back-ground of terra-cotta, are filled in with incandescent lamps for evening illumination. There are in all 1988 16-candle power lamps used in this decoration, 580 being for the head of Columbus, 585 in the scrolls, 260 in the name and dates, and 560 for the sign of the company. These lamps are of different voltages, varying from 95 to 110 in order to get the proper shadings. Owing to the hurry to get ready for the celebration on the th, white lamps will be used at present, but eventually colored lamps will take their place in order to produce the best effects.

A fine exhibit of leather belting is shown by A. Domage of 74 Boulevard Voltaire, Paris, in the French section of Machinery Hall. Specimens of single and donble belting, round twisted and link belting, which by the way differs from ours in having double links, that is, two of the ordinary links side by side. A 32 inch belt is shown made of strips of leather cut about three-quarters of an inch wide sewed together so that the edge of the leather is the bearing surface. This appears like a very stiff and strong belt, but must be very expensive. A frame is shown containing samples of leather of different quality and shape and samples of belting are arranged at the sides in ornamental forms.

The electric light buoys from Van Buren street wharf to the World's Fair Pier were started Saturday evening, July 1st. The light is said to be very brilliant and highly satis. factory to the lake pilots.

\section{The Lamp Case at Milwaukee.}

Hearing in the suit for injunction brought by the General Electric Company against the Electric Manufacturing Co. of Oconto, Wisconsin, was begun in the U. S. District Court at Milwankee, Monday the third; the court adjourned over the fourth to Wednesday morning. The Oconto Company is represented by its local counsel, Mr. Webster and Messrs. Witter \& Kenyon, who so ably defended the St. Louis case. The General Company has its full force of legal talent, including Mr. Fish. 


\section{WORLD'S FAIR NOTES.}

The Western Electric Co.'s scenic theater is attracting consiclerable attention, and it is especially amusing to listen to the comment of children who eagerly watch the changing effects. One little tot, as the shadows followed the fading light, inquired anxiously: "Is it going to rain, namma?"

Saturday, July 1st, was Dominion Day at the Fair. The programme included meting at the Canatian pavilion at at 2 р. x.; a procession to Festival Hall at 3 р. x. and speeches after that hour by the Canadian Commissioner and others. Mfusic was furnished by Tattersall's military and other bands.

The Electric Heat Alarm Co.'s exhibit is wortlyy of inspection. If it be visited on a sunshiny day, Mr. E. Nishold, the manager of the Chicago office and who is in charge of the exhibit, will show the visitor how sensitive are the thermostats used by the company by simply exposing one of them to the sun's rays for a few seconcls.

Albert \& J. M. Auderson, Boston, have an interesting exhibit of electric railway, light and power specialties in the Transportation building, showing, among other goods, the Ajax switchers and lighting arresters mannfactured for C. S. Van Nuis of New York. Mr. T. A. Matthews is in charge of the exhibit for a New York exhibitors' association.

The Western Electric Company added still another feature to its already large exhibit, last Saturday, in the shape of a large focusing lamp with the front lens concealed by a dise formed of richly colored pieces of eut glass, with the name of the company inlaid in glass of a different color around the edge. It is located just north of the scenic theatre and is destined to be one of the evening attractions.

A great deal of interest is manifested in the electric welding of small samples of metal, shown by the attendant at the exhibit of the Thomson Electric Welding Co. Short pieces of iron or steel wire are almost instantaneously joined by the automatic welder. On the opposite side of the building the electrical beating of metals for working, shown by the Electrical Forging Company attracts a large crowd whenever any of the machines are in operation.

One elderly lady approached Mr. Fox under the Tower of Light and inquired if the surrounding exhibits were those of the General Electric Co. Upon being assured they were, she watched the pumps, gazed on the drilling machine with a puzzled expression, and finally her eyes wandered to the illuminated monogram in colored light in Section B. Her face lit up and she exclaimed in pleased surprise: "How kind of them! C. E., Christian Endeavor"!

The Miyoshi Electric Works, of Tokyo, Japan, have just commenced the installation of an exhibit in the northeast corner of the Electricity Building, near that of Queen \& Co. They already show some-very handsome electroliers made entirely of bamhoo in varions forms; also a number of enlarged photos of views of the effects of earthquakes in Japan. The company was established in 1883 and manufactures dynamos, motors, telephones, telegraph and various other electrical material.

A very finely finished alternating current dynamo of the Zipernowsky pattern is exhilited in Machinery Hall, along with other prolucts of the firm of Schneidter et Cie of Creusot, France. At $j(10)$ revolutions the capacity is stated as 25 amperes at 2,000 volts. The shape and clesign is very much different from those in this country and the machine would have deservedly received much more notice in the Electricity Building than it does now, hicl away behind a lot of high power cannon and revolving turrets.

One of the finest exhibits of electrical fixtures ever placed on view is that of the Archer \& Pancoast Manufact. uring Co., New York, located in the New York State Building. The two $\$ 15,000$ electroliers in the Ball Room contain 72 lights each of 1 (j-candle power. Four 12-light gold plated standards ralued at from $\$ 2, ; 00$ to $\$ 3,000$ each are also to be seen in the Ball Room. Scattered throughout the building are 14 -six light standarels of artistic design. A 56 -light electrolier illuminates the main stairway, while over the main entrance is a 40-light gold lantern that has already been sold to Chicago parties.

Among new steam engines at the Fair is one that has not heretofore been seen in the East. In section M, No. 43, of Machinery Hall is an engine exhibited by the. Golden State \& Miners Iron Works, of San Franciseo, Cal. This engine, the invention of 1 . F. Thompson, is known as the slide valre Corliss, and the leading features are said to be one eccentric; all flat slide valves; exhaust valves fixed; steam valves quick opening and closing; and the fewest joints to accomplish the above results of any engine yet produced. The arrangement of lugs, dashjots, governor and other small detail is peculiar and deserve the great deal of attention from engineers the engine is now receiving.

The Javanese Village, Midway Plaisance, was the scene the other day of a most interesting series of experiments with the electrical current. The attendant was replacing burned out lamps and had one native assistant, to whom he tried to explain the nature of the current. First wetting his finger the instructor placed it in the socket, being careful not to make a connection. The little man from Jara put in his finger, minus the water. No effect. Then he wet it and tried again. The standing jump he made would have turned a college athlete green with envy! Not a word of complaint from the bright-eyed little foreigner, but the attendant had no sooner left than another native was initiated into the mysteries of electricity by the original investigator! Ant so it went; each in turn bringing another, till now it wonld be hard to find a more "highly charged" community.

The Wm. Powell Company, of 225 spring Grove Ave, Cincinnati, has a fine exhibit of engine and sight feed lubrieators in the sonthwest gallery of the Electricity Building. There are grease cups for all purposes, for locomotive and for street car motors, special sight feed oilers for triple expansion engines, for largedynamo bearings, in fact oilers for most places were lubricating oils are used. A fine exhibit is also made of Powell's patent regrinding seat globe valve. Not wishing to be inconveniencerl by using oil for showing the working of thesecups, the Powell Company has installed a small induction coil plant for driving sparks between two points inside the various sight glasses. This plant consists of a half horse power Jenney motor, belted to a small generator of the same capacity, this in turn runs a large induction coil, the spark from which procluces the required effect in the oilers. As none of the regular spring make ancl break vibrators would do for the heavy currents, used in this device Mr. Powell has constructed a very ingenious make and break, by the use of a mercury cup. The three cabinets of ebonized wood, trimmed in gilt, with curved glass fronts, show off to good advantage against a background of heavy dark curtains draped against the back of the space. It is intended to show some further electrical effects as soon as the apparatus can be got reacly. 


\section{PERSONAL.}

R. M. Bayles, of New York, formerly of the C. \& C. Motor Co., is a visitor at the Fair.

Mr. W. R. Brixey and family, of Ansonia, Connecticut is spending a couple of weeks at the Fair.

Mr. G. T. Williams, formerly Supt. of the Nickel Plate Railroad telegraphs attended the Fair a few days last week.

Mr. C. F. Scott, electrician of the Westinghouse Electric \& Mfg. Co., was in Chicago for a few days at the Fair last week.

Mr. J. H. Rhotehamel, of the Columbian Incandescent Lamp Co., accompanied by Mr. Menry Crobel, visited the Exposition this week.

Mr. D. H. Dorsett of Jamestown, New York, and a pioneer in undergound conduit construction was at the Fair during the last of June.

Prof. and Mrs. Thos. French, of the University of Cineinnati, are in town for a few days, and will return later for the electrical congress.

Mr. O. B. Schallenberger, consulting electrician of the Westinghouse Electric \& Manufacturing Co., with his wife visited the Fairlast week.

C. M. Lungren, of the Siemens-Lungren Lamp Co., is doing some work in the Department of Electricity for Appleton's Popnlar Scientific Monthly.

Mr. F. B. H. Paine of St. Louis, and the representative of Siemens \& Halske Co., in that city was registerea at the Institute headquarters last week.

Mr. Edwin F. Morse, of Morse, Williams \& Co., Philadelphia, who have an exhibit of electric elevators in the Transportation Building, was in town last week.

Prof. W. E. Ayrton and daughter arrived in New York on the Germanis a few days ago. After a brief stay in New York they will come to Chicago for six weeks.

Prof. $\Lambda$. Macfarlane, of the University of Texas, stopped in the city for a day or two last week. He will return again later to attend the Congress of electricians.

Mr. Henry A. Reed, general manager of Bishop Gutta Percha Company, New York, arrived in Chicago on Thursday of last week and is spending a few days at the Fair.

Mr. Nelson W. Perry, editor of the Electrical World, was married to Miss Marie Eugenia Bedell, at Brooklyn, N. Y., June 28. Electrical Industries extends congratulations.

Mr.James G. Kaelber, the Rochester agent of the Western Electric Company, is visiting the Fair this week, in company with J. S. Hays, electrician of the Carnagia Steel Company.

Mr. S. K. Bullard, of Sedalia, Mo., Supt. of telegraphs for the M. K. \& T. Railroad is in the city with his family on his way home from the meeting at Milwaukee. He will spend a few days visiting the Fair.

\section{OBITUARY.}

Mr. Wm. Stanley Sr., the father of Wm. Stanley Jr., died at his summer house in Great Barrington, Mass., June 28. He was a well known lawyer, and at the time of his death was 66 years of age.

\section{NEW PUBLICATIONS.}

Price list Number 6 has just been issued by the Oconite Company, 13 Park Row, New York, containing complete price lists of its insulated wires and cables. The wires and cables manu factured by this company include those adapted for high and low tension currents, aerial and sub-marine telegraph and telephone cables, electric light and railway wires insulated by Okonite and Candee insulation.

The new catalogue of the American Institute of Electrical Engineers has been received. It is corrected to June 1st, 1893, and contains alphabetically arranged lists of the members and associates together with a geographical distribution of the same. Names of past offices, rules of the Institute and a calendar of the dates of meetings for the ensuing year are also included. The book is marked with the eut of the new badge which will hereafter be found on all literature of the association. The member- ship has increased greatly in the past two years and doubtless many new names will be added during the Fair.

\section{BUSINESS NOTES.}

The Phoenix Glass Co. furnished the globes used by the Westinghouse Company in lighting its Kiosks.

The Western Electric Companx, Chicago, has been awarded the contract for wiring the Ferris wheel for incandescent lights.

Notice was given Saturday, July 1st, that a semi-annual dividend of four per cent has been declared by the Great Western Electric Co, and is payable on and after July 1st at the office of the Company, 207 South Canal street, Chicago.

The W. S. Edwards Mfg. Co., Chicago, has recently completed contracts for gas and electrical fixtures for the following buildings: Hotel Edinburgh, the Kedzie Building, the Teutonic Building and a new Government building at Fort Sheridan.

The American Electrical Works, Providence, R. I., is presenting its friends with a harmless piece of fire works which calls attention, not only to the national holiday, but also to the in. sulated wires, electric light and Faraday cables and other goods manufactured by this company.

The Electric Appliance Company has been working for some time in the telephone line with the idea of getting up a first class non-infringing electric telephone. They have at last succeeded in securing an instrument that is satisfactory to themselves. which is a sure guarantee that it is a first class instrument. They promise to proceed at once to make a few ripples in the telephone puddle.

\section{Amusements.}

Hooles's Theater-Mr. E. S. Willard, in "The Professor's Love Story." 149 Raudolph street.

Columbia Theater-Miss Lillian Russell, in "La Cigale." Seventh week. 108 Monroe street.

Grand Opera House - Sol Smith Russell, in "April Weather." 87 Clark street.

AUditoridy-Imre Kiralfy's Spectacle "America." Congress street and Wabash avenue.

MoVicker's Theater-Denmau Thomson, in "The Old Homestead." 82 Madison street.

Chloago Opera Hodse-American Extravaganza Company, in "Ali Baba," or "Morgiana and the Forty Thieves." Sixth week. Washington and Clark streets.

Schiller Theater-Chas. Frohman's Stock Company, in "The Girl I Left Behind Me." Sixth week. Raudolph, near Dearborn.

HaVerLi's Casino-Haverly's United Minstrels. Wabash avenue, near Jackson street.

Havlin's Theater - "The Cracker Jacks." Wabash avenue, near Eighteenth street.

Trocadero-Concert, Michigan avenue near Mouroe street.

The Grotro-Vaudeville. Michigau avenue near Monroe street.

Buffalo Bill's "Wild West." 63d street.

Pain's "Siege of Sebastopol," 60th street and Cottage Grove avenue.

ONE of the best known advertisers in the trade writes us as follows: "We were well impressed with the idea of your weekly issue and more so with the way you carried it out. As a bright and timely enterprise it certainly deserves a generous patronage."

For a new sensation try a camel ride.

The donkey drivers in the Cairo street do not need electric lights to see a dime. 


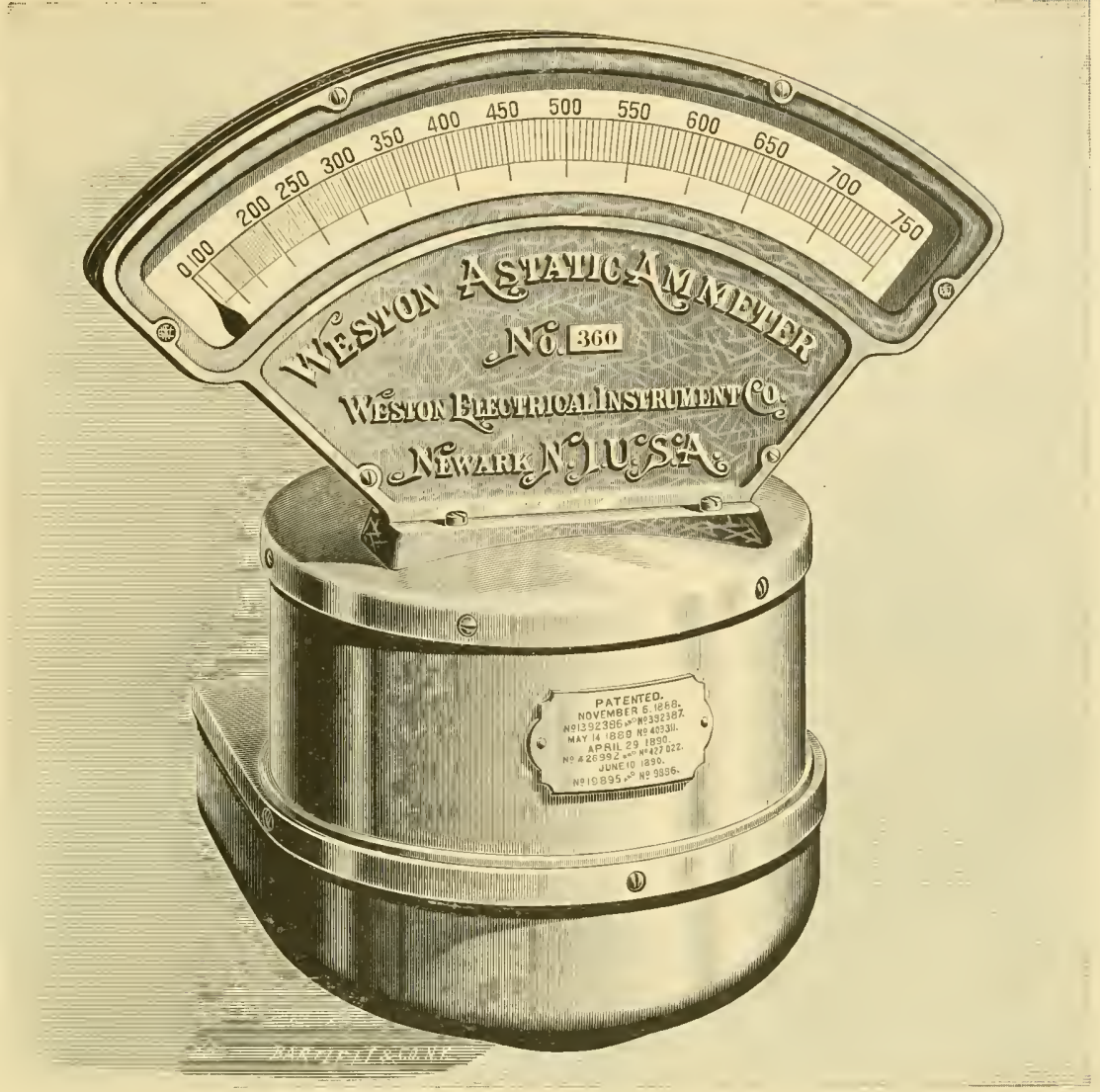

Central Station and Isolated Plant Astatic Ammeter (Cne-Half Size).

The Weston Standard Portable Direct Current Voltmeters and Ammeters are used in all parts of the Civilized World.

They are recognized hy all authoritie日 as the very hust ir Btrument ever
produced. produced.

During the pat year Mn. WEston bar given mach time to the forther ftudy and improvement of these inatrumente, and has hronght them to a liwher degre of permanency, dorah lity, accoracy aod excellence than we ever thought possible erior to the latter in all that contributen to a firet-clase ustrumedt. It jo the aciue of perfection, and 18 destined to become and remain

THE STANDARD PORTABLE INSTRUMENT OF THE WORLD.

Wi. lave perfected a larger model of these instroments-expressly adapted for use as absolute standards in atstions and laboratories.

WESTON PORTABLE ALTERNAIING CURRENT VOLTMETERS.

There instrumeots are absolutely permanent and very arcorate, and are jo comparably superior to any forsu of hot wire instrament known. They will be tion of alter ating cnrrent plunte.

We make multipliers for use with these instruments to extend their range so

We also make rixted diffirent ranges of moderate priced, bigh grade

DEAD-BEAT SWITCH-BOARD AMMETERS. (See Illustration.)
Dew eapacity range from 25 amperes to 750 amperes. These instromenta are pe, and are very accurate and well made. The gcales are very regular. ir indicatione are not eensibly affected by the moat powe rfrl external fielde. Cocrent

STATION AND ISOLATED PLANT VOLTMETERS,

in three sizea ard muny raogea. Theae inatruments are very dead-heat, and em-

bou man new and valoable featores. for are and ncandescent light circuite, and all other work requiring good and tharoug ly trustworthy Voltmeters. They are eepecially deaigned for awitch board use. We are also making a large line of high grade

\section{STATION AMMETERS.}

in ranges from 200 to 5,010 amperes. with aheolutely proportional ecalee through ont the entire range. The eensihility and accnracy of these ine' rumente hav ar noen the the ecale to the erming on or off of a siegle amp, and car be read in any part of permanent, dnrable : and well made, and moderate in price.

SEE OUR ELABORATE EXHIBIT AT WORLD'S FAIR S. E. CORNER SECOND FLOOR, ELECTRICITY BUILDINC, WHERE OUR REPRESENTATIVE WILL BE PLEASED TO RECEIVE VISITORS.

\section{THE WESTON ELECTRICAL INSTRUMENT CO,} 114-120 William St., Newark, N. J., U.S. A. 


\section{ELECTRICITY BUILDING-EXHIBITORS AND THEIR LOCAATION.}

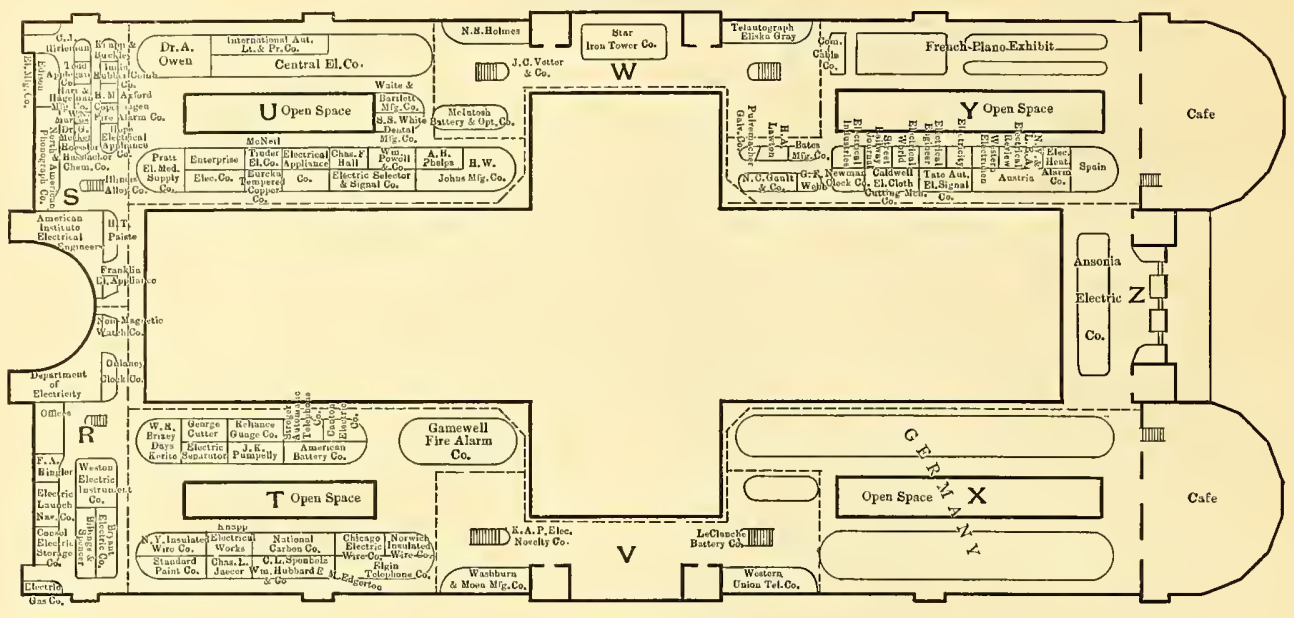

GALLERY.

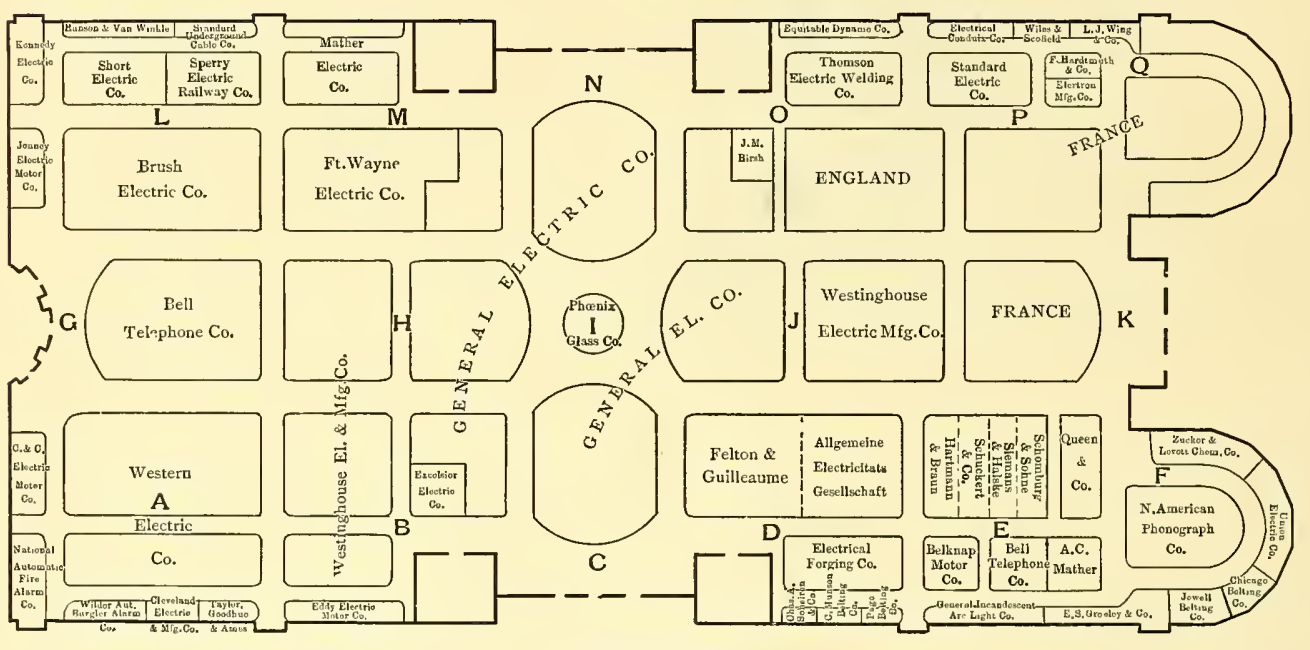

MAIN FLOOR.

\begin{tabular}{|c|c|c|}
\hline & & \\
\hline $\begin{array}{l}\text { Exhihitor. } \\
\text { A ustria }\end{array}$ & $\begin{array}{l}\text { Exhibitor- } \\
\text { Electrical Review ................... }\end{array}$ & $\begin{array}{l}\text { Exbibitor. } \\
\text { Jaeger, Chas. L...................Ti }\end{array}$ \\
\hline & & \\
\hline Am. Inst. of Elec. Eng....... & Electric GBg Co.... & Jewell Belting Co...... \\
\hline American Battery Co....... & Electrical Engineer & J nney Elec. Motor Co \\
\hline Axford, H. M............ & Electrical World ............ & Knapp Electrical Work\&.... \\
\hline Allg. Elec. Geselischaft.. & Eddy Electric Motor Co & K. A. P. Elec. Novelty Co \\
\hline Bates Mfg. Co.............. & Excelsior Electric Co..... & \\
\hline Bryant Electric Co........... & I Forging Cn.................... & \\
\hline Speucer.......... & Dynamo $\mathrm{Co} . . . . . .$. & $\tan$, H. A ........ \\
\hline R.......... & Elektron Mfg. Co ................. & LeClanche Battery Co... \\
\hline ap Motor Co....... & Electrical Conduit Co..... & McNeil-Tinder Elec: Co \\
\hline elephone co..... & England .................. & Marcus, W. N ......... \\
\hline lectric Co & Empire China Works. & Dr. G. \\
\hline h Cat. Mch, Co.. & In Elec. A ppliances. & sh Brt. \& Opt. Co \\
\hline age $\mathrm{Co} . . . .$. . & iano Exhibit........ & n, C., Beltî \\
\hline tes & Guilleaume. & r. A. C... \\
\hline Co. & $\cdots . \overline{\mathrm{K}}-\mathrm{P}-2$ & rElectric Co. \\
\hline & & \\
\hline 0 & c.. & ch Co. \\
\hline & flarm co....... & ire Co. \\
\hline$\ldots$ & $\mathrm{Co} \ldots \mathrm{B}-\mathrm{H}-\mathrm{N}-\mathrm{C}-\&$ & \\
\hline & 'e't Arc L't Co.......... & $\mathrm{N}$ \\
\hline g. Co..... & E. S., \& Co & raph Co... \\
\hline & & L. E. A.. \\
\hline 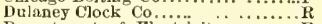 & Wm., \& Co... & t. Fire Alarm Co. \\
\hline ectricity. & , C. J.... & \\
\hline ELE & Co... & Dr. A... \\
\hline & Co.. . & $x$ Glass Co \\
\hline & (20. & \\
\hline & $\overrightarrow{\mathrm{H}}$ & $\mathrm{Pu}$ \\
\hline $0 \ldots$ & II & \\
\hline Co.. & Yinkla & led. Snp. Co. \\
\hline & & ell, $\mathrm{Wm}$. \\
\hline$r c_{0} \ldots . .$. & Hardtmnth, F., \& Co... & $\mathrm{ps}, \mathrm{A}, \mathrm{H} \ldots .$. \\
\hline & Illinois Alloy Co............. & \\
\hline Elec. Sel, \& Sig'] & & \\
\hline Electric Heat Alar & & \\
\hline
\end{tabular}

Exhibitor. Section Reliance G uage Co................ . . . Street Rail way Jonrnal.............. Y Strowger Ant. Telph. Co.............. T Standard Point Co.................. Sponholz, C. L.................... T Star Iron Tower Co...............W Spaie.......................... Cha D (n).... Siemens \& Halske. Schuckert \& Co. Sperry Elec. Railway Co................ Standard Underg. Cable Co............. Standard Llectric Co. Samson battery Co................... Tate Aat. El. Signal Co................ Y Taylor, Goodhne \& Ames.............. A Thomson Elec. Welding Co .......... Telaatograph, Elisha Gray ........W Union Electric Co .................. Vetter J. C. \& Co. Webt, Wathorn Western Union 'F'el. Co

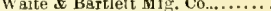
White, S. S., Dental Mfg. Co......... Western Electrician Wil. Co............. Wilder Aut. Burglar Al. Co........... A Westinghouse El. \& M f $_{g}$. Co ..... B-H.J Wiles scofield Zucker \& Levett Chem. Co............ 


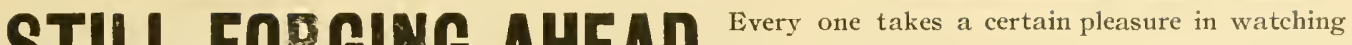

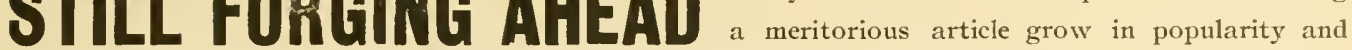
fill an ever increasing field of usefulness. It is undoubtedly this appreciation of a good thing that pushed the sales of the

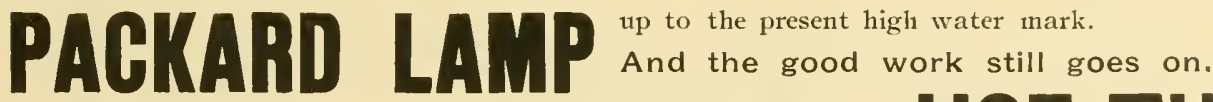

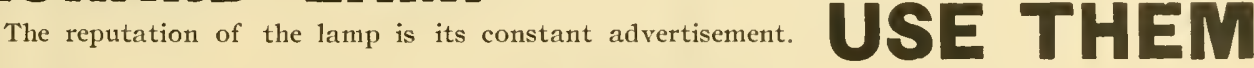

Electric Appliance Company, 242 Madison St. ELECTRICAL SUPPLIES.

CHICAGO.

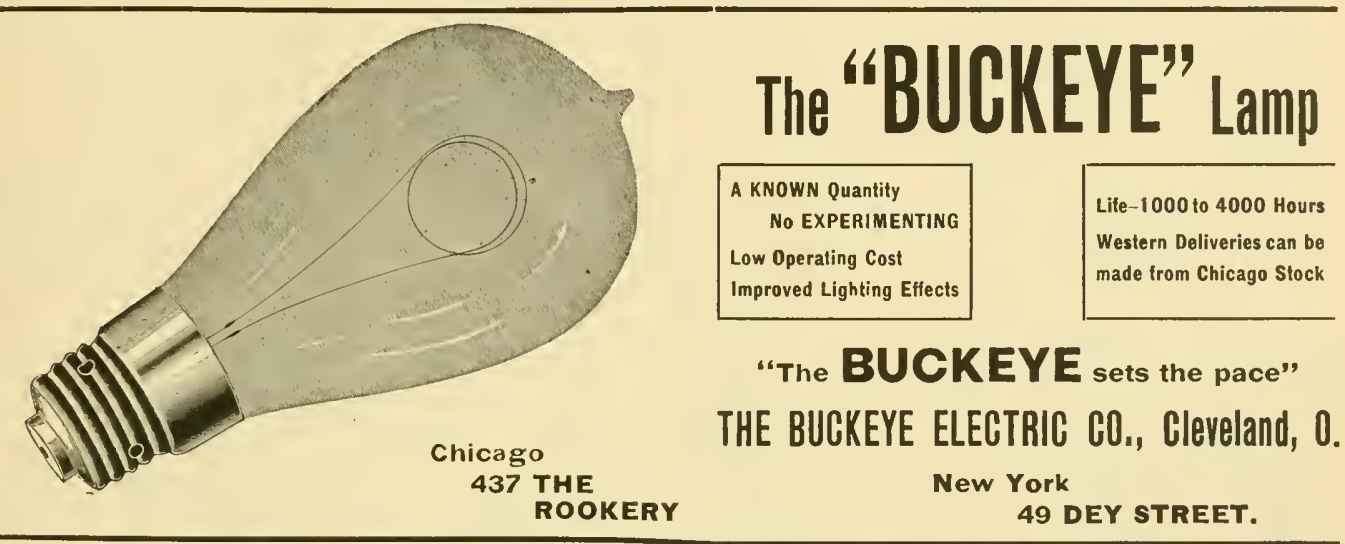

THE MATHER ELECTRIC CO, THE "NOVAK" LAMP.

MANCHESTER, CONN.

Dynamoss, Molotiss, Genereators,

Offices, Il6 Bedford St., BOSTON.

-AND-

CLAFLIN \& KIMBALL (Inc.)

General Selling Agents.

116 Bedford Street, BOSTON.

1002 Chamber of Commerce Bldg., CHIGAGO. 1002 Chamber of Commerce Bldg., GHIGAGO.

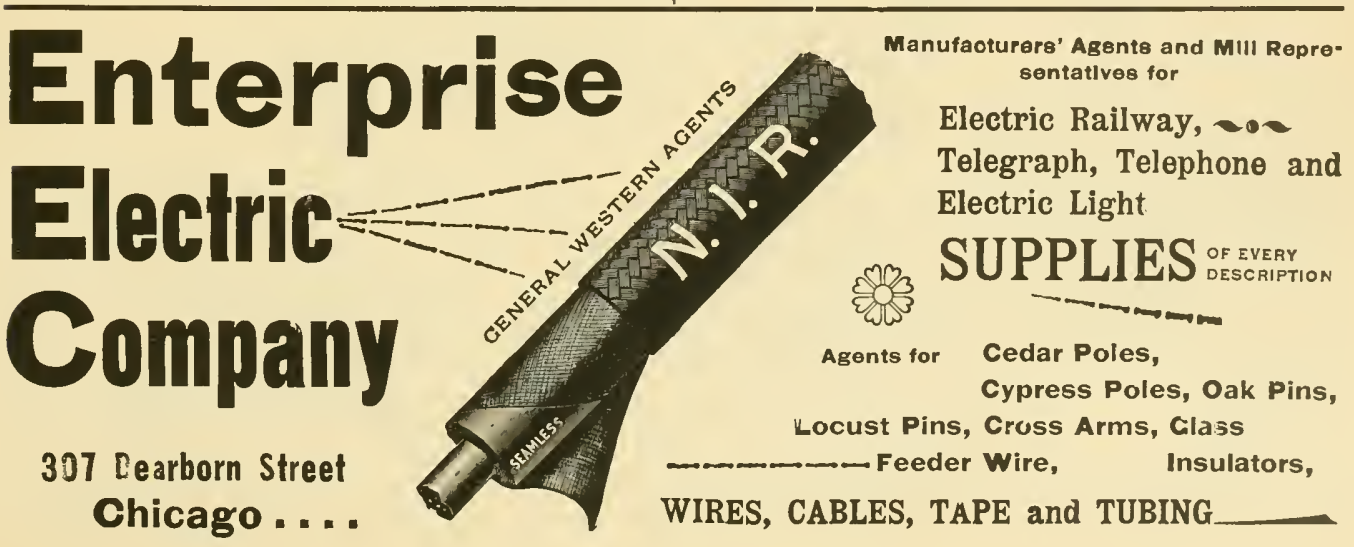




\section{Map of Chicago.}

Showing Location of its Eleetrical and Allied Business Interests, Principal Hotels, Theatres, Depots and Transportation Lines to the World's Fair Grounds. (Index numbers refer to the black squares.)
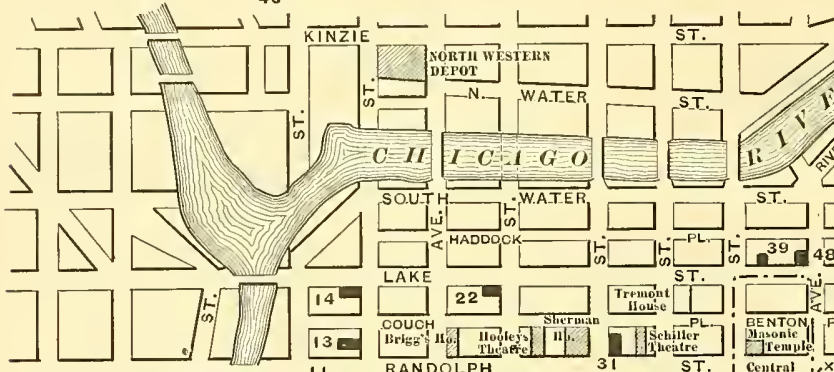

LAKE 22
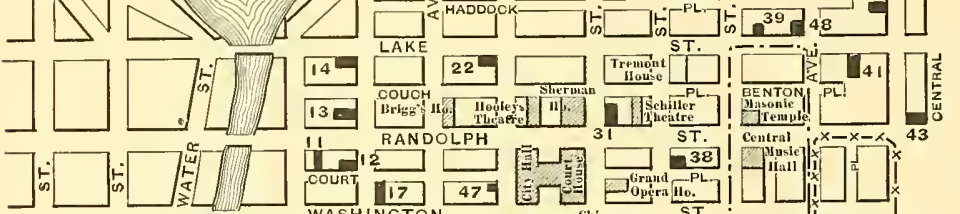

COURT 17 [7] 47

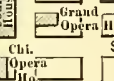

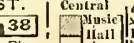

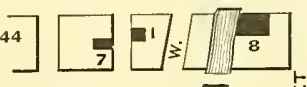

10 216
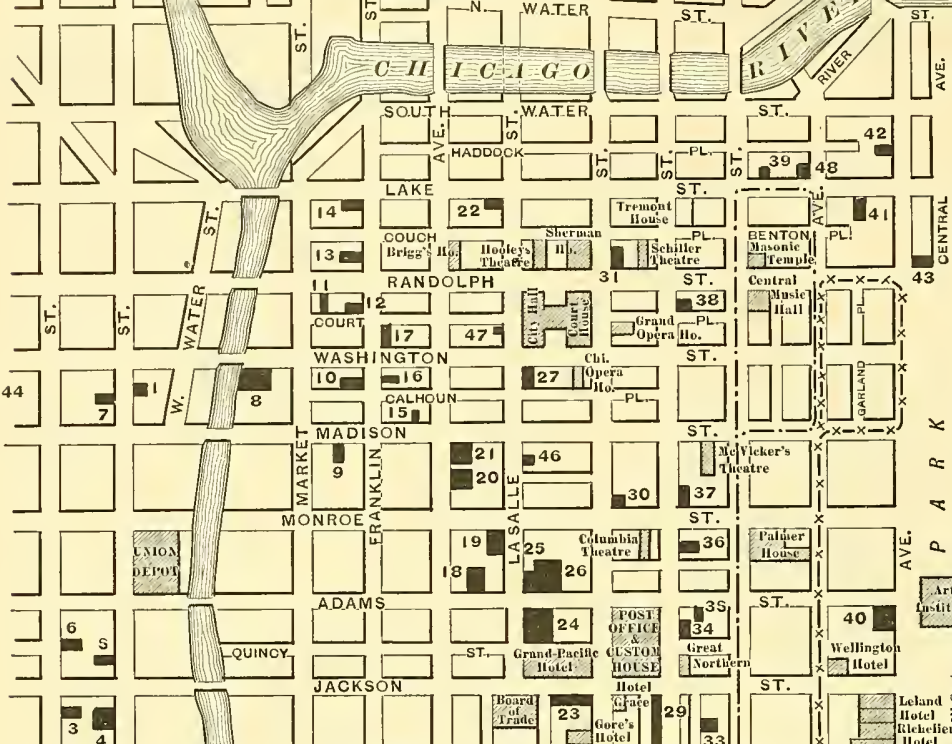


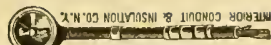
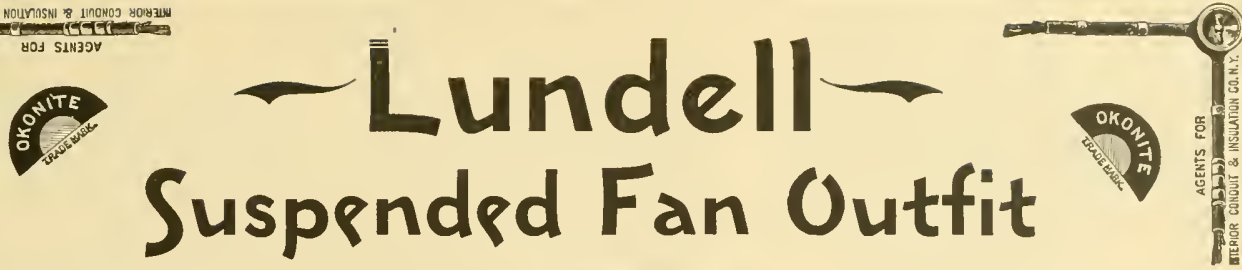

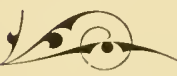

Black

Japan

Finish

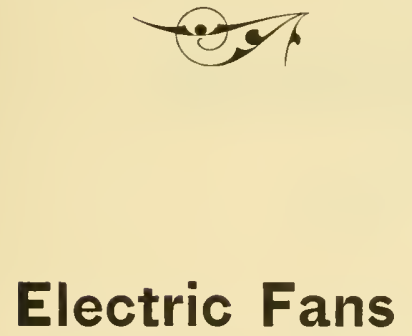

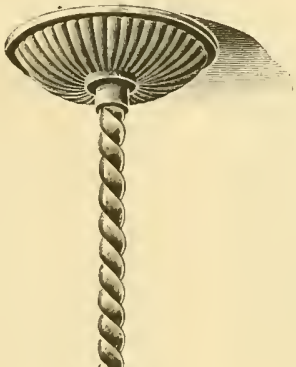

Self-0iling ....and

Self-Aligning Bearings

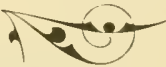

Electric Fans

\section{OKONITE WIRES}

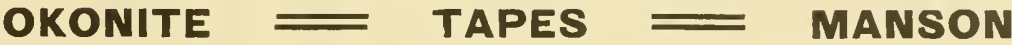

\section{INTERIOR CONDUIT.}

Batteries, Bells, Push Buttons, Annunciators, Volt Meters, Ammeters, Wheatstone Bridges, Line Wire Cross Arms, Brackets, Pins, Insulators, Tools.
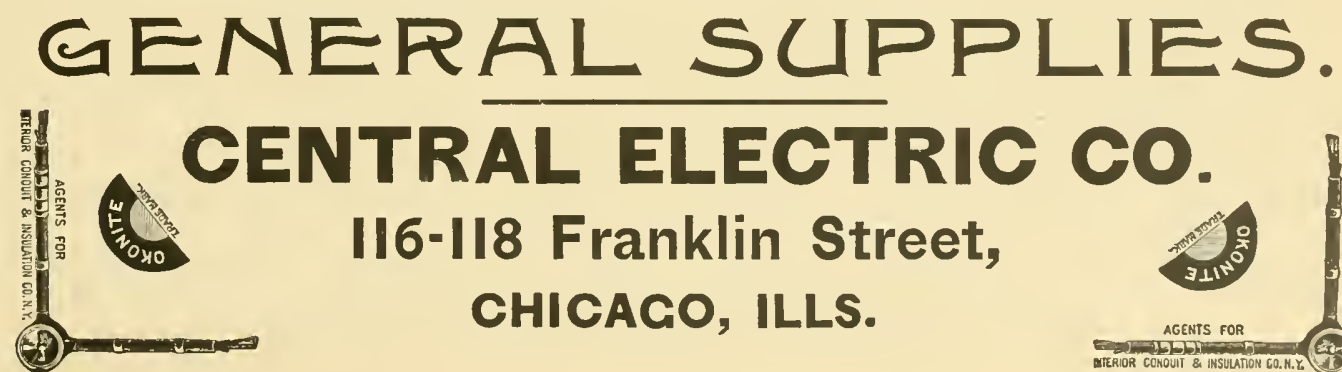

\section{ELECTRIC CO.}

II6-II8 Franklin Street,

CHICAGO, ILLS.

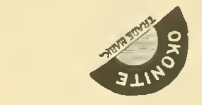




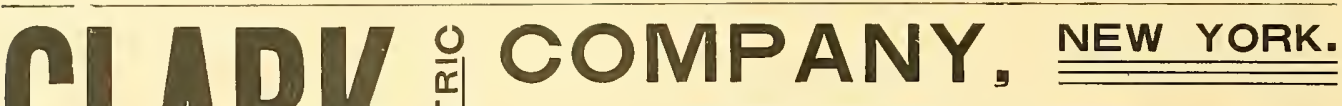 \\ 192 Broadway and II John Street. \\ MANUFACTURERS OF ARC LIGHTING APPARATUS FOR EVERY PURPOSE A SPECIALTY. The CLARK ARG LAMPS for use on EVERY CURRENT, have the reputation of being the best and most durable of any ever made in the United States.}

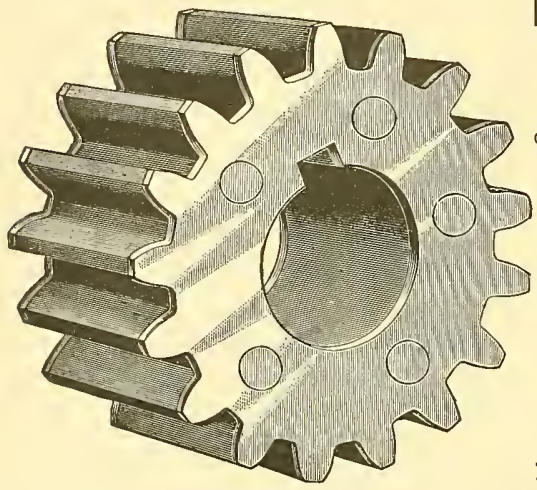

RAWHIDE PINIONS FOR ELECTRIC MOTORS A SPECIALTY.

RAWHIDE DYNAMO BELTING

Greatest Adhesive Qualities.

A Non-Conductor of Electriclty. Causes Less Friction than any other Belt.

THE GHIGAgO RAWHIDE MANUFACTURING CO. THE ONLY MANUFACTURERS IN THE COUNTRY.

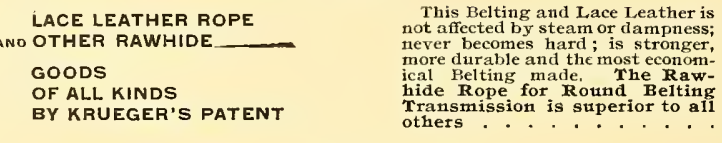

75 Ohio Street,

OHICACO. HLL

The Regular Monthly Edrtion of ELECTRICAL InDUSTRIES is the most complete Electrical Journal published-every issue containing descriptions of all the new applications of electricity, complete directories of the Manufacturers and Dealers, the Electric Lighting and Railway Companies in North America, revised and corrected to the date of going to press. These special features are found in no other Electrical Journal in the world, and consequently it is read by more actual buyers than any other publication, which fact makes it without a superior as an advertising medium.

ELECTRICAL IMDUSTRIES PUBLISHING CO., Monadnock Block, CHICAGO.

\section{STANDARD
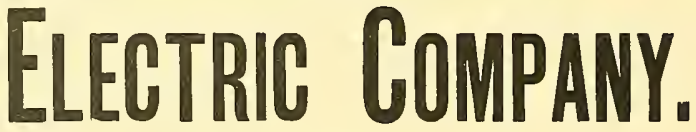

GENERAL OFFIGES: 625 Home Insurance Building. WORKS: So, Ganal Street,

CHICACO.

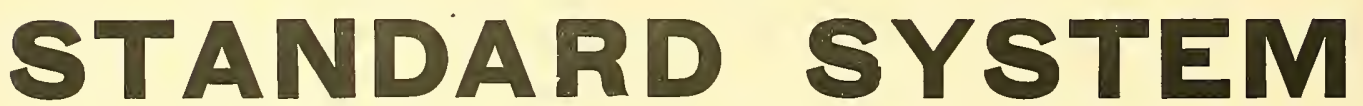
AT THE

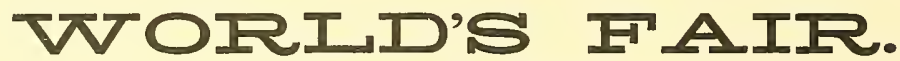

MACHINERY HALL, Sec. Q, 2 Standard Arc Dynamos. Sec. S, 20 " " "

ELECTRICITY BUILDING, Sec. P, Space 2, Arc Lighting Exhibit.

The Standard Lamps Light the Power Plant, Machinery Hall, Agricuitural Hall, Shoe and Leather Building, and Other Buildings and Portions of the Grounds.

See our Double Service All Night Lamp Before Buying an Old Style Two Rod Lamp. 


\section{Western Electric Company, CHICACO. NEW YORK.}

Arc Lighting Apparatus

High and Low Tension,

Double and Single Service Lamps,

All Night Single Lamps,

Theater and Focusing Lamps.

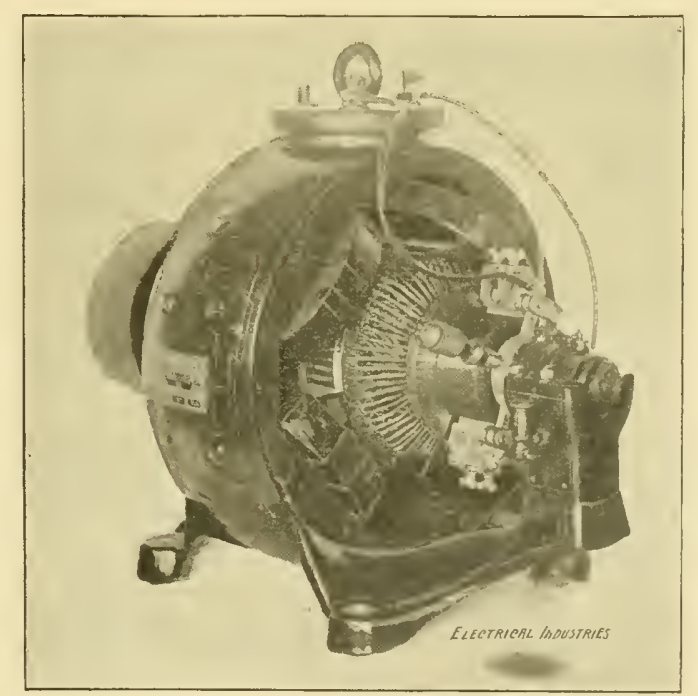

\section{ELECTRIC MOTORS}

FIGFI SPFFD

VARIAB工E SPFED

S工OW SPFED.

BUILT FOR SEVERE AND CONTINUOUS SERVICE. SPECIAL TYPES FOR SPECIAL DUTY. 


Exhibits:
East Gallery

NEW YORK, 42 Murray St.

PITTSBURGH, 43 Sixth Ave.

CHICAGO, 19-2I Wabash Ave.

\section{PHIENIX GLASS COMPANY,}

World's Fair Exhibit, Center Electricity Building.

Do not fall to call and leave your name for our new catalogue of electrlc and gas globes and shades.

\section{Consolidated Elpetric 6.}

Manulacturers and Dealers in all kinds of

\section{ELECTRICAL . SUPPLIES,}

115 Franklin Street,

CHICACO.

\section{CHAS, A. SCHIEREN \& CO,}

MANUFACTURERS OF

\section{Genuine Perforated Electric Leather Belting.}

46 So. Canal Street, - CHICACO.

Section 15, Dpt. F, Clm. 27. MACHINERY HALL.
Sectlon D, Space 3. ELECTRICITY BUILDING.
Weston Electrical Instrument Bo., PACE 9.

WAGNER ELECTRIC FAN MOTORS For Direct or Alteruating Currents.

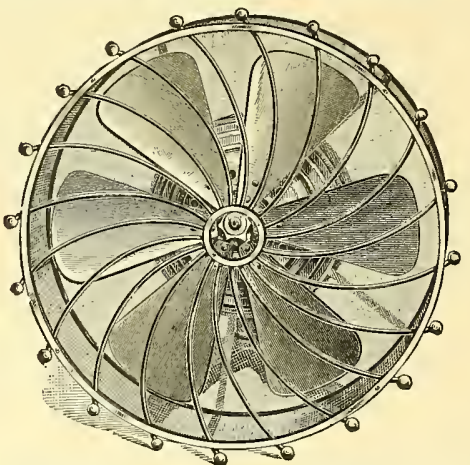

These motors give a stronger hreeze with less consumption of current tha any other fan motor on the market. They are fall $1-8$ horse power. Six bladed IT WILL PAY YOU TO SEE THE WAGNER BEFORE BUYING ELSEWHERE.

TAYLOR, GOODHUE \& AMES, 348 Dearborn Street, CHICACO.

See Our Exhibit of ELECTRICAL FIXTURES

IN SECTION "N", BETWEEN COLUMNS 62 AND 64, MANUFACTURES BUILDING,

GLOBE LIGHT \& HEAT CO., 52 \& 54 Lake St., CHICAGO. 


\section{Weekly World's Fair Supplement.}

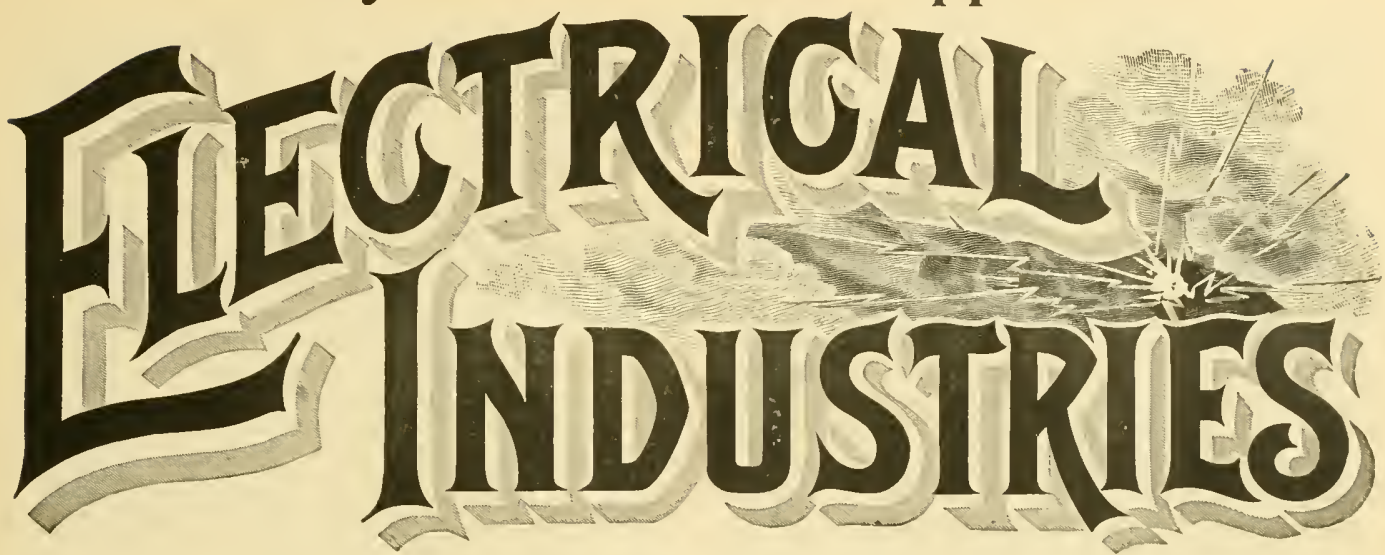

DEVOTED TO THE ELECTRICAL AND ALLIED INTERESTS OF THE WORLD'S FAIR, ITS VISITORS AND EXHIBITORS.

Vol. I, No. 5. CHICAGO, JULY 13, 1893.

The Siemens \& Halske Central Station Exhibit.

connected dynamos and compound engines and this station has grown until now there are 20 of these direet eonnected

During the past two or three years there has been a machines of the same size and type as the one shown in this strong tendeney towards the direct combination of dynamos exhibition. On the five wire systems, as shown here, stations and engine on one shaft and foundation. This has been have been eonstructed or are under contract in the follow-

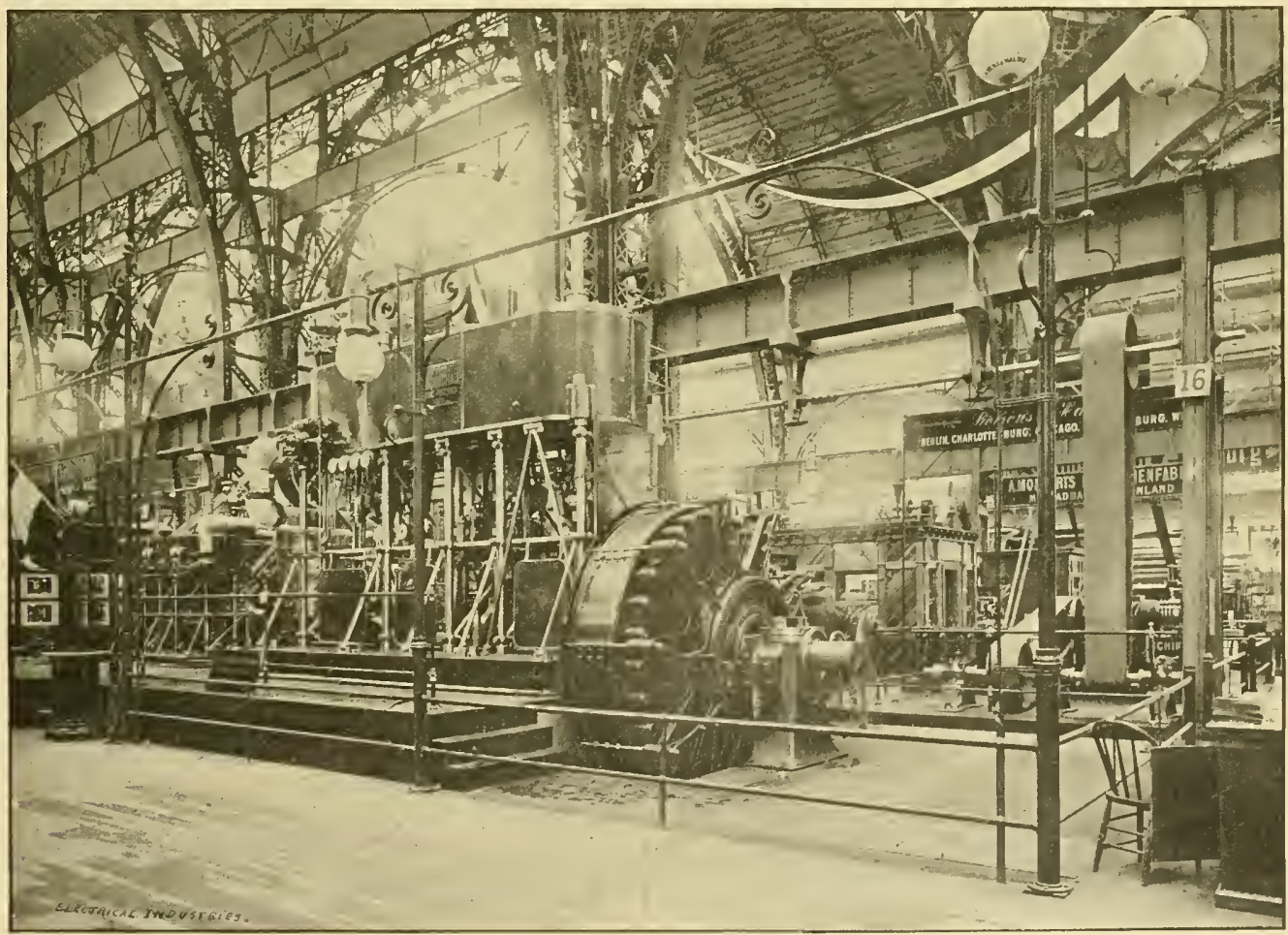

FIG, 1, - THE SIEMENS \& HALSKE CENTRAL STATION EXHIBIT,

noticeable especially in the heavier machines of the railway power house and it has grown in favor with eentral stations and isolated plants.

As early as 1857 the Siemens \& Halske Co. commenced the equipment of the Berlin central station with direct ing cities abroad: Two in Vienna, one in Sector Clichy, Paris, one in Trient, one in Rotterdam, and another now being built at Caje Town, South Africa. It will be seen that up to the present date European engineers have given more attention to this class of apparatus than those of our 
own country. The plant here shown is part of the exhibit of Siemens \& Halske Electric Co., being located almost in the center of Machinery Hall and consists of a large vertical engine, a dynamo connected directly to the end of the crank shaft, and the equalizer for distributing the current to the five wires used in the system of conductors.

The engine, built by F. Schichau, Elbing, Prussia, is of the vertical triple expansion type running 100 revolutions per minnte and rated at 1,000 to 1,200 -horse power. The high pressure cylinder is 22.86 inches diameter, the intermediate 37.4 inches, and the low pressure 57.08 inches; all having a stroke of 27.56 inches. The valves are balauced pistons with the cut-off valve surrounding the inner piston which is called the expansion valve and being controlled by the governor regulates the speed of the engine.

The control of speed is very accurate and it is said to vary but one to two per cent from no load to full load. The governor is one of the ordinary centrifugal type which through a simple system of levers turns the inner piston valve on its axis, the stem of the valve extending through the upper end of the steam chest for that purpose.

The ports in both valves are diagonal slots somewhat after the style of the old Ryder cut-off, and the turning of the inner valve changes the relative position of one opening to the other very rapidly and this cuts off the steam earlier or later in the stroke as the case may require, in order to lower or raise the rate of revolutions. This valve is said to admit steam for seven eighths of the full stroke when necessary.

The framing of the engine is light and graceful, but is so braced as to make the most of every pound of metal contained in it. For the capacity of the engine it takes but little space, about 9 by 18 feet and runs under full load without the slightest noise or jar. The lubrication, as in all machines of this type, is accomplished by means of small tubes leading to each and every joint from oil tanks on the rear of the cylinders. All stuffing boxes, bolts, nuts, and in fact every part that could in any way work loose, has been secured in some special manner, advantage having been taken of the firm's very extensive marine practice and experience on these points.

The dynamo known as type $I$ is shunt wound and is of the regular external armature type made by Siemens and Halske, having ten inside pole pieces, ten brush holders, about 1,700 windings on the armature which also serves as a commutator, the external surface of the drum having been turned true for that purpose. The method of taking the current directly from the armature in this manner is said to increase the output. At 100 revolutions the total output is $1,400 \mathrm{am}$ peres at 500 volts, and as but 22 amiperes are used in the shunt at full load and the resistance of the armature is extremely low, the electrical efficiency of the machine is rated at $98 \frac{1}{2}$ per cent and the mechanical efficiency approaches 96 per cent.

The construction of the dynamo is especially interesting. A heavy ring of soft iron forms a continuous yoke and support for the ten field magnets which radiate from the outer surface. The ends of the pole pieces spread out so that they form almost a continuous circle, thus presenting a large field surface to the armature revolving about them. This frame with the radiating fields is secured to the engine foundation. The engine shaft passes through the center of it and supports the arms to which the outside armature is attached. The armature core is constructed of thin soft iron plates that overlap each other, thus breaking the joints in the construction of the ring secured on the transverse pins which extend out from one side of the radial arms This frame is supported on a large bearing on which it may be moved away from the fields, thus giving plenty of room for inspection or repair. The windings of the armature are thin copper bars shaped to fit the core and securely soldered in place. By having no lead wires or connections many of the small attending evils are avoided and great simplicity of construction secured, allowing the armature resistance to be so low as not to require compounding. The same bearing that supports the armature spider also supports two other frames, one having radial arms, supporting from its ends the brush holder rods which are of steel and extend across the face of the armature.

This frame rotates a short distance for adjusting the brushes to the non-sparking point. The other frame supports a gear and short levers attached to the brush holder rods in such a way that when the frame and gear are rotated a short distance all the brushes are lifted from the armature surface at once. The insulation for all exposed parts is thick hard rubber, and the connections from the brushes to the connecting rings and from thence to the terminals are layers of thin sheet copper. The connecting of all the brushes of like polarity is accomplished through a very substantial ring supported on the armature bearing and to which the flexible leads from the brushes are connected, heavy flexible connections leading from these rings to the regular machine terminals.

Where it is necessary to make connections for very beavy currents, the surfaces of the contact blocks are grooved to give better contact and permit of greater pressure. Three brushes about $1 \frac{1}{2}$ inches wide and of small straight copper wire are used on each brush rod. It is said that the commutator surface of the armature of the machine first installed in the Berlin station in 1857 is as good today as when installed and shows but the slightest signs of wear.

From the dynamo heavy conductors are led to the small marbleized switch board on which are placed two large single pole switches, one for each side, an ammeter showing the total out-put of the machine, a volt meter recording to 600 volts, and a rheostat for the shunt the contact wheel being on the front of the board and the resistance back of it. There is also a special carbon contact switch for breaking the shunt field circuit gradually to avoid trouble from extra currents when stopping the machine. When the machine is running the switch is closed but when it is desired to stop, the switch is opened throwing the current through the carbon pencils which are then gradually separated. The current is carried from this board by two feed wires to the centers of distribution where are placed the equalizers. These equalizers are specially constructed shunt motors with very low resistance armatures, all connected on one shaft, the four separate machines being exactly alike. The fields are connected in series from one terminal of the 500 volt circuit to the other, the armature circuits being also connected in series between the same terminals. A resistance is placed in series with the armature circuit and used only for starting, in exactly the same manner as that in use with a shunt wound motor, and is cut out after the machines are up to speed. By this method the action of the equalizer is briefly as follows: the fields, being in series across the terminals, are practically independent of the machines themselves and exert the same influence all the time; in case one of the four circuits is loaded heavier than the others the particular machine on that eircuit acts as a generator and being driven by the others adds its current and makes up the balance; if the circuit is underloaded as com- 
pared with the others the machine is earried as a motor and thus balances for the overtlow. Of course if the circuits are all equally balanced no action takes place in the machines, the counter electro motive force simplybalancing the consumption of current excepting that needed to overconse the friction and machine losses, the machines need only be of sulficient capacity to take care of the largest difference in load between any two of the circnits, care being talien in mapping out the system to as nearly as possible balance the different circuits one with the other. In this special case the equalizers are wound for 125 volts pressure, 50 amperes of current and run 1650 revolutions per minute. At full load they are said to have 90) per cent efficiency, the armatures being of very low resistunce and the brushes taking current directly from the end face of the windings without special commutator, the machines are practically antomatic, the variation in pressure being not over one and one-half per cent from nothing to full load. It may be said that where terminals, the second and fourth the intermediates and the third the central wire which is used as one of the outsides in cases where only three wires are run.

The system permits of a great degree of flexibility and the fact of needing but two feed wires tends to rednce the apparent complexity due to the great number of wires. On the continent these circuits are laid directly in the ground about two and a half feet below the street surface and withont other protection than the iron or steel armor of the cables themselves. The insulation consists of a layer of jute saturated with some ozokerite compound next to the wire, then lead, this being covered with another layer of of jute and wonnd over all with two layers of iron or steel ribbon both in the same direction in order to cover the entire surface and give the proper amount of flexibility.

All connections for customers are made through junction boxes buried in the street and are quite similar to those made by some manufacturers in this country. Large feeder

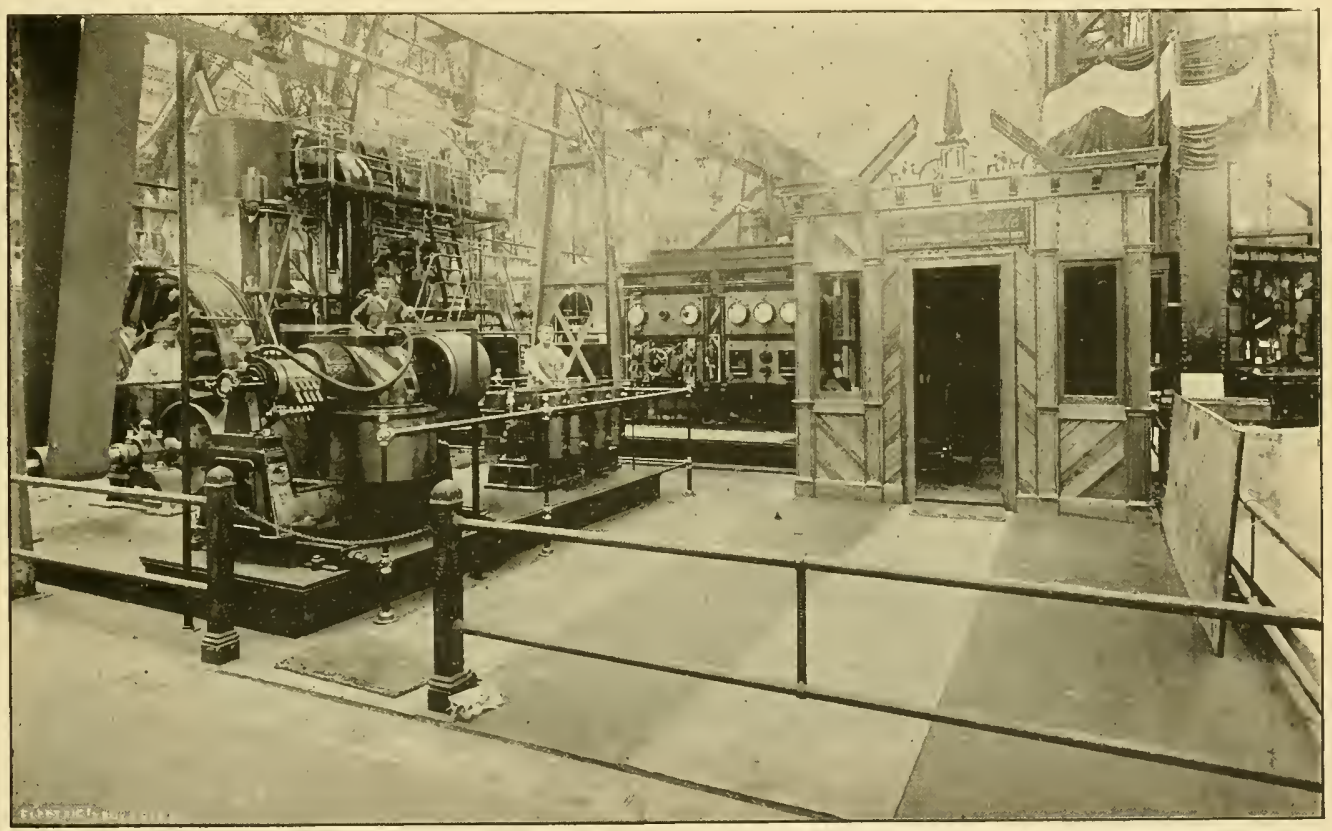

FIG. 2.-THE SIEMENS \& IILSKE CENTRAL STATION EXIIBIT.

the load is very uneven storage batteries are advocated by this company in place of the equalizers, as having a somewhat higher efficiency. They are placed across the terminals and connected up in precisely the same manner as the motor equalizers and have the same effect.

At the center of distribution the equalizer is placed between the terminals and five wires are run from it as distributing mains, one from each of the ontside terminals and one from each junction of the armature eircuit. As the potential difference at the dynamo is generally 500 volts and the lamps used are 110 volts a drop of 60 volts may be allowed between the primary dynamo and the lamp socket. It is not necessary to run five wires in every case, as side streets and buildings requiring but few lights need bat two or three wires, the system being balanced at some other point.

The comparative sizes of the five wires are about as fol lows: $1, \frac{1}{4}, \frac{1}{2}, \frac{1}{4}, 1$; the first and last being the outside boxes are placed at street junctions for connecting up and testing the system.

The plant exhibited here is used for lighting the Terminal Building, Festival Hall, Wooded Island, German sections in Machinery Hall and in the Electricity Building. Equalizers are placed in Festival Hall, Terminal Building, Electricity Building, the one for Machinery Hall forming part of the exhibit. On this system are carried 450 arc lamps, 3,000 incandescent and 250-horse power in stationary motors.

It was first intended to erect a complete generating plant for tri-phase work and show a street car truck equipped with a tri-phase motor running on a piece of track, but the proper space and concessions not being obtainable, the generator, transformers and motor truck are at present located in the German section of the Electricity Building.

Outside the plant just described is also shown a 600 ampere 110.volt bi-polar direct eurrent dynamo. The 
fields of this machine are very heavy and are flattened on the insides where they face each other, otherwise the machine is of much the same type and design as bi-polar machines of American make. The speed is 650 revolutions. This exhibit although not as extensive in its variety as some others, shows the great care and skill of the company in the design, construction and erection of its machinery.

A comfortable office, as shown in the engraving, is provided and Mr. W. Fricke, who is in charge, is always ready to explain any apparent intricacies of the five wire system used.

The steam engine part of the exhibit is in charge of Mr. Ludwig Gelbrecht for F. Schichau, his office and quarters being located on the west end of the engine platform.

\section{The Electric Launches at the World's Fair.}

One of the marked features of the Exposition grounds and one which renders them much more attractive than those of any previous Exposition, is the system of lagoons and water ways within the grounds. Much credit is due to feet 10 inches long over all by six feet three inches beam, draw 28 inches of water and will seat comfortably 30 persons. They were built and are operated by the General Electric Launch \& Navigation Company of New York.

The motive power is furnished by 72 cells of the $\mathrm{S}$ type of storage battery cells made by the Consolidated Storage Battery Co. of 120 Broadway, New York. These cells have seven positive and eight negative plates each, the containing jar being of hard rubber four and a quarter inches by seven and it quarter by nine inches high, with a hard rubber tight fitting eover, the connecting lugs coming out through a small hole in the center of the top. The plates are separated by the regular corrugated perforated hard rubber sheet now used by this firm and a new feature is the covering of the positive plate with a very thin perforated sheet of lead, which is folded around the bottom and prevents the active material falling out while in use. This sheet soon becomes formed and is said to add much to the economy and durability of the cell. The motor is fivehorse power eapacity, of the two field and four pole type,

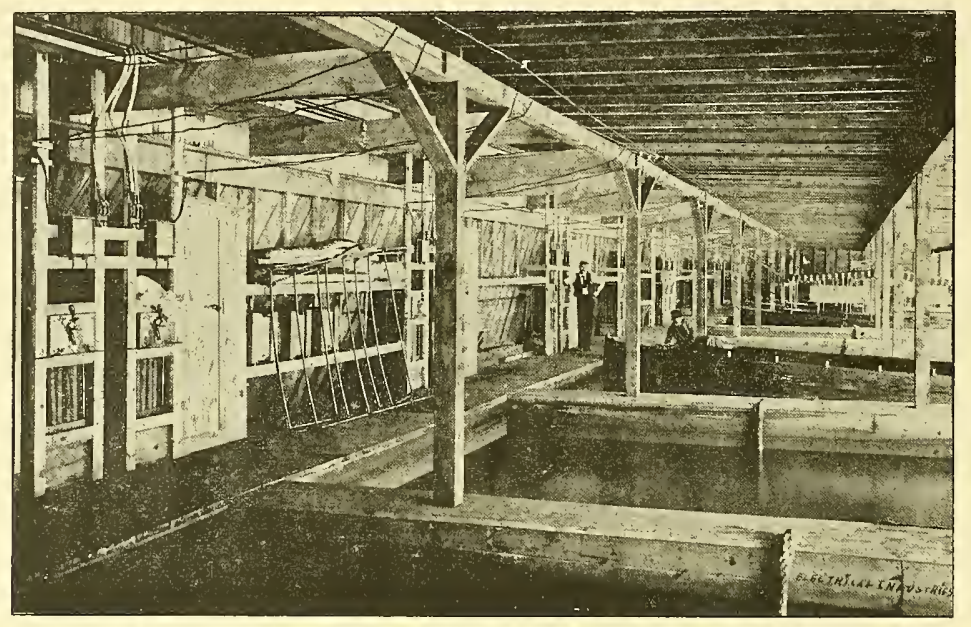

THE ELECTRIC LAUNCHES AT THE WORLD'S FAIR.

the landseape architect, Mr. Frederick Law Olmsted, for the improvement and development of this part of the grounds. The excellent taste displayed by those who selected the forms of craft which should be used on these water ways is also a credit to those who had the affair in charge. The gondolas with the Venetian boatmen not only afford a pleasant ride and excellent means of going around the grounds but are also an ornamental feature of the Exposition. These boats make regular trips for which a fee of 50 cents is charged, or they may be rented by the hour.

The electric launches, forming a prominent and attractive feature of the lagoons, are greatly appreciated by the visitors. They are a matter of interest to all as this means of propulsion is new and it has never before been tested on so large a scale. To the many visitors, who are unfamiliar with the rapid development and numerous applications of electricity, these boats gliding through the water swiftly with no visible means of propulsion are a matter of wonder and astonishment. The competition for this concession was very sharp at the time it was awarded, for the manufacturers of steam, naptha, electric and other launches entered into competition for the concession. The boats selected are 35 designed and made for this special purpose by the General Electric Company. The armature is cross connected, thus requiring but $t$ wo brushes, is made thoroughly moisture proof as is attested by the fact that motors have at times been run while half submerged.

There are four speeds at which the boats can be run forward, but two only have been provided for backing. The speed is controlled by a special electromagnetic switch, having mercury cup contacts, and an electromagnetic arc breaker, all being controlled by a handle in the bow of the boat. A special auxiliary switch is also provided, by which the circuit to the motor may be opened in case of tronble on the regular switches. Backing is accomplished by reversing the motor armature terminals in the usual manner. The four speeds are, three and a half, five, six and eight miles per hour, the second being the one most generally used. Following is the arrangement of cells for the different rates of speed:

First.-Three series of 24 cells, each in parallel with a rheostat in series to the motor.

Second.-Same as above with the rheostat short circuited. 
Third-Two series of 36 cells, each in parallel with the rheostat in series to the motor.

Fourth.-Same as third with rheostat short eircuited.

The first two are the only ones used for backing. Some idea of the smoothness and freedom from trouble with which these boats work, may be gained from the fact that on an average 48 boats are out all the time, each averaging 13 trips per day, a trip, being three and one-half miles, and consuming from 45 to 50 minutes.

As soon as the boats come in at night the wires are connected, and charging commenced. A current of $i 2$ amperes is used, the cells being arrauged in three series of 24 each in parallel, thus taking about $17 \frac{1}{3}$ amperes per series; the time taken for a full charge after using all dia is seven hours. Current is supplied by the large bi-polar generators of the General Electric Company in Machinery Hall, through two heary sets of feeders run in the Edison threewire tubing to the launch bouse at the southeast corner of the Agrieultural building wharf.

A stall and charging leads are provicled for each boat, the latter being taken from one side of the three wire system through a double pole fuse and switch, one side pun ning throughan ampere meter, and rheostat of two ohms,

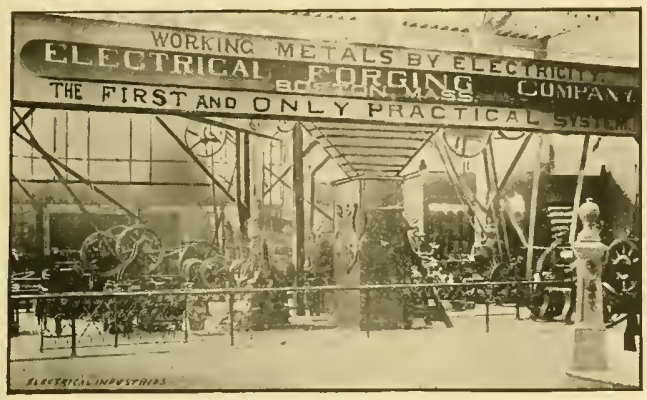

EXHIBIT OF TIE FLECTRICAI, FORGING CMMPANY

hence on to the boat, the other lead going directly from the switch to the boat.

The course of most of these launches is from the starting point on the north front of the Agrieultural building, to and along the south side of the Hall of Liberal Arts, thence up the north canal around by the Fisheries building and Clam Bake to the Art building, returning by the way of the Lagoon, in front of the Womans building, Horticultural Hall, Transportation building, Mines and Mining and Electricity buildings, to the starting point. One or more stops are made at all prominent points, the fare for the round trip being 50 cents, or 25 for a half trip. The boats are provided with earpets of perforated rubber mats, the seats with leather cushions stuffed with hair, and awnings of canvas in red and yellow stripes. The pattern and colors were selected by F. D. Millett, director of colors for the Exposition. The officers in inmerliate charge of the concession on the grounds are, General Manager, C.D. Wyman; Superintendent, C. H. Barney: Electrical Engineer, R. N. Chamberlain. A pilot and guard is provided for each boat, and a guard is also stationed at each wharf, where passengers enter through a turnstile, after buying tickets at the small booth jrovidet. Handsome blue uniforms with brass buttons are worn by all employes, the different chasses being designated by appropriate letters on the cap.

There is now no doubt of the success of the electric launch as a means of transportation, and after ricling in one se boats, gliding over the water so smoothly, one can have no doult of the future growth of the business. The record of one of these boats is deserving of special notice; after running over 1,20) miles without repairs, it made a continuous trip of 60 miles on one charge.

\section{Exhibit of the Electrical Forging Company.}

A very interesting exhilit of the Electrical Forging Company is located in section D, Electricity Building, just east of the German section. It contains three large C. $\mathrm{d}$ C. motors used to drive the two welding dynamos and the shafting over head to which are belted the special tools used in forging. There are also a number of other tools, rollers, etc., used in the practical exhibition of the process.

The company manufactures electrical welling and forg. ing tools and machines, a large number of which are shown and used in this exhibit. The dynamo used for generating the current is an alternating intermittent dynimo having ten field coils and five armature coils which have each a special winding by which it is claimed that not only more pulsations are generated per minute but the peculiar windings of the armature adds another feature in that the current is not evenly alternated but has an intermittent strength which stirs up the molecules more violently. The controlling rheostat is placed in the shunt field circuit of the exciter, the field circuit of the dymamo itself being in connection with the armature only. While this arrangement is not new as applied to lighting it is said to be new in this application. The two welding dynamos shown are of 75 -horse power eapacity at 1,600 volts pressure the exciter having a capacity of 220 volts and six amperes.

The transformer has a core formed of pieces of bare iron telegraph wire in the form of a large ring, the wires being placed so as to break joints. Wound around this ring at short distances apart are the primary coils of fine insulated copper wire, two coils being connected in series and the pairs in multiple. The secondary coils are sheets of copper east in the shape of a square spiral and slipped on to the iron core between the primary coils. The terminals are extensions from the connecting rings. Working terminals can be taken from any part of these rings thus permitting a number of kinds of work being done at once. The terminals shown with these machines are of different kinds and adapted to secreral kinds of work. A system of heating and welding by are curreuts is also shown. Various goods manufactnred by this process are exhibited among which is an ornamental fence in three sections one being made of copper, one of brass and the other of iron. The president of the company is Mr. George Burton, who is at present at the exhibit ready to explain the process to interested parties.

\section{An Injunction Granted.}

Judge Lacombe, of the United States circuit court of New York,has granted injunctions to the Edison Illuminating Company, of New York, against the Holland House and Imperial Hotel prohibiting them from using ineandescent lamps infringing the Edison patent. The Edison Illuminating Company is sole licensee for the city of New York for the Edison lamp.

Wil'ans \& Robinson, Ltel., are the English makers of the Willans engines erroneously call the Williams engines in it description of the engines at the World's Fair which recently appeared in this paper. The M. C. Bullock Mfg. Company, $1170 \mathrm{~W}$. Lake St., Chicago, Ill., is the American manufacturer of these engines. 


\section{ELECTRICAL INDUSTRIES.}

Futered it Chicago Postoffice as second-class mail matter.

\section{ELECTRIGAL INOUSTRIES PUBLISHING COMPANY, INCORPORATED 1839. \\ MONADNOCK BLOCK, CHICAGO. \\ TELEPHONE HARRISON 159. \\ E. L. POW ERS, PREs. AND TREAS. E. E. WOOD, SZCRETARY.}

E. L. POW ERS,

EDITOR.

H. A. Fos'ter,

W. A. REMINGTON,

E. E. WOOD,

FLOYD T, SHORT,

Assuctate Editors,

- EAstern Managel

EASTERN OFFICE, WORLD BUILDING, NEW YORK. World's Fair Headquarters, Y 27 Electricity Building.

FIVE MONTHS

SINGLE COPY

Ädvertising Rätes Upon Āpplieation.

News items, notes or communications of interest to World's Fair $V$ isitors are earnestlv desired for publication in these columns and will be heartily appreciated. We especially invite all visitors to call upon us or send address at once upon their arrival in city or at the grounds.

ELECTRICAL INDUSTRIES PUBLISHING CO.,
Monadnock Block, Chicago

Two notable and suggestive events have happened during the past week: The arrival of the caravels, models of the ships of Columbus in which he made his first royage, and the arrival of Capt. Anderson and his Viking ship, a supposed model of Lief Ericson's craft. Thus is brought to mind the discovery of the western world by two distinct races. One in about the year 1,000, but whose discovery made no stir in the world, and the voyage of Columbus in 1492 which brought cirilization to this continent.

THE small attendance on Sundays at the Fair has been a surprise to all. On last Sunday, July 9th, the attendance was but 44,000 . The reduction of the price of admission to 25 cents is strougly advocated by some of the daily papers. As many of the exhibits are closed, and but few attendants are with them that day, it would not seem to be bad policy to reduce the price of admission for the one day each week. The American public does not like the idea of paying the full admission price for seeing half a show.

Iт was confidently expected that the railroads wonld establish excursion rates to the Fair from all points; but in this there has been so far only dissappointment. What has been granted applies only to distant points and has been made in such a way as to deprive the traveler of all the comforts of travel. The half of the Fair is nearly over, and but a small portion of the people of this country has visited it. Some inducement in the railroad fare and some comfort and accommodation while on the way is the thing that will bring the people.

THe disastrous fire of last Monday afternoon was a never to be forgotten spectacle to the thonsands of visitors present. The death of nearly a score of firemen throws a shadow over the festivities of the Fair. The building, which was of staff construction, was used for cold storage and ice making machinery. It had also a skating rink on the up. per floor, for which the first coating of ice lrad just been frozen. The great tower in the center of the building formerl a trap from which there was no means of escape. It is probable that no other building on the grounds conId furnish the same conditions, but this fire has its lesson and will undonbtedly lead to greater precautions. As the first step, however, every building on the grounds should be provided with fire escapes. The fire department is vigilant and well organized but nothing should be left undone to make the buildings safe. In the Electricity Building the matter of insulation should be looked after with the greatest care so that no fire may be attributed to the electric current. We are confident the department will take this matter in hand at once.

One of the finest models shown at the Exposition is that of the four cylinder triple expansion engine made by Harlan \& Hollingsworth, in the south end of Transportation building. Engines of this style were built by the firm for the steamers "Maine" and "New Hampshire" of the Stonington Line, and are said to have been the first four cylinder triple expansion engines built in the United States. The dimensions of the cylinders of these engines are respectively as follows: $28,45,51$ and 51 inches with 42 -inch stroke.

The Chapman Valve Manufacturing Co., of Indian Orehard, Mass., have an exhibit in Machinery Hall, Main 26, K. 28 , where are shown the various sizes and styles of high pressure steam valves, such as are now in use by nearly all the steam and electric power stations. This valve is extra heavy in all its parts; has a gate giving full opening of pipe, ontside screw and packing, and in the very large sizes, such as 24 inches, has a small by-pass ralve admitting steam around the regular gate in order to even up the pressure on both sides before opening it. These valves all have moveable bronze seats, thus allowing quick and easy repairs. Samples of high class extra heavy flanges for steam pipe work are also shown. This company furnished the throttle for the large Allis Corliss engine, all the valves for the Intramural Power Station, and all valves used on the Heine boilers in the power house. Samples of hydrants and hose bibs for water works are shown, also samples of the large water gates made by the company. The exhibit is nicely located, well-displayed, and Mr. Edward L. Ross, the well-known agent of this company, is in charge and will take pleasure in making it comfortable for any visitors stopping at his gate.

The French section, in the Manufactures and Liberal Arts building, contains several exhibits of high grade electrical fixtures which are worthy of more than passing notice. A. Rollet, Paris, exhibits several beautiful electroliers, nearly all of which are designed after water fowls and aquatic plants. In price these goods range from $\$ 100$ to \$200. Goupier \& Dronart, Paris, show among other goods many artistic designs in bronze of one, two, three and four light fixtures. Female figures predominate, thongh one of the most attractive of the lot is a group of three children running holding incandescent lamps in their hands. In price the goods of this firm range from $\$ 130$ to $\$ 350$ for articles mentioned; Mr. Ch. Jacobson is in charge. The works of Goupier \& Drouart were Hors Concours at Paris Exposition, 1891. H. Houdebine, Pere et Fils, show one pair of vases, with thirteen light clusters, valued at $\$ 2,000$; also two female figures, life size, with raised arms supporting basket filled with lights; the pair are held at $\$ 5,000$. Maison F. Barbedinne, Paris, makes an exceedingly elaborate display of electroliers, the prineipal feature of which is two life-size female figures supporting a cornucopia filled with flowers in which are sockets for lamps; the pair is valued at $\$ 10,000$ ). 


\section{WORLD'S FAIR NOTES.}

The managers of the Turkish Cafe on Midway Plaisance gave a reception to the press on Friclay evening last.

A unique feature in the exhibit of the New Fork Insulated Wire Co. is a log eabin built entirely of vulea duet. It is high enough to stand in, and makes a valuable addition to the display.

The Worthington Pump Co. have a very large display of its celebrated steam pumps at the extreme southeast eorner of Machinery Hall. Some of the pumps are in eonstant use for the service plant, others are on exhibition only.

The arc lamp poles in the Javanese village have been giren native decorations. The hoods have been thatched with straw, and the poles covered with the long hairlike bark that grows on the sugar palm. The decoritions match the native huuses, but the are lights look rather strange under their Javanese cuvering.

Siemens \& Halske are fast completing their excellent exhibit in the Electricity Building. Among the articles shown is a resistance or rheostat in which the coil is made of eopper wire cloth. It has been little used in this country although possessing several atrantages, among others the rapid dissipation of the leat. An electric railway truck with tri-phase motor, together with generator, exciter and transformers are shown.

The Sloss-Stein Electric Co. of 21ऽ La Salle street, Chieago, is making an exhibition of electric gas lighters, in which a battery and spark coil are concealed under the canopy of each fixture, thus doing away with leat wires. The parilion is located in the southeast corner of Electricity building, and is decorated in a rery unique manner with spirler welns formed of cord with exaggerated flies and spiders fastened on the surface.

The headquarters of the American Institute of Electrical Engineers are now completely furnished. The rooms are comfortahle, cheerful and otler an excellent resting place. The files of electrical and daily papers, together with the library of eleetrical lrooks jresented by Van Nostrand, furnish reading material for visitors. I stenographer is located in the oftices, and long distance telephone and tolu. gra], lines are being put in so that cvery eonvenience will be afforded members. Varjous photograly and relic's are distributed about the rooms, making a risit to the head quarters interesting and instructive.

An exhibit of the application of electric motors to heary machine work is made by Heinrich Ehrhardt, of Dusseldorf, in the German section, Machinery Hall. A special motor made by Siemens and Halske, of Berlin, is used, and it is of much the same form and shape as the late Edison are dynamo, the size being modified to meet the sperial requirement. Most of the machinery is for sawing or cutting iron and steel, and is rather heavy in its nature. There is one upright band sawing machine for sawing scroll work in heavy iron plates; another for entting large bars of iron or steel in pieces and others for doing various kinds of work. One special feature is a method of keering a belt tight between the machine and counter shafts.

A rery complete exhibit in its line is that of the James Morrison Brass Mff.g. Co., Limited, of Torouto, Canada, in Section F., No. 2, Machinery Hall. It consists of vil eups of all kinds: gauges, gange glasses, cucks, cloeks for steam uses, steam gauges, rerolution counters, steam-ship ron- trollers, gongs, bells, steam whistles, inspirators of various sizes, cylinder oilers of different forms und sizes; in fact almost everything in the way of a steam engine fitting is shown in this space. The sizes of the different pieces of a)paratus are such as are in general use and many of extra large sizes are also shown. The exhibit is well arranged.

Messrs. Schaeffer \& Buclenberg of 66 John street, New York and 22. West Lake street, Chicago, have a very fine exhibit of their steam specialties in Machinery Hall, in the main hall and aisle near the entrance to the annex. Arranged around the edge of their space are a number of different sizes of the exhaust injector, while inside a cabinet of ehonized wood are samples of all the smaller material used or sold by this firm. Among others were noticed samples of heavy gauge glass, which are made in sections so as not to destroy but a small section in case of blow-out. The exhaust injector sold by this company is a feature which deserves mention. It is placed in the exhaust pipe of an engine and produees a partial racuum, which forces water into the boiler and at the same time taking most of the remaining heat out of the exhaust steam. In a frame hung over the dlesk are some forty medals that have been received at different expositions by the firm. Mr. A. L. Portong is the western manager and is in charge of the exhibit. He is pleased to meet his old friends at his exhibit and hopes to make a long list of new ones before the exposition is over.

The American Battery Company of $1 \mathrm{~s} 8$ Madison St., Chicago, is showing a storage battery carriage in the northwest corner of the Electricity Building. The carriage has three seats and is somewhat heavier in construction than carriages of the same type built for horses. There are twenty-four cells, eight under each seat. The capacity is 150 ampere hours and when fully charged are 2.2 volts each and are never run below 1.9 volts. The motor is a small bi-polar type placed on the rumning gear underneath the body and geared through three reductions to the rear axle. The speeds are 4,5 and 12 miles per hour and the carriage is said to be eapable of running (at miles on one charge. As high as 75 miles on one charge has heen ohtained. This carriage has been in use for the past 18 months and is saicl to show no deterioration whatever in the batteries. About three times a week the carriage is run around the grounds, aecommodating three or four people and excites very much interest from the visitors on the grounds.

\section{Foreign Visitors to the World's Congress.}

The following letter has been received from Professor H. S. Carhart:

De.ar Sir,-Dr. Elisha Gray has just received a letter from Professor von Helmholtz announcing that he will take part in the conference of the World's Congress of Electricians in Chicago, Aug. 2Ist, as the official delegate of the German Gurernment. He will be aceompanied by Drs. Fenssner. Kurlbaum, Leman, Lindeck, Lummer aud Pringsheim, his assistants in the Reichsanstalt in Berlin. These gentlemen have made important contributions to our knowledge of the values of the modern practical electrical units, and their work will doubtless form a basis of $\mathrm{Dr}$, von Helmholtz's recommendations. The presence of ron Helmholtz will render the Eleetrical Congress a notable oecasion.

Yours truly,

(Signed) Hexry S. Carhart, secretary. 


\section{PERSONAL.}

Mr. W. J. Hammer returned to New York on Saturday last.

Mr. W. R. Brixey, of Day's Kerite, returned to New York last Saturday.

Prof. N. M. Terry of the U. S. Naval Academy, Annapolis, is visiting the Fair.

Mr. R. Hornell, managing director for the de Laval Steam Turbine Co, is visiting the Fair.

Mr. C. A. Benton, of the Sprague Electric Elevator Company, New York, paid the Fair a visit last week.

Mr. James H. MeGraw, President of the Street Railway Journal, was a visitor at the Fair last week.

Mr. J. C. Chamberlain is stopping at the Auditorium for a few days, and is spending some time at the Exposition.

Mr. Julian A. Moses of the Electrical Review, New York, registered at the Institute headquarters on the 10 th.

Mr. Charles Seldon. of Baltimore, recently registered at the headquarters of the American Institute of Electrical Engineers.

Mr. J. Il Rhotehamel, president of the Columbia Incandescent Lamp Company, St. Louis, visited the Fair and Chicago last week.

Mr. Brainard Rorison, secretary of the Fort Wayne Electric Company, is in the eity with his family and will spend considerable time visiting the Fair.

Mr. R. O. Heinrich, of the Weston Electrical Instrument Co., has returned to his home in Newark, N. J., after supervising the installation of the company's exhibits.

Mr. J. Hammar, of Guttenburg, Sweden, member of the Institute of Electrical Engineers of Great Britain, is the engineer in charge of the de Laval Steam Turbine exhibit in Machinery Hall.

Mr. F. O. Blackwell, chief engineer of the mining department of the General Electric Co., at Lynn, Mass., is spending a few weeks at the Fair, with headquarters at the company's office in the Electricity building.

Mr. Carl K. MacFadden, formerly with Taylor, Goodhue \& Ames, and for two years or more engaged as expert on the Nutting are lamp, has recently been engaged by Bartholomew, Stow \& Co., of Chicago, the general selling agent for the Nutting system of are lighting.

\section{BUSINESS NOTES.}

The Enterprise Electric Company, Chicago, is still finding a good demand for fan motors.

Mr. L. E. Frorup, western manager of the General Incandescent Are Light Co., must be doing a lively business from the appearance of his headquarters at 169 Adams St., and his cheerful eountenance.

The Electric Appliance Company with its usual enterprise has come to the front with a Meston fan motor wound particularly for the low frequency alternating current at the World's Fair. It has succeeded in securing results that have been a surprise to all. The efficiency of the motors is very high and the company is making arrangements to have the motors rewound after the Fair at a nominal expense to operate on alternating circuits of ordinary frequency where customers so desire.

\section{DEPARTIENT OF ELECT RICITY.}

OFFICES: SECTION R, ELECTRICITY BUILDING.

Chief, JонN P. BARRETT,

Assistant Chief, J. Allex Horxsby.

General Superintendent, J. W. BLAESDELL.

Eleetrical Engineer, W. W. Pвıм.

\section{DEPARTMENT OF MECHANICAL AND ELECTRICAL ENGINEERING.}

OFFICES SOUTH OF MACHINERY HALL.

Mechanical Engineer, C. F. Foster

Electrical Engineer, R. H. Plence.

First Asst. Mechanical Engineer, JoHN MFADEN,

First Asst. Electrical Engineer, S. G. NEILER.
AMERICAN INSTITUTE UF ELECTRICAL ENGINEERS.

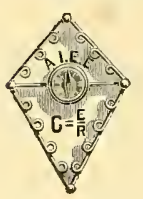

World's Fair Headquartere,

SECTION S. ELEOTRICITY BUILDING.

Ralph W. Pope, Secretary.

Open from 9 a.m. to 5 p.m.

\section{CHICAGO WORLD'S CONGRESS OF ELECTRICIANS. ADVISORY COUNCIL.}

President, Dr. Elısıla Grar, Highland Park, Ill.

Secretary, Prof. H. S. Carhart, Ann Arbor, Mich.

EXECUTIVE COMMTTEE.

Chairman, Prof. Elihu Thomson, Lynn, Mass.

COMMITTEE ON INVITATIONS.

Chairman, T. Commerford Martin. 203 Broadway, New York. COMMITTEE ON I'ROGRAM.

Chairman, Prof. T. C. Mendenhall, Washington, D. C.

COMMITTEE ON FINANCE.

Chairman, B. E. SUNNY, 175 Adams Street, Chicago.

\section{Amusements.}

Hoolex's Theater-Mr. E. S. Willard, in "The Professor's Love Story." 149 Randolph street.

Colunbia Theaten-Miss Lillian Russell, in "La Cigale." 108 Monroe street.

Grand Opera House - Sol Smith Russell, in "April Weather." 87 Clark street.

Audionidy-Imre Kiralfy's Spectacle "America." Congress street and Wabash avenue.

MoVicker's Theater-Denman Thomson, in "The Old Homestead." Second week. 82 Madison street.

Chicago Opera House-American Extravaganza Company, in "Ali Baba, or Morgiana and the Forty Thieves." Seventh week. Washington and Clark streets.

Schiller Theater-Chas, Frohman's Stock Company, in "The Girl I Left Behind Me." Seventh week. Randolph, near Dearborn.

Haverly's Casino-Haverly's United Minstrels. Wabash avenue, near Jackson street.

Trocadero-Concert. Michigan avenue near Monroe street.

The Grot to-Vaudeville. Michigan arenue near Monroe street.

Buffalo Bill's "Wild West." 63d street. Daily at 3 and 8.30 p.m.

Pain's "Siege of Sebastopol," 60th street and Cottage Grove arenue. Tuesday and Thursday nights.

Next week Mr. E. S Willard will appear in "The Middleman" and "Judah" at Hooley's.

Sol Smith Russell began the eleventh week of his successful engagement at the Grand Opera House last Sunday evening. This will be the last week of "April Weather" as Mr. Russell will appear next week in his famous play "A Poor Relation."

Ali Baba, the 500th performance of which oceured last Wednesday evening, goes on record as having been played the greatest number of times of any play in the west. It was intended to have replaced it with "Sinbad" before this, but its continued popularity will keep it on for some time.

Kiralfy's spectacle "America" is having an extraordinary suceess at the Auditorium. The Shaffers are popular favorites and a number of wonderful feats have recently been introduced by them which are surprisingly skillful and intensely interesting. 


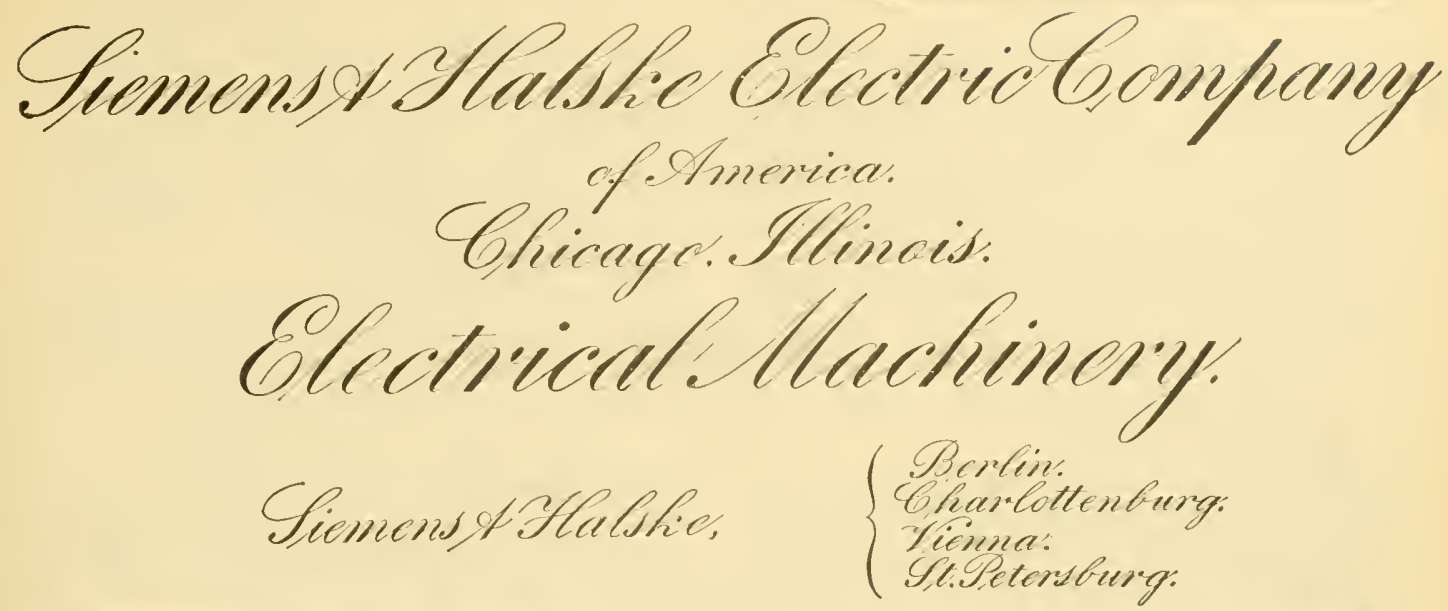

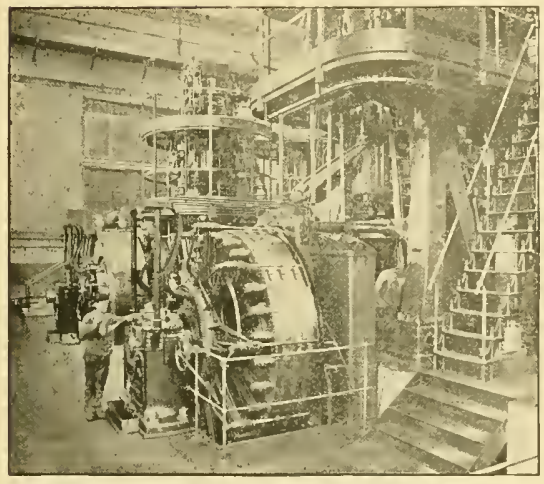

1000 H. P. DIRECT CURRENT GENERATOR.

\section{AGENCIES.}

GENERAL GFFICES :

Monadnock Bldg.,Chicago.

NEW YORK OFFICE:

136 Liberty Street.

CINCINNATI OFFI E:

Perin Building.

ST. LOUIS OFFICE:

Bank of Comme‘ce Bldǵ. MILWAUKEE OFFICE:

412 Broadway.

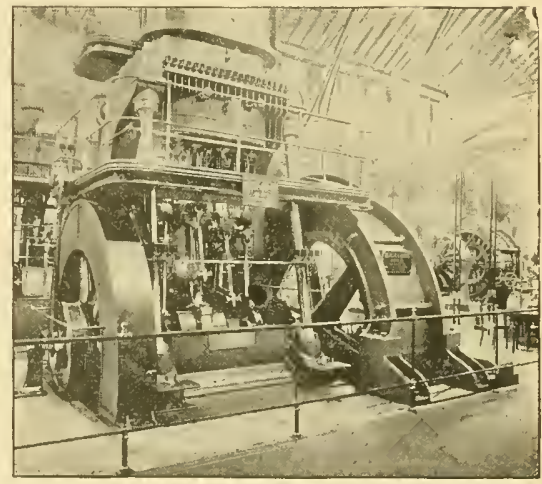

1000 H. P. ALTERNATING GENERATOR. MANUFACTURERS OF.....

\section{Direct Current Multipolar Dynamos:Generators}

These machines are constructed with outside, revolving armatures, without and with special commutator, as desired. They have proven remarkably efticient and ecouomical. Used largely in European Central Stations. They are slow speed machines, made for direct connection to engine withour belting, and in sizes from $20 \mathrm{H}$. P. to $1,500 \mathrm{H}$. P

\section{HICH SPEED BELTED SIEMEN'S DYNAMOS.}

These machines are copied extensively in this country as "Drum Type." We are building these machines in sizes from $1 \mathrm{H}$. P to $150 \mathrm{H}$. P.

\section{ALTERNATINC AND MULTIPHASE CURRENT DYNAMOS.}

Dynamos with laminated field and armature, in sizes from 1 H. P. to 4,000 H. P. for belted or direct coupling.

MOTORS.

Ifotors of every speed for direct, alternating or multiphase current, in sizes from one-tenth H. P. up to 4,000 11. P. Street car motors and kindred appliances; these motors have been made double reduction, single red iction and gearless. Durable and economical in operation.

\section{SIEMENS' BAND LAMPS.}

Lamps for direct and alternating current, for constant, potential and series machines.

\section{CARBONS.}

Siemens' arc light carbons, with either solid or soft cores, which are tbe most economical in the world, and give a steady light.

\section{INSTRUMENTS.}

All instruments requisite for the regula'ion of electrical apparatus; also the Siemens' voltmeters and ammeters and Automatic Devices made in Berlin.

\section{POWER TRANSMISSION.}

Profiting by our European experience and exhaustive tests, we are prepared to estimate on power transmission intelligently, and guarantee successful operation. 
ELECTRICITY BUILDING-EXHIBITORS AND THEIR LOCATION.

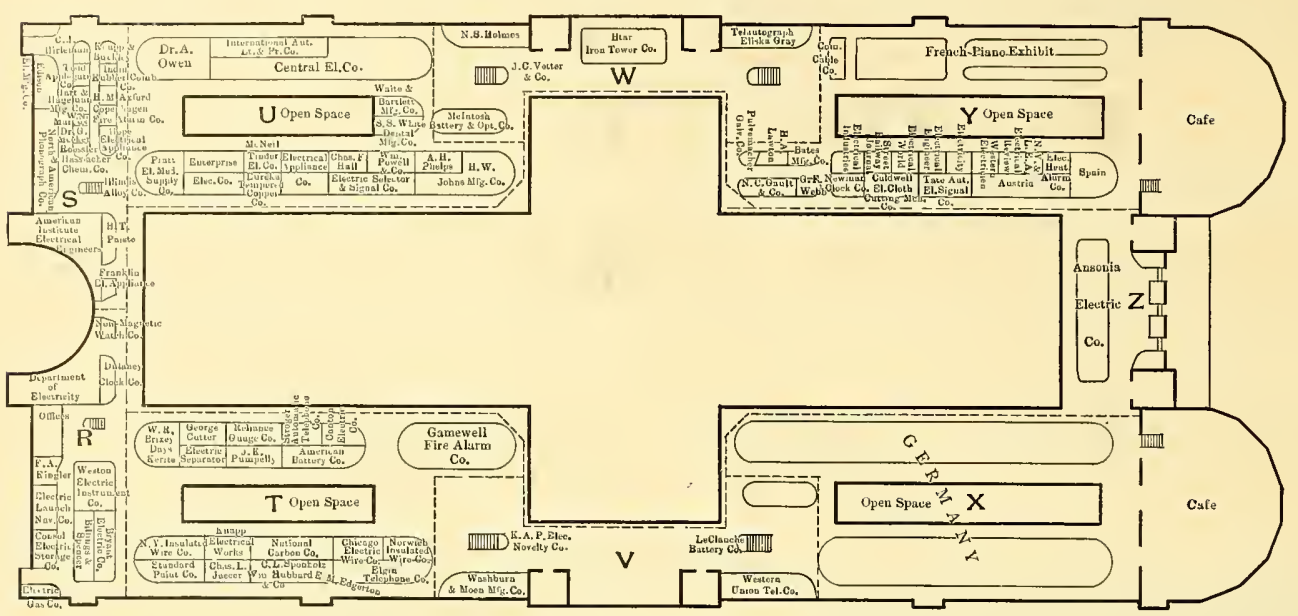

GALLERY.

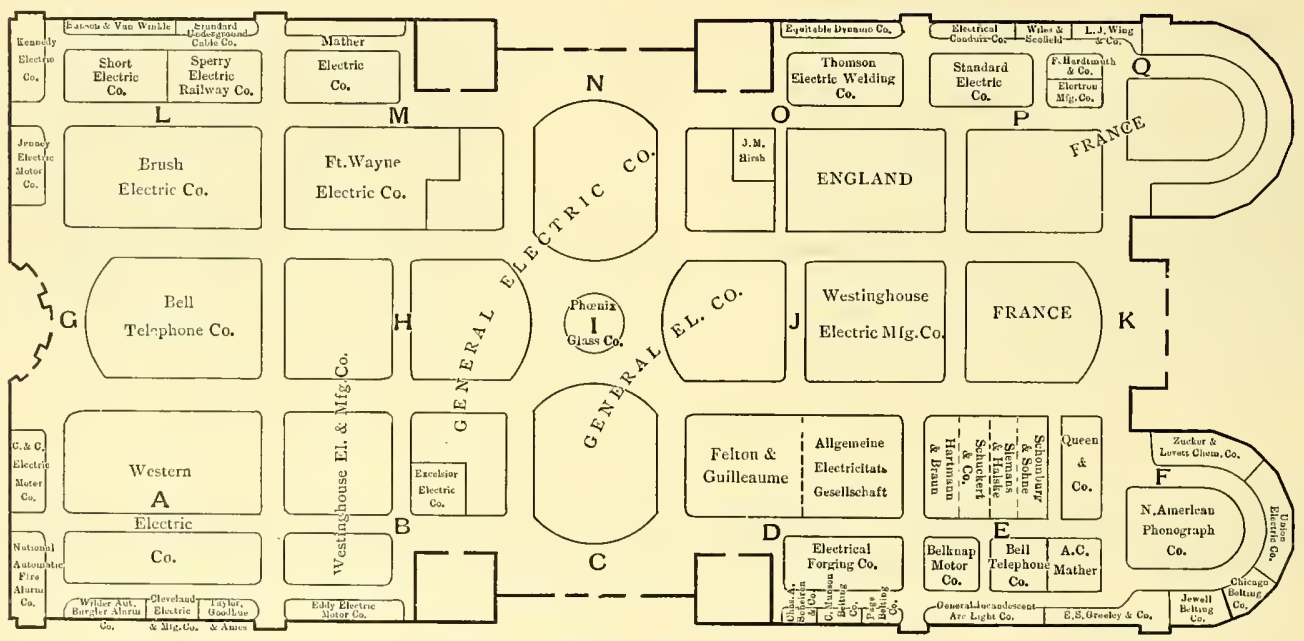

MAIN FLOOR.

Exhibitor.

Ansoria Electric Co.....

Am. Inst. of Elec. Eng.

American Batter

Allo. Flee Gesellschaft.

Bates Ml fg. Co...........

Bryant Electrie Co

Billings \& Spencer.

Brlknap Motor Co

Bell T'elephone Co.

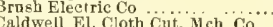

Consol. Elec. Storage Co

Cutter, George

Canton Elec. Co.........

Copenhagen Fire Alarm Co

Central Electric Co

C. \& C. E ec. Mlotor Cin

Cleveland Eipc. \& IIfg. Co

Cbieago Belting Co

Dulaney Clock Co.................

Department of Electricity

ELECTRTCAY INDUSTRIE

Electric Separator.

Edgerton, E. $M$........

Elgin Telephone $\mathrm{Co}$

Edison Elec. MIg. Co.

Enterprise Elee. Co...

Electric Appliance Co.

Flectric llent fileo

\begin{tabular}{|c|c|}
\hline \\
\hline & $\begin{array}{l}\text { Exhibitor. } \\
\text { Electrical Review }\end{array}$ \\
\hline ....... & Electricity................. \\
\hline & Electric Gas Co.... \\
\hline & Electrical Engineer. \\
\hline & Electrical World............. \\
\hline & Eddy Electric Motor Co. \\
\hline & Excelsior Electric Co..... \\
\hline & E'ectrical Forging $\mathrm{C}$, .................... \\
\hline & Equitable Dynamo Co................... \\
\hline & $\begin{array}{l}\text { klektron Mfg, Co } \mathrm{C} \ldots \ldots \ldots \ldots \ldots \ldots \ldots \\
\text { Electrical Conduit Co }\end{array}$ \\
\hline & 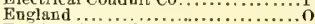 \\
\hline & Empire Cbias Works. \\
\hline & Franklin Elec. Applianceg......... \\
\hline & $\begin{array}{l}\text { French Piano Exbibit................ } \\
\text { Felton \& Guille gume. }\end{array}$ \\
\hline & $\begin{array}{l}\text { Felton } \\
\text { France }\end{array}$ \\
\hline & Ft. Wayne Elec. Co..................... \\
\hline & Gaalt \& Co, N. C.......... \\
\hline & Gamewell Fire Alarm Co „... \\
\hline & $\begin{array}{l}\text { General Eleetrie Co } \ldots \text { B-H-N-C-\& } \\
\text { Geberal In'rand's't Arc L't Co }\end{array}$ \\
\hline & Greeley, E. S., \& Co .. .............. \\
\hline & Germany .................. \\
\hline & 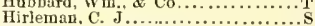 \\
\hline & Hart \& Hegemun M [g. Co... \\
\hline & Hope Elec. Appliance Co.. . . \\
\hline & 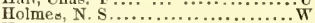 \\
\hline & Hartman \& Brann ....... \\
\hline & Hanson d Van Wirkla, ........ \\
\hline & Hardtmuth, F., \& Co...... \\
\hline & Illinois Alloy Co..... \\
\hline & er $\mathrm{Co}$ \\
\hline
\end{tabular}

Exhibitor.

Reliance Section.

Jaeger, Chas. I

Johus M M. Co. H. W

J nney Elec. Motor C........

A Plec Novelcy Co.

Knapp \& Buckley ........

Lawton, H. A .

LeClancbe Battery Co.

Marcas, W. N

.......................

IIunson, C., Belting Co

I1 uther A. C.............

Newinan Clock vo

Non-M " gnetic Watch Co.

National Carbon Co...

Norwich Irs. Wire Co

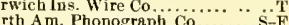

N. Y.\& L. E. A ................. Y

Ower. Dr. A

hoenix Glase Co...

pampelly. J. K .............

Powell, Wm. \& Co.

Page Belting Co.

Queen \& Co
Roessler \& Hasslacher chem. Co......

Street Railway Journal............. Y

Strowger Aut. Telph. Co.......... T

Sponholz, C. L...................... T

Star Iron Tower Co............... I

pain ......................

Schombnrg \& Sohne .... . . . . . . E

Siemens \& Halske...... . . . . . . . E

Sperry Elec, Railway co.............

sperry elec. Railway co.............

Standard Electric Co

Samson Battery Co...

Tate Aut. El, Signal Co...............

Todd, Applegate Co ...................

Taylor, Goodbue $\&$ Ames............... A

Telantograph, Elizha Gray ..........

Union Electric Co ...................

Vetter J. C. \& Co.........

Webb, G. . .......

Weston El. Instrument Co.............

Western Union Tel. Co.............. . V

ite \& Bartlett Mfg. Co.............

White, S. S., Denta] IIfg. Co......... U
Western Electrician $\ldots \ldots \ldots \ldots \ldots . .$.

Wilder Aut. Burglar Ai. Co.............

Western Electric Co $\ldots$.

Wiles $\&$ scofield .................... P

Wing, L. J., \& Co................... 


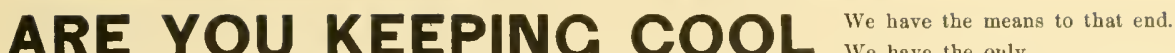

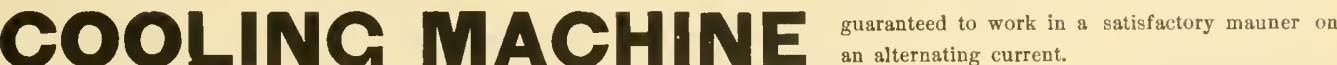 \\ THE MESTON MOTOR alternating current fan motor.}

This means that you will save the price of the motor in a few months,

\section{Electric Appliance Company, 242 Madison St. ELECTRICAL SUPPLIES. \\ CHICAGO.}

\section{THE MATHER ELECTRIC CO, THE "NOVAK" LAMP.}

MANCHESTER, CONN.

Dynamos, Motoors, Genereators,

Offices, ll6 Bedford St., BOSTON.

AND-C

1002 Chamber of Commerce Bldg., CHIGAGO.
GLAFLIN \& KIIBBALL (Inc.)

Ceneral Selling Agents.

II6 Bedford Street, BOSTOH.

1002 Chamber of Commerce Bldg., CHiCaGO.

THE REGULAR MONTHLY EDITION OF

ELECTRICAL INDUSTRIES

Is the most complete Electrical Journal published,

Every issue containing descriptions of all the new applications of electricity, complete directories of the Mannfacturers and Dealers, the Electric Lighting and Railway Companics in Nortl America, revised and corrected to the date of going to press. These special features are found in no other Electrical Journal in the world, and consequently it is read by more actual buyers than any other publication, which fact makes it without a superior as an advertising medium.

ELECTRICAL IMDUSTRIES PUBLISHING CO., Monadnock Block, CHICASO.

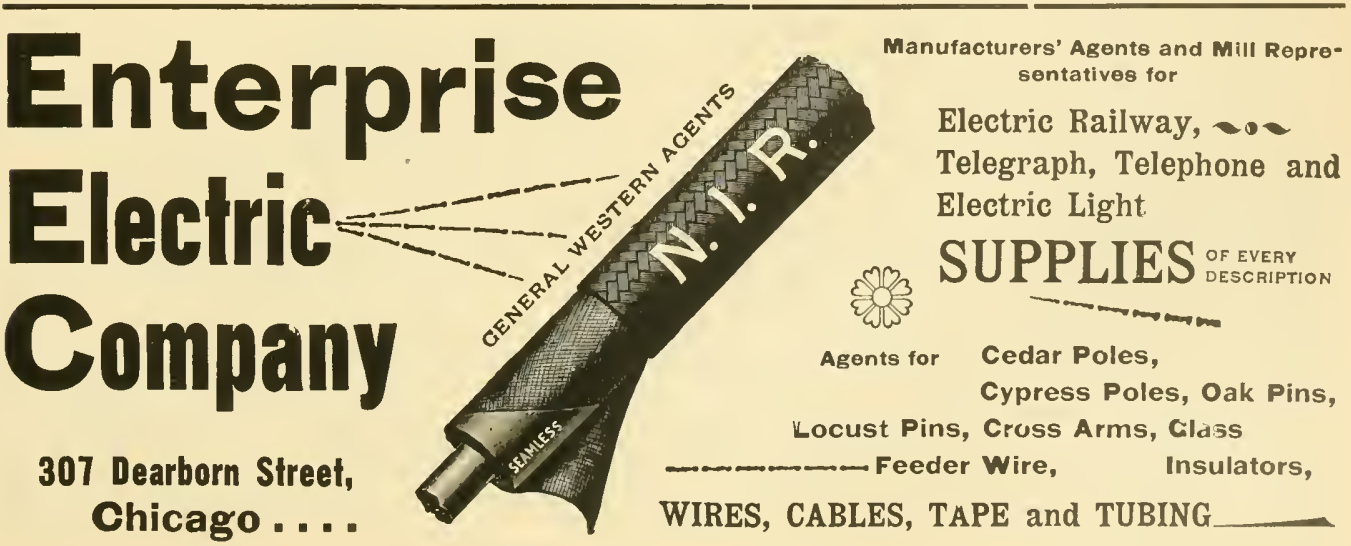


Map of Chicago.

Showing Location of its Electrical and Allied Business Interests, Principal Hotels, Theatres, Depots and Transportation Lines to the World's Fair Grounds. (Index numbers refer to the black squares.)
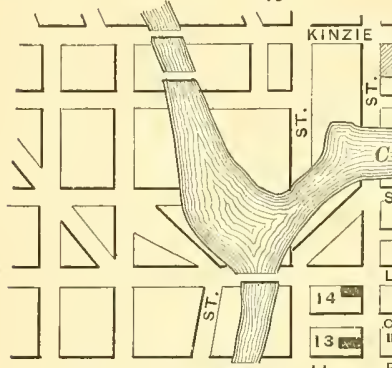

L L L L L L L
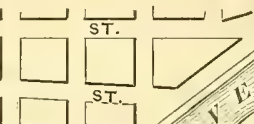

1. 1.
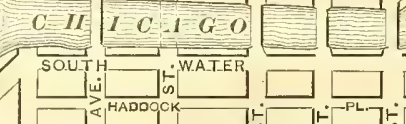

11.
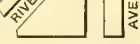

$\int$ SOUTH W.ATER

in $\mathrm{s}^{39}$

$\square^{42}$

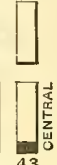

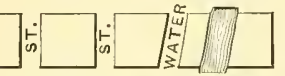

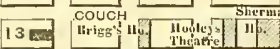

II RANDOLPH

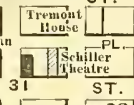

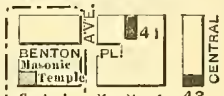

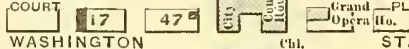

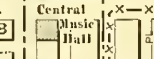
$\int_{x}^{x}$
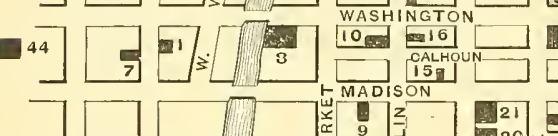

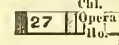
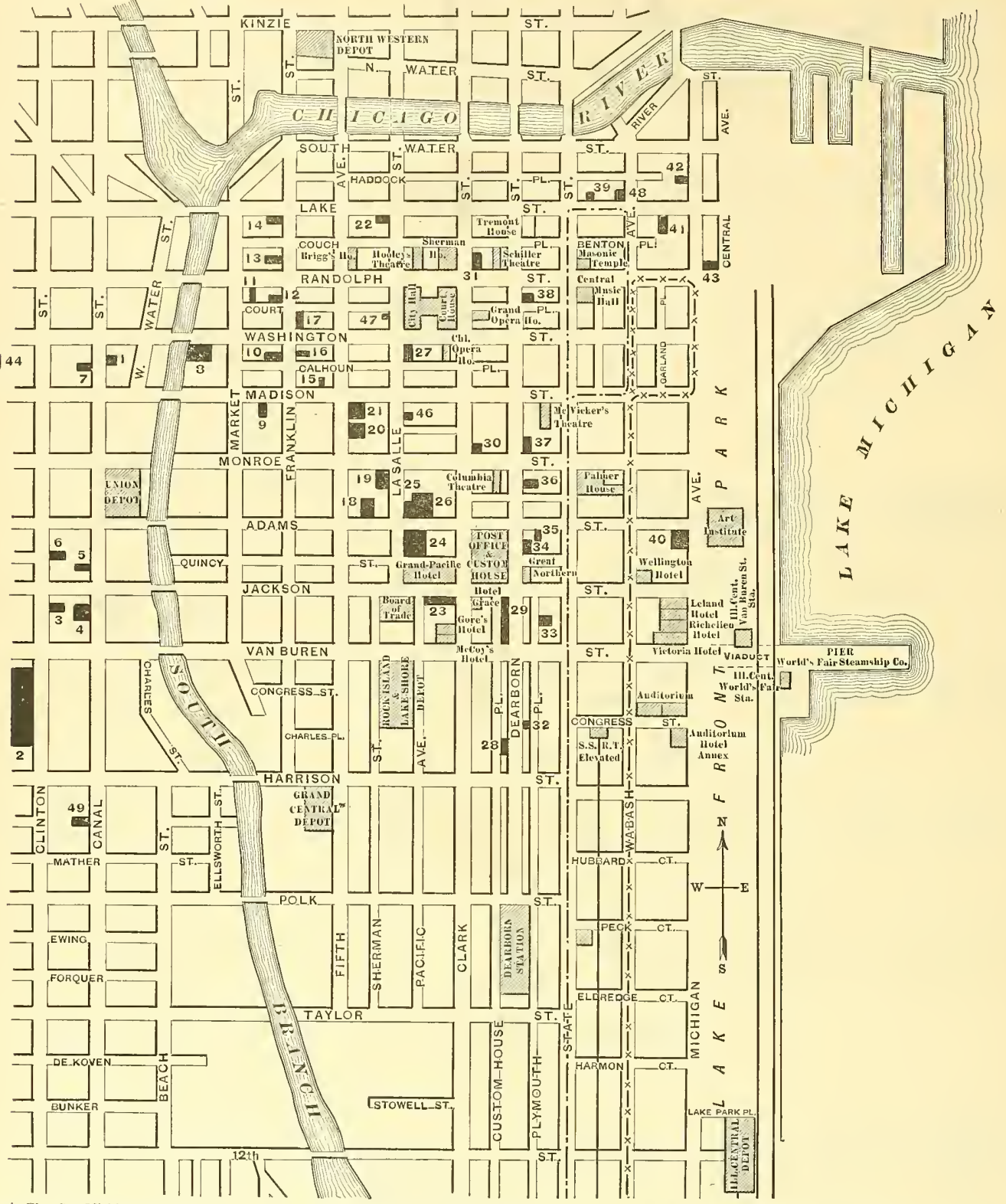

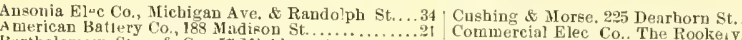

A merican Batlery Co, 188 Madizon

Bartbolomew, Stow \& Co, 57 Michigan A
13 rton \& Brown, 14:8 Monadnock Block.

Bennam, A. D., :00 s. Clinton

Brill Co..J. G., Phenix Bldg....

Brus Elect ic Co, Monadarek Bloek.

CaInnet Electrie yf or Rookery lidd

Clinton $\mathrm{S}$

Central Electrie $\mathrm{t}$. $\mathrm{e}$ Pr. Co. 185 Dearboru Central Eletric 618 Eranklin st...

(entril Telephon

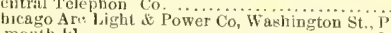

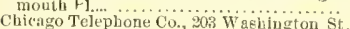

Chieago Edison Co

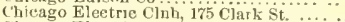

Chis.ago Rlectrie Motor Co., $313 \mathrm{~S}$. Canal

Uhica:o Insnlated Wire Co, 214 The Norther.............

Claftin \& Kimball, 1001 Chamber of C mmerce Bid

Cutter, Geo., 851 The Rookery...
29 C. \& C. Electrie Motor Co., 201 Miadi........

3 WUnger El. Telephone Co., Stock Exehange Bid Detroit Electrical Works, 917 Monadnock Block

If17 Mlonaduock Block Electric Const!nction \& Eupply Co., U uity Bldg

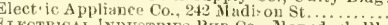
Enterprise Electric Co., 30; Dearborn si.

Et. Wayoe Elee, Co., 185 Deirhorta st. Globe light \& Heat Co. 5: Lirke St .... Gregory, Chus. E. Co. $49 \mathrm{~S}$. Jefferson St Gre tit Western Mfg. Co..203 S. Cunal St. General Inend. Arc L't. Co., 175 Adams St... Holto Illinoia Elec. Lamp Co., 171.173 S. Canil S Jenney Elec. Motor Co.. 932 Momadoek Block. Keystone Elec. Co., 345 S. Cumil st. \& Kobler Bros. 1 1 17 J Jonadoek Block.

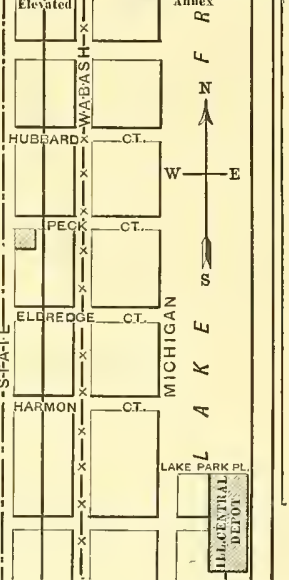

34 MeDongall \& Cummings, Unity Bldg...

(1).............. Hather Elee. Co, Chamber of Commerce Bldg........ 27 N.w York Insnlated Wire Co, 80 Frankln St........12 29 Postai Telegraph Co., Phenix Bldg.....................23 41 Pullman's Palace Car Co.. Pullman Bidg............40 29 Punpelly, J. K., 205 S. Cankal St................... Phoenix Glass Co., Wabash Ave. and Lake St......48
Ruilway Equipuent Co.. Pnllman Bldg.. ........40 Rockford Elec, $x \mathrm{Mlfg}$. Co., 94 Lit Salle St...........4 Sieme s-Halske Elec. Co. 1225 Monadnock 13lock...29 Star Elec. Lanij Go. 805 Chamber of com. Bldg.....27 Stirling $\mathrm{Co}_{\text {, }} 606$ Prllmin Bldg ....................41) Schierem, Chas. A., \& Co., 46. S. Canal St..... … I Short Elee. Railway Co. Monadnock Block.......29 Toda. Applegate Co., The. 340 Denrborn St.........28 Winddell- Enitz C , 1122 Mlonadnock Bloek ..........29 We-1ern Electric Co, 22\% s. Clinton St........... 49 Wolleneak, J. F., Lake and Franklin sts............... 13 Western Union Tele grapt Co., Plenix Bldg...........23 


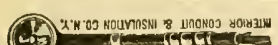

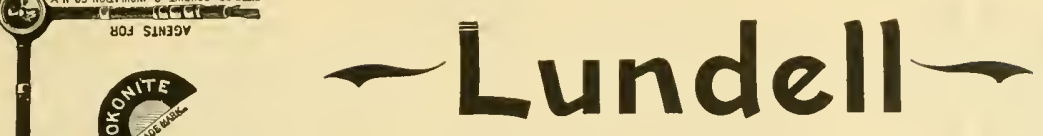

\section{Suspended Fan Outfit}

क्षे

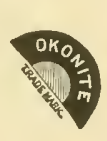

6

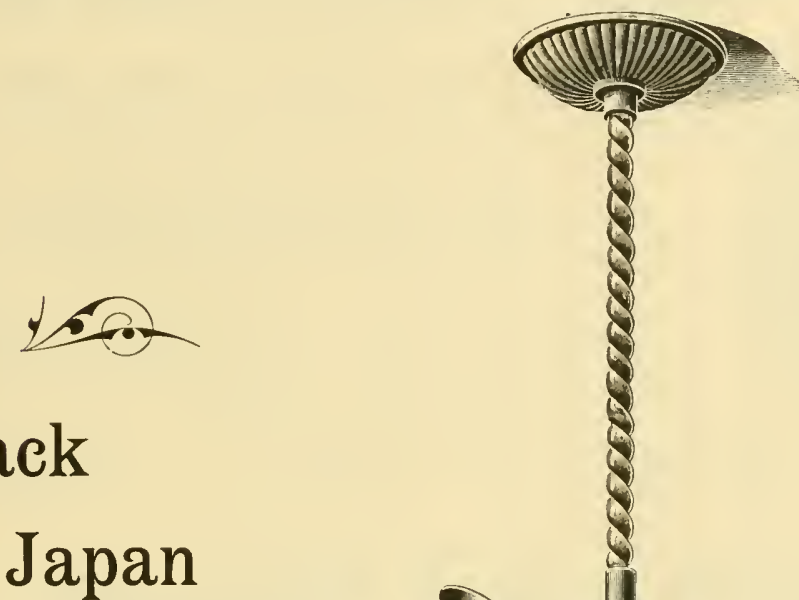

\section{Black
Japan}

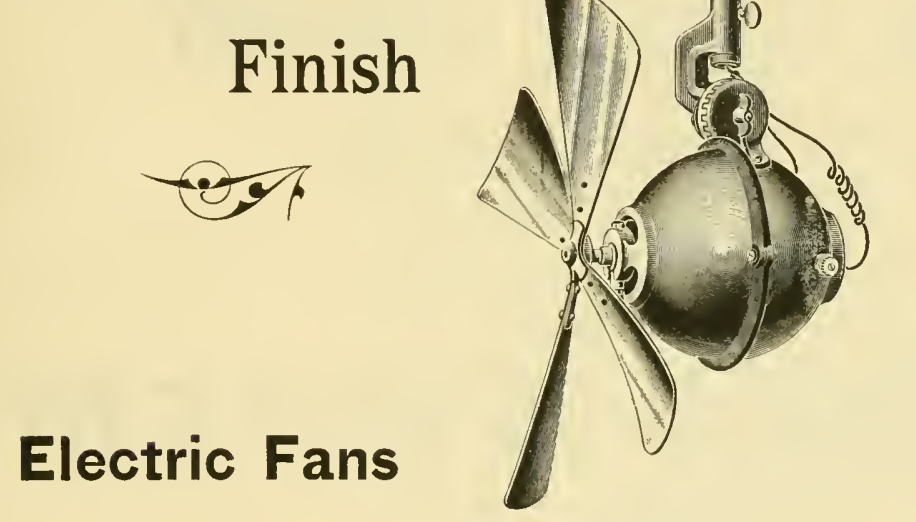

Self-0iling .....and

Self-Aligning Bearings

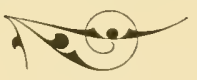

\section{Electric Fans}

\section{OKONITE WIRES}

OKONITE $=$ TAPES $=$ MANSON INTERIOR CONDUIT.

Batteries, Bells, Push Buttons, Annunciators, Volt Meters, Ammeters, Wheatstone Bridges, Line Wire Cross Arms, Brackets, Pins, Insulators, Tools.
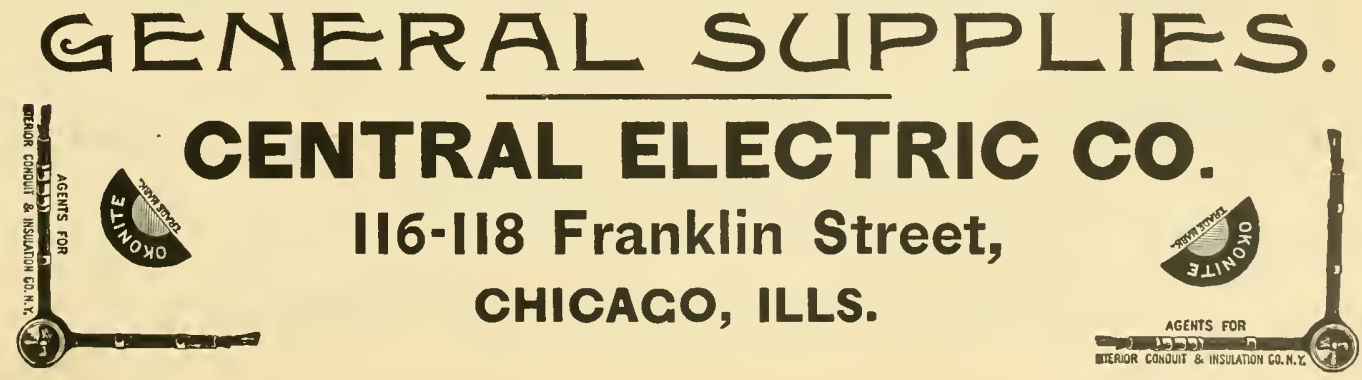


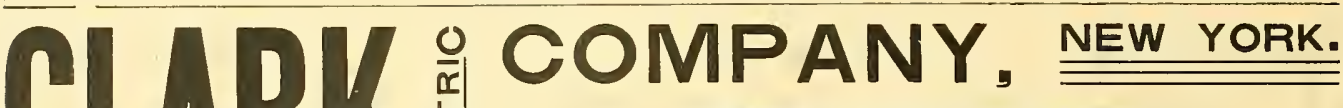 \\ 192 Broadway and II John Street. \\ MANUFACTURERS OF ARC LIGHTING APPARATUS FOR EVERY PURPOSE A SPECIALTY. The CLARK ARC LAMPS for use on EVERY CURRENT, have the reputation of being the best and most durable of any ever made in the United States.
}

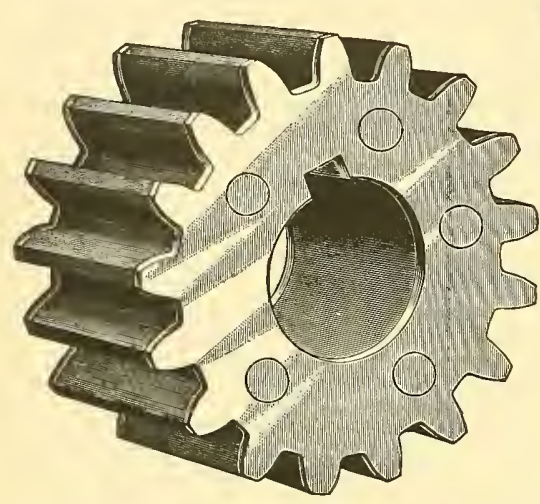

RAWHIDE PINIONS FOR ELECTRIC MOTORS A SPECIALTY.

RAWHIDE DYNAMO BELTING

Greatest Adhesive Qualitles. A Non-Conductor of Electriclty. Causes Less Friction than any other Belt.

\section{THE CHIGAGO RAWHIDE MANUFACTURING CO.} THE ONLY MANUFACTURERS IN THE COUNTRY.

\begin{tabular}{|c|c|}
\hline $\begin{array}{l}\text { LACE LEATHER ROPE } \\
\text { AND OTHER RAWHIDE }\end{array}$ & $\begin{array}{l}\text { This Belting and Lace Leather is } \\
\text { not affected by steam or dampness; } \\
\text { never becomes hard; is stronger, }\end{array}$ \\
\hline $\begin{array}{l}\text { GOODS } \\
\text { OF ALL KINDS } \\
\text { BY KRUEGER'S PATENT }\end{array}$ & $\begin{array}{l}\text { ical Belting made. The Raw- } \\
\text { hide Rope for Round Belting } \\
\text { Transmission is superior to all } \\
\text { others }\end{array}$ \\
\hline
\end{tabular}

\section{Standard Electric Company.}

GENERAL OFFIGES: 625 Home Insurance Building.

WORKS: So. Canal Street,

\section{CHICACO.}

\section{STANDARD SMST:
VTORID'S FAIR.}

MACHINERY HALL, Sec. Q, 2 Standard Arc Dynamos.

\author{
Sec. S. 20 .." " "
}

ELECTRICITY BUILDING. Sec. P, Space 2, Arc Lighting Exhibit.

The Standard Lamps Light the Power Plant, Machinery Hall, Agricultural Hall, Shoe and Leather Bullding, ard Other Buildings and Portions of the Grounds. 


\section{Western Electric Company, CHICACO. NEW YORK.}

Arc Lighting Apparatus

High and Low Tension,

Double and Single Service Lamps,

All Night Single Lamps,

Theater and Focusing Lamps.

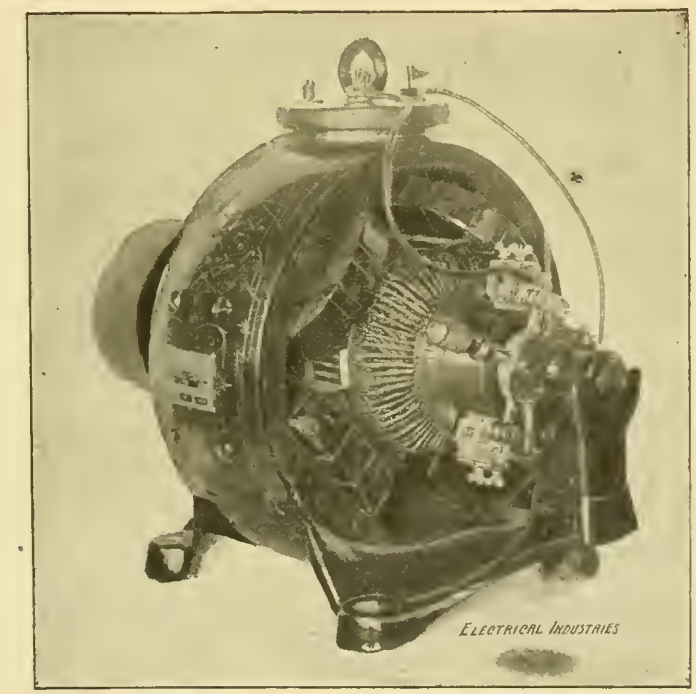

\section{ELECTRIC MOTORS}

FIGII SPFED

VARIABIF SPEFD

SLOW SPEFD.

BUILT FOR SEVERE AND CONTINUOUS SERVICE, SPECIAL TYPES FOR SPECIAL DUTY. 


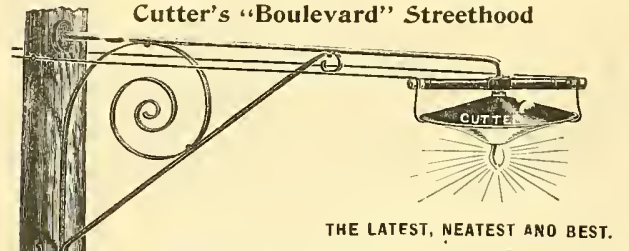

GEORGE CUTTER,

$8_{5} I=853=855$ The Rookery...CHICAGo.

\section{SIMPLEX WIRES}

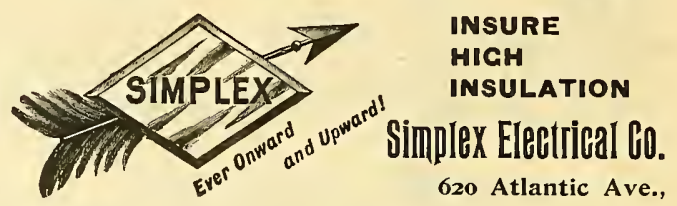

George Cutter, Chicago. Boston, MAss.

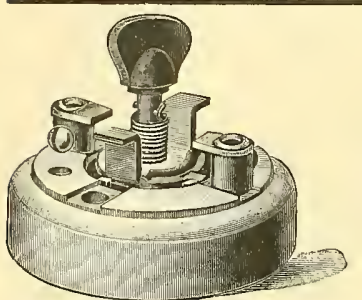

Made 5 amp. S. P.

amp. 3 way.

\section{XNTRIC}

"That's the Switch"

And we control that movement.

H. T. PAISTE, 10 South Ieth St., PHILADELPHIA, PA.

Consolidated Elpctric C.

Manulaclurers and Dealers in all kinds ol

\section{ELECTRICAL - SUPPLIES,}

115 Franklin Street,

chicaco.

... SEE AD ...

Siemens \& Halske Electric Gompany

PAGE 9.

\section{CHAS, A. SCHIEREN \& CO,}

MANUFACTURERS OF

\section{Genuine Perforated Electric Leather Belting.}

46 So. Canal Street, - CHICACO.

Section 15, Dpt. F, CIm. 27. MACHINERY HALL.
Section D, Space 3 ELECTRICITY BUILDING.

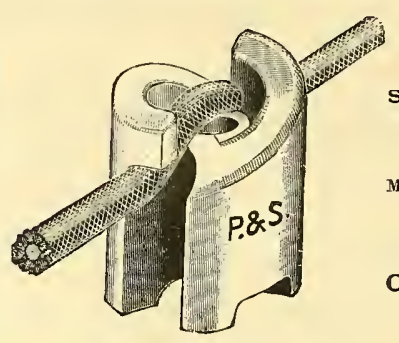

P. \& s.

WIRING INSULATOR, Saves TIME

TROUBLE and TIE WIRE

Made only by

Pass \& Seymour, SYRACUSE, N. Y.

George Cutter, CHICACO.

Manager Western Dept.

THE WADDELL ENTZ OO. MULTIPOLAR

DIRECT CONNECTED DYNAMOS. SLOW SPEED MOTORS.

II22 Monadnock Block, - CHICAGO. WAGNER ELEGTRIG FAN MOTORS

For Direct or Altemating Currents.

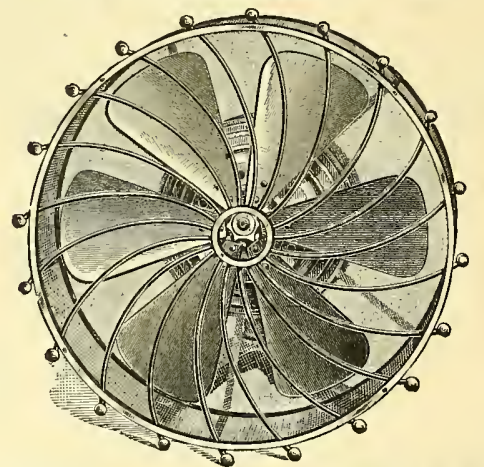

These motors give a stronger breeze with less consnmption of current than any other fan motor on the market. They are fnll 1.8 horse power. Six bladed ch fan. Self-oiling. Formished with or withont gnards.

IT WILL PAY YOU TO SEE THE WAGNER BEFORE BUYING ELSEWHERE.

TAYLOR, GOODHUE \& AMES, 348 Dearborn Street, CHICACO.

See Our Exhibit of ELECTRICAL FIXTURES

IN SECTION "N", BETWEEN COLUMNS 62 AND 64, MANUFACTURES BUILDING,

GLOBE LIGHT \& HEAT CO.. 52 \& 54 Lake St., CHICAGO. 


\section{Weekly World's Fair Supplement.}

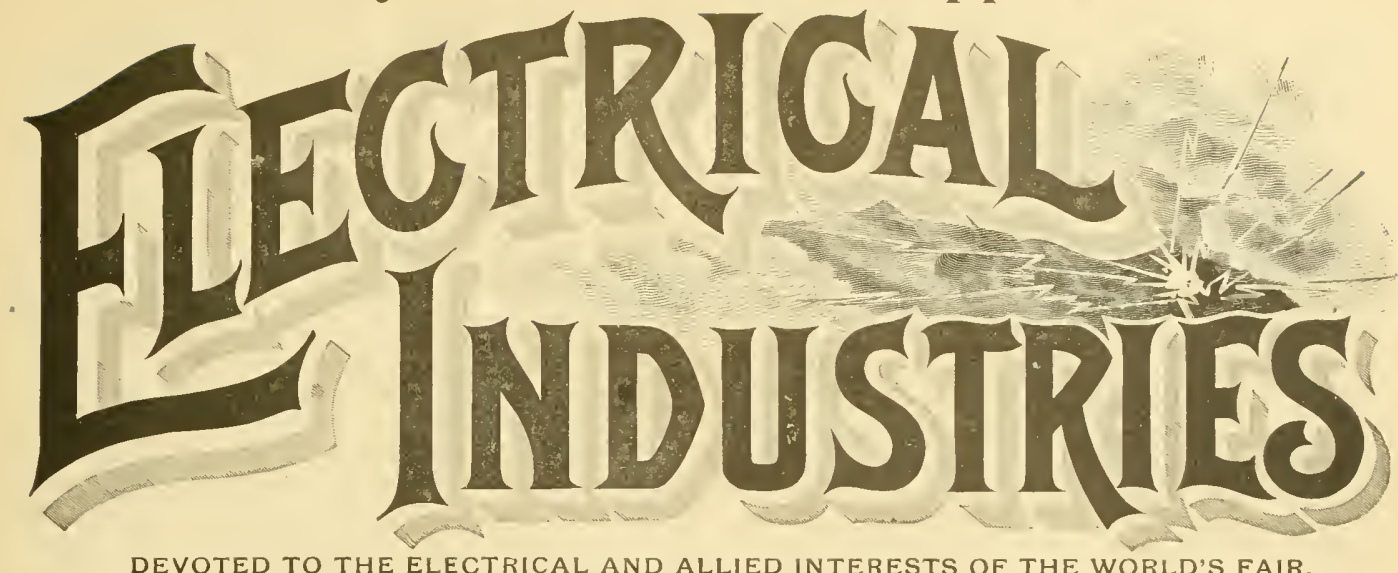

DEVOTED TO THE ELECTRICAL AND ALLIED INTERESTS OF THE WORLD'S FAIR, ITS VISITOHS AND EXHIBITORS.

Vol. I, No, 6, CHICAGO, JULY 20, 1893.

FIVE MONIHS \$1.00
TEN CENTS A COPY

Exhibit of Allgemeine Elektricitats Gesellschaft.

In the very extensive display made by (iermany in the Electricity Building the exhibit of the Allgemine Elektrieitats Gesellschaft, Berlin, attracts universal attention. It trimmings. The whole partition is surmounted by a very ornate bronzed wronght iron sign giving the name of the company and carrying 220 16-candle power incandescent lamps. The trusses on the side next to the main aisle are concealed from view by decorated panels. The column in

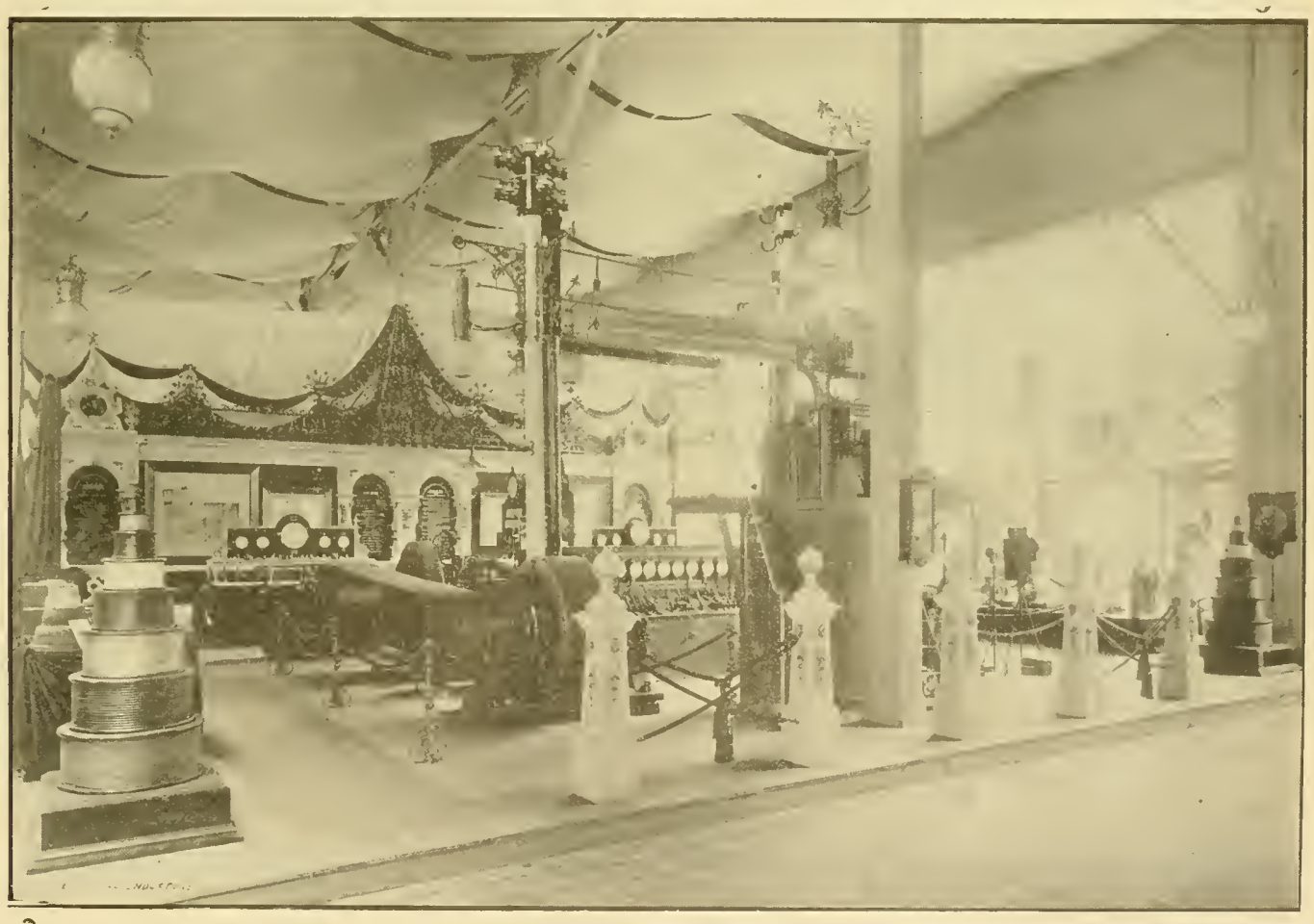

FIG. 1.- FXHHIT OF THE ALLGEMFINE ELEKTRICITATS G.1SELLSCILAT.

is situated in the German section just east of the long distance department of the Westinghouse Conpany. The partition wall between this exhibit and that of Felton a Guil. leaume at the south end is handsomely paneled in brown cloth, the columns being of wood printed white with tinted the center of the exhibit is draped in bromn, the ruling color of the decorations, and has two very handsomely ornamented are lamps suspended from it. Just under these is a crown-shaped decoration of gilded wrought iron, supporting $\mathrm{s}(\mathrm{f}$ or more incandeseent lampls. White posts, sup)- 
porting heavy brown rope with brass ormaments and tassels surround the exhibit and divide it inte parts. At the two entrances to the exhibit are placed cones formed of reels of bare copper wires and cables.

The principal feature and the one which attracts much attention from the electrical engineer, is the power transmission plant, consisting of a direct current shunt wound motor running 620 revolutions a minute and with a capacity of 150 amperes at 500 volts. This motor is supplied with current from Machinery Hall and drives by a belt a three phase generator made especially for the exhibit. The generator has a capacity of 150 volts and 500 amperes, separately excited by a continuous current of 110 volts. It has 14 poles and the speed is such as to give 50 periods per second; the efficiency is said to be 92 per cent. The three phase generator drives through proper wire connections a 50 -horse power three phase motor running at 725 panels. The front of the board is divided into two panels; the upper one is placed in a vertical position and contains the ammaters, volt meters, etc. The second panel, placed at an angle of 15 degrees from the horizontal and just below the first, contains the main switches and fuse blocks. The third panel, placed on the rear of the board, in a verticle position, contains the distributing bus bars, switches and fuses. The body of this board is made of the new insulating material called "stabilit", which is said to have all of the insulating properties of hard rubber and to be very much like it in every way excepting that it does not soften from heat. The particular material used on this board is of a reddish color, having the appearance of our American vuleanized fibre.

This switch board is supplied with all the necessary switches, cut-outs, fuses, bus bars and resistances, ampere meters, and volt meters necessary to control the current

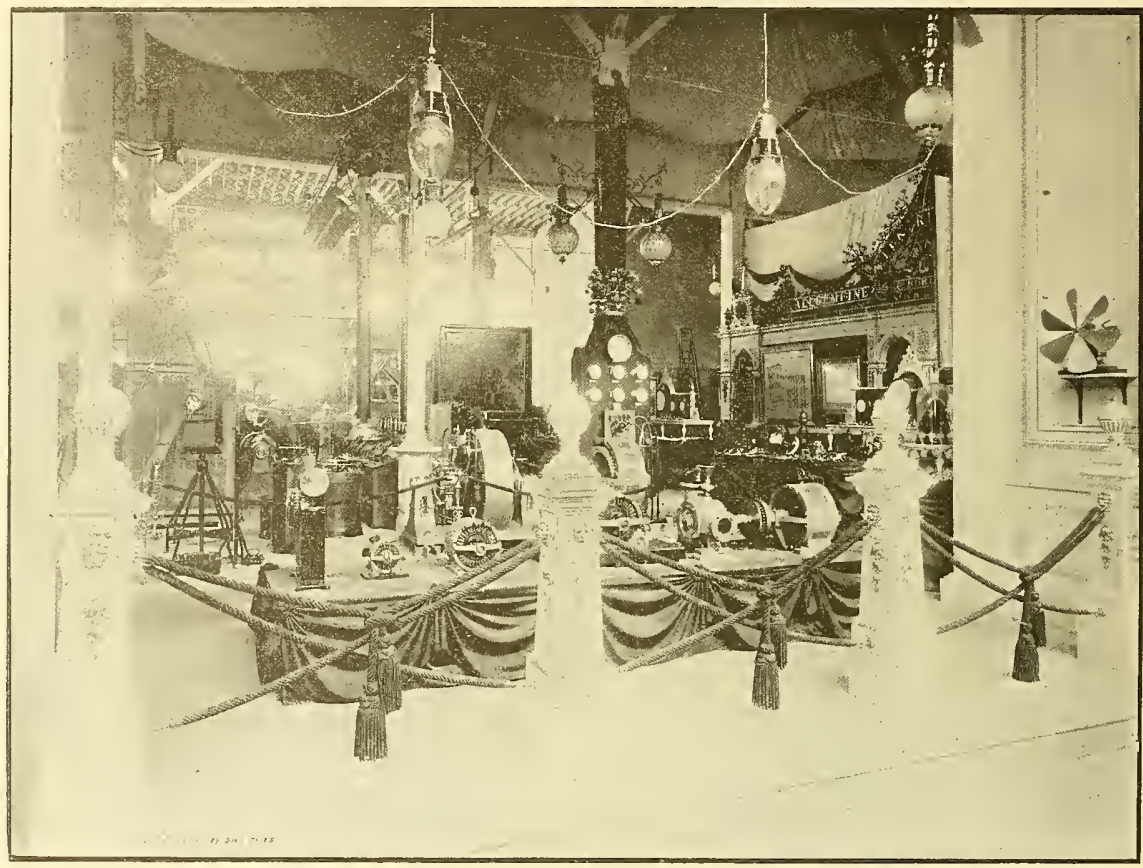

FIG, 2,-EXIIIIT OF THE ALLEGEMEINE JLEKTRICITATS FESELLSCHAFT.

revolutions and 120 volts pressure. It is said to have an efficiency of 91 per cent. This motor is directly connected through a brush coupling so called, to a direct current generator of 300 amperes eapacity at 120 volts, the current from which is used to stupply the arc and incandescent lamps for lighting the exhibit. A peculiarity in the construction of the direct current motor and generator used in this display is that a complete cast iron shell surrounds the armature between it and the faces of the pole pieces. The shell is about one inch thick over the pole pieces but thinner between them. It is pierced by a row of half inch boles half way between the pole piece. The effect of this shell is said to prevent the changing of the position of the neutral point when the load is raried to any great extent.

The switch board, on which are located the instruments ard switches for the control of the current used in the exhibit, is mounted on an iron frame and is arranged in three for the various machines and lamps in the exhibit. The switches, and in fact all of the apparatus, show a very high degree of finish and have some points of excellence that might well be copied by American makers. The starting resistances for the direct current machines are situated underneath the frame of the board with the wheels for the same on the frout. Another important feature in the exhibit is the theatrical outfit, consisting of an iron frame with a simple but comprehensive arrangement of levers and controlling stands. Tables are provided all about the space for displaying the minor products of the company. They are all handsomely draped in brown cloth and tassels. On a table near the main aisle is a sample of automatic resistance for controlling the shunts of dynamos and several samples of small three phase motors.

A handsomely arranged circular table displays a great number of samples of incandescent lamps with different 
bases and bulbs variously decorated. A cone under a glass cover, on top of the table, shows the filaments in all stages of preparation. Another table, near the front on the main aisle, exhibits rarions sizes of direct current motors from one-sixteenth-horse power to six-horse power. Other tables are loaded down with material for outside construction such as are used for line construction and for railroad work. The various grades and sizes of volt meters and ampere meters, switches and eut-outs in great number, instruments for testing and registering pressures, one of the latter deserving special mention in that it is a registering rolt meter which makes a curve, showing the state of the voltage for the entire 24 hours. The fuse ent-outs made hy this comprany are similar to the Edison serew base ent-outs. The plugs for the different capacities of fuse are of different lengths, graduated from that of the smallest capacity in the longest plug to that of the greatest capacity used in this form of cut-out which is the shortest plug. The screws are the same for all sizes but it will be seen that the plug with the heaviest fuse if screwed into the base requiring but a small fuse will not reach the bottom and therefore will not close ing circuit of an electrical system of distribution instead of having special electrical cireuits. An automatic device attached to the shunt of a dynamo and actuated by a master clock placed in the central station, at a certain time of day, reduces the regular potential of the circuit to $10(1)$ volts and the clocks by this action are set and wound. The whole arrangement takes but an instant of time and the shunt apparatus being immediately short circuited, the circuit potential returns to its former standard. A device for indicating the time of departure of trains and the stations at which they step, for use in railway stations, is also shown. The exhibit is one of the handsomest shown in the Electricity Building, is very comprehensive and includes practically all the details required in either central station or isolated work either for lighting or power.

\section{Exhibit of Queen \& Company.}

This company, located at the end of the German section in the northeastern part of the Electricity Building, is only a part of the company's entire exhibit at the Fair, as

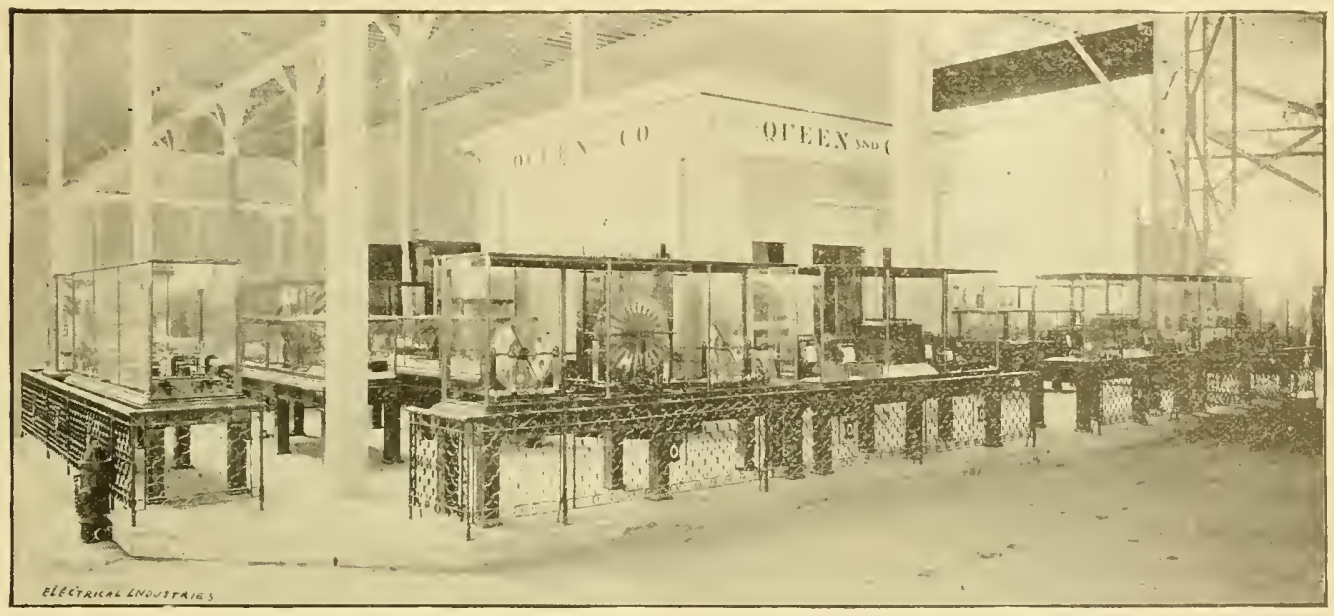

THE EXIHBT OF QUEEN \& COMPANY.

the circuit. Nearly all metallic contact surfaces are timned over to prevent oxidizing.

This company also exhibits a complete outfit of electrical heating derices such as teapots, flat irons, pipe and cigar lighters, and one instrument which has not been noticed among American exhibits of like material, being a long rod with a flat circular dise on the end containing the electrical heating device used for heating water in a pitcher or other receptacle. Numerous forms of switches for use with accumulator installations are shown. The sprecial fenture the company is exhibiting is a small shunt are lamp which it is said will burn on constant potential circuits, constant current circuits and alteruating current eircuits, and with the same mechanism will burn on one ampere of current or any amount above that to 30 anperes at 4 i volts. A small opal globe, about three inches in diameter, is so sus. pended from the upyer earbon holder as to conceit the are at all times, the regular glohe being put on over the lanıp in the usual manner.

Another feature is a system of self-winting and stif-set. ting clocks that is attached to the regular low tension light. they have many branches of business other than chectrical. Outside of the few instruments necessary for use in the general study of physies which are located in the hall of Manulactures and Liberal Artsall the electrical apparatus made or sold by the company is shown here.

The location being at the end of a section allows of a very open arrangement of the show cases. A handsome designed office occupies the center, the cabinets and show cases being arranged around the outer edge of the space. The office besides being fitted out very comfortably with desks and other necessary furniture is supplied with a well stocked electrical library. On one wall arranged in taste ful designs are samples of the Cardew hot wire rolt meters and several sizes of magnetic vane rolt meters and ammeters made by this company; these latter instruments while being very reliable and consuming little energy while in circuit are very reasonable in price. (In mother side of the office are arranged samples of Lord Kelvin ampere gauges reading in one instunes as high as fi, (1110 anperes, and of the type designed tor switchbeard use. There are also samples of switchboard form of multicellular rolt 
meter of the same make. These voltmeters being of the electrostatic type consume no energy whatever when kept in eirenit.

Back of the office and entered by a door leading from it, is a dark room for showing worlking samples of photometers, and in that connection the several forms of sight boxes, including the Lumner-Brodhun type. There is also a very complete collection of Geissler crooks and spectrum tubes, which will be shown in use as soon as current can be furnished. In the show cases and cabinets outside of the office, while some attempt at classification has been made, no fixed rule has been followed, so that the instruments have been arranged with a view to decorative effect. In galvanometers there are shown several new forms of the reflecting type, all of them hasing the finely drawn quartz fibre suspension. Corrugated hard rubber support posts are used in nearly all cases for increase of insulation, and all parts of the instrument hare been simplified so as to be easily and conveniently reached for adjustment.

In the high grade type of Thomson instruments the coils are all hinged in pairs on the frame of the instrument and contacts are all closed when the coils are shut against the frame. In some cases the terminals of the coils are brought outside the frame to a small plug switchboard by which all combinations of coils are easily and quickly made. The ballistic galvanometer shown is one of the finest and most complete of that type made. The suspension is quartz fibre and is got at by removing one screw from the outer case, which turns back and allows the front coil to be opened out; the needle is then entirely free for inspection. The peculiar construction of the needle and its magnets allow its sensibility to be increased or decreased without the introduction of any outside force. Other types are an Anthony tangent galvanometer of the Helmholtz-Gaugain pattern; a modification of the Wiedemann dead beat reflecting galvanometer; a sample of the Moler swinging arm tangent instrument which has an exceedingly wide range of reading, and samples of the new Queen pattern of D'Arsonval galvanometer. This last instrument has a very delicate suspension, and is very conrenient for use in intense and varying magnetic fields, its own field being so strong as to be entirely unaffected by outside influences.

Several types of scales, lamps and reading telescopes, as well as shunt coils for use with the galvanometers are also shown. One form of shunt coil shown is provided with a compensating coil which is introduced in addition to the regular multiplying shunts in order to make the resistance of the circuit the same as at first. There are also several new forms of discharge and contact lieys. A very large assortment of resistance boxes, rheostats and bridge sets are exhibited, one very small testing set known as the Acme deserving especial mention, as it is but eight inches long by six inches wide and high, and yet includes a battery of 10 cells, a D'Arsonval galvanometer, a rheostat of 11,112 ohms, that will measure by means of the reversing arrangement, as high as $11 \mathrm{meg}$-ohms, a carbon rheostat useful in calibrating with large currents, two large Anthony bridges which it will be remembered are provided with temperature coil and so arranged that the coils of the rheostat can be checked against each other, several forms of standard ohm coils which include one of a new type having besides the standard resistance a temperature coil and heating coil for determining temperature co-efficients.

In batteries the Carhart-Clark cell is shown. This is said to have an exeedingly small temperature coefficient and is provided with a coil of 100,000 ohms in series with a battery to prevent short eircuiting. Samples of the Queen aluminum iodine testing battery are also on exhibition. This cell is said to have one-and-a-half-rolts, and to be a great improvement over old forms. An extensive exhibit of Siemens dyuamometers is made, the form shown by this company having but one support, a pivot suspension in place of fibre and various other detail improvements, and arranged in sizes from a five ampere instrument to 500 amperes. There are samples of the Nascart electrometer and also of the Ryan modification of the same. The latter instrument has taken very well and several of them have already been sold.

For school purposes a large case of statical electrical apparatus for lectures and a fine set of apparatus, consisting of a hand dynamo eapable of furnishing either direct or multiphase currents, two motors for use with the same, and various other pieces of special apparatus are shown.

One unique exhibit is a large Hertz mirror for illustrating the oscillatory theory of electricity according to Hertz. Among the newer and special forms of apparatus shown is a new form of slide wire bridge embodying Willyoung's improvements for very accurate work, a set of apparatus for determining the difference in resistance according to the Cary-Foster method, and another which is the reverse of this for determining the conductivity of specimens. These last instruments are entirely new, and have not yet been placed freely on the market. The exhibit is in its line very comprehensive, and includes about every instrument required in the study and practice of electrical science. It is thought that a careful study of the instruments included will convince the most prejudiced mind that it is no longer necessary to go abroad for this class of material. The fact that the entire collection is ralued at something like $\$ 15,000$ will indicate the amount and class of material shown. A large number of these instruments have already been purchased by the Armour Institute of Chicago for use in their course of electrical engineering and their name will be found on many of the exhibits.

About half the material has never before been shown to the public, and has nearly all been made by Queen \& Company. Mr. C. W. Pike is in charge of the exhibits, and is ably assisted by Mr. E. R. Keller, M. E. Both gentlemen take pleasure in showing and explaining the use of the instruments.

\section{Exhibit of the Washburn \& Moen Manufacturing Company in Electricity Building.}

This well known firm has a very extensive exhibit of such of its products as are used in electrical work, in Section $V$ in the east gallery of the Electricity building. A platform raised about 6 inches above the floor, surrounded by a handsome brass rail gracefully hung with brown cord and tassels covers the entire space. The name "Salamander," made up of incandescent lamps, is supported orer the center of the front of the space, and American flags are gracefully draped on each side. A desk and chairs occupy one corner of the platform; a cabinet containing a battery of secondary cells used for showing the fire proof qualities of the new Salamander wire, occupies the center of the front side, and directly back of this is a large blackwalnut cabinet, or show case. Carpeted walks, railed off with brass, lead up to the large cabinet and around the testing platform.

On the left of the space next to the office, are arranged a 
number of coils of bare copper rod. Next to them are six large reels of weather proof wire running from No. 8 to No. 14 B. \& S. gauge. In the same space are also four large reels of weather proof insulated feeder wire of sizes between number 0000 and $0 \mathrm{~B}$. $\mathrm{d} \mathrm{S}$ gauge. The last men tioned reels are surmounted by coils of magnet and anumciator wire of various sizes and styles. One large reel of stranded cable 300,000 circular nills cross section; a reel each of number 0000 and 00,37 strand feeder wire, and a coil each of No. 2 and No. + B. \& S. gauge cotton covered magnet wire are shown, on top of which is a coil of bare twisted copper wire such as is used for lamp cord. By a peculiar process used by this company, it is made to retain its bright surface and not oxidize.

At the left of the testing cabinet and fronting on the aisle are a number of solid copper ingots just ready for rolling; a number of reels of magnet wire, coils of lyare copper and iron wire, spools of fine annunciator wire and a ten-foot sample of an insulated copper cable about an inch merous short samples of black and white covered wire are lined up under the serolls and around the center cone.

The battery eabinet contains 15 cells of accumulator and through suitable terminals and switches on top the current is used to produce a great degree of heat in short samples of different makes of insulated wire. Samples up to six inches in length of No. 14 of different makes are joined in series with a similar sample of the Salamander brand. On turning about 120 amperes of current through this series the heat immediately flestroys the insulation of all but the Salamander wire. At the right of the battery cabinet are coils of galvanized iron wire, bare copper wire and coils of various sizes of Salamander and cotton coverel lamp cord.

On the corner at the extrene right is a glass show case containing materials uset for the rubber insulation of wires, consisting of four grades of rubler, pure, red, white and black. The space also contains large reels of stranded railroad feeder wire of $500,(x)(\mathrm{C}$. M. cross section, a reel each of Nos. (OH), (0), and (1), rubber covered, taped and

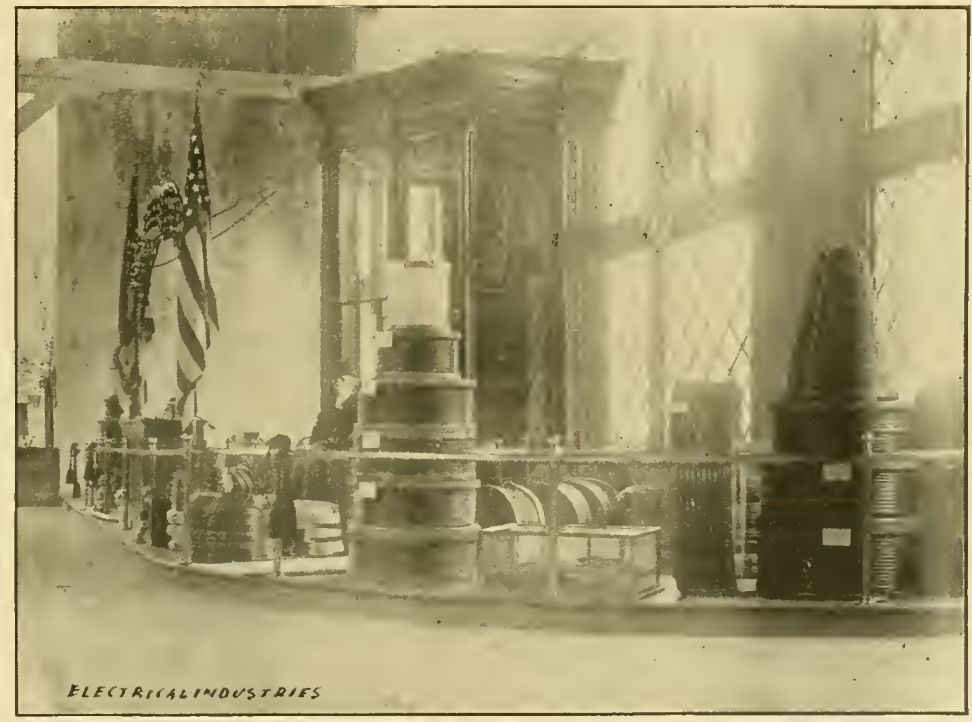

EXHBit OF THE WASHBCRN \& MOEN MANUFACTERING COMPANY IN ELECTRIClTY BUlLDING.

and a half in diameter, cut from a piece, supplied a plant used for the electrolytic deposition of metals. In this same space are also sample coils of red, bhe and green cotton and silk covered Salamander lamp cord, which lend color to the exhibit.

The glass paneled cabinet back against the wall contains as the most prominent object a half section of a large cone covered with alternate layers of red, blue and green Salamander lamp cord, surmounted by two copper whips made from copper rods about one half inch diameter, the size being redueed every three inches by drawing down, until at the end of the lash the copper is very fine, probably not larger than No. $40 \mathrm{~B}$. and $\mathrm{S}$. gauge, showing the quality of the material and the high degree of efficiency to which the workmanship and machinery has been brought.

Arranged on the bottom of this case are coils of all kinds of lamp cord, rubber, silk and cotton covered. The back of the case being lined with black relvet, the fancy scrolls and geometrical figures in copper and brass wire arranged on this dark background forms an attractive display. Nu- braided, all being surmounted by a cone formed of coils of rubber covered wire in sizes running from No. 6 to No. 18 B. and S. gauge. Cables of iron wire for guys and cross over wires are exhibited in coils. The exhibit is very comprehensive, including as it does about all the numerous styles of electrical conductors made by the company, but especial prominence is given to the new brand called Salamander. This wire is insulated as follows: First, a thin layer of rubber to render the insulation water proof, then a layer of "Salamander," that is, a composition somewhat like a fine clay or kaolin which is fireproof, this being covered with an outer braiding of soft white cotton over which is applied a heary coat of black insulating paint. The covering, as made up, is said to be fire and water proof, and from the tests shown here there can be little doubt of the former. The company refines its copper from the ore electrolytically, having erected duriug the past year or two a large plant for this purpose. Mr. F. A. Warren is in charge of the exhibit and will show the numerous samples and explain the insulation to those interested. 
ELECTRICAL INDUSTRIES.

Entered at Chicago Postoffice as second-class mail matter.

\section{PUBLISHED ETERY THURSDAY BY THE \\ ELEGTRICAL INDUSTRIES PUBLISHING COMPANY, INCORPORATEO 1889. \\ MONADNOCK BLOCK, CHICAGO. \\ TELEPHONE HARRISON 159.}

E. L. POWERS, Pres. and Treas.

E, E, WOOD, SECRETARY.

E. L. POWERS,

EDITOR.

H. A. FOSTER,

W. A. REMINGTON,

E. F. WOOD,

Assoctate EDitors.

FLOYDT. SHORT,

EASTERN MANAGER

AdVertising Departaent.

EASTERN OFFICE, WORLD BUILDING, NEW YORK. World's Fair Headquarters, Y 27 Electricity Building.

FIVE MONTHS

SINGLE COPY

SURSciptiox:

Ädvertising Rates Üpon Application.

$\$ 1.00$

News items, notes or communications of interest to World's Fair Visitors are earnestly desired for publication in these columns and will or send address at once upon theit artival in city or at the grounds. ELECTRICAL INDUSTRIES PUBLISHING CO.

Monadnock Block, Chicago

The Western Passenger Association meets tomorrow to again consider the question of World's Fair rates. It is hoped, for the good of the Fair and the people, the Association will decide on a general one way rate. The proposition to be submitted is an advance in the right direction, but why should people living within 200 miles of Chicago be excluded from this rate?

THE gate receipts of last Sunday, which was the last open Sunday of the Fair, were appropriated to the benefit of the sufferers by the recent fireat the Exposition grounds. The fund raised by contributions large and small together with what has been raised from benefits given by concessioners and others has become large enough so that the sufferers will be relieved from want. The action of the directors in thus disposing of the receipts on the last open Sumday was most appropriate.

In another column will be found a list of the jurors so far appointed in the Department of Electricity. The selection of the Jury of Awards has been a most difficult task but has thus far been most ereditably done. In looking over the list of names the number of men comnected with educational institutions is noticeable. It was advisable to select men not connected with electrical companies and for that reason the choice was confined almost entirely to prominent electricians comnected with educational institutions. At a meeting of the jury held on Tueslay afternoon Prof. H. S. Carhart was elected president.

LAST week the Board of Directors by a vote of 24 to 4 decided to close the Fair on Sunday. This decision of the directors seems to give, with a few exceptions, universal satisfaction. It will undoubtedly be a relief to the public to know that the matter is settled and the army of employes at the Fair will appreciate a day of rest each week. The wish of the people in this matter was shown by their staying away from the Fair on Sunclay; after a sufficient time for making a test the ahove decision has been reached. Chicago has many beantiful parks and places of interest, so that visitors if they desire will find abundant places to spend the Sabbath, and the increased attendance during the rreek will more than make up for the slight profit there would have been secured on Sundays.
The German Commission is arranging some very handsome decorations in the center of the east gallery. The plau is copied from the memorial to Dr. Von Siemens erected by the Emperor at Berlin. The panels will be of finest erimson silk plush with gold trimmings. A statue of Siemens is shown in the back ground while arranged in the foreground on tables are numerous cases of instruments and apparatus of historical interest.

The Hope Electric Appliance Co. of Providence is show ing a number of interesting pieces of apparatus in the Gallery of the Electricity Building Section S. A wooden arch over the center of the space supports a number of ineandescent lamps. A converter on a frame back of the arch supplies current for the lamps and serves to show the special donble pole dead cut-out switch for opening the primary circuit of an alternating current. The switch is in an iron box, has a rery quick motion, is insulated with porcelain and can be made with or without fuses. Samples of series are circuit cut-ont switches are also shown with the mechanical action and construction very similar to that of the primary alternating switch mentioned above. Other special switches are also shown in operation. A very clever device, Wright's automatic mast arm, is secured to one of the posts running up to the roof through the space. This arm eonsists of one long piece of pipe extending out from the post and strongly braced in all directions, secured to a easting at the post end and parallel to it underneath is a swinging arm, to the onter end of which the arc lamp is fastened. A thin tape of strong bronze metal about 5 inch wide is attached to the lamp, runs over a pulley on the outer end of the stationary arm, through that pipe to the post where it runs over another pulley and down the pole to a windlass. By paying out the tape at the windlass the lower arm swings down with the lamp attached. The wires from the circuit are first carried to a series cut-ont on the post, from thence through the movable arm to the lamp. In dropping the lamp for trimming, the circuit is entirely cut off, making it absolute safe to handle. The windlass is boxed in to present trouble from storms, and the bronze tape runs in a cleat down the pole. The company has also a mast arm for use on streets where there are trolleys; the lamp is in this case drawn in to the pole on the same level by means of an endless cable the circuit wires being looped for that purpose. The company orns numerous patents on and is making a specialty of these devices.

\section{The Electricity Building Gallery Exhibitors' Club.}

During the past week an organization has been perfected of the exhibitors in the galleries of the Electricity Building. It is called the Electricity Building Gallery Exhibitors' Club, and the object of it as stated is to advance the interests of the gallery exhibitors.

The officers are: President, Thomas R. Lombard, of the North American Phonograph Co.; Vice President, C. E. Lee, Chicago; Secretary and Treasurer, M. J. Sullivau, of the Electrical World. At a meeting on Monday afternoon a resolution was passed that members should contribute five dollars each to the treasury for a preliminary fund for immediate expenses, and committees were appointed as follows: General Committee: C. E. Lee, George Clark, Herr Lobach, M. J. Sullivan, Dr. A. Owen. Committee on eutertainment: Dr. Waite, E. Nashold, Prof. J. P. Barrett, Mr. Eckert, Dr, A, Orren. Committee to confer with American Exhibitors' Association: Lieut. E. J. Spencer, M. J. Sullivan, C. C. Breekner. 


\section{WORLD'S FAIR NOTES.}

The exhibit of the Newark factory of the Westinghouse Company is fast approaching completion and by the miclle of next week will be in rery good shape.

During the severe storm of Thursday last lightning struck the top of the northeast tower of Machinery Hall tearing the staff off for a considerable distance.

The Equitable Mannfacturing and Electric Company is showing an exhibit of printing telegraphs in the gallery of the Electricity Builling under the big Westinghouse sign.

Much interest is still manifested in the British Post office exhibit and Mr. Chapman, who is in charge, is kept constantly busy explaining the different pieces of aplaratus to interested listeners.

In order to have some repairs made the Wellington restaurant in the west gallery of the Electricity Builuing has heen closed for the present. This restaurant has been one of the most popular on the grounds.

The Excelsior Electric Company has nearly eompleted its exhibit. The decorative arrangement of fancy colored lamps and moving illuminated signs will probably be en tirely complete by the end of this week.

Mr. E. Nashold, western manager of the Electric Heat Alarm Company, has added new decorations to his exhibit in the west gallery. A canopy over the top with neatly Iraped curtains at the sides and an electric fan has made the booth attractive and comfortable.

\section{Jury of Awards Department of Electricity.}

About one half the total number of judiges for the Depart ment of Electricity have now been confirmed. The names are as follows:

Heury S. Carhart, University of Michigan.

Harris J. Ryan, Cornell Iniversity, Ithaca, N. Y.

Benj. F. Thomas, (thio State University, Columbus.

(reo. F. Barker, University of Pennsylvania, Philadelphia.

T. C. Mendenhall, United States Coast and Geodetic Survey, Washington, D.C.

Robt. B. Owens, University of Nebraska, Lincoln.

II. O'Dea, Notre Dame, Ind.

IV. M. Stine, Chicago.

Sam'l Reber, U. S. Army.

Henry A. Rowland, Johns-Hopkins Lniversity, Baltimore. E. P. Warner, Chicago.

Dr. Chas. E. Emery, New York City.

A. E. Dolhear, Tuft's College, Mass.

IV. E. Ayrton, F. R. S., London.

Geo. Forbes, M. A., F. R. S., London,

Director Rathenau, Berlin.

Daurath Clbricht, Berlin.

Pierre Dehausse, Belgium.

Wm. Shrader, Cniversity of Missouri.

S. Brown Ayres, Tulane University, Louisiana.

D. C. Jackson, University of Wisconsin Madison.

S. Thompkins, Clemson College, S. C.

R. II. Pope, Sec. Am. Inst. E. E.

An informal meeting of the jury was held at "2 o'clock Monday afternoon in the office of Prof. Barrett, nine members being present. The meeting was called to order by Dr. Hornsby, who acted as temporary chairman, and a general discussion of methods of procedure took place. It was decicted that the president of the jury should be an American and that two rice-presidents shall be chosen, one. of whom should be English and the other German, Other officers were not decided on, and the candidates were not discussed.

\section{How the Writing is Done.}

In the crowd in front of the "W. E. Co." writing machine there is always some one ready to explain its operation. The following explanations were orerheard in the course of an hour the other evening:

"O! Mr. Smith! isn't that perfectly lovely? I wonder how that funny little pointer lights those lamps."

"Why, Miss Jones, that pointer doesu't light the lamps. It doesn't touch them. I saw how it was done the first time."

"O! please tell me; I'm just dying to know."

"Well, the stick doesn't light the lamps but the current that lights the lamps makes the stick move. You know that a current of electricity will attract a magnet; just as in the telephone. When you talk into a telephone you turn the crank a while first; that charges the wire with electricity. When you talk, the vibrations of the air cause the electricity charged into the wire to ribrate too. The diaphragm at theother end is a magnet, and as the electricity in the wire vibrates the magnetic diaphragm is attracter and repelled; it follows the morements of the sharged electricity exactly and so produces the sound. Now, in this case, there is a magnet in the end of the stick. As the current is turned on to light the lamps it passes along from one lampl to another and the magnet is attracted and follows the current, and that is what makes the pointer follow the letters."

"O, I see now; but I thought electricity went faster than that."

"So it does, normally. But when we pass it through an apparatus called a rheostat it absorbs so many lines of force that it is retarded. You saw the rheostat over by the column that retarded the lightning there."

"Perhaps they do that by a brush clischarge from the end of the pointer. It could be done that way easily enough; but I think more likely it is a chemical process, because you see the wires on the back of the frame are painted with something. The stick may contain another chemical, or more likely is hollow and the chemical in the form of gas is blown through it against the chemical on the wires and so current enough is generated to light the lamps."

"Yes, I see: it could be lone that way; but how does the stick put the lights out when it goes back?"

"There is probably an automatic device to reverse the current when it goes back."

"O, aunt Mary! you must see this! see! it looks as if that pointer lighted the lamps but it don't. George read all about it to me out of a paper the other day; that box is full of cans and things and the electricity goes through the eans before it gets to the lights and the pointer doesn't have anything to do with it at all."

"Say, Mickey, tell us what makes de stick go:"

"O, I'm onto it; dere's a kid in de box w'at wiggles de stick, see?"

"Aw, come off; de kid couldn't do it all day; he'd be tired."

"Say, you make's me tired; dere's a hole in tle floor, and w'en de kid is tired he goes down and anoder one comes up, see?" 


\section{PERSONAL.}

Prof. George Forbes, of London, is registered at the Victoria Hotel.

Prof. and Mrs. Harris J. Ryan, of Cornell University, are visiting the Fair.

Mr. Walter L. Flower, of the Acme Filter Company, St, Louis, is visiting the Fair this week.

Mr. C. F. Scott, of the Westinghouse Company, Pittsburgh, is visiting the Fair with his family.

Prof. W. E. Ayrton, of London, arrived Monday, in time for the first meeting of the Jury of Awards.

Mr. Wellington W. Cummer, of the Cadillac (Mich.) Electric Light Company, and family were at the Fair last week.

Mr. Thos. W. Stewart, of the Thackara Manufacturing Company, Philadelphia, was a visitor at the Exposition last week.

Prof. Benj. F. Thomas, of the Ohio State University, is in the city to visit the Fair and attend the meetings of the Jury of Awards.

Mr. S. A. Drake, superintendent of the People's Gas \& Electric Light Company, Canton, Ill., is spending a few days at the Fair with his family.

Mr. A. A. Dion, superintendent and electrician of the Chaudiere Electric Light and Power Company, of Ottawa, Ont., is visiting the Exposition.

Mr. Clarence J. Reddig, treasurer of the Shippensburg Electric Light Company, of Shippenshurg, Pa., while doing the Fair last week, called on Electrical Industries.

Mr. Fred. A. Gilbert, of the Boston Electric Light Company, is spending a couple of weeks at the Fair and making a special study of the exhibits in the Electricity building.

Col. Henry S. Kearney, engineer of the New York Board of Electrical Control, is visiting the Fair and devoting a considerable time to the Electrical features of the Exposition.

Dr. Charles E. Emery, of New York, is visiting the Exposition and also attending the meetings of the Jury of Awards. The Department of Electricity should be congratulated on securing the services of Dr. Emery on the jury.

\section{DEPARIMENT OF ELECTRICITY.}

OFFICES: SECTION $R$, ELECTRICITY BUILDING.

Chief, JoHn P. BaRrett,

Assistant Chief, J. Allen Hornsby

General Superintendent, J. W. BLAESDELX.

Electrical Engineer, W. WV. Primar

\section{DEPARTMENT UF MECHANICAL AND ELECTRI AL ENGINEERING.}

OFFICES SOUTH OF MACHINERY HALL.

Mechanical Engineer, C. F. Fosten

Electrical Engineer, R. H. Pierce.

First Asst. Mechanical Engineer, JoHN -MEADEN.

First Asst. Electrical Engineer, S. G. Neller.

\section{AMERICAN INSTITUTE UF ELECTRLCAL ENGINEERS.}

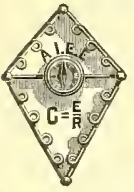

World's Fair Headquarters, SECTION S, ELECTRICITY BUILDING.

\section{RALPH W. POPE, Seeretary.}

Open from 9 a.m. to 5 p.m.

\section{CHICAGO WORLD'S CONGRESS OF ELECTRICIANS.}

OPENING BEXSION, MONDAT, AUGUST 21ST, 3 P, M ADVISORY COUNCIL.

President, DR. Elisha GraY, Highland Park, Ill.

Secretary, Prof. H. S. CARHART, Ann Arbor, Mich. EXECUTIVE COMMITTE.

Chairman, Prof. Elihu Thomsox, Lynn, Mass. COMMTTEE ON INVITATIONS.

Chairman, T. Commerford MArtin, 203 Broadway, New York. COMMITTEE ON PROORAM.

Chairman, Prof. T. C. Mendenhali, Washington, D. C, COMMITTEE ON FINANCE.

Chairman, B. E. SUnNy, I75 Adams Street, Chicago,
BUSINESS NOTES.

The Chicago Electric Wire Company has secured from the goverument a contract for the wire for the submarine cables to be attached to the automobile torpedoes which are being tested at Willetts Point, N. Y. The contract calls for the expendlture of $\$ 75,000$. This contract will take from one to two months to complete, and will require the uninterrupted work of the factory.

The Erectrical appliance Company report that it is very interesting to note the way in which the orders commence to pour in for Meston fan motors after a few consecutive hot days. It has already sold several hundred of these machines and is filling large orders every day for country as well as city trade. A very large number is now in use at the Fair and the Electric Appliance Company expects to have several hundred motors installed there before the fan season is over.

The Electrical Enerneering Company, St. Louis, Mo., through its manager, Mr. E. G. Bruckman, has been awarded the contract for the installation of the electric light work of the new Union Depot at St. Louis. This depot is one of the largest of its kind and the electrical work is of correspondingly large size. The contraet for some 6,000 lights required in the Union Trust Company's new building has also been awarded to the same company.

\section{Amusements.}

Hooley's Theater-Mr. E. S. Willard, in "The Middleman." Saturuay evening, "The Professor's Love Story." 149 Randolph street.

Coldmata Theater-Miss Lillian Russell, in "La Cigale." 108 Monroe street.

Grand Opera House - Sol Smith Russell, in "A Poor Relation. 87 Clark street."

Audtoriun-Imre Kiralfy's Spectacle "America." Congress street and Wabash avenue.

MoVicker's Theater-Denman Thomson, in "The Old Homestead." 82 Madison street.

Chicago Opera Hodse-American Extravaganza Company, in "Ali Baba, or Morgiana and the Forty Thieves." Eighth week. Washington and Clark streets.

Schiller Theater-Chas. Frohman's Stock Company, in "The Girl I Left Behind Me." Eighth week. Randolph, near Dearborn.

Haverly's Casino-Haverly's United Minstrels. Wabash avenue, near Jackson street.

Trocadero-Concert. Michigan avenue near Monroe street. The Grotro-Vaudeville. Michigan avenue near Monroe street.

Buffalo Bill's "Wild West." 63d street. Daily at 3 and 8.30 p.m.

Pain's "Siege of Sebastopol," 60th street and Cottage Grove avenue. Tuesday, Thursday and Sunday nights.

This week Mr. Willard has returned to "The Middleman," with the exception of Saturday night, when he will appear in "The Professor's Love Story." The cast is the same as that of six weeks ago and the reappearance of this play has been greatly appreciated.

"A Poor Relation," in which Mr. Russell appears this week, has proved, it is said, to have been the most satisfactory in $\mathrm{Mr}$. Russell's repertoire. This comedy was written by E. E. Kidder and has never failed to receive a large patronage.

Various scenes in "Ali Baba" seem to render it especially adapted for the summer season. The waterfalls, the forests, and caves, the moonlit garden, and other suggestions of cool retreats, seem to modify through the imagination the heat of the body. The American Extravaganza Company has done much toward making Chicago a profitable place during the summer, having opened the summer season seven years ago with the production of "Arabian Nights."

The great popularity of the spectacle "America" was shown last week when on the hottest nights of the season the theater was filled. Every World's Fair visitor comes with at least one evening reserved for seeing this spectacle, it has become so generally recognized as one of the great attractions of the World's Fair season. The Schaffers still hold the highest place in public favor. Persons present at the Wednesday matinee were fittingly reminded of the 100 th performance by a handsome souvenir. 


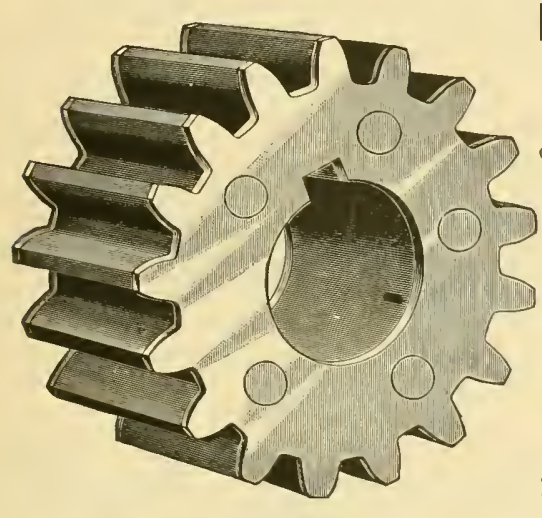

RAWHIDE PINIONS FOR ELEGTRIC MOTORS A SPECIALTY.

RAWHIDE DYNAMO BELTING

Greatest Adhesive Qualities. A Non-Conductor of Electriclty. Causes Less Friction than any other Belt.

THE CHIGAGO RAWHIDE MANUFACTURING CO. THE ONLY MANUFACTURERS IN THE COUNTRY.

LACE LEATHER ROPE
ND OTHER RAWHIDE
GOODS
OF ALL KINDS
BY KRUEGER'S PATENT

75 Ohio Street,

\title{
Standard Electric Company.
}

GENERAL OFFICES: 625 Home Insurance Building.

WORKS: So. Canal Street,

\section{CHICACO.}

\section{STANDARD \\ AT THE

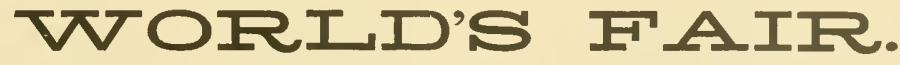

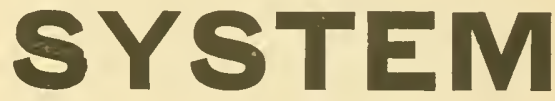

MACHINERY HALL, Sec. Q, 2 Standard Arc Dynamos.

\author{
Sec. S, 20 " " "
}

ELECTRICITY BUILDING, Sec. P, Space 2, Arc Lighting Exhibit.

The Standard Lamps Light the Power Plant, Machinery Hall, Agricuitural Hall, Shoe and Leather Building, and Other Buildings and Portions of the Grounds. 
ELECTRICITY BUILDING-EXHIBITORS AND THEIR LOCATION.
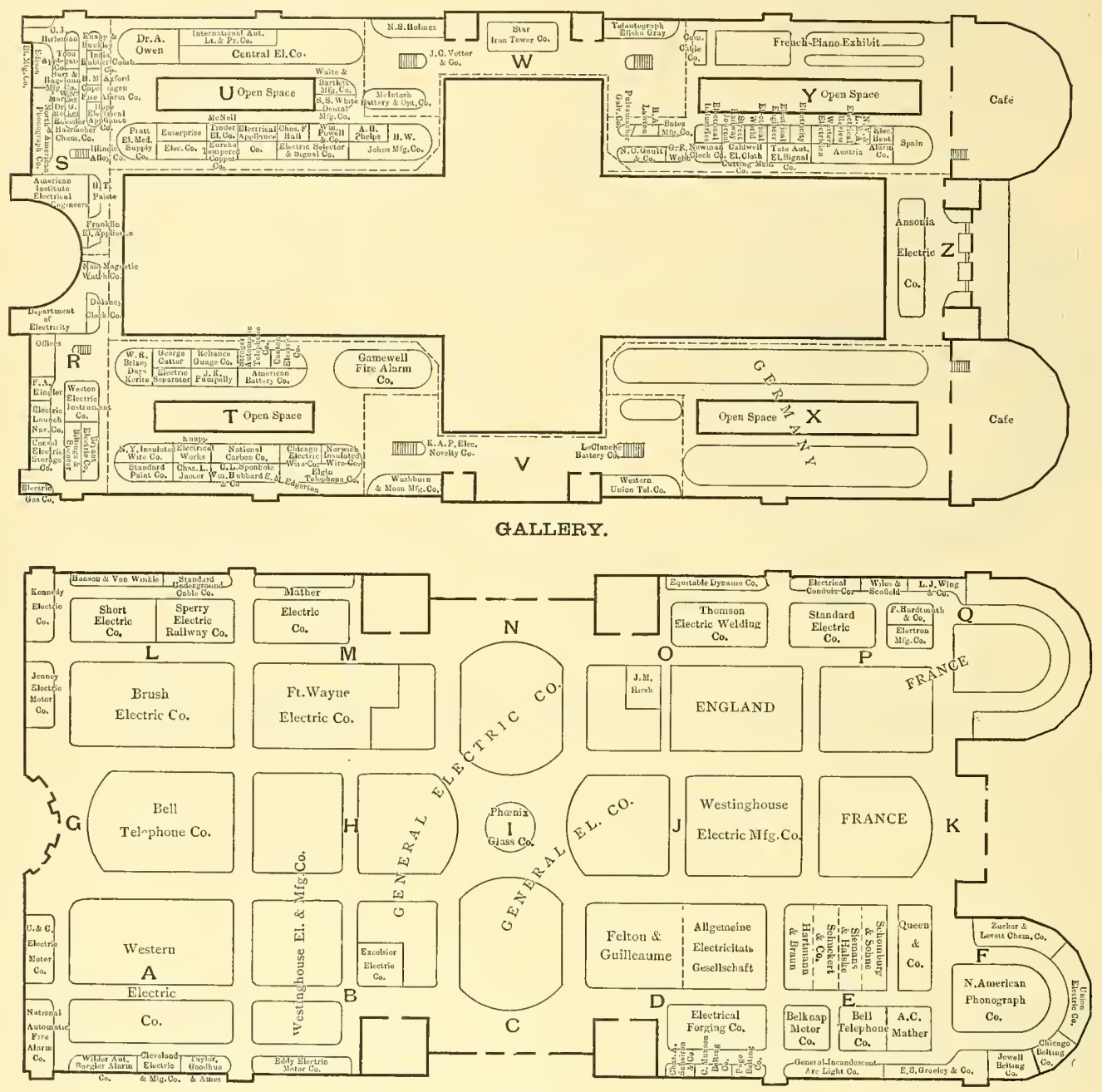

MAIN FLOOR.

Exhibitor.

Aneonja Ejectrie Co...........

American Battery Co. Eng.

Axford, H. M.

Allg. Elec. Gesellechaft.

Bryant Electric Co

Billinge \& Spence

Brixey, W. R....

Bell Telephone Co.

Braeh Electric Co

Co

Cutter, George

Chican Elec. Wire C.......

Copenhagen H'je Alarm Co

Central Electric Co

commercial cable co...

C. \& C. E ec. Motor Co

Chicago Belting Co

Dulaney Clock Co.

Department of Electricity...

ELECTRICAI, INDURTRIES

Elec. Launch \& Nav. Co...

Electric Separator.

Elgia Telephone Co

Enterprize Elec. Co.

Enreka Temp. Copper

Electric A ppliance Co

Elec. Sel. \& Sig'] Co.
Exbibitor.

Electricity...

Electrical Engi.....

Electrical World

Eddy Electric Motor C.

Exceleior Electric Co...

Equitable Dynamo Co..

Elektron Míg, Co........

England

Franklin Elec. Appliance.

rench Piano Exhibit.

France \& Guilleaume.

Ft. Wayue Elec. Co

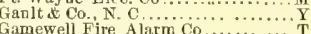

Gameral Electric Co.... B-H-Ÿ-C-\& J

General Inrand' 'A't Arc L't Co

Greeley, E. S. \& Co

Hobbard, Ww., \& Co

Hart \& Hegeman ilig.

Hope Elec. Appliance Co.

Hall, Chas. H.

Holmes, N. S ...........

Hartman \& Brauu...

Hardtmuth $\mathrm{F}$ co

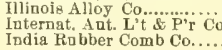

Section. Exribitor.

Sectiou,
Jaeger, Chan, L...................

Jewell Belting Co

T. uney Elec. Motor Co.

Knapp Electrical Works......

T. A. P. Elec. Novel

Kennedy Electric co

Law ton, $\mathbf{H}$.

LeClanche Battery co.

McNeil-Tinder Elec. Co...

Marcoe, W. N

Meeker, Dr. G....................

Mnnoon, C. Belting Co

Taron, $\mathrm{C}$

Mather Electric Co.

Nou-M $\rightarrow$ gnetic Watch Co.

N. Y. Inealated Wire Co...

National Carbon Co...

Norwich Ins. Wire Co.............

N. $Y$. A.

Nat. Ant. Fire Alarm Co.

Nat. Engraving Machine Co...

Owen, Dr. A....

Paiste, H.

Pulvermacher Galv, Co.

Pumpelly . K K .............

Pratt El. Med. Sup. Co
Powell, Wm. Co...

Phelps, A. H ...

Page Belting $\mathrm{C}$

Queen \& Co
Exhibitor. "Section. Reliance G uage Co................. . . Street Rail way Journal.............. Y sar fron Tower Con..............

chieren, Chą. A. \& Co ................ ...........E Siemente sohn

chuckert \& Co

perry Elec. Railway Co...... Standard Underg. Cable Co........... L Samson Battery Co ....................... Tate Aut. El. Sigual Co .............. Taylor, Goodhue $\$$ Ame............... Thomson Elec. Welding Co Telantograph, Elisha Gray ........W Cuioo Electric Co Weber $\mathrm{C}$. \& Co. Weston El. Iustrument Co..............

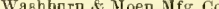

Westeru Union Tel, Co

Waite \& Bartlett Mrg, Co...

White, S. S., Dental MIfg. Co......... Wilder Aut Burglar Ai. Co..............

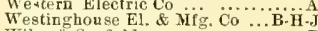
Wilee $\&$ Scofield .................. Wing, L. J , \& Co.............. P 


\section{ELECTRICAL SUPPLIES}

We confine our attention entirely and strictly to electrical supplies. We are

\section{NOT COMPETING}

with our own trade in the sale cf electrical machinery or in electrical contracting.

\section{ELECTRIC APPLIANCE COMPANY, 242 Madison Street, CHICAGO.}

We are thus enabled to be more in sympathy with the trade and by giving entire attention to one line of the business can secure more satisfactory results for ourselves and our customers than would be attained by trying to spread ourselves over every department of the electrical field.

\section{ELECTRICAL SUPPLIES.}

\section{THE MATHER ELECTRIC CO, THE "NOVAK" LAMP.}

MANCHESTER, CONN.

Dynamos, Motors, Generertors,

Offices, 116 Bedford St., BOSTON.

CLAFLIN \& KIMBALL (Inc.)

Ceneral Selling Agents.

116 Bedford Street, BOSTON.

1002 Chamber of Commerce BIdg., CHICAGO. 1002 Chamber of Commerce Bldg., CHICAGO.

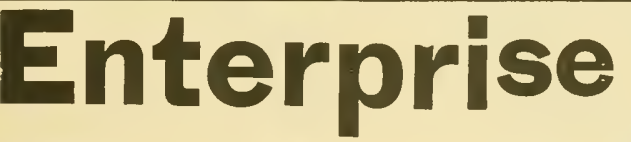

Electric

\section{Company}

307 Dearborn Street, Chicago ....

Manufacturers' Agents and Mill Representatives for

Electric Railway, Telegraph, Telephone and Electric Light SUPPLIES

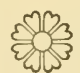

Agents for

Cedar Poles,

Cypress Poles, Oak Pins, Locust Pins, Cruss Arms, Glass - Feeder Wire, Insulators,

WIRES, CABLES, TAPE and TUBING

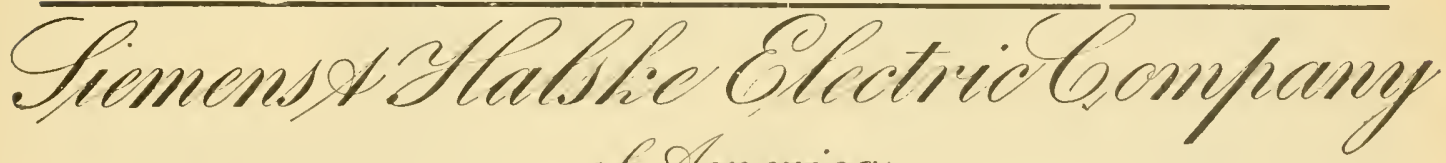

of America:

Colicio<smiles>C#CCC#C[Te]</smiles>

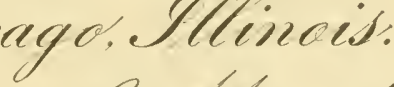
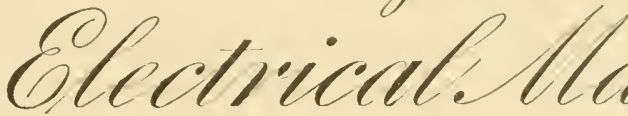


\section{Map of Chicago.}

Showing Location of its Electrical and Allied Business Interests, Principal Hotels, Theatres, Depots and Transportation Lines to the World's Fair Grounds. (Index numbers refer to the black squares.)

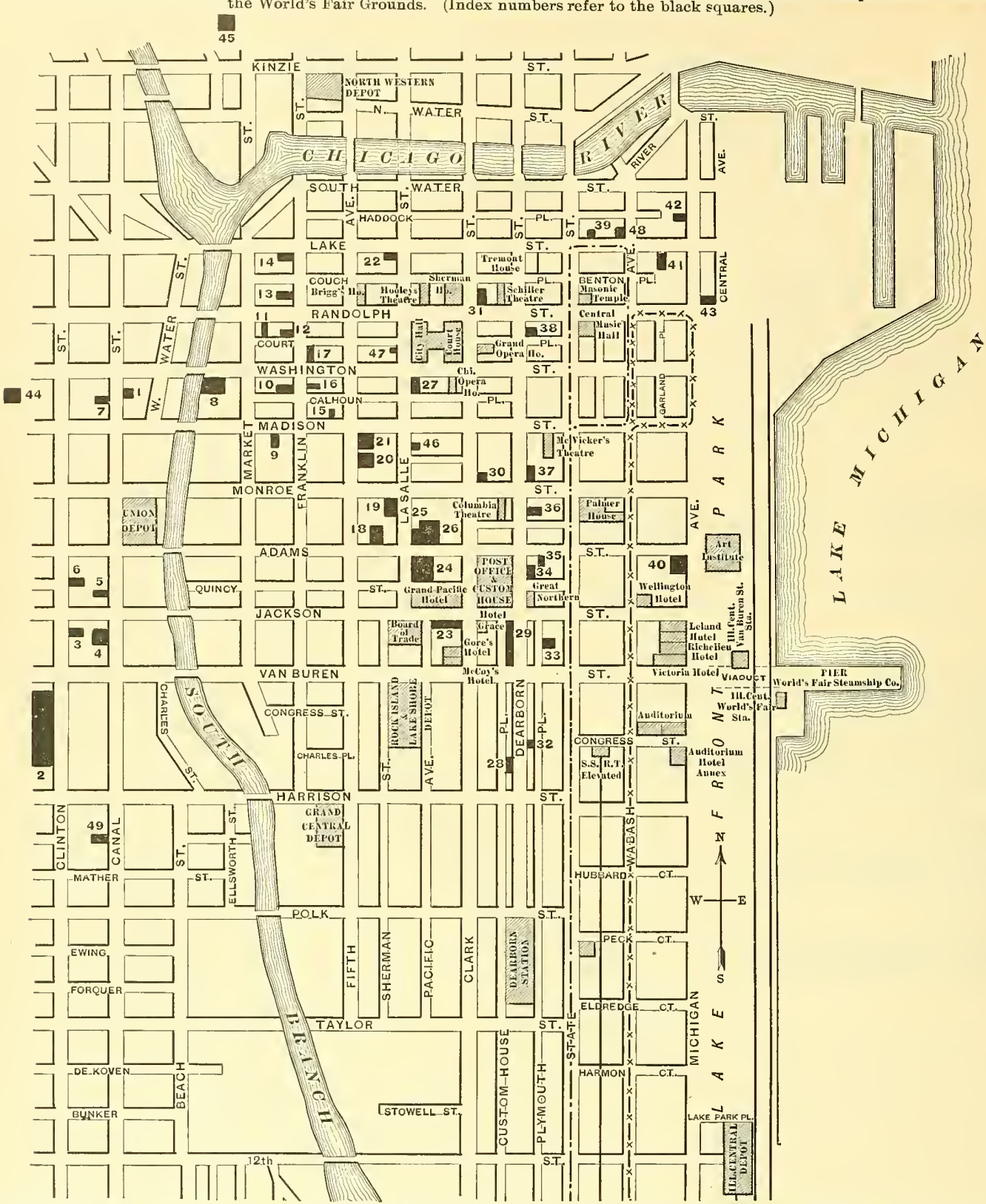

Ansonia Elec Co., Micbigan Ave, \& Randolpb St...34 Cushing \& Morse, 225 Dearborn St.

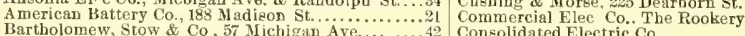
Barton \& Brown, 1428 Monad Michigan Aveck Block.

Benham, A. D., $200 \mathrm{~S}$. Clinton St.
Brill Co., J. G., Phenix Bldg.........

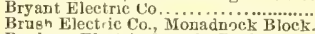

Bnckeye Electric Co.. 437 Rookery Bld

Calwmet Electric Mfg. \& Engineering Co., $17 \%$ S

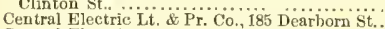

42 Consolidated Electric Co

Co. 201 Madian St.

Detroit Eloctricaphone Co., Stock Exchange Bld

Edwards, W. S. Mfg. Co., 21 Lake St.

34 McDongall \& Cumminge, Cnity Bldg.............. 38 24 McLean \& Schmitt, 195 S. Canal St............... 4 16 Mather Elec. Co., Chamber of Commerce Bldg......27 5 New York Inenlated Wire Co., 80 Frankln St........ 12 Electric Constrnction \& S17 Monadnock Block.......29 Pumpelly, J. K., 205 S. Canal St.....................49 \begin{tabular}{|l|l|l} 
Electric Constrnction \& Supply Co., Unity Bldg....38 & Phoenix Glass Co., Wabash Ave. and Lake St......48 \\
Electric Appliance Co., 242 Madion St.......... & Railway Equipment Co. Pullman Bldg.. ........40
\end{tabular} ELzctrical lndustries PuB Co., Monadock Block. 10 Ft Wayne Flec Co. 185 Denrborn St.....

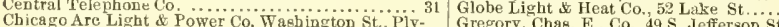
Chicago Arc Light \& Power Co, Washington St., Ply- Gregory, Chas, E.. Co., 49 S. Jefferson St.

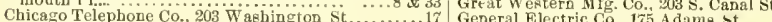

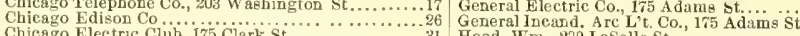

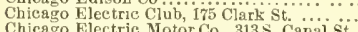

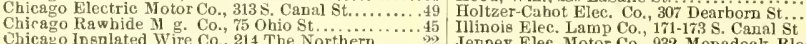
Holtzer-Cahot Elec. Co., 307 Dearbo.m St Chieago Insalated Wire Co., 214 The Northern........22 Jenney Elec. Motor Co, 932 Monadoek Block. Claflin Jimball, 1001 Chamber of Commerce Bldg.27 Keystone Elec. Co., 345 S. Canal St. \begin{tabular}{l|l} 
Cutter, Geo., 851 The Rookery.......................24 & Kohler Brog., 1417 Mlonadock Block.
\end{tabular}

Rockford Elec. \& 1 fo. Co., 94 La Salle St............. Standard Elec. Co., 625 Home Ins. Bldg.........25
Siemens-Halske Elee. Co., 1225 Monadnock Block..29 Star Elec. Lamp Co, 805 Chamber of Com. Bldg.....27 44 Stirling Co, 606 Pnllman Bldg....................40 49 Schieren, Chas. A., \& Co., 46 \$. Canal St.......... 1 Short Elec. Railway Co. Monadnock Block $\ldots . . . . . .29$
Trylor, Goodhue \& Ames, 348 Dearborn St........28 Todd. Applegate Co., The, 340 Dearborn St..........28 Westenti...... Westers Electric Co., 227 S. Ċlinton St 49 Wollensak, J. F, Lake and Frauklin St8............... 


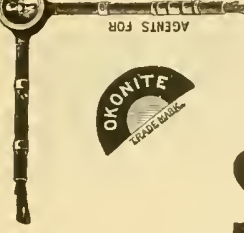

\section{- Lundell-}

Suspended Fan Outfit

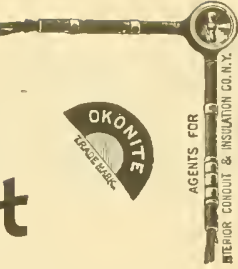

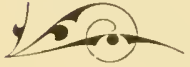

Black

Japan

Finish

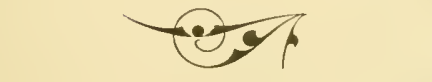

Electric Fans

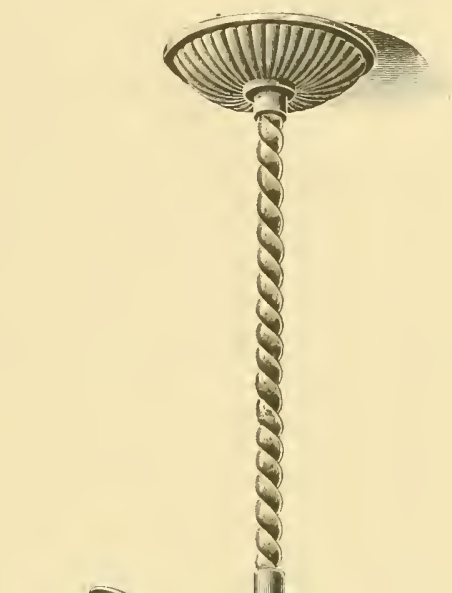

Self-0iling ....and

Self-Aligning Bearings

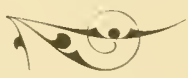

\section{Electric Fans}

OKONITE WIRES

\section{OKONITE $\overline{\text { TAPES }} \overline{\text { MANSON }}$ INTERIOR CONDUIT.}

Batteries, Bells, Push Buttons, Annunciators, Volt Meters, Ammeters, Wheatstone Bridges, Line Wire Cross Arms, Brackets, Pins, Insulators, Tools.
GENERA
AL
SUP
PLIES. 


\section{Books for Electrical Men.}

THE MEASUREMENTS of ELECTRICAL CURRENTS and OTHER ADVANCED PRIMERS of ELECTRICITY by Edwin J. Houston, A. M., 429 pages, 169 illustrations, price \$1. An elementary electrical treatise for students and non-technical readers giving in simple but exact terms the principles and apparatus upon which are based the practical operations of electrical measurements.

PATENTABLE INVENTION by EDW. S. RENWICK. A brief and concise summary giving the Law of Patents for inventions. An invaluable work of reference for every inventor. Bound in Sheep, price $\$ 2.00$.

THE ELECTRIC RAILWAY in THEORY and PRACTICE by O. T. Crosby and Dr. Louis Bell. Second edition revised and enlarged. 416 pages, 182 illustrations. Price \$2.50. A practical work on the electric railway that should be in the hands of every railway man.

ELECTRICITY and MAGNETISM by Prof. Edwin J. Houston, A. M. 306 pages, 116 illustrations. Price $\$ 1$.

\section{ANY OF THE ABOVE WORKS SENT POSTPAID ON RECEIPT OF PRICE,}

\section{Electrical Industries Publishing Co. Monadnock Block, CHICAGO.}




\section{Western Electric Company, CHICACO. NEW YORK.}

Arc Lighting Apparatus

High and Low Tension,

Double and Single Service Lamps,

All Night Single Lamps,

Theater and Focusing Lamps.

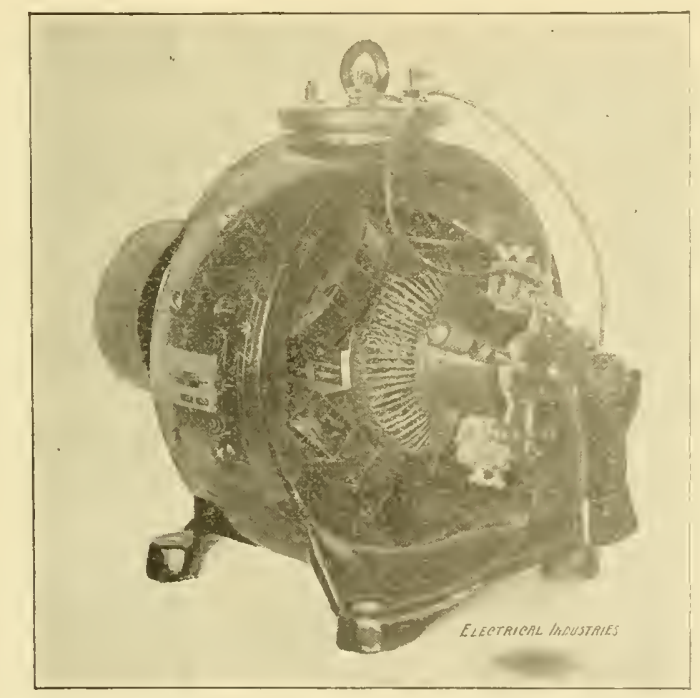

\section{ELECTRIC MOTORS}

FIGFI SPEFD

VARIAB工E SPFED

SLOW SPEFD.

BUILT FOR SEVERE AND CONTINUOUS SERVICE, SPECIAL TYPES FOR SPECIAL DUTY, 


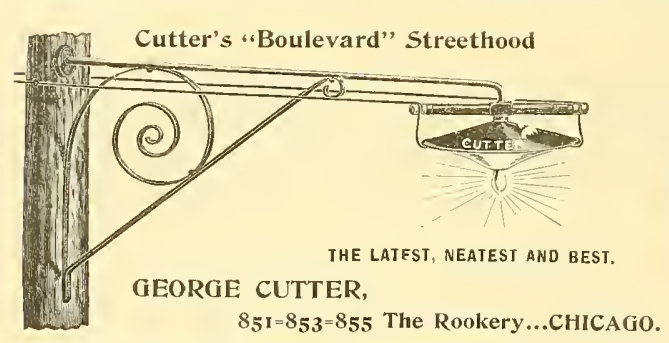

\section{SIMPLEX WIRES}

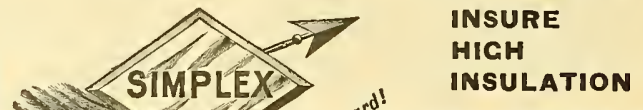

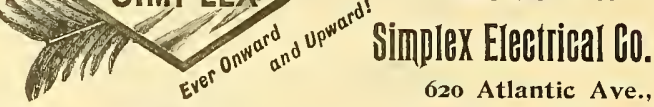

George Cutter, Chicago. Boston, MAss.

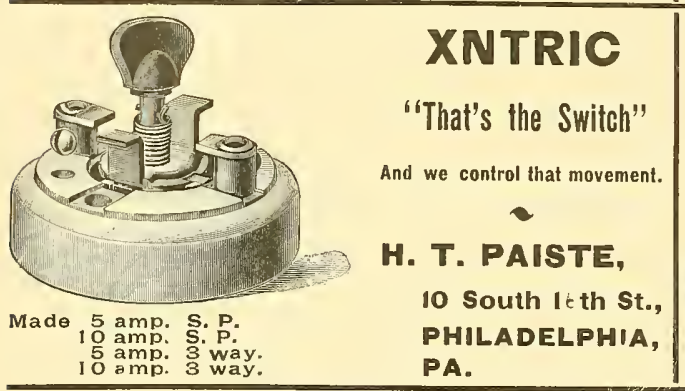

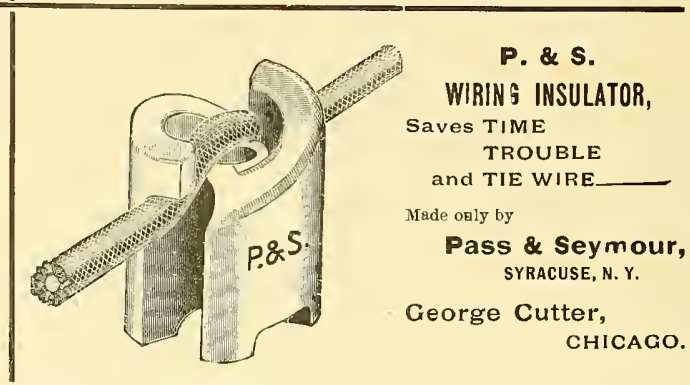

Consolidated Elpctric 6.

Manulaclurers and Dealers in all kinds of

\section{ELECTRICAL . SUPPLIES,}

115 Franklin Street,

CHICACO.

GEORGF PORTER, Contractor for All Kinds of

ELECTRICAL WORK.

Room 67, 143 La Salle St., CHICAGO. Crary Block, BOONE, IOWA.

\section{CHAS. A. SCHIEREN \& CO,} manUfactuners OF

\section{Genuine Perforated Electric Leather Belting.}

46 So. Canal Street, - CHICACO.

Section 15, Dpt. F. CIm. 27.

MACHINERY HALL.
Section D, Space 3 ELECTRICITY BUILDING.

\section{J. HOLT GATES,} Manager Western Dept.

\section{THE WADDELL-ENTZ CO.} MULTIPOLAR

DIRECT CONNECTED DYNAMOS. SLOW SPEED MOTORS.

II22 Monadnock Block, - CHICAGO.

\section{WAGNER ELECTRIC FAN MOTORS}

For Divect or Alternating Currents.

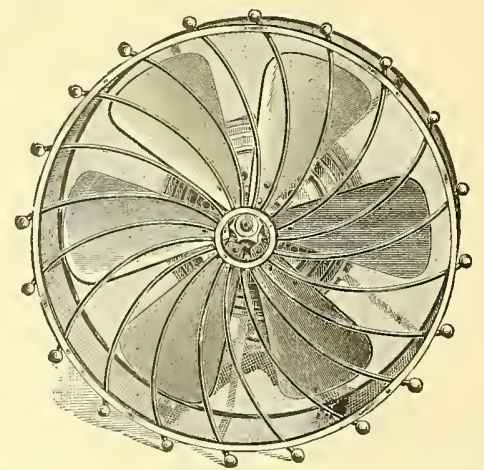

These motors give a strorger breeze with less cossumption of carrent thas any other fau motor on the market. They are fnll 1.8 horse power. Six bladed IT WILL. PAY YOU TO SEE JHE WAGNER BEFORE BUYING ELSEWHERE.

TAYLOR, GOODHUE \& AMES, 348 Dearborn Street, CHICAGO.

See Our Exhibit of ELECTRICAL FIXTURES

IN SECTION "N", BETWEEN COLUMNS 62 AND 64, MANUFACTURES BUILDING,

GLOBE LIGHT \& HEAT CO.. 52 \& 54 Lake St., CHICACO. 


\section{Weekly World's Fair Supplement.}

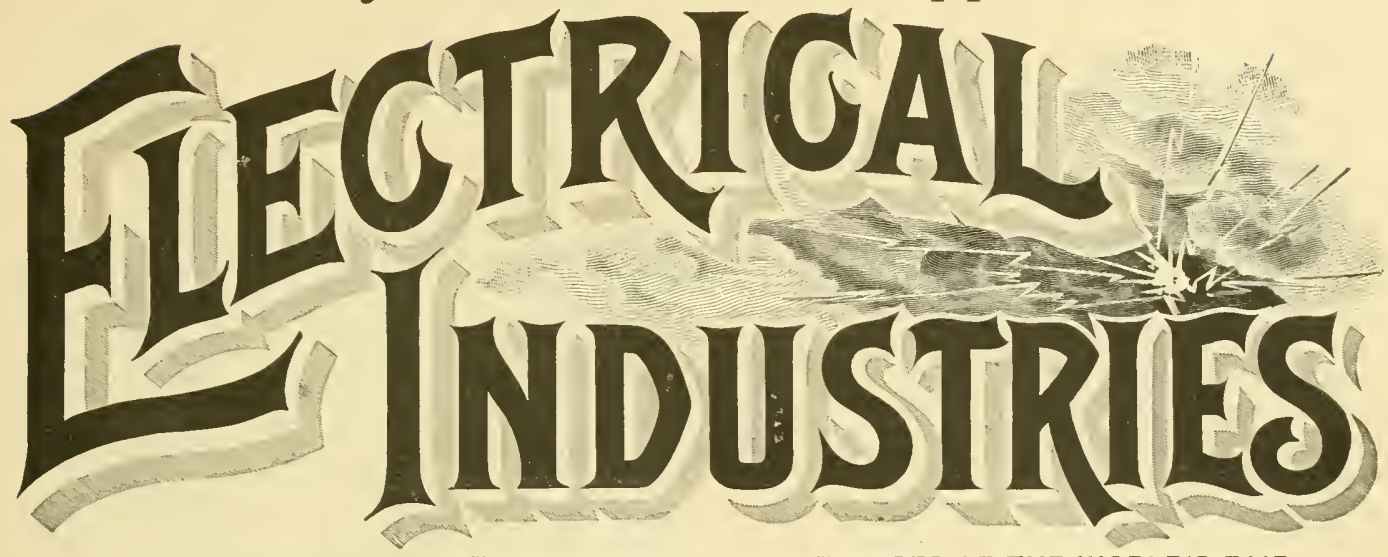

DEVOTED TO THE ELECTRICAL AND ALLIED INTERESTS OF THE WORLD'S FAIR, ITS VISITORS AND EXHIBITORS.

Vol. I, No, 7 . CHICAGO, JULY 27, 1893.

FIVE MONTHS S1.00
TEN CENTS A COPY

Exhibit of the Brush Electric Company.

This exhibit, situated just west of the temple of the Bell Telephone Co., contains representative machines and appliances manufactured by The Brush Electric Company, the
The feature of the exhibit which attracts the most attention artistically is a square temple of Grecian style of architecture, at the south end of the space. The outer surface is painted white with the lightest of blue tinted trimmings. An entrance at either encl. back of the row of Corinthian

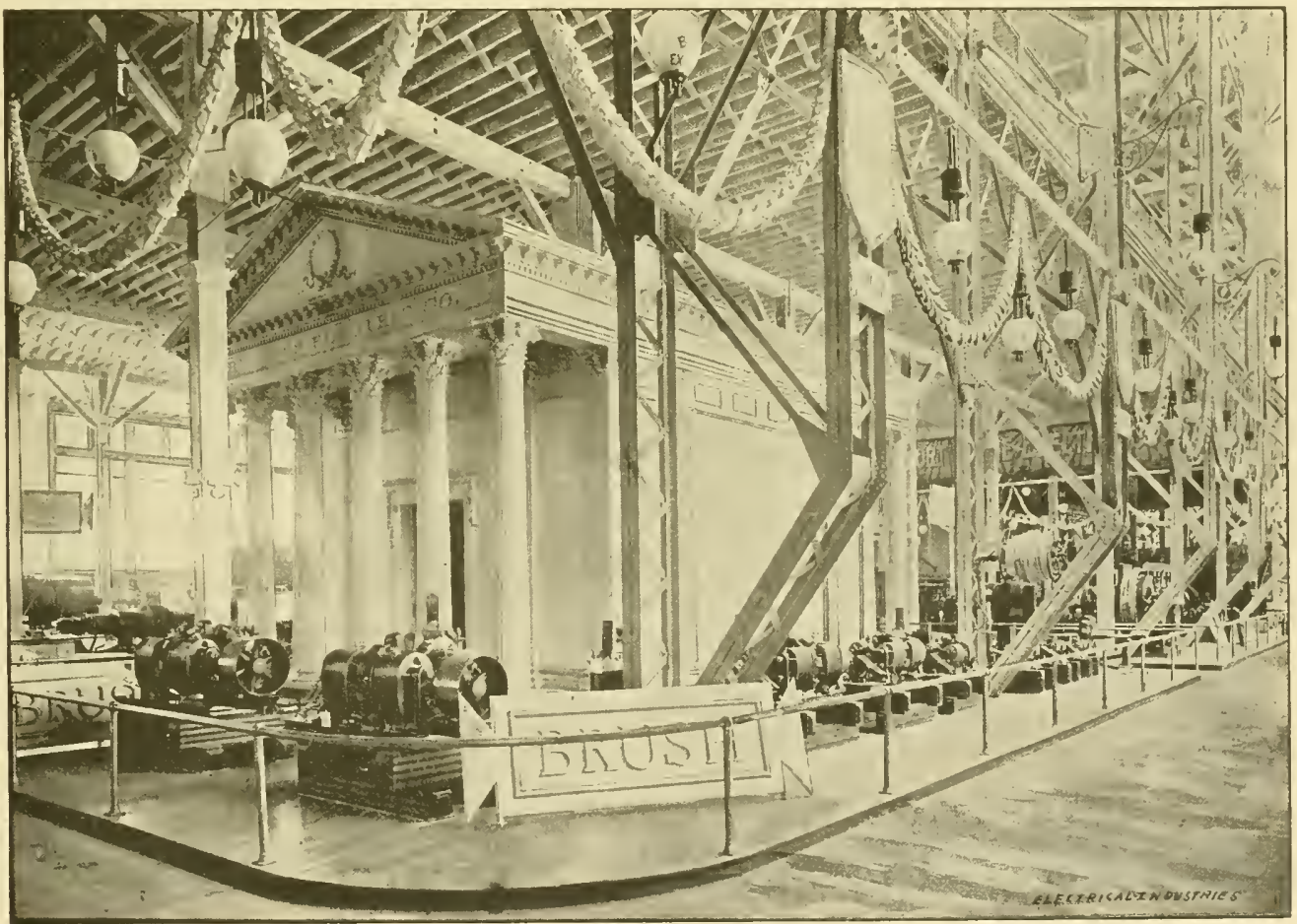

earliest in the field with practical electric lighting apparatus. Although it was in the serenties that Charles Francis Brush constructed the first are lighting dynamo bearing his name, and which by the way is exhibited here, little change is to be noted except in the substitution of a laminated armature core for one of east iron. columns supporting the roof, leads to a circular interior that is surmounted by a dome. At the right and left are doors leading to closets and store rooms. The central post supporting the donse is surroumled by an upholstered seat for the arcommodation of visitors.

The object of the peculiar shaped interior of this temple 
is to show a method for lighting theatres, churches and other large assembly rooms. Incandescent lamps are entirely concealed from view behind the frieze at the base of the dome. The light from the lamps is thrown upward on to the surface of the dome and from there disseminated throughout the room, lighting the whole interior evenly and softly.

The required effect is secured without a dazzling light tiresome to the eyes. Mr. I. R. Prentiss, who is in charge of the entire exhibit, has advocated this system of lighting for some time, and the results seem to justify him. The temple was constructed by the Henry Dibblec Company of Chicago. Without the temple on the east side of the space are displayed the eight regular sizes of Brush standard are lighting dynamos, from one light to 65 lights eapacity, each equipped with ampere meter and dial regulator. The new Brush are dynamo, ealled No. 9, having a capacity of 120 to 12510 ampere arc lamps, at 500 revolutions, will be shown coupled direct to a Willans engine, running 460 this dy namo and 20 in each half of the field. One special feature is the flexible coupling between the motor and the dynamo; while it is perfectly rigid as far as rotation is concerned it is capable of movement slightly out of line; it consists substantially of a jaw eluteh with four small teeth, two on each of the large flanges, with proper recesses to receive the teeth in the opposite flange. Another direct coupled exhibit is a 50-light are machine, connected by a flexible coupling to a 21 -inch 35 -horse power shunt wound crane motor, 220 volts, at 900 revolutions. An old No. 7 , 16-light are machine is accompanied by a letter from the former owners, saying it had been in use for 14 years with no repairs other than segments and brushes.

Other dynamos, ete., shown are: a 40-light are with 10 of the original lamps sold in 1881 and used until shipped here; a 100 kilowatt 1,000 volt constant potential dynamo, such as is used at the Calumet \& Hecla mines for furnishing current to motors for pumping purposes; a crane motor showing the design of motors made in sizes of from

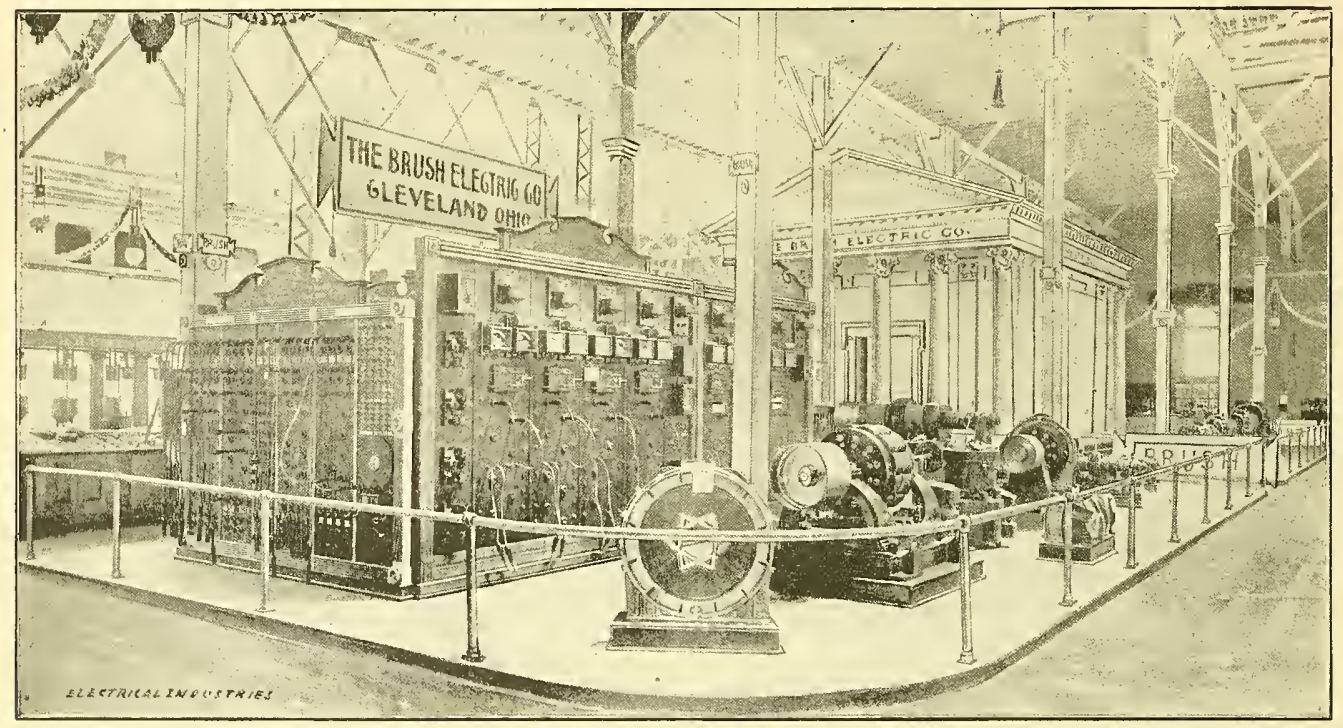

FIG. 2.-THE EXIIEIT OF THE BRUSH ELECTRIC COMIANY.

revolutions per minute and at that speed will have a capacity of 100 or more lights.

On the west side of the temple are arranged samples of the Brush direct current, constant potential, compound wound dynamos of 20,30 , 50, and 100 kilowatt capacity, the two first being 100 volts and the two latter 110 volts. While the regular copper wire brush is used on all these dynamos it is supplemented on the constant potential machines by one carbon brush in each set, which is pushed slightly forward of the others and prevents all sparking.

Another very interesting item in this exhibit is a 150 kilowatt 2,000-volt alternating dynamo of the standard Brush type with the armature coupled up to produce 110 volts for use in the exhibit at such times as it is necessary to supply current to the three wire system current for which is furnished by the Exposition at 110 volts.

This large machine is direct coupled to a 250 -horse power 220-volt brush motor, running 600 revolutions per minute, the exciter being belted from the alternating current dynamo. There are ten bolbbins in the armature of five to 33-horse power; an iron clad mining motor, 15 by 23 inches 220 volts and running 750 revolutions; a 36 kilowatt and a 60 kilowatt 2,000 volt alternating current dynamo, the armature of one being ont of the machine and the armature of the other being taken apart to show the construction. Sample converters are shown of the brush types.

In switch boards the company has a very fine exhibit, in cluding some four or five different sizes and types. The regular service board used for the exhibit is constructed of white marble on an iron frame, and has all the switches for the various motors, dynamos, lamp and power circuits used in and around the exhibit. One special feature of the board is the jointing by an iron bar of two of the regular double pole, double throw, knife switches in such a man ner that when thrown one way the incandescent lamp cireuits are joined onto the regular three wire system, and when thrown in the opposite direction cuts the same circuits onto the two wire system of the large brush alternating current dynamo in the exhibit. 
The fuses are all placed on the back of this board and consist of copper strips cut down to a width for the proper carrying capacity. The fuses are cluplex, that is, there are two, one being in circuit until blown when by putting a plug in its socket, the remaining one is cut in until the first can be replaced. There is a considerable space between

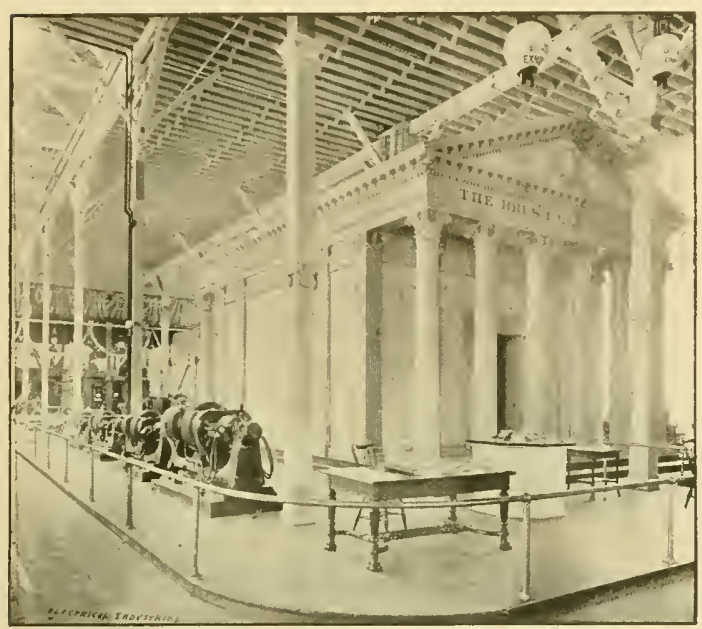

FIG. 3.-THE EXIHBIT (HF TIE BRUBH ELECTRI COMPAXY.

the front and back of this board, used in this case for making the circuit connections, and the end of the space between is taken up by a white marble arc-boarl. The io double carbon arc lamps used about the exhibit are connected from this board.
Machinery Hall. On the east side is another ase board for 36 dynamos and 36 circuits, with the regulation safety plug and eable. A ground detector is placed on one end of the board, consisting of a bank of lamps with a revolving switch or commutator for cutting them in or out individually in order to balance np against the resistance of a ground. These boards are all made in panels, each complete in itself and having all its contacts perfectly insulated from the slate by hard rubber bushing. The plug used has a substantial hard rubber handle and a long sleeve of the same material slips over the brass contact piece to protect the hand from an accidental contaet in Irawing out or pushing in the plug. The plug socket is on the back of the board and at the end of a beavy bush ing of hart rubler being joined to the other sockets and circuits by wire bush bars, the several panels being connected together in this manner. The south end of the board is used to show the different styles of panels. The center one is on hinges and swings like a door, allowing access to the interior for examination of the comnections.

On the west side of the quadrangle is a four unit alternating incandescent board capable of caring for 5,000 lights. Each panel is complete for one circuit and four machines, having a volt meter, ammeter magnetic cut out, which by the way is placed on but one leg of the circuit in this system. A ground detector at the end of the board serves for all the circuits. A larger board of this same type but of (1) unit size is placed just back of the Brush carbon exhibit across the aisle to the west. It has a set of instruments for the feeders, a set for each dynamo and a magnetic eircuit breaker for each line. The instruments for use with the dynamos placed at either end, the feeder switches and other apparatus being on the central panels. Near the center of the exhibit space is a long table or bench

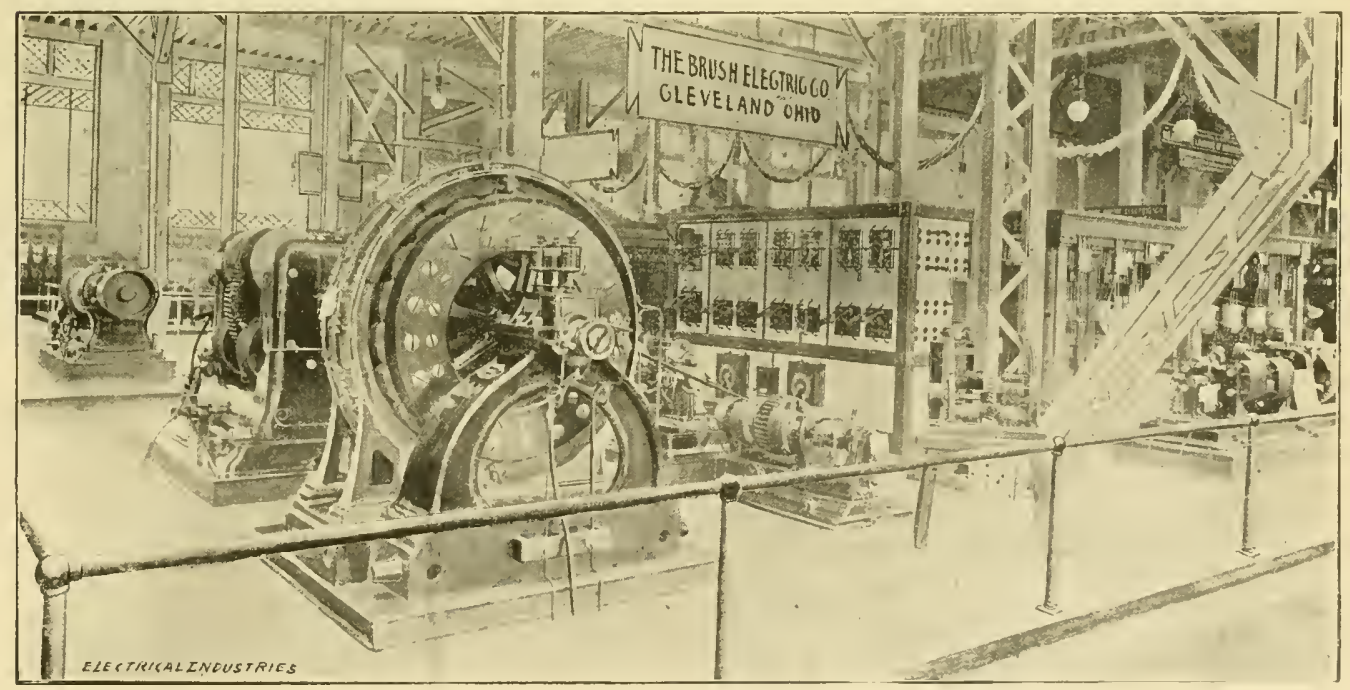

FIG 4. -THE EXHIBT OF THE RRISA ELECTRIC CWUAYY.

In special designs of standard boards, there are shown in the northwest corner of the space ty]es of the are and alternating incandescent boards of different capacities, all on black enameled slate so placed as to form the four sides of a quadrangle. On the end towarls the north is a duplicate of the are board used in the Brush service plant in covered with olive green cloth on which are displayed a number of the smaller parts of a dynamo, such as the commutator, and a lanıp unassembled. Back of this is a test rack for arc lamps, with lamps hanging in place, the sheet iron testing globe on each for allowing the are to be seen through colored glass without injury to the eyes. The 
sliding volt meter for testing the lamps to a standard is also shown.

Various other detail parts are displayed on benches, among others a commutator for a 250-horse power motor. Across the aisle to the west is the exhibit of Brush carbons including all sizes from the smallest up to those huge pieces used by the Cowles Smelting Company at Lockport, being three feet long by three inches in diameter. All are tastefully arranged in geometrical figures on a platform, with statistical tables showing growth from five millions production in 1882 to twenty-six milllions in 1892. Numerous pictures of the different forms of apparatus made by the Brush company are placed about the exhibit and handsome painted signs are suspended over each portion of the company's space. Festooned from post to post between the are lamps marking the outline of the space occupied are handsome wreaths of staff setting off the outlines. A great deal of credit is due to Mr. Prentiss for getting his display in so good shape in spite of the many difficulties in the way. The scheme of interior lighting menticned above and especially advocated by him is deserving of special attention.

\section{Electrical Exhibit of the Brazilian Government.}

The Brazilian government has recently installed a very interesting exhibit of electrical apparatus in Section $V$, of the gallery of Electricity Building. It consists mostly of telegraph instruments made at the government workshops, Rio de Janeiro, although many pieces of electrical apparatus for fire alarm, telegraph, torpedo work, and maps of the entire system of government telegraphs have been added.

The regular Morse instruments shown are finely finished and well made. Sample relays, resistance boxes, switchboards, which, by the way have all metal surfaces tinned to prevent oxidation, galvanometers and lightning arresters are displayed about the tables in the space. The naval department shows a set of instruments after the pattern of Lieut. Bradley Fisher's range finder for locating ressels over mines, with resistance boxes, testing and firing keys, also samples of electric exploders for use with mines and torpedos.

One very large map at the south end of the exhibit gives the location of all the telegraph lines now completed and under construction. Portfolios containing maps showing every section of telegraph line in the country are displayed at the table in the center. The country now has some 8,700 miles of line in operation with 17,400 miles of wire and 300 stations. Among special features is the peculiar porcelain insulator used by this government. It consists essentially of two parts, that is the insulator itself and the lead ball used to hold the same in place.

The insulator is of hard glazed porcelain with double pettycoat and secured onto an iron pin which fits into the cross-arm. The shape is somewhat like a truncated cone. In the top is a circular depression about an inch in depth and two notches are cut in opposite sides of this depression in which the circuit wire is laid. A hole in each of the other two sides at right angles with the notches serves to hold the cross-wire which is pushed through orer the circuit wire and bent at right angles at either eud.

The principal feature, however, is the lead or tin ball, about $\frac{3}{4}$-inch in diameter, which is applied to the wire in halves and being placed over the wire at the proper spot is dipped into solder and thereby securely fastened in place. The wire and ball are then dropped into place in the top of the insulator and the tie wire passed through the small holes over the ball preventing it from rising and holding the wire securely in place, the insulation being of the very best. These insnlators were made by the Siemens \& Halske Co. in Berlin; as are the caloles and many of the heavier pieces of machinery.

The booth is covered with a handsome canopy in the national colors of green and yellow and is surrounded by a substantial railing.

The decorations and arrangements reflect great credit on Capt. I. M. de Lemos Basto, the Brazilian commissioner who is also director of telegraphs in Brazil. An attendant is always at hand to explain all the interesting features of the exhibit in many languages.

\section{The Photophone.}

During the past week the American Bell Telephone Co. has been making experiments with the photophone, in the transmission of sounds by a ray of light. The transmitter placed in the west gallery of the Electricity Building was used to direct the rays into the receiver placed on the steps at the north end of the telephone temple.

The apparatus is very simple and the experiment is said to be an unqualified success. The transmitter is made up of a very thin diaphragm of glass mirror set in a brass frame, with a mouthpiece facing the silvered side. The reflecting side receives the ray of light from an are lamp directed through a strong lens. This ray is reflected from the mirror into a parabolic receiving reflector which concentrates the light on a small glass bulb filled with very dry burnt cork. Two wires are taken ont of this bulb to small ear pieces similar to those used with the phonograph. The vibration of the transmitting diaphragm by the voice converges or diverges the ray of light, making it stronger or weaker in the parabolic receiver. The heating of the bulb of carbon is varied, thus causing a variation in the vibrations of the carbon which are transmitted to the ear pieces. The experiment is very neat although at present it is difficult to imagine to what practical use it can be put.

The Director General has issued an order to the departments and the department heads have issued a circular to all pass holders, ordering them to call at the department offices to have passes examined and approved. If such term passes are considered necessary and are approved by the department officials a form will be filled ont for the pass holder who will then visit the office of the department of admissions either at 64 th street or 62 nd street, and there get his pass stamped, "Good on and after August 1, 1593." Truly the life of the pass holder. is not one of unalloyed bliss.

One class of machinery seems so far to have escaped the touch of the electrie motor to any extent, that is saw mill machinery; yet one would think that the high speeds at which such apparatus is run would invite the application of electric motors. A fine exhibit of wood sawing machinery is being made in a pavilion back of Machinery Hall, just west of the department of Mechanical and Electrical Engineering. Some of this machinery is so automatic and vigorons in its aetion as to appear almost human.

The Electrical World should read the WORLD's Fa1R Suppleuent of Electrical Industries and avoid the publication of illustrations of machines that never saw the western continent, as World's Fair exhibits. 


\section{ELECTRICAL INDUSTRIES.}

Exhibit of the Reliance Guage Company.

The Reliance Gauge Company, of Cleveland, Ohio, has one of the most attractive exbibits in the gallery of the Electricity Building, showing a full line of the well-known Reliance safety alarm water column for steam boilers. There are samples of the ordinary sizes in iron, brass and aluminum. Some very large sizes, one being shown like those uset on the 1, (1) -horse power "Climax" boiler in the power plant in Nachinery Hall.

Other sizes, ranging through all capacities and for every class of service are exhibited. The copper float for the alarm whistle is usually a weak point for use in connection with high pressures of steam, lut the samples shown by this company give evidence of heing very strong and substantial. The lieliance safety alarm column is for use in the place of the ordinary water column and asikle from having all the adrantages of the plain column adels that a patrons and friencls and all others who are interested in the deviee, to whom he will be glat to explain the work ings and goor qualities. The boilers in Machinery Hall are equipped with the lieliance colmmn, where they can be seen daily in practical operation.

Stum \& Co.. of Viemna, Anstria, have a small but very choice case of incandescent lamps in the northwest gallery of Electricity Building. It contains lamps of different tle sign, eandle power and color, also several styles of base.

The Sitar Iron Tower Co., is not to be beaten on decoration. It is painting a very handsome sign on the wall back of the sample fower in the west gallery of Electricity Building, which will be on a par with like decorations in other parts of the building.

The Newman Watehman's Clock exhibit has been movet

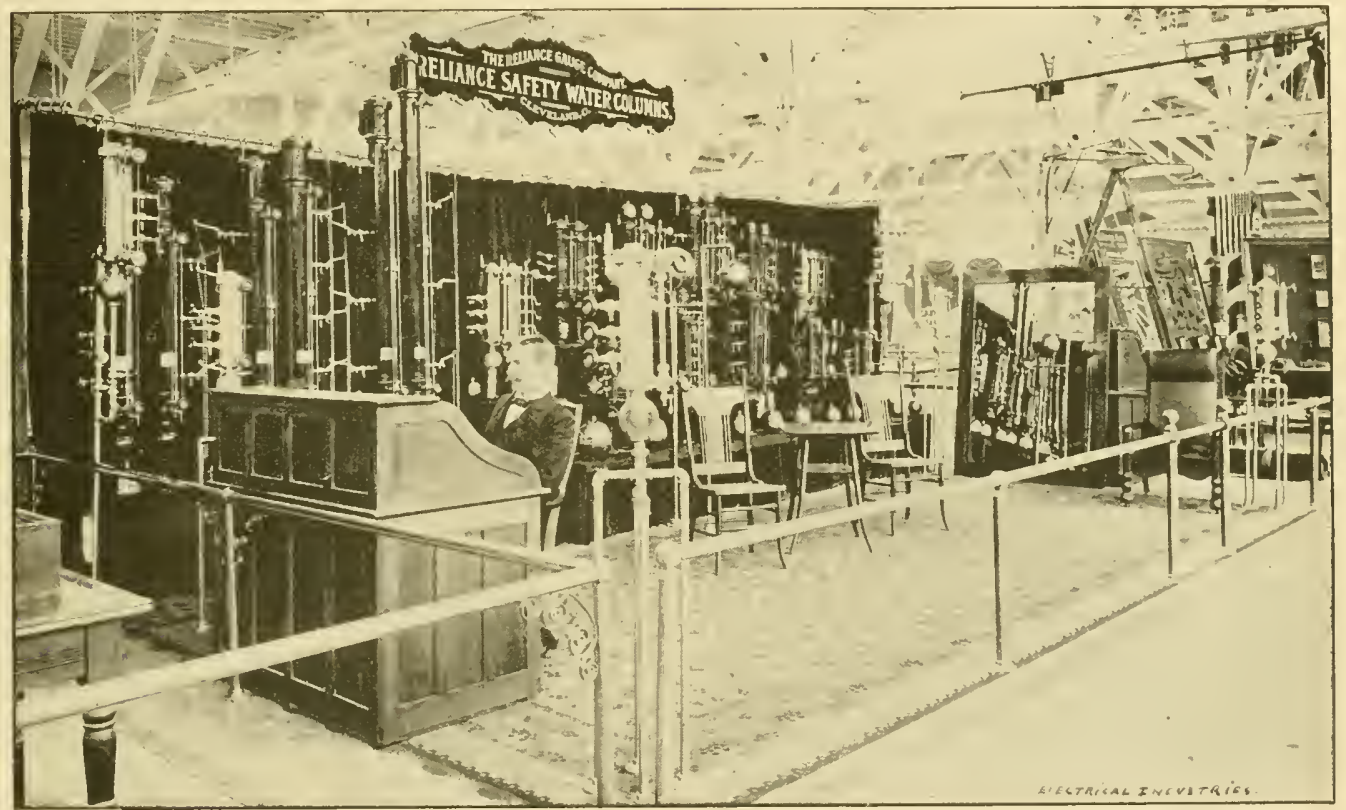

EXMIBIT OF TIE REIIXCE GAUAE COMPANY

safety device by which a signal whistle is blown in case the water in the boiler gets above or below a certain point. The column body is large and two oblong floats are placed in it, one at the top and one at the buttom; both join through simple lesers to the valve of a small whistle placed on top of the casting. These floats holl a normal position as long as the water level is between the two pre-determinel points, any abnormal change of level affects one or the other of these fluats and the valve opens, allowing the steam to es. (alpe to the whistle and thus give the alarm to the fireman.

The whole device is very simple ancl etlective. The exhithit is handsomely and tastefully arranged, the floor being covered with Brussels earpet, the stands with plush, and fine olive draperies furnish the background for the exhibit. The highly polished brass and aluminum columns adcling to the general luster. Mr. George 13. Clark is in charge for the company and will be pleased to meet his many to a much better location at the head of the northwest stairway of the Electrieity Building, occupying the space formerly set aside for Spain.

A small but eminently practicable exhibit may be seen in the British section of the amnex of the Transportation Builling. It is Webb's Electric Tube Cutter, and consists of a small electric motor on the end of a four foot bar, with a guide and gauge for use in removing surplus tube after placing the same in the heals of a boiler.

So far the month of July has seen little increase in the attendance at the Fuir. The total admissions for the month will barely exceed the 2,675,000 of the month of June. Even the more conservative estimates have not been realized. The warm weather, which on the whole has been very moderate, has not been comlucive to sight seeing. 


\section{ELECTRICAL INDUSTRIES.}

\section{ELECTRICAL INDUSTRIES PUBLISHING COMPANY, INCOAPORATED 1809 . \\ MONADNOCK BLOCK, CHICAGO. \\ Telephone Harrison 159.}

E. L. POWERS, Pres. and Treas.

E. E. WOOD, SECRETARY.

\author{
E. L. POWERS, \\ H. A. FOSTER, \\ W. A. REMINGTON, \\ E. E. WOOD,
}

EDITOR.

Associate Editols.

Eastern Manager

FLOYD T. SHORT,

Advertising Department.

EASTERN OFFICE, WORLD BUILDING, NEW YORK. World's Fair Headquarters, Y 27 Electricity Building.

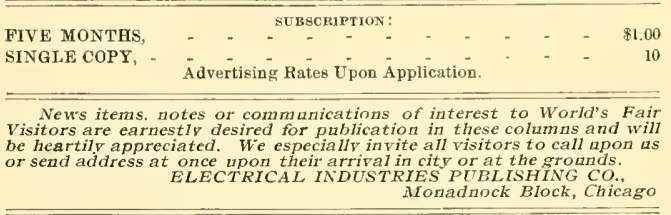

As improvement that might be made in the Department of Electricity and also in other departments at the Exposition is the institution of more live exhibits in which electrical instruments and machines great and small are being made or assembled. The popularity of and interest taken in this class of exhibits is shown by the crowds that collect around the exhibit of the Sperry Company while they are winding armatures or some of the exhibits in the gallery where gold and silver plating is being done. A greater number of such exhibits, especially in the gallery would be an improvement.

Tне decision of Judge Seamans in the lamp case at Milwaukee was watched for with great interest The defendants, the Electric Manufacturing Company of Oconto, Wis., had followed out the same line of defense as that taken by the Beacon Vacuum Pump Company at Boston, which was unsuccessful, and also followed by the Columbia Incandescent Lamp Company at St. Louis, and which in that case was successful. Thus each side rictorious in a similar case had endeavored to strengthen its case by additional testimony so that the decision of the judge was difficult to predetermine. The decision which grants to the plaintiffs the injunction asked for, strengthens the decision of Judge Colt, but the next step will be watched with interest.

\section{The Jury of Awards, Department of Electricity.}

In addition to the appointments published last week one more name has been added, Adolpho Aschoff, of Brazil. Prof. IV. E. Anderson, of Virginia is secretary to the executive committee.

A committee consisting of Messrs. Pope, Thomas and Ulbricht appointed to formulate rules for the guidance of judges, arranged the following schedule:

I. Title of exhibit.

II. Description (including diagrams or euts when desirable).

III. Specific claims of exhibitor.

IV. Report (stating character, details and results of examination or test).

$\mathrm{V}$. Finding of Jndge.
1. As to originality (defined by determining whether an exhibit has been in commercial use).

2. Merit.

$a$, Utility; $b$, Simplicity; $c$, Ingenuity; $d$, Reliability; $e$, Economic features; $f$, Workmanship; $g$, Finish; $h$, Design. 3. Claims sustained by examination.

VI. Recommendation as to award.

The committee suggests that there are undoubtedly many collective exhibits possessing no distinctive individual features entitled to an award; in other cases certain instruments or systems embraced in a collection may be of such special merit as to entitle them to distinct awards.

In such cases it is recommended that special awards be made for such parts of a collection as the judge may consider deserving of such honor.

It is proposed to test a number of the larger direct coupled dynamos for the purpose of ascertaining the consumption of steam and the electrical and commereial efficiencies of the apparatus under various loads. Tests of smaller apparatus of this kind may be decided upon later, but arrangements for the same are not yet completed.

Tests will be made for the purpose of helping the jury to form an estimate of the value of the exhibits. Where the jury are able to come to a conclusion without carrying ont such tests they may grant awards based on an examination of the exhibits. It will only be practicable, in relation to the particular exhibits referred to herein, to test such representative apparatus as is located favorably in relation to steam supply and ean be operated under a desirable load. It is, therefore, to be understood that the awards on the apparatus for which tests are herein provided are to be "granted upon specific points of excallence or advancement," the same as other exhibits, but that an abstract of the general results of the tests will be added to the report for an award, with references to the detailed report on the subject.

There are to be three classes of tests of each apparatus, to be designated $\mathrm{A}, \mathrm{B}$, and $\mathrm{C}$. They are:

"A" tests: No less than one or more than three complete tests are to be made with each apparatus, to ascertain the economy in the use of steam and the relation of the indicated horse-power to the electrical output. One of such tests to be made with a load corresponding substantially with the maximum efficiency, one near the minimum allowable load, and one near the maximum allowable load.

"B" tests: Partial tests, supplementary to the above, without measuring the water evaporated, but varying the load by gradual increments through the practicable range, to be made for comparing the indicated horse-power with the electrical output.

"C" tests: These tests are designed to aid in distributing the energy dereloped in the engine in excess of that shown by the total output in watts to include friction tests of engine and a determination of the resistance caused by exeiting the field with the main circuit open; they include also tests of electrical resistance, heating of armature, field, etc.

The order of tests provides that the apparatus shall be first operated at six-tenths of its maximum load for at least four hours before commencing the tests. The first complete or "A" test is then to be made, to be followed by the minimum " $\mathrm{A}$ " test, and that followed by the maximum " $\mathrm{A}$ " test. In case all of these tests cannot be made in succession the rule as to operating the dynamo four hours, at sixtenths load to be followed previous to each test. The same preliminary rum to be made also before commencing the "B" tests.

The following sub-committees have been chosen:

Sub-committee No. 1: To have charge of Groups 122, 
123 and indicators, registering meters, ammeters and roltmeters of (iroup 126. Messrs. Ayrton (chairman), Mendenhall, Rowland, Owens, Stine and Thomas.

Sub-committee No. 2: To have charge of Group 124. Messrs. Dolbear, Stine and Shrader.

Sub-committee No. 3. To have charge of Groups 125, 127 and 125, and j, of 13S a. Messrs. Carhart, Emery, Forbess, Jackson, Reber, Ryan and Rathenan.

Sub-committee No. 4: To have eharge of Groups No. 126 and 129. Messrs. Thomas (chairman), Ayres, ()wens (sec'y), O'Dea, Thompkins and L'lbricht.

Sub-committee No. i: To have charge of (iroujs No. 130. 131 and 133 and L. M. of 134 a. Messrs. Barker, Ayres, Rathenau and Warner.

Sub-committee No. 65: To have charge of Groups 133 and 134. Messrs, Ayres, O'Dea (sec'y), Pope (chairman), and libricht.

Sub-committee No. 7: To have charge of Groul No. 135. Not yet appointed.

Sub-committee No. S: To have charge of Groups 136, 137, 138 and 135 a. Not yet appointed.

Space hat been secured on the ground floor of the Electricity Building just west of the Jenney Motor Company's exhibit for testing incandescent lamps: this space will be entirely enclosed by wire netting so the tests ean be witnessed by visitors, no attempt being made to conceal any part except the photometer tests which necessarily have to be dark.

Space for battery testing has been secured on the west side of the building in that marked off for the Equitable Dynamo Co. The room at the northwest corner of the building and now used as an office by the Wellington Cater ing Co. will be fitted up for testing instruments.

Rooms for meting of committees have been provicled at the south end of the gallery between those of the Department and the American Institute of Electrical Engineers.

General meetings of the jury take place every day at 12 oclock noon, the sub-committees meeting directly afterwards.

\section{WORLD'S FAIR NOTES.}

The new Ifood 3,000 light alternator arrived early last week and was put in place Saturday; it seems to fulfill as far as appearance goes all the promises made as to iti merits and as it is to be supplied with power one can soon test its running qualiteis.

A meeting of the Gallery Exhibitors Club was held last Saturday. Another committee was appointed, consisting of Messrs. Newman, Clark and Eckert, with power to provicle signs, elevators, sourenirs, and such other devices as may in the opinion of the committee be desirable.

John Stephenson, the oldest and best known street ear builder in the world. has an exhibit in the Transportation Building annex, showing his latest style of truck for electric street cars, a closed car with electric truck and a sample of the closed cable car, as made for the Broadway road. New York.

A very interesting exhibit at this day is that of $\mathrm{A} . \mathrm{S}$. Hallidie, of San Francisco, Cal., consisting of the first dummy or grip car, the first trailer used for the purpose and a section of first calle tulue and grip, as originally used on the Clay street roard in San Francisco, Angust 1, 1573. As compared with the present heavy and solicl construction, the woden brarerl rasting used for the cable conduit. together with the wooden sleepers for the rails, makes one wonder how the cable road ever reached its present condition. A very fine collection of more modern cable grijs is also shown.

Another instance of the liberality of the chief of the Department of Electricity is shown in the caps worn by the department officials. Recognizing that much trouble and annoyance wonld be saved the public if some way of designating an officer or employe of the department could be had, and linowing that the Directory woukd spend no money for the purpose, he supplied the eaps at his own expense.

The perpetual motion erank has at last arrived. He reported at the Institute headyuarters last Friday and talked one of the members into a fit that was only cured by a trip to the Mirlway enabling him to get his brain composed again. He (the crank) said he harl offered to explain his device to the Germans and French but they were so prejudiced that they said they wonkd not go across the street to see it.

C. S. Yan Nuis, of 136 Liberty St., New York, is showing a line of "Ajax" specialties in the annex to the Transportation Building, samples of the Ajax lightning arrester, which might be called a magazine fuse box, switchboards of enamelerl slate with Weston instruments, Ajax switches and fuses, also a glass show case containing various other samples and specialties. Albert \& J. M. Anderson show in the same space the Boston pivotal trolley and a show case with numerous samples of line material, insulators, overhead frogs and switches, and a lot of other material for trolley line work.

In the present day of question as to the style and weight of rail to be used for electric roads, not to mention the kind of joint, one can do no better than to visit the very exhaustive and comprehensive exhibit made by the Gelese Inseum in the annex to the Transportation Building. From the old plank road and first short sections of cast iron rail laid on stone blocks up, throngh the varions styles to the 127 pound self-supporting rail used without ties or sleepers and with lap joints and rery heary fish or joint plates, nearly everything is shown as nsed on the European continent. Our American railway engineers may criticise. but will donlstless get some valualsle points.

The Chicago Rawhide Manufacturing Company, Chicago, has a very nice exhibit in Section $15 \mathrm{~J}, 2 \mathrm{~S}$ and '), Machinery Hall, consisting of rawhice helting, both flat and round, together with samples of all the varions gooks of its manufacture. The flat belts shown consist of several rolls from one inch to twenty-four inches in width, while the round belting includes samples from 1-32 of an inch to $1 \frac{1}{2}$ inches in cliameter. The flat belts inclucle everything from small thin belts to dynamo and heavy belts. Rawhide lace leather is also shown in sicles and cut laces, together with harness leather halters and straps. Rawhide pinions for electric cars, of which the company makes a specialty, are exhibited, together with a large roll of hydranlic packing. The company has, in acldition to its clisplay of manufactured goods, a large :34-inch belt in operation in Machinery Hall, running a Willans high speed engine in the British section; also an 1 S-inch belt rumning a smaller IVillans engiue. These belts attract a great amount of attention from their extreme smooth rumning. A large number of other smaller belts made by the company is also in operation on various parts of the grounds. 


\section{PERSONAL.}

Prof. George Forbes was called to Niagara Falls last week on business.

Prof. Ulbricht, of Dresden, Germany, and a member of the jury of awards, has arrived.

Mr. E. E. Wood, eastern manager of the ElectRical INDUSTRIES has been visiting the Fair for a few days.

Prof. N. M. Terry, of the U. S. Naval Academy of Annapolis, has returned home after a two weeks' visit to the Exposition.

Mr. W. B. Grimes, of Grimes Bros., electrical engineers and contractors, Grand Bend, Kas., is in the city visiting the Fair.

Prof. R. B. Owens, of the University of Nebraska, arrived last week and expects to remain in Chicago for a couple of months.

Mr. A. J. Martin, superintendent of the West End Light Company, of Philadelphia, spent several days at the Exposition last week.

Prof. A. E. Dolbear, of Tufts College, Mass., arrived in Chicago last week and is devoting himself to the work of the jury of awards.

Prof. Brown Ayres, of Tulane University, is now in the city and attending the meetings of the jury of awards, of which be is a member.

Mr. James J. Wood was at the Fair a couple of days last week looking after the erection of the 3,000 light alternator which had arrived.

Mr. Marcellus Reid, formerly with the Short Electric Railway Co., Cleveland, has been in the eity visiting the Exposition for the past few weeks.

Mr. F. R. Starr, Jr., manager of the Gonzales Light and Power Company, Gonzales, Texas, accompanied by his father, recently made an extended visit to the Fair.

Mr. Aaron C. Wright, of the Hope Electrical Appliance Co., Providence, R. I., has completed arrangements for the handling of his company's goods by local agents in Chicago and other western points.

\section{DEPARTMENT OF ELECTRICITY.}

OFFICES: SECTION R, ELECTRICITY BUILDING.

Chief, JoHN P. BARRETT,

Assistant Chief, J. Allen Horssby.

General Superintendent, J. IV. BLAESDELL.

Electrical Engineer, W. W. Prisм

\section{DEPARTMENT OF MECHANICAL AND ELECTRICAL} ENGINEERINA:

OFFICES SOUTH OF MACHINERY HALL.

Mechanical Engineer, C. F. Foster

Electrical Engineer, R. H. PIERCE.

First Asst. Mechanical Engineer, JoHN MEADEN.

First Asst. Electrical Engineer, S. G. NerLer.

\section{A MERICAN INSTITUTE OF ELECTRICAL ENGINEERS.}

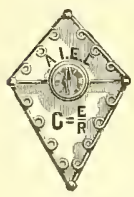

Wozld's Fair Headquarters,

SECTION S, ELECTRICITY BUILDING.

RALPH W. Pope, Secretary.

Open from 9 a.m. to 5 p.m.

CHICAGO WORLD'S CONGRESS OF ELECTIRCIANS.

GPENING SESSION, MONDAY, AUGUST 21ET, 3 P. M. ADVISORY COUNCIL.

President, Dr. ElishA GriY, Highland Park, 111.

Secretary, I'rof. H. s. CARll ARt, Ann Arbor, Mich. EXECUTIYE COMMITTEE.

Chairman, Prof. Einue Thomson, Lynn, Mass. COMMTTEE ON INVITATIONS.

Chairman, T. Commerford MARTin, 203 Broadway, New York. COMMTTTEE ON PROGRAM.

Chairman, Prof. T. C. Mendenhal, Washington, D. C. CONMITTEE ON FINANCE.

Chairman, B. E. Sunny, 175 Adams Street, Chicago.

\section{BUSINESS NOTES.}

Mr. W. L. Аввотт, 119 La Salle street, Chicago, has been retained by the council of Rochelle, Ill., as consulting engineer for the municipal plant to be installed.

L. K. Coustock, 1419 Monadnock Block, Chicago, has just completed several large wiring contracts, among which are the Columbus Memorial building, the New Era building and the Polk St. depot.

QUEEv \& CoMPAYr (Ine) has in its exhibit of high grade instruments much that attracts attention. Some $\$ 3,000$ worth of the instruments in the exhibit have been reserved for the Armour Institute, Chicago.

The Jenney Electric Motor Company, Indianapolis, Ind., bas had a very busy season at its western office, Chicago. i number of large orders and a steady stream of small ones has kept this office busy.

The Electric Appliaxce Company, 242 Madison st., Chicago, reports a continued large demand for the swinging ball light ning arrester. It is a frequent sight to see a line of poles with cone shaped boxes on every fifth or tenth pole, as 10 or 1.2 of the swinging ball lightning arresters are used on a circnit.

The Ansoxia Electric Company, Michigan Ave, and Randolph streets, (hicago, finds the warm weather has so stimulated the sale of fans that it has been almost unable to supply the demand. It makes a specinlty of fans operated by primary batteries and this summer there lıas been a large demand for them. The Edison motor, operated by the Edison Lelande batteries bas been found very popular and a large stock is earried.

'The Brightman Stoker Companr, Cleveland, Ohio, report among recent sales the following: American Straw Board Company, Circleville, Obio, 16 machines; Pittsburgh Water Works, 10 machines: Rocket River Paper Company, Pottsdam, N. Y., 2 machines: Brown \& Co. (Inc.), Pittsburgh, Pa., 8 machines; Bailey-Farrell Manufacturing Company, 2, and W. H. Birge \& Sons, Buffalo, N. Y., 2 machines. The works of this company have been very busy this season and the outlook is very bright for the later summer and fall.

\section{Amusements.}

Hooler's Theater-Mr. E. S. Willard, in “The Middleman." Saturday matinee, "The Professor's Love Story." 149 Randolph street.

Colunbia Theater-Miss Lillian Russell, in "La Cigale." 108 Monroe street.

Grand Opera House - Sol Smith Russell, in "A Poor Relation. 87 Clark street."

Auditonidi-Imre Kiralfy's Spectacle "America." Congress street and Wabash avenue.

MoVicker's Theater-Denman Thomson, in "The Old Homestead." 82 Madison street.

Chicago Opera House-American Extravaganza Company, in "Ali Baba, or Morgiana and the Forty Thieves." Washington and Clark streets.

Schiller Theater-Chas. Frohman's Stock Company, in "The Girl I Left Behind Me." Randolph, near Dearborn

Haferty's Casino-Haverly's United Minstrels. Wabash avenue, near Jackson street.

Trocadero-Concert. Michigan avenue near Monroe street. The Grotro-Vaudeville. Michigan arenue near Monroe street.

Buffalo Bill's "Wild West." 63d street. Daily at 3 and 8.30 p.m.

Pain's "Siege of Sebastopol," 60th street and Cottage Grove avenue. Tuesday, Thursday and Sunday nights.

The season of America, which ends in October, is about half over and still the attendance is only limited by the capaeity of the Auditorium, which bids fair to continue to the end of the season. The trapeze comiques, Basco and Roberts continue to afford unrestrained fun by their inimitable act in the Merrymount.scene.

The ninth week of the second successful run of Ali Baba began at the Chicago Opera House last Sunday night. It is certainly one of the most popular entertainnents of the World's Fair season. While the spectacular, musical, comic and terpsi. chorean features please the adults, the amusing donkey, the extraordinary lion and the wonderful dragon, construeted from designs not known to naturalists, afford the greatest amusement to the younger members of the family. 


\section{Weatherproof Wire.}

We are the largest manufacturers of weatherproof wire in the west.

We guarantee the quality of our wire to be equal, if not superior, to any other wire of like character in the market.

Special prices on application.

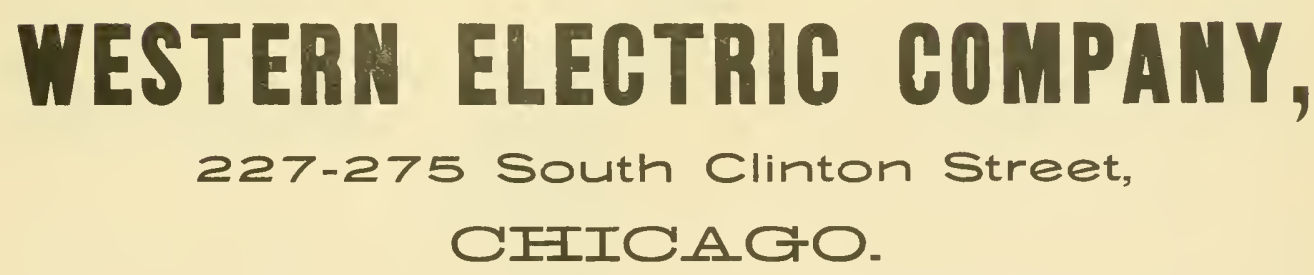




\section{HIGH GRADE ONLY.}

This applies not only to our specialties but to our general line of supplies. Send for a sample of anything we carry and we will guarantee that you will take no exception to the above claim. Remember thst our

\section{“O. K." AND PARANITE}

PACKARD LAMPS continue to burn as brightly as ever and the

MESTON MOTOR revolves with its accustomed effectiveness.

\section{ELECTRIC APPLIANCE COMPANY, ELECTRICAL SUPPLIES,} 242 Madison Street, OHIOAGO.

\section{THE MATHER ELECTRIC CO. THE "NOVAK” LAMP.}

MANCHESTER, CONN.

\section{Dynamos, Moloors, Gepererators,}

Offices, 116 Bedford St., BOSTON.

$$
\text { - AND - }
$$

1002 Chamber of Commerce Bldg., CHICAGO. 1002 Chamber of Commerce Bldg., CHICAGO.

\section{Enterprise}

Electric

\section{Company}

307 Dearborn Street,

Chicago....
CLAFLIN \& KIIMBALL (Inc.)

Ceneral Selling Agents.

116 Bedford Street, BOSTON.

Manufacturers' Agents and Mill Representatives for

Electric Railway,

Telegraph, Telephone and Electric Light

SUPPLIES

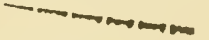

Agents for Cedar Poles,

Cypress Poles, Oak Pins, Kocust Pins, Cruss Arms, Glass

Feeder Wire,

Insulators,

WIRES, CABLES, TAPE and TUBING

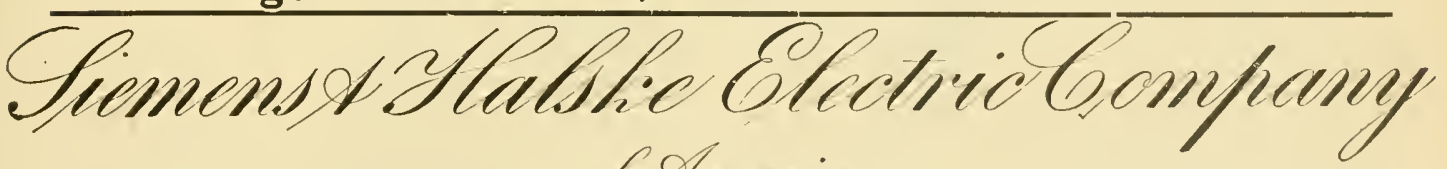

\section{of America.}

CPicio

Tlfosed

ago.e llivais.
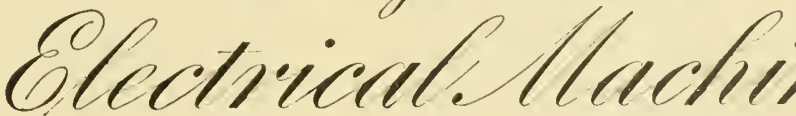
Map of Chicago.

Showing Loeation of its Electrical and Allied Business Interests, Principal Hotels, Theatres, Depots and Transportation Lines to the World's Fair Grounds. (Index numbers refer to the black squares.)

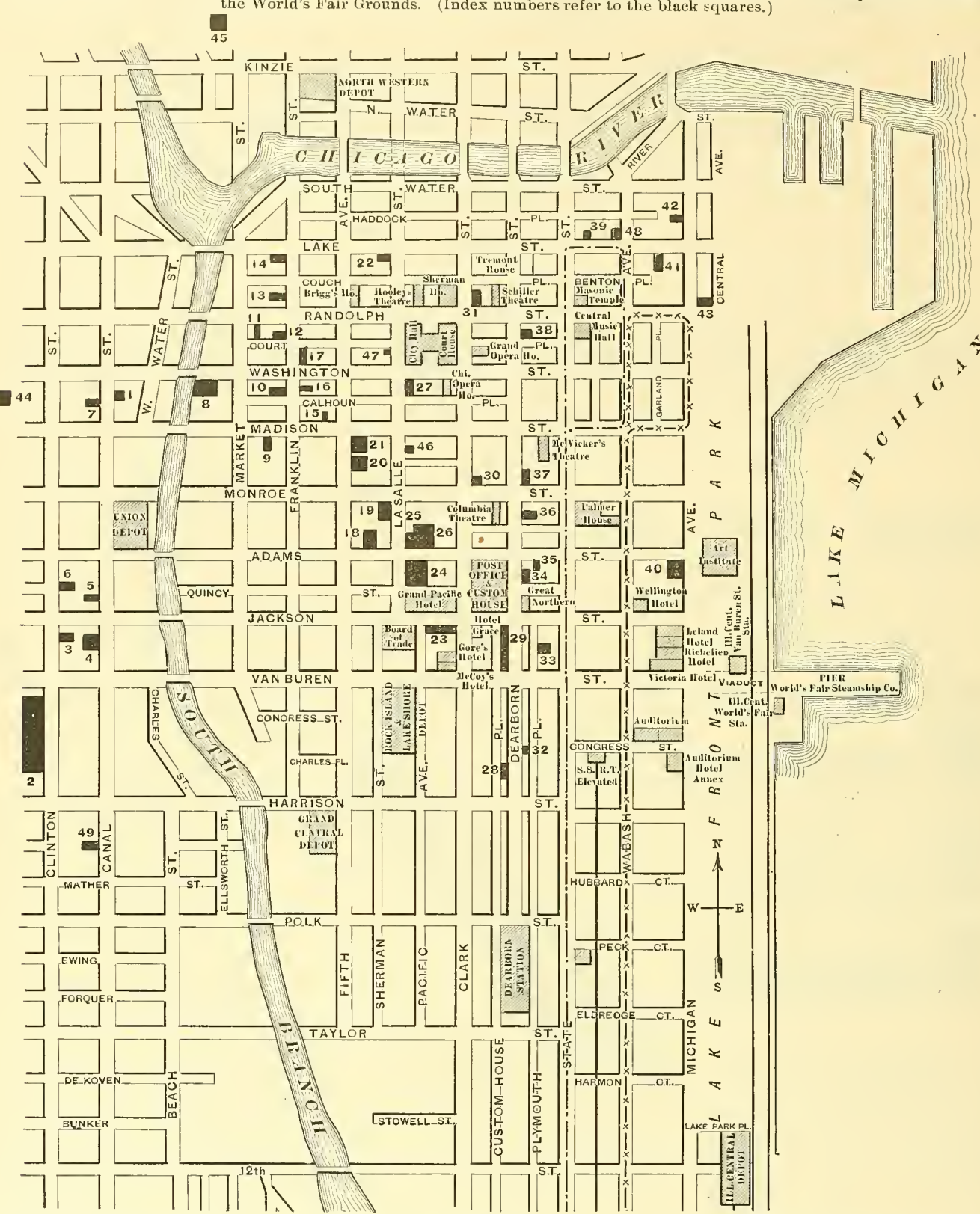

Ansunia El c Co., Micbigan Ave. \& Rando ph St,...34 Cusbing de Morse, 205 Dearhorn St.......... American Battery Co., 188 Madieon St.............., Commercial bitec Co.. The Rookery. Bartibolomew, Stow \& Co, 57 Mlicbigan Ave. Benham, A. D., 200 S. Clinton St

Bryant Electric Co. Wi............................... Brneh Elect ic Co., Monadnock Block.
Buckeye Electric Co., $t 37$ Rookery Bld Calnmet Electric Mifg \& Engine Bld g. C............

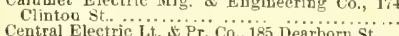

29 C. \& C. Electric Motor Co., 201 iladi on St 10 Unger El, Telopone Co Stock Exchan B........

McDougall \& Curnmin?s, Tuitv Blido 16 Matber Eler. Co., Chamber of Commerce Bidg....... . 4 5 New York [nsnlated Wire Co, 80 F ranklu St .......... 19

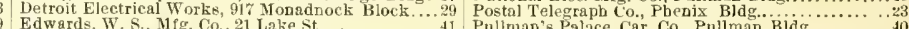
9 Edwards, W. S. Mfg. Co, 21 Lake St................11 Pullman's Palace Car Co.. Pullman Bidg..............

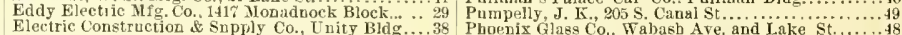
Electric Construction \& Snpply Co., L nity Bldg....38 8 Phoenix Glass Co., Wabasb Ave. and Lake St.......48

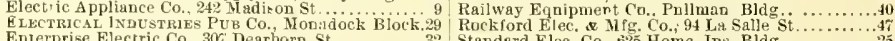

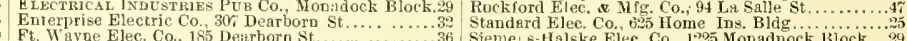

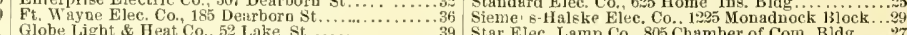

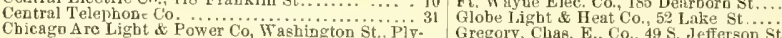

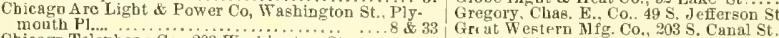

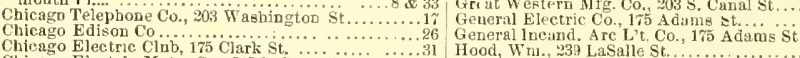
chico

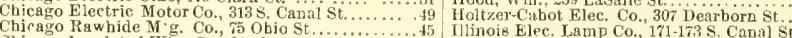
Chicas Ineulated Wire Co., 214 The Northern.......2 Cleveland Electric \& 11 fg. Co

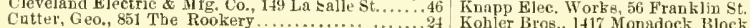
Stirling Co 605 Poll sto Chamber of Com. Bldg....... 49 Schieren, Clas, A., \& Co, 16 S. Canal St.................. 18 Sbort Elec. R:iilway Co. Monadnock Block ........29 8 Taylor, Goodbne \& Ames, 348 Dearborn St..........28
Todd. Applegate Co., The, 340 Dearhorn St........28 Wradell-kintz Cn., 1122 Monadnock Block .............29 Westinghouse Electric \& Mlf 9 Weatern Electric Co., 927 s. Clinton St............. 49 Wollensak, J. F., Lake and Franklin Sts............... 


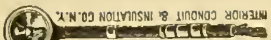

(6) ג

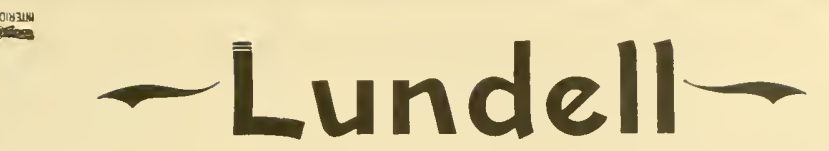

of

Suspended Fan Outfit

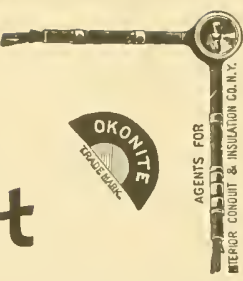

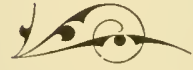

Black

Japan

Finish

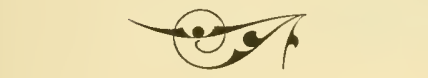

Electric Fans

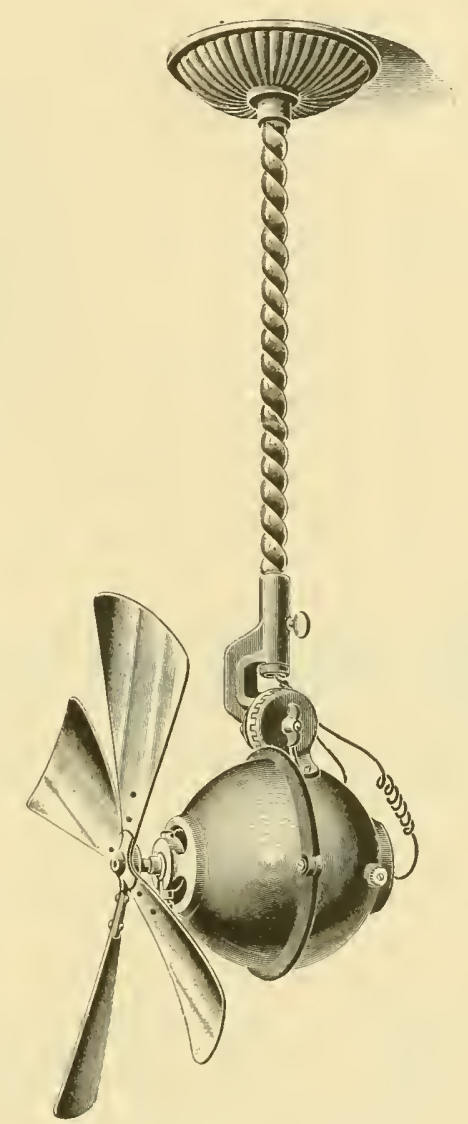

Self-0iling ....and

Self-Aligning Bearings

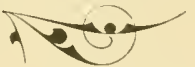

Electric Fans

\section{OKONITE WIRES \\ OKONITE $=$ TAPES $=$ MANSON INTERIOR CONDUIT.}

Batteries, Bells, Push Buttons, Annunciators, Volt Meters, Ammeters, Wheatstone Bridges, Line Wire Cross Arms, Brackets, Pins, Insulators, Tools.
GENERAL
SUP
PLIES.

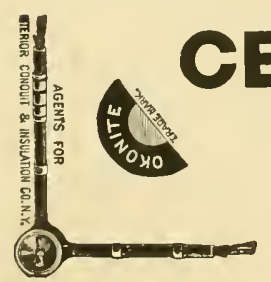

\section{ELECTRIC CO.}

II6-II8 Franklin Street,

CHICAGO, ILLS.

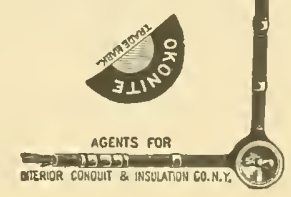




\section{THE BRUSH ELECTRIC COMPANY, OLFVEIAND, OFIO.}

World's Fair Exhibit, Section L, Electricity Building. 


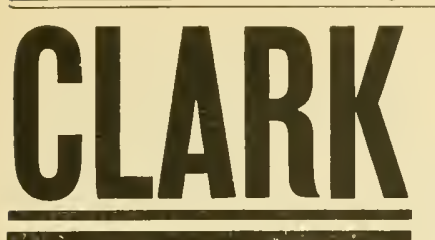

COMPANY, NEW YORK.

192 Broadway and II John Stree'.

MANUFACTURERS OF ARC LIGHTING APPARATUS FOR EVERY PURPOSE A SPECIALTY. The CLARK AR: LAMPS for use on EVERY CURRENT, have the reputation of being the best and most durable of any ever made in the United States.

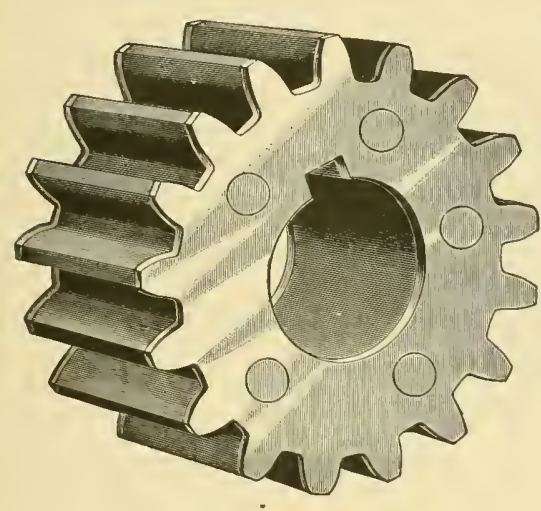

RAWHIDE PINIONS FOR ELECTRIC MOTORS A SPECIALTY.

RAWHIDE DYNAMO BELTING

Greatest Adhesive Qualities. A Non-Conductor of Electricity. Causes Less Friction than any other Belt.

THE CHIGago RAWHIDE MANUFACTURING CO. THE ONLY MANUFACTURERS IN THE COUNTRY.

\begin{tabular}{|c|c|}
\hline $\begin{array}{l}\text { LACE LEATHER ROPE } \\
\text { ANO OTHER RAWHIDE }\end{array}$ & $\begin{array}{l}\text { This Belting and Lace Leather is } \\
\text { not affected by steam of dampness; } \\
\text { never becomes hard; is stronger, }\end{array}$ \\
\hline $\begin{array}{l}\text { GOODS } \\
\text { OF ALL KINDS } \\
\text { BY KRUEGER'S PATENT }\end{array}$ & $\begin{array}{l}\text { more durable and the mest econom- } \\
\text { ical Belting made. The Raw- } \\
\text { hide Rope for Round Belting } \\
\text { Transmission is superior to all }\end{array}$ \\
\hline
\end{tabular}

75 Ohio Street,

CHICACO, KL

\section{Standard Electric Company.}

GENERAL OFFICES: 625 Home Insurance Building.

WORKS: So, Ganal Streef,

\section{CHICACO.}

\section{STANDARD SYST
WORLDTS FATR.}

MACHINERY HALL, Sec. Q, 2 Standard Arc Dynamos.

Sec. S, 20 " " "

ELECTRICITY BUILDING, Sec. P, Space 2, Arc Lighting Exhibit.

The Standard Lamps Light the Power Plant, Machinery Hall, Agricultural Hall, Shoe and Leather Building, and Other Buildings and Portions of the Grounds. 

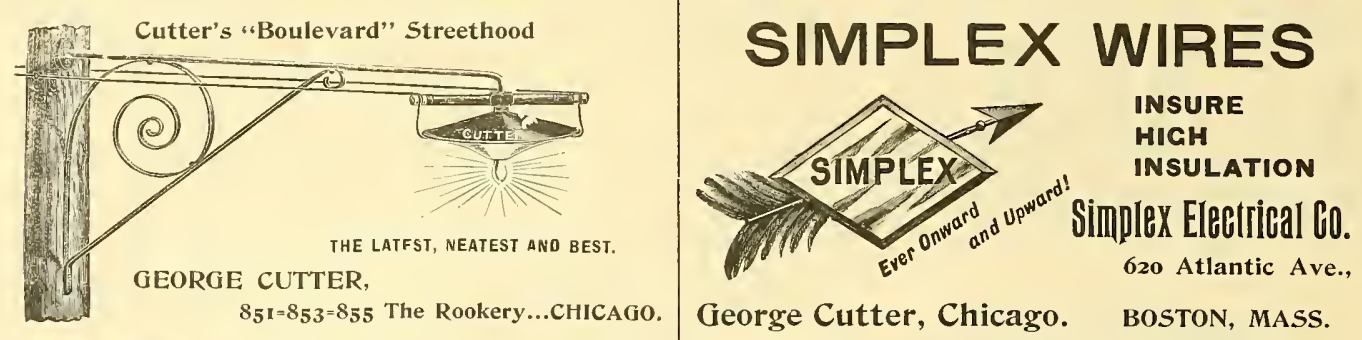

$8_{5} \mathfrak{I}=853=855$ The Rookery...CHICAGO.

George Cutter, Chicago.

BOSTON, MASS.

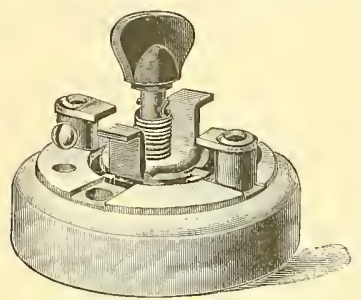

Made 5 amp. S.: P.

5 amp. 3. way.

\section{XNTRIC}

"That's the Switch"

And we control that movement.

H. T. PAISTE, 10 South 18 th St., PHILADELPHIA, PA.

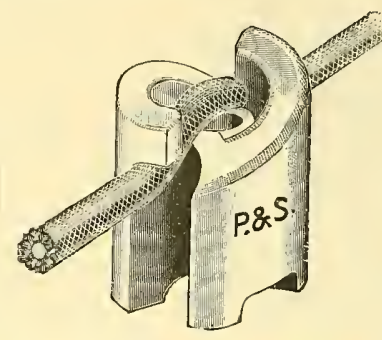

P. \& S.

WIRIN 3 INSULATOR,

Saves TIME

TROUBLE

and TIE WIRE

Made only by

Pass \& Seynour, SYRACUSE. N. Y.

George Cutter,

chicago.

Consolidated Elpctric (6.

Manufaclurers and Dealers in all kinds of

\section{ELECTRICAL . SUPPLIES,}

115 Franklin Street,

CHICACO.

\section{GEORG耳 PORTHR,}

Contractor for All Kinds of

\section{ELECTRICAL WORK.}

Room 67, 143 La Salle St., CHICAGo.

Crary Block, BOONE, IOWA.

\section{CHAS. A. SCHIEREN \& CO,}

\author{
MANUFACTURERS OF
}

\section{Genuine Perforated Electric Leather Belting.}

46 So. Canal Street, = CHICACO

\section{BEAR IN MIND}

that the regular monthly issue of ELECTRICAL INDUSTRIES contains the most complete and correct directories published of the electric light central stations and the electric railways in North America.

World's Fair Headquarters Y 27 Electricity Building. CITY OFFICES, Monadnock Block.

WAGNER ELEGTRIG FAN MOTORS

For Direct or Alternating Currents.

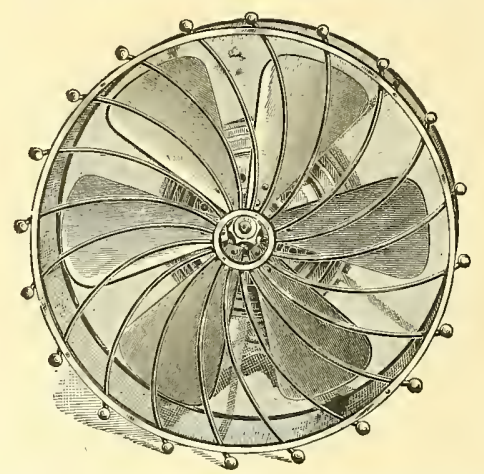

These motors give a stronger breeze with less consumption of eurrent than any other fan motor on the market. They are fall 1.8 horse power. Six bladed IT WILL PAY YOU TO SEE THE WAGNER BEFORE BUYING ELSEWHERE.

TAYLOR, COODHUE \& AMES, 348 Dearborn Street, CHICACO. 


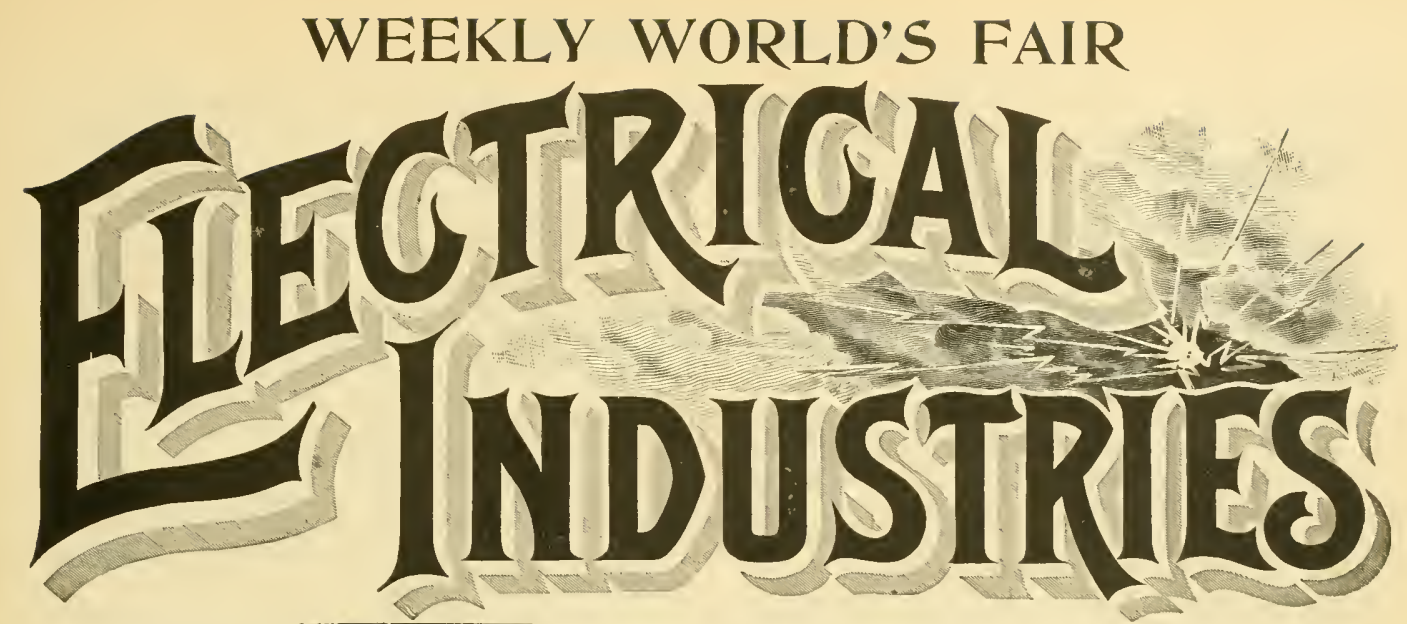

DEVOTED TO THE ELECTRTCAL AND ALLIED INTERESTS OF THE WORLD'S FAIR, ITS VISITORS AND EXHIBITORS.

Vol. I, No, 8. CHIGAGO, AUGUST ?. 1893.

FIVE MONTHS S1.00

De Laval's Steam Turbine.

The exhibit of the De Laval stean turline in conneetion with electrie lighting is located in the Swedish section, K, 22, Machinery Hall. Iu these days of the large compound and in place of taking steam all around its circumference of blates at the same time, it nses a limited number of nozzles directed tangentially against one side of the wheel, admitting steam at great velocity against a portion of the blades. As the speed of this wheel is something terrific,

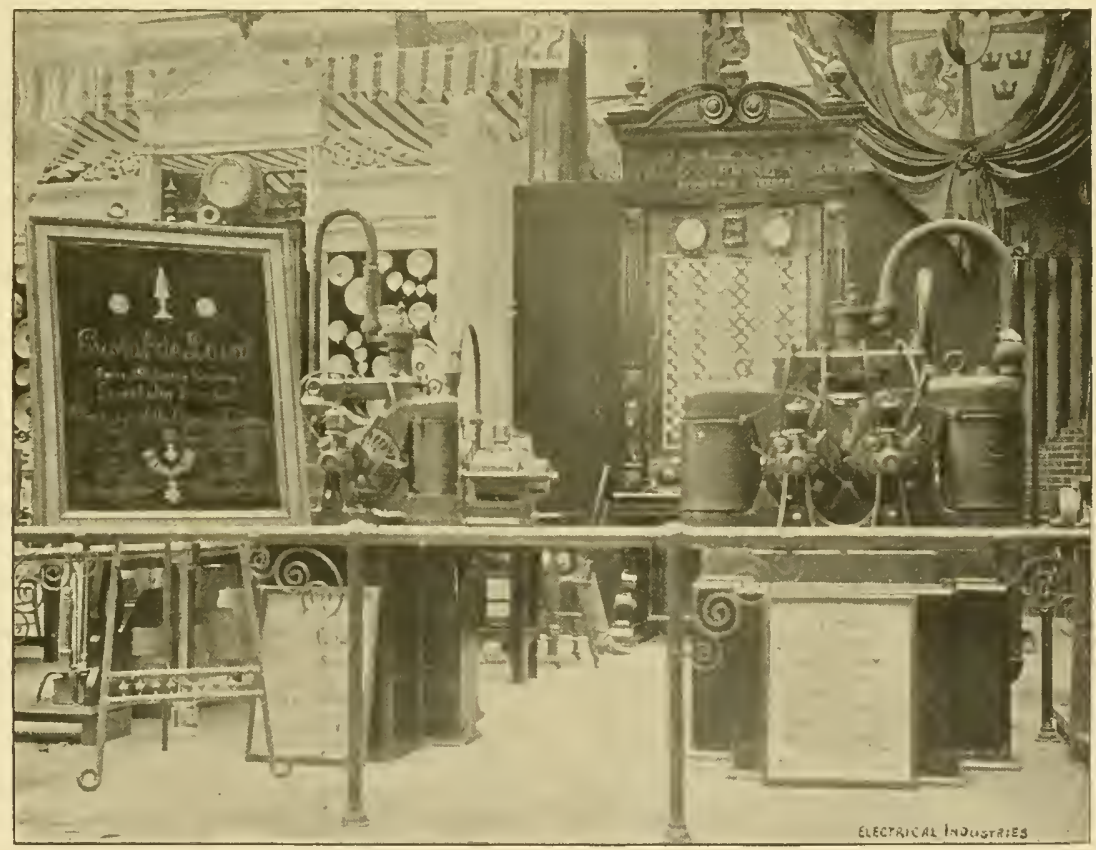

THE EXHIBIT OF DE LAYAL'S STEAM TURBINE.

and triple compound steam engine, a novelty of this sort is sure to be interesting to steam engineers and users.

Steam turbines have been in use for some time past, and of late, after the development that comes with use, their economy has been made something great for such small machines. Instead of using a number of turbine wheels, one exhausting into the next and so on until the pressure of steam is wholly used, this machine has but one wheel being 30,000 revolutions per minute for the five-horse power machine; and about 22,000 for the 20 -horse power. A unique style of gear has been invented to accomplish a reduction in the speed. This gear reduces the speed to one-tenth that of the turbine.

In the larger engines, as many as eight nozzles are used,four being arranged with valves that may be controlled from outside by hand, so varying the power and speed as two to one, 
Great difficulties were met with in overcoming faults and troubles developed by the very high speed. However carefully the turbine may be manufactured, it is impossible, on account of unevenness of the material, to get its center of gravity to correspond exactly to its geometrical axle of revolution; and however small this difference may be, it becomes very noticeable at such high velocities. De Laval has nevertheless succeeded in solving the problem, by providing the turbine with a flexible shaft, the wheel disc being placed on the thin portion of the shaft and at a considerable distance from the bearings, the shaft for 20 horse power being about three-eighths of an inch in diameter for a distance of about four or five inches each side of the disc.

A yielding shaft allows the turbine at the high rate of speed to adjust itself and revolve around its true center of gravity, the center line of the shaft meanwhile deseribing a surface of revolution. If the shaft were stiff, the vibrations of the turbine wheel would be communicated to the bearings, which would then run warm. The purpose of allowing an adjustment of the wheel can also be accomplished by making the journals yielding; but this arrangement requires complicated and expensive details of construction. The bearing of the free end of the flexible shaft is provided with a ball fastening, in order to allow it to adjust itself to the shaft. Moreover, all the journals are provided with lubricating grooves and anti-frietion metal, thus being specially adapted for effective lubrication.

The gear for the 20-horse power engine is about one and a quarter inches in diameter, with a double face for teeth, about five inches long over all. There are 23 teeth, there being screw threads of that number and of very steep pitch, thus forming a multiple spiral gear, the teeth on the two faces running in opposite directions, to prevent any end thrust. The teeth on the large gearare of like pattern, and as some 20 or 30 of them mesh at the same time and enter with a long sliding motion, the teeth meet with no shock and need not be excessively strong. These gears run with practically no noise. The governor is a simple, centrifugal device, not unlike many others, but of small and neat appearance. It acts on the throttle valve in the main steam inlet.

A copy of a certificate is shown, stating the results of an economy test made at Stockholm, Sweden, on the 13th of May last. In an eight hours run, the consumption of water is said to have been 19.69 pounds and of coal 2.67 pounds each per brake horse power. In connection with this engine, and to provide for the different sizes shown, there are several constant potential dynamos directly coupled to the engines. They are made after the Manchester type, but with different winding, owing to the high speed at which they are run. One is a dynamo with two armatures in the same frame, with the turbine gear meshing in between the armature gears. Leads from this machine can be coupled in multiple or series, as desired. A bank of incandescent lamps is provided for load, and may be cut on or off, as desired, to show the regulation of both dynamo and engine.

The exhibit, though small, is cery finely arranged, the engines being placed on pedestals, to show that heavy foundations are not necessary.

A brass rail surrounds the space and in one corner is exhibited, in a handsome frame, medals and decorations presented to Gustaf De Laval, the inventor.

The machine is creating as much interest among engineers as did the other steam turbines when they came out.
Although it has been in use in Sweden for some three years, it has not previously been shown to the American public.

\section{The International Electrical Congress.}

Preparations for the meeting of the Congress of Electricians in this city on the 21st of August are progressing rapidly. Many inquiries being received regarding railroad facilities, etc. Mr. C. O. Baker, Jr., has been appointed chairman of the transportation committee by Dr. Elisha Gray; this alone gnarantees the comfort of guests from the east. Mr. Baker will have his headquarters at the office of the National Electric Light Association, 136 Liberty street, New York, Secretary Porter having placed it at his disposal. Mr. Baker will soon issue a circular for the benefit of the eastern members and in all probability a special congress train will be run.

The Congress committee on invitations has already finished the larger part of its work but will probably be busy up to the very opening day. Upwards of 950 individual invitations have already been issued of which 600 are Ameriean and Canadian, including some of the foreign electricians attached to the World's Fair. General invitations have also been issued to twelve foreign electrical and scientific societies, of which the membership is upwards of 3,000 , only a small proportion of which may be expected to attend.

It is believed that the attendance at the Congress will be at least 500. The individual invitations have all been canvassed by Dr. Gray and the committee on invitations and it is safe to say that a more representative body of seientifie, professional and practical men has never before met in this country. Many very distinguished foreigners will attend. The program for papers and topics is in preparation and will be issued shortly before the meeting of the Congress.

\section{Exhibit of the Sperry Electric Railway Company.}

This exhibit, located just north of the Brush earbon display and across the aisle from the large exhibit of the Brush Electric Company, is unique in showing the company's ideas of what is the proper design of gearing for street car motors. Although the idea of beveled gears with one motor in the center is perhaps not new with this company, the designs shown are of recent construction. Trouble has heretofore been experienced from the very rigid connections necessary in order to keep gear teeth in good bearing. This trouble has been attacked by the Sperry Electric Railway Company and the result is shown on the McGniretruck equipped with a new type of Sperry motor and jacked up from the floor so that the motor may be shown running.

The special feature in this gearing, in which it differs from other similar types, is the flexible connection between the motor shaft and the gears at each end. This connection is formed of a series of links so arranged that while the shafts are freely movable out of line in every direction the rotating movement is as solid as though it were a straight clutch coupling. The pinion and gear are arranged in a solid casting in such manner that it is impossible for them to become separated in the least. A solid cast iron case encloses the gear and pinion against all dirt and dust and with a liberal amount of grease the gearing runs with very little noise. The motor itself is suspended from the side bars of the truck with its shaft at right angles with the axles and from this position is attached to the motors on either axle. This method of suspension allows the motor free 
play over rough ground and prevents many of the small evils due to the heavy jar from the usual methouls of suspension.

Another truck near the first, having no platform shows the arrangement of motor, gears and connections. The first design was to have the link flexible connection encased to keep out dirt and other obstructions but by improving the design of the links they are now left open and free and are easily examined for defects. At the north end of the exhibit on a wooden frame is shown one of the company's street car motors with one half of the field thrown back to show the armature and arrangement of the fields. The type of motor is after the style of the old Wenstrom dynamo, having two field coils and four poles, two of them being consequent poles. The special feature of the machine which removed many of the difficulties attending this special design is the dividing of the easting at diagonal corners insteal of in the centers either top or bottom. In this way about two-thirds of the surface of the armature is commutator. This avoids much trouble due to the old methods of eross connections. Numerous sample armature cores are exhibited; some hare, some partially insulated and others partly wound.

One of the most interesting features of the exhibit and the one which attracts the most attention from hoth the lay and the professional public is the armature winders in one corner of the exhihit who are at work insulating and wind ing armatnres for this railway motor. So much interest is manifested in this part of the work that it is astonishing that there is not more of it done in the Fair. On the west side of the space is a table on which are displayed varnous parts of the motor and accessories. The exhibit is sur rounded by a handsome railing and a large sign in white and gold is suspended over the center of the space. This eompany claims to have received many orders for its particular style of car equipments anl to have met with very satisfactory results on such roads as have so far been equipped. Special attention is called to the flexible connection

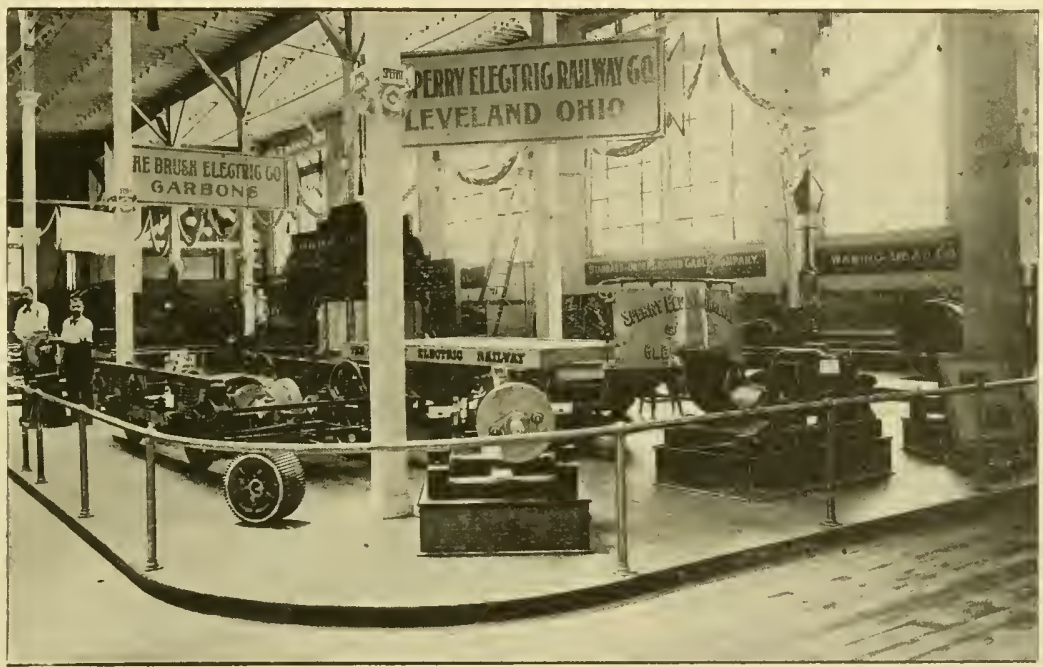

EXHIBIT OF THE SPERRY ELECTRIC RAILWAY COMPANY.

exposed to view for examination. One field coil can be entirely removed and all parts of the machine are as readily accessible as any type of motor so far examined.

The machine is very simple and much surprise is expressed by most visiting electricians to see it run with the top half of the machine entirely removed as it is here. The armature is of the iron clad type wound with ribbons of wire about three-eighths of an inch wide in radial slots cut in the surface of the core and secured in place after the usual manner of the day by wedge shaped hard wood sticks driven in under the converging edges of the slot over the coil of wire after it is wound. The connections between the armature coils and the commutator are made by flexible copper wire heavily insulated with cotton and the cross connections are accomplished by a heavy hard wood ring placed over the armature shaft aud next to the commutator. Insulated flexible copper comnections are wound on this ring hefore it is put in place so that all that remains is to connect to the ends of the armature wiudings one of the ends of these ring connections and the other end of the connections comes in proper position to connect directly to the between the gearing and armature shaft as explained above and a thorough examination will amply repay anyone interested in this class of apparatus.

\section{Exhibit of the Telegraph Construction Main= tenance Company.}

The problem of electrical communication between the shore and light ships anchored ontsicle has been before naval boards for a long time. Direct cable connection has never been accomplished to the extire satisfaction of all concerned, owing principally to the fact that ticles vere the ship around and entangle the cable and anchor chains.

An exhibit model shown by the Telegraph Construction and Maintenance Company, limited, 3S Old Broad street, London, near the center of the Transportation Building, seems to have eliminated most of the objectionable features and is claimed to have been in use from 1585 to 1859 on a light ship, nine miles off the east coast of England, until a committee of the Board of Trade decided that the expenditure involved was not commensurate with the adrantages gained. 
The ship is anchored by a chain from the bow, which at a short distance below the surface of the water is attached to a heavy swivel having a hollow bolt. The chain divides here and two chains are led in opposite directions to anchors. The swivel forms a point, around which the ship swings.

The cable from the shore runs up through the hollow bolt of the swivel, and following the chain to near the ship enters a hole provided for the purpose, and following along the deck is led through an apertnre to a drum below. This drum, holding a considerable length of extra cable, is so hung as to be capable of revolving not only on its own axis, but at right angles thereto, permitting twists to be taken out, in case the ship swings around often.

It was found that the regular stranded conductor was easily broken when the ship strained at the anchors in a storm, and a spiral conductor was substituted that is said to have given no further trouble in that line. allowing considerable movement of the axle and shaft, avoiding any jar to the motor, which is suspended wholly from the arc truck.

A number of diagrams are shown stating the efficiency of this motor as compared with others with single and double reduction gearing.

A Dorner \& Dutton improved flexible truck on one side of the exhibit is equipped with two of the latest type of 20 -horse power gearless motors. It is supported above the floor leaving the wheels free so the motors may be run. Along side of this truck is a stand supporting the motor controller and rheostat so that both may be easily and closely examined. Other samples of the rheostat are also shown. It is made entirely of iron and asbestos and is most thor. oughly fire proof.

One each of the 20 and 30 -horse power motors with single reduction gearing are shown.

Among the larger exhibits is a 500 -horse power, 500 .

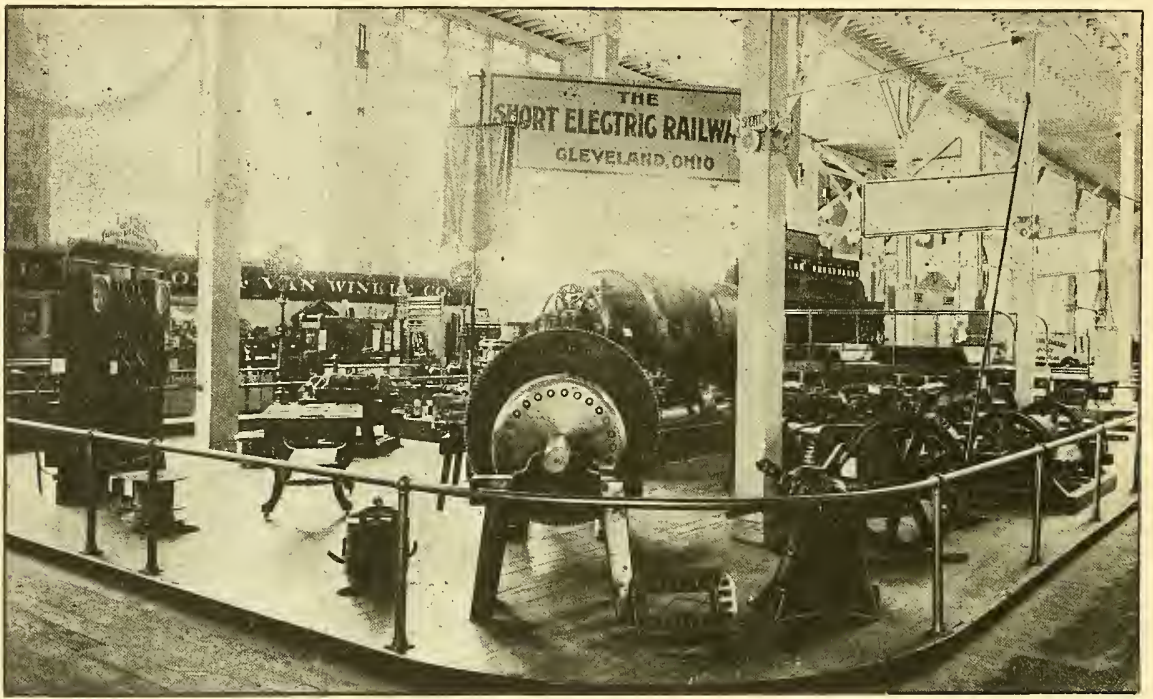

EXHIBIT OF THE SHORT ELECTRIC RAILTAY COMPANY.

In the United States, the Light-house Establishment has tried numerous methods, but never to their own complete satisfaction. With some few improvements, that conld be easily added, it seems as if this system might be made successful.

\section{Exhibit of the Short Electric Railway Co.}

This exhibit is located just across the aisle to the west of the Greek temple of the Brush company. It embodies everything in the line of electrical apparatus for railway work, from the generator to the moror.

This company was one of the very earliest in the field with a practicable gearless motor and its faith still clings to it as is shown by the special exhibition made of that style of apparatus. The original type is exhibited and the different styles designed since are represented, up to and including the latest, which is constructed with three field coils and six poles half of them being consequent poles. This last motor embodies many new improvements, runs at 100 to 175 revolutions per minute, and has flexible link connections between the axle and hollow armature shaft volt generator having six field coils on a side and a capacity of 300 kilowatts at 300 revolutions. A special feature of this machine is a device attached to one of the main bearings of the armature for moving that part endwise so as to center the armature windings in the fields. An extra armature for this large generator is exhibited and attached to it is one of the bearings fitted with the above mentioned shifting device.

The casting to which the bearing is attached is square, having surfaces parallel with the axis of the journal, across the bottom of this casting at right angles to the axis of the bearing is a wedge, fitting into a recess of the main casting having another loose wedge. A screw attached to the loose wedge and extending through the side of the main casting may be turned by the hand wheel attached shifting the journal bearing one way or the other as may be found necessary. The usual rings found on all Brush armature shafts are located on the shaft in this bearing and prevent side play of the armature.

These machines are very compact, well finished and run at a very low rate of speed.

On a cloth covered bench at one side are displayed 
numerous parts of the armatures and other apparatus, including automatic cut-outs, switches, eommutitors ant various parts of the motor fields.

A very fine black enamelexl slates switchboard in pavels like all other well arranged hoards of today, is exhibited fully equipped with all the instruments, apparatus and rlevices necessary for controlling the railway eurrents of two generators. In arlution to the circuit breakers provided for each machine, very long fuses are supplied, mounted on the backs of long single insulaterl black switches, so that when a fuse blows there is no trouble in replacing it.

The exhibit covers the field in a very comprehensive manner, shows good julgment in its selection, and is standard all the way through, embodying as it does only such types of apparatus as are advocated for practical every day use. Numerous pictures of Short ilppliances and apparatus are distributed about the space, and a large sign in white and gold is suspended over the center of the exhibit.

\section{Exhibit of Hart \& Hageman.}

The exhibit of switches by Hart d Hageman I' $\mathrm{f}^{\prime} \mathrm{g}$ Co., of Hartford, Conn., located in Sec. S, space J), Electricity building, is in charge of George S. Searing, the western

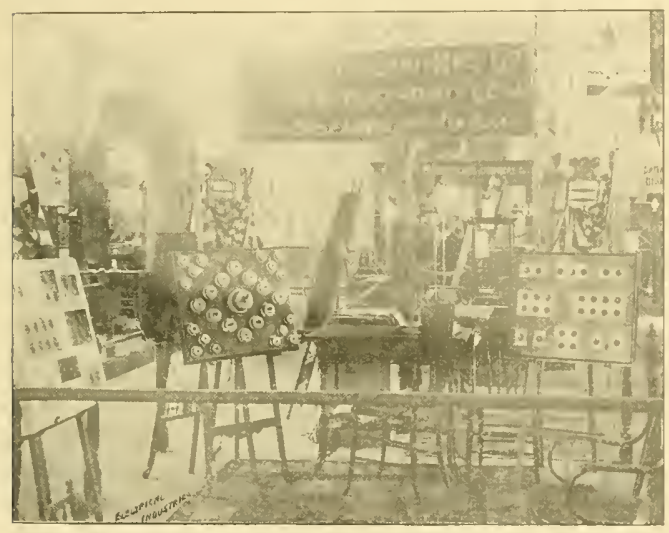

EXHIBIT OF HART \& HAFEMAN.

manager. Since it was first installed, more space has been secured, and the display somenhat enlarged. Rugs, table and chairs give an air of comfort to the place. A brass rail on oak posts surrounds the space with gates on both sicles. The real exhibit of the comprany consists of various sizes and styles of the Hart switch arranged in yeometrieal figures on small pauels in mahogany, white and ebonized wood. The two mahogany loards support the various sizes of the standard three-point, single and donble pole Hart switches, which are well known to the trade. The flush switches, of which this company makes a specialty are shown in various styles and finish on the white and ebonized board, the different colurs of finish showing well in contrast to the white and the black of the panels. These flush switches are male in single units or in any multiple desired. The principal styles of finish are nickel plater, dark copper, mottled steel and bronze. Special orters are filled in any color the purchaser may desire. Colored banners, in two corners, with the words "Harel switches," and a sign across one end with the natme of the complany, attract the attertion of visitors. Mr. Senring is prosent most of the time, and takes pleasure in showing the Hart switch to visitors.

\section{Brewster Electrolytic Disinfectant Plant.}

The recent installation of an electrical disinfecting plant at Brewster, New York, gives evillence of a new field for the use of the electric current. The Electrical Engineer recently described this plant which contains one 1ij-horse power engine conpler? to a Zucker d Levitt dynamo with a capacity of $70(0)$ amperes at fire volts. Near the dynamo is an electrolyzing tauk with a capacity of 1,000 gallons, in the bottom of which are placed three copper plates platerl witl platium alternating with four carbon plates. This tank is fed from a larger tank and the sujply is so regulated that the mater is electrolyzed and overflows into the sewer.

As a result of the threntened invasion of cholera, examinations were made of New York's water suply, aud it was found that the sewerage from Brewster which drained into a marsh situated on an elevation, percolated through the soil and finally reached one of the streams forming the awter supply of New York. As these marshes were also a a muisance to the health of the citizens of Brewster, the at1thorities of both places were interested in means for relief.

The ordinary methods employed for the purification of sewerage and the destruction of the germs to which cholera is due, and by which it is disseminated in drinking watar, involve the use of chemicals containing hypochlorites and chlorides more or less expensive. Dr. Eilson was led by the great difference in cost and other adrantages to adopt the system proposed by Mr. Albert E. Woolf.

The chlorides, hromiles, etc., in sea water are converted by the passage of the electric current into hypochlorites, hypobromites and various other eompounds. When il solution of hypochlorite of sorlinm is brought into rontact with organic matter decomposition takes place and if the solution is strong enough the matter is completely disinfected.

The use of this system at Brewster is said to be entirely satisfactory. The offensive olors are alsent from the marshes and the green algie and other vegetal)]e matter have become bleached since this plant has been operated. Tests of the Woolf disinfectant show that it equals in strength a one per cent solution of chloricle of lime. A one per cent solution of chloride of lime costs about 1.4 cents per gallon with lime at six cents per pound, while the estimaterl cost of the electrolyzed sea water is only 10 cents per 1,100 gallons. The electrolyzed sea water is harmless, while many of the chemical disinfectants are harmful in the hands of inexperienced parties.

The Babeock \& Wilcox Company has an exhibit in Мa(hinery Hall, section 25, M-23, The space is nicely carpeted and providerl with desk, chairs and talule. On the table are displayed samples of the tubes used by the company bent in a great variety of ways to show the yuality of the metal. Samples of the cast mud drum, of the cast and wrought iron heals are shown. A very neat railing sur. rounds the exlibit on side being made of brass tube while the other three sides are malle of boiler tubes with headers. In a glass cabinet is showu a rery landsome model of a single drum boiler. It has all the attachments of a full sized boiler. On the Exposition grounds there are installed 6,1)(1)-horse power of Babeock \& Wileox hoilers, 3,001) of which are in the power house of the Intramural Railway and $:, 0(1)$ in the Machinery Hall boiler plant. 


\section{ELECTRICAL INDUSTRIES.}

PURLISHED EVERT THCRSDAT BY THE

\section{ELECTRIGAL INDUSTRIES PUBLISHING COMPANY,}

\section{INCORPORATED 1889.}

MONADNOCK BLOCK, CHICAGO.

TELEPHONE HARRISON 159.

E. L. PoWers, Pres. and Treas.

E. E. WOOD, SEcret ARY.

\author{
E. L. POWERS. \\ H. A. FOSTER, \\ W. A. REMINGTON, \\ E. E. WOOD,
}

FLOYD T. SIIORT,

EASTERN OFFICE, WORLD BUILDING, NEW YORK. World's Fair Headquarters, Y 27 Electricity Building,

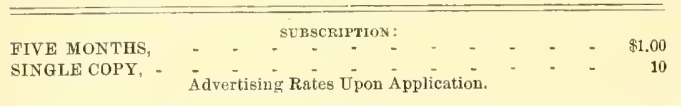

News items. notes or communications of interest to World's Fair Visitors are earnestly desired for publication in these columns and wil be heartily appreciated. We especially in vite all visitors to call upon us or send address at once upon their arrival in city or at the grounds.

ELECTRICAL INDUSTRIES PUBLISHING CO.,
Monadnock Block, Chicago

Monday, July 31, was mechanical engineers' day at the Fair, and the American Society of Mechanical Engineers visited the Fair in a body, going at 1:30 P.M., on the Illinois Central R. R. A regular program had been provided by Mr. H. F. J. Porter for their entertainment. They inspected the Multi-platform Railway on the Pier, after which a reception by the engineers of the Exposition was held at Music Hall at which the engineering features of the Exposition were described. After a trip to the Krupp Pavilion, where they were entertained by the representatives of Fried lirupp, and to the pumping station of Henry R. Worthington, they separated to a number of the more amusing features of the Exposition.

As proposed some time ago it has now been decided to close a majority of the Exposition buildings at 7 p.x. The Electrieity Building, Machinery Hall and some other building will remain open. On Monday evening Horticultural Building will be open; on Tuesday Manufactures and Liberal Arts Building; Wednesday, Transportation Building; Thursday, Art Gallery, Anthropological, Forestry and Shoe and Leather Building; Friday, Agricultural and Fisheries; Saturday, Mines and Mining. This order goes into effect immediately. By this arrangement exhibitors can easily keep their exhibits open all the time the building is open, and the visitor will be assured of seeing a majority of the exlhibits in the buildings on their open night. Electricity Building has no reason to complain of lack of visitors at night; so far the attendance has been very good. With its interesting exhibits, its handsome decorations, and brilliant illumination it is one of the greatest attractions of the Fair.

A very interesting type of engine is that shown by the Dake Engine Manufacturing Company, of Grand Haven, Hich., in Column G. 1-87, Machinery Hall annex. It is exceedingly simple in construction, having but two moving parts outside of the crank itself, and consists of a thin, oblong rectangular box containing the piston. The piston is double, the outside prart sliding from end to end of the box; the other part, being inside the first, slides up and down in a direction at right angles to that of the first. Steam is admitted through ports cast in the casing to the center of the shell and exhausts through a circular port surrounding the central admission port. Owing to the double piston and double action, there are no dead points and the engine will start from any part of the strolse. It is said that the engine may be run at any speed up to a thousand revolutions per minute.

The Baltimore Car Wheel Company has an exhibit in the annex to Transportation Building, a sample truck for electric street railway motors. It is equipped with two Baxter motors, and has oil and dust tight axle boxes. As is usual in electric car trucks at the present time, the car bearings overhang, giving all the effect of a long wheel base.

\section{Chicago World's Congress of Electricians.}

As the time approaches for the assembling of the Wortd's Congress of Electricians, August 21, something of its history may be of interest to our readers. The congress is held under the direction of the World's Congress Auxiliary of the World's Columbian Exposition, the Electrical Congress Committee having the matter in charge. In the work of preparation the congress committee of the American Institute of Electrical Engineers has assisted. As early as 1889 , the Institute appointed a committee to prepare for a congress during the World's Fair. The adjournment of the Frankfort Congress in $\mathbf{1 8 9 1}$ to meet during the World's Fair in 1893, seemed to confirm the work of the Institute. Having had the advantage of experience in two electrical congresses, the Institute proceeded in a systematic manner in the work of preparation. After the appointment of the Electrical Congress committee of the World's Congress Auxiliary, with Prof. Elisha Gray at its head, the two committees have co-operated. Electricians in all parts of the world hare become interested in the congress, and in the technical press have appeared many discussions of subjects which will be brought up at the congress. As many new units have appeared in connection with the growth of electrical knowledge and the use of electricity, the necessity of adopting universal terms which would be international has lead to a general discusssion.

As already announced, the congress will be divided in three sections, which will meet at 10 o'clock A.M., on Tuesday, Wednesday, Thursday and Friday of congress week. Prof. H. A. Rowland has been appointed temporary presiding officer of section (A) of pure theory, including electric waves, theories of electrolysis, electric conductors, magnetism, etc.; Prof Charles R. Cross, of section (B) of theory and practice, including studies of dynamos, motors, storage batteries, measuring instruments, materials for standards, etc.; and Prof. A. Graham Bell, of the section (C) of pure practice including telegraphy and telephony, electric signalling, electric traction, transmission of power systems of illumination, etc.

At one o'clock p.м., Friday, the congress will assemble as a whole to hear reports, etc., and will adjourn at three o'clock P.n. Several prominent electricians have signified their willingness to deliver lectures of a popular character which will be delivered on Tuesday, Thursday and Friday evenings of congress week. While the public can attend the meetings of the congress only those who hold cards of invitation from the committee on invitations will be permitted to take part in the deliberations of the congress. 


\section{WORLD'S FAIR NOTES.}

The Ferris Wheel was completely lighted for the first time last week. The rows of lights on the sides of the rim of the wheel and the rows on the towers supporting the axle produce a striking scene at niglit.

J. M. Jones \& Sous, of West Troy, N. Y., show two styles of electric street cars in the ammex to Transportation Building. One is an open car, the other of the closerl type. Both exhibit fine design and workmanship.

A considerable amount of interest is taken in the rertical marine engine of the General Electric Company in Machinery Hall. It is fitted with Corliss valve gear. In the same space are shown two dynamos of the type constructed especially for steamships.

The Westinghouse company has recently started in the southeast corner of Machinery Hall a large continuous current multipolar generator coupled direct to a cross compound horizontal Alles Corliss engine. The armature is on the shaft between the two main bearings, and a fly wheel is provided to steady the speed.

The electrical apparatus of Prof. Galileo Ferraris of Turin, Italy, is expected to arrive abont August Ioth. This apparatus has been rery unfortunate on the way having been sunk in the harbor of Genoa. Afterwards reeor ered, repaired and started again for the World's Fair on July 230 .

The scenic theater of the Western Electric Company is again running in its new quarters in the southeast corner of Electricity Building. A number of additions have been made in the stage equipment, and chairs have been provided for the audience. A piano adds to the attractiveness of the entertainment. The storm and rainbow effects are especially applauded. It requires 20 minutes for the production of the different light effects, and it is intended to give performances every half hour.

The Electric Appliance Company has recently adderl to its World's Fair exhibit a lot of twenty finely finished fancy reels of Paranite wire. The reels are stacked in the four corners of the splace in such a way as to form fou pyramids of reels tapering from very large at the bottom to small at the top. These reels thus serve the double jurpose of helping to mark out the space and making an attractive exhibit of Paranite. This addition just about fills up the Electric Appliance Company's space, and seems to be about all that was wanting to make it symmetrical in arrangement and complete in detail.

A grate bar which will be found of interest to steam users will be found in an exhibit in the British section of Machinery Hall. It is made by Caddy \& Company, Limited, Daybrook Tron Works, near Nottingham, England. The bar is a hollow piece of chilled cast iron. The top edge is harder aud wider than the lower. The rear eud enters a chamber in the bridge wall at the back of the furnace while the front end projects in front. Thus a current of air passes through the bar. The bars are said to wear much longer on account of the air keeping them cooler and the air entering the back of the furnace the gases are consumerl that would be otherwise passed out as smoke.

Just beyond the door at the right of the sonth entrance to the Government Builcling is a very interesting exhibit of photographs of nearly all the electrical apparatus used by Joseph Henry in his electrieal experiments. The Sturgeon magnet, the quantity magnet, Henry's inteusity magnet made in 1829. pole changers and the induction coils used by him in the discovery of the laws of induction are shown. There is also a picture of the first electro-magnetic: motor made by Henry in 1 $\$ 31$, and called the father of all electro-motors. As the originals themselves are nearly all on exhibition in the Prineeton College exhibit these photographs are interesting only as a matter of recorcl at the Fair.

In the Maunfactures and Liberal Arts Building, just north of Tiffany's beautiful exhibit, is that of the SelfWincling Clock Company, of New York. The booth is a large square room, with one side open. The walls are hung with elocks of all styles, sizes aul purposes, each being provided with the electric winding arrangement owned by this company. The standard time elocks rented all over the country by the Western Union Telegraph Company are of this make, and are syncronized with the standard time of the Naval Observatory at Washington, D. C., at noon each day. The company also shows samples of devices, for use with clocks, to strike a starting bell for street car lines and for any purpose where it is desirable to have a bell struck at a given minute of time. The large clocks and chimes in the central clock tower in the Manufactures and Liberal Arts Building are all furnished and rum hy this company, the bells being struck from a lesk loeated in the front of its exhibit, and connected with it by electric wires and the proper eleetrical devices.

H. T. Paiste, of Philadelphia, has a very attractive exhibit at the south end of the gallery in Electricity Builuing. The space which is next to the wall is surrouncled by a rery neat railing, is carpeted and furnished with chairs and desk. At the ends are easels, one of which supports a polished oak board on which are switches illustrating the evolution of the Paiste switch. On the wall on a very handsome baekground are arranged main and branch entouts, switches, etc. In the center of the background cutouts are arranged showing the outlines of the "xntric" movement of the switch, with the words, "Nintrie; that's the switch." The exhibit is very tastily arranged and reflects great credit on the designer. Mr. E. A. Jenkins is in charge of the exhibit.

\section{Cutter's Economic Door Switch.}

Among the most norel derices which are on exhibition at the electricity building are some which George Cutter bas been developing, aud which are only now ready for the

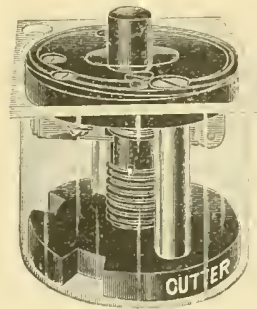
market. One of these is a switch for controlling the current by the opening aud closing of a door, so as to keep the eost of the lighting at a minimum. Most housekeepers know how expensive it is to light elosets, store rooms aud the like as the hired help will persist in burning the lamps continuously. Such a waste of current is easily avoided by setting an economic door switch into the rabbit of the door jam, so that the door itself will operate the switch. Then the light will burn only so long as the door is open, and the saving in eurrent and in the life of lamps will soon pay for the controlling device.

Our cut shows the general appearance of this new switch which has a spring action, is well built and carefully insulated. Having a cylindrieal casing, it is very easy to fit to the woodwork, no expert being required. Other uses for this switch will soon suggest itself, and it looks as if Mr. Cutter ought to find a wide murket for it. 


\section{PERSONAL.}

Prof. George Forbes has returned from Niagara Falls and is now at the Fair.

Mr. Frederick A. Scheffler, of The Sterling Co., New York, is visiting the Exposition.

C. C. MeNutt, president of the Warren Electrical and Specialty Co., Warren, Ohio, is visiting the Fair this week.

Prof. N. M. Terry of the U. S. Naval Academy at Annapolis, has returned home after an extended visit to the Fair.

Prof. D. C. Jackson, of the University of Wisconsin, will remain at the Fair for some time on work connected with the awards.

Mr. W. R. Brixey of Day's Kerite, is again at the Fair extending his already large acquaintance among the electrical fraternity.

Mr. Leo Daft, one of the earliest pioneers in electric railway work, and now settled at Seattle. Washington, is in the city stopping at the Great Northern.

Mr. W. C. Cheney superintendent and engineer of the Port land (Oregon) General Electric Company made a short visit to the Fair last week while on his way east.

Prof. E. Hospitalier of Paris, delegate of the French Government to Chicago World's Congress of Electricians arrived in Chicago on the 2rith after a two weeks stay in New Ycrk.

Prof. H. A. Rowland, of Johns Hopkins University, arrived in the city Monday, July 31 , and will attend the meetings of the Jury of the Department of Electrieity, of which he is a member.

Prof. Baurath Ulbricht of Dresden, Germany, has been elected first vice-president and Prof. W. E Ayrton of England second vice-president of the Jury of Awards Department of Electricity.

Mr. Harold B. Smith, superintendent of the draughting department of the Elektron Manufacturing Co., has accepted the professorship of electrical engineering in Purdue TTniversity, Lafayette, Ind.

Mr. Alfred A. Cobb, of the India Rubber Comb Company, sales agent for the Chicago Electric Wire Company, designed and arranged the company's exhibit of wire. He has shown excellent taste in the arrangement as he has in conducting other affairs of his company.

The many friends of Mr. L. W. Burnham, manager of the Electric Gas Lighting Company, Boston, will be pained to learn that just as he was ready to start on a visit to the Fair last week he was taken with a sudden illness. $\mathrm{He}$ is, however, improving slowly and will, we hope, be able to visit the Fair a little ater in the season.

DEPARTMENT OF ELECTRICITY.

OFFICES: SECTION R, ELECTRICITY BUILDING.

Chief, JOHN P. BARRETT,

Assistant Chief; J. AlleN HorNSBY.

General Superintendent, J. IV. BLAEsDeis.

Electrical Engineer, W. W. Prim

DEPARTMEN'T OF MECHANICAL AND ELECTRICAL ENGINEERING.

OFFICES SOUTH OF MIACHINERY HALI.

Meehanical Engineer, C. F. Foster

Electrical Engineer, R. H. Pience.

First Asst. Mechanical Engineer, JoHn MFADFr.

First Asst. Electrical Engineer, S. G. NEILEr.

AMERICAN INSTITUTE OF ELECTRICAT ENGINEERS

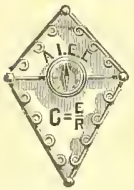

World's Fair Headquartere, SECTION S. ELECTRICITY BUILDING.

RALPH W. POPE, Secretary

Open from 9 a.m. to 5 p.m.

CHICAGO WORLD'S CONGRESS OF ELECTIRCLANS.

OPENINE SESSTON, MONDAY, AUGUST 21 ST, $3 \mathrm{~T}$. M

ADVISORY COUNCIL.

President, Dr. Elisha Grax, Highland Park, Ill.

Seeretary, Prof. H. S. CARHART, Ann Arbor, Mich. EXECUTIVE COMHTTEE.

Chairman, Prof. Erinu Thomson, Lynn, Mass. COMMITTEE ON INVITATIONS.

Chairman, T. Commerford Martin, 203 Broadway, New York. COMMTTEE ON PROGRAM.

Chairman, Prof. T. C. Mendenhal, Washington, D. C. COMMITTEE ON FINANCE.

Chairman, B. E. Sunny, 175 Adams Street, Chieago.

\section{BUSINESS NOTES.}

WM N. Marcus, of 218 North Second street, Philadelphia, has a small exhibit of his patent auxiliary mouth pieces for telephones in section S Electricity Building, next to the Hart \& Hegeman exhibit. This devise is applied to the Blake transmitter of the ordinary commercial telephone and is adjustable for persons of any height.

CUTLER \& 1 AMMER, Chicago, manufacturers of electrical goods, are pushing rapidly to the front. Their shop is receiving orders for all the workit can turn out and instead of being obliged to lay off some of their men, as many of the older shops are doing, they have been obliged to increase their force. The new "C. \& H." snap knife switehes are meeting with a large sale.

The C. H. Stoelting Manufacturing Company, Chicago, are manufacturing several electrical specialties, among others the Blair Lamp Adjuster. This adjuster bas been improved lately in construction by using a poreelain base, so made that wires can be run under it and the metal cover locks on to the base, giving easy access to the roller. The roller is now being so constructed that it will a much larger amount of cord.

\section{Amusements.}

Hooley's Theater-Mr. E. S. Willard, in "The Middleman." Saturday matinee, "The Professor's Love Story." 149 Randolph street.

Conurbia Theater-Miss Lillian Russell, in "La Cigale." 108 Monroe street.

Grand Opera House - Sol Smith Russell, in "A Poor Relation. 87 Clark street."

Auditorioß-Imre Kiralfy's Spectacle "America." Congress street and Wabash arenue.

MoVlcker's Theater-Denman Thomson, in "The Old Homestead." 82 Madison street.

Chicago Opera House-American Extravaganza Company, in "Ali Baba, or Morgiana and the Forty Thieves."

Vashington and Clark streets.

Schiller Theater-Chas. Frohman's Stock Company, in "The Girl I Left Behind Me." Randolph, near Dearborn.

Haverly's Casino-Haverly's United Minstrels. Wabash avenue, near Jackson street.

Trooadero-Concert. Miehigan avenue near Monroe street. The Grotto-Vaudeville. Michigan avenue near Monroe street.

Buffalo Bill's "Wild West." $63 d$ street. Daily at 3 and 8.30 p.m.

Pain's "Siege of Sebastopol," 60th street and Cottage Grove avenue. Tuesday, Thursday and Sunday nights.

"The Girl I Left Behind Me" has had a very successful run at the Schiller during the last ten weeks, and the advance sale of seats seems to promise a continuance of the success. On Aug. ust 16 th, the 250 th performance, handsome souvenirs will be presented to the ladies in attendance.

This week is the closing week of Mr. E. S. Willard's engagement at Hooley's. His season has been most suceessful. Thursday an I Saturday evenings he appears in "The Middleman," Triday evening in "The Professor's Love Story."

The special attractions of the Trocadero, Amami, the mimic, Paquerette, the electric fire works, and the music of the Von Bulow band and the Rosenbecker orchestra are specially attractive, while the dancers, the acrobats, the jugglers and Sandow who is making his first appearance in the eity are intensely interesting and amusing to all lovers of vaudeville.

"Ali Baba" is keeping up its reputation for genuine suceess so well established in its previous productions. The 33rd week it has been played at the Chicago Ôpera House began last Sun. day night. Several new people with special parts have been engaged and will shortly appear. The production has grown so large that at the close of the season in Chicago it will be be taken to only the larger cities.

In "America" is found a genuinely cosmopolitan entertainment. It is not an uncommon sight to see groups of Turks, Japanese, Singalese, and representatives from other nations in the audience applauding the different parts of the spectacle. The vivid scenes and the pantomimic action makes the piece understood by everyone. The play is now at its zenith. 

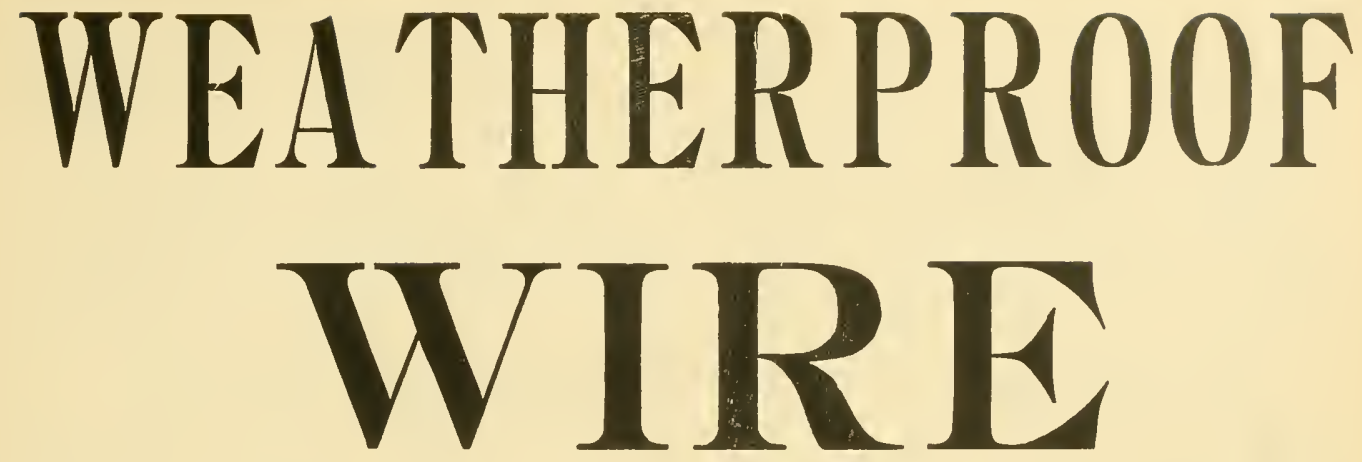

We Are The Largest Manufacturers of

\section{WEATHERPROOF WIRE...IN THE WEST}

WE GUARANTEE THE QUALITY OF OUR WIRE TO BE EQUAL IF NOT SUPERIOR TO ANY OTHER WIRE OF LIKE CHARACTER IN THE MARKET.

\section{SPECIAL PRICES ON APPLICATION.}

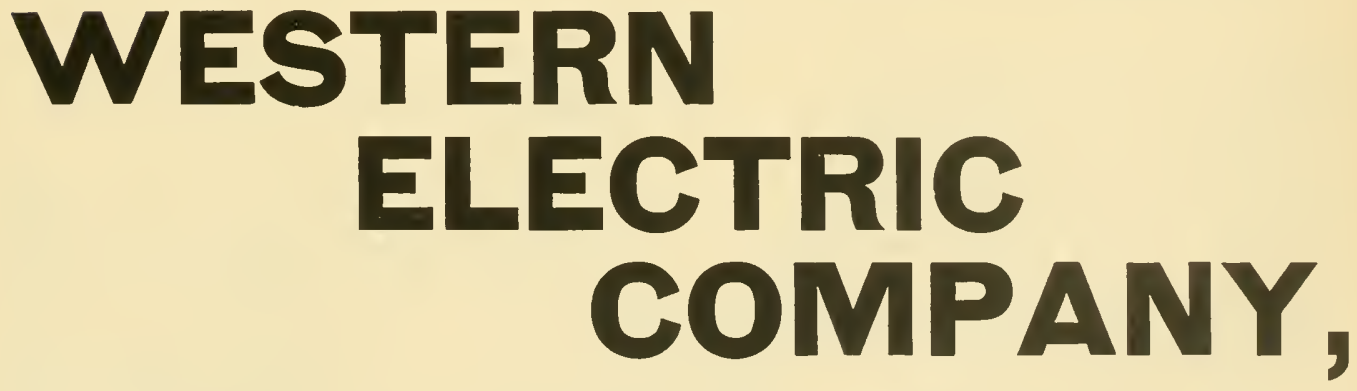

227-275 South Clinton Street,

\section{CHICAGO.}


ELECTRICITY BUILDING-EXHIBITORS AND THEIR LOCATION.
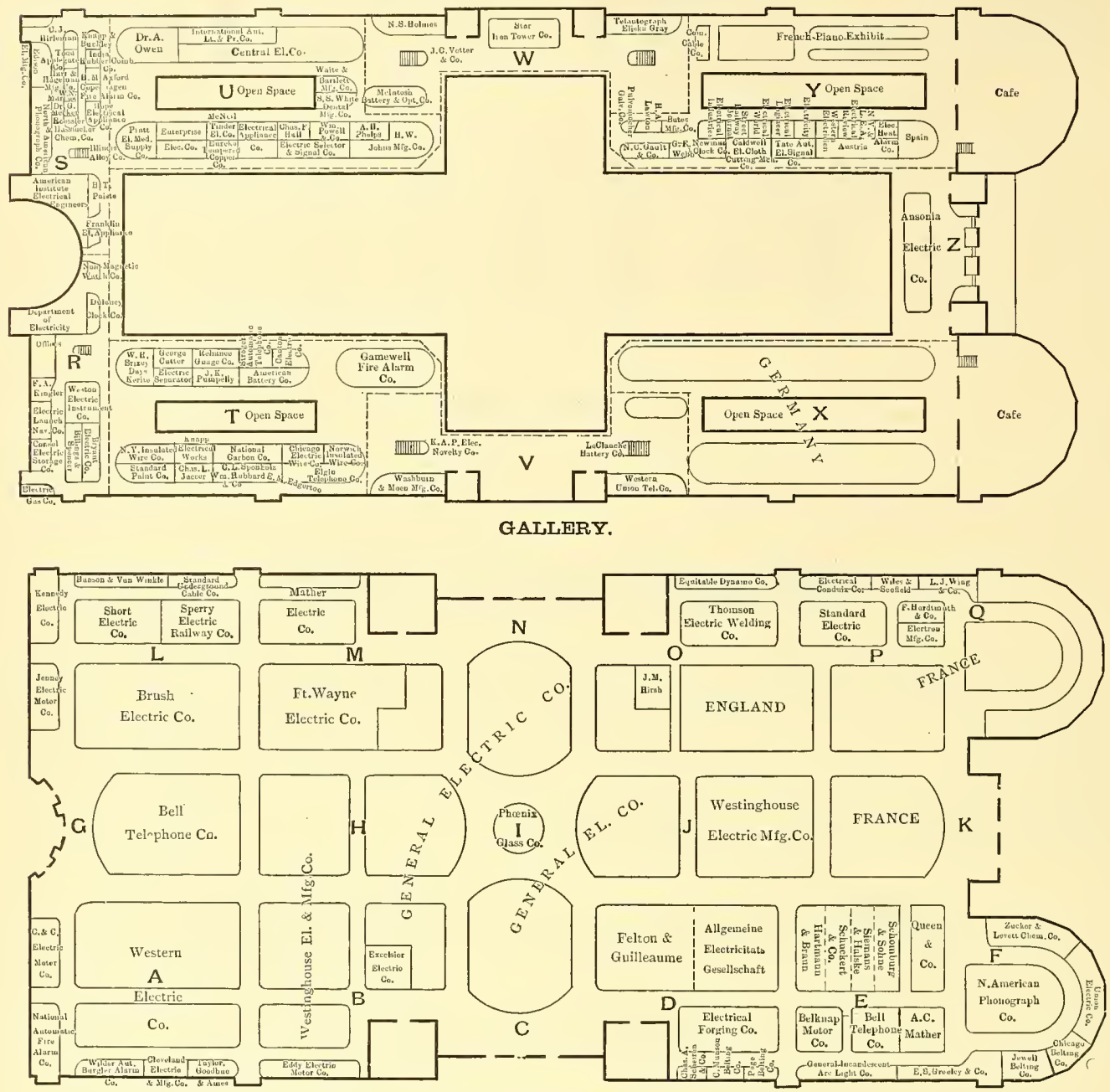

MAIN FLOOR.

Exhihitor.

Anstria.

Ansonia Electric Co...

Am. Inst. of Elec. Eng.

American Batter

Allg. Elec. Gesellechaft.

Bryant Electric Co

Billings \& Spencer

Belknap Notor Co

Bell Telephone Co.

Brush Electric Co .................

Caldwell El. Cloth Cut. Mch. Co.....

Consol. Elec. Sturage Co

Canton Elec

Chicago Elec. W'ire Co...

Copenhagen Hire Alarm Co....

Central Electric Co

Commercial Cable Co.

C. \& C. Elec. Motor Co

Chicago Belting Co

Department of Electricity.

ELECTRICAL INDUSTRIE
Elec. Launch \& Nav, Co.......

Electric Sepa

Edgerton, E. M..............

Elgin Telephone $\mathrm{Co}$
Edison Elec. Hfg. C

Interprize Elec. Co.

Eureka Temp. Copper co

Electric A ppliance Co

Elec. Sel. \& Sig'l Co.
Section, Exhibitor.

Exhibitor. Electricity .........

Electrical Engine

Electrical World

Eddy Electric Motor C

Eiectrical Forging Co....

Equitable Dynamo Co.

Elektron Mfg. Co.

Electrical Conduit Co...

Empire china Wैork

Franklin Elec, Appliance

Felton \& Goilleaume.

France

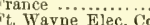

...............

Gamewell Fire Alarm co............

General Electric Co .... B-H-N-C-\& J J

General Incand' $\mathrm{z}^{\prime} \mathrm{t}$ Arc L't Co......... E

Greeley, E. S., \& Co

Hobbard, Wm.. \& co.

Hart \& Hegeman vifo. $\mathrm{Co}$

Hope Elec. Appliance Co.

Hall, Chas. I

Holmes, N s ...............

Hansou \& V Braun Winkl.

Hardtmuth, $W_{i} \& \mathrm{Co}$

Illinois Alloy Co.................

Iudia Rubber Comb Co...
Exbibitor.
Jaeger, Chas. L...................

Jewell Belting Co

J nney Elec. Motor Co...

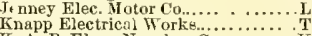

K. A. P. Elec. Novelty Co........... V

Kunpp \& Buckley ..........

Kennedy Elect

LeClanche Battery Co.

NeNeil-Tinder Elec. Co.

Marcos, $11 . N$

MeIntosh But. o opt co.

Munson, C., lselting Co

Mather Electric Co

Newman Clock Co.

Non-Nignetic Watch Co.

National Carbon Co....

Norwich Ins. Wire Co....

North Am. Phonograph

Nat. Aut. F'ire Alarm Co.

Nat, Engraving Machine Co.

Owen, Or. A

Phoenix Glae

Pulvermacher Go...............

Pompelly, J. K ….

Pow. Co

Phelpe, A II

Page Belting Co.

Queen \& $\mathrm{Co}$
Frhibitor.

Section Roessler \& Hasslacher chem. co...... Street Rail way Journal...... ........ Y er Aut. Telph. Co.

Standard Paint Co.

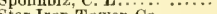

Spar fron Tower Co................. W

Schieren, Chas. A. \& Co .............

Schomburg \& Sohne

Siemens \& Ialske.

Schuckert \& Co......

. Cable $\mathrm{C}$

Samson Battry Co.

Tate Aut. El. Signal

Taylor, Gaodhue de Ames................

Thomson Elec. Welding Co .........

Webb, G. Washbarn \& Hoeu Mfg. Co.......... V Western Union Tel, Co............ . Y Waite \& Bartlett Mfg, Co............ Western Electrician ................ I Wilder Aut. Burglar Al. Co. .......... A Westinghonge El. \& Mfg, Co........ Wiles \& Scofield .................. Wing, L. J... \& Co.....................
Zucker \& Levett Chem, Co.......... 


\section{SLOW MONEY.....makes Low Prices}

Now is the time to begin to lay in your supplies for Fall Extensions.

WE ARE STILL SUPPLYINC

PRIGES AWAY DOWN....QUALITY AWAY UP

Meston Alternating Current Fan Motors in large quantities to those who know a good

thing when they see it. Are you going to get in line before it is too late?

\section{ELECTRIC APPLIANCE COMPANY,} ELECTRICAL SUPPLIES.

\section{THE MATHER ELECTRIC CO, THE "NOVAK" LAMP.} MANCHESTER, CONN.

Dynamos, Motors, Generators,

Offices, 116 Bedford St., BOSTON. -AND-

1002 Chamber of Commerce Bldg., CHICAGO.
CLAFLIN \& KIMBALL (Inc.)

General Selling Agents.

II6 Bedford Street, BOSTON.

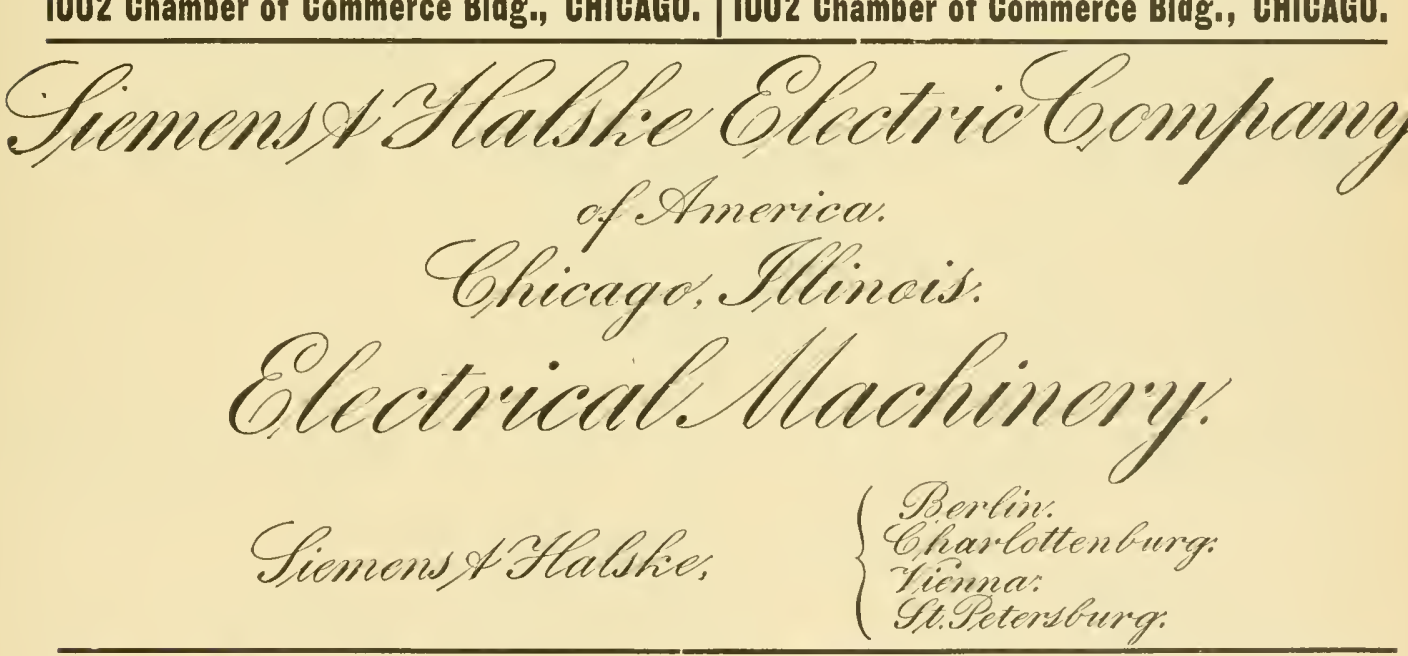

Enterprise sentatives for

Enterprise Electric Company

307 Dearborn Street, Chicago ....
Electric Railway, Telegraph, Telephone and Electric Light

SUPPLIES of eveny

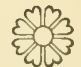

Agents for

Cedar Poles,

Cypress Poles, Oak Pins, Kocust Pins, Cross Arms, Glass

- Feeder Wire. Insulators,

WIRES, CABLES, TAPE and TUBING 


\section{Map of Chicago.}

Showing Location of its Electrical and Allied Business Interests, Principal Hotels, Theatres, Depots and Transportation Lines to the World's Fair Grounds. (Index numbers refer to the black squares.)

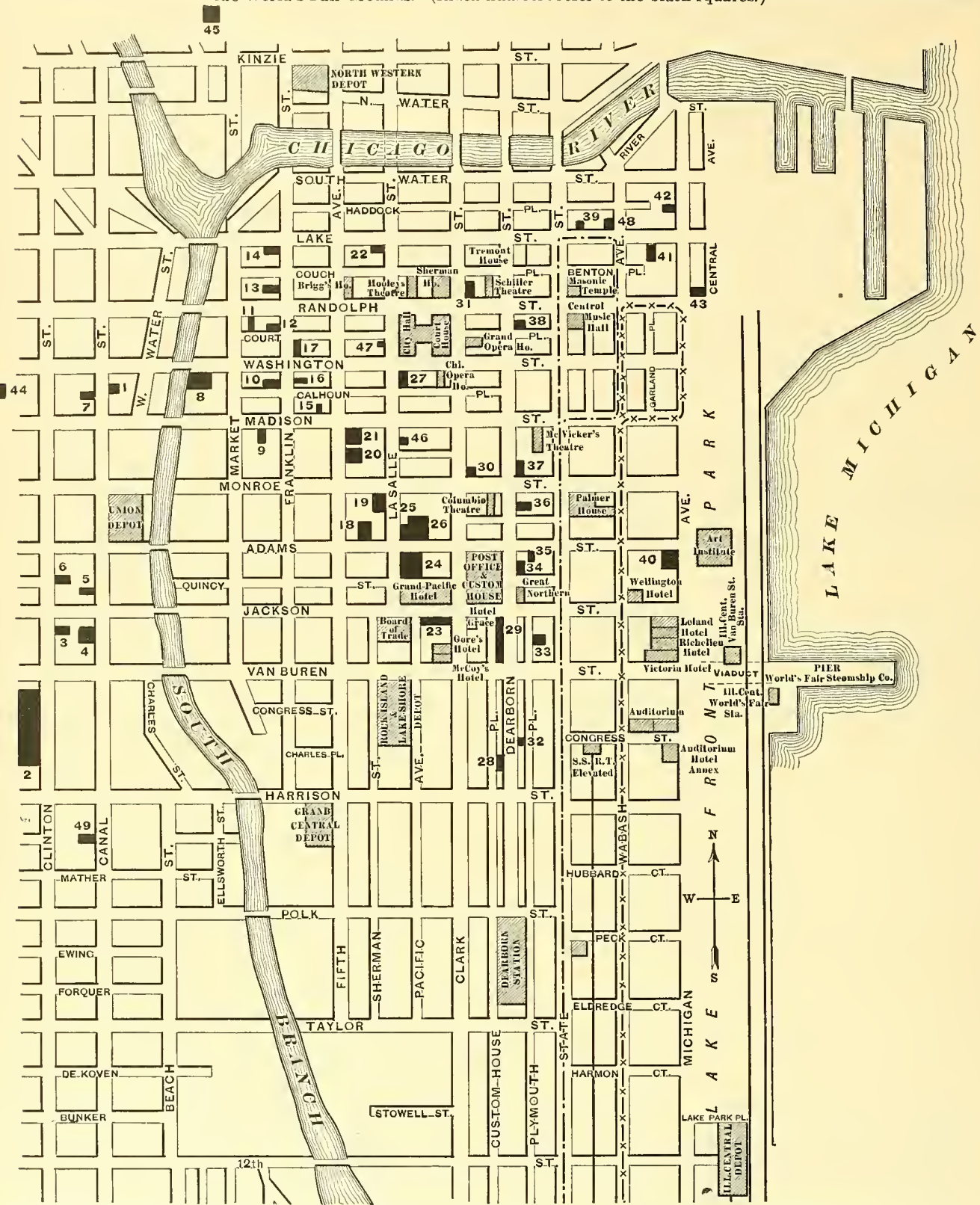

Ansonia Elec Co., Michigan Ave. \& Randolph St....34 Cushing \& Morse. 225 Dearborn St.............

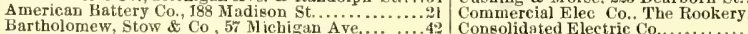

Bartholomew, Stow \& $\mathrm{Co}, 5 \mathrm{H} M$ ichigan Ave.

Barton \& Brown, $14 \% 8$ Monadnock Block.

Brill Co., J. G., Phenix Bldg...

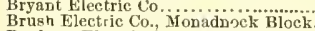

Brush Electric Co., Honaduock Block.....
Buckeye Electric Co. 437 Rookery Bldg.

Calumet Electric Mfg. \& Engineering. Co...........

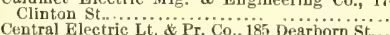

34. Me Dougall \& Cummings, Uvity Bldg....

29 C. \& C. Electric Motor Co., 201 Hadian St.

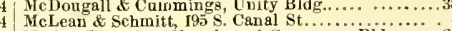

16 Mather Elec. Co., Chamber of Commerce Bidg........20

15 New York Iusulated Wire Co., 80 Frankln St..........17

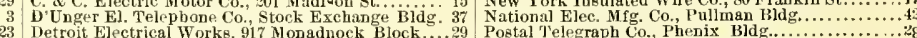
23 Detroit E]ectrical Works, 91 7 Monadnock Block...2.29 Postal Telegraph Co., Phenix Bldg.................28

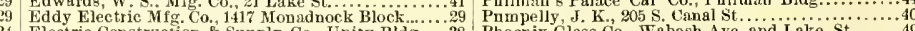

Electric Construction \& Supply Co., Unity Bldg...38 38 Phoenix Glass Co., Wabash Ave. and Lake St......49

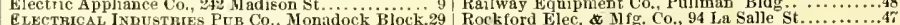

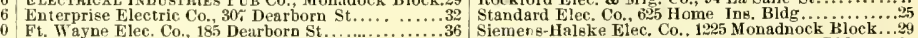

\begin{tabular}{l|l|l} 
Central Electric Co, 118 Franklin St............. 10 & Ft. Wayne Elec, Co,, 185 Deturborn St.... \\
Gentral
\end{tabular}

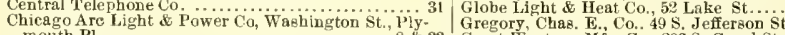
mouth Pl................................. ... 33 Gre at Wertern Mfg. Co..203 8. Canal

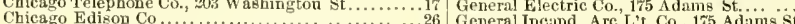
Chicago Electric Clibb, 175 Clark si.

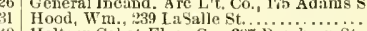

49 Holtzer-Cabot Elec. Co., $30 \%$ Desirborn st.

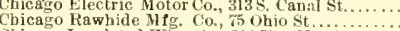
Chicago Insulated Wire Co., 211 The Northern ......... Jenney Elec, Motor Co, 932 Monadoek Block. tlaflis \& Kimball, 1001 Chamber of Commerce Bldg. 27 Keystone Elec, Co., 315 S. Caual St.... Cutter, Geo, 85t The Rookery.............46 Kinapp Elec. Works, 56 Franklin St....

36 Siemen s-Halske Eitec. Co..1225 Monadnock Block...29

39 Star Elec. Lamp Co., 805 Chamber of Com. Bldg.......27

44 Stirling Co., 606 Pnlliman Bldg...................... 18 Short Elec. Railway Co, Mlonadnock Block ..........29 18 Taylor, Goodhue \& Ames, 348 Dearborn St.........28 Todd. Applegate Co., The, 340 Dearborn St.......28 Waddell-Eutz Co., 1i2z Monadnock Block,..........29

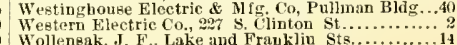
49 Wollensak, J. F., Lake and Fraukliu Sts............ 


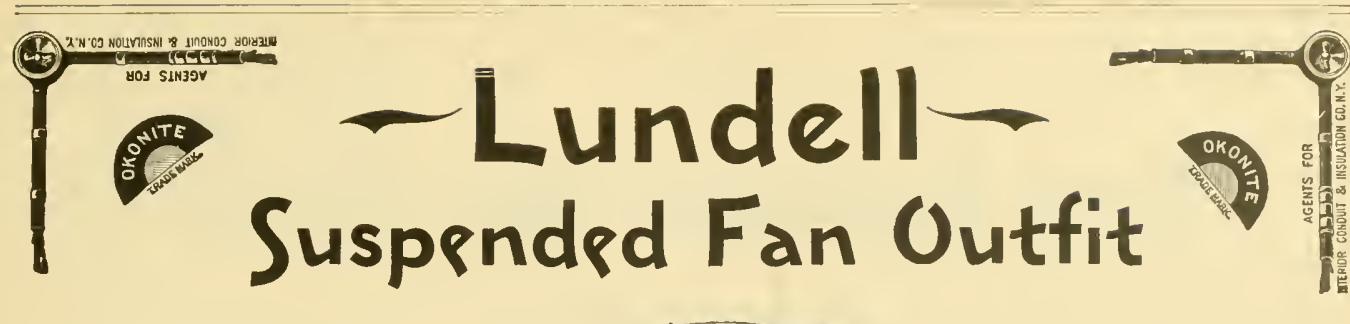

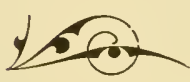

Black

Japan

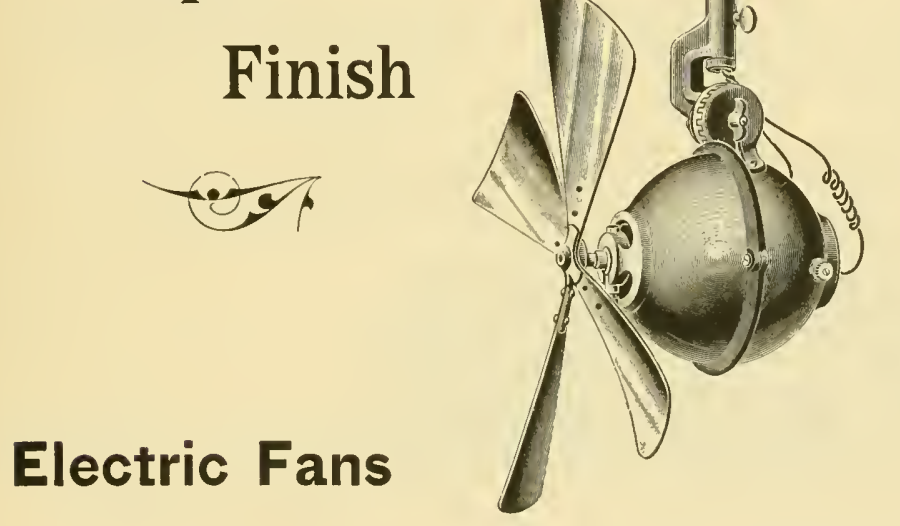

OKONITE WIRES

OKONITE $=$ TAPES $=$ MANSON

INTERIOR CONDUIT.

Batteries, Bells, Push Buttons, Annunciators, Volt Meters, Ammeters, Wheatstone Bridges, Line Wire Cross Arms, Brackets, Pins, Insulators, Tools.
GENERAL
SUP

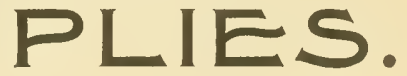

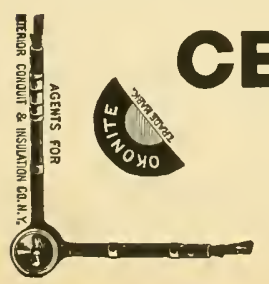

\section{ELECTRIC CO.}

II6-II8 Franklin Street,

CHICAGO, ILLS.

Electric Fans 


\section{VISITORS SHOULD NOT FAIL TO SEE THE}

\section{First Souvenir lialf Dollar}

\section{...AT THE EXHIBIT OF...}

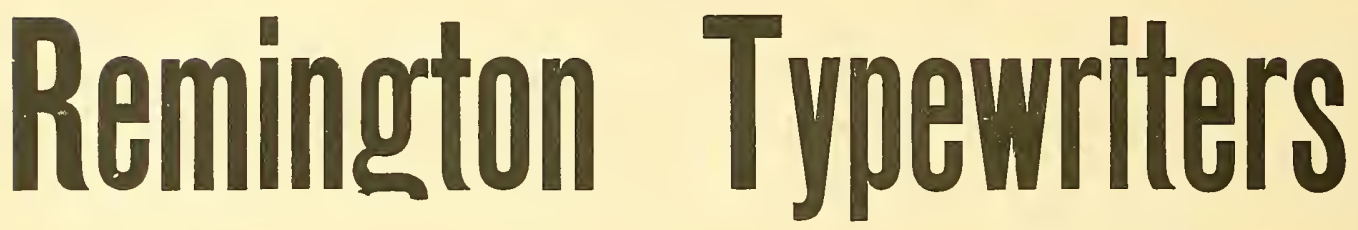

in the N. E. Corner of the Main Gallery of the Manufactures and Liberal Arts Building.

$\$ 10,000$ was paid for this coin, making it the most valuable piece of silver in the world.

\section{THE MONTHLY ISSUE FOR AUGUST}

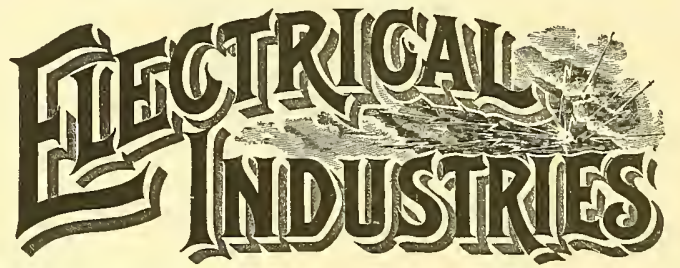

Should be read by everyone interested in electrical matters. In its table of contents is the following:

"Incandescent Lighting at the World's Fair."

"The Electric Power Plant of the Chicago City Railway."

"Steam Engine Efficiency-Its Possibilities and Limitations" by W1n. H. Bryan.

"Alternating Arc Lighting for Central Stations" by H. S. Putnam.

"Hard Rubber as an Insulator in Street Railway Work" by W. R. Mason.

"A Brief Review."

Together with illustrations of the recent applications of electricity.

The paper also contains regularly

A Buyer's Directory of Manufacturers and Dealers in Electrical Supplies and Appliances.

A Complete Directory of Electric Light Stations in North America and a Complete Directory of Electric Railways in Nortl America.

These directories are revised each issue to the date of going to press and are to be found in no other electrical journal in the World. Its articles are read carefully and its directories used constantly by all the buyers in the trade. These facts make it without a superior as an advertising medium. Sample copies and rates sent on application.

Subscription price $\$ 3$ per year. Six months trial $\$ 1$, if ordered during the next 30 days.

\section{ELECTRICAL INDUSTRIES PUB. CO., Monadnock Block, CHICAGO.}




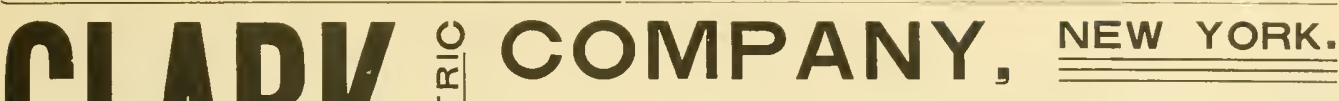 \\ 192 Broadway and II John Stree'. \\ MANUFACTURERS OF ARC LIGHTING APPARATUS FOR EVERY PURPOSE A SPECIALTY. The CLARK AR: LAMPS for use on EVERY CURRENT, have the reputation of being the best and most durable of any ever made in the United States.}

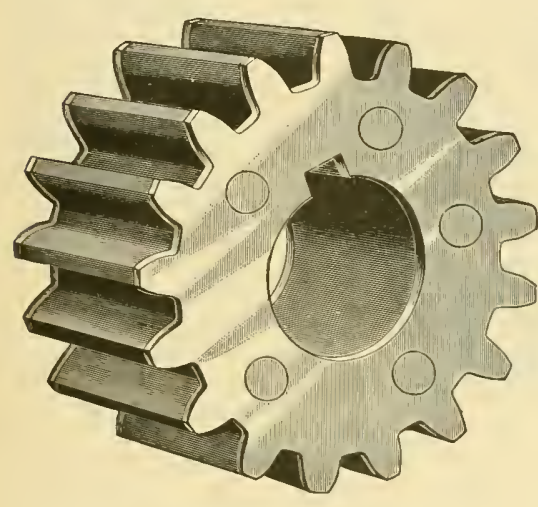

RAWHIDE PINIONS FOR ELECTRIC MOTORS A SPECIALTY.

RAWHIDE DYNAMO BELTING

Greatest Adhesive Qualities. A Non-Conductor of Electricity Causes Less Friction than any other Belt.

THE CHICAGO RAWHIDE MANUFACTURING CO.

THE ONLY MANUFACTURERS IN THE COUNTRY.

LACE LEATHER ROPE AND OTHER RAWHIDE.

GOODS

OF ALL KINDS

BY KRUEGER'S PATENT

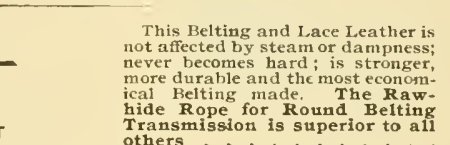

Transmission is superior to all

75 Ohio Street,

CHICACO, HL

\section{Standard Electric Company.}

GENERAL OFFICES: 625 Home Insurance Building,

WORKS: So. Canal Street,

\section{CHICACO.}

\section{STANDARD SYSTE
WORIDTS FAIT.}

MACHINERY HALL, Sec. Q, 2 Standard Arc Dynamos.

Sec. S, 20 " ".

ELECTRICITY BUILDING, Sec. P, Space 2, Arc Lighting Exhibit.

The Standard Lamps Light the Power Plant, Machinery Hall, Agricultural Hall, Shoe and Leather Building, an Other Buildings and Portions of the Grounds. 

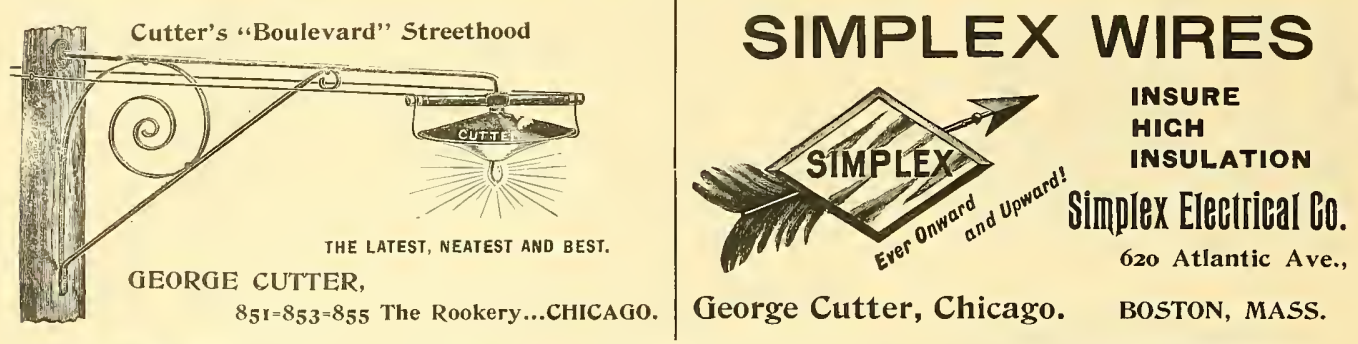

George Cutter, Chicago. BosTon, MASs.

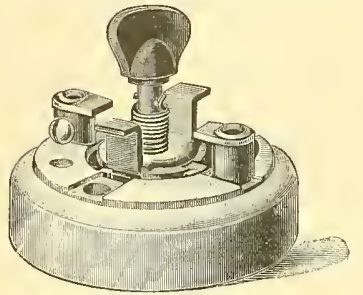

Made 5 amp. S. P.

10 amp. 3 way.

\section{XNTRIC}

"That's the Switch"

And we control that movement.

H. T. PAISTE, 10 South 18th St., PHILADELPHIA, PA.

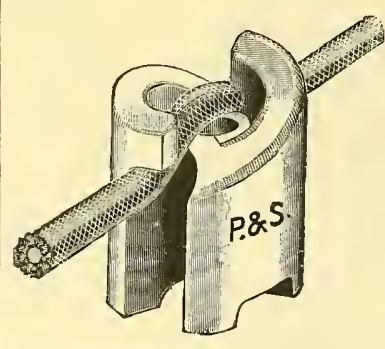

P. \& S.

WIRING INSULATOR, Saves TIME

TROUBLE and TIE WIRE Made only by

Pass \& Seymour, SYRACUSE, N. Y.

George Cutter, CHICAGo.

\title{
BEAR IN MIND
}

\section{ELECTRICAL . SUPPLIES,}

115 Franklin Street,

\section{CHICACO.}

GEORGE PORTHR,

Contractor for All Kinds of

\section{ELECTRICAL WORK.}

Room 67, 143 La Salle St., CHICAGO.

Crary Block, BOONE, IOWA.

\section{CHAS. A. SCHIEREN \& CO,}

\author{
MANUFACTURERS OF
}

\section{Genuine Perforated Electric Leather Belting,}

46 So. Canal Street, - CHICACO

that the regular monthly issue of ELECTRICAL INDUSTRIES contains the most cemplete and correct directories published of the electric light central stations and the electric railways in North America.

World's Falr Headquarters Y 27 Electricity Building. CITY OFFICES, Monadnock Block.

WAGNER ELECTRIC FAN MOTORS

For Direct or Alternatiug Current:

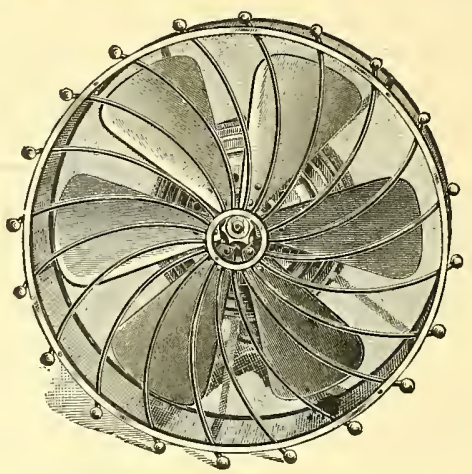

These motors give a stronger breeze with less consumption of current than ny other fan motor on the market. They are fan IT WILL PAY YOU TO SEE THE WAGNER BEFORE BUYING ELSEWHERE.

TAYLOR, GOODHUE \& AMES, 348 Dearborn Street, CHICACO. 


\section{WEEKLY WORLD'S FAIR}

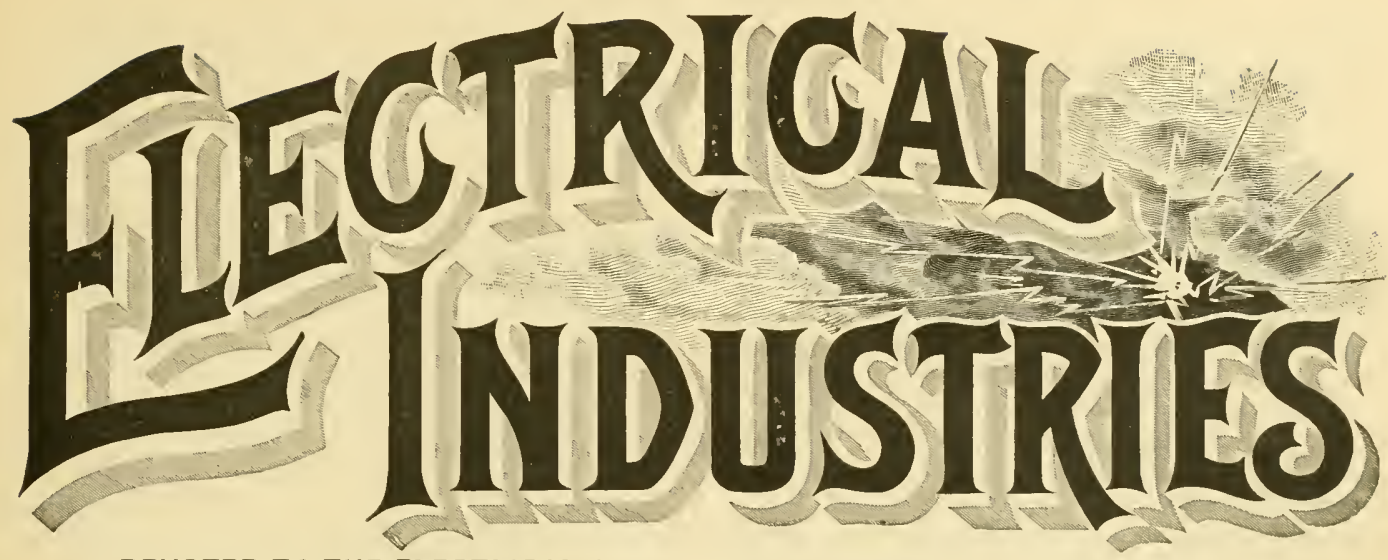

DEVOTED TO THE ELECTRICAL AND ALLIED INTERESTS OF THE WORLD'S FAIR, ITS VISITORS AND EXHIBITORS.

Vol. I, No, 9. CHICAGO, AUGUST 10, 1893. FIVE MONTHS \$1.00
TEN CENTS A COPY

Exhibit of the Westinghouse Electric \& Manufact= uring Company.

While the lighting system of the Westinghouse company is best shown in the electric plant of the Exposition, its ex- the latest system of long distance power transmission of this company.

Another section oceupying a similar space but toward the south of the building, contains an exhibit of railway power machinery. Directly to the east of this exhibit is the

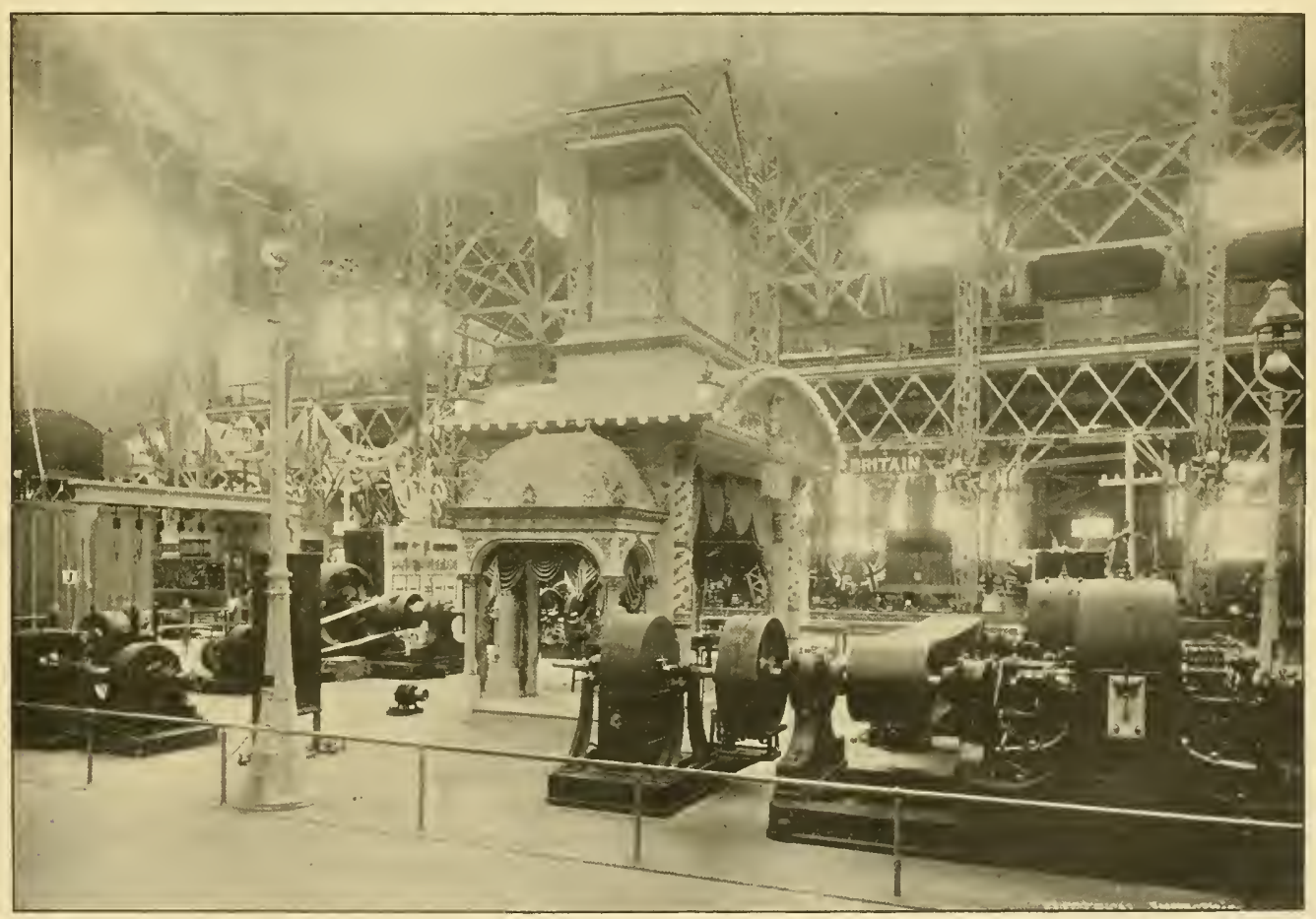

FIG. 1.-EXHIBIT UF THE WEATINGHUUAE ELECTRIO A MANUFACTURING COMPANY.

hibit in Electricity Building better represents the varied products of its factories. The exhibit is divided into sections, each representing a particular branch of the industry. The section located near the center of the building between the Barbier display of lighthouse lenses and the Edison Incandescent lamp exhibit, contains an exhibit representing display of both are and incandescent lighting. The Shallenberger meter, lighting arresters and apparatus showing some novel effects of the two phase alternating currents are also displayed in this section. In the corner of the space a room has been built in which are shown a nnmber of startling experiments in high tension currents. Mr. 
Tesla expects to be present to utilize this room for exhibitions for invited guests during congress week. To the east of this section is the space in which representative machines from the Newark factory of the company are shown. In addition to the letter and horizontal type several machines of the Manchester type are shown. Also a 50 -horse power multipolar direct current machine made in Pittsburg. The different sections are surrounded by substantial and ornamental railings open at the corners which are closed by brass chains.

The exhibit of long distance power transmission system consists of a complete plant with all the machines and apparatus necessary for the transmission and the reception of the electric current. The plant consists of a 500-horse power, two phase alternating current generator directly connected to a pelton waterwheel as illustrating the source of power while the real power is furnished by a 500-horse power two phase Tesla motor which is belted to the generator by a 24 inch belt. The prime generator is of the new type now known as the rotary transformer, although why it is so named is hard to say as it is simply a commutating sion plant proper. The greater number of the switches monnted on the board are used for controlling the Tesla motors supplied from the lighting circuits and used in this case to furnish power and exciting current to the transmission plant. All the connections and contacts are made on the back of the board, only the handles of the specially designed switches and the fuse blocks are on the front of the board. All the wires have Okonite insulation and are fastened on porcelain. All terminals for the instruments are insulated so that it is almost impossible to come in contact with the current on the front of the board. The fuse blocks are specially designed single pole blocks and the fuses are of a non-oxidizing metal requiring but a small mass of metal in comparison with the ordinary fuse. The block is eight inches long by four wide, of two pieces an inch thick. The pieces are recessed for the fuse and the outer block has a hole above the fuse through which the melted fuse may pass when blown out.

The bearings of the fuses are two long brass plugs an inch wide by three-eights inch thick and about six inches long extending ont at right angles from one side and fit in-

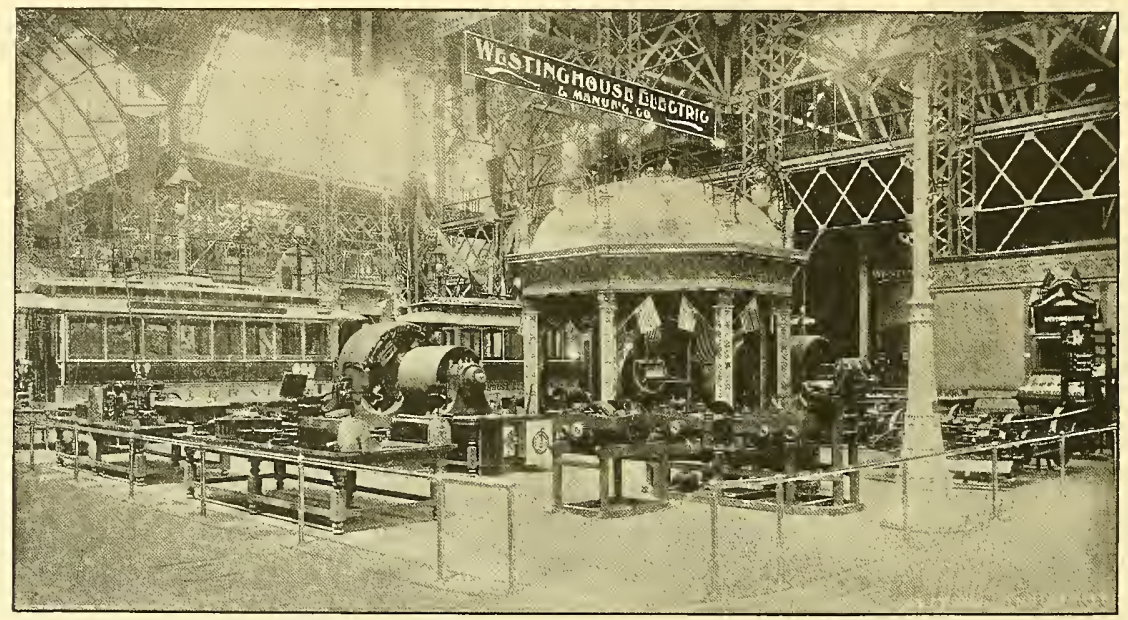

FIG. 2.-EXHIBIT OF THE WESTINGHOISE ELECTRIC \& MANUFACTURING COMPANY.

device for an alternating current and might better be called a commutating machine. As used in this case the full horse power output can be taken off either in alternating or direct current or any proportion of both currents at the same time.

The machine is separately exeited by a five-horse power direct current dynamo directly coupled to a Tesla motor of the same capacity. The dynamo may be easily made self exciting. The primary voltage is of course provided for according to distance and load, in this case the voltage is 380 . From the generator the current is conveyed to the switch board by the wires which are concealed beneath the floor. From the switch board the current is conveyed to the step up transformers for long distance transmission. This switch board is of white marble mounted on an iron frame and is arranged after a design specially made for this work. It is provided with the necessary switches for controlling the 500-horse power moter and the current from the generator so arranged that the current may be thrown from the step up transformers to any part of the exhibit.

The switch board contains much more apparatus than is required by the 500 -horse power generator of the transmis- to suitable contacts on the back of the board, holes in the marble permitting the placing of the block from the front. Other instruments on the board are as follows: Four 300 ampere ammeters; two 100 ampere ammeters; four 120 volt volt meters; two switch board transformers; one rheostat; three double pole switches for exeiters; two fuses for direct current lines and eight for alternating current lines. The back of the board is protected on the back by a closet about three feet deep, with doors at the ends allowing access to all connections.

Just back of the switch board on glazed tiling are the six step up transformers. A frame is built over them to support the four primary and four secondary wires. The 360 volt primaries of the three transformers are connected to one pair of wires from the switch board and generator and the primaries of the other three to the remaining two wires. The high tension secondaries, in this case 1,200 volts, are connected in the same grouping to the two pairs of transmission wires which rum on a couple of poles to the step down transformers at the opposite side of the space. The insulators used are of the type employed by the Westinghouse Electric \& Manusacturing Company in the plant now 
operating at Pomona and at San Barmardino, California. Usually the transmission wires would be conducted directly to the receiving switch board first, before reaching the transformers so in ease there were trouble with the trans. formers, eurrent conld be entire cut off from them.

The connections of the transmission wires to the step down transformers are precisely like those of the same at the power end of the line. The board varying only from the fact that connections, instruments, switches and other appliances are provided for control of all the various apparatus used to illustrate the methods of using the power. The principal machine shown at this end of the transmis. sion is another $50($ )-horse power motor or rotary transformer which takes the two phase current into the four rings at one end of the armature from the switch board and at 360 volts, and running as a motor supplies power to several machines belted from its pulley and direct eurrent from the commutator on the opposite end of the armature for use in a number of direct current motors used for varions purposes, thus illustrating the great flexibility of the system. The roltage from the direct current end is 5ex, being somewhat greater than the alternating current roltage supplied to the motor. current from this machine. Samples of the Ingersoll-Sargeant rock irill, and coal cutter are also shown. Connected to the alternating current switch board, current for which is taken from the secondaries of the step down transformers, are coupled direct to a 1,000 -volt constant potential alternating dynamo; the other being employed simply as a rotating transformer giving out a continuous current of 50 rolts, showing that low voltage can be liad for electrolytic or electroplating, and electric tanning, etc. It is intended to employ current from this machine to operate one of the large schuckert search lights in Electricity Builcling.

This covers the mechanical and electric part of the section and fully illustrates the drvelopment today of the two-phase long distance electrical transmission of power. In the center of the space on a platform slightly raised above the surrounding floor is a very han'some kiosk or booth, that is used as a reception room and office, tables and chairs are provided and files of the electrical journals are supplied for the visitor.

This booth is oblong in shape, made in wood and staff, the lower or supporting part consisting of columns at either end, the roof curving over and a square tower rising from

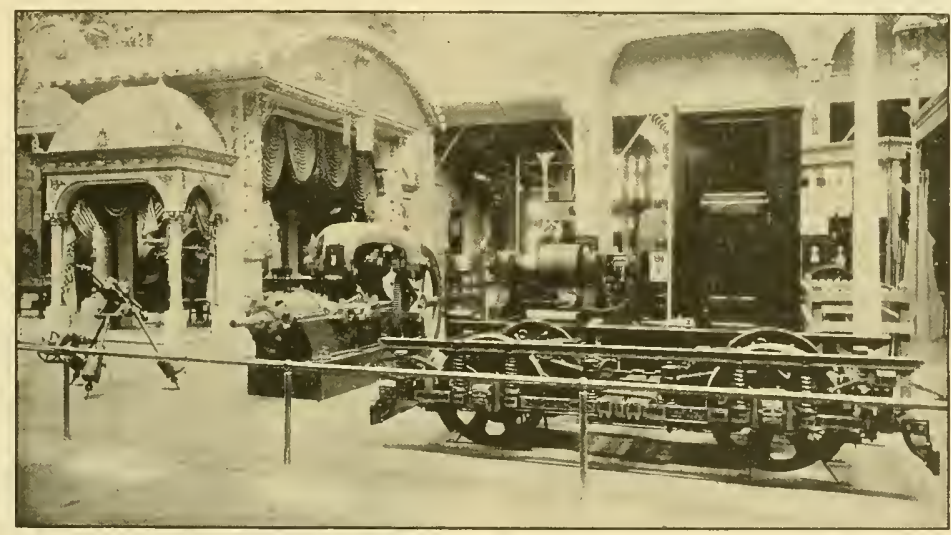

FIG. 3.-EXHIBIT OF THE WESTINGHOUSE ELECTRIC \& MANUFACTURING COMPANY

Driven by belt from the pulley of this machine is a large Worthington pump which supplies water to the Pelton wheel which is coupled to the shaft of the prime generator, and is done to show the regulator of the Pelton wheel which naturally should form a part of the power end of the exhibit.

Besides the pump, from another pulley on the same shaft is also driven by belt a 40 light alternating arc dynamo running $1,(100$ revolutions per minute, supplying a 10$)$ ampere current for 25 arc lamps suspended in a frame on the side of the space. A small switch board for controlling the output of this machine is provided near the dynamo.

Leads from the commutator end of the rotary transformer are taken to a portion of the receiving switch board where all the necessary bus bars and switches are provided for utilizing the current for running a pair of Westinghouse 30-horse power railway motors, mounted on a Dorner \& Dutton truck, the object being to show the ease with which this style of long distance transmission apparatus cau be connected to the existing railway lines, which might be lo. cated in towns sufficiently near to the plant.

An Ingersoll-Sargeant air compressor equipped with a 60 horse power 500-volt direct current motor is also run by it to the height of several feet, all being highly ornamented in clesign and painted in cream color, with the points touched out with gold. Flags and curtains are draped around the sides and ends, the margin of the cornices are ormamented and lighted by numerous incandescent lamps with globes of various designs and the interior is lighted by three highly ornamented short are lamps running on the alternating current. These are lamps are of the constant potential A. C. type. A large number of these lamps are supplied with current from the incauleseent lighting circuits throughout the Exposition grounds.

The name Westinghouse Electric d Manufacturing Company Tesla Polyphase System is in large letters on the north and south sides of the square tower on top of the pavilion. This is one of the handsomest exhibits in the Fair and is attracting a great deal of attention, as the system is new and not yet generally unclerstood by the public.

The section of the Westinghouse company's exhibit coming next in point of interest is the railway department, located between the two main aisles just north of the Bell Telephone temple. This display is intender to include a complete list of the apparatus necessary for use in con- 
nection with street railway power, with samples of such types as are considered embodying the most points of excellence. A very handsome octagonal kiosk occupies the center of the space furnished with tables and chairs and files of several trade journals. Curtains are draped across the openings, and it is illuminated by arc and incandescent lamps from the alternating circuits.

Ornamented wrought iron brackets are raised around the roof dome, from which are suspended eight short are lamps, very highly decorated in Berlin black finish. These serve to light the exhibit space as well as to ornament the booth. Suspended over the pavilion is a sign in black and gold displaying the Westinghouse company's name.

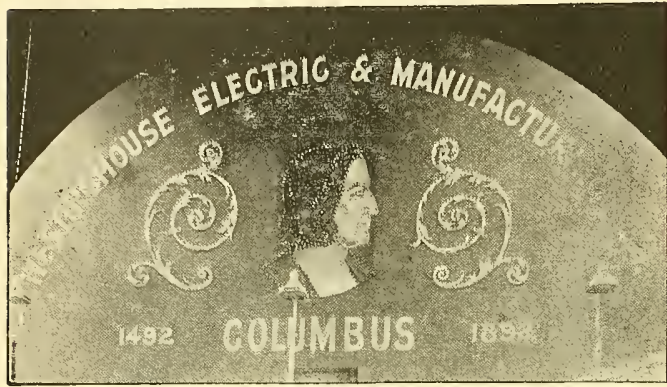

FIG. 4.-EXHIBIT OF THE WESTINGHOUSE ELECTRIC \& MANUFACTURING COMPANY.

The most noticeable feature of the exhibit is the "Kodak," or 270-horse power, 500.volt compound wound railway generator on the same base with and directly coupled to a Westinghouse compound engine, with cylinders 16 by 16 and 27 by 16 . This generator is over-compounded about eight per cent, is very compact and said to be highly efficient. Another heavy piece of apparatus is a 400 -horse power, 500-volt compound wound belt driven railway gen erator located on the opposite side of the pavilion from the "Kodak." Both of these machines have the special windings and all the latest features of the Westinghouse systems and are mechanically and electrically well balanced. On proper frames for the purpose are two generator armatures, one for a belt driven dynamo of 250 -horse power, and another for a 160 -horse power direct coupled machine.

In motors there are shown, one of 20 -horse power and one of 25-horse power on frames, with the fields thrown back to show the manner of construction and repair; another of 30-horse power capacity is elosed just as it goes on the truck. A"Three Rivers" equalizing truck on the south end of the space is equipped with a pair of the standard 30-horse power motors, which may be run as the truck is raised from the floor. The motor armatures here shown are of the toothed type in which the wire is first wound on a forn, then applied to the core in coils, the connections being made after the coils are placed.

On polished oak tables at the west side of the space are shown a sample field coil such as is used on the large compound wound railway generators; rheostats for the shunt fields of generators, these rheostats being thoroughly fireproof, the front of marble, the box of iron and the insulation as far as possible of porcelain. A pair of bearings and a complete set of brush holders with the yoke and attachments, a trolley stand and pole are also shown.

Another table displays the company's well-known series parallel controller for street cars, with miscellaneous parts of motors, controllers, commutators, canopy switches, connecting wires from motors to the controller, which by the way are run in a light canvas hose that is easily fastened to the underside of the car floor, motor fields, a diverter or resistance for use with the series parallel controller, and another for use with the plain rheostat.

A set of motor gears are shown of the proportion of three and one-half to one, motor bearings, trolley wheels, carbon brushes, lightniug arresters, which are of the air gap type with carbon contacts in an asbestos lined box.

The fuse shown for use in connection with street car work is of peculiar form. A double lignum vitae block is made, one part having a slot cut in it into which fits the other part. A small copper wire is used for a fuse which is donbled around the ends of one part of the block, and entirely protected from all other parts of the connections.

On a rack placed in the front part of the exhibit and made to imitate part of a skeleton switch board, is a Wurtz tank lightning arrester. As is well known this is a device for connecting onto railway eireuits only during heavy storms, and at such times current flows directly from the cireuit wire into a tank of rumning fresh water in connection with the ground. The special device for diverting the lightning from the machines is a series of simple copper wire coils or helices, the inductive or reactive effect of which is enough toturn the current off into the water ground provided for it. Another section of frame shows the method of making connections between circuit or terminal wires and bus bars.

Arranged on one of the sloping sides of a strong bench made for the purpose are samples of the automatic carbon

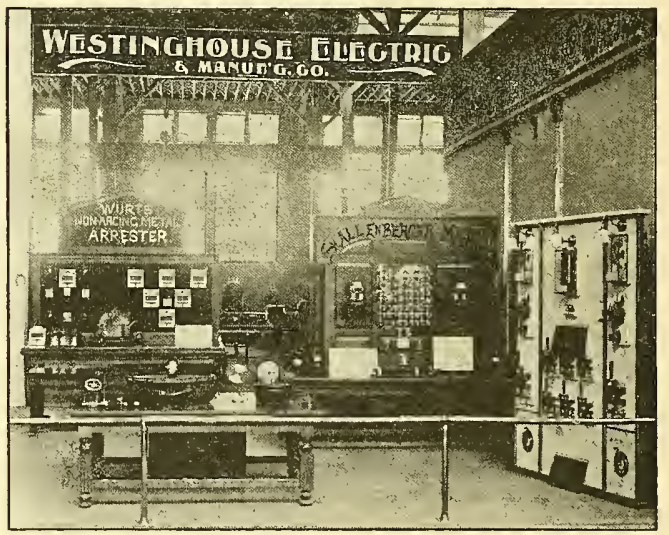

FIG. 5.-EXHIEIT OF THE TESTINGHOUSE ELECTRIC \& IANUFACTURING COMPANY.

shunt circnit breaker, running from 150 to 1,500 ampere capacity, and having the trigger adjustable by small weights or washers, each one representing 50 amperes capacity.

Another well designed switch is for use on feeders, and like the automatic switch it has the carbon shunt but is operated by hand.

Samples of the rarious sizes of eurrent and potential indicators are shown running in eapacity from 100 to 4,000 amperes. These instruments are all on bases of white marble, with sides and front made of plate glass with metallic fastenings. Double pole knife switches are shown as well as single pole, both in capacities from 30 to 1,600 amperes. On another table alongside the last are shown the heavy triple-point knife switches used on generator 
switch boards, and in capacities from 200 to 1,600 amperes. Ou a track over a pit running the whole length of the north end of this space are two street cars, one a Brownell 20.foot accelerator and the other a Stephenson 18-foot car with Tackaberry truck, both having $6 \frac{1}{2}$-foot wheel base. Both these cars are fitted throughout with the Westing house staudard 30-horse power equipment, with the series parallel coutrollers, and all the lamps and other devices that go with a car, complete and ready for the road. The New Haven fare register is used, and is quite neat in appearance as compared with the old style of circular dials in common use on old lines. The machines a re connected to a 500 -rolt circuit so that their actual operation is shown to visitors.

Nothing seems to be missing from this exhibit that can be needed or useful in a railway power station, aud with the courteous attendants always present to explain matters, visitors should be well pleased and get a fair knowledge of what the Westinghouse company has in this most interesting line.

In the section to the east are shown the various machines and apparatus used in electric lighting. Sample dynamos, converters, switchboard instruments and devices, lightning arrestors, etc., are exhibited. The transformers and meters are shown complete, and their unassembled parts showing the construction. The exhibit of the Wurtz non arcing lightning arrester is neatly arranged in the center of the space. The exhibit of dynamos ineludes sizes ranging from a 25 light to a 7,500 light, of both continuous and al. ternating current dynamos. Sample field rheostats, ground detectors, theater regulators with numerous other devices are shown.

While the Westinghouse company have arranged the exhibits of a practical nature of the greatest interest to the electrician, the mechanic and the capitalist, the decorative features have not been overlooked. One of the most noticeable features at night is the large illuminated sigu on which the name of the company, the dates 1492 and 1892 with the head of Columbus in the center are thrown out in the artistically arranged incanclescent lights.

A rery interesting novelty is the Columbus egg, as it is called, shown in the lighting exhibit. On a table on the west side of the space are placed a pair of large induction coils for exhibiting the effects of the two-phase rotary current. A wooden table is placed over these on which metal objects commenced to spin around as soon as placed upou it. Two copper eggs, one small, the other about eight inches long, when placed over these coils commence whirling and soon turn up on the end and continue to whirl In the room provided for the exhibition of high tension currents a series of tranformers and Leyden jars are so arranged as to give heary discharges over glass and rubber plates.

\section{The Cook Elevated Electric Railway.}

Near the Westinghouse Air Brake exhibit in the Trans. portation Building is a working model of the Cook Elevated Electric Railway. A single row of truss iron pillars, placed from 20 to 50 feet apart and of the desired height, supports the girders, which are constructed in the most approved style of brace work. The top of the girder has an outward and upward flange. The truck ruus the entire length of the upper right hand side of the car, the weight resting on two anti-friction wheels placed near either end of the truck, and ruming on the inside of the flange.
The driving wheel, which is directly conneeted with the armature shaft and made with bevelled edge, travels on the track at the lower part of the girder, which is made to slope ont and down. As the speed increases the driving wheel climbs the track and takes a portion of the load from the truck wheels, which ordinarily support four-fifths of the weight of the ear. The driving wheel and the truck wheels are compensating, thus lessening noise and vibration.

A guide wheel runs on the under side of the lower Hange and serves the double purpose of preventing the truck from learing the upper track and of increasing the traction of the driving wheel when desired, being controlled by a lever in the motor room. A shoe brake, also controlled by lever, bears on the outer edge of the lower flange and is wouderfully efficient in conjunction with the under running guide wheel in making quick stops. In practical tests, made last fall at Tacoma on a 600 foot eliptical wooden track, a speed of 42 miles per hour was developed, and stops were made inside of 600 feet while running at this speed, and without incouvenience to the passengers,

The current is applied through a flat copper conductor placed in a perfectly insulated trough on the under side of the upper track, where it is necessarily protected from rain, sleet or snow. A metal brush trolley is used, which will be perfected later so as to allow the car to move in either direction. The motor is of the ordinary street railway type, that used in the Tacoma tests being of the Sperry manufacture. The ground is made by the contact of the driving wheel with its track.

Among the claims made for this system by Mr. Cook, who is personally in charge of the exhibit, are the following: A speed of 200 miles per hour; an absence of any jerking or surging motion in starting or stopping; minimum possibility of accidents to passengers or the public generally; low cost of construction; small amount of ground space required for the single line of pillars; one abore the other can be constructed on the same line of supports; a modifieation of the system can he used for express or parcel transportation.

A company has been formed and it is expected that at least two miles of track will be in operation in Chicago before the end of the present year. Such an eminent specialist on the rapid transit problem as Prof. Haupt, of the University of Pennsylrania, unhesitatingly pronounces in favor of the Cook system.

A well-known electrician was heard to remark the other day that electricity could show the only notable progress of any thing at the World's Fair. In art, science, manufacture, and nearly every branch of industry, he said, the advance made could not be compared with electricity. The Jumbo dyuamo was one of the first incandescent machines built. and is now on exhibition at the World's Fair. Compare that machine with those of to-day and a person sees the improvement at once. This cannot be shown of the steam engine or any other class of machinery in so marked a de. gree. In transportation the progress made has been that of electric traction. In fact, electricity is the one feature of the Fair that is always interesting and constantly reveals some new wonder to the thousauds of people who visit the Exposition both day and night.

England, Germany, Belgium, Brazil and Turkey are now represented ou the jury of awards; Ahmed Fahri Bey, an electrical engineer of Constantinople, having recently been appointed. 


\section{ELECTRICAL INDUSTRIES.}

PUDLISHED EYERT THURSDAY BY THE

\section{ELECTRICAL INDUSTRIES PUBLISHING COMPANY, INCORPORATEO 1889. \\ MONADNOCK BLOCK, CHICAGO. \\ TELFPHONE HARRISON 159.}

E. L. POWERS, PReg. and Treas.

E. E. WOOD, SEcretary.

E. L. POWERS,

Editor.

H. A. FOSTER,

W. A. REMINGTON,

E. E. WOOD,

FLOYD T. SHORT,

- Eastern Manager. Advertiging Department

EASTERN OFFICE, WORLD BUILDING, NEW YORK. World's Fair Headquarters, Y 27 Electricity Building.

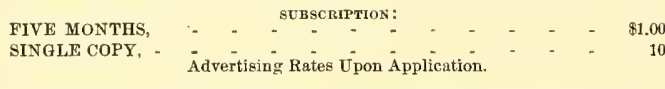

News items, notes or communications of interest to World's Fair Visitors are earnestly desired for publication in these columns and will be heartily appreciated. We especially in rite all visitors to call upon $u$ or send address at once upon their arrival in city or at the grounds. ELECTRICAL INDUSTRIES PUBLISHING CO.,

THE interest taken in the World's Congress of Electricians by foreign nations and societies is a matter of commendation. The Electrotechnischer Verein of Vienna has just appointed the following of its members delegates to represent it at the meetings of the congress: Nikola Tesla, A. Prosch, inspector of the Austrian State Railways; Ernst Egger, Dr. Johann Sahulka, constructor at the Imperial High School, Vienna, Fred W. Tischendorfer and Joseph Wetzler.

THIs month will be the crowning one to all interested in electricity who are able to visit Chicago and the World's Fair. The number of electricians now here is being constantly increased. Prof. Helmholtz, whose name is familiar to everyone, is expected to arrive in Chicago in a few days. The educational advantages of this meeting can hardly be estimated. To all who are in any way interested in electricity, the congress and the Fair will be found of the greatest interest and benefit. Electricity Building affords mexcelled advantages for edncational improvement. The exhibits, with the attendants in charge who are ready to explain any part of the exhibit; the various features intalled, not so much to show the practical side of electricity as to show what ean be done with the electric current; the popular lectures and other attractions arranged by the department afford opportunities never equalled. The congress, with the men prominent in arts and science assembled from distant cities, will also afford to all interested in electricity, no matter in what branch, an opportunity of gathering a mass of information such as would otherwise require years to gather.

\section{Popular Lectures in Electricity Building,}

The Department of Electricity desiring to create as much general interest as possible in the exhibits in Electricity Building, has mapped ont a course of free lectures to be given every Tuesday, Thursday and Saturday afternoon from now on until the close of the Fair. Mr. Hawley, of the Department of Electricity has the matter in charge.

The regular course will begin next week and various subjects pertaining to the uses and application of electricity will be treated under the following heads: Lighting (a), Are (b), Incandescent; Power Transmission; Experiments in High Potential, High Frequency and Alternating Current; Electrical Signals; Electrical Railways; Electricity applied to Mining and Milling Machinery; Wires and Insulation; Ocean Cables; The Telegraph; The Telantograph; The Phonograph; Metal Working; Scientific Instruments; Patent Law Applied to Electricity.

Preliminary to the regular course on Tuesday this week, Mr. C. P. Frey, electrician, with E. S. Greeley \& Company, New York City, gave a talk on "Electrical Test Instruments," and on Thursday, Mr. Fred W. Tischendoerfer, representative of Schuckert \& Company, Nuremberg, Germany, will speak on "Search Lights," and on Saturday of this week "The Fire Alarm and Police Telegraph" will be discussed by Mr. E. Bruce Chandler, of the Gamewell Fire Alarm \& Telegraph Company of New York.

The lectures will all be given in the new seenic theatre of the Western Electric Company in the southeastern corner of the Electricity Building, and will begin promptly at 2 o'clock P. 1. It is expected that they will not last more than an hour. As soon as the program for the entire course is completed it will be announced in full in Electrical INDUSTRIES.

\section{The Importance of Practical Experience.}

The importance of practical experience in the training of electrical engineers is emphasized by Prof. S. P. Thompson in a letter to the editor of Electrical Plant and Industry, London, in which he says: "The education of a student of electrical engineering, whether liberal or illiberal, must be an education obtained from things and men, in the laboratory, the workshop, and the drawing-office, can be aided by books and lectures; but these do not and cannot constitute the education of an electrical engineer. From that point of view there is more educational value in a half-yearly volumn of one of the weekly technical journals than in a ton of text-books. Give the student of electrical engineering the run of a laboratory well equipped with modern electrical machinery and instruments, and a good library of books of reference, and bring him into daily contact with men who are themselves both electricians and engineers, he will want few books beyond his own note-books and a pocket-book of numerical data. It is a real disaster to the electrical industry, and to the thousands of young men who are just now swarming into it on all sides, that the idea should prevail that so essentially practical a subject can be crammed up by mastering a certain list of books. It is mainly because we are convinced of the evil wrought by such misinformed ideas that Mr. Knapp and I, who have now for two years been colleagues as examiners in this subject in the City and Guilds Techmological examinations, have determined to set such questions as shall be impossible to be satisfactorily answered by the mere paper electrician, whilst they shall be comparatively easy to answer by the candidate who has really mastered his subject by becoming practically acquainted with it in the laboratory, the drawing-office, and the workshop, the lighting station, or the testing-room. Electrical engineering can no more be learned from books than ean railway engineering, or hydraulic engineering, or any other branch of the great electrical industry. 


\section{WORLD'S FAIR NOTES.}

The exhibit of the Hicks (Troy) Electrical Door Operator on the west gallery, near the Enterprise Electric Co., is nearing completion.

Dr. N. S. Keith, of San Francisco, expects to shortly install an exhibit of constant current motors, similar to those used largely on the Pacific Coast.

Sidney Smith \& Sons of the Basford Brass Works, Nottingham, Eng., have displayed in a neat case in $\mathrm{Ma}$ chinery Hall a line of brass goods, including steam boiler alarms, gauges, valves, water columns, ete.

The Yale \& Town traveling crane with a band of music and a number of visitors, traveling back and forth the length of Machinery Hall and Annex orer the heads of risitors and exhibitors was watched with a considerable of interest last week.

The new scenic theater of the Western Electric Co. is "playing to large houses." People can be seen crowcling around the entrance awaiting the next performance from the time the theater is opened till it is closed in the after noon.

A large jeweled sign, 21 feet 4 inches in length, bearing the words, "Western Electric Company," is to be hung in front of the Egyptian Temple, near the southeru entrance to Electricity Building. Ten arc lamps will be placed at the back of the sign to give the jewel effects.

The Association of Edison Illuminating Companies, of which Mr. M. J. Jenks, of the legal department of the General Electric Company, is Secretary, are holding their annual meeting this week at the Fair. The opening ses-

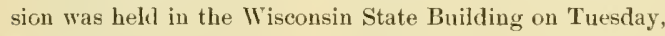
August Sth.

In Machinery Hall the ormamental posts in the railing which surrounds the service plant have attracted a good deal of interest. The tops which support incandescent lamps in very neatly designed shades are very handsome. The different colors of the shades which were made by the Phoenix Glass Company give a variety to the combination.

The register of the American Institute of Electrical Engineers contains much interesting data. On August 4th, there were nine entries only, but these nine are literally from the four corners of the globe. We give the addresses in order: San Francisco, Constantinople, Vienna, Stockholm, Darmstadt, Cornwall-on-Hudson, Morgantown, IT. Va., Lafayette, Incl., and New York City.

Preparations for the California Midwinter International Exposition is progressing rapidly at Golden Gate Park at San Francisco, Cal. The Park covers some 100 acres and will contain five prineipal buildings, viz: Manufactures and Liberal Arts, Agricultural and Horticultural, Fine and Decorative Arts, Mechanical Art and Admmistration buildings. Besides these buildings there will be numerous smaller buildings occupied by various concessions.

McIntosh, Seymour \& Company of Auburn, N.Y., have in use in the service plant in Nachinery Hall a 1,200-horse power engine of the double tandem compound type belted to one of the large Westinghouse alternators. Among the special features of the construction of this engine are the water jackets for the guides and main bearings, the latter being of ball and socket pattern with oil settling chambers and pumps for continuous oiling, copper heating coils in the receiver fed from high pressure cylinder jacket, and a drag link shaft which gives motion to the governor placet on the outside of the frame. Engineers will find many things about this engine of interest.

\section{What to see in the Electricity Building in the Daytime.}

"There is nothing worth seeing in there," is a remark one quite frequently hears made in reference to the Electricity Buileling. Of course it is always made by visitors who are not well acquainted with the grounds and haring no special interest in electrical matters. This is to be rery much regretted, for there certainly are many exhibits of interest to the general public in the Department of Electricity.

Entering the Electricity Building at the north door the visitor should take the electric elevator directly in front of the entrance, or the one in front of the French section on the west sicle of the building, to the gallery. At the north center of the gallery is the exhibit of the Ansonia Electric Company, and in the east end of its pavilion is the exhibit of the American Electrical Heating Company, where the visitor may witness the exceedingly novel and interesting sight of cooking by electricity. This, of course, is more especially interesting to ladies.

Going west from the Ansonia exhibit and then south past the French piano exhibit the visitor will come to the booth of the Commercial Cable Company, where the sending and the receiving of cablegrams is something that the visitor should not go away without seeing.

Opposite to this booth is Prof. Gray's telautograph and everyone of course wishes to carry away from the Fair a souvenir telautogram as well as to have explained the workings of the mysterious little instrument that not only duplicates a message hundreds of miles away, but produces it in an exact facsimile of the sender's hand-writing.

Continuing down the main aisle to the extreme southern end of the gallery the visitor will arrive at the exhibit of the North American Phonograph Company, where will be found the Edison Phonograph applied to all its various uses. Directly opposite the phonograph exhibit is one of the most interesting pieces of mechanism in the Fair, the National engraving machine, a machine capable of engraving one's nawe in characters so fine that a magnifying glass is necessary to decipher them.

Descending to the main floor the Grecian temple of the Brush Electric Company is directly in the foreground and opposite it is the smaller but no less attractive temple of the Jenney Electric Motor Company. Opposite the main southern entrance is the exhibit of the Bell Telephone Company with all of its historical apparatus. Here is to be seen the photophone by means of which sounds are transmitted through the medium of a ray of light.

Directly east of the Bell telephone exhibit is that of the Western Electric Company. If the day is warm the visi tor should pass through the Egyptian temple and enjoy the cool breeze produced by the large exhaust fans, then if the scenic theatre is open a visit should be paid to it. The automatic writing machines at the northern end of this exhibit are extremely novel. Near by a magnetic lift offers an opportunity for the "strong man" to exercise his muscle.

Farther north past the main eastern entrance is the exhibit of the Electrical Forging Company, which, it is to be regretted, is too seldom in operation. Next north of this exhibit is that of the Belknap Motor Company where the visitor will get another refreshing breeze from a large exhaust fan and have an opportunity of witnessing the amus ing spectacle of "fishes swimming in the air." 


\section{PERSONAL.}

Mr. Wm. Stanley has been spending a few days at the Fair and about Chicago.

Mr. Luther Stieringer arrived in the eity last Thursday and will spend a few days at the Fair.

Dr. Chas, E. Emery is now in New York but will return later when the active work of the jury commences.

Ar. R. A. Falconer, of the Falconer Mfg. Co., Boston, was a caller at the booth of ELECTRICAL INDU8Tries this week.

Prof, George F, Barker, of the University of Pennsylvania, one of the judges of electrical exhibits, is now in the city.

Mr. Richard 0 . Heinrich, of the Weston Electrical Instrument Co., Newark, N. J., is at the Fair again for a few days.

Mr. J. T. Burke, secretary of the Western Electrical Supply Company, Omaha, Neb., has been in the city for some days past.

Mr. John M. Marvin, of Milwaukee, the inventor of Marvin's Electrical Brick Baker, has been a visitor at the Fair the past week.

Prof. Henry A. Rowland, of Johns Hopkins University, Baltimore, is attending the jury meetings of the department of electricity.

Mr. Phillip H. Campbell, general manager of the India Rubber Comb Co., New York, is spending a few days in Chicago and at the Fair.

Prof. Horace S. L. Verney, from the Stevens Institute, New York, is registered at the office of the American Institute of Electrical Engineers.

Mr. Adolpho Ashoff, of Brazil, has been appointed on the jury of awards of the Department of Electricity as one of the foreign members. He is now in attendance.

Prof, George F. Barker, of the University of Pennsylvania, is now in attendance at the Exposition. He is on committees No. 1 and 2 of the jury of awards of the department of electricity.

Dr. N. S. Keith, of San Francisco, Cal., arrived in Chicago on Friday last and will spent a few weeks at the Fair. Dr. Keith was one of the originators of the American Institute of Electrieal Engineers.

Mr. S. D. Greene, general manager General Electric Co., New York; Mr. A. D. Page, assistant manager of the Edison Lamp Works, Harrison, N. J.; and Mr. Jno. W. Howell of the Edison Lamp Works, Newark, N. J., are in Chicago this week.

\section{DEPARTMENT OF ELECTRICITY.}

OFFICES: SECTION R, ELECTRICITY BUILDING,

Chief, JoHx P. BA ReretT,

Assistant Chief, J. Allen Hornsky.

General Superintendent, J. WV. BLAISDEIL.

Electrical Engineer, W. W. PRimM.

\section{DEPARTMENT OF MECHANICAL AND ELECTRICAL} ENGINEERING.

OFFICES SOUTH OF MACHINERY HALL.

Mechanical Engineer, C. F. Fostex

Electrical Engineer, R. H. Pierce.

First Asst. Mechanical Engineer, JoHn MEADEN.

First Asst. Electrical Engineer, S. G. NerLER.

\section{A YERICAN INSTITUTE OF ELECTRICAL ENGINEERS}

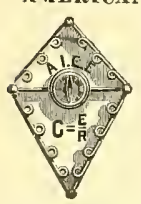

World's Fair Headquartere,

SECTION S, ELECTRICITY BUILDING.

Ralph W. Pope, Secretary.

Open from 9 a.m. to 5 p.m.

CHICAGO WORLD'S CONGRESS OF ELECTIRCIANS.

OPENING SESBION, MONDAY, AUGURT $21 \mathrm{sT}, 3 \mathrm{P}$, M. ADVISORY COUNCIL.

President, Dr. EuIsna Gray, Highland Park, Ill.

Secretary, Pzof. H. S. Cakhart, Ann Arbor, Mich. EXECUTIVE COMMITTEe.

Chairman, Prof. Elrhu Thomson, Lynn, Mass. COMMITTEE ON INVITATIONS.

Cbairman, T. Commerford Martin, 203 Broadway, New York. COMMTTTEE ON PROGRAM.

Chairman, Prof. T. C. Mendenhall, Washington, D. C. COMMITTEE ON FINANCE.

Chairman, B. E. SUNNY, 175 Adams Street, Chicago.

\section{BUSINESS NOTES.}

The Electric Appliance Company, 242 Madison St. Chicago, reports that it has a surprise in store in the shape of something new and progressive in the transformer line and advise intending purchasers to correspond with them before making any converter contracts or placing any transformer orders.

The Central Electric CoMpany, Chicago, reports having just secured the contract for the complete installation with Okonite wire of the new Y. M.C. A. Building on LaSalle St. The company also secured the contract for the complete equip. ment of the great Ferris wheel with Okonite wire. The strue ture of this wheel being entirely of iron it was found necessary to have a very high grade of insulation and the fact that this brand was selected speaks volumes for that popular wire.

Electrical Fngineering Company, 249 Second Ave., south, Minneapolis, Minn., formerly the Electrical Engineering \& Supply Company, of St. Paul, is handling a large line of Electrical machines and supplies, including National incandescent and Standard are dynamos, Eddy and Holtzer-Cabot motors, Paranite, Grimshaw and $0 . K$. Weatherproof wires and electrical supplies and specialties of all kinds. The company just completed the installation of a 2,500 light alternator with the necessary transformers, etc., at Brainard, Minn., and has several large contracts on hand

\section{Amusements.}

Hooley's Theater-Mr. Nat C. Goodwin, in "Mizzoura." 149 Randolph street.

Columbia Theater-Miss Lillian Russell, in "The Mountebanks." 108 Monroe street.

Grand Opera House - Sol Smith Russell, in "A Poor Relation." 87 Clark street.

AcDitoriuy-Imre Kiralfy's Spectacle "America." Congress street and Wabash avenue.

MoVicker's Theater-Denman Thomson, in "The Old Homestead." 82 Mfadison street.

Chicago Opera House-American Extravaganza Company, in "Ali Baba, or Morgiana and the Forty Thieves."

Washington and Clark streets.

Schiller Theater-Chas. Frohman's Stock Company, in "The Girl I Left Behind Me." Randolph, near Dearborn.

Haverdy's Casino-Haverly's United Minstrels. Wabash avenue, near Jackson street.

Trocadero-Vauderille. Michigan avenue near Monroe street.

The Grotro-Vaudeville. Michigan avenue near Monroe street.

Buffalo Bill's "Wild West." 63d street. Daily at 3 and 8.30 p.m.

Pain's "Siege of Sebastopol," 60th street and Cottage Grove avenue. Tuesday, Thursday and Sunday nights.

The Alhambra Theater opens Saturday evening with Corinne in "Henrick Hudson."

The principal attraction at the Trocadero this week is the appearance of the strong Prussian, Sandow, whose feats requiring great strength are a surprise to all.

"The Mountebanks" by Gilbert and Cellier, is being presented this week at the Columbia by The Lillian Russell Opera Comique Company, Miss Russell appearing as Teresa.

"America" is enjoying its sixteenth week at the Auditorium. This fascinating spectacle once seen leaves an impression that cannot be effaced, and repeated visits are made with increased pleasure. The Schaffers are still one of the great attractions of the piece.

The principal event of this week has been the appearance of Mr. Nat C. Goodwin at Hoolev's in "In Mizzoura," a play of which Augustus Thomas is the author. The play has been favorably received by good houses, which seem to be more enthusiastic on each succeeding night.

At the Chicago Opera House "Ali Baba" is having the same erowded houses. New ideas and new hits keep the play fresh. The jokes of the players keep pace with the times and some of the local hits are especially amusing. Norman's "Midway Plaisance" is a decided hit. It is announced that the piece is soon to be taken from the boards and will make a tour of the principal cities. 


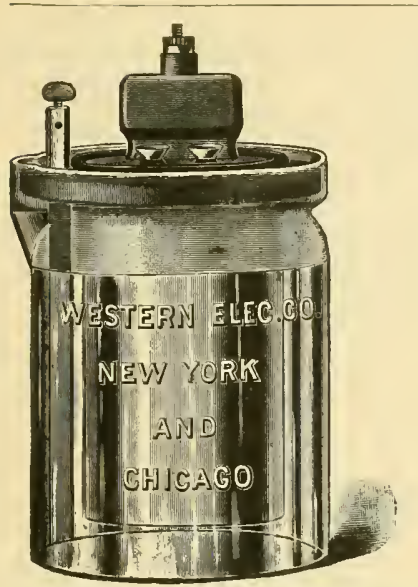

Disque La Clanche Batterv.
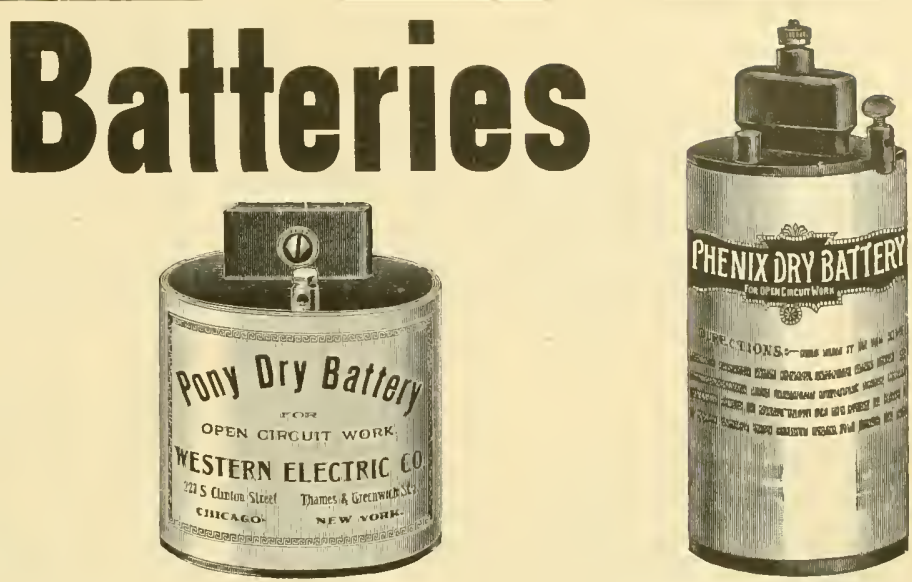

Phoenlx Dry Battery.

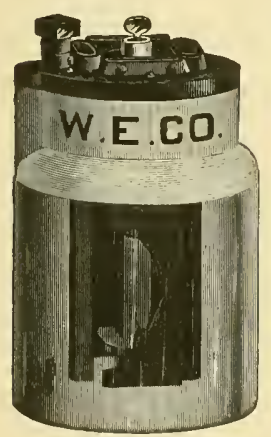

Quad Battery.

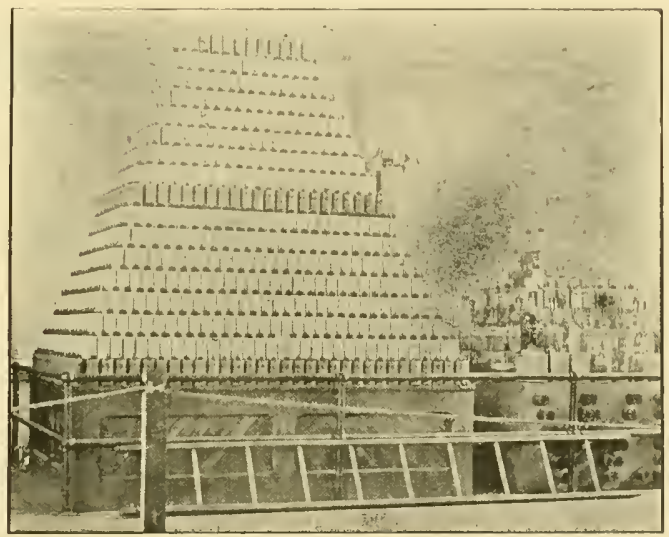

Battery Exhibit Electricity Bldg, World's Fair.
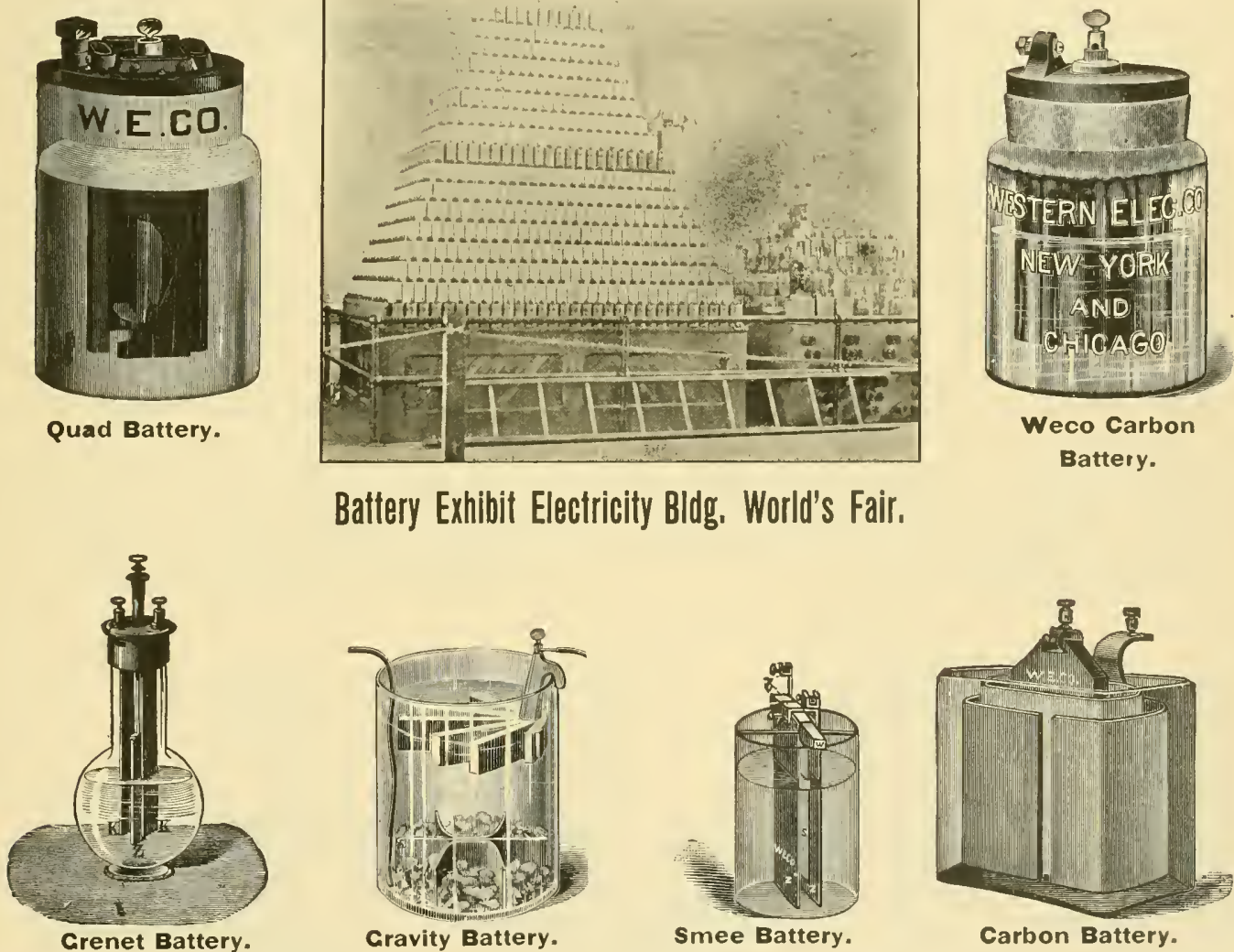

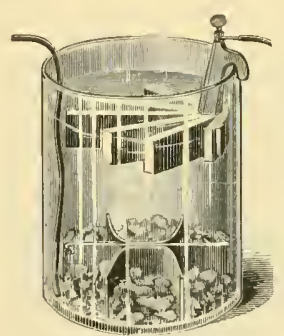

Cravity Battery.

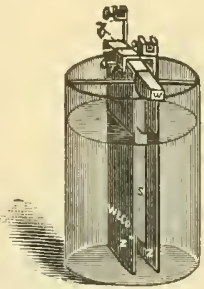

Smee Battery.

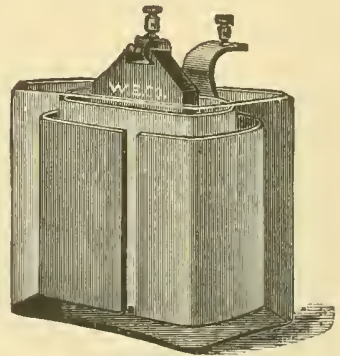

Carbon Battery.

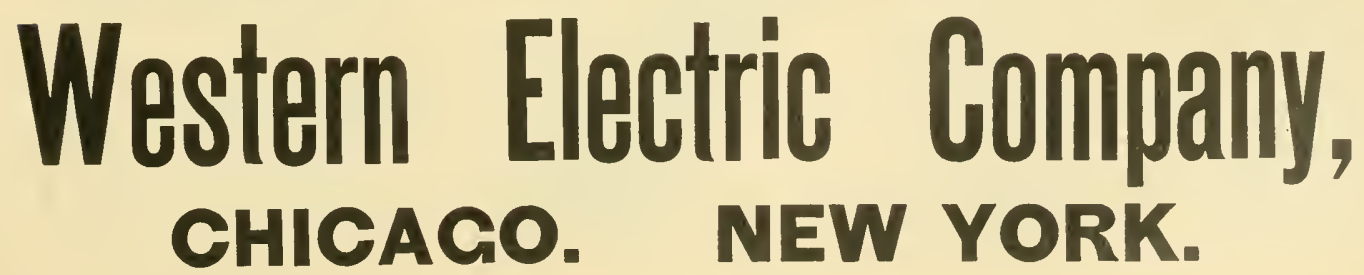




\section{ELECTRICITY BUILDING-EXHIBITORS AND THEIR LOCATION.}

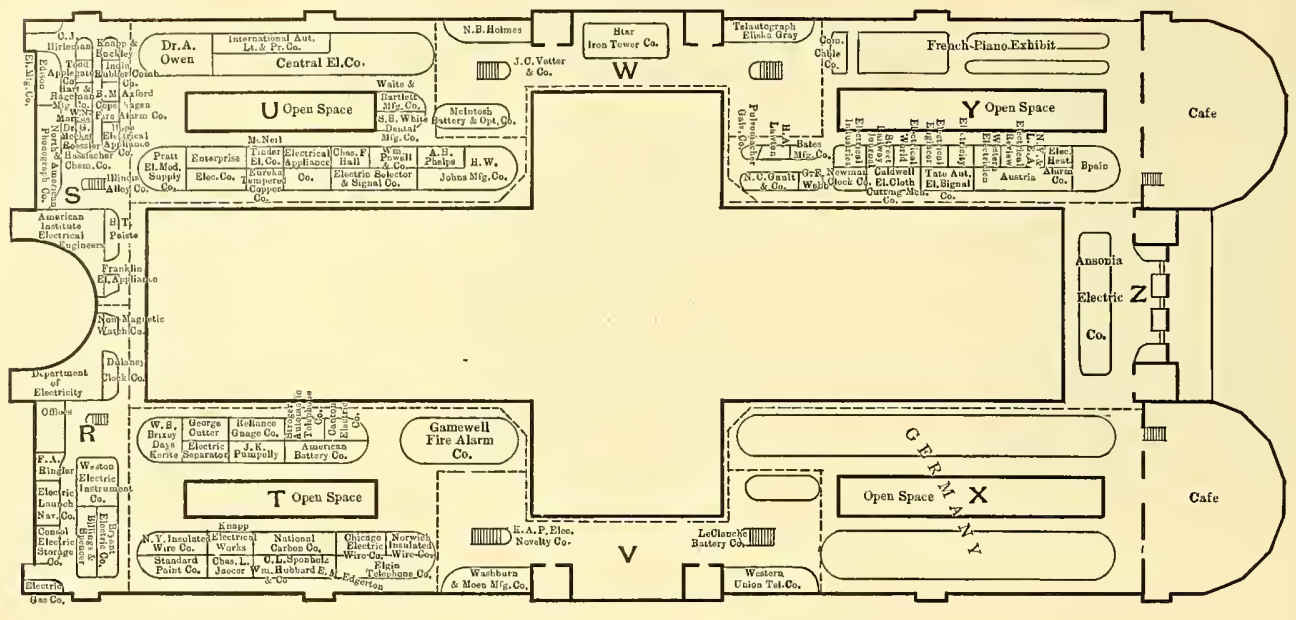

GALLERY.

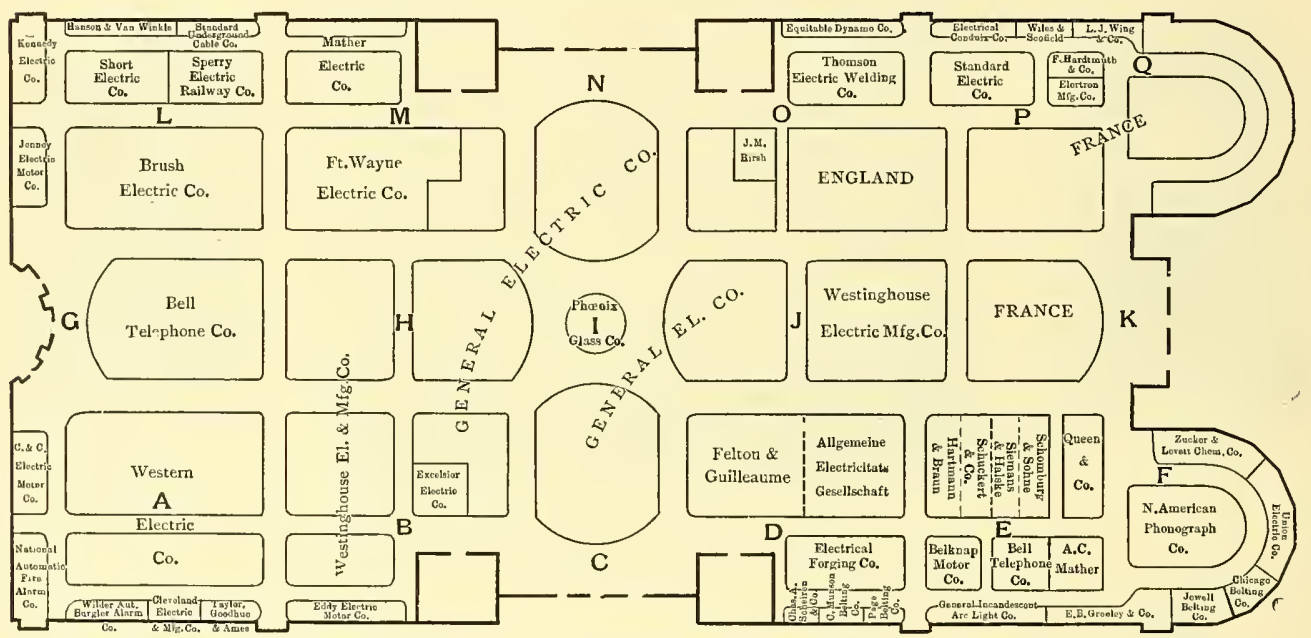

MAIN FLOOR.

\begin{tabular}{|c|c|c|}
\hline & & \\
\hline Angtria............................... & Electrical Review ................. & Jaeger, Chas, L... \\
\hline Aneonia Electric Co $\ldots \ldots \ldots \ldots \ldots \ldots$. & Electricity ......... & Johne Mfg: Co, H. W. \\
\hline $\begin{array}{l}\text { Am. Inst. of Elec. Eng.. ............. } \\
\text { American Battery Co.......... }\end{array}$ & $\begin{array}{l}\text { Electric Gas Co..... } \\
\text { Electrical Engineer. }\end{array}$ & Jewell Belting Co ........ \\
\hline 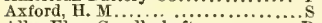 & Electrical World........... & Kuapp Electrical Work४... \\
\hline llg. Elec. Gesellschaft............ & Eddy Electric Motor Co.. & K. A.P. Elec. Novelty Co \\
\hline Bates Mfg. Co..................... & Excelsior Electric Co.... & Kuapp \& Buckley..... \\
\hline Bryant Electric Co... & Electrical Forging Cn.... & Kenuedy Electric Co \\
\hline illings \& Spencer... & Equitable Dynamo Co... & ton, H. A..... \\
\hline Brizey, W. R... & Elektron Mf́g. Co.... & ache Battery Co... \\
\hline & Electrical Conduit $\mathrm{Co}$ & Tinder Elec. Co \\
\hline ..E-G & & \\
\hline 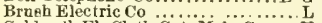 & China Worke & \\
\hline th Cut. Mch. Co.. & n Elec. Appliances. & McIntosh Bst. \& Opt. C \\
\hline Storage Co........ & French Piano Exhibit....... & C., Belting Co \\
\hline atte & Felton \& Guilleaume. & 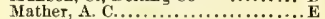 \\
\hline $\mathrm{Co}$. & nce .............. & 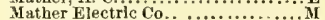 \\
\hline co................ & e Eler & \\
\hline arm Co.. & & Watch co \\
\hline & Alarm co. & $d$ Wir \\
\hline & & \\
\hline & $\mathrm{L}^{\prime} \mathrm{t}$ Co.... & \\
\hline g. Co.. & $\therefore 0$ & aph $\mathrm{C}$ \\
\hline & & N. \\
\hline & $\& \mathrm{Co}$ & Nat. \\
\hline ity.... & & $\mathrm{M}$ \\
\hline & Co. & \\
\hline Co.............. & H & Glass co. \\
\hline ................. & U & \\
\hline Edge & N. S $\cdots \cdots$ & acher Galy \\
\hline Elgi & \& Braut & y. J. K . \\
\hline & & El. Med. sup. Co: \\
\hline & & 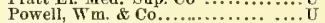 \\
\hline Co $\ldots$ & $\mathrm{P}$ & \\
\hline & ..s & 1ting $\mathrm{Co}$ \\
\hline Elec. Sel. \& Sig'l Co........... & Internat. $\Lambda$ ut. L't & \\
\hline Electric Heat Alarm Co........... & India Rubher Comb Co............. & Ringler, F. A...... \\
\hline
\end{tabular}

Exhihitor. Section Reliance Guage Co.................. T Street Rai] way Journal...... ........ Y Strowger A t. Telph. Co................ T Standard Paint Co................. T Sponholz, C. L ................... T Star Iron Tower Co................. W Spain.............. \& Co .............. Sehorb, Siemens \& Helete Schuckert \& Co...

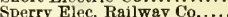
Standard Underg. Cahle Co............. Standard Electric Co...... Tate (n)............ Todd, Applegate Co ................ Thomeon Elec. Welding Co Telautograph, Elisha Gray ........W Union Electric Co ................... Vetter J. C. \& Co. (n)....Y Toment Co........... Weatern Union Tel. Co Waite \& Bartlett Mfg. Co............ U White, S. S., Dental Mfg. Co......... U Western Electrician $\ldots$ ii.............. Y

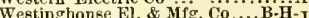
Wiles \& Scofield...................... Wing, L.J., \& Co................... 


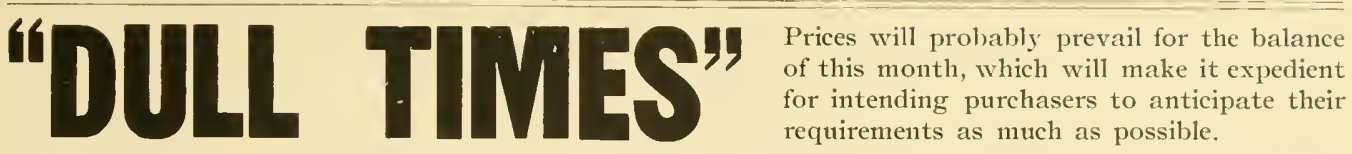

Get in your orders before prices are sent skyward by favorable legislation in

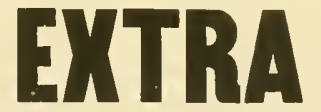

SESSIOK,

\section{ELECTRIC APPLIANCE COMPANY,}

ELECTRICAL SUPPLIES AND SPECIALTIES,

\section{EXTRAORDINARY,}

242 Madison Street, - - OFIOAGO.

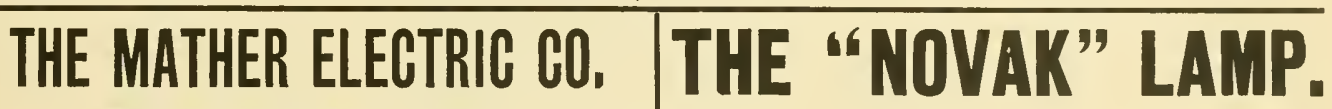
MANCHESTER, CONN.

Dynamos, Motors, Generiators,

Offices, 116 Bedford St., BOSTON.
CLAFLIN \& KIIBBALL (Inc.)

General Selling Agents.

116 Bedford Street, BOSTON.

1002 Chamber of Commerce Bldg., CHICAGO. 1002 Chamber of Gommerce Bldg., CHICAGO.

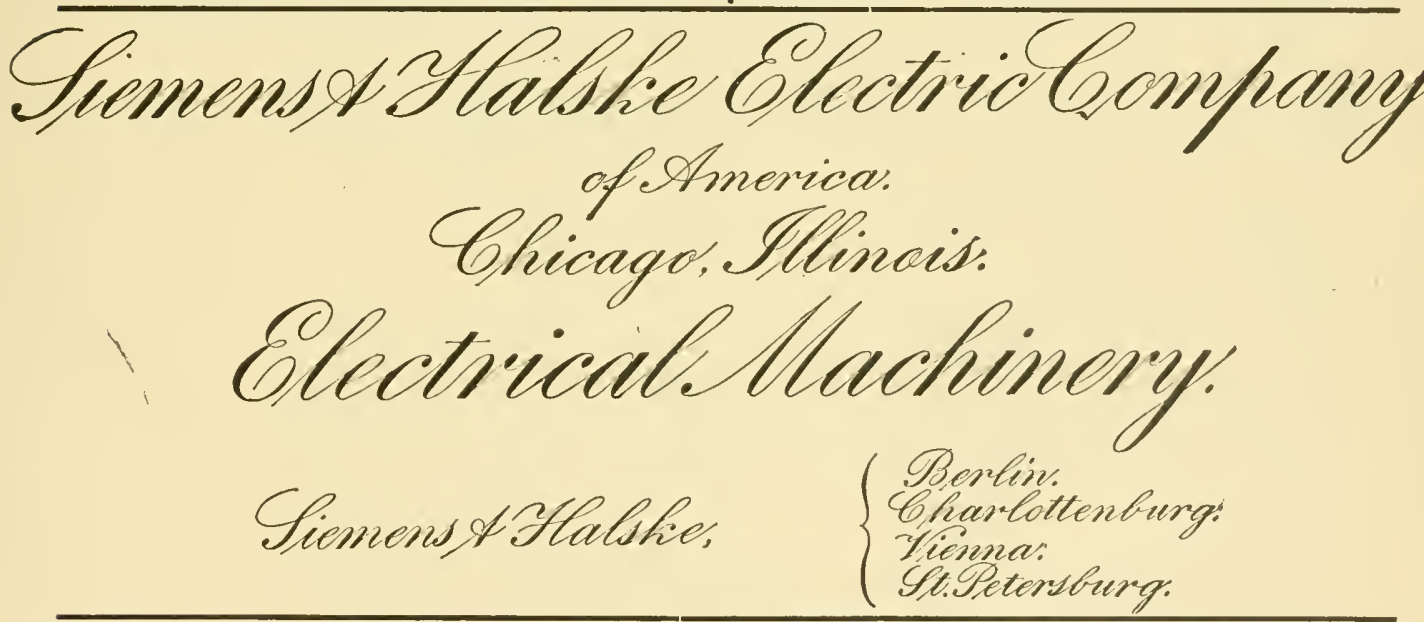

\section{Enterprise}

Electric Company

307 Dearborn Street, Chicago ....

Manufacturers' Agents and Mill Representatives for

Electric Railway,

Telegraph, Telephone and Electric Light

SUPPLIES of vegar

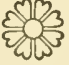

Agents for Cedar Poles,

Cypress Poles, Oak Pins,

Locust Pins, Cruss Arms, Class

Feeder Wire,

Insulators,

WIRES, CABLES, TAPE and TUBING 
Map of Chicago.

Showing Location of its Electrical and Allied Business Interests, Principal Hotels, Theatres, Depots and Transportation Lines to 45

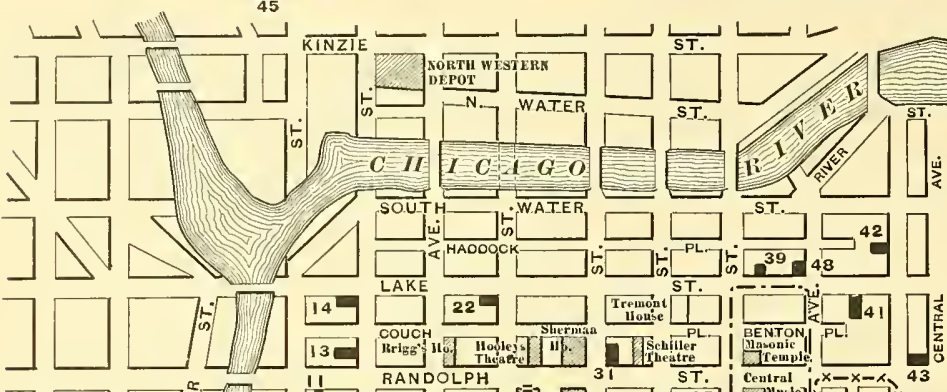

$\int$ in
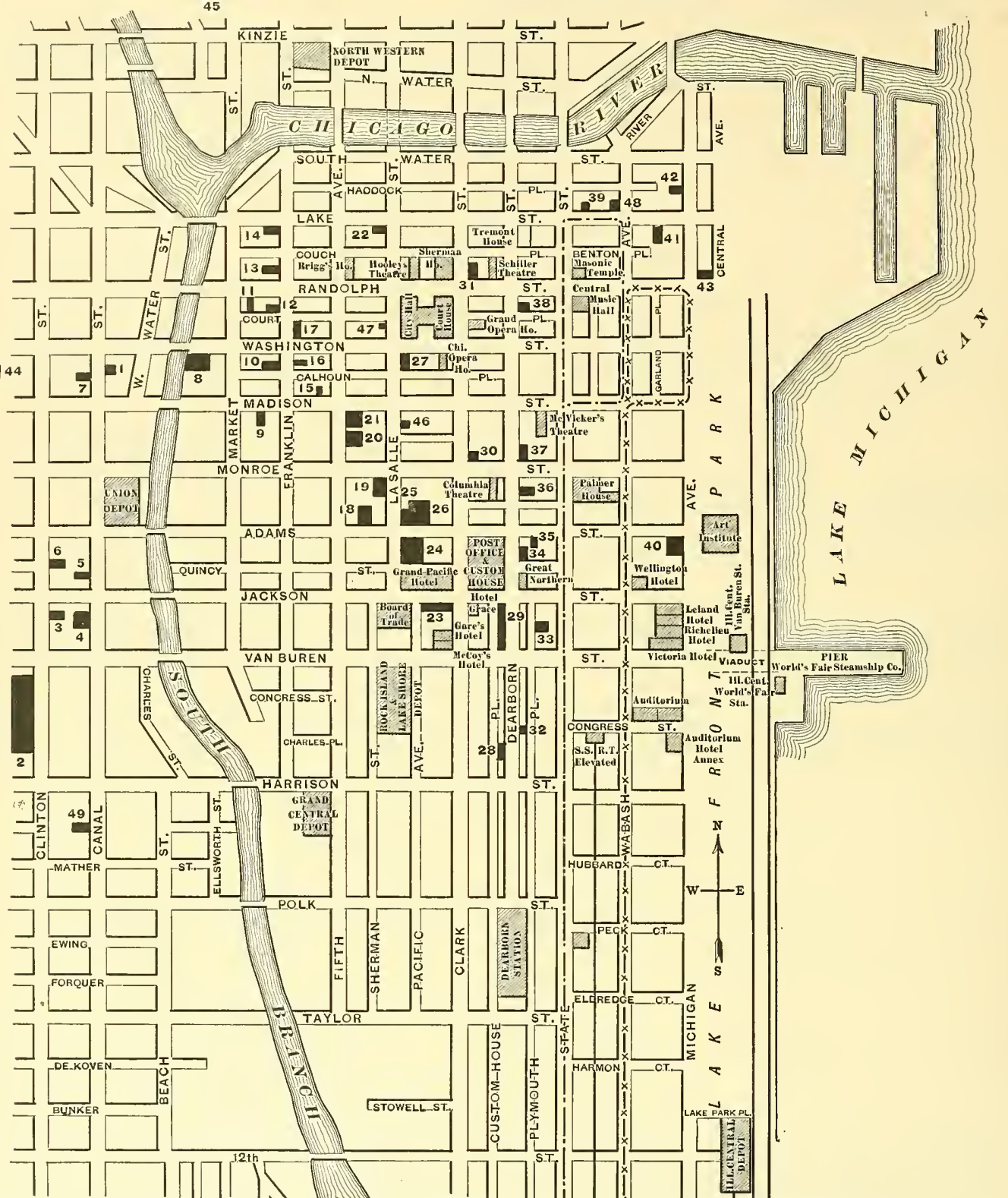

Ansonia Elec Co., Michigan Ave. \& Randorph St..... American Battery Co, 188 Madison St Bartholornew, Stow \& Co, 5 \% Michigan A

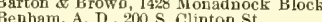
Brill Co. A. G Phenix Bldg

Bryant Electric 6

Brueh Electric Co., Mionadnock Biock.

Buckeye Electric Co.. 437 Rookery Bldg.

Calumet Electric Mifg. \& Engineering Co., iri S.

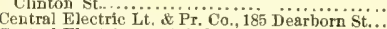
Central Electric Co."

34 Cubbing \& Morse, 225 Dearborn St.

Commercial Elec Co. The Rookery.

42 Consolidated Electric Co

C. Llectre Motor Co., 201 iradians $\mathrm{S}$ Detroit Electrical Work Co, Stock Excbange Bijg. Edwarda, W. S. Mifg. Co ol Lake St .

Eddy Electric Mfo. Co., 1417 Monadnock Bioci............ Electric Construction \& Supply Co., Unity Bld Electric Appliance Co., 242 Madieon' St.

6 RLectrical Industries PuB Co., Monadock Biock. 10 Ft. Wayne Elec. Co., 185 Dearborn St. Globe Light \& Heat 180 Dearborn st.

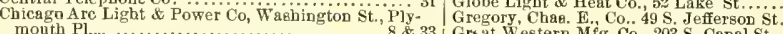

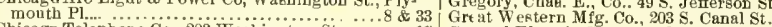

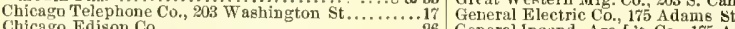

Chicago Electric Club, 175 Clark St..............26 General Incand. Arc L't. Co., 175 Adame St

Chicaro Electric Motor Co $313 \mathrm{~S}$ Cangis

1 Hood, Wm., 239 LaSalle St

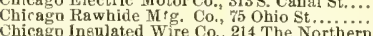

49 Holtzer-Cabot Elec. Co., $30 \%$ Dearborn St.

政

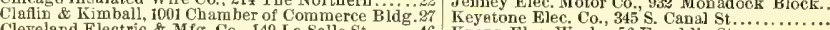

Cleveland Electric \& M fg. Co., 149 La Salle St.......46 Knapp Elec. Workв, 56 Franklin St..

46 Koapp Elec. Worke, 56 Franklin St.

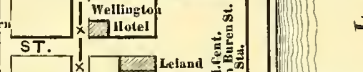

5

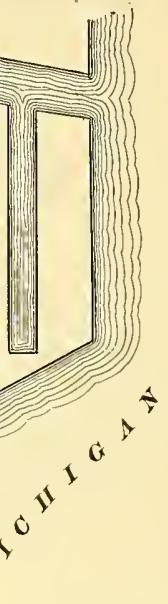



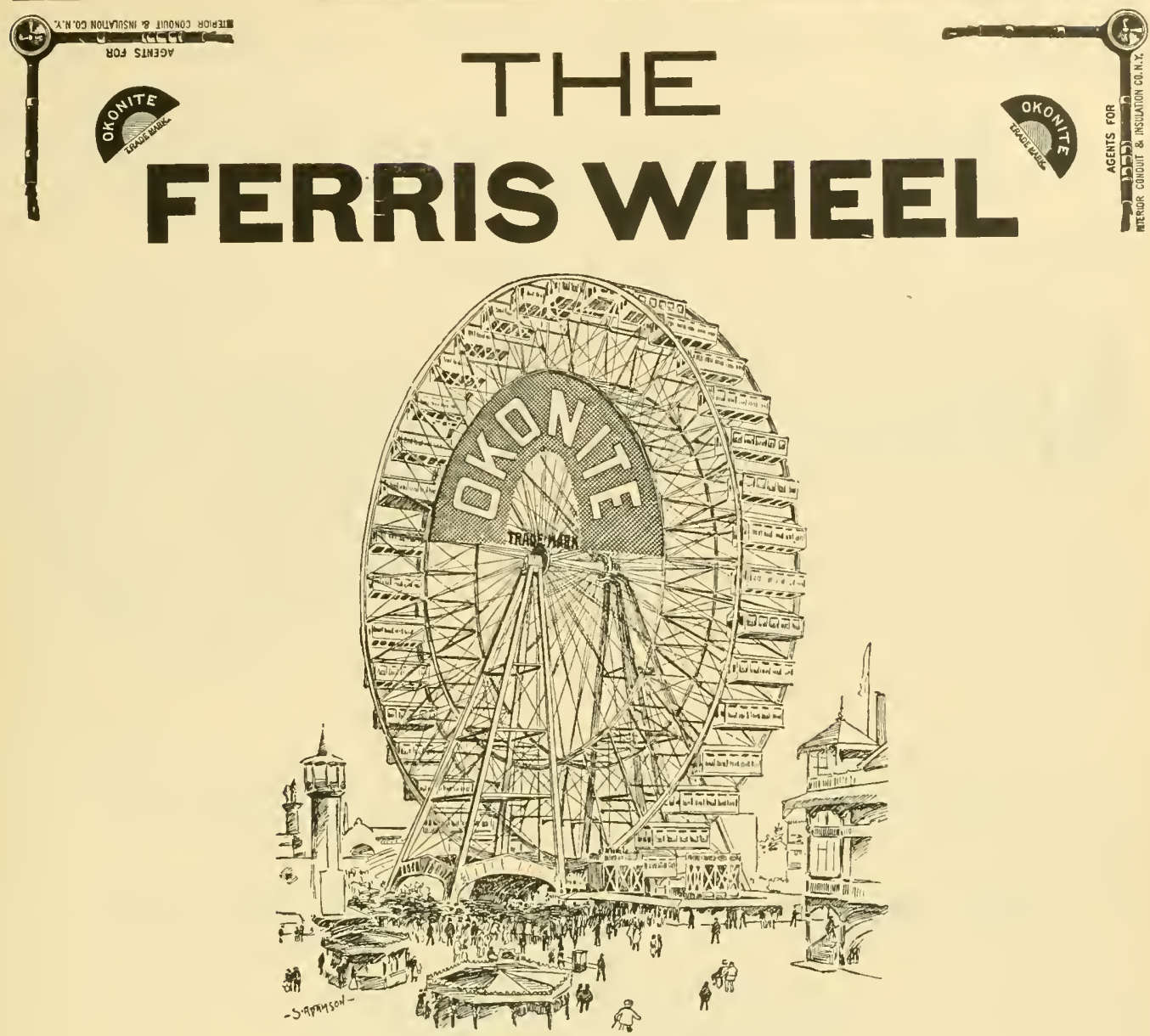

When you visit the World's Fair, you will naturally take a ride on the FERRIS WHEEL and be interested in the ELECTRIC LIGHT INSTALLATION, which is wired throughout with

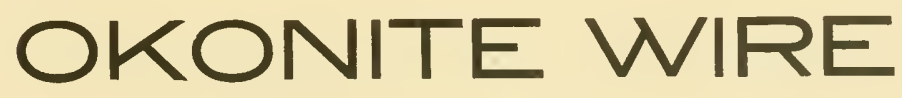

FURNISHED BY THE

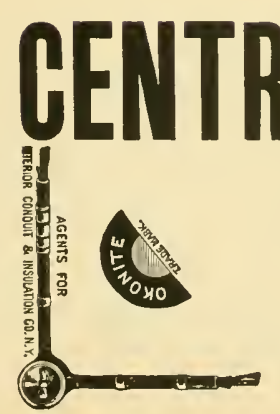

BL ELEGTRIC COMPANY,

116-118 Franklin Street, 


\section{VISITORS SHOULD NOT FAIL TO SEE THE}

\section{First Souvenir Half Dollar}

\section{...AT THE EXHIBIT OF...}
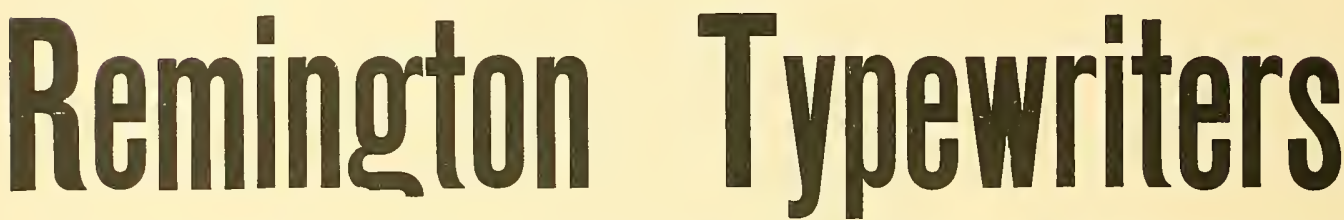

in the N. E. Corner of the Main Gallery of the Manufactures and Liberal Arts Building.

$\$ 10,000$ was paid for this coin, making it the most valuable piece of silver in the world.

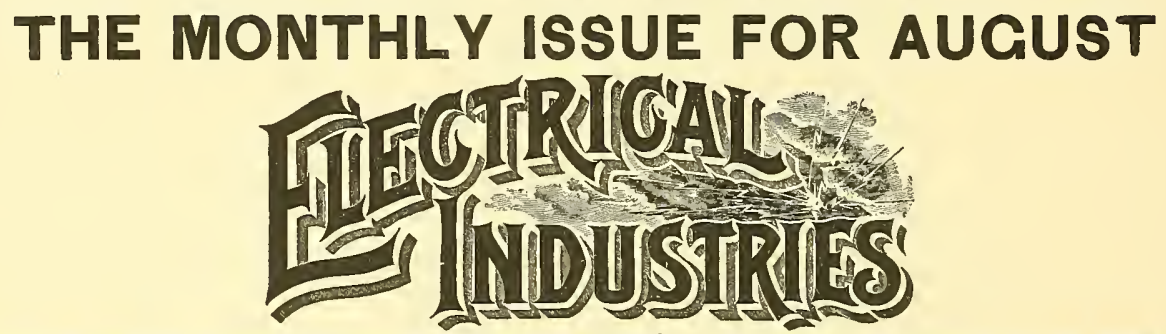

Should be read by everyone interested in electrical matters, In its table of contents is the following:

"Incandescent Lighting at the World's Fair."

"The Electric Power Plant of the Chicago City Railway."

"Steam Engine Efficiency-Its Possibilities and Limitations" by Wm. H. Bryan.

"Alternating Arc Lighting for Central Stations" by H. S. Putnam.

"Hard Rubber as an Insulator in Street Railway Work" by W. R. Mason.

"A Brief Review."

Together with illustrations of the recent applications of electricity.

The paper also contains regularly

A Buyer's Directory of Manufacturers and Dealers in Electrical Supplies and Appliances.

A Complete Directory of Electric Light Stations in North America and a Complete Directory of Electric Railways in North America.

These directories are revised each issue to the date of going to press and are to be found in no other electrical journal in the World. Its articles are read carefully and its directories used constantly by all the buyers in the trade. These facts make it without a superior as an advertising medium. Sample copies and rates sent on application.

Subscription price $\$ 3$ per year. Six months trial $\$ 1$, if ordered during the next 30 days.

\section{ELECTRICAL INDUSTRIES PUB. CO.,} Monadnock Block, CHICAGO. 


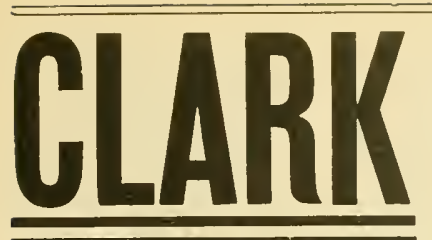

\title{
$\frac{0}{\alpha} \mathrm{O} O \mathrm{MPAN}$, NEW YORK.
}

192 Broadway and II John Street.

MANUFACTURERS OF ARC LIGHTING APPARATUS FOR EVERY PURPOSE A SPECIALTY. The CLARK ARC LAMPS for use on EVERY CURRENT, have the reputation of being the best and most durable of any ever made in the United States.

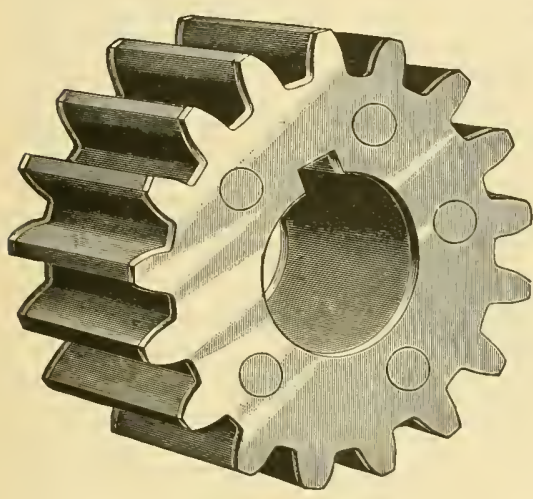

RAWHIDE PINIONS FOR ELECTRIC MOTORS A SPECIALTY.

RAWHIDE DYNAMO BELTING

Greatest Adhesive Qualitles. A Non-Conductor of Electricity. Causes Less Friction than any other Belt.

\section{THE CHICAgO RAWHIDE MANUFACTURING GO.}

THE ONLY MANUFACTURERS IN THE COUNTRY.

LACE LEATHER ROPE AND OTHER RAWHIDE

GOODS

OF ALL KINDS

BY KRUEGER'S PATENT

-

75 Ohio Street,

This Helting and Lace Leather is not affected by steam or dampness: never becomes hard; is stronger, more durable and the most economcal Belting made. The Rawhe Rope for Round Belting "

CHICACO, UL

\section{Standard Electric Company.}

GENERAL OFFICES: 625 Home Insurance Building.

WORKS: So. Canal Street,

\section{CHICACO.}

\section{STANDARD SYSTEM}

AT THE

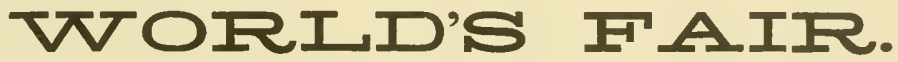

MACHINERY HALL, Sec. Q, 2 Standard Arc Dynamos.

\author{
Sec. S, 20 " " "
}

ELECTRICITY BUILDING. Sec. P, Space 2, Arc Lighting Exhibit.

The Standard Lamps Light the Power Plant, Machinery Hall, Agricultural Hall, Shoe and Leather Building, an Other Buildings and Portions of the Grounds. 


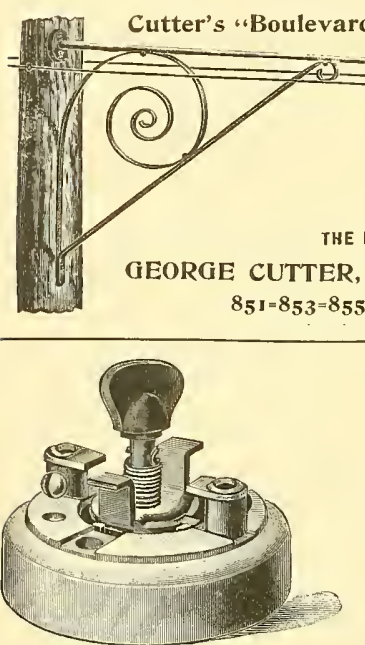

Made 5 amp. S. P:

10 amp. 3 way.

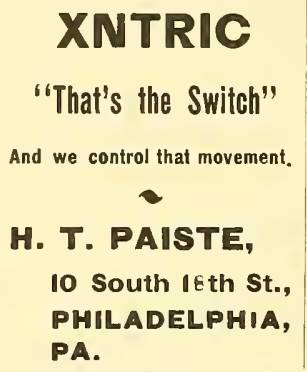

PA.

\section{SIMPLEX WIRES}

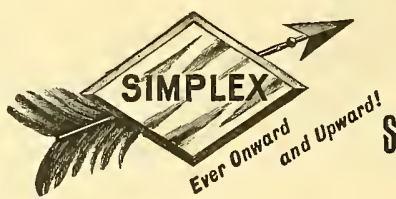

INSURE

HICH

INSULATION

Simplex Elebtrical lo.

620 Atlantic Ave.,

George Cutter, Chicago. Boston, MAss.

\section{Consolidated Elpctric (6.}

Manulaclurers and Dealers in all kinds ol

\section{ELECTRICAL - SUPPLIES,}

115 Franklin Street,

\section{CHICACo.}

GHORGE PORTER,

Contractor for All Kinds of

ELECTRICAL WORK.

Room 67, I 43 La Salle St., CHICAGO.

Crary Block, BOONE, IOWA.

\section{CHAS, A. SCHIEREN \& CO,}

MANUFACTURERS OF

\section{Genuine Perforated Electric Leather Belting.}

46 So. Canal Street, - CHICACO

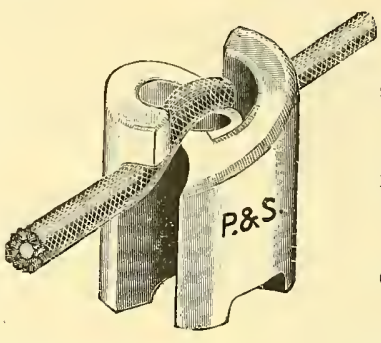

P. 8 .

WIRING INSULATOR, Saves TIME

TROUBLE

and TIE WIRE

Made only by

Pass \& Seymour, SYRACUSE, N. Y.

George Cutter, CHICAGO.

\section{BEAR IN MIND}

that the regular monthly issue of ELECTRICAL INDUSTRIES contains the most cemplete and correct directories published of the electric light central stations and the electric railways in North America.

World's Falr Headquarters Y 27 Elec ricity Building.

CITY OFFICES, Monadnock Block.

\section{WAGNER ELECTRIC FAN MOTORS}

For Direct or Altemating Currents.

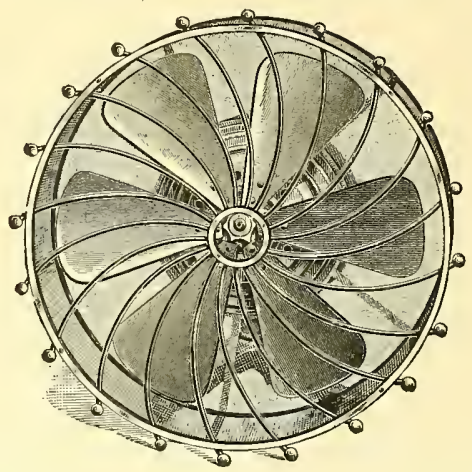

These motors give a stronger breeze with less consumption of current than gny other lan motor on the market. They are fall $1-8$ horse power. Six hladed 2-inch fan. Self-oiling. Furnished with or without gaards.

IT WILL PAY YOU TO SEE THE WAGNER BEFORE BUYING ELSEWHERE.

TAYLOR, GOODHUE \& AMES, 348 Dearborn Street, CHICACO. 


\section{WEEKLY WORLD'S FAIR}

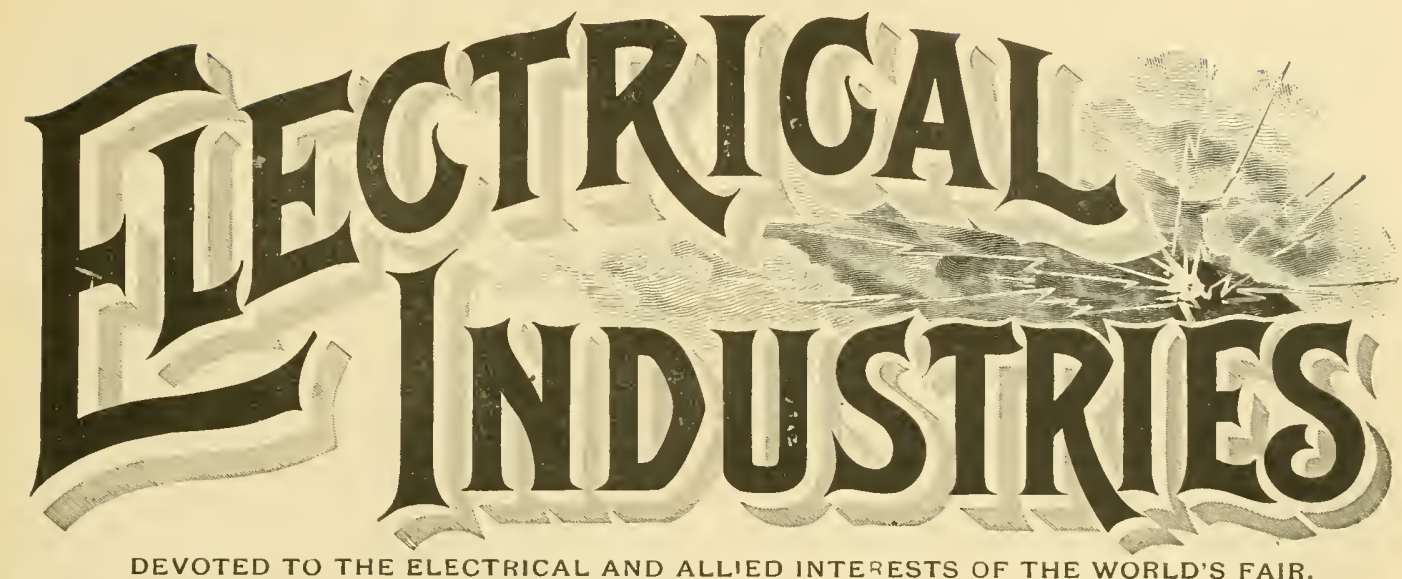

DEVOTED TO THE ELECTRICAL AND ALLIED INTERESTS OF THE WORLD'S FAIR, ITS VISITORS AND EXHIBITORS.

Vol. I, No, 10. CHICAGO, AUGUST 17, 1893.

FIVE MONTHS SI.00

Exhibit of George Cutter in Electricity Building.

An exhibit that has been arranged with a view to the comfort of visitors as well as the clisplay of electrical goods
The exhibit is interesting to electrical people in many different ways and shows the variety of devices which the electrical specialist of the west has put on the market. Oc cupying a central position is a large panel on which are

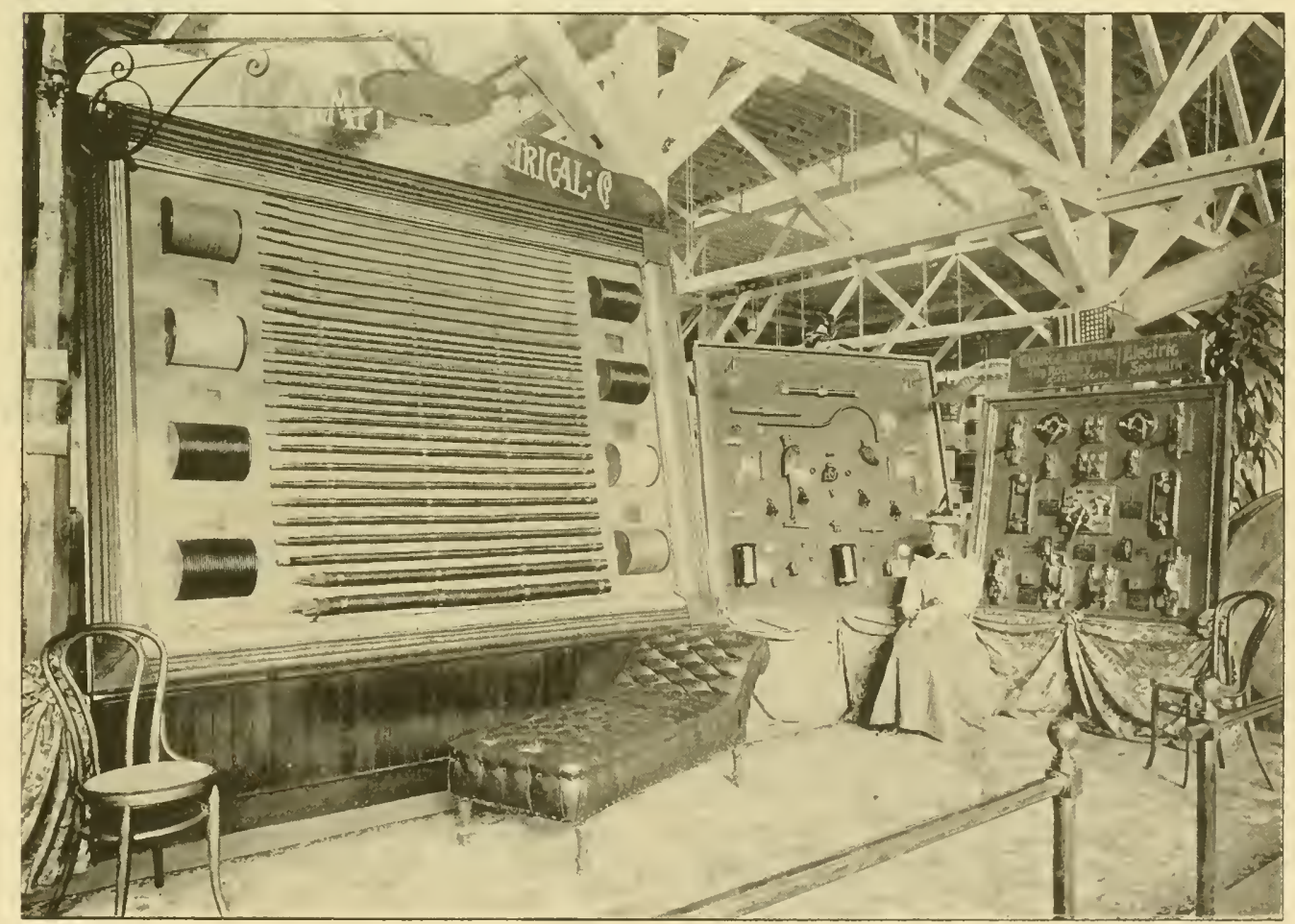

is that of George Cntter in the southeastern part of the gallery of Electricity Building. The goods are arranged in attractive figures on panels about the space which is fitted with a handsome carpet, comfortable chairs and other furniture. A brass railing markis the front of the spacee. displayed Simplex wires in a variety of sizes and kinds which Mr. Cutter has been pushing in the west. Large eables plain and arnored form an artistic border to the pranel. In the center are shown different simplex wires from the suallest to the largest with the insulation and 
armor slipped back to show its character. At the sides of these samples of wire are shown the wire on spools. The arrangement on the antique oak background makes an interesting display.

Part of the space has also been given to the display of the Pass \& Seymour specialties. Insulators of almost every kind. Several sizes of the self fastening porcelain insulator, ontlet insulators, etc, eut-outs in numerous styles and sizes are shown. The line of switches is one that has only recently been developed and contains some novel features. The most striking point is the abandonment of the inner contact, the current being carried through the shaft as well as through a series of conducting ribbons. The ribbons increase the carrying capacity of the switch without adding to the power required to throw the switch, a point specially noticeable in the large sizes. The display includes sizes up to 1,000 amperes in single, double and three pole styles. The arrangement of the snap spring in these switches is also novel.

On the same board are shown several of the new economic door switches as well as the voltmeter and in the center of the board an eight point switeh. This switch is a special four way switch designed for alternating current work. Are light cut-outs are next shown in a number of styles, among which is the Dow hanger board shown in several sizes. The exhibit would hardly be complete without the Cutter lamp supporting pulleys used so largely in central station lines. One special form is shown in connection with the Cutter mast arm that surmounts the exhibits. On the same mast is also shown Cutter's boulevard streethood. A large variety of smaller devices and specialties are shown, among which are mining sockets, tree insulator's and lightning arresters. The goods shown in this exhibit of Mr. Cutter's are noticeable for their originality as well as for their practical design.

\section{The Baker Gas Engine.}

Joseph Baker \& Sons of 58 City Road, London, England, have an extensive display of gas and oil engines in the east end of Machinery Hall. Several types are shown, some running with, others without, load; some as regular gas engines and others of the same type with the necessary parts added running as oil engines.

The special claims made for it are, that it can bechanged from an oil to a gas engine or vice versa in a very short period of time; will use any commereial oil of flash test between 140 and 300 degrees; is very economical of fuel and can be started in from 7 to 10 minutes. The engine as a gas engine is of the common Otto Cycle type with exhaust and air valves, gas flame, water jacket and pump. To make the same machine an oil engine, there is bolted onto the rear end of the gas cylinder a vaporizing eylinder which being first heated to a proper degree by the flame from a blow lamp raporizing the oil flowing into it and the heat is maintained by the explosions of the oil in the cylinder. A lamp on the outside is furnished with oil and a wick, the air blast from a pump blowing the flame into the igniting tube where it lights the gas. A double pump on the side of the cylinder actuated by an eccentric on the engine shaft, pumps water to the cylinder jacket and furnishes air to the lamp and cylinder. A rery small pump attached to the under side of the vaporizing cylinder and actuated by the same shaft that moves the gas valve levers, pumps oil a few drops at a time into the vaporizer. The supply is controlled by the governor which is remarkably simple.
A crank on the end of the valve shaft moving in a slot in the upper end of a vertical lever that is pivoted below moves the lever back and forward for a space of about two and a half inches. Attached to the end of this lever at its upper end by a pin, is a flat finger about six inches long by three-fourths of an inch wide. On the end of the lever next to where it rests on the pin is an arm extending downward at an angle and sliding on this is a ball of iron which ean be fastened at any point on the rod by a set screw.

This weight almost exactly counter-balances that of the flat arm and at slow speed the arm impinges against a notch in the end of the oil pump lever, pushing it forward and pumping a few drops of oil into the vaporizer. In case the speed increases the momentum or inertia of the ball being slow the lever falls and does not eatch on the pump rod so no fuel is supplied and the engine slows down. A very slight variation in speed causes the governor to act. Common commercial burning oil is used, a small supply being kept in a tank at the side of the engine and conducted by very small copper pipes to the pumps.

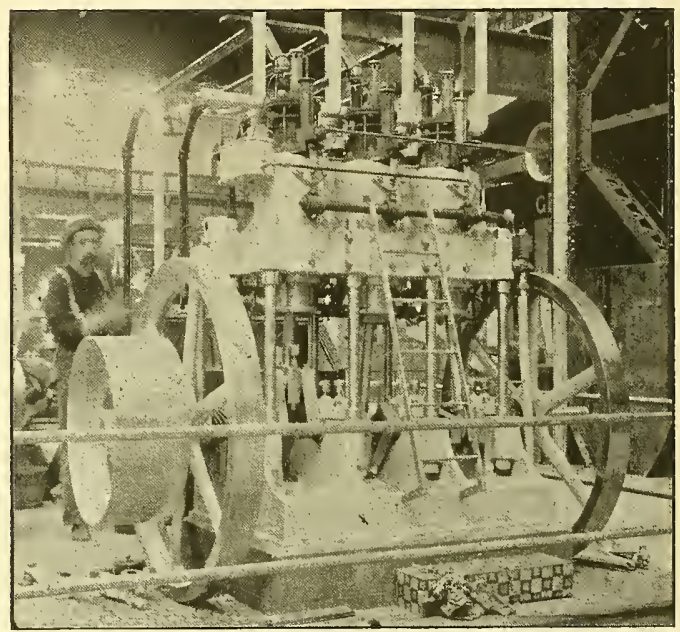

THE BAKER GAS ENGINE.

The amount of fuel required per borse-power per hour is said to be abont one half pint. The cut herewith show's the three cylinder rertical oil engine displayed in the front part of the exhibit. The cranks are set at 120 degrees from each other to provide smooth running, and each cylinder is a complete engine in itself, being provided with running gear so that any one or two or all engines may be rum at once. About the only difference is the change of governor to meet different conditions. A special feature on the machine not often seen in this country, is the style of gear used to run a shaft at right angles to the main or crank shaft; the gears have diagonal teeth cut in their peripheries and mesh at right angles, one acting as an exaggerated worm.

The application of oil engines seems to have been quite extensive both in England and on the continent and it would seem as if they might be nsed to advantage in this country if once properly introduced. It is probable that with gas at present prices the gas engines will not be universally used, but with the large supply of oil, the oil engine could be used economically. 
The Exhibit of the Elektron Manufacturing Company.

In the northwestern part of the Electricity builling opposite the French section is located the exhibit of the Elektron Manufacturing Comprany. The sprace has aisles on three sides allowing the machinery arranged about the space to be easily examined.

The electric elevator in the space forms a very attractive part of the exhibit as well as a most convenient way of reaching the gallery. The Elektron company has had an extended experience in the applications of electric power to elevator service and this elevator with the accompanying machines and apparatus demonstrates in an excellent manner the adaptability of electricity to this purpose.

A wooden frame with guides was erected on the platform in the space to the proper height above the gallery floor. The lower part is surrounded with an ornamented iron network for protection. Running in this frame is an ordinary elevator car rather prettily ornamented. The regular counter-balance weights are applied over pulleys at the top as usual. The elevator machinery consists of a 10-horse thrown by means of the controlling rope and sheave which at the same time raises the brake. The starting switch turns the current into the motor and automatic rheostat and before atmitting the current sets the reversing switch in the proper position for ascending or descending. The automatic rheostat switch always stands at the point of al] resistance in except when the car is in motion and thus protects the motor from any rush of current in ease the primary current is cut off for any purpose and the starting devices left on. When current is turned on, a strong sole noid magnet attacled to the rheostat lever working against the dash pot very gradually cuts the resistance out and the motor gets up to speed slowly and safely. As this automatic rheostat has no mechanical conneetion with any part of the elevator machinery it can be set in any convenient place and wires rum from the motor.

The main brake is a strap of iron almost surrounding the brake flange on the worm shaft. The compound lever actuating this brake terminates in a roller engaging with a cam on the shaft that turns the switch, thus whenever the switch is moved the brake is applied by the falling of the

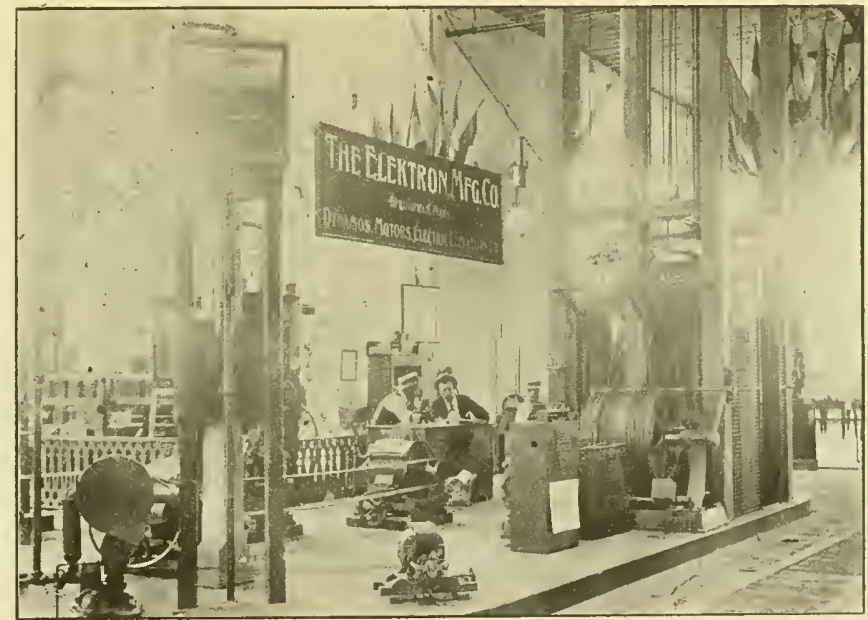

TIE EXHIHIT OF THE ELEKTRON MANTFACTURING (UMTANY.

power Perret six pole motor directly connected through an insulated universal couphing to the worm and gear attached to the cable drum. The whole machine was designed and constructed by the Elektron company.

The gear or the drum shaft has bronze teeth and cast iron hub on which is a good sized flange to prevent any danger from the keys between drum and shaft working loose. This hub flange is bolted to another similar flange on the head of the drum itself. A strap brake is provitled for the drum and is automatically applied in a number of ways; for instance, if the car should happen to be very much overloaded when eoming down and attempt to race, a couple of weights inside the drum spread apart by centrifugal force and through connections to the outside, trip a lever supporting the brake weight, allowing it to fall and instantly apply the safety brake, gradually bringing the ('ar to a stop. Again, in case the car comes to a standstill or meets with an obstruction in its descent, the consequent slacking of the cablc causes a pulley riding against the eable to fall is the slack gains, tripping the brake and shutting of the jowrer.

The motor is expipped with a starting switch which is weight at the end of the lever; if the switch is off, the brake is on and vice versa. The entire machine is well designed, compact and seems to embody all the safety devices neces. sary to meet any emergency that can occur to such a machine. This particular machine has a lifting capacity of $1, \pi 00$ at 150 feet per minute.

In the exhibit of electric motors for stationary work there is, first, a 15 -horse power 500 volt Perret motor of the six pole type receiving current from Machinery Hall and running at 600 revolutions per minute. This motor is belted to another similar machine which as a generator produces 7i) ampreses of eurrent at 110 volts for some of the motors in the exhibit. Current from this generator is conducted to a marblized slate switch board and from there distrib uted to the various motors and other apparatus. The board is provided with Queen \& Company's magnetic vane instru ments, a rheostat built into the board, and all the necessary switches and cut-outs.

In order to show the adaptability of electric power to rumping water for domestic use, a one horse power 110 volt motor is belterl to a Gould triplex pump which raises water from a tank under the floor to another raised on sup, 
ports a considerable height above the floor. In the upper tank is a copper float which by a chain attached to a snap switch cuts off the current when the water reaches a certain height and ents it on again when the water level is lowered, an automatic rheostat similar to the one used with the elevator prevents rush of eurrent through the motor.

Glass in the side of the tank permits inspection of the action. Several electric fan motors are shown: one, a quarter horse power, is of the new inverted type ancl carries a fan 15 inches in diameter; uses pencil carbon brushes and has ring coiled bearings. Other small motors are displayed, two motor generators, one giving out continuous current at 60 volts and the other alternating eurrent at 100 volts, one armature is used with two windings in these machines.

Four Mosher eonstant potental are lamps, run two in series are used to light up the exhibit at night. There is also a four-horse power motor belted to a 50 ampere 110 volt dynamo. As a display of stationary motor work and incidentally of constant potential generators this exbibit is comprehensive, well arranged and enables the lay visitor to learn just what is being accomplished today in this line. with brass body, up to rery large sizes, with iron bodies, as used in the heaviest steam work. Samples are shown of large brass valves of this make as used by the naval department on the new cruisers. Others with quick-opening handles are also shown.

Numerous samples of globe valves with regrinding seat are shown. In this valve there is a small hole in the stem anct a corresponding one in the socket of the disc; by placing a pin in the two when in line, they are joined together, so that the process of grincting may be carried on.

A simple type of sight feed hubricator for use on threshing-machine engines and in other similar places, is exhibited. This instrument has the condenser bulb attached to a short piece of pipe extending from the upper side, and requires but one opening to the steam pipe for the entire apparatus, and but one valve is used to turn oil on or off after the first adjustment.

Dynamo oil cups, with patent feed, set so that oil may always be started instantly and feed the same. Grease cups, both with automatic compression feed and plain serew feed, the latter with a spring irside, so arranged as to prevent the

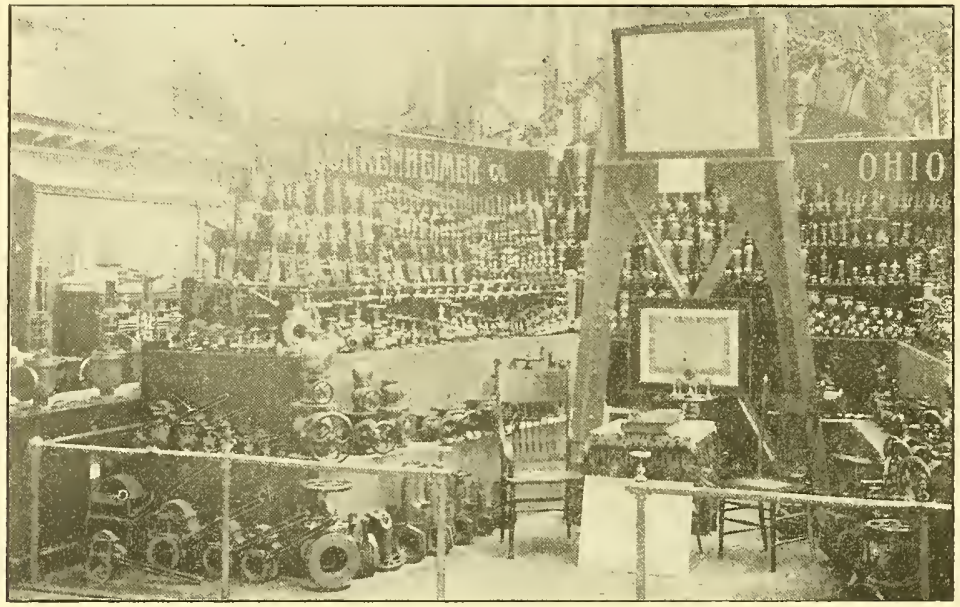

EXIUBIT OF THE LUNKENHEIMER COMPANY,

Mr. M. H. Robbins, Jr, in charge of the exhibit, will be found constantly on hand and ready to explain all the apparatus,

\section{Exhibit of the Lunkenheimer Company.}

The Lunkenheimer Company, of Cincinnati, Ohio, has an exhibition of valves and other similar material in Sec. 25, Col. Q 24, Nachinery Hall. Broad platforms have been built and covered with yellow and black velvet, forming three terraces for the display of the company's prorluct.

The company is making a specialty of the Lunken gate valve, which has an renewable seat, renewable dise, removable top, and is self balaneing for steam pressure by the simple process of releasing the pressure on the handle, thus opening a small by-pass hole through the gate. The top containing the serew, nuts and stem is secured to the Falve body by a $\mathrm{U}$-shaped elasp surrounding the body and passing up through holes in the top casing, packing being inserted between the two parts. The remoral of the two nuts bolding this clasp enables one to take the entire valve to pieces.

These valves are exhibited in all sizes, from half inch, cover coming loose, glass sight gauges for ring oiled bearings, so constructed as to keep oil in easy and plain sight; and rarious other sight feed derices for attaching to points where bearings are oiled from a general system of piping, are shown in many sizes and styles.

The company makes water columns, pop valves, and a specialty of steam whistles, both the regular type and the famous mocking-bird whistle, such as is furnished to the Fair for signaling purposes, this one being an eight-inch cylinder and run on 125 lbs. of steam. The exhibit is well arranged, quite comprehensive in the material shown and receives much attention from visitors.

The large engine manufactured by the Sioux City Iron Works seems to attract attention, placed as it is near the center of the Machinery Hall annex among looms, printing presses, lath's, ete. It is finished in nickel plate and white, of the Corlis pattern, 400 -horse power and : 4 by 48 in dimensions. The fly wheel is 16 feet by 14 inches and weighs 16 tons. It is belted by two sehieren electric belts ruming side by side to the two lines of shafting by which power is distributed throughout the annex 
The Western Electric Company's Exhibit of Primary Batteries.

In the exhibit of primary latteries made by the Western Electric Company in Electricity Building will be found bat. teries of every desired size and type. There are batteries displayed from small dry batteries that can be placed in a wine glass to the largest used. Arranged in a pyrawid are twelve hundred dry batteries and porous cups, and next to this pyramid is another pyramid of wet batteries.

The dry batteries shown, the Phoenix ant Pony, are the results of the extended experience of the manufacturers and on tests show excellent results. The resistance is very low and the electro-motive force is as high as the LeClanche. The Phoenix battery is shown in the standard size adopted of eight inches high by three and three-quarters in diam. eter, while the Pony battery is but one-half as high. These batteries are largely used on electric bell circuits.

Several crowfoot gravity batteries of the size used on the telegraph lines are shown. The zinc and copper of these batteries are made of specialty refined metal free from impurities. Several sizes of Grenet batteries, finely finished and

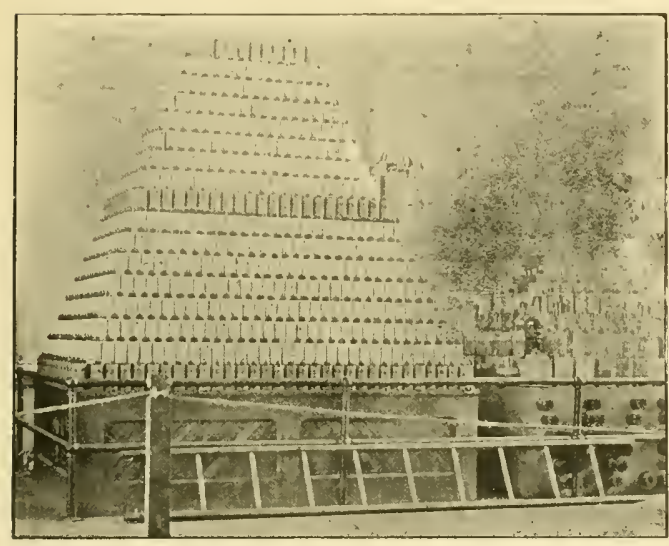

TUE WESTERN ELECTRIC CO'S EXHIBIT OF PRIMARY BATTERIES.

designed for laboratory use, are shown; also the Smee battery, which is very simple and plain in construction, using dilute sulphuric acid for the liquid. Daniell, Fuller's mercury bicromate and other batteries are shown. Several of LeClanche batteries, which have been so successfully used on electric gas lighting, bell and other circuits, are exhibited.

The various kinds of carbon batteries made by the Western Electric Company, in which the carbon used is of such a form that a proportionately large surface of earhon is presented to the acid are shown. The acid and manga nese used by the company are remarkably free from iron and other impurities. To secure pure material has required a numberof years of persistent effort.

The porous eups used by the company are made from special clay found in but few places in the United States. In connection with the exhibit are shown the different parts of the batteries and the liquids used in them. This part of the exhibit is especially interesting as showing how each battery is made up. A number of specially designed porous cups in which by different means the walls are decreased in thickness are shown, it being the ubject to lower the resistance of the cells.

\section{Exhibit of the Chapman Valve Manufacturing Company.}

The Chapman Valve Manufacturing Company, of Bos ton, U.S.A., whose works are at Indian Orehard (Spring field), Mass., have a fine aud extensive exhibit in Machin ery Hall at $\mathrm{K} 2 \mathrm{H}$, center aisle.

The question of valves has become of such paramount importance in the consideration of the economic generation of power, that this company has taken advantage of the World's Columbian Exposition to give visiting managers and engineers a chance to see for themselves the great advance made by them in this line, especially calling attention to the valves recently designed for high pressure steam service.

The high pressure, renewable bronze seat valves, just mentioned, are shown with the bypass arrangement, the outsicle screw and yoke, the self-packing spindle, by means of which the valve may be repacked when wide open with the steam on the line; and with the bodies heavily ribbed so that the valve is not affected by the expansion of the pipe line. In addition to these features all kinds of end

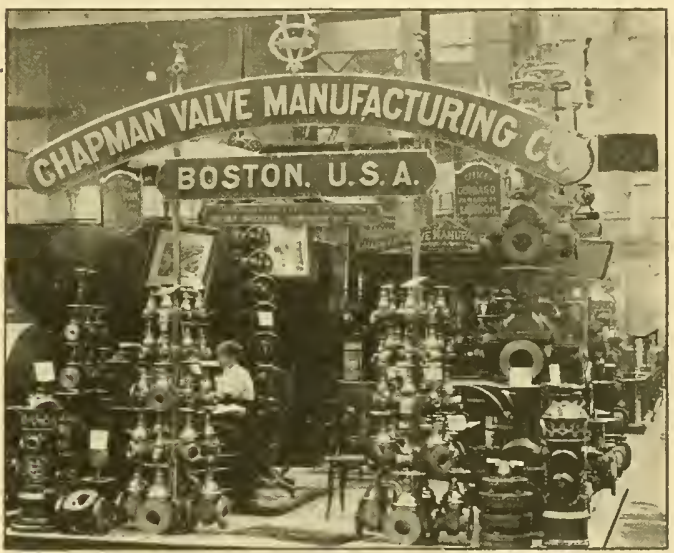

EXIIITT OF TIE CHAPMAN VALVE MANUFACTURING COMPANY.

connections indicating devices and methods of opening are shown.

The display is arranged in a very appropriate manner. valves for like purpose being bolted or screwed to brass or iron masts in tiers, or arranged in columns ranging from very large at the bottom to fuite small at the top.

The line of fianges shown are intended for use in connection with high pressure steam, and are shown, both plain, tongued and grooved. These may be used either bolted to valve or as flange unions.

All kinds of brass and iron valves are shown, adapted to feed and circulating systems, exhaust and low pressure steam; also aumonia valves for mechanical refrigeration, water valves and fire hydrants for use on cast-iron pipe.

Besides the Machinery Hall exhibit, working displays may be seen at the Intramural Electrie Railway power house, on the Heine boilers in the boiler house annex to Machinery Hall, and upon the lig engine in Machinery Hall itself, which was made by the F. P. Allis Manufacturing Company, of Milwaukee, Wis.

Edward L. Ross, M. E., is representing the company, and gives a hearty welcome to visitors at the space in Machinery Hall. 


\section{ELECTRICAL INDUSTRIES.}

\section{PUBLISHED EVERY THURSDY BY THE \\ ELECTRICAL INDUSTRIES PUBLISHING COMPANY, INCORPORATED 1889. \\ MONADNOCK BLOCK, CHICAGO. \\ TELEPHONE HARRIBON 159. \\ $\begin{array}{ll}\text { E. L. PoWers. Preg. and Treas. } & \text { E. E. Wood, Secretary. }\end{array}$}

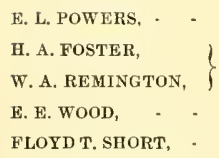

Associate EDitors.

- Eastern Manager. Advertising Departaent.

EASTERN OFFICE, WORLD BUILDING, NEW YORK. World's Fair Headquarters, Y 27 Electricity Building.

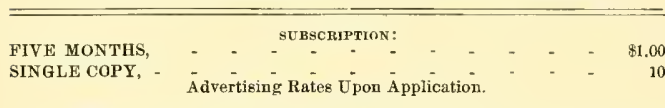

News items. notes or communications of interest to World's Fair Visitors are earnestly desired for publication in these columns and will be heartily appreciated. We especially invite all visitors to call upon us or send address at once upon their arrival in city or at the grounds.
ELECTRICAL INDUSTRIES PUBLISHING CO.

The total paid admissions to the Fair to date reaches nearly eight millions. The pleasant weather and lower railroad rates have brought more people during the last few days. The interest showu in the popular amusements arranged by the management should encourage their continuance. They not only furnish amusement for the visitors but a diversion for the exhibitors and attaches of the Fair, while the participants in the swimming and canoe contests seem to enjoy them greatly.

THE Electric Committee of Underwriters meet this week at 157 LaSalle street, Chicago, to discuss the recently adopted international rules and will themselves formally adopt rules and regulations for electric light and railway circuits. The members of the committee in the city are Mr. F. E. Cabot, Boston, chairman; Mr. LeLoup, New Orleans; Mr. Devitt, Philadelphia; Mr. E. A. Fitzgerald, Syracuse; Mr. Geo. P. Low, San Francisco, and Mr. E. A. Van Geissen. While in session the committee hope to devise some means for standardizing municipal and automatic fire alarm systems.

\section{The World's Congress of Electricians.}

About one thousand invitations have been sent out and from the number of acceptances received, it looks as though the congress would be well attended. At the meeting of the Advisory Council held January 17th., a committee was appointed to decide on the number of members that each foreign country should be invited to send to sit in the Chamber of Delegates. Their apportionment was as follows:

Five each for England, France, Germany, Austro-Hungary and the United States.

Three each for Belgium, Italy and Switzerland.

Two each for Norway and Sweden, Holland, Denmark, Russia and Spain.

One each for Portugal, British North America, Australian Colonies, India, Japan, China, Mexico, Brazil, Chili, Peru and the Argentine Republic. Making fifty-five in all.

$\mathrm{Up}$ to the present moment eight of the more important countries have officially responded to the call. We give below the names of the delegates in the order of their official appointments.

England.-W. H. Preece, F. R. S.; Prof. W. E. Ayrton, F. R. S.; Prof. S. P. Thompson, D. Se., F. R. S.; Alex. Siemens, Major Carden, R. E.

France.-M. Maseart, M. Hospitalier, M. Violle, M. de la Touanne.

Germany will be represented by Dr. H. von Helmholtz who requests that the following gentlemen of the Physikalische-Technische Reichsanstalt of Charlottenburg, be allowed to attend the meetings of the Chamber of Delegates, namely: Dr. Feussner, Dr. Kurlbaum, Dr. Leman, Dr. Lindeck, Dr. Lummer and Dr. Pringsheim.

United States.-Prof. H. A. Rowland, Prof. T. C. Mendenhall, Dr. H. S. Carhart, Prof. Elihu Thomson, Prof. Edward L. Nichols.

Switzerland.-M. le Dr. A. Palaz, M. Thury, M. le Dr. Weber.

Italy.-Prof. Gallelio Ferraris.

Mexico.-Senor Don A. M. Chavez.

China.-Mr. Peng Kuang-Yu, Mr. Teng Shen, Mr. Shon Yen.

The reply of the Electrotechnische Verein of Vienna published in our last issue will be referred to the committee on credentials at the opening of the congress.

\section{Program of Popular Lectures.}

The hour for the lecture course in the scenic theatre of the Western Electric Company has been changed from 2 р.м. to 11 А.m. The course, under the supervision of $\mathrm{Mr}$. Hawley of the Department of Electricity, is exciting interest in the exhibits of electrical wares, and the idea so far has been extremely well received. The program, for this week and next, will be as follows: Tuesday, Mr. George C. Holland, representative of the North American Phonograph Company, lectured on the Edison phonograph. In another column will be found a summary of his address.

On Saturday Mr. R. O. Heinrich, electrical engineer for the Weston Electrical Instrument Company, will talk of electrical testing apparatus.

On Thursday, Mr. E. J. Jenness, representing the Western Electric Company, will speak on the subject of are lighting.

Tuesday, August 22, Mr. Wm. Carroll, superintendent of city construction (Chicago), will deliver an address on municipal are lighting.

Thursday, August 24, the address will be on safety alarm water columns, and Mr. Geo. B. Clark, manager of the Reliance Gauge Company, will be the lecturer.

Saturday, Angust 26, Mr. Geo. D. Benton, president of the Electrical Forging Company (Boston), will speak of electric bath heating and electric heating and welding.

\section{Obituary.}

The many friends of Mr. Louis W. Burnham, vice-president and general manager of the Electric Gas Lighting Company, Boston, were pained to hear of his death on Wednesday the 9 th instant. His recovery was confidently expected up to within a very short time of his death and the sudden termination of his illness was a shock to his family and friends.

Funeral services were held at his late residence in Dorchester Friday noon and the burial took place in his family lot at Palmer, Mass. 


\section{WORLD'S FAIR NOTES.}

Director Emil Rothenat of the German exhibit and Prof. Ulbricht started on their returu to Berlin Wednesday the 16 th.

Prof Louis C. Hill of the School of Mines, Colo., Dr. W. J. Herdman of the Lniversity of Michigan and Dr. Louis Dunean have recently been appointed on the jury of awards.

The General Electric Company installed an additional exhibit on the experimental track at the side of the Terimal Station last week in the shape of a 30-ton high speed electrical passenger locomotive of the gearless type. It will soon be seen in operation.

The exhibit of the Mather Electric Company, Electricity Building is at last completed, and is exciting much admiration and farorable comment both from attaches of the building and from risitors.

The ventilating exhaust fans just placed in the boiler annex of Machinery Hall will be greatly appreciated by the visitors as well as the attendants. The Jenney Electric Motor Company has installed 3 three-horse power motors to operate them, which are of the well known Jenny type.

The Hoppes Manufacturing Company has an exhibit of feed water heaters in the boiler annex showing close together a new heater and one that has been used with the pans incrusted with scale. In a case are shown numerous samples taken from heaters which are interesting to steam users.

Major Geo. A. Benton, rice-president of the Standard Signal Company, Rochester, N. Y., accompanied by Mr. W. W. Hibbard, the inventor and electrician for the company, is in Chicago this week, showing a working model of the company's fire and auxiliary alarm system at the rooms of the Fire Inderwriters Association in the N. Y. Life Building.

The Maharajah of Kapurthala reviewed the military organization at the Fair at jo oclock p. s. on Tuestlay. The band pavilion near the north entrance of Electricity Building was used as the reviewing stand. The Maharajah was escorted from the boat landing to the pavilion by Director General Davis and the official representatives of virious foreign countries in full uniform.

An informal meeting of the American Institute of Electrical Engineers has been called for Wednesday evening, August 23d, at the World's Fair headquarters. It is to be of a social character for extending personal acquaintance between members. A good attendance is expected as a large number of members are in the city attending the Congress and Fair.

Some exceedingly novel electroliers are shown in connection with the exhibit of earthquake instruments from Japan. The electroliers are constructed of bamboo bent in a very artistic manner. The sockets are concealed within leaf shaped pieces made of small pieces of bamboo. The different parts are well put together and make a very ornamental electrolier.

The elevators at the north end of Electricity Building put in by the Frisbie Elevator \& Manufacturing Company, of New Haven, Comn., are greatly appreciated by visitors to whom the stairs seem like mountains after walking around the grounds. This easy and quick way of reaching the gallery largely increases the number of visitors to that part of the building. This elevator is very appropriately operated by electricity. The motion is easily regulated; the ear stopped or started. It is also fitted with safety devices by which the car would be stopped automatically should the cable break or the speed of the car exceed the limit for which the device is adjusted. A 10 -horse power Crocker $\&$ Wheeler motor furnishes the motive power. The motor runs in one direction and is not reversed. The reversal being effected by a friction clutch which when thrown in different directions changes the direction of the drums.

The varions special attractions at the Exposition arranged by the management have drawn large crowds to the part of the gromds where they took place. This was especially true of the swimming contests of last Friday when this course was lined with interested spectators. These races were entered by the foreigners at the Fair, the prizes offered being five dollar gold pieces. The race of the Turks won by Conaste and the Dahomey race won by Bretoglan were particularly amusing.

In response to an invitation from Mr. W. A. Crant, of Niagara Falls, general manager of the Niagara Falls Park \& River Railway, the eastern members and friends of the Electrical Congress will take a ride over the above road Sunday morning August 20th. The special train will stop at Niagara Falls giving time for all to see the beautiful scenery about Niagara. This electric road runs for 12 miles in view of the falls and rapids. The ride will take about two hours. Special cars will be provided.

The American merchant might learn a thing or two from His Highness of Kapurthala. The Maharajah wished to purchase a supply of electrical ventilating apparatus. $\mathrm{He}$ wrote Mr. L. J. Auerbacher, of the E. S. Greeley \& Co., to call on him at his hotel. Mr. Auerbacher ealled, and $\mathrm{His}$ Highness invited him to lunch with himself and his wife, and after luncheon was over he placed a thousand dollar order for goods, and we venture to suggest he paid less for them than he would have paid had he been wined and dined at the expense of the firm that secured the order.

\section{Exhibit of the Joseph Dixon Crucible Company.}

The extent to which graphite is used in some form or other in nearly every branch of business makes the exhibit of the Joseph Dixon Crucible Company of interest to every one.

In the electrical industry graphite is largely used and its prorluction is consequently of great importance to the trade. The two exhibits of the company, one in the northeastern part of the gallery of Mining Building, and the other in the northeast gallery of Manufactures and Liberal Arts Building, show the graphite in both the crude form and the manufactured product.

The space in Mining Building, 25 by 28 feet is very handsomely finished and arranged. In upright cabinets are displayed numerous articles made of graphite, crucibles, retorts, ladles, stopper heads, graphite boses, resistance rods, incandescent filiments, moulds and other goods. The process of electrotyping in which graphite is used is illustrated in a case placed in the center of the room.

In other cases are shown graphite lubricants, stove polish, foundry facings, paints, etc, etc. Distributed about the room are samples from all the different sources from which that article is obtained. One sample from the island of Ceylon weighing nearly 300 pounds seems to attract attention. The space is handsomely carpeted and furnished with comfortable chairs, tables, etc. 


\section{PERSONAL.}

Mr. E. Egger, Vienna, is paying the Fair a visit.

Mr. Ch. Lotter, Zurich, was seen in the Electricity Building last week.

Dr. Martin Kellmann, Berlin, called at the office of the A. I. F. E. this week.

Mr. Geo. R. Metcalfe, editor of Electricity, New York City, is at the Exposition this week.

J. M. Rich, electrical engineer, New York, was a caller at the office of ELECTRICAL INDUSTRIES this week.

T. C. RAFFERTY \& Co., Chicago, have located their offices in the Como block, and are now ready for business.

IIr. W. H. St. John, electrician of the Lozoo Company, Lazoo, Miss., called at the World's Fair office of ElEctrical INDUSTRIES.

Mr. Stephen L. Coles, the associate editor of the Electrical Review, is looking over the Fair, and the Flectricity Building especially.

Mr. M. J. Sullivan, of the Electrical World, was married on Tuesday of this week to Miss Frances Read at Freeport, Ill. A number of Chicago friends attended. Electrical Industries extends congratulations.

Mr. Geo. B. Ellison, formerly engineer with the North Western Thomson-Houston Company, of Portland, Ore, has just accepted a position as engineer for the western department of the Waddell-Entz Company, with offices at 1140 Monadnock building.

Mr. Geo. P. Low, the well-known insurance inspector of the Pacific coast, is in the city accompanied by Mr. W. F. C. Hasson. Both gentlemen are the delegates from California to the Electrical Congress, and while here will visit the Fair. Mr. Hasson is the special agent of the electrical department of the Fair to be held in San Francisco next winter. It is hoped to have an electricity building at this Fair, and while in Chicago Mr. Hasson will do what he can to secure exhibits for his department.

DEPARTMENT OF ELECTRICITY.

OFFICES: SECTION R, ELECTRICITY BUILDING.

Chief, JoHN P. BarRetT,

Assistant Chief, J. Allen Hornsby.

General Superintendent, J. W. BLAisiert.

Electrical Engineer, IV. WV. Prims.

\section{DEPARTMENT OF MECHANICAL AND ELECTRICAL} ENGINEERINH.

OFFICES SOUTH OF MACHINERY HALL.

Mechanical Engineer, C. F. Foster

Electrical Engineer, R. H. Pierce.

First Asst. Mechanical Engineer, JoHN MEADEN.

First Asst. Electrical Engineer, S. G. NEILER.

\section{A UERICAN INSTITUTE (IF ELECTRI SAL ENGINEERS.}

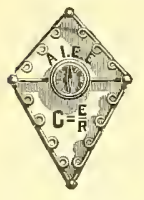

World's Fair Headquartere,

SECTION S, ELECTRICITY BUILDING.

RALPH WV. Pope, Secretary.

Open from 9 a.m. to 5 p.m.

CHICAGO WORLD'S CONGRESS OF ELECTIRCIANS. PENING SESSION, MONDAY, AUGUST $21 \mathrm{ET}, 3 \mathrm{P}$. M ADVISORY COUNCIL.

President, Dr. Elisha Gray, Highland Park, Ill.

Secretary, Prof. H. S. Carhant, Ann Arbor, Mich, EXECUTIVE CONMTTTE.

Chairman, Prof. Elihu Thosson, Lynn, Mass. COMMITTEE ON INVITATIONS.

Chairman, T. Commerford MARtin, 203 Broadway, New York. COMMTTEE ON PROGRAM.

Chairman, Prof. T. C. MlendenhalL, Washington, D. C COMMIITTEE ON FINANCE.

Chairman, B. E. Sunxy, 175 Adams Street, Chicago.
BUSINESS NOTES.

The Chicago Rawhide Manufacturing Company, Chicago, reports that the foreign demand for its rawhide products is increasing in spite of the present dull times. The company has just received an order by cable for 5,000 feet of belting. It also made a large shipment of goods to Australia last week.

The Mosher Electric Company, Chicago, is having many inquiries and making a number of shipments of its street railway arc lamps. Among the orders recently filled are those to the South Chicago Railway; Paducah, Ky., and the Los Angeles Street Railway. The alternating are lamp recently brought out by this company is also selling well.

The Western Electric Company, Chicago, has just secured the contract for the complete installation of a electric lighting central station for the eity of Rochester, Minn. The plant will consist of 80 Western Electric Company arc lights and 1,000 alternating incandescent Westinghouse. The entire construction of the plant will be done by the Western company.

The Enterpise Electitc Compans, Chicago, has just received contract for the entire electric equipment for the Medina Temple, corner Jackson St. and Fifth Ave. The McFell Elec. tric Construction Company is doing the work of installation. The entirc plant is to be wired throughout with N. I R. wire, for which the Enterprise Company is the general western agent.

Electric Appliance Company report that their business in electrical house goods does not seem to feel the depression that exist in other lines of electrical trade and is proving a valuable line to fall back on at a time that in otjer departments is comparatively quiet. The Electric Appl: ance Company are building up a splendid trade in this line of goods, which has been comparatively neglected for the past few years in the interest of electric light supplies, and their electrical house goods have already established for themselves a first class reputation among the trade of this material.

\section{Amusements.}

Hooles's Theater-Mr. Nat C. Goodwin, in "Mizzoura." 149 Randolph street.

Colunia Theater-Miss Lillian Russell, in "The Mountebanks." 108 Moнroe street.

Grand Opera House - Sol Smith Russell, in "A Poor Relation." 87 Clark street.

Auditorion-Imre Kiralfy's Spectacle "America." Congress street and Wabash avenue.

MoViCKer's Theater-Denman Thomson, in "The Old Homestead." 82 Madison street.

Chicago Opera House-American Extravaganza Company, in "Ali Baba, or Morgiana and the Forty Thieves." Washington and Clark streets.

Sohiller Theater-Chas. Frohman's Stock Company, in "The Girl I Left Behind Me." Randolph, near Dearborn.

Haverly's Casino-Haverly's United Minstrels. Wabash avenue, near Jackson street.

Trodadero-Vauderille. Michigan avenue near Monroe street.

The Grotto-Vaudeville. Michigan avenue near Monroe street.

Buffalo Bill's "Wild West." 63d street. Daily at 3 and 8.30 p.m.

Pain's "Siege of Sebastopol," 60th street and Cottage nights. Grove avenue. Tuesday, Thursday and Sunday

Sol Smith Russell, at the Grand Opera House, continues to have good houses. This is the sixteenth week of his present engagement, and the present piece "A Poor Relation," in which Mr. Russell has been such a favorite, will be continued some time longer.

"Ali-Baba" has but three more weeks torun, when "Sinbad," the revival of which has been postponed several times on account of the continued suceess of "Ali-Baba," will be again placed on the stage. The various productions of the American Extravaganza Company form a remarkably successful list. The first one, "The Arabian Nights" was presented at the Chicago Opera Housee 96 times, "Sinbad" ran 122 times; "Bluebeard Jr.," 125; "The Crystal Slipper," in two engagements, 206 times, and "Ali-Baba," when it closes its present engagement, September 2 , will have been played 331 times in Chicago. 


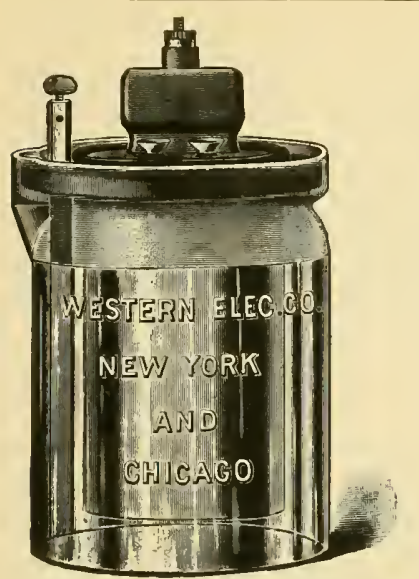

Disque La Clanche Batterv.
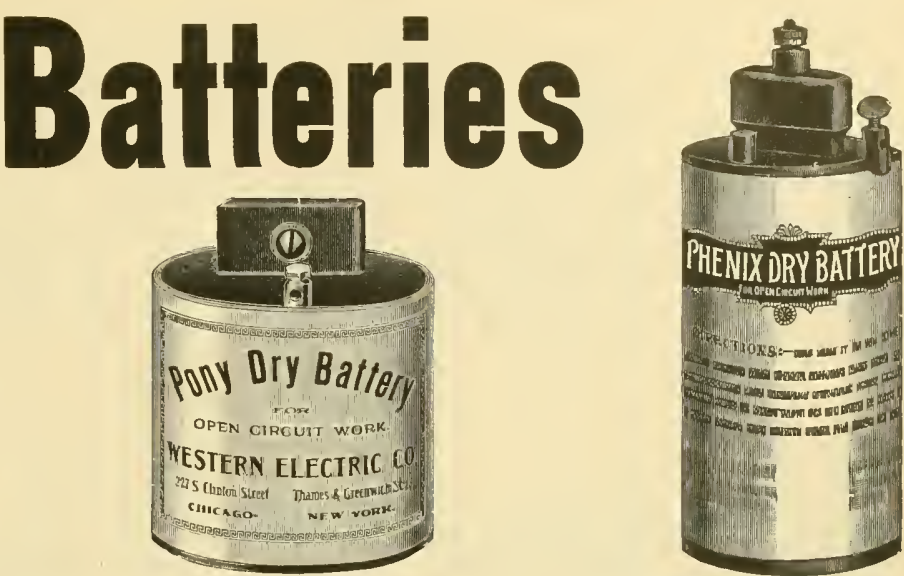

Phoenix Dry Battery.

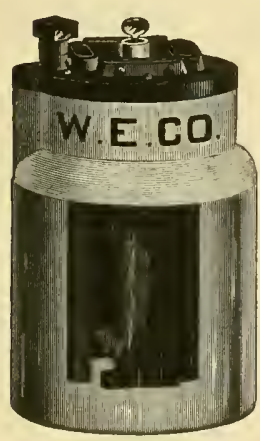

Quad Battery.

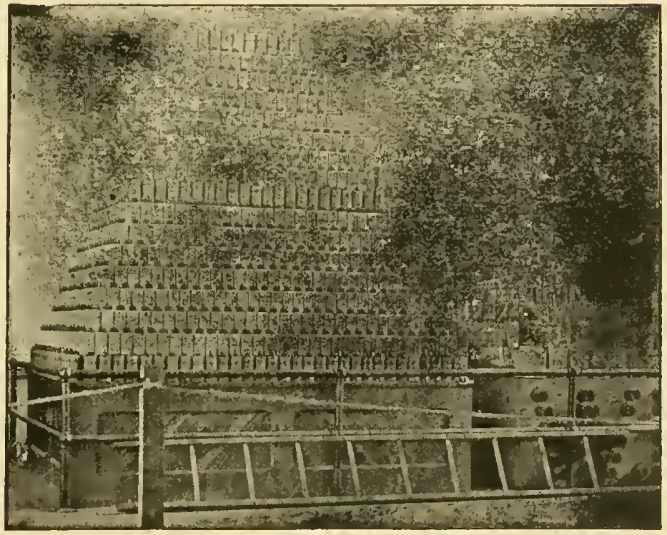

Battery Exhibit Electricity Bldg, World's Fair.

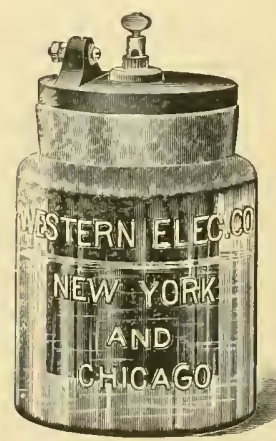

Weco Carbon Battery.

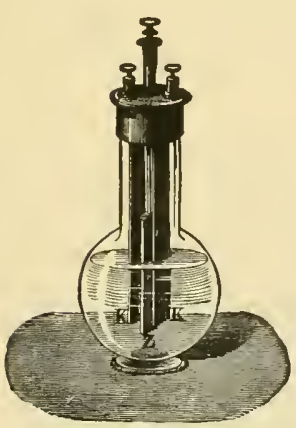

Crenet Battery.

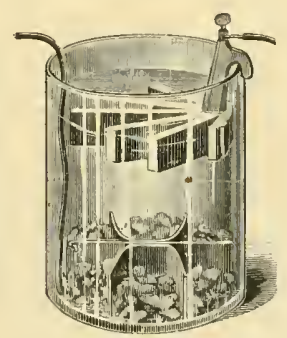

Gravity Battery.

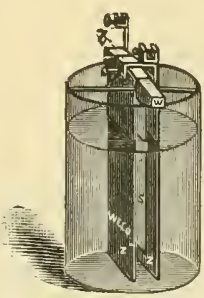

Smee Battery.

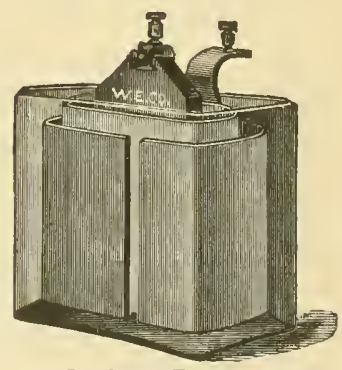

Carbon Battery.

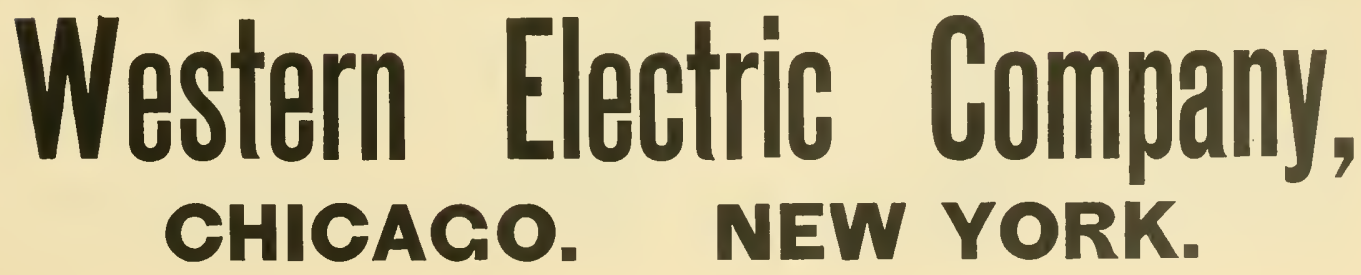


would undoubtedly be a good thing for certain sections of the conntry, but we would respectrully remind the trade that our specialties and supplies are

30 in any section of the country and it is a mistake MONEY WILL BUY MORE SUBMITTE FOR YOUR CONSIIDEATION BY THE

\section{ELECTRIC APPLIANCE COMPANY,}

\section{ELECTRICAL SUPPLIES}

242 Madison Street, - - OFIOAGO THE MATHER ELECTRIC CO. THE "NOVAK” LAMP. MANCHESTER, CONN.

Dynamos, Motors, Generatiors, Offices, ll6 Bedford St., BOSTON.

$$
\text { -AND- }
$$

1002 Chamber of Commerce Bldg, CHICAGO. 1002 Chamber of Commerce Bldg., CHICAGO.
CLAFLIN \& KIMBALL (Inc.)

General Selling Agents.

116 Bedford Street, BOSTOH.

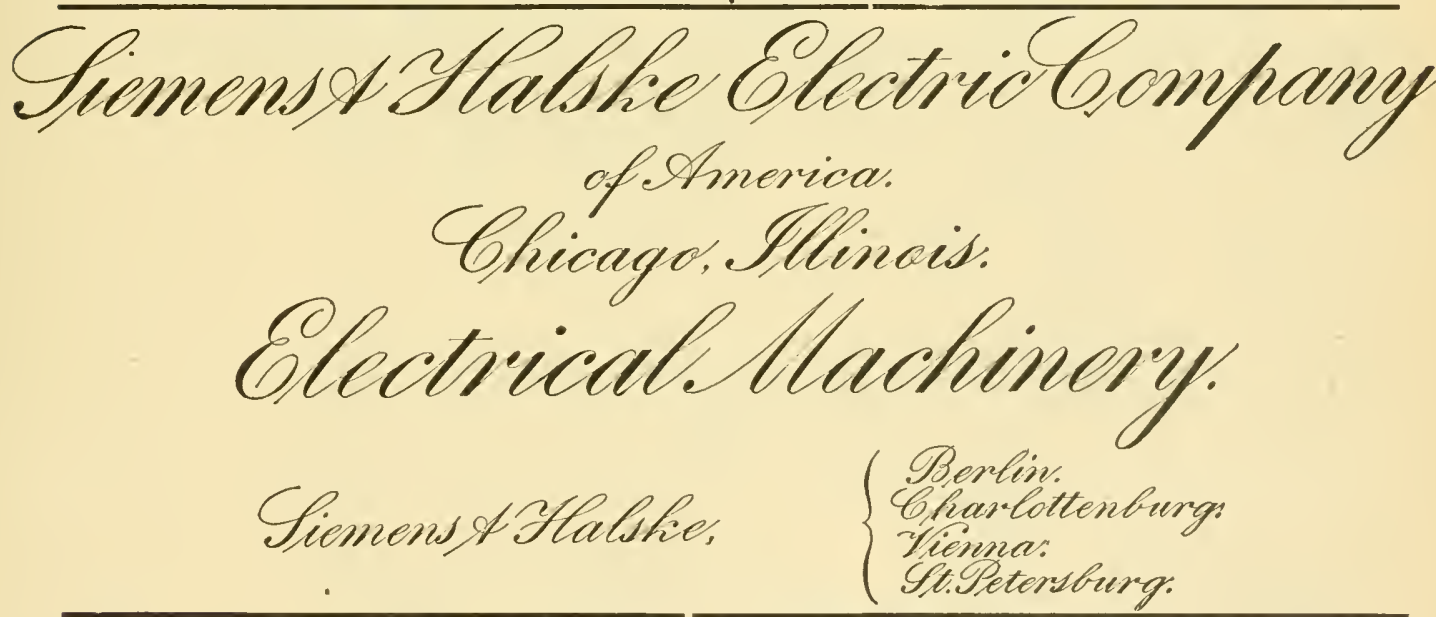

\section{Enterprise}

Electric

207 Dearborn Street. Chicago .... .

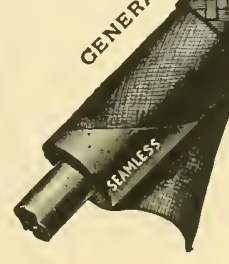

Manufacturers' Agents and MIII Representatlvee for

Electric Railway, wo Telegraph, Telephone and Electric Light

SUPPLIES $S_{\substack{\text { of Everp } \\ \text { oscalpro }}}$

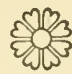

Agents for Cedar Poles,

Cypress Poles, Oak Pins, Locust Pins, Cross Arms, Glass Insulators,

WIRES, CABLES, TAPE and TUBING 
Map of Chicago.

Showing Location of its Electrical and Allied Business Interests, Principal Hotels, Theatres, Depots and Transportation Lines to the World's Fair Grounds. (Index numbers refer to the black squares.)

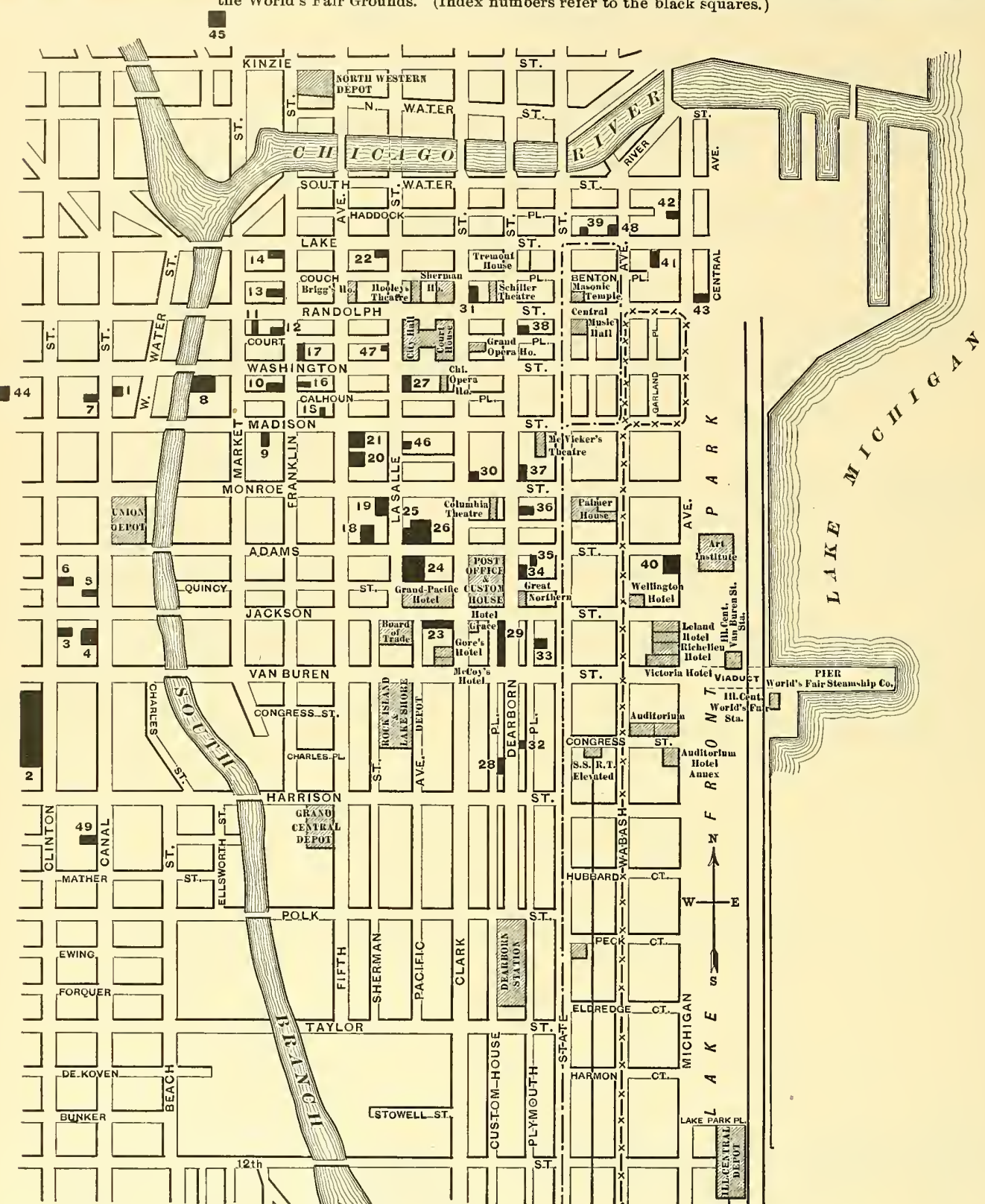

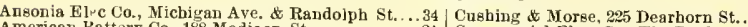

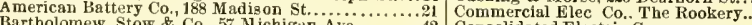

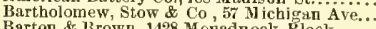
Benham, A. D. $200 \mathrm{~S}$. Clinton St. Block..

Brill Com, A. 200 S. Clinton st...

42 Conmolidated Electric.

34 McDongall \& Cuumings, Unity Bldg..............38

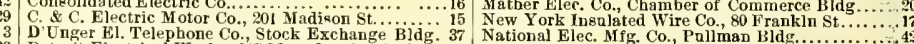

16 Matber Elec. Co., Chamber of Commerce Bidg.........

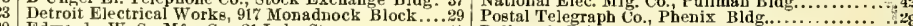
Edwards, W. S.. Mfg. Co., 21 Lake St..............41 Pollman's Palace Car Co., Pullman Bidg..............4 Eddy Electric $\mathrm{M}$ fg. Co., 1417 Monadnock Block.......29 Pumpelly, J. K., 205 S. Canal St........................40 Brusb Electric Co., Monadninck Block

Electric Construction \& Supp]y Co., Unity Bldg.... Electric Appliance Co., 242 Madigon St.

Coctric Mfg \& En gineering Co.

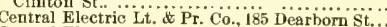
Electrical Industries Pú Co., Monad Ft. Waype Electric Co, $30 \%$ Dearborn $\mathrm{St}$

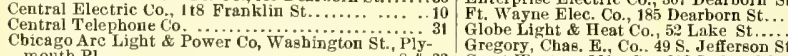

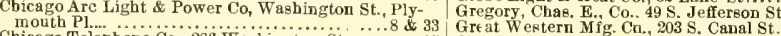

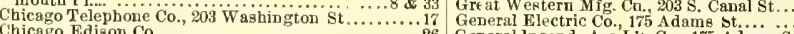

Chicago Edison Co

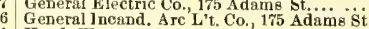
hicago Electric Motor Co., $313 \mathrm{~S}$. Canal sit................

Hood, Wm. 239 Lasill.

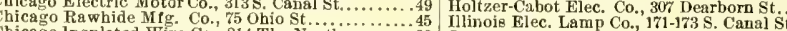

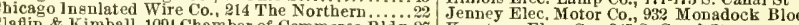

Cleveland Klectric \& Mfo. Co 149 Commerce Bldg.27 Keystone Elec. Co., 345 S. Canal St.

Catter, Geo, 851 The Rookery.....................24

9 Phoenix Glass Co., Wabash Ave..... and Lake St..........49 Rockford Elec. \& M $\mathrm{Mg}$. Co., 94 La Salle St............47 Standard Elec. Co., $6 \%$ Home Ins. Bldg............... Siemet \&-Haleke Elec. Co., 1225 Monadnnck Block...29 Star Elec. Lamp Co., 805 Chamber of Com. Bldg......27 Stirling Co, 606 Pollman Bldg...................40 Schieren, Chas. A., \& Co., 46 S. Canal St............. 1 Short Elec. Railway Co., Monadnock Black........29
Taylor, Goodhue \& Ames, 348 Dearborn St,.......28 Taylor, Good hne \& Ames, 348 Dearborn St..........28
Todd. Applegate Co, The, 340 Dearhnrm St.......28 Waddell-Entz Co., li22 Monadnock Block............29 Westinghouse Electric \& Mfg. Co, Pullman Bldg...40 Western Electric Co,, 227 S. Clinton St............ Wollensak, J. F , Lake and Franklin Sts.............. 


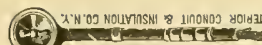

- THE

FERRIS WHEEL

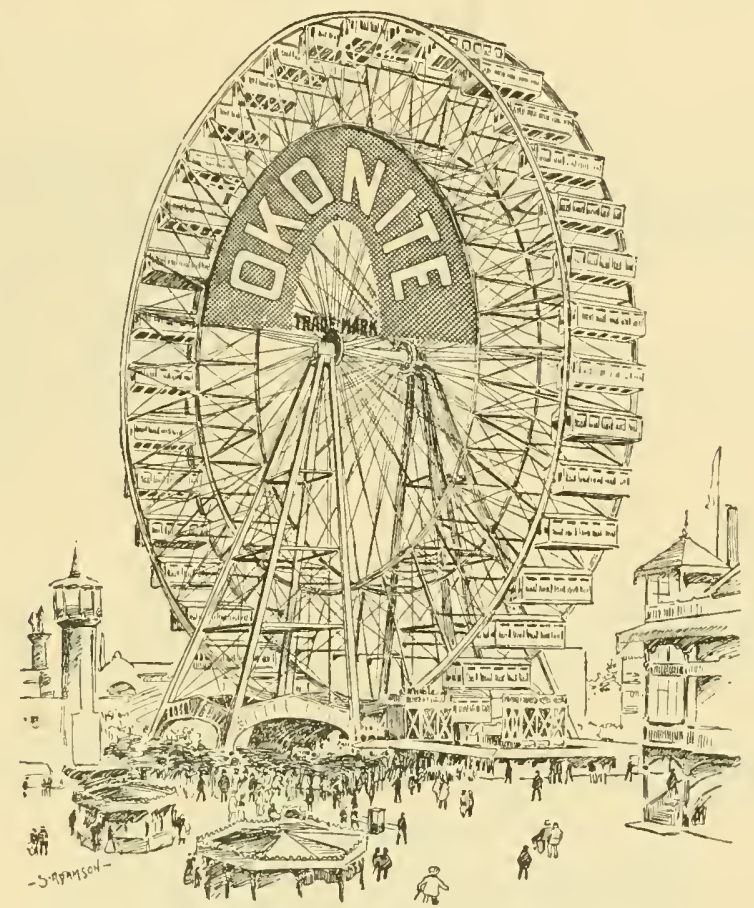

When you visit the World's Fair, you will naturally take a ride on the FERRIS WHEEL and be interested in the ELECTRIC LIGHT INSTALLATION, which is wired throughout with

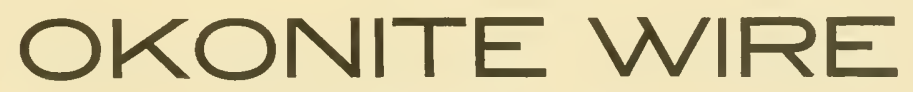

FURNISHED BY THE

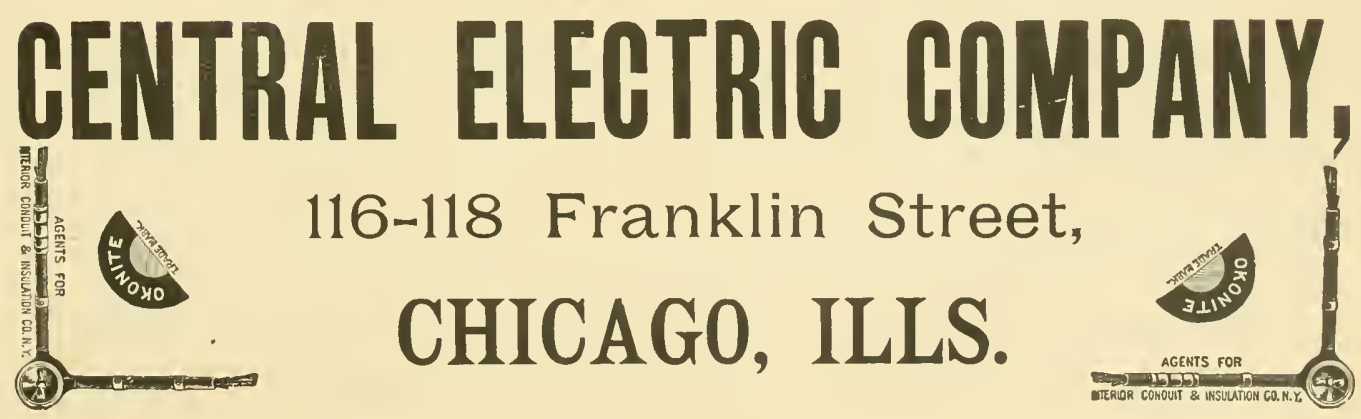




\section{VISITORS SHOULD NOT FAIL TO SEE THE}

\section{First Souvenir Half Dollar}

...AT THE EXHIBIT OF...

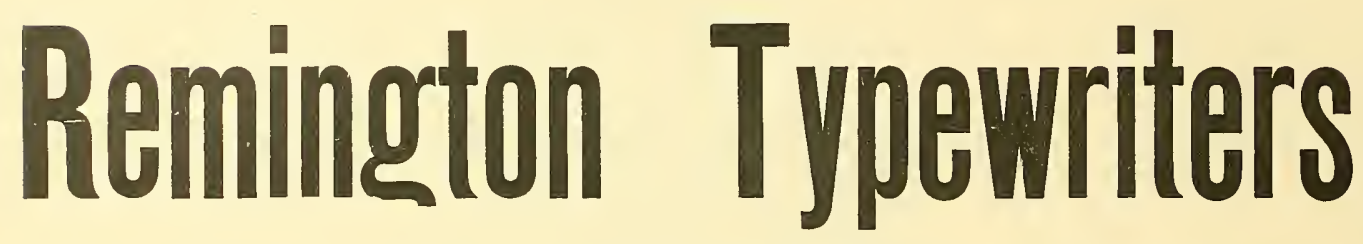

in the N. E. Corner of the Main Gallery of the Manufactures and Liberal Arts Building.

$\$ 10,000$ was paid for this coin, making it the most valuable piece of silver in the world.

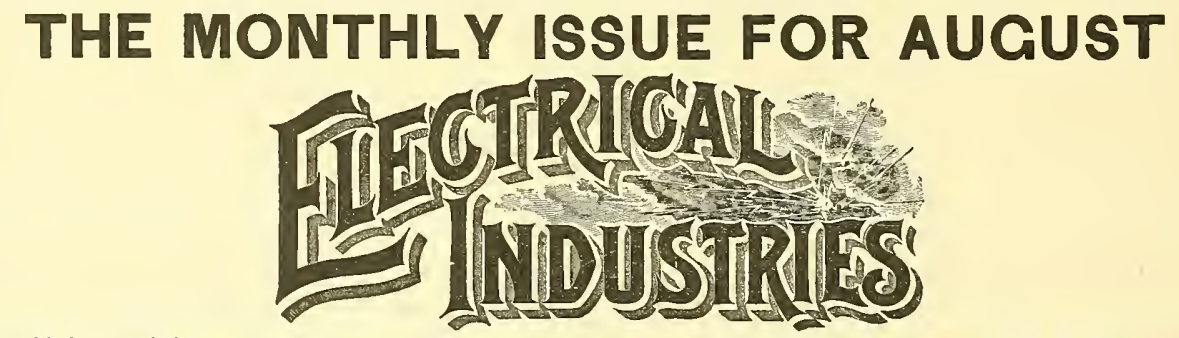

Should be read by everyone interested in electrical matters. In its table of contents is the following:

"Incandescent Lighting at the World's Fair."

"The Electric Power Plant of the Chicago City Railway."

"Steam Engine Efficiency-Its Possibilities and Limitations" by Wm. H. Bryan.

"Alternating Arc Lighting for Central Stations" by H. S. Putnam.

"Hard Rubber as an Insulator in Street Railway Work" by W. R. Mason.

"A Brief Review."

Togetler with illustrations of the recent applications of electricity.

The paper also contains regularly

A Buyer's Directory of Manufacturers and Dealers in Electrical Supplies and Appliances.

A Complete Directory of Electric Light Stations in North America and a Complete Directory o, Electric Railways in North America.

These directories are revised each issue to the date of going to press and are to be found in no other electrical journal in the World. Its articles are read carefully and its directories used constantly by all the buyers in the trade. These facts make it without a superior as an advertising medium. Sample copies and rates sent on application.

Subscription price $\$ 3$ per year. Six months trial $\$ 1$, if ordered during the next 30 days.

\section{ELECTRICAL INDUSTRIES PUB. CO., \\ Monadnock Block, CHICAGO.}




\section{COMPANY, NEW YORK.}

192 Broadway and /I John Stree".

MANUFACTURERS OF ARC LIGHTING APPARATUS FOR EVERY PURPOSE A SPECIALTY. The CLARK ARC LAMPS for use on EVERY CURRENT, bave the reputation of being the best and most durable of any ever made in the United States.

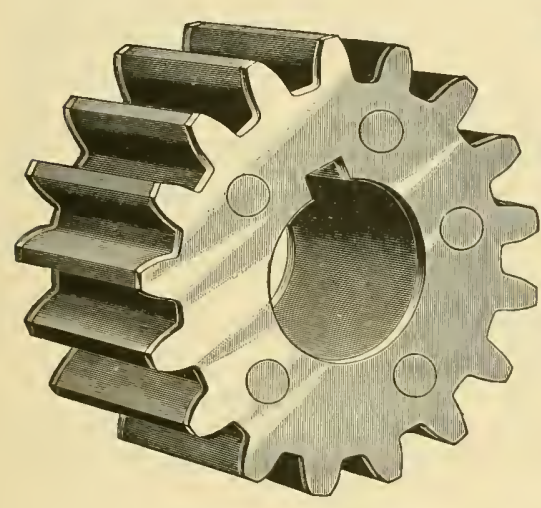

RAWHIDE PINIONS FOR ELEGTRIC MOTORS A SPECIALTY.

RAWHIDE DYNAMO BELTING

Greatest Adhesive Qualities. A Non-Conductor of Electricity. Causes Less Friction than any other Belt.

\section{THE CHICAGO RAWHIDE MANUFACTURING CO.}

THE ONLY MANUFACTUREAS IN THE COUNTRY.

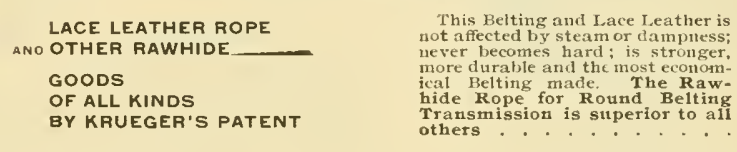

\section{Standard Electric Company.}

GENERAL OFFICES: 625 Home Insurance Building.

WORKS: So. Canal Street,

\section{CHICAGO.}

\section{STANDARD SYSTEM}

AT THE

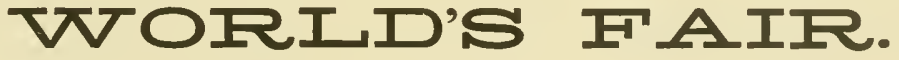

MACHINERY HALL, Sec. Q, 2 Standard Arc Dynamos.

Sec. S, 20 " " "

ELECTRICITY BUILDING. Sec. P, Space 2, Arc Lighting Exhibit.

The Standard Lamps Light the Power Plant, Machinery Hall, Agricultural Hall, Shoe and Leather Building, and Other Buildings and Portions of the Grounds. 


\section{FERRIS WHEEL}

Wired with mile upon mile of

Simplex Wire

(We don't claim it all)

GEORGE CUTTER, ${ }_{\text {The Rookery, Chicago. }}^{851=85}$

\section{SIMPLEX WIRES}

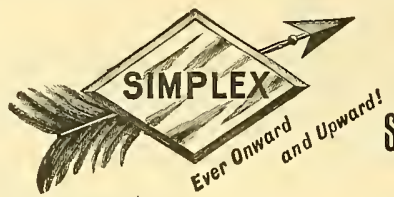

INSURE

HIGH

INSULATION

Simplex Elegtrical bo. 620 Atlantic Ave.,

George Cutter, Chicago. BOSTON, MASS.

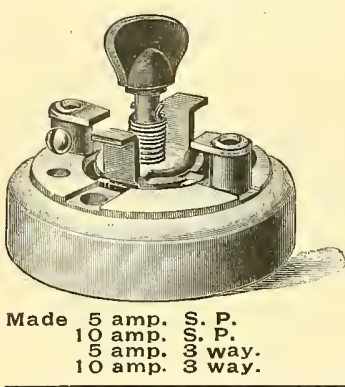

10 amp. 3 way.

\section{XNTRIC}

"That's the Switch"

And we control that movement.

H. T. PAISTE, IO South IBth St., PHILADELPHIA, PA.

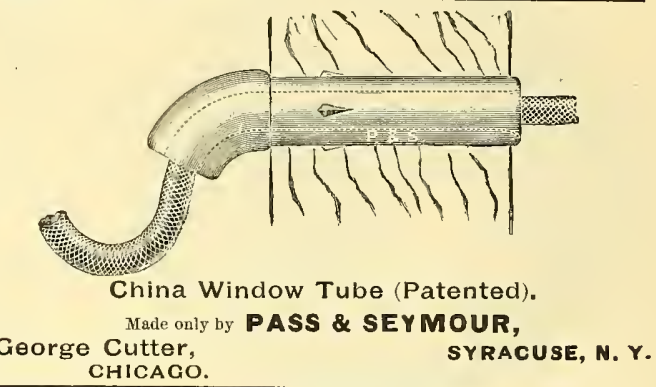

\section{Consolidated Elpctric 6.}

\section{ELECTRICAL . SUPPLIES,}

115 Franklin Street,

chicaco.

\section{GHORGE PORTER,}

Contractor for All Kinds of

\section{ELECTRICAL WORK.}

Room 67, 143 La Salle St., CHICAGO.

Crary Block, BOONE, IOWA.

\section{CHAS, A. SCHIEREN \& CO,}

MANUFACTURERS OF

\section{Genuine Perforated Electric Leather Belting.}

46 So. Canal Street, = CHICACO

CALL AND EXAMINE

\section{Lawton's Call Indicator.}

Indispensable for hotels, railroad offices, school buildings, hospitals, etc.

Section Y, Space 45, Gallery Electricity Building, WORLD'S FAIR.

OFIOAGO, ILI.

\section{WAGNER ELECTRIG FAN MOTORS}

Hot Divert of Alternating Currents.

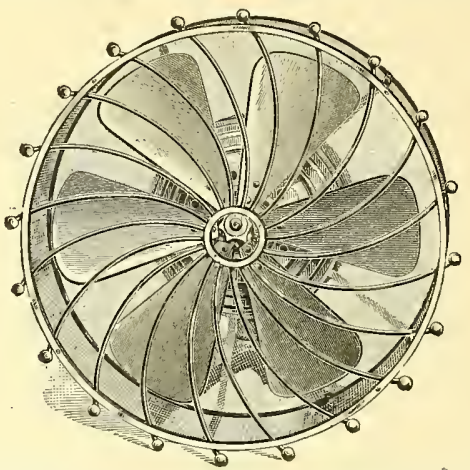
any other pan motor on the market. They are full 1.8 horse power. Six bladed IT WILL. PAY YOU TO SEE THE WAGNER BEFORE BUYING ELSEWHERE.

TAYLOR, GOODHUE \& AMES, 348 Dearborn Street, CHICACO. 


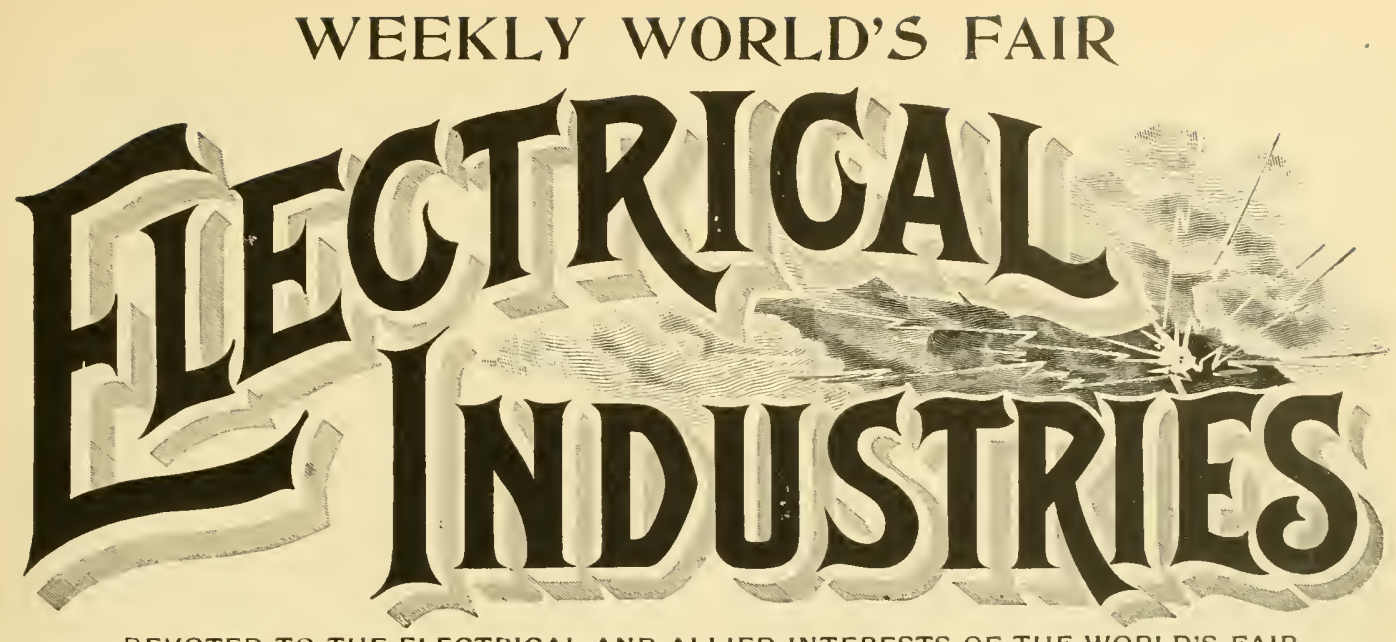

DEVOTED TO THE ELECTRICAL AND ALLIED INTERESTS OF THE WORLD'S FAIR, ITS VISITORS AND EXHIBITORS.

Vol. I, No. II. CHICAGO, AUGUST 24, 1893.

FIVE MONTHS \$1.00
TEN CENTS A COPY

Arc Lighting Plant of the Standard Electric Company at the World's Fair.

In Machinery Hall, section $S$, is located one of the largest are lighting plants of the Exposition supplying current for er. The other lights are distributed in the Agricultural, Anthropological, Forestry. Shoe and Leather buildings and around the Peristyle and in other parts of the grounds.

The 20 dynamos are arranged in two rows and are belted to shafts beneath the floor. The wiring is all concealed be

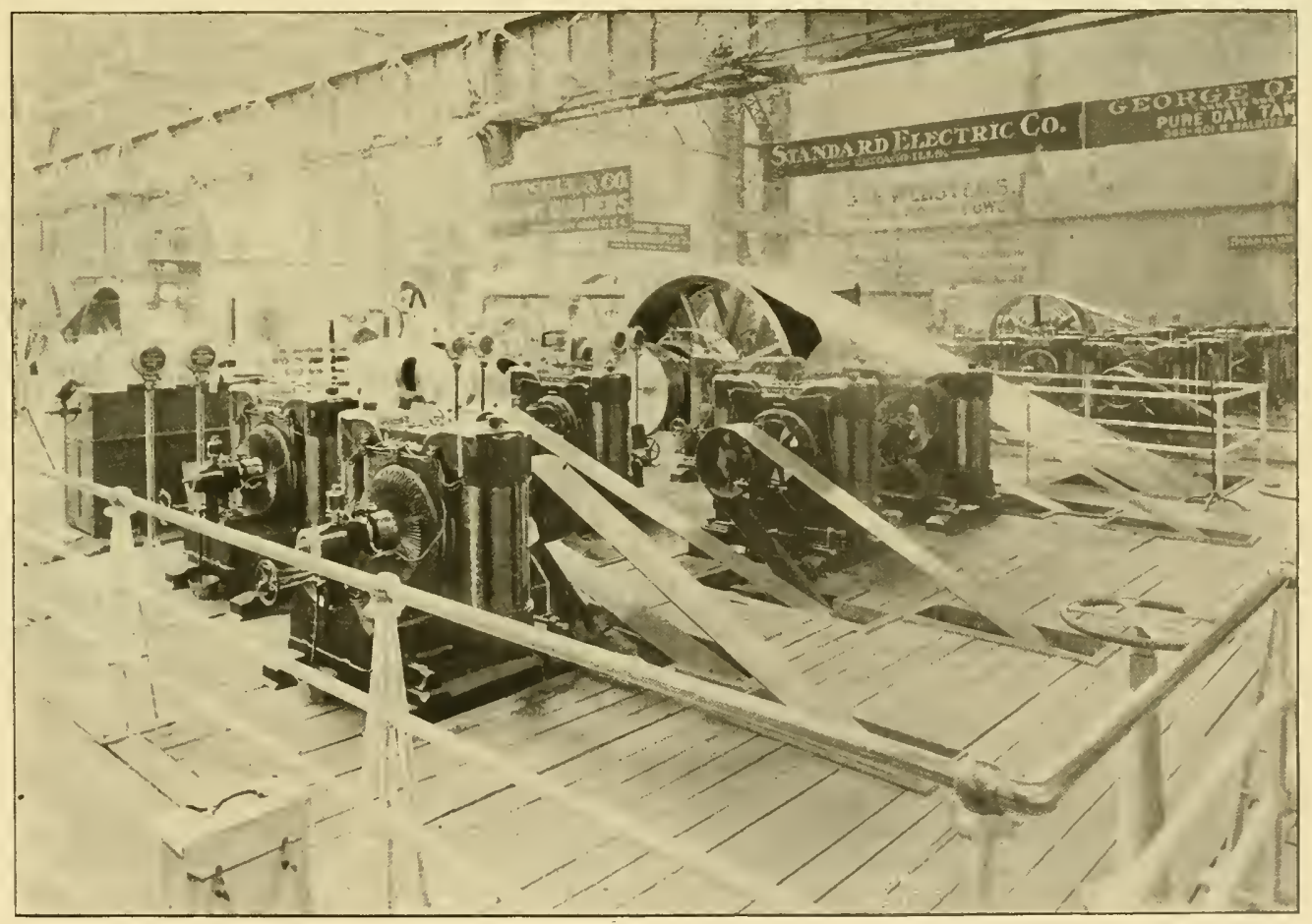

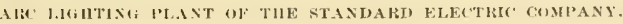

orer 1.100 are lamps. This plant which was installed by the Standard Electric Company, Chicago, contains 20 dynamos, each having a capacity of 502,000 candle power lights while in section $\mathrm{Q}$ are one 50 and one 60 light machines, used in the illumination of the power plant prop. neath the floor, both the leads to the switch board and the wires to the ammeters which are after a special design of the Standard company. These ammeters are raised on standards to a courenient height and are placed sufficiently near to be easily read by the dynamo tender from the 
dynamo. The metallic cases and standards are nickel plated, presenting a neat appearance. The wires are run from below inside the standards so that there are no exposed wires to be injured or to oppose the free morement of the attendants about the machine.

The dynamos are of the well known standard type. The frame is an adaptation of the Manchester type. The pole pieces which form the main portions of the frame are of sott cast iron of a character especially designed for this purpose. In the field magnets mrought iron is used. The journal supports are made self adjusting and aligning. The bearings are made long and are fitted with self oiling lining of

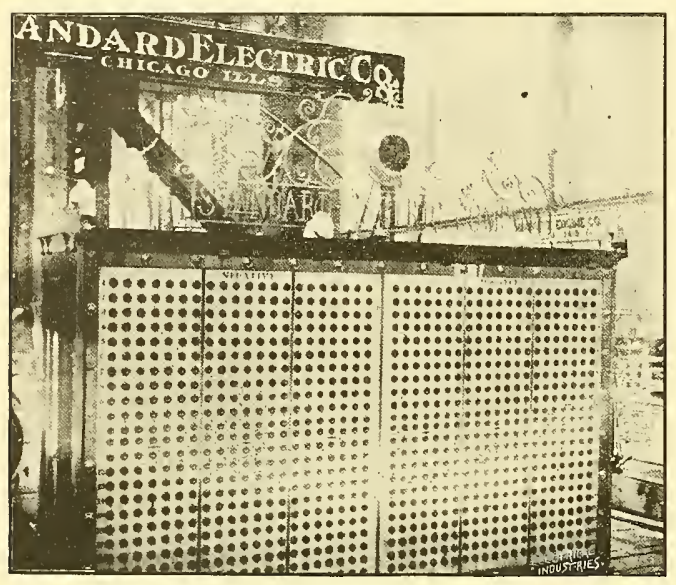

ARC LIGHTING PLANT OF THE RTANIARI ELACTRIC COMPANY.

an improved pattern. The armature is easily removed by taking out the journal support at either end. This armature has many special features the excellence of which are apparent on inspection. The large open interior permits of a free ventilation of the armature which is so essential to the perfect operation. From this construction both the interior and exterior surface is open to the air.

To remove and replace a coil requires little time or trouble and a coil may be renewed with ease on the armature on account of the armature being free trom internal supports. In case of aecident to one of the coils it may be disconnected from the commutator and the dynamo run until such a time as repair can be conseniently made. Many visitors have remarked on the smoothness with which these machines run, there being no sparking and heating at the brushes a fact which is quickly noticed by nsers of many are machines of other manufacture. All screws, bolts and nuts used about the machine are made from standard com. mercial taps and dies so that repairs may be quickly made. no matter how remote a plant may be from the factory. As a whole the machine commends itself to the visitor as simple, solid and compact.

Three engines turnish the power for this plant. The first engine which is a 24 by 24 by 15 by 24 double tandem compound furnishes power for 12 dynamos. It is a four ralve independent exhaust Russell engine. It is fitted with Detroit lubricator and sight feed oil cups of the latest pattern. The fly wheel, which is 10 feet in diameter and 60 inches wide is belted by a nol inch George Oberne $\mathrm{A}$ Company's belt to a shaft beneath the floor to which each dynamo is independently belted. The next four dynamos are run by a 20 by 20 by 13 single valve Russel engine. The fly whee] which is eight feet in dianneter by soluches is belted similar to the above by a 26 inch belt. The last four dynamos are belted tandem to a 200 horse power engine rumning 275 recolutions per minute. This engine which was built by the Erie City Iron Works is fitted with a Webber automatic governor, Detroit lubricator, sight feed oil cups and other improred devices.

The dynamos in section $Q$ are run by an ided engine manufactured by A. L. Ide \& Son. The power is transmitted by the ldeal system which makes a most compact combination. The dynamos and engine which is 125 horse power requiring no more room than if they were directly connected. This plant though oceuying but little space has a capacity of 1102.000 candle power are lights and is worthy of more than a passing notice.

In the center of the large plant is erected a molel switch board capable of aceommodating 21 circuits and 21 dynamos. It is of marble, of the plug pattern and so arranged that the current from any dynamo in the block may be turned on any circuit. The board is extremely simple and compact. The company also furnishes the operating department with a 12 circuit board used as an exchange board. In case the dynamos or engines in any plant should become disabled from any cause, by means of this board current from other plants may be turned on.

The lamps used on the circuits of this plant are all of the Standard company's make. The lamps used in the Machinary Hall power plant, on the patrol circuits, and in the grounds are of the double service weather proof pattern while the others are of the single service pattern. These lamps have been in use a number of years and improve ments have been added naking the lamps in every way efficient. In the outdoor weather proof lamps the unsightly hood has been abandoned and the lamps present a trim and substantial appearance. All the working parts and connec-

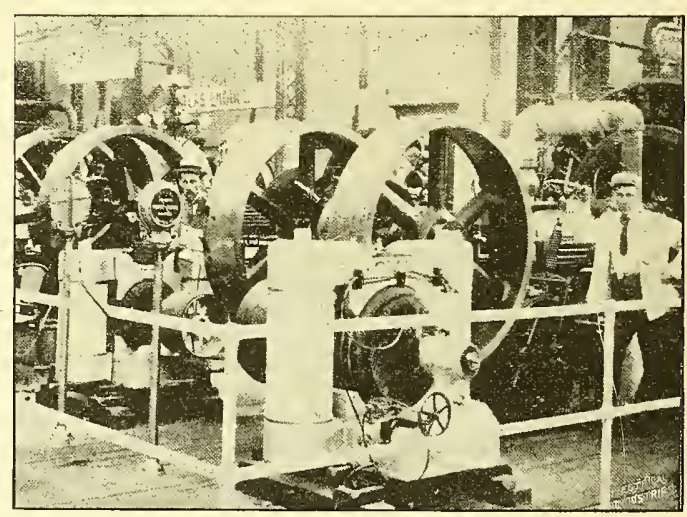

AISC LIGHTING PLANT GF THE STANDARI ELECTRIE COMPANY.

tions are enclosed in a tight weather proof cap which ean easily be removed. The lamp may be quickly disconnected from the line withont opening the circuit. The carbon feeds smoothly and without any jerking motion, thus giving a clear and steady light.

The hangers used for smplorting these lamps were described and illustrated in our. July issue but the eredit for the designs was given to the dejrartment which should have been given to the Standard company, as we have since been informed that the design originated in the factory of this company where the hangers were made.

Every part of this plant has been installed in the most substantial and workmantike mamer and to those inferested 
in central station construetion au examination of the plant in detail will be found of interest. Ifany impromements in construetion and methods of operation bave feren atclopted.

\section{World's Congress of Electricians.}

After monthe of preparation the Electrical Congress lads issumbles. The electricians bave betn gathering in Chueago $f_{(1)}$ sonetime in anticipation of the congress anel the attendance at the opening, both in numbers and the prom incrue was fully up to expectations. When the congress "pened there ware on the plat form the following gentlemen. whose names are familiar to all delegates from their re spective countries to the congress: Dr. H. Vou Helmholtz, Dr. E. Voigt. Germany; Prof. E. Hospitalier, Prof. E. Mascart, Franee; Dr. A. Palaz, M. Thury, Switzerland; I'rof. Elilu Thomson, Dr. T.C. Mendenhall, Prof. H. A. Row land. Prof. H. S. Carbart. Lnited States; Prof. Silvanus Thompsom. Alexander Siemens, Prof. W. E. Ayrton, W H. Proeece, England: Dr. Lohann Sahulka, Anstria: Prof (ralilee E'erraris. Italy.

$$
\text { OPENING SESSIOX. }
$$

The Chicagen World's Congress of Electricianm was called to order in Columbus Hall of the Art Institute by Prof.

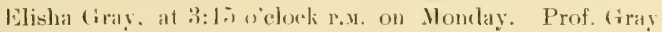
read an akdrose welcoming the delegates and the menters of the eomgress, and at the end ralled for nominations for temporary chaiman. Mr. W. H. Prece, a delegate from (treat Britain, in a very neat little speceld, proposed for temporary "haiman Elilu Thomson. of Lymm, Mass, wh" was elected by acelamation. Prof. Thomson, on taking the chair, made a short speech which was receired with ap 1) latuse.

(1) calling for mominations for temporary secretary, Prof. E. R. Cross, of the Massarhusetts Hustitute of Technologry Boston, joroposed Prof. F. B. Crocker, of Columbia College. New Vork, who was electerl by acclamation. The ehais then appointed as a committee for the nomination of $\boldsymbol{p}^{-x}$ manent officers Prof. T. C. Mendenhall, Prof. B. F. Thomas, Dr. Lonis Dunean, Prof. Silvams P. Thompon, Prof. E. Hospitalier. Dr. A. Linbeck, and Dr. A. Palaz, who thesu retired. Prof. Thomson abled on Prof. W. E. Ayrton to say a few words on the sulject of the World's Fair as serell by a foreigner.

Prof. Ayrton stepled forward, prefacing his spreech hy saying that the ebaiman had made a mistake in calling him a foreigner, as no Englishman conld he a foreigner in Ameriea. He preferred to be called a stranger. He then went on to say that Chicago is a long way from the seas, and he thunght that a stranger's impression on electrical natters hegan long before he arrived at the whits cits. After describing what impressions a stranger would receiv. in his journey to Chicago in the varions eastem eities l,. might risit. he said: $H_{e}$ is as much astonisherl with the (w) urtesy with which he is shown every detail in the factorias ats by the magnitude of the undertakings. His expectir tions are aroused to such a piteh. flat he expects that when he comes here to Chicago, to find a display which will east all previous electrieal exhibitions into the shade. Well, tak. this stranger into the Electricity Building blindfolded, no that his judgment will not be warped by the glories of the ontside surroundings, and leave him there, and after a while, if lie be candid and if he can master up conrage to say a word which might eause pain to those whose kinduess has made them dear to him, be will say he is a little disal. pointed that the world hats not better answered the invita tion to show the Electricity. Builking what it could do.

The stranger feels that the real electrieal display of America is not in tha. Electricity Building but in exery street where there are trolley wires, in every town and village where there are electrie lightn-and where is the town in this country where there are not? lint if the stranger be thoughtful, be in not disalpointed. In Frank fort it was what was inside the Electricity Building that clazzled the mind; at Jacksem Park it is what is ontside of the Electrieity Building that riwets his attention. The committee now returned. and Dr. Mendenhall, as chairman. rejorten the nominations as follows: For homorary president of the congress his exeellency Dr. H. Von Helmholtz. of Germany; as permanent chairman of the congress, Prof. Elisba Gray, of Chicauso: as vire-presidents, representing the Cnited States. Edw. Wentom: Great Britain, W. It. Preece: France, E. Maseart; Germany, Dr. Voigt: Austria, J. Salulka: Italy, Prof. Galileo Ferraris; Switzerland. Dr. H. F. Weber, who were alected by acelamation. Prot. F. B. Crocker was then nominated as jermatsent seceretary and was elected by acclamation.

In presenting Dr. Fon Helmbolte as the houorary pres. dent of the couggress. the rhairman. ['rof. Thomson. ealled attention to bis very great andienements and to the fase that at the heginning of his ailerer but a trifle wals known of the

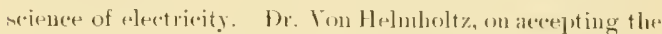
presiclency, was received by the audienere standing and with the heartiest applauns. He spolie shortly of the homon that lie consitered was enferred on him by the position. and satel in his remarks: "The beginning of ny career was when the phenomena of electricity were most delicate ex. periments which were gerformed by some physicists in their laboratories. We can mow at present great machines of the greatest power. At the time $\mathrm{f}$ hegan the study of electricity, we could not mose a fittle magnetic needle suspernded on a silken cord, the finest that we could find. We conld not move the slightent apparatus, but we showed that there were feeble corrents. We were ubliged to work with the simple elements zinc and copper, withont sulphate. of copper, elements which alteresl every moment; which at the first instance bath in great electromotive foree, then went down amel down. so that after sulue imstauces there wan (m)ly a trace of the limmer force."

In conclusion, he said: "The histery of the world and the history of seience has grown rapjidly during onr life tine, and it is a great pleasure for lls old ment, to see now what electricity has reached in its new stages and to admire the newest developments that are collected on this festival accasion here in your great exhibition." Prot. Gray was then introdueed by the chair an the permatuent chairman of the congress and made a slowt sjeech of acceptance, and then entrolucerl in turn $\mathrm{Mr}$. W. H. Preece as vice-president representing (ireat Britain, whome speecels of acceptanew wats brief but heartily alplatuderl. The rhairman then introheserl Prof. Nascart, whe made a short speech. Dr. Mendenhall, on belalf of the program committee, made a few remarks as to the conditions for membership of the. congress. ete. The delegrates to he distinguished by a white hadge, and all persons who have recoived invitations. and those whose name appears on the prinfed list of reference will receive a rerl badge: to others they will be issued on the presentation of a card endorsed by the con. mittee. Mr. R. W. Pope. W. E. Auderson, and Dr. J. Allew Hornshy were appointed a committer on entertainment and 
will, from time to time, report such arrangements as were made.

TEESDAY'S SESSION

The different sections of the congress assembled in the halls assigned. Section $\mathrm{A}$ of pure theory was called to order at 10:30 by its chairman, Prof. H. A. Rowland. The chair appointed a committee to nominate the permanent officers of the section. The following names rere recommended by the committee and elected by acclamation: Prof. H. A. Rowland, chairman; Prof. Galileo Ferraris, vice chairman, and Dr. A. S. Kimball, secretary. After disposing of other details of organization the section adjourned till 10 A. M. TVeduesday morning.

Section B was called to order by Prof. Chas. R. Cross, of the Institute of Technology, Boston, at 10:15 A. M. The first business in order was the appointing of a committee to nominate permanent officers for the section, a chairman suda secretary, and at the suggestion of the temporary chairman a third officer was added to the list, which was composed of Prof. Silvanus P. Thompson, London; Prof Louis Duncan, Baltimore, Md, and Lieut. W. F. C. Has san, San Francisco. The committee retired and returned in a few minutes recommending that Prof. Cross be continued in the chair, Lieut. Samuel Weber appointed permanent secretary with Prof. Dolbear as the third officer of the section. Prof. Elisha Gray announced that section A would meet in Hall VI., section B in Hall VII. and section C in Hall VIII.

The reading of the regular papers on the program was then taken up and Mr. W. H. Preece, F.R.S., read the first paper on "Signaling through Space by Means of ElectroMagnetic Vibrations." Starting from the discovery by Henry in 1842 of the transmission of signals through the vibration of the magnetic needle in the cellar charged by a Leyden jar in an upper room of his house, Mr. Preece lear down to 1881 when it was first reported to him that messages in transit orer the underground wires of the London telegraph system had been read over a telephone, the wire of which was 80 feet distant, and incidentally referred to Edison's experiment in 1885 in the transmission of mes sages from a moving train on the Lehigh $\mathrm{V}$ alley Railroad to the wires on the side of the track.

Mr. Preece was last year appointed a member of the Royal Commission to investigate the communication by electricity betreen light houses, light ships and the shore, and his address was a description in part of the experi ments made by this commission on the coast of Bristol Channel. Mr. Preece did not read his paper in full but gave the convention the results of the investigation and the particularly interesting points leading up to them. The result of these experiments were due entirely to the electromagnetic induction; the self induction aud the electro-static induction playing but very slight parts in the general results. The main experiment consisted in the running of a grounded line three-quarters of a mile long on the shore of the channel and the running of a parallel line of the same length on a small island something over three miles disance from the shore, and a third line parallel to the other cwo and of the same length on a second island some five miles distance from the shore. With a steam launch cables were laid at various distances and experiments made as to the possible reading, on such eables through a telephonic connection, of signals sent with an ordinary Morse instrument over the land wire. It was found that when the cable laid on the surface of the water (as it did when being rapidly played out from the steam launch, one end of it being attached to a buoy, the signals could be rery distinctly heard. While, when the cable had sunk under the water to a depth of 6 inches or more the induction ceased. This lead Mr. Preece to make certain experiments which estab lished beyond donbt the fact that electro-magnetic waves are reflected from the surface of the water and do not perculate. With 15 amperes of current and a frequency of 192, experiments were made between the land and the three miles island wire, with the result that the signals were read by telephone and the notes were very clear. In experiments with the wire on the five mile island, and with the same frequency and current on the shore wire, the signals were heard but the current was not strong enough to make the Morse code readable. Mr. Preece is of the opinion that had he had five amperes more of current at hand the signals would have been as clear on the five mile island at 20 amperes as they were on the three mile island at 1 i amperes. In all of these experiments the readings were made by from three to five different persons to preclude any possibility of the supposed effect being the result of imagination. With wires 30 miles long on each side of the British Channel Mr. Preece is confident that communication by electro-magnetic induction could easily take place between England and France, though he donbts very much if this method will ever come into commercial use for various reasons; principally owing to its being more expensive than the present cable system. The English light houses and light ships, as a result of these experiments, will be connected to the main line by regular calbles, though it is highly possible that induction may be nsed by the light houses and light ships for the transmission of signals to ressels during time of fog. The engineer of the coast of Scotland is at present engaged in the introduction of a system for the protection of ressels approaching the coast by the laying of a cable at the 20 fathom line along the coast and using electro-magnetic induction for the transmission of signals between the shore and the ships through this cable. No practical results have yet been attained in this direction.

In the discussion that followed the reading of Mr. Preece's paper, Mr. T. D. Lockwood, electrician for the American Bell Telephone Company, Boston, delivered a somewhat lengthy expression of opinion and gave a resume of some similar but far less important or interesting experiments that had been made in this comtry. He also expressed his doubts in regard to the transmission being due entirely to the electro-magnetic induction but inclined to the opinion that water played a rery important part. In his final remarks at the close of the discussion, Mr. Preece, in a rery few words, showed Mr. Lockwood that he was in error. Owing to the length of Mr. Lockwood's comment Prof. Carhart of Ann Arbor, felt called upon to move that the discussion by any one member of a paper that had been presented be limited to five minutes. The chairman declined to put the motion but suggested that the members so understand it. Dr. Carroll expressed his appreciation of Mr. Preece's paper and recited an incident that eame to his attention some 15 years ago where messages had been transmitted over telephonic circuit, the wire of which had been broken and the two ends resting some ten feet apart on a large block of stone. The incident at the time was considered so improbable that the Doctor had never mentioned it until Mr. Preece's paper had proven to him the entire possibility of the oceurrence being true. Prof. Jamieson desired to inquire what was the greatest distance from the cable in the north of Scotland at which signals conld be 
received by an approaching ship. Mr. Preece replied that the distance would be regulated by the length of the ship. or the length of the cable on the shij.

Mr. Heaviside, the associate of Mr. Preece who har charge of the experiments described in the latter's palper, was introduced by Mr. Preece and made a short anthess in which he described an experiment he recently conducted in the pit of a colliery, where he man a line on two sicles of a triangle and made the comnection for the third side by means of a gromnd, it not being possible to run the third side owing to the location. He then constructed a similar triangle on the surface, having all three sides of wire. Sig nals were transmitted by electro-maguetic incluction from the lower circuit to the uppor, and received by telephone. The practical result of this experiment can be utilized for communications between imprisoned miners and the ont side world, provided cables can be constructed in some way so as not to be hroken by the falling rock. Dr. Emery called the attention of the congress to the different principles employed in Mr. Preece's experiments and the American experiments sited by Mr. Lockwood. Messrs. Delaney. Wiegand. Wynn and Lem], asked various minor questions which were replied to by Mr. Preece. Prof. Cross also made a suggestion with reference to the loss of energy in reflection by the electro-magnetic wave.

The second and third papers on the progran "Material. for Standards of Resistance and their Construction," lyy Dr. St. Lindeck and "Variation of P. D. of the Electric Are Current, size of Carbons and Distance Apart," by Prof. W. E. Ayrton, F. R.S., were not read owing to the alssence of the two gentlemen mentioned. The fourth jajer on the program was by Dr. Silvanus P. Thompson, entitled "()cean Telephony." Prof. Thompson finished his paper at 12:4. and the congress adjourned till the following morning.

SECTION C. was ealled to order at 10:2() A. 3., ly the temporary chairman Prof. E. J. Houston. The committef on nominations present the following lists of names: Permanent chairman, Prof. Edwin J. Houston: vice-chairman. George P. Low and secretary Prof. E. P. Roberts; committee for the section George Blodget, Dr. F. H. C. Perine and Townsend Wolcott. The report was accepted and short speeches were made by Prof. Houston and Messrs. Lowe, Roberts, Jackson and others. A rery interesting paper was read by Mr. Franz Shulze-Berge, of Brooklyn on "Rotary Mecurial Air Pumps" which was illustrated by comprehensive diagrams. After a brief discussion of the section adjourned and those present attended the reswion of section $B$.

$$
\text { WEDNESDAY'S SESSION. }
$$

At this session of section A., Prof. A. Macfastane read a paperon "The Analytical Treatment of Alternating Current" which was discussed by Mr. Chas. P'. Steinmetz. The pajer of Drs. Bedell and Crehore, "General Diseussion of the Curren Flow in Two Mutully Related Circuits Costaining Capacity," was presented.

Section B was called to order at 10:10 Wednesday by Chairman Cross and after the reading of the minutes of previous meeting by secy. Weber the discussion of Prof. Silvanus P. Thompson 's papees was taken up. Dr. Carroll desired to present the congress a tube made of an alloy of Hhuminum, silver and coppes prepared in his laburatory, and rxpressed the belief that such an alloy would be better litted for telephonie purposes than the conductors now userl. Prof. Jamieson male the point that whereas the present eables used cost but $\mathfrak{f} 40,000$ per mile a cable made in acerolance with Prof. Thompsoris paper with three con ductors would cost probably three times as much. He also desired to know how Prof. Thompson woukd localize faults or flaws.

Mr. Lockwood had to suggest that severd pieces of un lergrouncl cable of similar construction be spliced until a cable be produced with which the practicability of Prof. Thompon's idras coukd be tested. Mr. Kennelly called attention to the ideal methor devised several years ago by Mr. Oliver Heaviside for absolutely eliminating eflects of electro-static induction. Mr. Cuttress, electrician for the Il Kay-Bumett cable system, described certain experiments made under his direction with a two wire eable connerted in straight corl, metallic and multiple circuit, the result of which show but slight rariation in the three styles of con nection. He also offered to jlace the cables of his rom pauy at the disposal of Prof. Thompson for the conclucting of further experiments. Mr. Heavisid. expressed his ap preciation of Prof. Thompson's paper both from a scientific and commercial point of riew and added that his experience since $1 \times 77$ confirmed the principles laid down in the paper.

Mr. Wilkinson incuired whether the effect of the three wires dicl uot tend to canse further retardation of the signals. Mr. Siemeus, of Siemens Bros., London, the cable manufacturers, said that such a cable as Prof. Thompson proposed would be extremely difficult to construct and would cost much more than cables, for telegraphic purposes at least, which would give a similar speed. He called attention to the fact that capacity is not the only enemy of the telegraph but that the insulating materials play an im. portant part. Prof. Cross made the point that while, with the telegraph and the siphon recorter, from the point of extreme legihility to illegibility there is considerable latitude, with the telephone, from audibility to inaudibility there is but a slight step. Prof. Thompson replied quite humorously to the rarious criticisms made on his paper and ex]ressed himself as believing that he is still on the right side and sincerely hoped that one effect of the reading of his paper will be the giving of his plans a practical trial, which can only be done when the large cable interests cooperate in making such a trial possible.

Dr. St. Lindeck of the Reichsanstalt. Berlin, rear an interesting paper on "Materials for Standards of Resistance and their Construction," in which he describud the result of the experiments made by Dr. Feusuer and himself at the Reichsanstalt during the past four rears. Ho described tests made of platinum-silver, german silver, patent nickel and manganese alloy. He fouml that where the percentage of zinc was less in the alloy there was less variation of resistance. The variation in the first two alloys mentioned proved them to be unfit for standards; while the patent nickel alloy used by Siemens \& Halske, of Berlin, and composed of 2 " parts nickel and 75 parts copper stood the tests remarkably well; an alloy called maganin and composed of $\$ 4$ parts copper, 12 parts manganese and four parts nickel stood the test for a space of two years with a variation of but a few thousandths of one per cent.

Mr. Elw. Westun of Newark, N. J., discussed Dr. Lindeck's paper at eomsiderable length. the rule as to the time being suspended in this instance. He sail that such pa. pers as Dr. Lindeck's tend to increas the confidence of the electrical fraternity in these alloys as standards. In 1844 , Mr. Weston began a series of researches of alloys for resistance purposes at his laboratory at Newark. N. J., examining in the neighborhood of 400 of them. About 150 


\section{ELECTRICAL INDUSTRIES.}

\section{ELECTRIGAL INDUSTRIES PUBLISHING COMPANY, INCORPORATED 1889 \\ MONADNOCK BLOCK, CHICAGO. \\ TELEPHONE: HARRISON 159.}

E. L. POW ERS, Pres, and Treas.

E. E. WOOD, SECRETARY

\author{
E. L. POWERS. \\ H. A. FOSTER, \\ W. A. REMINGTON, \\ E. E. WOOD, \\ FLOYD T. SHORT,
}

AdEertising Depaetment.

EASTERN OFFICE, WORLD BUILDING, NEW YORK. World's Fair Headquarters, Y 27 Electricity Building.

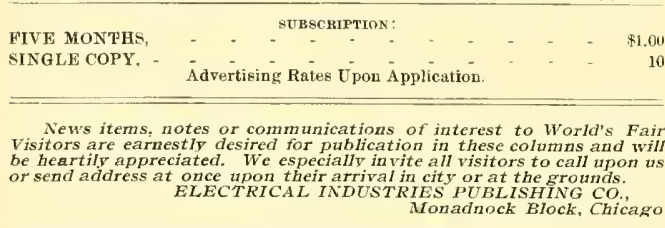

Fon some time Chicago has been the Mecea towards which the eyes of all true electricians have been looking and there are now gathered in this city the most prominent men in science and the arts, an array of eminent names such as this wonderful city of the west has never previously seen. The number of electricians at the congress is fully up to expectation and the enthusiasm shown gives evidence of the interest taken in the congress by the representatives from the different countries. The committees having the preparation for the congress in charge seem to have been most thorough in their work. Thearrangements made have met with the approval of the congress so that it has proceeded directly with the work laid out for it. The committees have not only provided for the work of the congress but for many diversions at the Fair and in the eity. Through the kindness of various conces sioners and companies at the Fair a most enjoyable program was arranged for yesterday afternoon for visiting various attractions at the Fair. The banquet this evening at the Grand Pacific Hotel is the medium through which the foreign and domestic members will meet in a social way. The lecture of Nikola Tesla in the assembly hall of the Agricultural Building at the Fair on Friday even ing. at 8 o'clock will be an interesting feature of the week.

\section{List of the Papers of the Congress.}

$$
\text { Section A. }
$$

"On the Analytical Treatment of Altermating Currents," Prof. A. Macfarlane.

Complex Quantities and their Application in Electrical Engineering," Charles P. Steinmetz.

"General Discussion of the Current Flow in Two Mutually Related Circuits Containing Capacity," Dr. Frederick Bedell and Dr. Albert C. Crehore.

"Explanation of the Ferranti Phenomenon," Dr. J. Sahulka. "Measuring the Porrer of Polyphase Currents," A. Blondel. "Extended Use of the Name Resistance in Alternate Cur. rent Problems," Prof. II. E. Ayrton, F. R. S
SEOTION B.

"Signaling through space by Means of Electro-Magnetic Tibrations," W. H. Preece, F. R. S.

"Materials for Standards of Resistanee and their Construetion," Dr. St. Lindeck.

"Variation of P. D. of the Electric Arc with Current, Size of Carbons and Distance Apart," Prof. W. E. Ayrton, F. R. S.

"Ocean Telephony," Dr. Silvanus P. Thompson, F. R. S.

"Iron for Transformers from the Magnetic Point of View" Prof. J. A. Ewing, F. R. S.

"Note on Photometric Measurement," Prof. B. F. Thomas.

"Some Measurements of the Temperature Variation in the Electrical Resistance of a Sample of Copper," A. E. Kennelly.

"Various Uses of the Electrostatic Volmeter," Dr. J. Sahulka.

"On a Method of Governing an Electric Motor for Chronographic Purposes," Prof. A. G. Webster.

"On the Construction of Cables for Subterranean High Tension Circuits," Dr. A. Palaz.

"Periodic Variation of the Candle Power of Alternating Are Lights," Prof. B. F. Thomas.

"Transformer Diagram Experimentally Determined," Dr. Frederic Bedell.

"London Electrical Engineering Laboratories," Prof. Andrew Jamieson.

"On the Source and Effects of Harmonics in Alternating Circuits," Prof. H. A. Rowland.

"A Pair of Electrostatic Voltmeters," Prof. H. S. Carhart. "On the Maximum Efficiency of Are Lamps with Constant Number of Watts," Prof. H. S. Carhart.

"On Direct Current Dynamos of Very High Potential," Prof. F. B. Crocker.

"On an Improved Instrument for Measuring Magnetic Reluctance," A. E. Kennelly.

"The Swinburne-Thompson Unit of Light," Dr. Silvauus P. Thompson, F. R. S.

\section{SECTION C.}

"Rotary Mercurial Air-Pumps," F. Shulz-Berge.

"A Hundred-Hour Electric Arc Light," L. B. Marks.

"The Conrersion of Alternating into Continuous Currents," Dr. C. Pollak.

"The Use of Accumulators in Central Stations." Dr. C. Pollak.

"Underground Electric Construction in the United States," Prof. D. C. Jackson.

"A New Incandescent Arc Light," L. B. Marks.

THE CHAMBER OF DELEGATES.

The following topics will be considered by the Chamber of Delegates:

Adoption of definitions and value of fundamental mits of resistance, current and electro-motive force.

Adoption of definitions and values of magnetic units.

Adoption of definition and value of the unit of self-induction.

Definitions and values of light, energy and other units.

The standardization of electric lights.

The consideration of an international system of notation and conrentional symbols and of a more uniform and ac curate use of terms and phrases in electrical literature.

A commercial standard of copper resistance.

Together with such other topies as may properdy eour before this borly. 
[Contmued from prege :.]

of this number he was able to work satisfactorily and to get from them good and thin wires, and ont of this 1.20 the alloy which suited his purposes luest was that deseribed hy Dr. Linbeck as manganiu. He also expressed the hope that this congress will pass npon these alloys and decide on a unit as a substitute for mercury. Prof. Thompson ob. jected to magnanin on the ground that it is rendered entirely useless as a standard when heated above a certain temperature. Dr. Lindeck replied that the use of any standard necessarily involved eare; and donbted whether any standard could be estahlished that could not be subjert to a sufficient strain to destroy its usefulness.

Mr. A. E. Fennally read a paper on "Somp Measure ments of the Temperature Variation in the Electrical Re sistance of a Sample of Copper" which he stated was the joint production of Prof. Reginald Fessenden of [niversity of Pennsylvania and himself. The paper lescribed the experiments of Matteson and Dr. Siemens and the rarying re sults obtained by them, together with the experiments of later investigators and scientists to establish the tempera ture co-efficient of copper. He then deseribed the experi ments made by the two authors of the paper at Mr. Edison: laboratory at Newark, N. J., and gave the mathematieal re sult of such researches which coincided very nearly with the results obtained by those inrestigators following in the footsteps of Matteson and Siemens. Mr. Preeces thankerl Mr. Kemmelly for his investigations and imsured him on be half of the English electricians that the eorefficient estahlished by himself and Prof. Finsenden will he areepeted in England without hesitation.

The next paper was a "Note on Photometric Meanurement" by Prof. B. F. Thomas. As a result of his investi gation Prof. Thomas showed quite conchusively the impos sibility of making accurate photometric measurements with ont taking into consideration the reflection from the rear surface of the chimney used on a standard light. He said that he believes this reflection is sufficient to account for the difference in measurements made by varions laloratories of the same light. He suggested that square metallic chimneys with black baekground and the mica front be userl so as to avoid the reflectire and lenticular effects. Referring to the tests of the cundle power of incandescent lamps Prof. Thompson remarked that the only way to arrive at a correct measurement of the candle power would be to have the lamp revolve at the rate of say 1.000 revolutions per minute. and this ean be done only with short or anchored filament lamps. Owing to the lateness of the hour discus sion of Prof. Thompson's pilper was postponed until Jll I. s., Thursday.

This session of scetion C. Was opened by the reading of the paper of Prof. Jackson on "Cuderground Electrical Construction in the Enited Staten." The rarious syintems were deseribed in detail and the discussion which followed was entered into by a number of those present. Mr. A. W. Heaviside described in a general way the conduit work as constructed in England for plectric lighting. Prof. Jackson answered the large number of questions in a most satis. factory manner. At the conclusion of the discussion Dr. A. Sahulka read a paper. "The Various Lses of the Electrostatic Voltmeter. Dr. Sahulka was followed by Mr. L. B. Marks with a paper on "A Hundred Hour Electric dre Lamp." The paper was discussed by Prof. E. L. Nichols and Prof. S. P. Thompson who in his discussion deserihed some of his experiments with the are lamp. Also by Mr. Geo. P. Lowe, Prof. E. P. Roberts and Dr. X. S. Keith.

\section{The Congress at the Fair.}

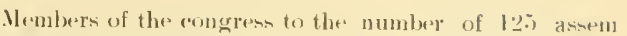
bled Wednesday afternoon at the Van Buren St. Pier to carry out a program arranged by the committee on entertainment. The Whaleback steamer Christopher Columbus through the courtesies of the World's Fair Steamship, Company was waiting to convey them to the Exposition grounds. On their arrival at the Casino Pier the party made a trip aromal the moring sidewalk and stopped to examine the construction. The party then visited the lirmp Pavilion which was placed at thei, disposal.

Commissioner Carl Richter weleomed the party. and Ir. Lauter, the genial representative of the Krupp company showed the guns aud methods of operating them to the party. The Intramural power house was visiterl and its machinery insperted, then the party made a trip on the Intramural Railway to the north loop and from there weut to the parade grounds where seats had lxen reserved from which they could view the dress parade of the West Point 'adets, after which they separated pleased with the trip' and expressing their thanks to those through whose kind ness they were indehted for the pleasures of the aftermon.

\section{Meeting of the American Institute of Electrical Engineers.}

The Ameriean Institute of Electrical Enginers met informally at the headquarters in Electrieity Building at $>$ riclnek Wednesday evening. At $\checkmark: 30$ the party, which numbered about 100, adjourned to the lanuches which were provided through the courtesy of the General Electric Launch Company. A trip was made around the lagoon, and at the Woman's Building the party disembarked. The Ferris wheel was next risited, and uncler the care of $\mathbf{M r}$. Ferris the party made the trip around the wheel. The German village was next visited, where lunch had been provided by Mr. W. R. Brixey. The party was called to order by Mr. Ralph W. Pope, the secretary, in the absence of the president, Prof. Houston. After the lunch speeches were made by Dr. Keith, Prof. Thomas and others. after whieb the Institute adjourned.

A very interesting type of pugine is that shown by the. Dake Engine Manufacturing Company, of Grand Haven, Wich., in Column G, 1-37. Machinery Hall annex. It is exceedingly simple in construction, having but two moring parts outside of the erank itself, and consists of a thin. oblong rectangular box containing the piston. The piston is double, the ontside part sliding from end to end of the box: the other part, heing inside the first, slides up and lown in a direction at right angles to that of the first. Steam is admitted through ports east in the casing to the center of the shell and exhausts through a cireular port surrounding the central admission port. Owing to the double piston and double action, there are no dead points and the engine will start from any part of the stroke. It is said that the engine may lo rum at any speed up to a thousand revolntions per minute.

The PHoEnix IBon Works Cumpany, 519 The Rookery, has been awarded contract for a complete steam power plant for the eity of St. Clair, Mich., eomprising one of its 150-horse power tandem compound condensing engines and Manning vertical tandem compound condensing engines and Manning rertical
boiler. Also from Pittsburgh Construction Company two 100horse power tandem compound engines, for the Ferris wheel lighting plant. 
At the Congress.

Among those in attendance at the Electrical Congress are the following:

Dr. Von Helmholtz, Alex. Graham Bell. Prof. Elisha Gray, Prof Elihu Thomson, Prof. W E A rrton, Dr T C Mendenhall, Washington, D. C.; Dr. Arthur G. Webster, Worcester; Camillo Olivetti, Turin, italy; Prof. Francisco Grassi, Milan: Prof. Galileo Ferraris, Turin; L. M. Hancock, Chicago; E Sederholm, Stockholm: Otto Lemisch, Klagenfurt, Austria: Robert McAlloyd, New York; Dr. IV. E. Geyer, Hobokeu, N. J. B. J. Arnold, Chicago: Dr. Schrader; Dr. Chas. Pollak, Frankfort: Dr. W. Wedding, Berlin; John Cassidy, Hocolulu; Dr. Frederick Bedell, Ithaca, N.Y.; Prof. Edw. L. Nichols, Ithaca. Carl. Herring, Philadelphia, Pa.; Prof. F. B. Crocker, New York.; Geo. P. Lowe, san Francisco,

Lieut. W. F. C. Hasson, San Francisco; E. G. Acheson, Pittsburgh; D. B. Grandy, St. Louis; Austin M. Knight, U. S. Navy; Hermann S. Hering, Baltimore; Chas. F. Kent, Chicago; C. M Goddard, Boston; F. E. Cabot, Boston; Dr. Johann Sahulka, Vienna, Austria; Kuno Thurnauer, Nuremberg, Germany; E. Braun, Clarendon Hills; Prof. Josef Pechan, Reichenberg, A ust ria; H. C. Parker, Brooklyn; M. D. Law, Washington, D. C.; Frank T. Lyman, Cincinnati; W. S. Jenks, New York; A. Sutton; Rye, N. Y.; E. A. Wheeler, New York; Gano S. Dunn, New York; S. D. Mott, Passaic, N. J.: Dr. S. S. Wheeler, New York IVm. J. Danielson, Providence, R. I.; L. P. Hall, New York Fredk. Reckinzann, West Hoboken; W. A. Preece, London Prof. Elihu Thomson, Lynn; Prof, Harry A. Rowland, Baltimore; J. R. Cullinane, Dennison, Tex.; F. MeCarthy, Chicago; Tos, Wetzler, New York: Max Lery Galveston, Tex; Dr. E. Voit, Munich; Geo. P. Squirs, U. S. Army; Luji Lambardi, Eng.: Dronero Cuneo: Wralter s. Wiley, South Omaha, Neb. Chas. W. Livermore, Manchester, N. H.; J. Violle, Paris; Lud wig Weber, Frankfort, Germany; L. Eddy, Darrville, Ky.; Capt. L. Sventorzetcary, st. Petersburg; Prof. Fdwin I. Houston, Philadelphia: Camilto Cerrati, Turin, Italy; Tito Galrao, Rio de Janeiro, Brazil; J. W. Sterns, Jr., Denver; Ormond Wyman, Ottawa; J. W. Johnson, New York; Cecil P. Poole, Va.; A. F MleKissick, Auburn, Ala.; Harry NI. Palmer, Washington, Pa.: J. J. Thoresen, Washington, Pa.: Alfred E. Wiener, Schenectady.

Alex. Siemens, London, Eug.; B. Rosa, Middletown, Conn. IV. W. Ryder, Chicago; Dr. Chas. E. Emery, New York; Wm. Maver, Jr., New Iork: Geo. T. Gibson, Des Moines; Thos. D Lockwood, Boston; M. E. Rice, Lawrence, Kas.; Wm. Elmer, Jr., Princeton, N. J.: H. W. Frund, Vincennes, Ind.; Hermann Lemp, Lyna; Geo, A. Hamilton, New Yorlk; Holbrook Cushman, New York; J. Edward Lisson, St. Petersburg, Russia; A. L. McRae, Rolla, Mo.; Dr. Chas. E. Doremus, New York: C. Courtney, Wharton, Cinti.; Dr. F. A. C. Perrine, Palo Alto, Cal.; E. L. Zaliuski, U. S. Army: Stephen D. Field, Stockbridge, Mass.; H. H. Fairbanks, Worcester; Capt. A. de Khotinsky, Marlborough, Mass.; Jas, Allen Pentz, Philadelphia; Major Capel L. Holden, Woolwich, Eng.; Major A. H. Bagnold, R. E. Chatham, Eng.; F. A. Wessel, New York City: Edwin R. Weeks, Kansas City; Francis IV. Willeox, Atlanta, Ga.; A. Langstaff Johnston, Richmond, Va.; A. IVickenheise, Pokor, Russia; Otto Frick, Malmoe, Sweden; Douglas Burnett, Broolklyn.

Geo. M. Phelps, New York; Jas, Waring, Manchester, Conn. Edward A. Colby, Newark: W. B. Cleveland, Chicago; R. Reckinzann, Youkers; Carl P. Siemens, Berlin; Chas. F. Scott, Pittsburgh; P. B. Delany, South Orange; C. A. Mailloux, New Y ork E. E. Bernard. Troy; L. B. Marks, New York: L. L. Summers, Chicago; F. W. Jones, New York: Chas, P. Steinmetz, Lynn: H. L. Rodgers, Windsor, Conn.; H. A. Reed, New York; C. H MeIntire, Newark; F. E. Jackson, Newark; Prof, E. P. Roberts, Chicago; Hammond V. Hayes; T. W. Voeter, Pittsburgh; Harold B. Smith, La Fayette, Ind; W. E. Goldsborough, Fayetteville, Ark.; J. A. Cabot, Cincinnati; Henry W. Frye, E. W. New York; A. Buys, N. J.: Keijiro Nakamure, Private Secretary to Mr. Nirva; Lewis Searing, Denver, Colo; J L. Javne, U. S. Navy; I. H. Farnum, Boston; H. Bergholtz, Ithaca; Frank C. Perkins, Buffalo; Chas. Cuttriss, New York; 1). George Finze, Milan; E. L. French, Pittsfield.

\section{BUSINESS NOTES.}

The BRUSH ELECTRIC COMPANY has sold 300 double carbon arc lamps similar to those on exhibition at the Fair to the Edison Light \& Power Co. of San Franciseo, Cal., and 100 to the Indianopolis Light and Power Co. of Indianopolis, Ind. The larger thirty-thousand light switch board which has attracted so much attention at the Fair is to be shipped to Manilla in the Phillipian Islands at the close of the Fair.

The Electric Appliance Conpayy are meeting with considerable sucess with their new Acme Lamp socket. It has a number of small improvements in the details of construction which are meeting with the approval of the trade and making some very large sales. The recent cool weather has interfered somewhat with the fan motor business, but the Electric Appliance Company reports that it has only a few left of the large stock of fan motors and expect by making some special induce. ments in price to close them ont in a very few days.
DEPARTMENT OF ELECTRICITY.

OFFICES: SECTION R, ELECTRICITY BUILDING.

Chief, JohN P. Barrett,

Assistant Chief, J. Allen Honnsir.

General Superintendent, .J. W. BLAISDEII.

Electrical Engineer, W. WV. Pвімм.

\section{DEPARTMENT OF MECHANICAL AND ELECTRICAI \\ ENGINEERINA.}

OFFICES SOUTH OF MACHINERY HALL.

Mechanical Engineer, C. F. Foster

Electrical Engineer, R. H. PIERcE.

First Asst. Mechanical Engineer, JoHy MEADEN,

First Asst. Electrical Engineer, S. G. NElLER.

\section{AMERICAN INSTITUTE OF ELECTRICAL ENGINEERS.}

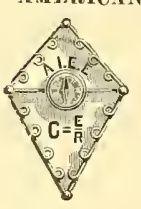

World's Fair Headquartere,

SECTION S, ELECTRICITY BUILDING.

RALPH W. POPE, Secretary.

Open from 9 a.m. to 5 p.m.

CHICAGO WORLD'S CONGRESS OF ELECTIRCIANS.

OPENTNG SESSION, JONDAY, AUGUST 218T, $3 P$, M ADVISORY COUNCIL.

President, Dr. Elisila Grax, Highland Park, Ill.

Secretary, Prof. H. S. CARHART, Ann Arbor, Mich. ExECUTIYE COMNTTEE.

Chairman, Prof. Elinu Thomson, Lyna, Mass. COMMITTEE ON INVITATIONS.

Chairman, T. Commerford Martin, 203 Broadway, New York. COMMITEE ON PROGRAM.

Chairman, Prof. T. C. MeNDenhali, Washington, D. C. COMMITTEE ON FINANCE.

Chairman, B. E. Sunny, 175 Adams Street, Chicago.

\section{Amusements.}

Hooley's Theater-Mr. Nat C. Goodwin, in "Mizzoura." 149 Randolph street.

Columbia Theater-Miss Lillian Russell, in "The Mountebanks." 108 Monroe street.

Graxd Opera House - Sol Smith Russell, in "A Poor Relation." 87 Clark street.

Aтdiтовıм-rumre Kiralfy's Spectacle "America." Congress street and Wabash avenue.

MoV'icker's Theater-Denman Thomson, in "The Old Homestead." 82 Madison street.

Chicago Opera Hodse-American Extravaganza Company, in "Ali Baba, or Morgiana and the Forty Thieves." Washington and Clark streets.

Schiller Theater-Chas. Frohman's Stock Company, in "The Girl I Left Behind Me." Randolph, near Dearborn.

HaverLy's Casino-Haverly's United Minstrels. Wabash avenue, near Jackson street.

Trocadero-Vaudeville. Michigan avenue near Momroe street.

The Grotro-Vaudeville. Michigan avenue near Monroe street.

Buffalo Bill's "Wild West." 63d street. Daily at 3 and 8.30 p.m.

Col. Cody and Mr. Salsbury have added a new feature to their already colossal show. This new feature is the representation of the battle of the Little Big Horn in which Gen. Custer and his band of 240 men were wiped out. Col. Cody was then ehief of scouts, and he now has with him a number of scouts that took part in that campaign. Extensive scenery, correctly made from photographs and sketches made on the ground, is used. Thus the scene is realistic. A historical scene, in which many of the original participants take part is something entirely new in the amusement line. 


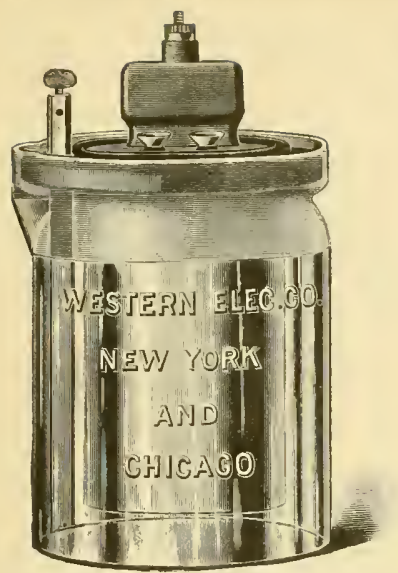

Disque La'Clanche Batterv.
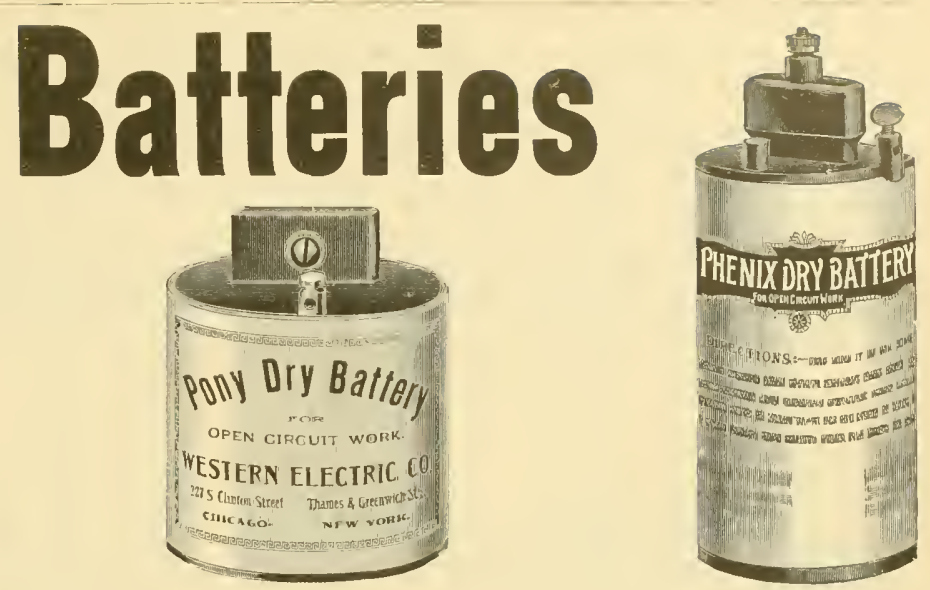

Phcenix Dr, Battery.

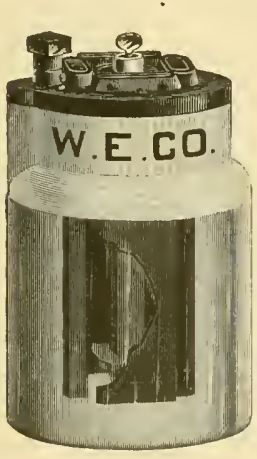

Quad Battery.

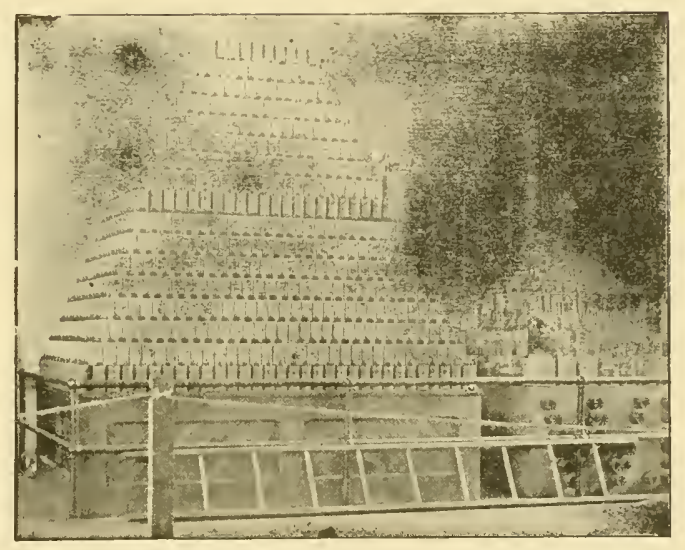

Battery Exhibit Electricity Bldg, World's Fair.
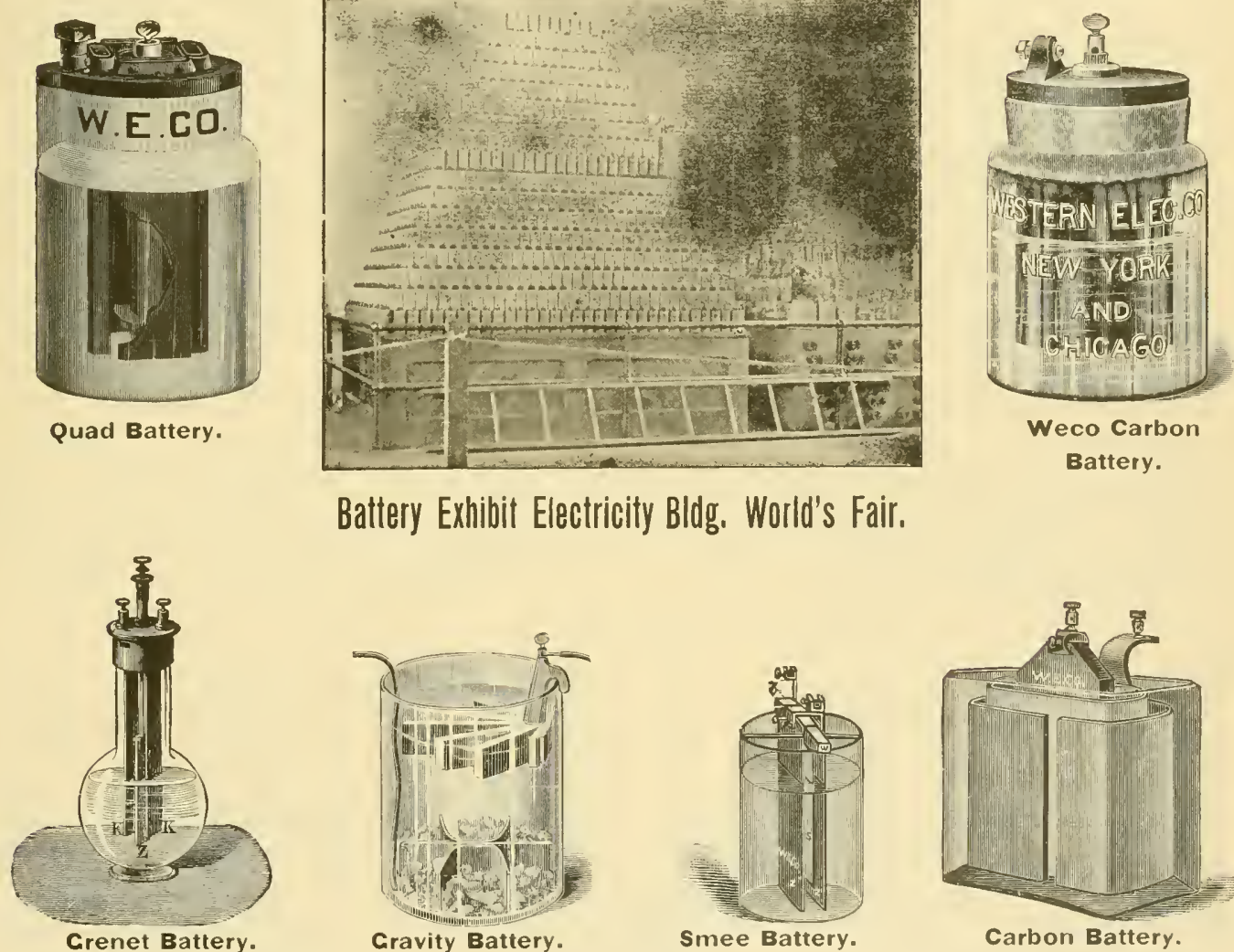

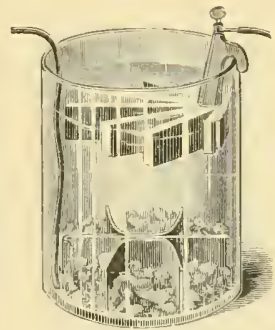

Cravity Battery.

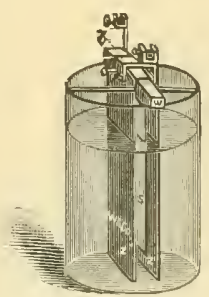

Smee Battery.
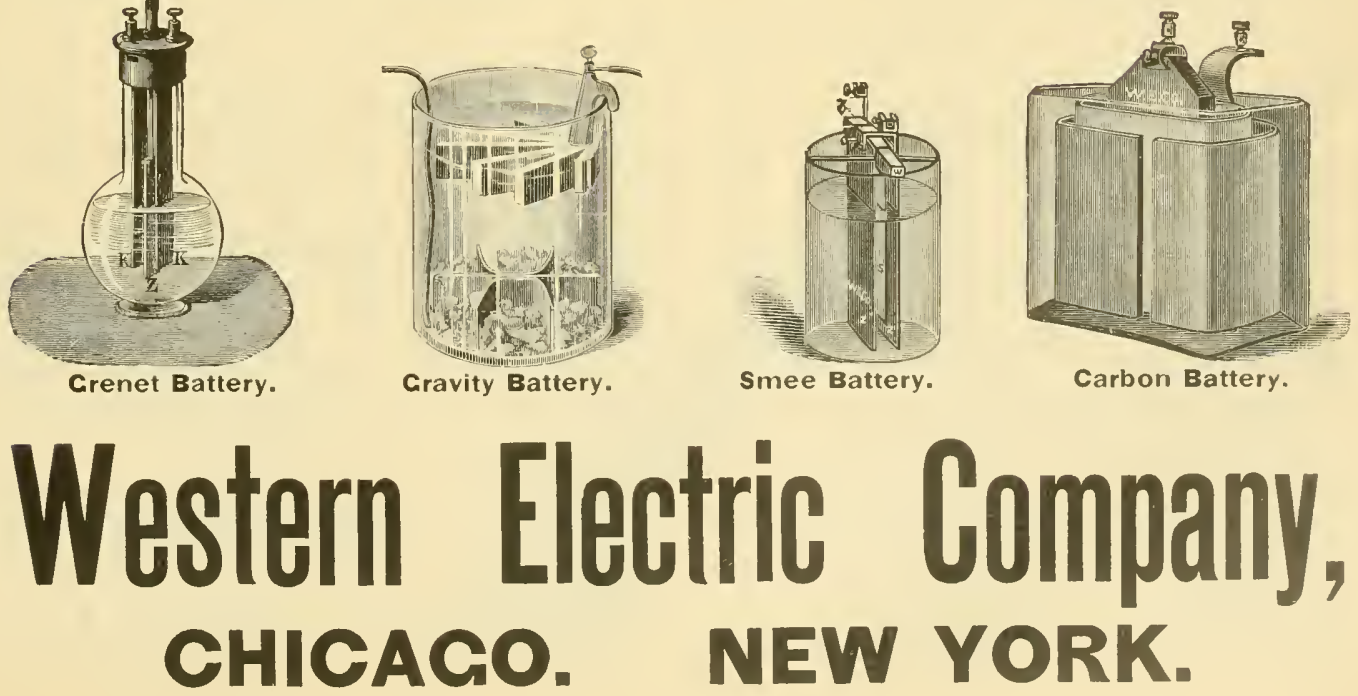
ELECTRICITY BUILDING-EXHIBITORS AND THEIR LOCATION.

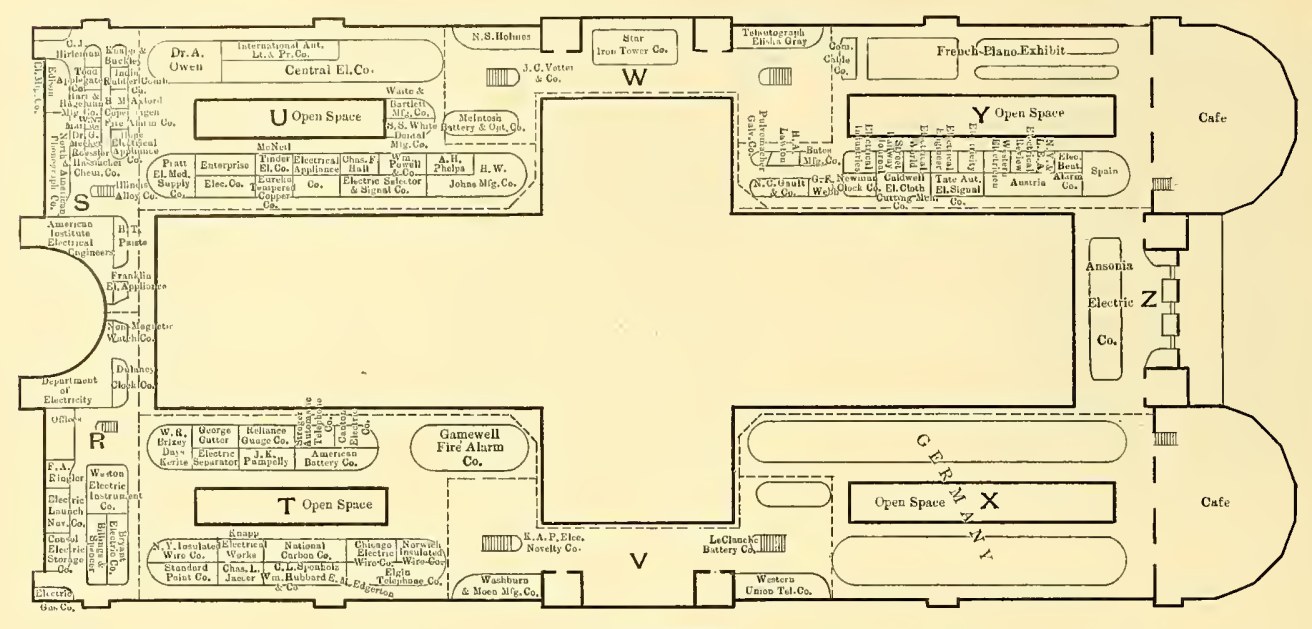

GALLERY.

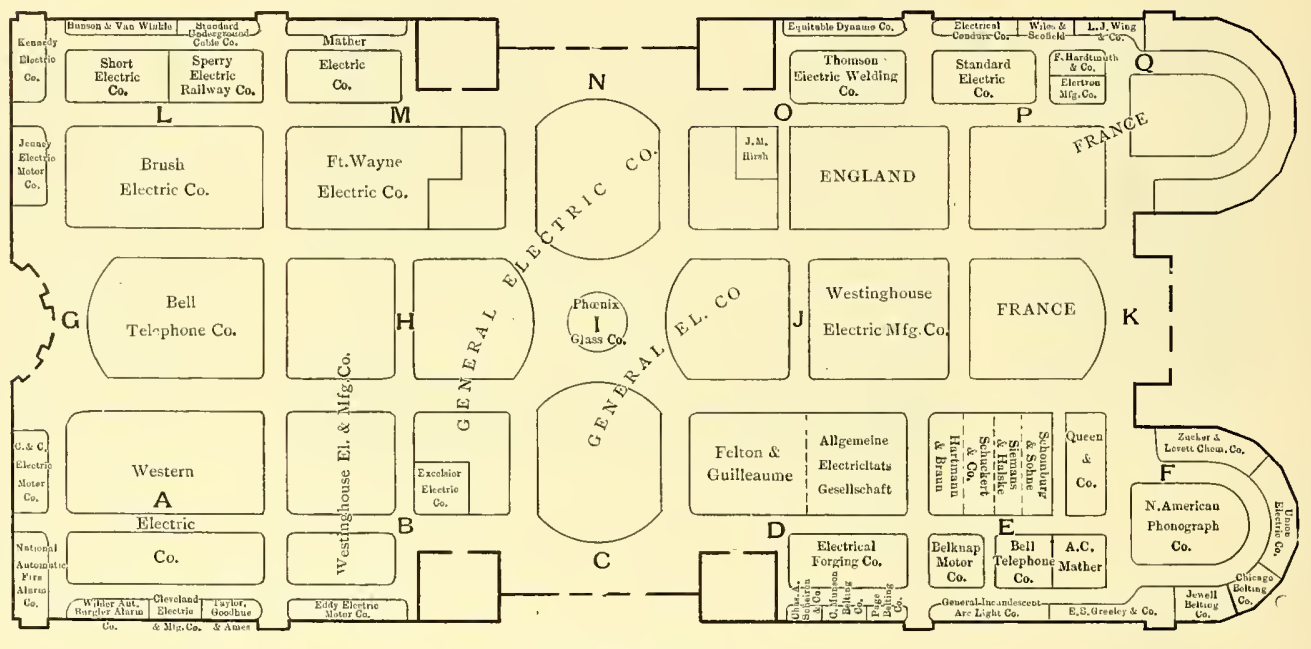

MAIN FLOOR.

Exhibitor.

A ustria.

Am. Inst. of Elec. En

American Battery Co.

Axford, H. M

Allg. Elec. Geselischaft.

Bryant Electric Co

Billinge \& Spencer

B rlknap Motor Co

Bell Telephone Co

Brash Electric Co .................. E-G

Caldwell El. Cloth Cut. Mcb. Co

Consol. Elec. Stora

Cutter, George

Chicago Elec. Wire Co.

Copenhagen Fire Alarm Co

central Electric Co

commercial Cable Co...

C. \& C. E'ec, Mlotor Co

Chicago Belting Co...

imulagey Clock

Department of Electricity....

ELECTRICAI INDUSTRIES

Elec. Launch \& Nav. Co...

Electric Separat

Edgerton, E. M.........

Figin Telephone $\mathrm{Co}$

Enterprise Elec Co.

Eareka Temp. Copper co

Electric Appliance Co

Elec. Sel. \& Sig'l Co
Electric Heat Alarm Co.

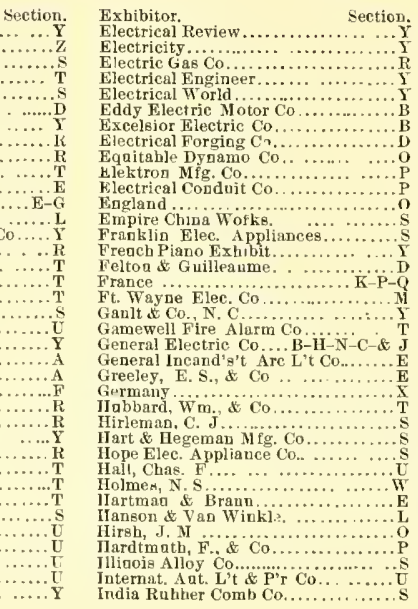

Exhibitor

Jaeger, Chas. L...

Jewell Belting Co.

Tinney Elec. Motor Co.

Knapp Elpetrical Works...

Kuapp \& Buckley....

Kennedy Elect

LeClan, B..................

Mc Neil-Tinder Elec Co....

Morcos, W. N

Meeker, Dr. G...........

MeIntosb Brt. \& Opt. Co

Muason, C., Belting Co

Iather Electric Co.

Newman Clock Co

Non-M $M g n e t i c$ Watch Co.

Y. Y. Insalated Wire Co....

National Carbon Co.....

Norwich Ine. Wire Co..............

N. Y \& L E A

Nat, Ant Fire Alarm Co.

Not. Engraving Machine ${ }^{\prime}$.

Owen, Dr. A .

Phoenix Glase

Pulvermacber Galv. Co.

Pumpelly, J. K .............

Powell, $\mathbb{W}$. \& Co..

Phelps, A. H

Page Belting $\mathrm{Co}$

Queen \& Co.
Ringler, F. A.
Section. Exbibitor. Section

Relíance Guage Co.................. Street Railway Journal............... Strowger Ant. Telph, Co......... T Standard Paint Co.

Sponbolz, C. L.

tar Iron Tower Co..

Spain

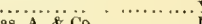

Siemens \& Halske.

Schuckert \& Co

sperry Elec. Railway Co..........

tandard Electric Co...

Samson Brttery Co.

Tate Aat El Signal Co.

. Ames............. A

Thomson Elec. Welding Co

Telactograpb, Elisha Gray .

Tetter $C$.

Tebb, $\mathrm{G}$ Washhorn it Hoen Mfg. Co

Western Union t'el. Co.

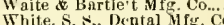

Western slocital

Te lero Electric Co

Westinghonse El. \& M fg. Co .... B-H-.l

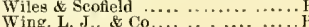

Wing, L. J.. \& Co C................. 
A FINAL WHIRL. are going to move. The meaning of this is plain. There is only one way we can do it.

Write for prices. You can get the value of the outflt if you have no other opportunity to use it than during

INDIAN SUMMER. ELECTRIC APPLIANCE COMPANY, ELECTRICAL SUPPLIES

242 Madison Street, - - OFIOAGO.

\section{THE MATHER ELECTRIC CO. THE "NOVAK" LAMP.} MANCHESTER, CONN.

Dynamos, Motors, Generators,

Offices, 116 Bedford St., BOSTOH. AND-

1002 Chamber of Commerce Bldg., CHICAGO.

\section{OLAFLIN \& KIIBBALL (Inc.)}

General Selling Agents.

116 Bedford Street, BOSTON.

1002 Chamber of Commerce Bldg,, CHICAGO.

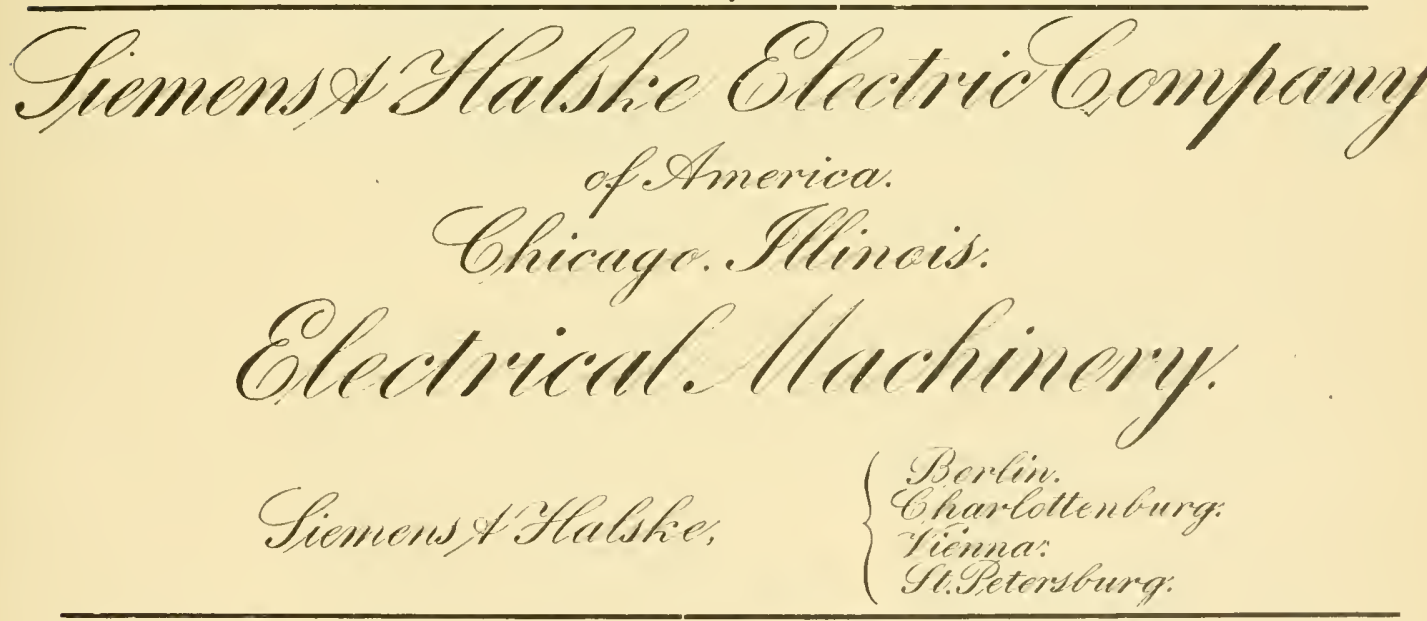

\section{Enterprise}

Electric

Company

307 Dearborn Street, Chicago ....
Manufaoturers' Agents and Mill Repre. sentatives for

Electric Railway, $-\infty$

Telegraph, Telephone and Electric Light

SUPPLIES

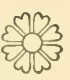

Agents for Cedar Poles,

Cypress Poles, Oak Pins,

Locust Pins, Cruss Arms, Class

- Feeder Wire,

Insulators,

WIRES, CABLES, TAPE and TUBING 
Map of Chicago.

Showing Location of its Electrical and Allied Business Interests, Principal Hotels, Theatres, Depots and Transportation Lines to the World's Fair Grounds. (Index numbers refer to the black squares.)
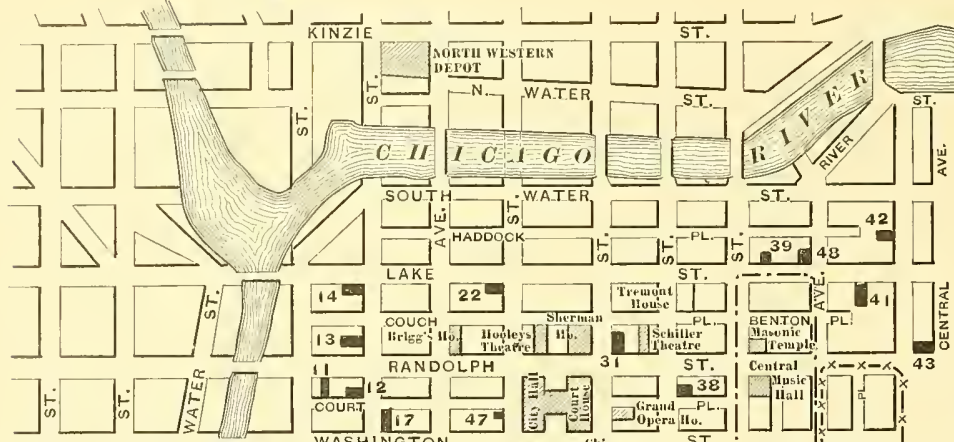

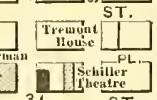
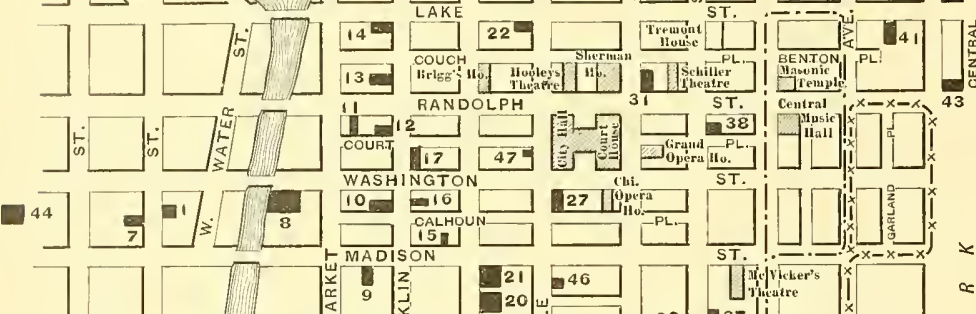

$\longrightarrow$
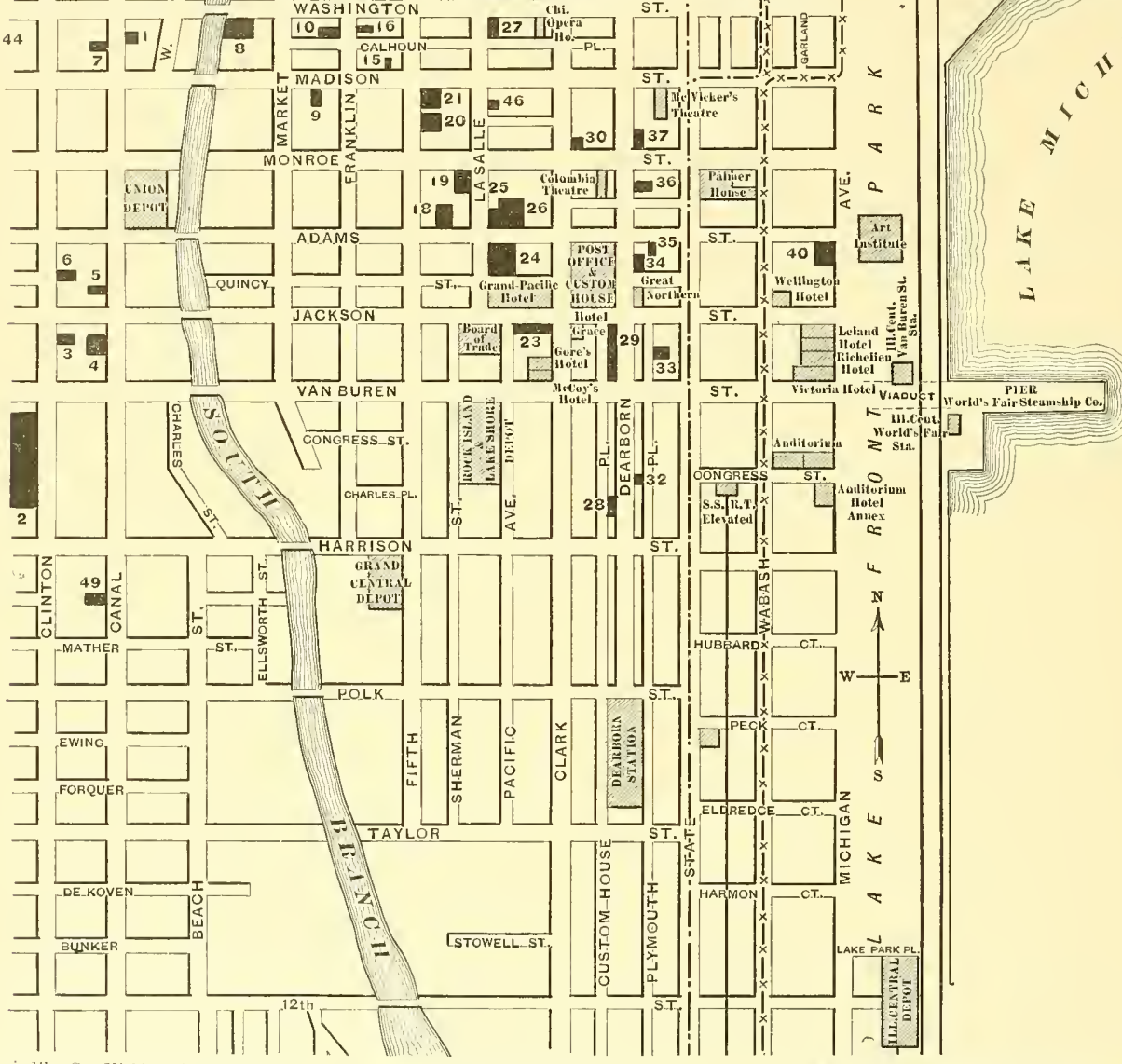

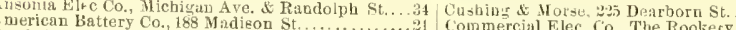
firtholomew, Stow \& 60,5 . Michion Barton \& Brown, 1428 Monadnock Block.

Benham, A. D, $200 \mathrm{~S}$. Clinton

Bryant Electric co.

Brush Electric Co. Mionadnoek Block.

Buckeye Electric Co

Calumet Electric Mig. \& Engineering co., i i 74 s.

entral Electrie Lt. \& Pr. Co... 185 Dearhorn st.

entral Electrie Co., II8 Franklin St

42
29
C. \& C. Electric Motor Co, 201 Hadikon St

3 D Unger El. Telephone Co, stock Exchange Bid

34 McPongall de Cummings, Tnity BIdy.

16 Tather Elec Co. Chamber of Commerce Bidg

15 New York ineulated Wire Co., 80 Frankls St St

Detroit Electrical Works, 917 MIonadnock Block Edry tiectric Mrg. Co. $141 \%$ Monadnock Block....
Electric Construction is Supply Co., Unity Bldg.

Electric Appliance Co, 242 Aladison st............................

41 Pullman's Palace Car Co., Pullman Bidg.

9 Pumpelly, J. K., 205 S. Canal St.................... Railway Eqripment Co Prllman Bldg St.......4 Rocleford

36 Enterprise Electric co. 307 Dearborn st Ft. Thayne Elec. Co, Is5 Deurhorn St...

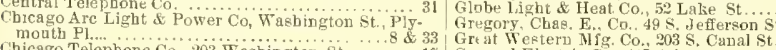

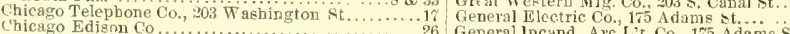

bicago Electric Club, iz5 Clark sit.

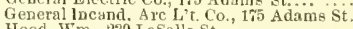

Hood, Wm.; 239 LaSalle St..........................

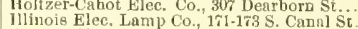

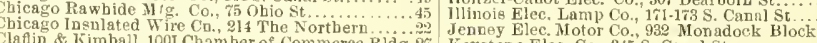

Claftin \& Kimball, 1001 Cbamber of Commerce Bldg.27 Keystone Elec, Co, $345 \mathrm{~S}$. Canal St.

Cutter, Geo, 851 The Rookery.......... 34 Kohler Bros, 1417 Monadock Block ...

22 Standard Elec. Co. 625 Home Ins. Bldg............ Siemers-Haleke Elec. Co., 1225 Monadnock lilock ...'? Star Elec. Lamp Co., 805 Chamber of Com. Blag.......

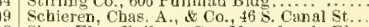

8 Short Elec. Railway Co. Monadnock Block.

Taylor, Goodhne \& A mes, 348 Dearborn St.......

Todd. Applegate Co., The, 340 Dearhorn St . .....

Westing-Entz Cn., 1122 Monadnock Block...........29 Wertern Electric Co., 227 s. Clinton St....

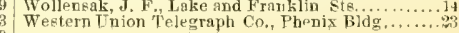



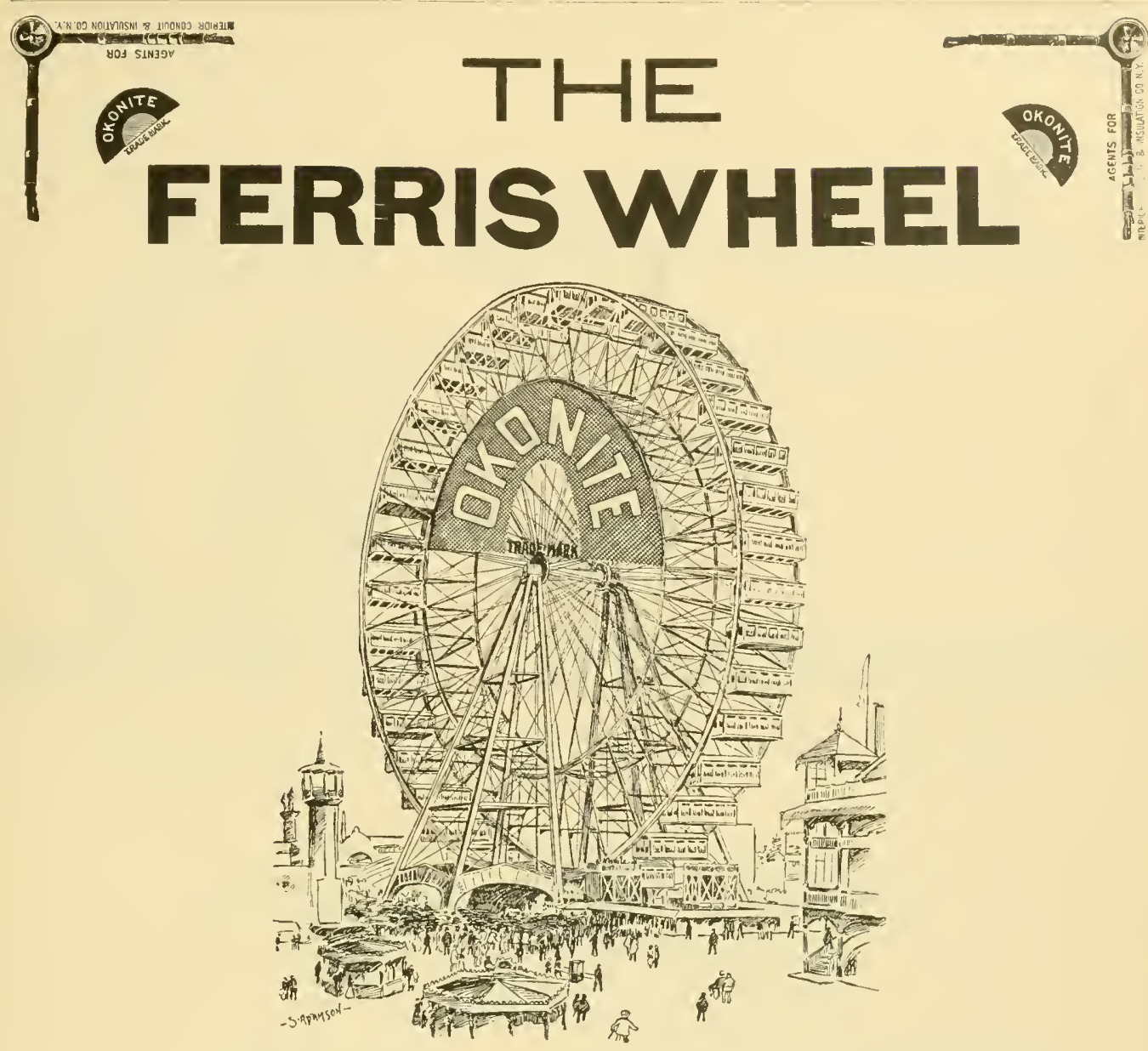

When you visit the World's Fair, you will naturally take a ride on the FERRIS WHEEL and be interested in the ELECTRIC LIGHT INSTALLATION, which is wired throughout with

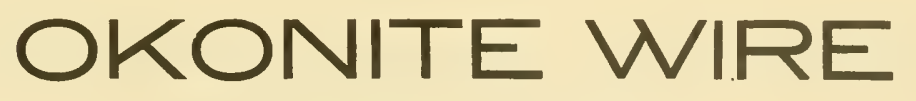

FURNISHED BY THE
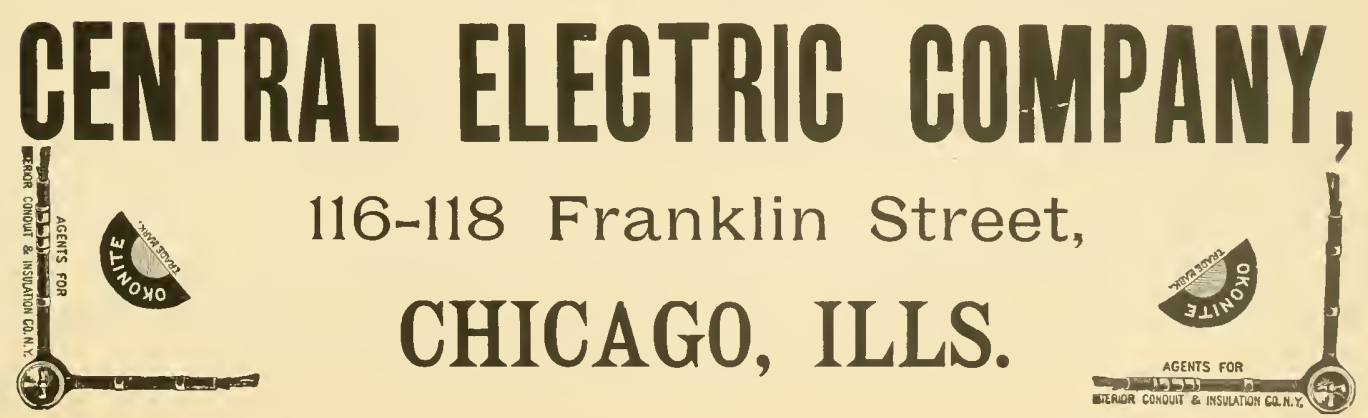

116-118 Franklin Street, 


\section{Standard Electric Company.}

GEHERAL OFFICES: 625 Home Insurance Building,

WORKS: So. Canal Street,

\section{CHICAGO.}

\section{STANDARD SYSTEM \\ AT THE

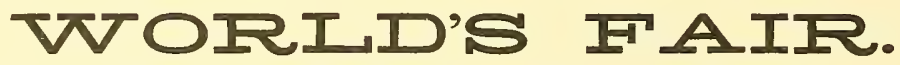

MACHINERY HALL, Sec. Q, 2 Standard Arc Dynamos.

Sec. S, 20 " " "

ELECTRICITY BuILdinc, Sec. P, Space 2, Arc Lighting Exhibit.

The Standard Lamps Light the Power Plant, Machinery Hall, Agricuitural Hall, Shoe and Leather Building, and Other Buildings and Portions of the Grounds.

See our Double Service All Night Lamp Before Buying an Old Style Two Bod Lamp. 


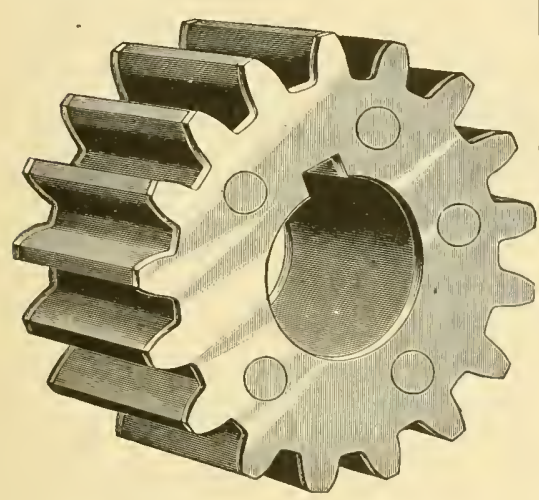

RAWHIDE PINIONS FOR ELEGTRIC MOTORS A SPECIALTY.

RAWHIDE DYNAMO BELTING

Greatest Adhesive Qualities, A Non-Conductor of Electricit Causes Less Friction than any other Belt.

THE CHICAgO RAWHIDE MANUFAGTURING CO. THE ONLY MANUFACTUREAS IN THE COUNTRY

LACE LEATHER ROPE ANO OTHER RAWHIDE.

GOODS

OF ALL KINDS

BY KRUEGER'S PATENT
This Belting and Lace Leather is not affected by steam or dampnes: never becomes hard; is stronge: more durable and the most economhide Rope for Round Belting Transmission is stiperior to all others

CHICACO, UL

\section{THE MONTHLY ISSUE FOR AUGUST}

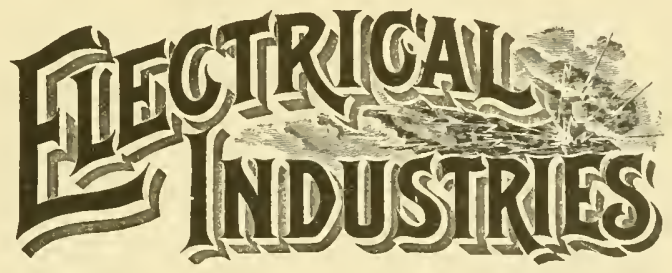

Should be read by everyone interested in electrical matters. In its table of contents is the following:

"Incandeseent Lighting at the World's Fair."

"The Electric Power Plant of the Chicago City Railway.

"Steam Engine Efficiency-Its Possibilities and Limitations" by Wm. H. Bryan.

"Alternating Arc Lighting for Central Stations" by H. S. Putnam.

"Hard Rubber as an Insulator in Street Railway Work" by W. R. Mason.

"A Brief Review."

Together with illustrations of the recent applications of electricity

The paper also contains regularly

A Buyer's Directory of Manufacturers and Dealers in Electrical Supplies and Appliances.

A Complete Directory of Electrie Light Stations in North America and a Complete Directory on Electric Railways in North America.

These directories are revised each issue to the date of going to press and are to be found in no other electrical journal in the World. Its articles are read carefully and its directories used constantly by all the buyers in the trade. These faets make it withont a superior as an advertising medium. Sample copies and rates sent on applieation.

Subscription price $\$ 3$ per year. Six months trial $\$ 1$, if orderesl during the next 30 days

\section{ELECTRICAL INDUSTRIES PUB, CO.,}

Monadnock Block, CHICAGO. 


\section{FERRIS WHEEL}

Wired with mile upon mile of

Simplex Wire

(We don't claim it all)
SIMPLEX WIRES

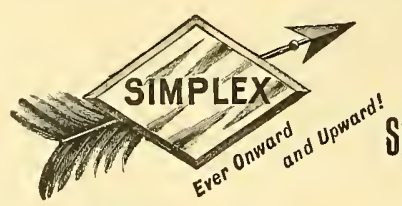

INSURE HIGH INSULATION Simplex Elegtrical bo. 620 Atlantic Ave.,

George Cutter, Chicago. Boston, MAss.

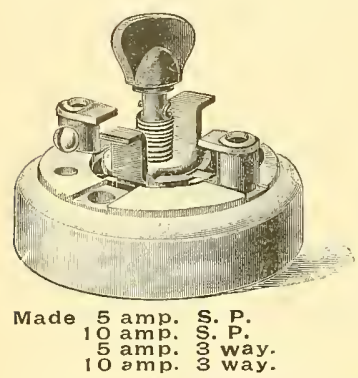

Consolidated Elpctric (6.

Manufacturers and Dealers in all kinds of

\section{ELECTRICAL . SUPPLIES,}

115 Franklin Street,

\section{CHICACO.}

GHORGE PORTER,

Contractor for All kinds of

\section{ELECTRICAL WORK.}

Room 67, 143 La Salle St., CHICAGO.

Crary Block, BOONE, IOWA.

\section{CHAS, A. SCHIEREN \& CO,}

MANUFACTURERS OF

\section{Genuine Perforated Electric Leather Belting,}

46 So. Canal Street, - CHICACO

Section 15, Dpt. F, CIm. 27.

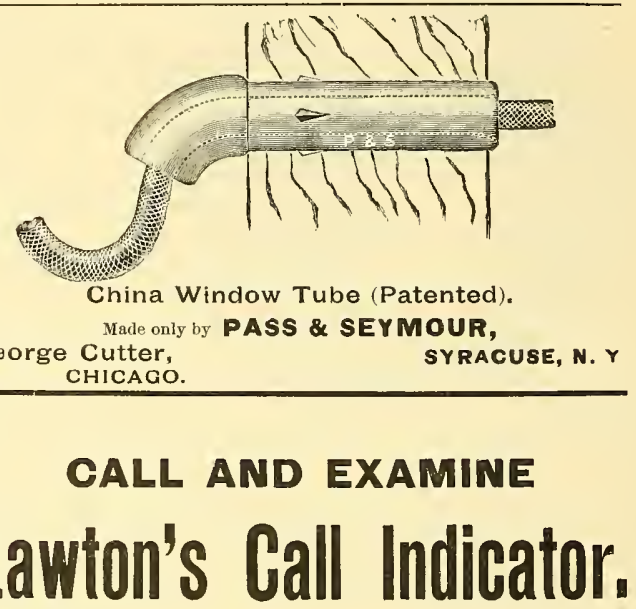

Indispensable for hotels, railroad offices, school buildings, hospitals, etc.

Section Y, Space 45, Gallery Electricity Building, WORLD'S FAIR.

OHIOAGO, ILI.

\section{WAGNER ELEGTRIC FAN MOTORS}

For. Divert or ilternatiny Currents.

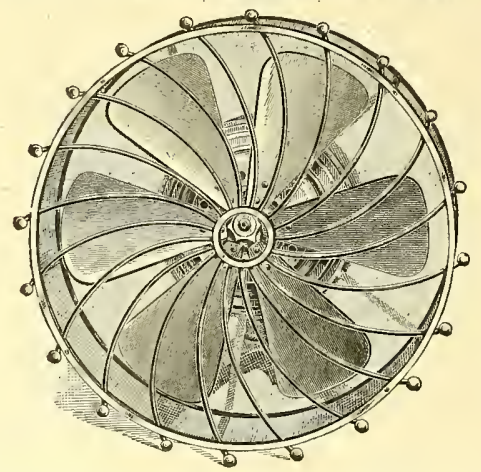

These motory give a etronger breeza with less consumption of current thas any other fan selp-oiling. Fnnished rith or withont huere pawer, Six bla

IT WILL PAY YOU TO SEE THE WAGNER BEFORE BUYING ELSEWHERE

TAYLOR, GOODHUE \& AMES, 348 Dearborn Street, CHICACO. 


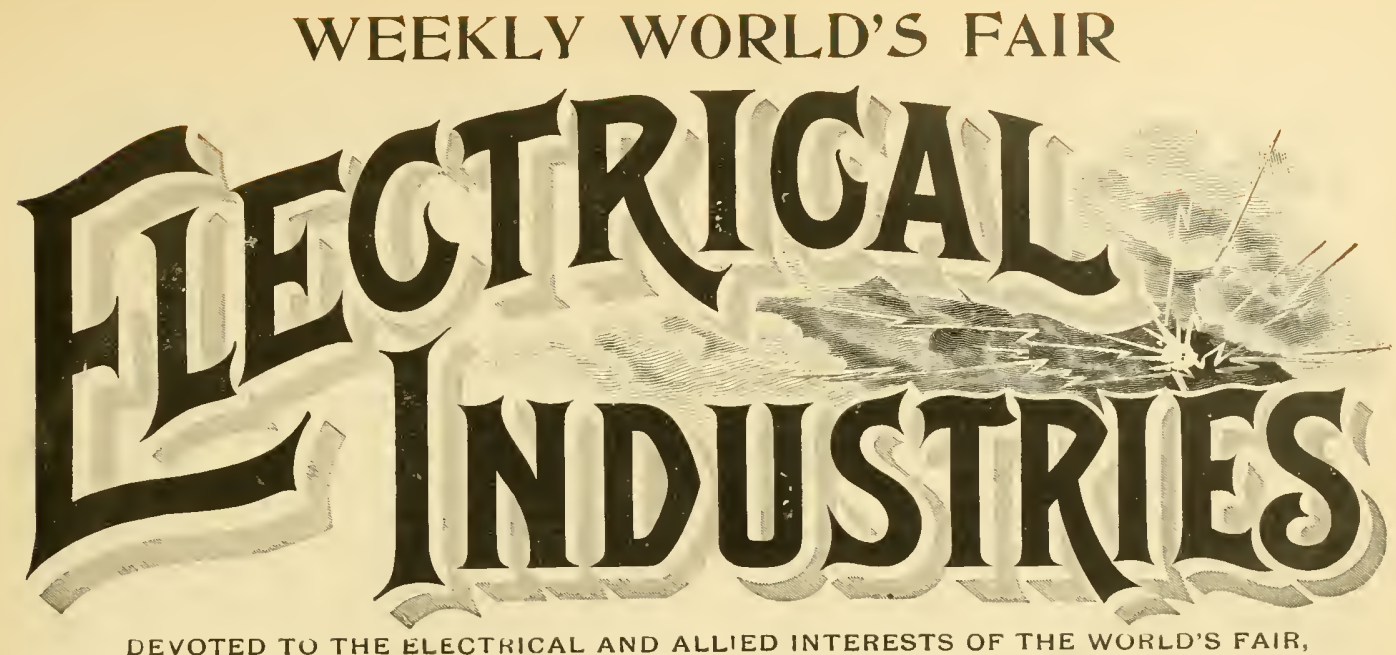

DEVOTED TO THE ELECTRICAL AND ALLIED INTERESTS OF THE WORLD'S FAIR, ITS VISITORS AND EXHIBITORS.

Vol. I, No, 12. CHICAGO, AUGUST 31, 1893.

FIVE MONTHS $\$ 1.00$
TEN CENTS A COPY

WORL.D'S CONGRESS OF ELECTRICIANS.

At the adjournment of the eongress on Frillay, ELEcTrical INDrstries secured a photograph of the delegates assembled on the steps of the Art Institute where the

with Prof (iray in the center. To the right of Prof. Cray is Dr Von Helmholz, next to whom are Mr. IT. H. P'rece, Prof. Rowland, Prof. W. E. Ayrton, and Alex. Siemens. In the next row, back between Profs. Rowland and Ayrton, is Dr. Silvanus Thompson, to whose left is Prof. Elihu

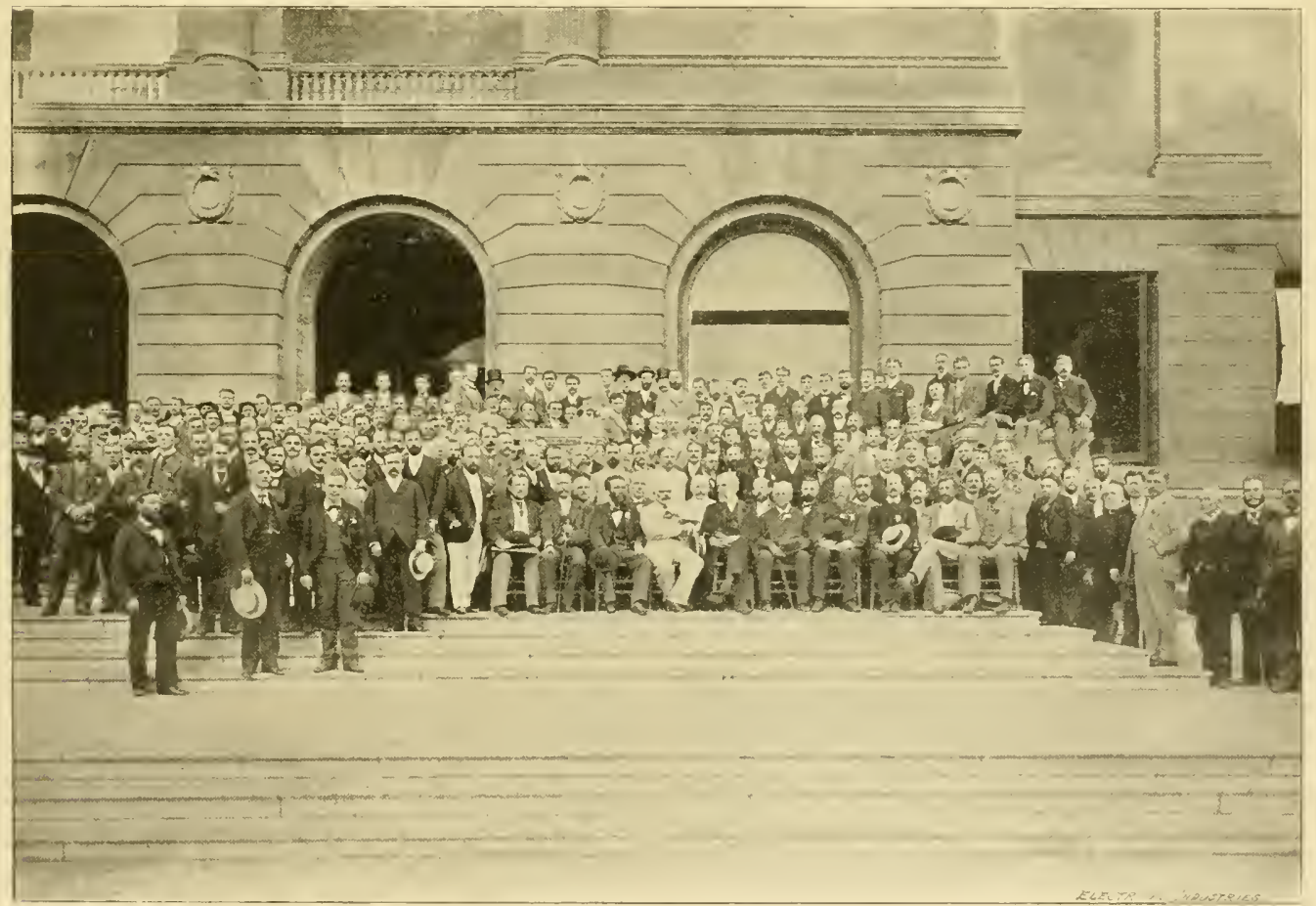

FOILD'S CWNGRERS OF ELECTRICLANS.

sessions of the congress were helı. The accompanying engraving was taken trom this photograph. Our readers will uncloubtedly appreciate the picture, especially those who did not attend the congress and who are not familiar with the appearance of the many eminent scient ists present.

seated in the foregromul is the chamber of delegates,
Thomson. To the right of Prof. (iray are Prof. E. Maseart, Prof. Cialileo Farraris, Dr. Tiolle and Prof. E. Hospitalier.

TRURSDAY SESSION.

On Thurstay, section A was culled to order at $10: 15 \mathrm{~A} .3$. with Prof. Ealdy in the ehair. Dr. Bedell furnished the 
reading of his paper on mutual induction and capacity. Dr. John Sahulka then read a paper "On the Explanation of the Ferranti Phenomina." after which the section adjourned until Friday.

Section B was called to order by Prof. Cross, and the section proceeded with the discussion of Prof. Thomas' paper. The question was discussed by Carl Hering and others. At 10:45 Prof. Henry S. Carhart read a paper on "A Pair of Electrostatic Voltmeters," describing an instrument which he had had in use for some time past. The needles and mirror being suspended by fibre from the top and steadied by a small spiral spring from the bottom. He said that the instrument was very accurate and excellent for laboratory use.

At 11:10 Prof. Webster read a paper on "A Method of Gorerning an Electric Motor for Chronographic Purposes." The purpose of the governing was to control the revolutions of the ehronograph absolutely so that the error in time would be very slight. The means of doing this was through an electro-magnetic arrangement of a tuning fork. The secretary, Lieut. Reber, then read Prof. J. A. Ewing's paper in "Iron for Transformers from the Magnetic Point of View." At 11:30 the section was adjourned until 12 oclock. On reassembling after adjournment a paper was read by Prof. Andrew Jamieson on "London Electrical Engineering Laboratories." The author said that the title of the paper was somewhat incorrect, and that he had no idea of being called on for such a paper when he arrived. From the way with which the subject was handled it was evident that he is thoroughly familiar with the subject. In his remarks he said: It lias often been brought to my notice that the question of a boy's education cannot always be decided by rules and that it must be decided largely from the bent of the boy himself. The Professor said that if the boy evinced a tendency to flightiness of disposition or showed a disposition to slight things and to play with batteries and other small tools, his education certainly should begin with an apprenticeship to some good shop where he would learn the value of work, and would be kept down to it until his flightiness ceased. He should then be sent to some good technical school to complete his educacation. On the other hand if the lad was studious, steady in his habits and had a good head for mathematics it would be much better for him to besent immediately to college and get his practical apprenticeship afterwards. He said that in many cases in the city of London schools; the night student who had to work hard all day and studied evenings outstripped his more fortunate competitor who was enabled to attend thecolleges suring the day. He described the laboratories of the various technical schools, starting first with the city and guilds of London Institute of which Prof. WT. E. Ayrton is the head, and which Prof. Jamieson thonght was the best type. Others which he described in detail were the Siemens laboratory under the charge of Dr. John Hopkinson, the laboratory conducted by Mr. Kiennedy, and entered into quite a detailed deseription of the Finsbury College conducted by Sylvanus P. Thompson. Others were also described. There was more or less discussion by Dr. Boehm, Prof. Reed of Ann Arbor and Prof. Cross of Boston. Dr Bedell read his paper on "Transformer Diagrams Experimentally Determined."

Section $\mathrm{C}$ was called to order at 10:10 A.x. After disposing of the routine business of the section, Prof. F. B. Crocker presented his paper "On Direct Current Dynamos of Very High Potential," in which he described various experimental machines made mder his direction having very high potential. Dr. Keith, at the close of the paper, called attention to the fact that dynamos of high potential had been in use in San Francisco since 1857, and that at the present time there are not more than half a dozen motors in that eity which are not'operated by high potential current.

At the close of Dr. Keith's remarks the discussion on long distance power transmission was opened with a very able paper by Dr. Lonis Duncan of Baltimore. Dr. Duncan was followed by Mr. Scott of the Westinghouse company who described, with the assistance of large diagrams, the Tesla polyphase system as exhibited at the Fair. Lieut. Hasson of San Francisco spoke very humoronsly and laid stress upon the point that while there are many beautiful theories there has not as yet been a practical application of long distance electrical power transmission within his knowledge which has stood the test of actual use.

Dr. Bell of the General Electric Company spoke decidedly in favor of alternating currents for power transmission because they can be twisted around to better advantage than the direct current, and the single phase motor in its present state of development can be considered nothing more than a poor polyphase motor. There are two systems of polyphase according to Dr. Bell, the independent and the dependent circuit system. Personally Dr. Bell is an adrocate of the dependent circuit of the polyphase system for such transmissions of power. Mr. Stillwell of the Westinghouse company made a few remarks, in the course of which he said he hoped that after the large companies had gone to so much labor and expense to perfect a new system for power transmissions, that the consulting engineers would not force them to install the plants at their own expense and guarantee the dividends before they (the engineers) would be convinced of the practicability of the system.

Mr. Frick, of Germany, deseribed the various power transmission plants in his country which have been working from one to two years, giving entire satisfaction, and said he believed do one system the best for all purposes; each has its good points. Prof. Thompson read from notes made by Mr. Thury, of Switzerland, a description of power transmission plants located at various points on thecontinent, and afterwards made some very interesting remarks, and give it as his personal opinion that the polyphase system is prefer. able only where no general distribution of power is to take place at the receiving end of the line, but. that where distribution is to take place the alternating system is preferable. Prof. Forbes, of London, arrived while Prof. Thomson was speaking, and at the conclusion of the professor's remarks, expressed his belief that while the three phase system is attractive from its beauty the two phase system is much better adapted to practical uses.

Mr. Steinmetz closed the discussion by calling attention to the fact that the continuous current is still more largely used than any other, and expressed the opinion that the single phase system will be the system of the future, that suchobjectons as are now raised to it will be soon overcome, and that we are nearer the ideal condition than is generally supposed.

The next paper on the program was that of Dr. C. Pollak on "The Conversion of Alternating into Continuous Currents," which was appreciatedly received but not discussed owing to the hour for adjournment having considerably passed. The machine described in Dr. Pollak's paper can be seen in operation in the German section of the Electricity Building at the Fair. 
ER11)

Section A. was called to order at 10:10 a. m. and the Secretary read by title two paners, one by Prof. A. Blondel on "Measuring the Power of Pulyphase Currents," the other, by Prof. W. E. Ayrton, F. R. S. on " Extended Ise of the Name liesistance in Alteruating Current Problems." The session then adjommed to the afternoon sesion when the report of the chamber of clelegates is to be mesenterl.

Section B. After the reading of the minutes of the pro. vious moting the section listened to a paper read by Prof. II. E. Ayrton, F. R. S., on the "Variation of the P. D. of the Electric Are, Current, Size of Carlous and Distance Apart. Prof. Ayrton's paper was a very able description of th" experiments made under his direction during the pas five years for ascertaining an absolutely reliable formula for the potential difference between the rarbon points of the electric arc. These experiments have not been fully completed nor the computations made, so Prof. Ayrton was not able to gire the congress the corrected formula which will be the final result of his experiments and calcula. tions in this direction.

In the discussion which followed the reading of this pa. per Prof. Elihu Thomson made a brief acldress in which he stated that experiments conducted by him in jsist and since that time coincided in results quite closely with those described by Prof. Ayrton. Prof. Cross. Mr. Henricues, Prof. MacFarlane and Dr. Silvanus P. Thomson participated in the discussion. The next paper was on the " Light and Heat of the Electric Are" and was read in French by Dr. J. Toille. Dr. Silranus P. Thompson gave an abstract of the laper in English after the reading of the same in French by the anthor, in which he said that a translation of a similar article hy Dr. Voille could be found in the London Electrical Review for dug. 1, 1593.

Prof. Elihu Thomson, Prof. Wehster and Mr. Hemrigues participated in the disenssion of the paper, some of the gentlemen addressing their remarks to M. Toille in his own language, to which Dr. Toille responded.

Dr, Silvanus P. Thomjuson presented his paper on " The Swinburme-Thompson [nit of Light" without reading. as the time for adjourmment was approaching. The paper was intended to prove that a square millimeter of the surface of the crater of the positive carbon should be taken as the unit of life.

Prof. F. B. Thomas presented a short paper on "Periodic Variation of the Candle Power of Alternating Ar. Lights" together with a liagram of curves showing the results of measurements made hy him in recent experiments. There was no discussion of this pajer. The last paper on the program was that of Prof. H. S. Carhart on "The Maximum Efficiency of Are Lamps with Constant Number of Watts." The author had intended to simply have this pajer rend by title but on request gave a brief outline of it without reading it in full. The paper was a suggestion to rate are lamps by the number of watts exjonded upon them instead of by the candle power as is the present enstom. Prof. Carhart merely offers the groj. usition as a suggestion, realizing that there are objections as well as points in faror of this idra. Prof. Ayrton expressed his appreciation of Prof. Carhart's pajer as it had to do directly with his own line of experiments. The follow ing papers were presented but not read: "On the Sourc" and Effects of Harmonics in Alternating Circuits" by Prot. H. A. Rowland, "Sour 1" Are a Constant le Lu. miere" and "Nonvelles Recherches sur J'Arc a Curmuts Alternatifs" Jy A. Bondel. This section then adjourned to mest in Colmmbus Hall at 3 p. x. to hear the report of the chamber of delegates.

Session C was called to order by Prof. Houston at 10:15) A.3. Dr. Pollak read a few notes on the convertion of al trmating into contimuous currents for charging storage bat teries. Mr. Frick, of Germany, then spoke in reference to the load line of central stations as determined by tests made on days in three different portions of the year. He exhibited diagrans of these load lines and showed how acemmu lators could be applied for easing 11 , the use of the machin ery as well as being less costly to install. He sairl that accumulators were in nse in all stations in Germany and in nearly all stations on the continent of Europe, and that without exception they were well liked by all who had them in use.

At 10:30 Prof. Geo. Forbes, of London, the consulting - Hectrician for the Cataract Construction Company, of Niagara Falls, reopened the discussion on long-distance pownr transmission that was started yesterday. Hesaid that as 1 (र) he had stated it as his opinion and lad since sern no rasom to ehange it, that the two-phase alternating current was the jroper thing to use for long distance trans mission, the two separate circuits being kejt independent. In some shops single phase motors can he used, in others two phast, aud where direct current is needed alternating wotors of either style could be nsed to drive direct current dynamos. He called attention to the commutating machines now commonly known as rotary transformers and said that white this was perfectly feasible he thought the expense of the machine and the losses in efficiency due to its construc. tion would prohibit its use. Some simpler form of ("i)mmu tating levice might be made which would not consume so much entregy.

He ex]ressed as his oprinion that not very tar in the future we should he in possession of a simple device for this purjose, which would change alternating eurrents into direct currents and that without the consumption of any large jercentage of energy, and instancel as snch the very ingenious machine exhibited and ${ }^{2 x}$ slained by Dr. Pollak. He stated that Gramme's first alternating dymamo was two phase with a stationary armature. In reference to the question as to whether he would faror the direct production of the re. yuired high potential by the machine itself or would use stej-up) transformers, the (lymamo being run at high pressure, he favored the first method as with the standing armature it would be ferfectly feasible to obtain the requisite potential without danger to the machine.

From a financial point of view it was very much eheaper as the transformers for such work would cont nearly if not yuite as much, as the dynamo itself, and three or more per cent of such loss in such transformation would amount to $\$ 3,(x)($ per year, counting the eust per horse jower at $\$ 20$, which, eapitalized at ì per cent, would be $\$(1),(1)(0)$, or more than the entire cost of the dynamo. In regard to the conductors to be used and the location of the same, he very much favorel the use of hare wires in a large subway so con structed that the inspector could walk through it. In any overhad construction there would be more or less trouble from sleet and various other difficulties, while the use of conduits for clrawing cables in and out would be impos. sible.

After speaking for an hour Prof. Forbes was followed by Prof. H. A. Rowland, of Johns Hopkins, who argued that the mere loss of three per cent in the efficiency of the trans. former, could be easily made up by turming on a little mors water, that he lid not think itcut any figme at all, and that 
as for the direct production of the excessively high pressures in the armature itself, hevery much favored the use of the step-up transformer as liable to be of less trouble for repairs and shut downs. He had considerable to say in regard to the frequency which would be best to use in this general transmission as a frequency that would be proper for motors would not be right for the incandescent lamp as at 35 or less periods per second, the effect on the eye was decidedly unpleasant, and also could not be used for synchronous motors.

\section{CLOSING SESSION.}

The afternoon session was held in Columbus Hall, the chamber of delegates taking their place on the platform at 3.10 P.x. The report of the chamber of delegates was read by Prof. E. L. Nichols, and was as follows: Gentlemen of the International Congress: The chamber of delegates has made a careful investigation in accordance with the program laid down, and has reached certain decisions which it is my duty as secretary to report. The first question which came before the chamber had to do with the adoption of definitions and values of fundamental units of resistance, current and electro-motive force. The following resolutions on this point have been passed by the chamber of delegates:

Resolved, That the several governments represented by the delegates in this international congress of electricians be and they are hereby recommended formally to adopt as legal units of electrical measure the following:

As the unit of resistance the international ohm, which is based upon the ohm equal to $10^{9}$ units of resistance of the initia] C. G.S. system of electro-magnetic units and is represented by resistance offered to an unvarying electric current of a column of mercury at the temperature of melting ice, 14.4521 grammes in mass, of a coustant cross sectional area and of a length of 106.3 centimeters.

As a unit of current the international ampere, which is one-tenth of the unit of current of the C. G. S. system of electro-magnetic units, and which is represented sufliciently well for practical use by the unvarying current, which, when passed through a solution of nitrate of silver in water, in accordance with the accompanying specifications, deposits silver at the rate of 0.001118 of a gramme a second.

As a unit of electro-motive force the international volt, which is the electro-motive that, steadily applied to a conductor whose resistance is one international ohm, will produce a current of one international ampere, and which is represented sufficiently well for practical use by 1,000 . 1,434 of the electro-motice force between the poles or electrodes of the voltaic cell known as Clark's cell, at a temperature of 13 degrees centigrade, and perpared in the manner described in the accompanying specifications.

As the unit of quantity the international coulomb, which is the quantity of electricity transferred by a current of one international ampere in one second.

As a unit of capacity, the international farad, which is the capacity of a conductor charged to a potential of one international volt by one international coulomb of electricity.

As the unit of work, the joule, which is $10^{7}$ units of work in the C.G.S. system and which is represented sufficiently well for practical use loy the energy expended in one second by an international ampere in an international ohm.

As the unit of power the international watt, which is the expual to $10^{7}$ units of power in the C. G. S. system and which is represented sufficiently well for practical use by the work done at the rate of one joule per second.

Concerning the adoption of a definition and value for the unit of induction the chamber of delegates has resolved, upon the motion of Prof. Mascart of France, and seconded by other foreign members, that the unit of induction shall be called the henry, which is the induction in a circuit when the electro-motive force induced in this circuit is one international volt while the indueing current varies at the rate of one ampere per second. With regards the question of the selection of names for magnetic units and the units of light and energy, it was resolved that in these cases no specific name should be applied but that these units should be designated as C. G. S. units.

In addition to these topics two others have been considered. The question of standards of light was considered and a committee was appointed to deliberate on this very rexed question of the electrical engineer. I have the pleasure of reading the report of the committee, which report has been receired and adopted by the chamber of delegates. The committee says it has had much discussion upon the various forms suggested for standards, and in particular upon the two special forms of lamp known respectively as the amylacetate lamp of Von Hefner Alteneck and the pentale lamp of Vernon-Harcourt. The committee recommends that all nations be invited to make researches in common on well-defined practical standards and on the convenient realization of the absolute unit.

Finally there was before the chamber the question of the modification of electrical notation and nomenclature, and an extended and carefully matured scheme was presented by M. Hospitalier and others. After due consideration and after some amendments and modification of this plan had been made, it was moved that the report be received and printed as an appendix to the regular pro. ceeding and as the report of a sub-committee.

Prof. Gray then stated that he had a few announcements to make relative to to-morrow's work or to-morrow's pleasure and that Mr. Preece also had an announcement to make.

Mr. Preece spoke as follows: "Ladies and Gentlemen: My announcement is an extremely simple one. As president of the Institution of Electrical Engineers in England, it was my wish to invite the members of the Institute of Electrical Engmeers in America to meet me at Victoria House in the grounds of the World's Fair, especially as they have done me the great honor of making me an honorary member, there are only two and I am one of them, of their body. I had this great difficulty that the addresses, either of the members of the American Institute or of the Congress, have not been very earefully kept, and therefore I now invite all the members of this Congress, whether members of the American Institute of Electrical Engineers or not, to allow me to have the pleasure of receiving them to-morrow afternoon between the hours of five and seven, in my present British home, Tictoria House, World's Fair grounds."

Dr. Von Helmholtz then arose and addressed the congress, saying: "Ladies and Gentlemen: We have come forward here to do a really important work and one which I trust will have good fruit for future time in correcting the incongruities of electrical science and electrical notions, so that all scientific and industrial men can understaud each other in the simplest and best way. It was rather a hard piece of work to do in these hot days in continual meetings of the delegates and members of the congress, and he who has had the greatest part of the exertion and 
work in this connection is our president, Prof. Elisha Gray. I therefore trust you will express to him your thankfulness and give him a vote of thanks." M. Mascart of France then spoke in French in substance as follows:

"My assoziates join with me in heartily seconding the proposition of Dr, ron Hehmloltz, to express our thanks to the distinguished I'resident of the Congress of Electricians. We have admired the urbanity, grase and ability with which he has conducted the work, and are grateful for the courtesy with which he has treated us, and for all the hospitality and kinduess that we have received in America."

Mr. Preece: "I move that a rote of thanks be accorled to this fine old man, as the newspapers call him, but who is in reality a younger man than myself." The motion was unanimously carried and Prof. Gray responded as follows: "I cannot tell you how gratifying this is to me. I have worked for the last two years in organizing this congress under many difficulties and those difficuties hare continued right up to the present moment. Those steam engines outside do not even give us a chance to ex]ress ourselves. I want to thank you before we leave, I want to thank the members of this congress for the part they have talien and I want to thank you for the good part in which yon have taken all the difficulties under which you and I have had to labor. I think on the whole the congress has been very successful and I trust yon will go away feehing that this is true, and that you will think of us kindly; and you, gentlemen, who come from foreign shores, when you go home and look back, do not think only of smoke, of noise, and of high buildings, but think of us over here as having warm hearts, as wishing you well, and that we are all pray ing that you will have smooth seas and a warm-hearted welcome home to your friends and dear ones. Now, gentlemen this closes the work of the International Electrical Congress at Chicago in $159 \%$, and 1 now declare the same acljournecl."

\section{Nikola Tesla's Lecture.}

Mr. Tesla's lecture on "Mechanical and Electrical Oscil lators" was delivered in Assembly ILafl at the sonthwest corner of the Agricultural Building at the World's Fair grounds on Friday evening as announced in the program. Every member of the congress with one or two exceptions was present and the greatest interest was manifested in the experiments that were shown.

It was twelve minutes after eight when Prof. Elisha Gray introduced Mr. Tesla to the audience in the following words: "I came down here to-night for the purpose of introducing to yon a gentleman whose name needs no introduction as it is a household word with all electricians, but I wanted to do him the compliment of coming here as the oflicial hearl of the World's International Congress of Electricians and to extend to him the compliment of an introduction for them as well as for myself. This compliment loses none of its force when I tell you that I have another official duty to prerform to-night and it will be necessary for me to leare immediately, lut if I should follow my inclinations I should stay, for no one wants to hear and see these experiments more than myself. I have the honor, ladies and gentlemen, of introducing to you Nikola Tesla. I wish to add one word, inasmuch as I have to lease; I am going to ask Dr. T. C. Mendenhall to do the honors for the rest of the evening."

Immediately the hearty applause subsided Mr. Tesla said: "Ladies and Cientlemen: We are told in a delight- ful aneclote how, many years ago, when science was still in its infancy, a man to whom the world is largely indehted for the discovery of a great truth was meditating in his garden when the idea came to him, and how on that oceasion he was carried away by his enthusiasm. Be that an actual fact or not it is certain that the search for truth through the centuries that have elajsed has exercised an immense power on the imagination of man. It seems as though we are actual witnesses of the researches and experiments made by the discoverers and inventurs of ages gone by, and that we are alnust in a condition to know how they felt at the moment of sublime inspiration.

"I an sure in this audience there are many who have felt this most exquisite pleasure and whose presence here will forever fix the recollection of this evening upon my nind To feel this pleasure is accorded to hut few; however, I can say myself that 1 have felt it and am still under the impression of the pleasure which the accomplishinent of a few insignificant thoughts that have come to me and the spreculation on the possibilities of their future development have caused. In these results I am, inventor like, quite taken up, and I hardly dare hope to he able to develop them as I wish, but I feel that I must explore them: and again I have doubted my ability to present them satisfactorily. Iet I an sure of the practicability of investigations in this manner from the few results I have so far obtained.

"I can hest tell you what I have attempted if I comply with the scientific duty and tell you exactly the history of these inventions. It was at a time when I wastrenuously endeavoring to solve a question or two which was considered insolvable, first, Was it possible to operatea motor without slicling contart, and second; was it possible to develop, comstant currents in a certain (lirection? I found the solution to the one problem and produced dynamos without commutators and that suceess emboldened me to go aheart and apply whatever of knowledge and experience I possessed to the solution of the other problem.

"On the oceasion of my first visit to this country I stepperl intn the exposition at Philadelphia and 1 saw there a very thick copper washer provided with handles that risitors would move within a magnetic field. That day it occured to me that when the plate was moved slowly in the field there was experienced resistance, and that when the plate was suddenly pressed in therewas a rebound as though it struck against something solicl. After returning from the exposition the thought occurred to me that if I took a conductor and moved it into the fiekd and then rapidly with. drew it. Icould in this way obtain whatever of electro-motive force there was. In the first place I was impressed with the analogy of this device to the induction coil, in which the same process takes place. When we impart current to the primary cireuit we put lines of foree slowly into the field and when we break the current we take the force swiftly away. I began to think of a mechanism which would be capable of fultilling these conditions.

"During my work with induction coils and motors which succeeded I hecame familiar with currents of high freInency, and then I clearly realized the prohtem before me. I convinced myself that in alternating distributions we must induce currents of more thad one phase and that we must have a better organization and a perfected mechanism capable of renclering the current into steady oscillations before we could obtain the desired results. Here then I was confronted with this difficulty. I constructed small machines of the ordinary type which enabled me to investigate, but when I encleavored to construct machines with a 
greater number of alternations for higher frequency I foumd that I met insurnountable mechanical difficulties.

"And then the idea came up and I asked, how it would be if $\mathbf{I}$ took a very strong field and reciprocated very rapidly a conductor in that field, would I not have a similar machine and one which would not involve loss in the iron? And now I began to consider this matter very seriously aud Jater I considered this question, knowing what has been dove in the field of harmonic telegraphy and supposing that instead of the ordinary dynamo we take dynamos constructed like the pendulum of a clock and on a harmonic vibration principle, would we not then obtain alternating currents of a perfectly defined and absolutely constant period, which it is impossible to accomplish with an ordinary machine because it possesses so great inertia? And then again I thought like this, with such powerful machines there is a possibility of transmitting energy through the air and by means of this energy of transmitting messages. This, then, is one of the mainsprings which has driven me into this work."

Here by means of diagrams Mr. Tesla deseribed the construction of the engine which he has invented for producing these absolutely constant oscillations and which is operated by eompressed air under 100 pounds pressure and delivered at the rate of 40 cubic feet per minute. One of these engines having a diameter of about two inches and a half and of about that length operated a small motor and has a capacity of nearly one-half horse power. After this Mr. Tesla showed the operation of the larger engine having a piston and plunger weighing 20 pounds which was oseillated at the rate of 78 times a second, and stated that 5,000 or 10,000 oseillations per second conld be as readily produced. The next experiment was made by attaching a horse shoe magnet having a wire about two feet in length inserted through it to show the vibration to the plunger of the engine. The engine was then set in motion, a current communicated to the magnet through wires attached to the nodes of the magnet wire. A copper disc revolving on an axis was then introduced by Mr. Tesla between the poles of the magnet while the same was being oscillated by the engine. The result of the experiment was that the copper dise began slowly to revolve, thus disproring the theory that there is no electro-magnetic force at work in the disc and that the force was simply one produced by induction as has been believed universally heretofore.

Mr. Tesla next attempted to show an experiment with what might be called a three coil generator, but the apparatus had been damaged in some way and refused to work. The next experiment was one with a large engine similar to that last described, having attached to the plunger of the oscillator a core of iron which played through four field magnets exeited with a current at 5,000 volts from the Westinghouse plant. A current was generated by the apparatus, and was used to rum a small registering motor, thus proving that generators ean be construeted on the ideas evolved by Mr. Tesla in accordance with these more recent experiments, and having an absolutely constant current. It should be arded that one of the claims made by Tesla for these oscillators is that the period will not be varied after the machine is started, whether the pressure be 10 pounds or 100 pounds, and that the electrical currents produced from small units will oscillate just as as the pendulum oscillates, and be unaffected by the eireuit load or any imaginable condition. The oscillators are so constructed that they can be adjusted
ELECTRICAL INDUSTRIES.

\section{ELECTRIGAL INDUSTRIES PUBLISHING COMPANY,}

INCORPORATEO 1889.

MONADNOCK BLOCK, CHICAGO.

Telephone Harrison 159.

E. L. POWERS, Pres. AND Treas.

E. E. WOOD, SFCRETARY.

E. L. POWERS,

EDITon.

H. A. FOSTER,

W. A. REMINGTON,

E. E. WOOD,

- Associate Editolis.

FLOYD T. SHORT,

- Eastern Mavaget.

EASTERN OFFICE, WORLD BUILDING, NEW YORK.

World's Fair Headquarters, Y 27 Electricity Building,

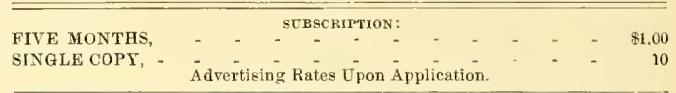

News items, notes or communications of interest to World's Fair Visitors are earnestly desired for publication in these columns and will be heartily appreciated. We especiallv in rite all risitors to call upon us ot send address at once upon their arrival in city or at the grounds.
ELECTRICAL INDUSTRIES PUBLISHING CO.

\section{Monadnock Block. Chicago}

so as to run with practically no noise, and with the entire absence of any pounding effect.

\section{Banquet to the Foreign Delegates.}

The erent of last week soeially was the banquet given by the American electricians to the foreign delegates to the international congress on Thursday evening at the Grand Pacific hotel. In parlor 44 there were gathered the foremost electrical scientists of the world. Dr. Ton Helmholtz of Berlin, upon whom all looked as one of the fathers of the science, and Thos. A. Edison, the great American inventor, divided the honors of the erening. The toastmaker, Prof. Elisha Gray, occupied the center chair at the table of honor. At his right sat Dr. Von Helmboltz, Prof. Rowland, Dr. Maseart, Prof. Carhart, Dr. Budde, Prof. Nichols, Dr. Violle, Prof. Houston, Prof. Thompson, Mr. Loekwood, Prof. Dolbear, Prof. Brown-Ayres, Dr. Tourrane, Dr. Lnmmer, Mr. Wenmann and Dr. Sahulka, while on his left sat W. H. Preece, F. R. S., Dr. Mendenhall, Prof. Farraris, Prof. Thomson, Prof. Ayrton, Prof. Cross, Dr. Shrader, Prof. Crocker, Dr. Palaz, Prof. Thomas, M. Hospitalier, Dr. Toit, M. Chavez, and Messrs. Wetzler, Pope, and Phelps. At the table directly opposite Prof. Gray sat Mr. Thos. A. Edison with Messrs. Emery, Wheeler, Insull, and Kennelly. The following is the menu served: MENU.

Little Neck Clams Consomme Royal Fresh Penobscot Salmon, Moliandaise Dressed Cucumbers

Chatean Lauterne Fillet of Beef, Larded, Financiere Browned Potatoes New Lima Beans Mumm's Extra Dry weetbreads in Cases French Peas Siberian Panch

Breast of Young Chicken with Truttles

Pontel Canet Tomato Nayonnaise

Charlotte Glace Roquefort Peaches and Cream Fancy Cake Coffee

At 8:30 Prof. Gray arose and presented the first toast, "The International Electrical Congress," and called on 
Dr. Yon. Helmholz to respond, who said, " We Europeans have come over here with the feeling of a good father rejoicing in the success of his children, to whieh he himself could not attain. Europe is too narrow for the splendiel march of electrienl progress and Ameriea has grandly performed the task set before it. We see in you the result of better conditions and prospects than we have enjoyed, and we rejoice with you in your remarkable advaneement. Gentlemen, I drink my glass to the great American Nation." Prof. Gray then proposed "Our Guests, the Official Foreign Delegates," to which Mr. IT. H. Preeree, Prof. E. Maseart and Prof. Ferraris responded. Prof. IV. E. Ayrton of Loulon responded to "The Ameriean Electrienl Engineers", and Prof. E. J. Honston to "The Amr rican Institute of Eleetrical Engineers." The other speaker's were Prof. s. P. Thompson, Dr. Mendenhall, T. D. Loekmood, Prof. H. A. Rowland and Prof. Elihu Thomson.

\section{Exhibit of the Standard Underground Cable Company.}

Just west of the exhibit of the sperry company in the on hangers from an iron wire. The poles are low enough so that every detail is in plain view of the visitor.

A special feature of the exhibit is the presentation of the rarious means of terminating the cables in appliances known as terminals, whereby the end of the eable is hermetically sealed and yet presenting an easy and effective method of reaching the ends of the wires for tests or connections. Iuter this liead are shown the distributing boxes by means of whieh a main cable may be cut into, the wires for various services may be taken ont without disturbing the working abilty of other lines in the cable. This is practically shown in the taking from the manhole and up the pole a section of underground cable and comected through a terminal to the aerial cable for distribution above ground. On a table wear the center of the space are exhibited numerous sections of lead covered cables which the method of making different kinds of joints. Main line joints, branch eonnections, ete., in eleetric light and power eables, in telephone, messenger and other eables are shown.

Near by is a pile of eases containing the ozite compound extensirely used as an insulation for filling cable joints.

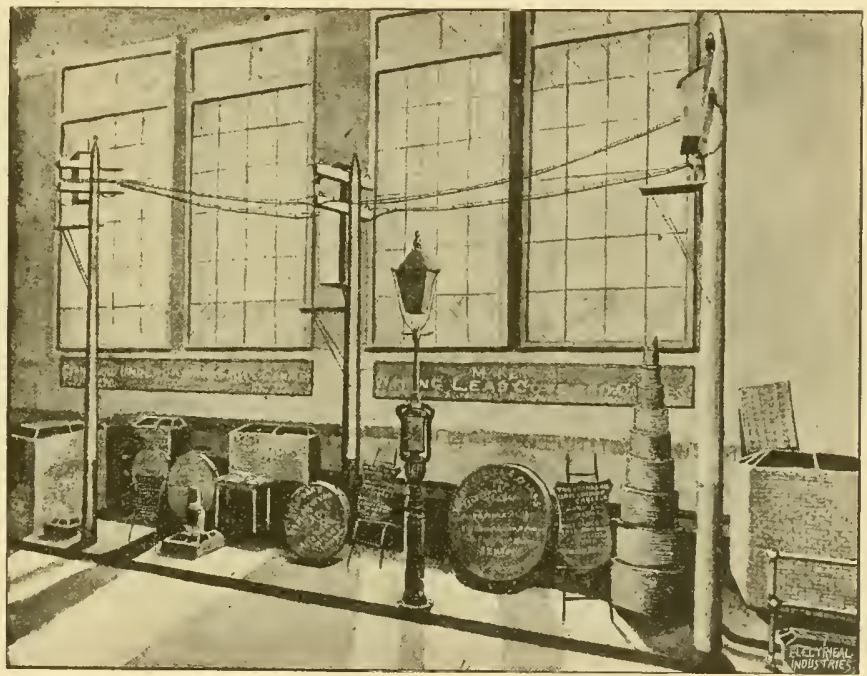

THE EXIHBIT OF THE STANIARD UNDERGROUND CABLE COMIPAY

south-western part of Electricity Building on the main floor the Standard Enderground Cable Company has placed its exhibit. As a background to the exhibit there has been erected a representation of an elevation of a street showing the pavement on top, the soil beneath and the position and method of laying the Standard L'nderground system.

The conduit is slown as it actually appears in the ground. Manholes are eonstrueted in the line of ditlerent kinds and through the open side the interior is exposed to the view of the visitor. The fead covered cable is there shown with the joints and branches, matle aceording to the methods adopted by the company. The manholes are covered with frames and cosers of the latest patterm. All details have been so faithfully earried out that the risitor almost believes himself in a trench in the street. There has also been erected in this spice a pole line showing the Stanclard company's overhead system. Several poles have been placed at convenient distanes apart for displaying the system. From these poles are strung a line of duplex eable suprorted cable terminals, splice boxes, converters, ete. Variously distributed about the space are reels, showing the kinds and character of wires and eables manufaetured by this company. The line inchudes wire for every branch of the electrical industry. In pyramid form are arranged reels of wire and eables with the large lead covered messenger and telephone calle at the bottom, above which are placed smaller cables and wires, both brailed and waterprouf, then the smaller wires, lamp cord and annumciator wires. Several large reels of the lead covered duples cable specially adipted for the alternating eurrent are shown, also cables for high tension light and porrer eircuits, and numerous samples of the Waring anti-induction eables of the that and elover leaf styles. A complete set of tools is also shown for removing the lead casing and the insulation from the wires, showing the perfection of this branch of the work and the facilities for performing quickly and easily any alterations.

While the exhibit shows in a general way the range of the business of the company an inspection of the lighting and power distributing system of the Exposition will show 
the capabilities of the company for complete and extensive installations. Within the grounds of the Exposition 390,000 feet of feeders and mains used in the distribution of the alternating eurrent for the incandescent lighting of the grounds and buildings have been installed and maintained by the Standard Underground Cable Company.

This company has offices both in New York and Chicago, although its main offices and factories are in Pittsburgh, Pa.

\section{The Western Electric Company Sues the General Electric Company.}

The exhibitors in the Electricity Building have until recently been friendly and pleasant in their relation with each other and what rivalry there has existed has been unmarred by any ill feeling. Prof. Barrett, the chief of the department, has been most equitable in the management of his department. On July 17th some one removed the signs of the Western Electric Company from its lamp posts in the Electricity Building, a most eowardly act, and one that no one with any manhood or the least appreciation of respectable business methods would degrade himself to do in dealing with a competitor. The result of this is the suit brought by the Western Electric Company agaiust the General Electric Company et al. on Aug. 23. The following is au abstract of the declaration:

STATE OF II LiNoIS,
County of Cook.

$$
\text { In the Superior Court of sald County. }
$$

To the September Term, A. D., 1893.

Western Electric Company, a corporation organized and existung under and hy virtue of the laws of the State of Illinois, plaintiff, by Williams, Holt \& Wheeler, its attorneys, complains of the General Electric Company, a corporation organized and existing under and by virtue of the laws of the State of New York, and E. J. Spencer, R. W. Hofstede-Crull, John Doe, James Rogers, Henry Smith and William Wilson in a plea of trespass on the ease.

That heretofore, to-wit, prior to the first day of May, 1893 , the World's Columbian Exposition, a corporation of the State of Illinois, by John P. Barrett, chief of its electrical department, solicited the plaintiff to exhibit its electrical devices and products at the Fair or Columbian Exposition, conducted under the auspices of said corporation in the eity of Chicago during the summer of the year 1893 , and the plaintiff, believing that by sodoing, it would not ouly add to the interest and value of said Exposition, but would secure to itself great advantages by bringing its products and machines into favorable notice among the visitors to said Exposition, eonsented to make an exhibit, but as a part of such exhihit, the plaintiff was solicited by said Barrett and consented to furnish iron poles or posts, such as are used upon streets for earrying electric lights, which posts to the number of 30 were agreed to be placed at various points on the main floor and in the gallery of the Electrical Building in said Exposition and especially in the public passagerays of said building. That it was further agreed between said World's Columbian Exposition and the plaintiff that upon certain of said posts, arc lights manufactured by the plaintiff should be placed and upon others of said posts, are lights manufactured by the defendant, General Electric Company, should be placed, the designation of the particular posts to be occupied by the lamps of the respective manufacturers to be made by the said Barrett, chief of the electrical department of said Exposition; and it was further agreed that in consideration that the plaintiff would furnish said posts that the plaintiff should be allowed to mark sa:d poste with the name of the plaintifi, not only upon brass plates screwed upon said posts near the base thereof, but also upon glass signs inserted in the hood or covering at the top of said posts in the manner in which are customarily inserted signs bearing the names of streets in cities. And it was further agreed that the lamps furnished by manufacturers other than the plaintiff and placed upon said posts should be marked with the names of the respective manufacturers, so that said manufaeturers should have due eredit for their lamps, and the plaintiff should have due credit for its posts. That the said posts were manufactured and erected by the plaintifi and signs placed thereon in accordance with its agreement, as aforesaid, and that said posts were especially designed and adapted for their purpose, and possessed great advantages over the posts eustomarily made by other manufacturers, and it was and is of great advantage to the plaintiff to have its name plainly appear on all the said posts and upon the glass signs aforesaid, and that said privilege was and is of great value to the plaintifi, to-wit, of the value of ten thousand dollars $(\$ 10,000)$.

That the defendant, the General Electric Company, prior to the first day of May, 1893, had agreed with the said World's Columbian Exposition that it would also exhibit its products and machines in the said Electrical Building, and among other things, that it would furnish lamps as aforesaid to be placed upon certain of the posts manufactured by the plantiff, as aforesaid, to-wit, to the number of 27 . That the defendant, E. J. Spencer, who, at all the times herein mentioned, was and is the agent of the defendant, the General Electric Company, in charge of its exhibit at said Exposition, conspiring with said General Electric Company to injure the plantiff and deprive it of its advantage from the exhibition of said glass signs upon its posts aforesaid, repeatedly and continuously endeavored, to-wit, from the first day of May, 1893, to the 17th day of July, 1893, to secure the removal of said glass signs bearing the name of the plantiff from those posts which had been designated by said Barrett to earry the lamps of said General Electric Company. That at various times between the dates last above mentioned, said General Electric Compay, by said Spencer and its other agents, demanded that said glass signs be removed and replaced by plain glass, and at various times threatened, if its said demands were not complied with, that it would remove its entire exhibit from said Electrical Building, and the said General Electric Company continuously neglected and refused to place its lamps upon the posts designated for that purpose by said Barrett, as aforesaid, unless and until the said signs bearing the name of the plantiff should be removed from said post, although the General Electric Company did place a small number, to-wit, three or four lamps upon posts adjacent to its own exhibit.

That the sald Barrett declined to yield to the improper and unlawiul threats and demands of the said General Flectric Company and spencer, made in pursuance of the conspiracy aforesaid, and insisted that the said General Elecric Company should comply with its agreement and place its lamps properly marked upon the posts of the plaintiff designated by said Barrett, and that to wit, on the 17 th day of July, 1893, the said defendants, said General Electric Company, E. J. Spencer, R. W. Hofstede, John Doe, Henry Smith, James Rogers and William Wilson, conspired to injure the plaintiff and to take possession of its property and deprive $1 t$ of $i$ ts benefit and advantage aforesaid from the exhibition of its posts, and thereupon during the night, between the hours of eleven o'clock P.M. on July 17 and two A.M. on July 18, the said defendants, R. W. Hofstede-Crull, John Doe, Henry Smith, James Rogers and William Wilson, acting in pursuance of said conspiracy and under the direction of said General Electric Company and E. J. Spencer, did enter the said Electrical Building and unlawfully and feloniously remove and take away the glass signs aforesaid bearing the name of the plaintift, but only from the posts which had been designated as aforesaid to carry the lamps manufactured by the General Electrical Company, and not from the posts designated to carry the lamps of the plaintiff; that the guards employed in and about the said building did not interfere with such removal for the reason that the said defendants, Hoftede-Crull, Doe, Smith, Rogers and Wilson, engaged in such removal were men who were known by said guards to be in the employ of said General Electrical Company, and were therefore supposed to have the right and authority to remove said signs.

By reason whereof and of all the actings and doings of said defendants in the premises the plaintiff has suffered great loss in the value of said signs so feloniously taken and removed, and in the money expended in and about the putting of said signs in place and in the loss of the benefit and advantage of advertising its posts and devices, as aforesaid, to the damage of the plaintiff of ten thousand dollars $(\$ 10,000)$, and therefore the plaintiff brings its suit. 


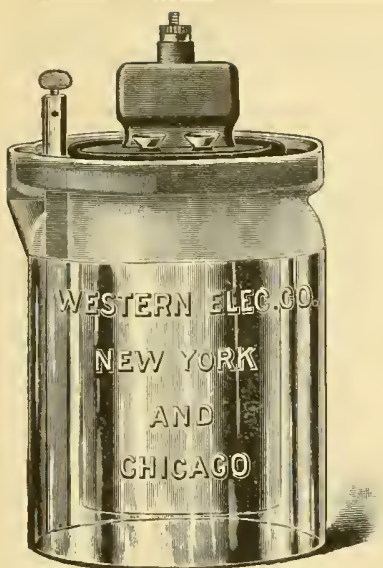

Disque La Clanche Batterv.
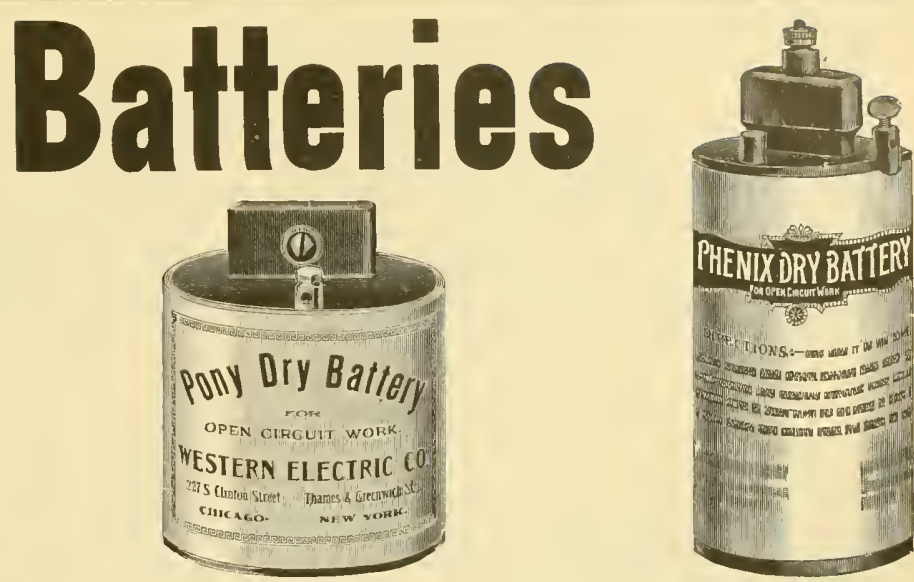

PhoenIx Dry Battery.

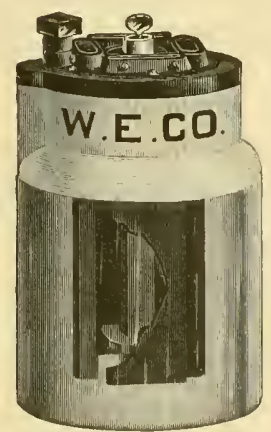

Quad Battery.

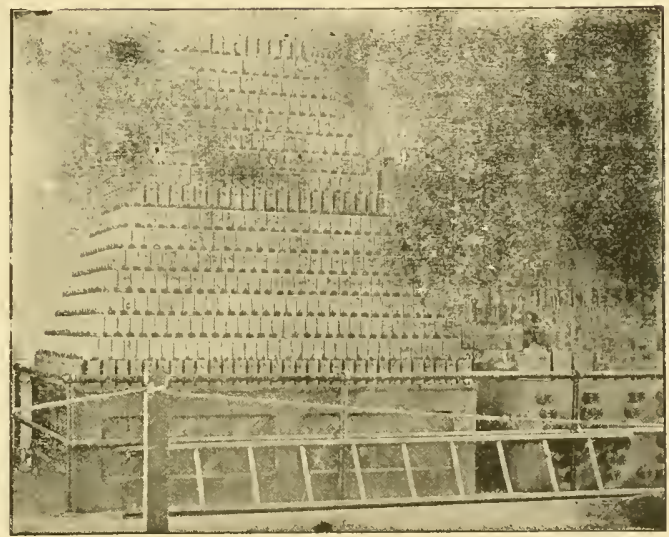

Battery Exhibit Electricity Bldg, World's Fair.

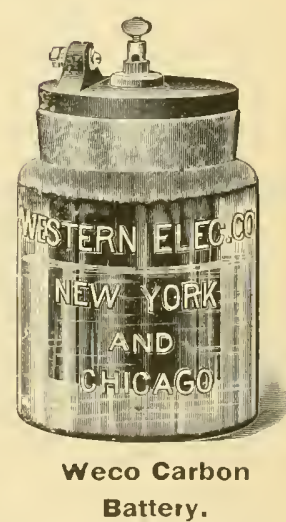

Battery.

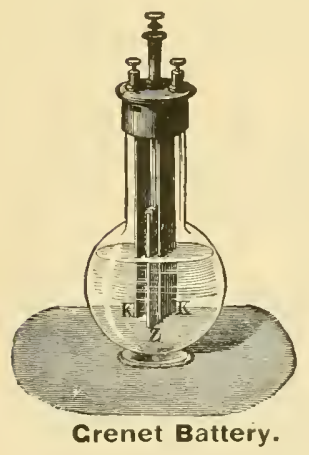

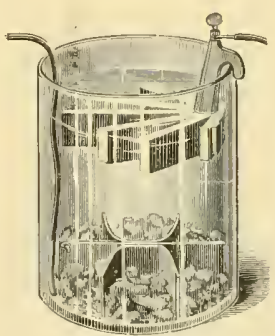

Cravity Battery.

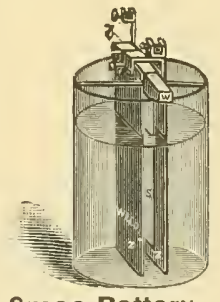

Smee Battery.

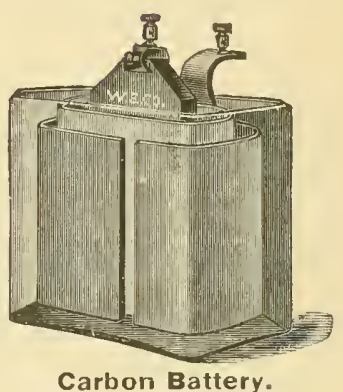

Carbon Battery.

\section{Western


ELECTRICITY BUILDING-EXHIBITORS AND THEIR LOCATION.

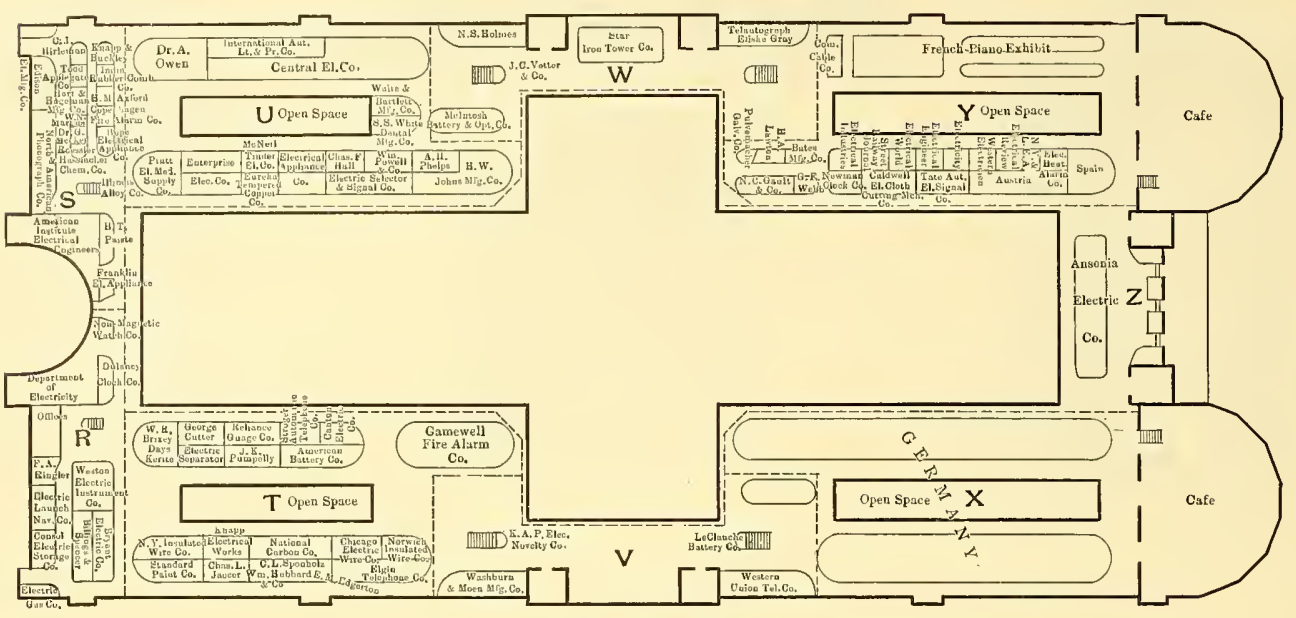

GALLERY.

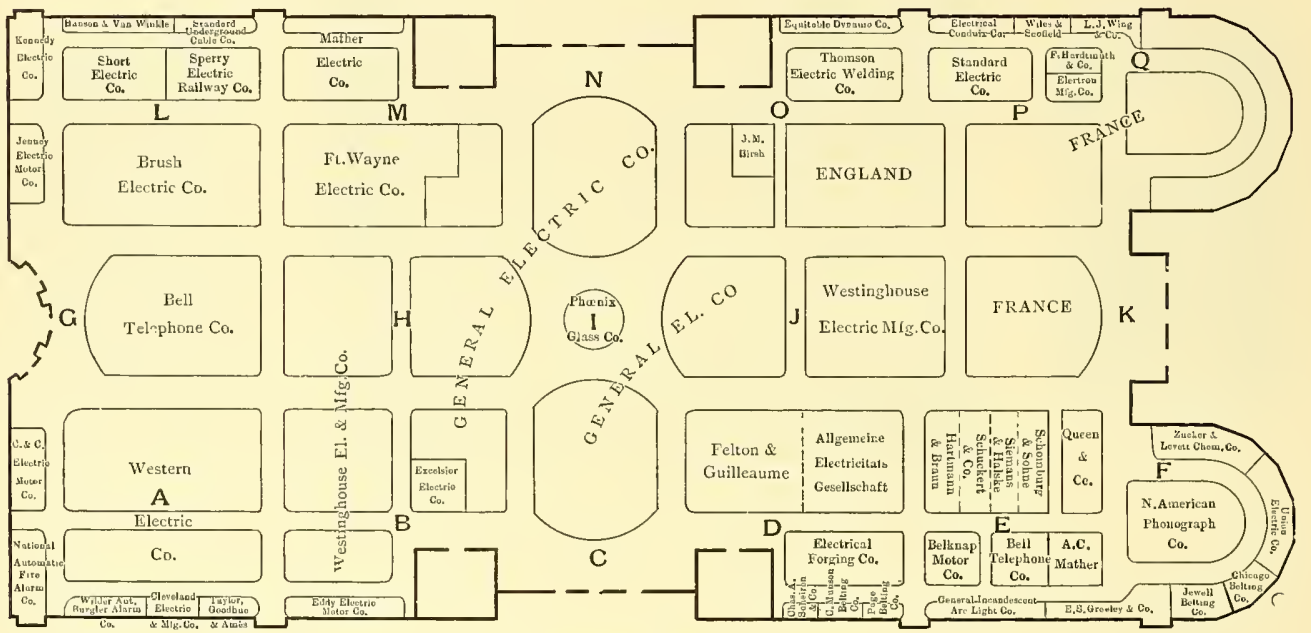

MAIN FLOOR.

\begin{tabular}{|c|c|c|}
\hline $\begin{array}{l}\text { Exhibitor. } \\
\text { A nstria ................................ Y }\end{array}$ & $\begin{array}{l}\text { Exhibitor } \\
\text { Electrical Review.................. }\end{array}$ & $\begin{array}{l}\text { Exbibitor. } \\
\text { Jaeger, Chas. L....................T }\end{array}$ \\
\hline Ansonia Electric Co...................... & & \\
\hline Am. Inst. of Elec. Eng.. ............. & Electric Gas Co..... & Jewell Belting Co..... \\
\hline American Battery Co.............. T & Electrical Engineer. & T. nney Elec. II otor Co. \\
\hline Axford, H. M.... & Electrical Torld ............. & Kuapp Electrical Works..... \\
\hline Allg. Elec. Gesellschät............... & Eddy Electric Motor Co.. & K. A.P. Elec. Novelty Co. \\
\hline 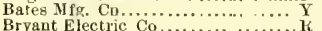 & & Knapp it Bockley .......... \\
\hline Bryant Electric Co ................. & Electrical Forgiog C $\ldots . .$. & Kenuedy Electric \\
\hline llings \& Spencer........ & able Dyoamo Co.. & \\
\hline 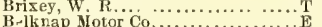 & ou Mig. Co................. & e Battery Co.... \\
\hline Bell Telephone Co...................E-G & 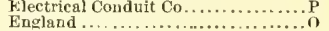 & Teil-Tinder Elec. Co.. \\
\hline 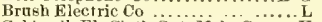 & Empire China Works. & Mleeker, Dr, G.... \\
\hline th Cut. Mch. Co... & Frankin Elec. Appliancë. & McIntosh B-t. \& opt. Co. \\
\hline Consol. Elec. Storage Co ......... & h Piano Exhi & Munson, C., Belting Co \\
\hline Cutle & $\mathrm{O} \& \mathrm{Gn}$ & A. C... \\
\hline Cantr & & \\
\hline & & \\
\hline $\operatorname{arm~Co....~}$ & & $\mathrm{b} \mathrm{Co}$ \\
\hline 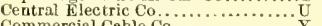 & Co. & $\mathrm{Co}$ \\
\hline & a..... B- & $\mathrm{N}$ \\
\hline $0 \ldots$ & 's't Arc L't Co.... & $\mathrm{N}$ \\
\hline Co.. & E. S., \& $\mathrm{Co}$ & Phonogi \\
\hline & & N. Y. \\
\hline . & $\mathrm{i}, \mathrm{Wm}, \mathrm{aco}$ & Nat. A \\
\hline tricity.......... & i. C. J.............. & raving N achine Co.. \\
\hline G........Y & Hegeman Mfg. Co. & \\
\hline (1) & liance $\mathrm{Co}$.. & Glas $\mathrm{Co}^{-}$ \\
\hline .. $\ldots \ldots \ldots$ & का & \\
\hline 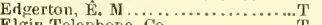 & $\mathrm{H}$ & Galy. Co. \\
\hline $\mathrm{T}$ & $\mathrm{W}$ & \\
\hline & Winkl? & led. Sup. Co . \\
\hline & & n. $\& \mathrm{Co} . . . . . .$. \\
\hline Lo & F., \& Co & \\
\hline & y Co............ & Page Beliug Co. \\
\hline $\begin{array}{l}\text { Elec. Sel \& Sigrl co co.............. } \\
\text { Electríc Heat Alarm co }\end{array}$ & $\mathrm{P} r \mathrm{Co} \mathrm{C}_{2} \quad \ldots . \mathrm{U}$ & \\
\hline & & \\
\hline
\end{tabular}

Exhibitor. : Section Roessler $\&$ Hasslacher Ċe.............. Street Rail way Journal.............. Y Strowger Aot. Telph. Co........... T
Staudard Paint Co................ T Staudard Paint Co.

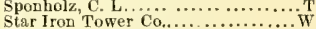
Spain .......................... Y Schieren, Chas. A. \& Co .............. Schomburg \& Sohne .............. Siemens \& Halske...... . . . . . . . . E schuckert a co. Short Electric Co..................... Standard Underg. Cable Co.............. Stavdard Electric Co................... Samson Battery Co Tate Aut. El. Signal Co................. Y Todd, Applegate Co .................. S Taylor, vioodhue \& Ames............ A Telautograph, Elieha Gray .......... W Union Electric Co ..................... F Vetter J.C. \& Co Webb, G. F (n.............. Y Washburu \& Moen Mfg. Co........... Western Union Tel. Co $\ldots . . . \ldots \ldots . .$. . White, S. S ., Dental Mfg. Co.......... U Western Electrician $\ldots \ldots \ldots \ldots \ldots$. Western Electric Co $\ldots . . . . \ldots \ldots \ldots . . .$. Westinghouse El. \& Mifg. Co .... B.H. Wiles \& scofield

Wiog, L. J., \& Co................. 
LINE SUPPLIES.

GONSTRUGTION MATERIAL. INGANDESGENT LAMPS.

RUBBER COVERED WIRES. WEATHER PROOF WIRES. ELECTRICAL HOUSE GOODS.

TELEPHONE SUPPLIES.

TELEGRAPH SUPPLIES.

ELECTRIC APPLIANCE COMPANY,

CHICACO... 242 Madison Street,

... CHICAGO.

THE MATHER ELECTRIC CO, ITHE "NOVAK" LAMP. MANCHESTER, CONN.

Dynamos, Milots, Generrators,

Offices, II6 Bedford St., BOSTON.

-AND-

1002 Chamber of Commerce Bldg,, CHICAGO. 1002 Chamber of Commerce BIdg., CHIGAGO.

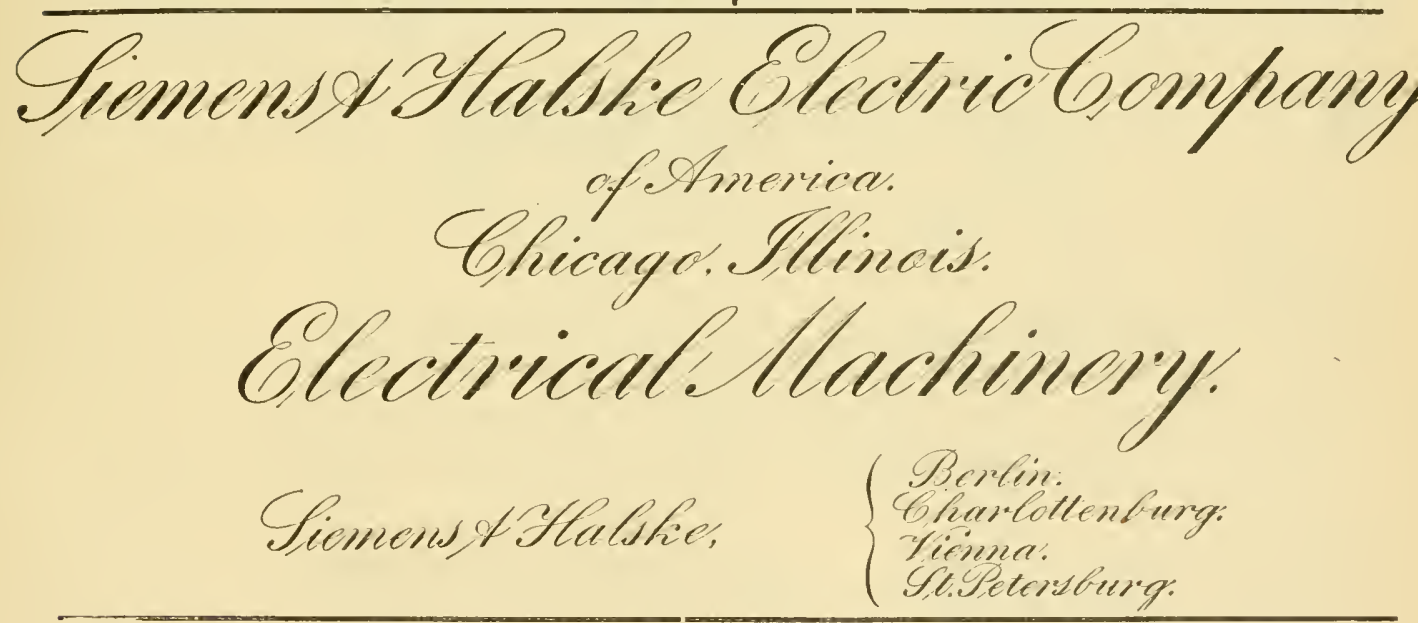

\section{Enterprise}

Electric

207 Dearborn Stree\}.

Chicago ....
CLAFLIN \& KIMBALL (Inc.)

General Selling Agents.

116 Bedford Street, BOSTON. 
Map of Chicago.

Showing Location of its E'ectrical and Allied Business Interests, Principal Hotels, Theatres, Depots and Transportation Lines to the World's Fair Grounds. (Index numbers refer to the black squares.)
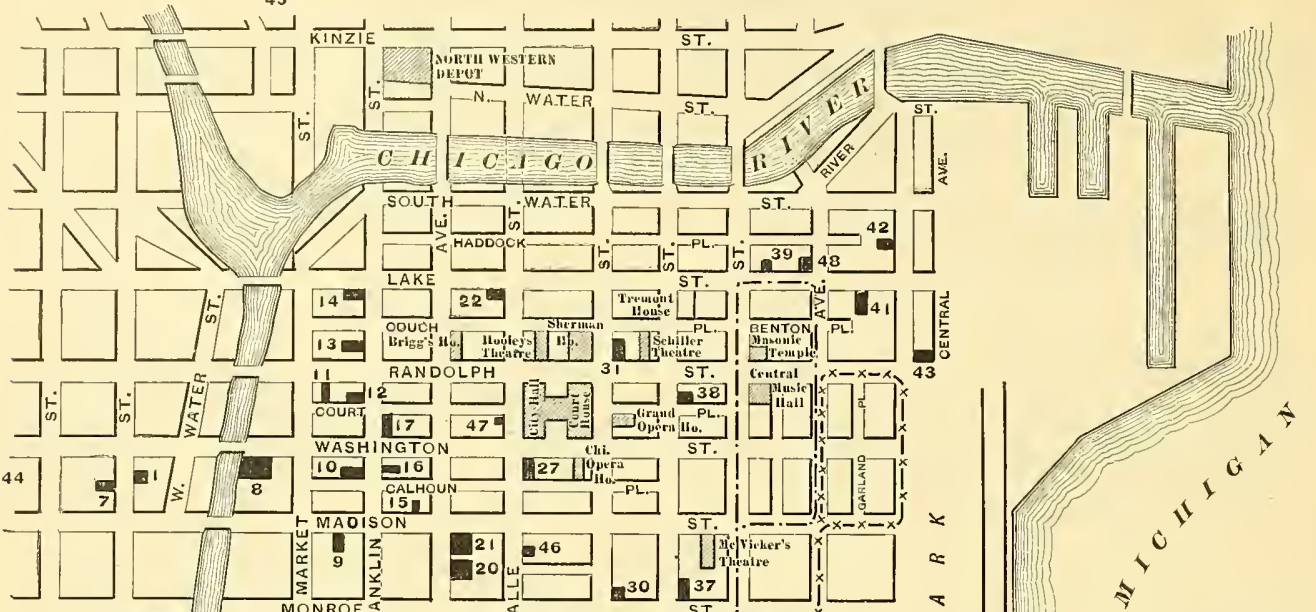

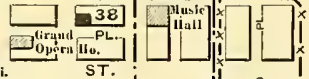
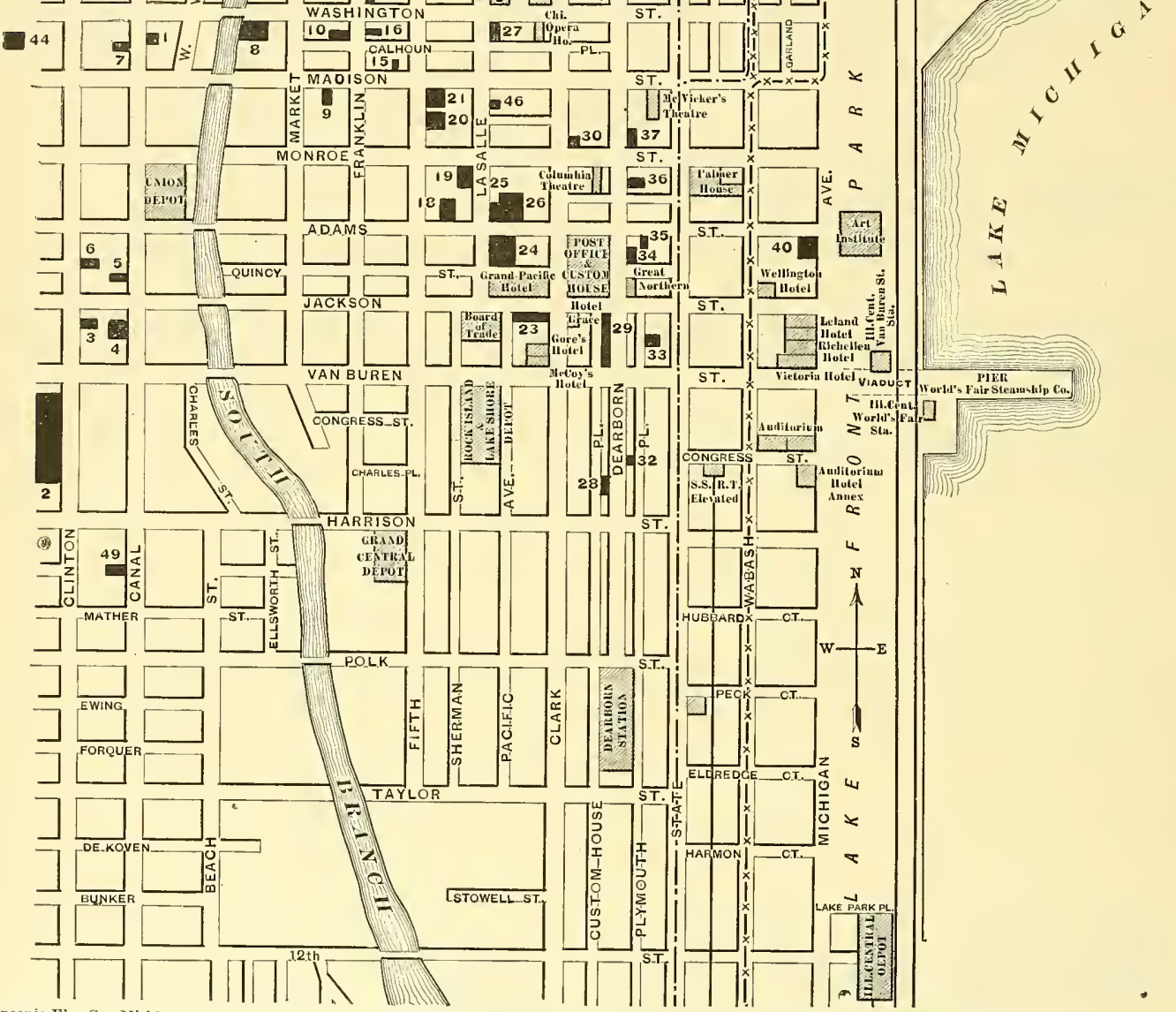

Ansonia Elec Co., Michigan Ave. \& Randolph St. .. 34/Cushing \& Morse, 295 Dearborn St. American Battery Co., 188 Madiron St...

Bartholomew, Stow \& Co, 5 Michigan Ave.

Barton « Brown, 1428 Monadnock Block.

Brill Co. $J$.

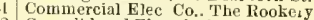

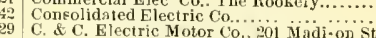

..34 McDougall \& Cummings, Tnity Bldg.

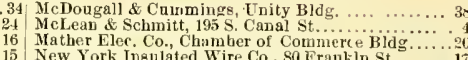

Brnsh Electric Co., Miozadojek Biock.

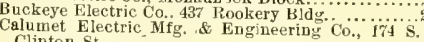

Central Electric Lt. \& Pr. Co... 185 Dearborn st.

Central Telectric en, 118 Franklin St.

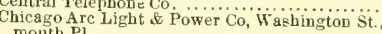

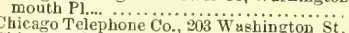
Detroit Electrical Work

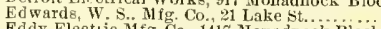
Electric Construction \& Suppiy Co., Unity Bldg 6 Electrical Industrieg PUB Co., Monadock B.......9 National Elec. Mfg. Co., Pullman Bldgin St... 29 Postal Telegraph Co, Phenix Bldg.........................

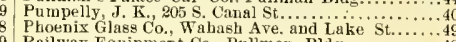
Railway Equjpment Co.. Pullman Bldg
Rockford Elec. $\&$ Hifg. Co, 94 La Salle St...........47

10 Enterprise Electric Co., 30t' Dearborn St

Standard Elec Co 605 Home

$8 \& 33$ Gregory, Chas. E.. Co., $49 \mathrm{~S}$. Jefferson St

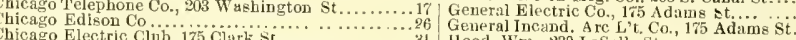

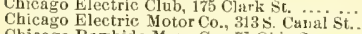

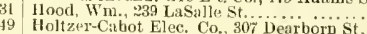
Chicago Rawhide $\mathbf{M}$ g. Co., 75 Obio St ............. 45 lllinois Elec. Lamp Co., 171-173 S. Canal Si

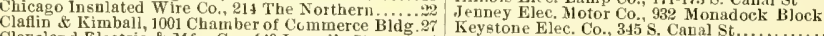

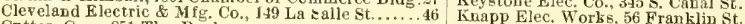

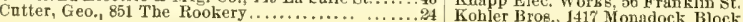

. 9 Star Elec. Lamp Co.. 805 Chamber of Com. Bldg.....2\% 9 Schieren, Chas. A. \& Co. $46 \mathrm{~s}$. Canal St.............40 8 Short Elec, Railway Co. Monadnock Block............29

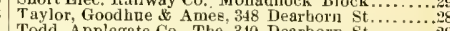
Todd. Applegate Co., The, 340 Dearhorn St........... Wrddell-Entz Cn, , 11,2 Monadnock Block............29 Westinghouse Electric \& Mfg. Co, Putw. Wollensak, J. F. Lake and Fraultin St...

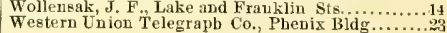




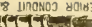

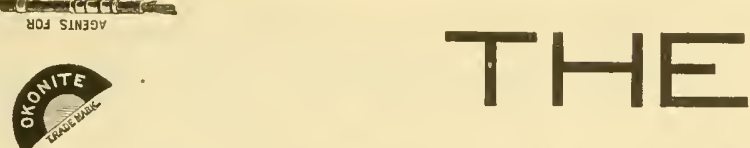

FERRIS WHEEL

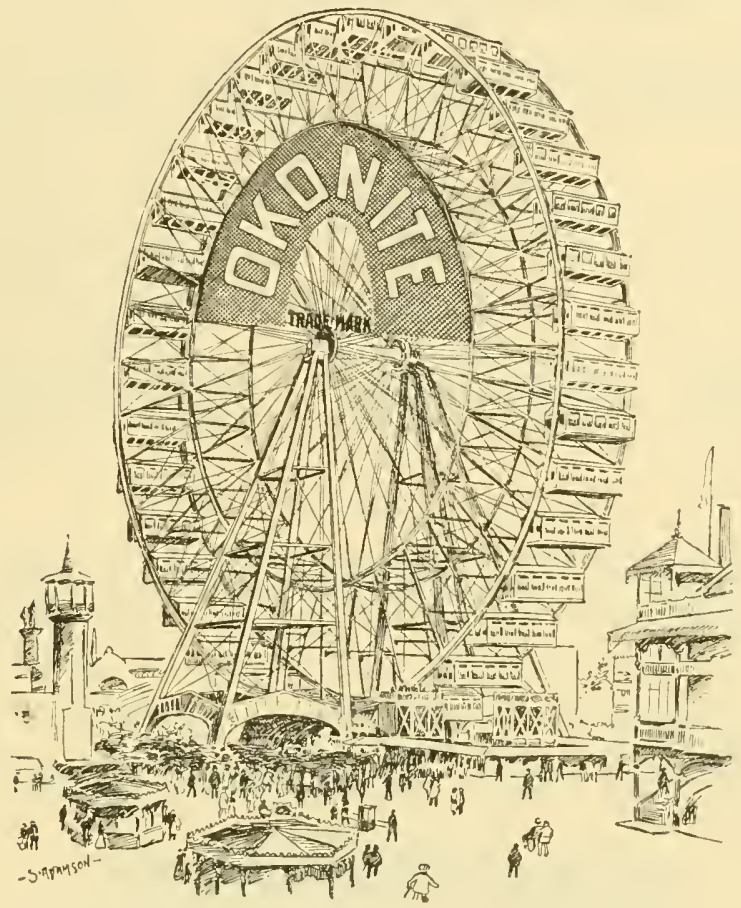

When you visit the World's Fair, you will naturally take a ride on the FERRIS WHEEL and be interested in the ELECTRIC LIGHT INSTALLATION, which is wired throughout with

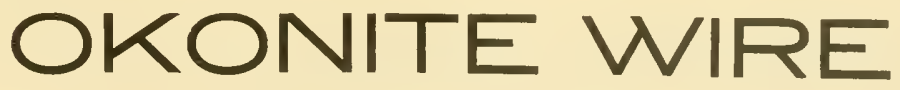

FURNISHED BY THE

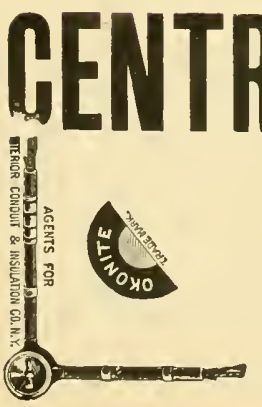

116-118 Franklin Street,

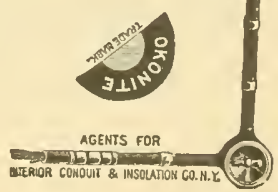




\section{The Standard Underground Cable Co.}

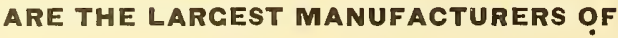

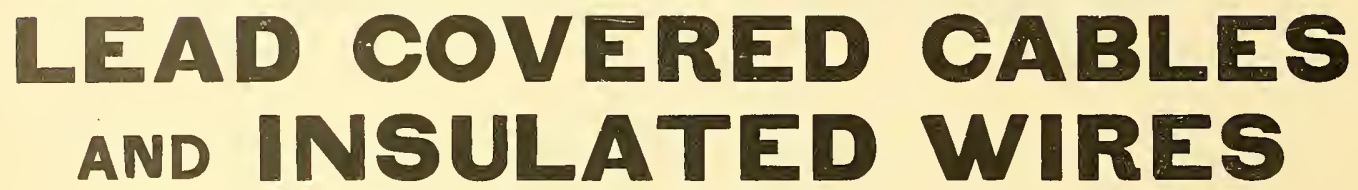

In THE UNTEE S STATES.

And Prepared to offer bids on any or all installations of

Underground or Aerial Systems for Telegraph,

\section{TELEPHONE, ELECTRIC LIGHT AND POWER. Westinghouse Building,}

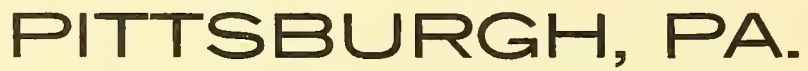

Rookery, CHICAGO. Times BIdg., NEW YORK.

\section{THE MONTHLY ISSUE FOR AUGUST}

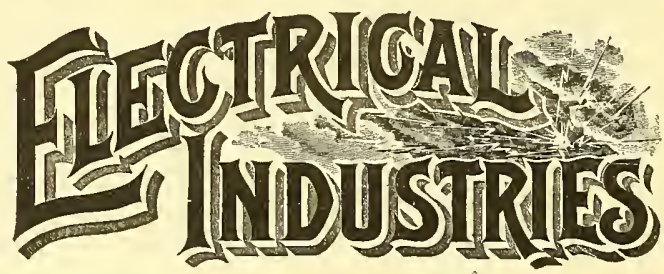

Should be read by everyone interested in electrical matters, In its table of contents is the following:

"Incandescent Lighting at the World's Fair."

"The Electric Power Plant of the Chieago City Railway."

"Steam Engine Efficiency-Its Possibilities and Limitations" by Wm. H. Bryan.

"Alternating Arc Lighting for Central Stations" by H. S. Putnam.

"Hard Rubber as an Insulator in Street Railway Work" by W. R. Mason.

"A Brief Review."

Together with illustrations of the recent applications of electricity.

The paper also contains regularly

A Buyer's Directory of Manufacturers and Dealers in Electrical Supplies and Appliances.

A Complete Directory of Electric Light Stations in North America and a Complete Directory on Elcetric Railways in North America.

These directories are revised each issue to the date of going to press and are to be found in no other electrical journal in the World. Its articles are read carefully and its directories used constantly by all the buyers in the trade. These facts make it without a superior as an advertising medium. Sample copies and rates sent on application.

Subscription price $\$ 3$ per year. Six months trial $\$ 1$, if ordered during the next 30 days.

\section{ELECTRICAL INDUSTRIES PUB. CO.,}



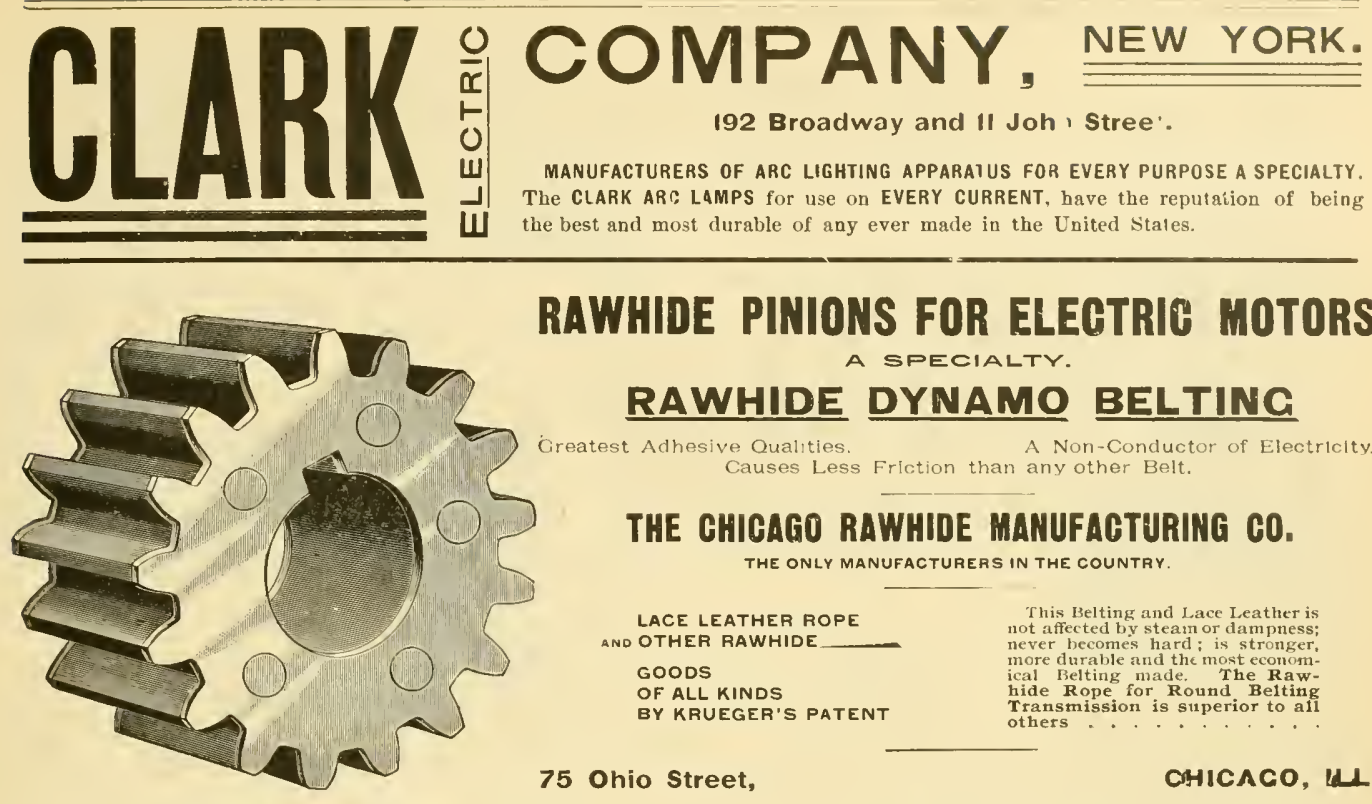

RAWHIDE PINIONS FOR ELECTRIC MOTORS A SPECIALTY.

RAWHIDE DYNAMO BELTING

Greatest Adhesive Qualities. A Non-Conductor of Electrlcity. Causes Less Friction than any other Belt.

THE CHIGAgO RaWHIDE manUfaCtURING CO. THE ONLY MANUFACTURERS IN THE COUNTRY.

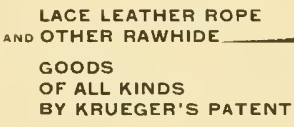

\section{Standard Electric Company.}

GENERAL OFFICES; 625 Home Insurance Building.

WORKS: So. Canal Street,

\section{CHICAGO.}

\section{STANDARD SYST
WORIDTS FAIR.}

MACHINERY HALL, Sec. Q, 2 Standard Arc Dynamos.

Sec. S, 20 " " "

ELECTRICITY BUILDING, Sec. P, Space 2, Arc Lighting Exhibit.

The Standard Lamps Light the Power Plant, Machinery Hall, Agricuitural Hall, Shoe and Leather Building, and Othar Buildings and Portions of the Grounds. 


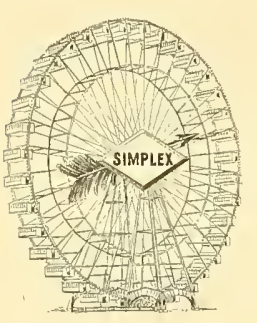

Tlile after mile of

\section{SIMPLEX WIRE}

Supplied to the

FERRIS WHEEL

By...George Cutter,

The Rookery, CHICAGo.

\section{SIMPLEX WIRES}

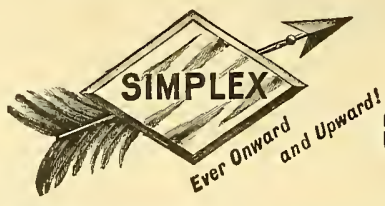

INSURE

HICH

INSULATION

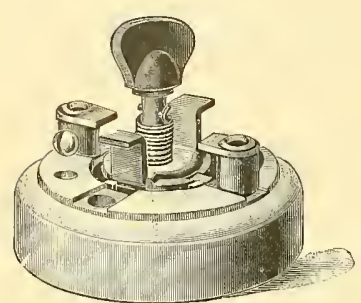

Made 5 amp. S. P.

15 amp.

10 amp. 3 way.

\section{XNTRIC}

"That's the Switch"

And we control that movement.

H. T. PAISTE, 10 South It th St., PHILADELPHIA, PA.

George Cutter, Chicago. BOSTON, MASs.

Consolidated Elpetric 6.

Manulaclurers and Dealers in all kinds of

ELECTRICAL . SUPPLIES,

115 Franklin Street,

CHICACO.

GEORGE PORTER,

Contructor for All Kinds of

ELECTRICAL WORK.

Room 67, 143 La Salle St.. CHICAGO.

Crary Block, BOONE, 'OWA.

\section{CHAS, A. SCHEREEN \& CO,}

MANUFACTURERS OF

\section{Genuine Perforated Electric Leather Belting:}

46 So. Canal Street, - CHICACO

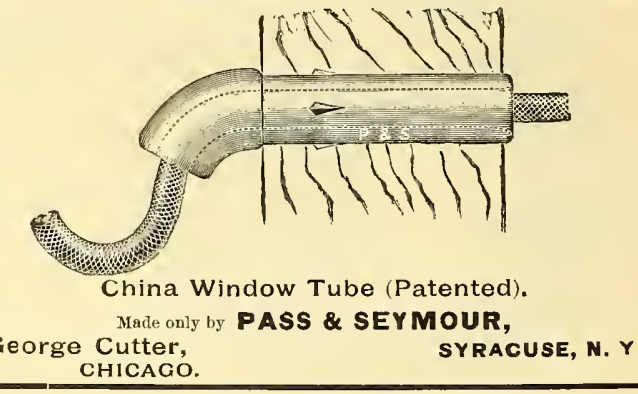

CALL AND EXAMINE

\section{Lawton's Call Indicator.}

Indispensable for hotels, railroad offices, school buildings, hospitals, etc.

Section Y, Space 45, Gallery Electricity Building, WORLD'S FAIR.

OHIOAGO, ILI.

\section{WAGNER ELECTRIG FAN MOTCRS}

For Direct or Alternating Curvents.

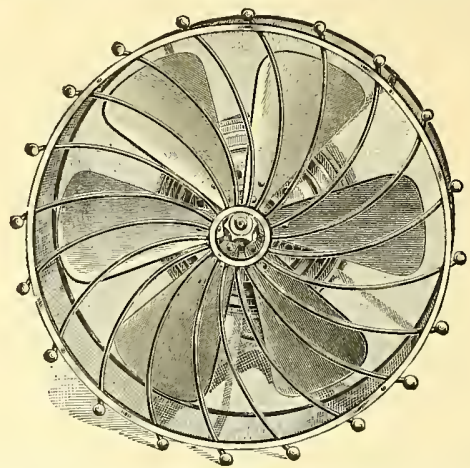

These motors give a stronger breeze with less consumption of eurrent than any other fan motor on the market. They are fnll 1-8 horse power. Six bladed

IT WILL PAY YOU TO SEE THE WAGNER BEFORE BUYING ELSEWHERE

TAYLOR, GOODHUE \& AMES, 348 Dearborn Street, CHICACO. 


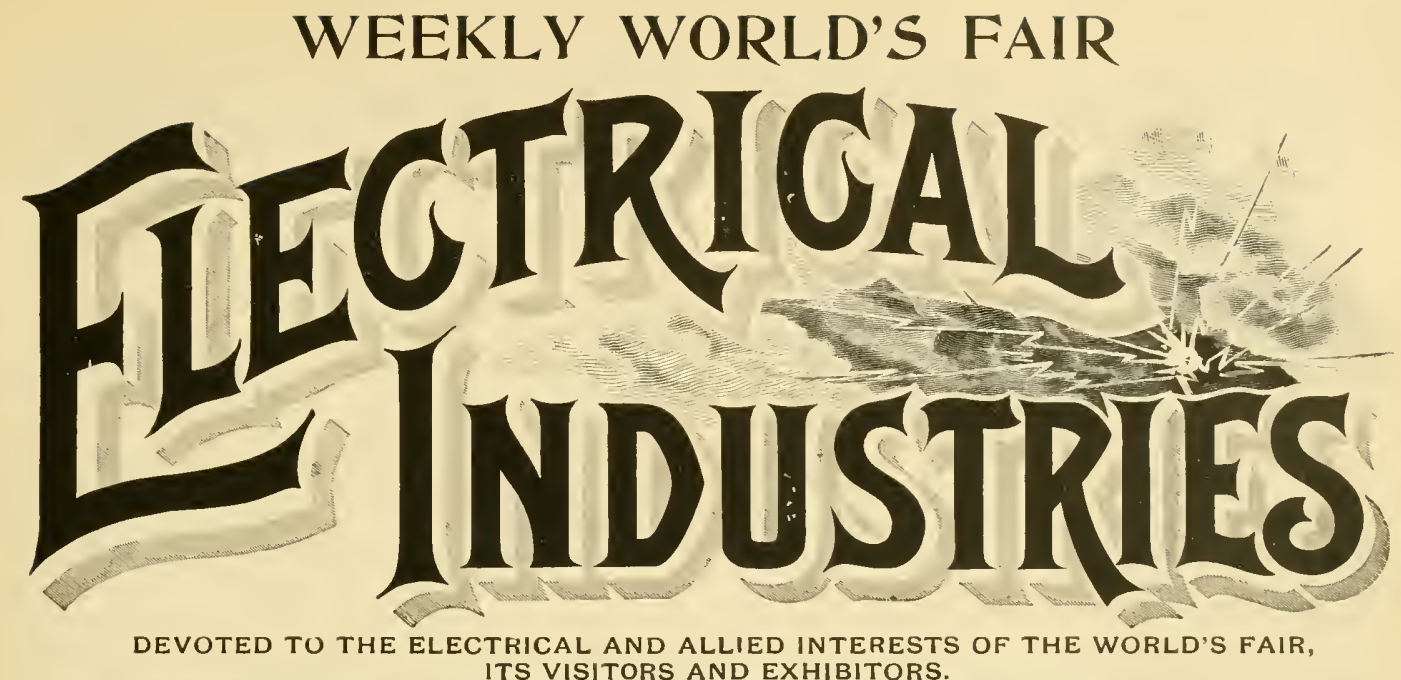

Vol. I, No, 13.

CHICAGO, SEPTEMBER 7, 1893.

FIVE MONTHS $\$ 1.00$
IEN CENTS A COPY

Exhibit of the Central Electric Company.

Walking through the southwestern part of the gallery of Electricity Building one meets with sonu mammoth reels nearly six feet in diameter of wire and calsle, the. well known product of the Okonite Co., of New York. These constitute a portion of the exhibit of the Central Electrie Company, of IIS nite trate mark. Something of the variety of electrical conductors which the Olionite comprany manufacture is shown in this exhibit. Reels of the heary armored eon cluetors for sulmarine lines, large, many cirenit, Jeanl covered telephone and trlegraph cables for mulergromal and conchit lines, braided acrial abules and numerous sizes of the smaller insulated wires are exhibiterl.

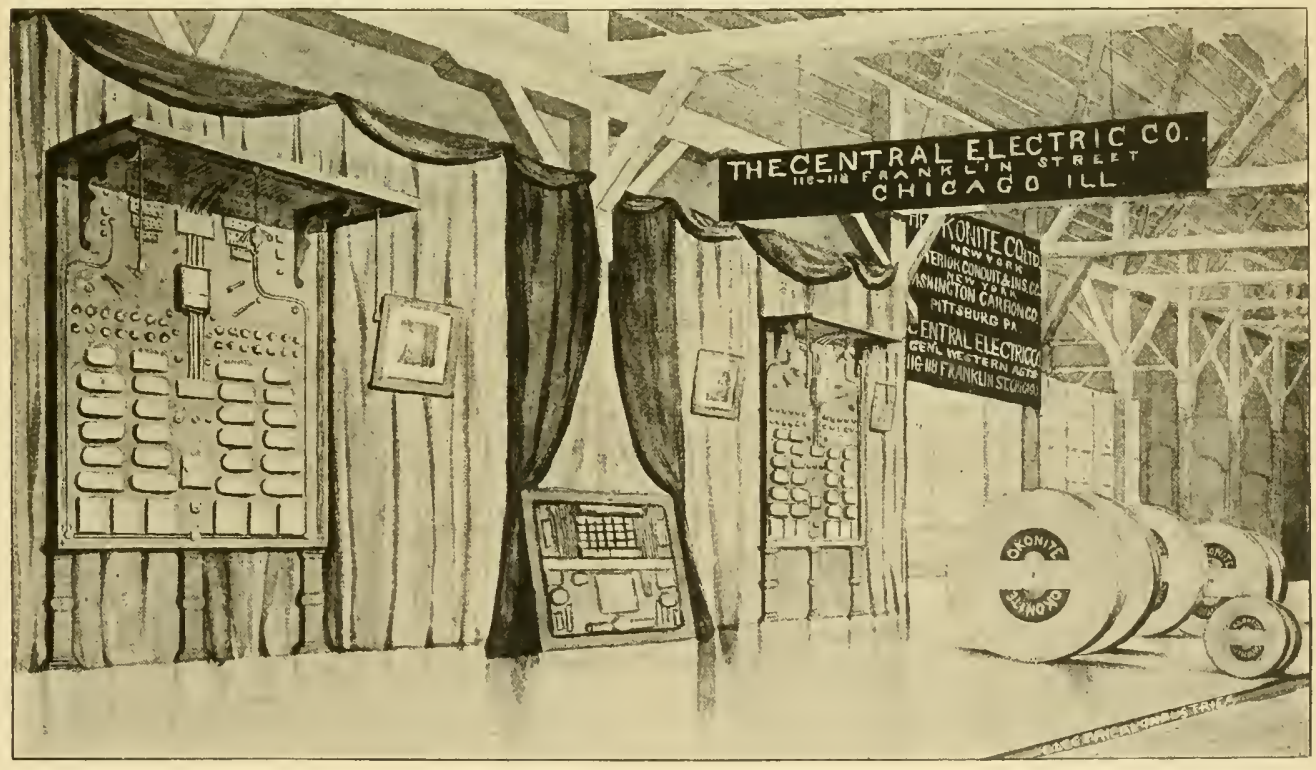

Franklin St., Chicago. This exhilbit as a whole is peculiar in two special features which constitute the principal points of electric light installations, namely the wire used and the system of installing the wire.

The great reels of calble standing almost as high as the visiturs hearl have attracted more attention since it was Insed in wiring the great Ferris wheel. These reels are paintert white and on the sules apjear the well known (1) lio-
These cables are used by the telephone and telegraph companies in their regular work and were mate in accord ance with their specifications. The insulation known as Okonite is a special high grade patented rubber compound which is thoronghly seasoned and tested. The Okonite Co., received a gold medal at the Paris exposition in 18S? Searly tio miles of Okonite wire was used in the installa tion of the police patrol and the fire alarm systems at the 
Fair. The feeders for the Intramural Railway and the wires of the lighting system of the Libbey Glass Works are also of this kind of insulated cables and wires. A number of large photographic views of the Okonite factory adorns the walls of the exhibit which show the works and the method of insulating these wires.

One of the most interesting parts of the exhibit of the company is the exhibit of the conduit system of wiring. This system is that of the luterior Conduit lnsulation company, of New York, for which the Central Electric Company is general western agent.

On two large panels with projecting tops the conduit and various fittings and appliances are displayed. The conduit is of two kinds, plain and brass armored, the fittings and attachments for each being very much alike except the ont. ward finish. The system is so complete, necessary fittings being made for turning corners and connecting the different lines and branches, that there is no part of the wire in a building but what is enclosed and protected by the conduit;
The conduit is shown in sizes that will admit wire or cable from one fourth inch in diameter to two aud one-half inches in diameter. Between these panels is a panel showing samples of carbon of the various kinds handled by the Central company from the works of the Washington Carbon Company, of Pittsburgh.

In contrast is shown the raw unmoulded carbon and the marketable article. Sample carbons for arc lights in a large number of sizes, battery carbons of the shapes best adapted to the different kinds of carbon batteries are shown. Also carlon plates for electrolytic plants, carbon brushes for motors and dynamos and samples showing something of the capacity of the works, are cxhibited.

Another of the many articles handled by this company and exhibited in a practical way at the Fair is the Lunclel power motor which is nsed in a number of exhibits. One of these is in constant use in the United States Whip Co's. exhibit in the making of the souvenir pen holders. In the the Linotype type-setting exhibit which has received

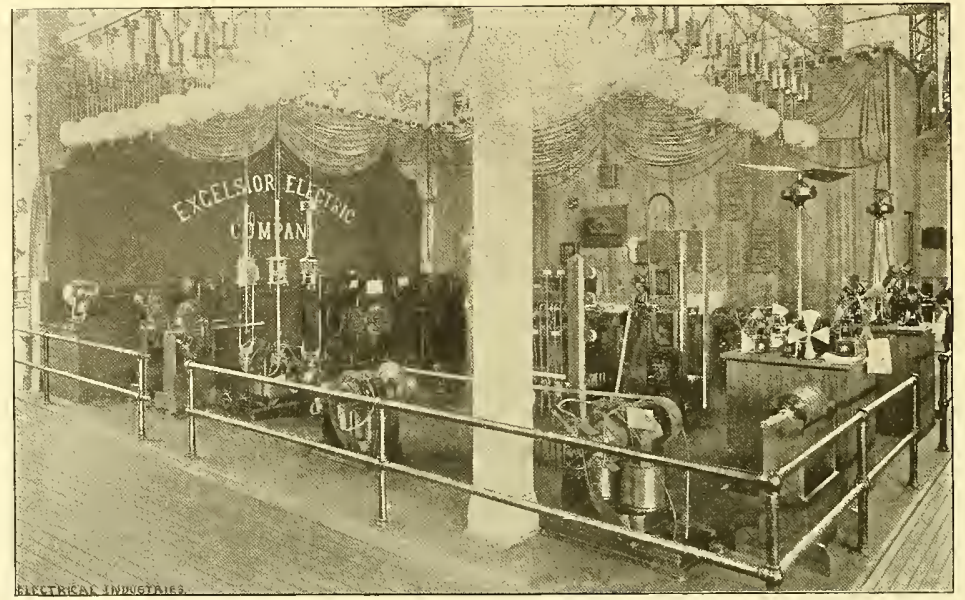

EXHIBIT OF THE EXCELSIOR ELECTRIC COMPANY.

and the wire in any part or all of it may be withdrawn and new wire inserted.

The stringent rules of the fire underwriters and the extra rates charged for poor methods of wiring have caused this system to be used to a large extent. The system is adapted for any system of wiring and is as easily applied to the three or five wire systems as the two wire. The conduit will all be concealed beneath the plaster or if run open it is furnished in colors to match the interior finish of the build. ing. The joints are all neatly and tastily made and the junction boxes and terminals fitted with covers of any de sired finish makes the system present an excellent appearance.

In plastered buildings the terminals are concealed under the fixture canopy and the cut-out or junction boxes may appear almost anywhere without marring the appearance of the room, as nothing but the top appears abore the plaster over which a handsome cover is placed.

On these panels are shown the porcelain cut-out blocks both for the large and small boxes of such size and shape that they just fill the boxes and yet leave room enough for the connections. There is also shown neatly arranged on the panels the necessary coupling and cutting tools, pliers, etc., needed in the installation of this system. a good deal of attention another of these motors is used. Others are used about the Fair two being put to the novel use of propelling the Japanese launch.

Above the exhibit there have been erected a number of signs the largest of which gives the names and factories of the three large companies for whom the Central Electric Company is the general western agent.

\section{Exhibit of the Excelsior Electric Company.}

Just to the left of the east entrance of Electricity Building is loeated the exhibit of the Excelsior Electric Company. The rows of are lamps suspended above the railing that surrounds the exhibit immediately attracts the attention of the passing visitor. In this exhibit of lamps are the various styles of are lamps the company manufacturers. Lamps adapted to the different places in which the are lamp is used, weather proof lamps for the street, lamps for interiors with high ceilings, short lamps for low ceiling with the arc but 15 inches from the top, in this lamp both the upper and lower carbons move.

Lamps for use on steamboats with lenses, focusing lamps for photographic purposes etc., are shown. The latest duplex street lamp is shown which is so arranged that while 
the first set of carbons is burning the other set is held up. The top of the rod of the first carloon is provided with a button which trips a lever when that carlon is burned out and throws the second set of earbons into nse. Sipecial attention has bren given in the construction of these lamps to the facilities for cleaning them easily. The switch on the lamp when turned throws the lamp entirely ont of eir. cuit, thus the safety of the trimmer is assured.

In the front part of the space is a $3(1)$ arce light dynamo with case opeened so als to show the armature and healrings, and on comnters are shown fan motors of various sizes from one tenth horse power up. (1n the left is a f(1.horse jower motor belterl to a 120 (1)-ampere inciudescent 110 - volt dymano at the side of which is placed a skeleton switchloard with ammeter, voltmeter, fuse, switches, etc, rery neatly ar. ranged. In the center of the exhibit is a 21 - rolt $2,4(1)$ ampere plating machine around which are placed motors, commun tators and parts of motors and dynamos showing the con struction of the different parts. Back of this is placed a 1011-light 2,00() eandle power are dymamo belted to a shaft beneath the floor. At the sides are placed racks bolking a
The Excelsior Comprany manufacture these outfits in a number of sizes. They have been used successfuly in a variety of places and have been found especially efficient for raising water to the upper stories of buildings where the pressure on the street mains was not sufticient.

The exhibit is in charge of Mr. (teo. H. Amon whe is looking after the interests of the company at the Fair.

\section{Exhibit of the Stilwell=Bierce \& Smith=Vaile Co.}

The exhibit of heaters, waterwheels and pumps madt by the Stilwell Bieres of Sinith Vaile. Company is lecated in the ammex to Machinery Hall cohumn d., 37 seetion 14. direetly opposite the booth of the mechanical trade jonmal. Sinere the consolidation of the two companies representerl fy the above name early in the year the construction of both water jower and stean apluaratus has been largely undertaken by the new firm.

A prominent prosition is given to different sizes and types of the victor turbine. A 15 inch horizontal donthe rictor wheel with register gates, a good representation of the

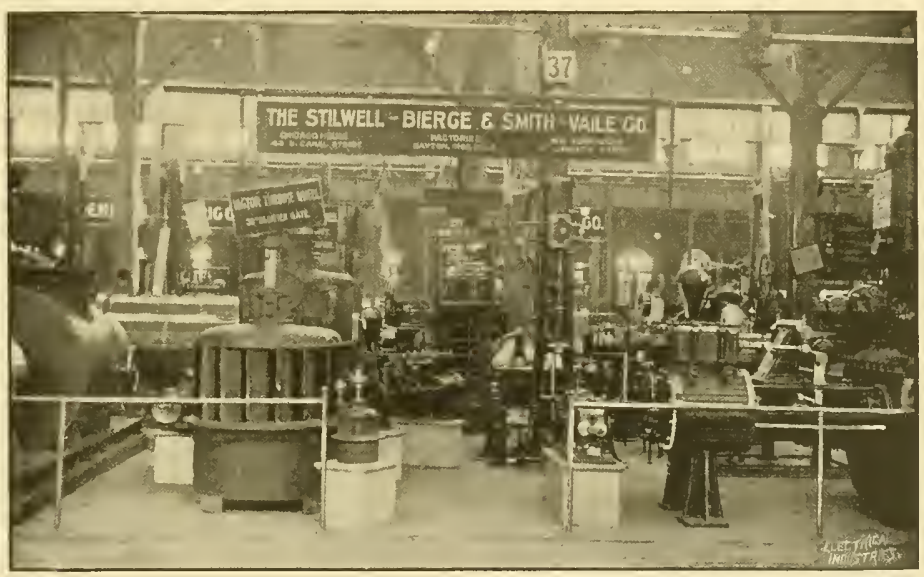

EXHIBIT OF THE STILELL-BHERCE \& SMTTH-YALE CWMHANY

dozen armatures of different sizes with their brightly polished shafts.

(In stands near the walls are shown a number of prower notors of on", three and five horse power adajted for are and incandeseent light and power eirevits, also plating dynamos of different eapacities. On the wall to the right are placed connecting boards, rheostats, switches, meters. starting boxes, etc. The name of the comprany in large white letters covers the west wall. The motors of this company have been used to drive all kinds of machinery. The company building motors for different voltages has been able to supply motors for almost any circuit.

A part of the exhibit that attracts the attention of the passing visitor is the motor and pump shown in operation. Two tanks are placed one above the other. From the lower tank a liue of wrought iron pije leads to the upyer in which is placed a small rotary jump. This jemp which can be placed in any line of water pipe as easily as making a connection, is operated by a on half horse prower motor. This ontfit that oecurpies a space not mor than three feet square is saik to be able to raise stlo gallons of water an lomr (1) feet and at a cost of about 10 conts pres hour for enrent. horizuntal type of modern turbine. Another five inch horizontal wheel for high pressures and using a gate valve are shown. In the regular type with rertical shaft there are shown a $27 \frac{1}{2}$ inch with eylinder gate, a 30 inch with register gate and a six inch with the same gate. The wheels are all well finished, simple in construction and have a lepe utation for very high clticiency. The stillwell live steam purifier is exhibited with one end open to show the nethod of construction and to explain the working of the same. It will be remembered that this purifier is a cylinder or chamber placed a lew feet higher than the water level in the boiler and to which live steam is admitted at boiler pres. sure. The feed water enters at the top and being fed very slowly strikes the tol one of a series of shallow pans which tij) slightly in opposite directions; the water traversing these in a thin sheet is thoronghly heater to the boiler pres. sure and any impurities contained in the same are deposited either in the pans or are filtered out in the cole tilter pans at the bottom. Water enters the boiler from this heatur and purifies by gravity and at the same temperature as that in the boiles. The frinciple is one of common sense and should meet with the most extended suceress as it will easily save its cost in a very short periex?. 
A sample of the Stillwell rertical improved exhaust heater, purifier and filter combined is shown. This is somewhat similar in prineiple to the one above described and has an additional convenience in an automatic water inlet valve which controls the supply of feed water and prevents too much entering at a time. The new Stillwell close leater is also exhibited. This derice has brass tubes in a $\mathrm{L}$ form expanded into a heater that is bolted to one end of a cylinder. A partition in the cylinder between the turn of the tubes prevents the leed water going straight throngh and another partition in the easting bolted into the base directs exhaust steam into one end of the tubes and out of the other. This heater is laid on its side and the support form a mud drum from which is taken all the deposits froms impure water.

In the pump part of the exhibit are samples of various sizes and styles of the Smith-Vaile duplex pumps. A large compound pump with duplex tandem steam cylinders, a large Underwriters pump with duplex cylinders a capacity of 750 gals. per minute with 16 by 9 by 12 cylinders are shown. Also a receirer pump for the return end of steam beating system is shown; this pump has an antomatic float controller with 6 by + by 6 cylinders.

Other pumps, one a duplex 7 by $4 \frac{1}{2}$ by 10 , another duplex 3 by 2 by 4 and another a deep well pump $9 \frac{1}{3}$ by 30 steam cylinder, are shown. All the products of this company are of the best design and slow a degree of finish and workmanship equal to any.

If they will now add a first class water wheel regulator to their other products, one that will do for electric light and power work, the Stillwell-Bierce \& Smith-Vaile Co. will be able to sujply an equipment that will meet all the wants of the motive power end of any large plant.

\section{A Chicago Branch of American Institute of $E$. E.}

On Saturday evening of last week a meeting of the Chicago members of the American Institute of Electrical Engineers was held and the advisability of establishing a branch at Chicago was cliseussed. Mr. Pope addressed the meeting on the Institute and its work. Prof. W. N. Stine, of the Armour Institute offered the free use of the lecture room and laboratory for the use of the branch. A number of others spoke, among whom were Dr. Keith, of San Franeiseo, and Mr. W. H. Preece, of London. A eommittee consisting of Messrs. B. J. Arnold, H. A. Foster and R. H. Pierce was appointed to canvass the members and ascertain the support such a branch would receive.

\section{California Mid=Winter Exposition.}

The management of the California Mid-Winter Exposition announces that the success of the enterprise is assured. A large number of exhibits have already been promised, and the plans for the buildings decided upon. Special arrangements have been made with the railroads for the transportation of exhibits. Just what part electricity will take in the exposition we are as yet uninformed, but it is safe to say that it will do its share. Whether it will pay electrical manufacturers to make extensive exhibits is a matter they alone can judge, but in any event a large amount of light and power will be required to operate the exhibition successfully.

The Mason Battery Company, New York, has placed a line of batteries on exhibition in section $\mathbf{S}$, just east of the Paiste switeh display.

\section{ELECTRICAL INDUSTRIES.}

\author{
PUBLISHED EVERT THURADAY BY THE
}

\section{ELECTRIGAL INDUSTRIES PUBLISHING COMPANY,}

INCORPORATED 1 QBS.

MONADNOCK BLOCK, CHICAGO.

Telephone Harrison 159.

E. L. POWERs, Pres, and Treas. $\quad$ E. E. WOOD, Secretary.
E. L. POWERS,
H. A. FOSTER,
W. A. REMINGTON,
E. E. WOOD,
- Assoctate Entoris.
- eastern manager.
FLOYD T. SHORT,

EASTERN OFFICE, WORLD BUILDING, NEW YORK. World's Fair Headquarters, Y 27 Electricity Building.

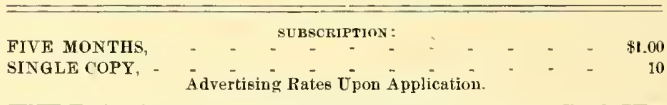

News items. notes or communications of interest to World's Fair Visitors are earnestly desired for publication in these columns and wil be heartily appreciated. We especially invite all visitors to call upon us or send address at once upon their arrival in city or at the grounds. ELECTRICAL INDUSTRIES PVBLISHING CO.,
Monadnock Block, Chicago

To many persons the electric fountains at the Fair have been something of a disappointment. The fountains are but a part of the great basin and consequently are not placed so as to form a center of attraction, but to form one part of a great whole. In order that they might harmonize with their surroundings they were placed inuch below the level of the plaza about the Administration Building; consequently to persons in the rear of a crowd the fountains look small in this "city of grand proportions." They are also contrasted with the Lineoln Park fountain, which on its eleration is a most beautiful sight, appearing as it does against the clark background of the trees. But the whentsheafs and other water effects, which form a special feature of the Columbian fountains, are not as perfect. The best view is secured from the basin. To persons in a boat a scene unsurpassed in billiancy is presented, but the fountains are not the central object and some of their brilliancy is lost in the bright light of their surroundings, but the colors appear clear and beautiful. There will undoubtedly be a great improvement in their operation since they have now passed under the management of the Exposition. The same hand will now manage both the water and light supply and the full power of the fountains will be displayed.

The reception given by the Department of Electricity through its genial chief, Prof. J. P. Barrett, to members of the Electrical Congress on Saturday evening of congress week was an enjoyable ending to a day at the Fair. The members of the congress had spent the day at the Fair viewing more especially the electrical features of the Exposition, and they promptly arailed themselves of the opportunity of discussing that part of the Fair. The refreshments serred were excellent and of a kind conducive to a friendly interchange of opinions on the various features of the Fair or rather were not, as one member remarlied as he arose with both hands and his mouth full to make a speech.

Dr. J. A. Hornsby, assistant chief of the department, was attentive to the wants and comfort of the guests and his remarks on the electrical features of the Exposition were 
pertinent and interesting. Prof. Elihu Thomson. Dr. Emery, Prof. Houston, Mr. DeCamp, Prof. S. P. Thompson, Prof. G. R. Barker, Mr. Weston and Dr. Keith each responded to the toasts propused loy Prof. Barrett who ocenpied the ehair of honor in the center of the parts.

The Department of Electricity has always been very generons in its treatment of visitors and this special enter taimment which it provided was greatly appreciatted hy all who were present.

\section{WORL.D'S FAIR NOTES.}

The "xhilit of the Ansonia Electrie Conmpany was rlosed a prortion of last weeli in ronserpuence of the asisignment of the compans.

Bartholomew, Stow d Co., arm installing an exhibit of Nutting are lamps at the south end of the gallery, near the phongraph exhibit.

The popular electrical lectures that were being given in the seenic theatre of the Western Electric Co. have been discontinued for the present.

The Belknap Motor Company has arleded to its exhibit a direct eomected dynamo and vertical type engrine of small size. At present the dymamo runs the eligine.

()hicial photographer Arnold obtained some very goord megatives of many of the prominent delegates te) the ifurhl: Electrical Congress while they were at the Fair.

The control of the electrical fontains is now in the hand of the Exposition. Displays of the intrieate water elfects are now made during the day and the fombans are illumin ated erery evening.

Since Sept. Ist, the Elektron Mfg. ('i), has carried an average of over fifteen limulred persons daily in its display elevator in the northwest coner of Electricity Building. The accommodation that is thus afforded is highly appreciated by both the public and the gallery exhibitors

The Iury of Awards has been progressing very rapidly with its work. The work of testing the lamps ancl instruments has been delayed somewhat but the laboratories are now fully equipped and the tests will be soon moler way. It will probably be very near the close of the Exposition hefore the tests will be completed.

An interesting use of the phonograph may bes seen in a number of the edncational exhibits in the gallery of the Manufactures and Liberal Arts Building. Records have been secured of the singing by the children in the varions schools, and in this way the progress macte in the art of rearling musce is very easily shown.

The popularity of the gallery of the Electrical Building shows the success of the efforts male by the (iallery Exhibitors Club. Neat sigus announcing the attractions in the gallery have been placed in conspicuous places, a liberal number of seats have been provided and an artistic little sonvenir is given away to visitors. The increased attend. ance must he a source of satisfaction to the committee who have hat the matter in charger.

The fonr large. Westinghonse vertical engines, directly ronnerted to Westinghouse dynamos placed close together in the power plant in Machinery Hall form a rery compact plant as well als ote of great power. Each engine is of 1,1000-horse power eal acity and each dyuamo has a capacity of $f(t, O H) ~ 14$; candle power lights. In this block there is then a plant of $f 1,(1) x+$ lights. The engines are double acting steeple compromel engines and run 2(m) revolutions per minute. The low pressine eylinder is phacel illowe the high pressure, and the cylinders are respectively thirty-seven and twenty-two and one-half inches in diameter and have a stroke of twenty two inches.

Many of the official delegates attending the World's Electrical Congress remained in the city to enjoy the varied features of the Fair. Dr. H. ron Helmboltz is spending two weeks in the Yellowstone National Park. Prof. Alex. Siemens and Prof. M. Maseart have already returned houe. P'rof. Ayrton sails this week on the Germania, and Prof. Cialileo Ferraris will leave Sumday on the Paris. P'rof. W. H. Preece will spent some time at Niagara hefore returning to England.

An attractive addition to the decoration of Electricity Building is being plaeed this week, by the Department of Electricity, between the exhibits of the Brush Co., and the Ft. Wayne Cor. An artistie arrangement of Hags made of many different colored incandereent lamps will bes shown. The lighting of the lamps will be antomatically controlled so as to give the flags a waiving effect. The artistic signs and electrical effects that have been added during the past month by the varions exhibitors has mueh improved the apspearance of the building.

The writer of fairy tales has told of the doors that were opened by unsten hands on the approach of the hero of the. story and noiselessly closed after he had passed throngh. That doors of this kind shonld berome a commereial articte, was beyond our comprehension when we read those tales, but among the other womlerlul and mysterious things to the uninitiated in Electricity Building are a number of doors that open as a persom approaches them and elose alter him. These doors are operated by the Hicks-Troy electric cloor operator, and a visit to the exhibit in the west gallery will be of interest.

In the German section of the Manufactures Building Heinrich Seitz exhilits two unilgue fixtures for electric light. ing. They are both three quarter size figures in bronze. One represents the figure of an old peasant holding an oldfashioned square lantern at arm's length and shadling his eyes with the other land to get a celearer view into the sur rounding darkness. The other is the figure of a conntryman who is evidently having his first experience with the physieal effects of an electrical battery. Clasped in either hand are the electrodes, with sockets for lamps in the upper ends, while the expression of the faee and pose of the body plainly indicate that the current is on.

The three Climax boilers in the boiler-roon annex to Machinery Hall have attracted a great deal attention on account of their odd shape which is very much different from that of the ordinary water tube builer. These boilers are two of 5110 and one of $1,(x)(1-h o r s e$ power eapaeity and 13 and $15 \frac{1}{2}$ feet in diameter. The latter standing 37 feet high. This boiler is said to be the largest boiler in the world and is guaranteed to evaporate 30,140 pounds every hour. The total heating surface is 10,11110 syuare feet, the surface of 1, (1) n tubes 12 feet long. The construction of these boilers is not very complex. It consists of a vertical eylinder of sufficient strength to withstand the internal steam pressure. From its outer surface these tubes come ont and then bend back and again enter this vertical cylinder. This is surroumderl ly a shell lined with material that will prevent the radiation of the heat. The furnace is placed beneath the boiler and as will be readily seen the hot air and gases. pass over a large amomt of surface before reaching the stack. These boilers were built by the Cloubrok Steam Builer Works, Brokklyn, N. Y. 


\section{PERSONAL.}

Mr. F. S. llunting, of the Ft. Wayne Electric Co., is now at the Fair.

Mr. H. A. Lawton returns from an extended trip East, the latter part of this week.

Mr. W. Il. McKinlock has associated himself with the Enterprise Electric Co., Chicago.

Mr. Caryl 1). Haskins, of the General Electric Co., Boston, is in the city visiting the Fair.

Mr. E. R. Knowles, engineer for the Sthuyler Electric Co, Middletown, Conn., is among the arrivals this week.

Mr. A. L. Daniels of the Miamisburg Electric Co, Miamisburg, Ohio, is spending a few days at the Fair this week.

Mr. W. E. Dresser. superintendent of telegraphs from ('osta Rica, has been spending some time at the Exposition.

Mr. F. W. Fairfield, eity electrician from Nashville, Tenn. has been in the eity visiting the Exposition during the past week.

Mr. Coleman Sellers, the well known engineer of Philadel phia, registered at the Windermere last week, and was an interested visitor of the electrical exhibits.

Mr. Mignel E. Horta, an engineer from the liepublic of Uruguay, South America, is now at the Exposition, making a special study of electrical rail way exbibits.

Mr. D. I. Carson, of New York eity, seeretary and general superintendent of the Southern Bell Telephone \& Telegraph $\mathrm{Co}$, is spending some time at the Exposition this week.

Mr. Henry D. Wilkinson, engineer of the British World's Fair Commission, accommpanied by Frederic A. Hamilton, M. Inst. E. E. London, were visitors at the headquarters of the Ameriean Institute of Electrieal Engineers last week.

The New Lamp of the Pennsylvania Electrical En= gineering Company.

In the accompanying cut is illustrated the new non-infringing lamp now being manufactured by the Penneylrania

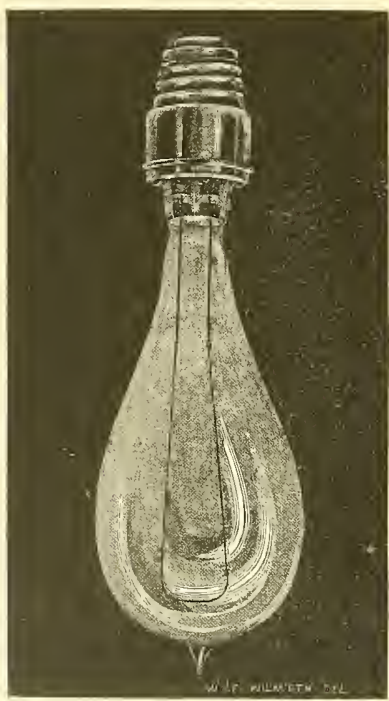

NEW LAMP OF THE PENNSYIAANA ELECTROAL ENGINEERING (U,

Electrical Engineering Company, Penn Mutual Bld., Philadelphia, $\mathrm{Pa}$.

The receiver is not an all glass reeeiver and the leading in wires do not pass through the glass consequently the amp does not come under the claims of the Edison lam]' patent. A number of patents have been secured on numerous details in its construction. It is decidedly original in design and contrary to the nsual method, the leading in wires are of iron instead of the more expensive metal platinum.

The lamp las been named by the company the "Maggie Murphy" lamp, and it is able to supply them in any quantity to suit the purchaser.

\section{DEPARTMENT OF ELECTRICITY.}

OFFICES: SECTION R, ELECTRICITY BUILDING.

Chief, John P. Barrett,

Assistant Chief, J. AlLen Honssby.

General Superintendent, J. WV. BIAllswel..

Electrical Engineer, W. W. Pнмм.

\section{A MERICAN INSTITUTE WF ELECTRICAL ENGINEERS.

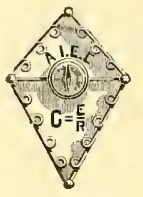 \\ World's Fair Headquarters. \\ SECTION S. ELECTRICITY BUILDING \\ RALi'B W. POI' \\ Upen from 9 a m. to 5 p.m.}

\section{Amusements.}

Hooley's Theater-Mr. E. S. Willard in "Wealth." 14 ! Randolph street.

Columbia Theater-Daniel Frohman's Lyceum Theater Co. in "The Charity Ball." 108 Monroe street.

Grand Opera House - Sol Smith Russell, in "A Poor Relation." 87 Clark street.

Auditoriux-Imre Kiralfy's Spectacle "smeriea." Congress street and Wabash arenue.

McVicker's Theater-Denman Thomson, in "The Old Homestead." 82 Madison street.

Chicago Opera House-American Extravaganza Company, in "Ali Baba, or Morgiana and the Forty Thieves." Washington and Clark streets.

Schiller Theater-Chas. Frohman's Stoek Company, in "The Girl I Left Behind Me." Randolph, near Dearborn.

Haverly's Casino-Haverly's United Minstrels. Wabash avenue, near Jackson street.

Trocadero-Vaudeville. Miehigan avenue near Monroe street.

The Grotto-Vaudeville. Miehigan avenue near Monroe street.

Buffalo Bill's "Wild West." 630 street. Daily at 3 and 8.30 p.m.

1) nniel Frohman's Lyceum Theatre Company appears at the Columbia this week in "The Charity Ball." This play has been seen here a number of times and has alwazs been well received. This is announced as the opening of the regular season although there has been no intermission during the summer.

Mr. E.S. Willard begins this week another engagement at Hooley's. A new play is presented entitled "Wealth," by Hen. ry Arthur Jones. "A Fool's Paradise," "Judah" and "The Middleman" will follow in each of which Mr. Willard is familiar to Chicago people.

Mr. Sol Smith Russell appears next week in "A Peaceful Valley", a play in which Mr. Russell bas been very suceessful. For its presentation new scenery has been prepared and the third act has been rewritten by the author so that it will be like seeing a new play with all the beauties of the old.

The sign "standing room only" is displayed in the lobby of the Auditorium every evening before the curtain rises so great has been the demand for seats. Extra afternoon presentations of "America" have been instituted. This arrangement will allow thousands to see this spectacle which has come to be considered a part of the visit to the World's Fair, who have heretofore been turned away.

"Ali Baba" continues to draw crowded houses at the Chicago Opera house. On Octoher Ist "Sinbad or Maid of Balsora" wil take the place of "Ali Baba". This piece is being rehearsed, the scenery is ready and the costumes designed by Howell Russell of London are being made. New music, new people and lots of fresh dialogue will make the piece lively and amusing. 


\section{OUR IMPROVED SYSTEM}

\section{... OF . .}

\section{Automatic fire Alarm,}

covered by patents recently issued, is the

embodiment of all factors contributing to the

GREATEST SAFETY,

\section{and the MOST RELLABLE}

PROTECTION FROM FIRE.

\section{Western

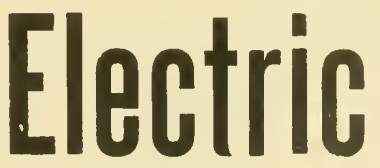 \\ Company,}




\section{ELECTRICITY BUILDING-EXHIBITORS AND THEIR LOCATION.}

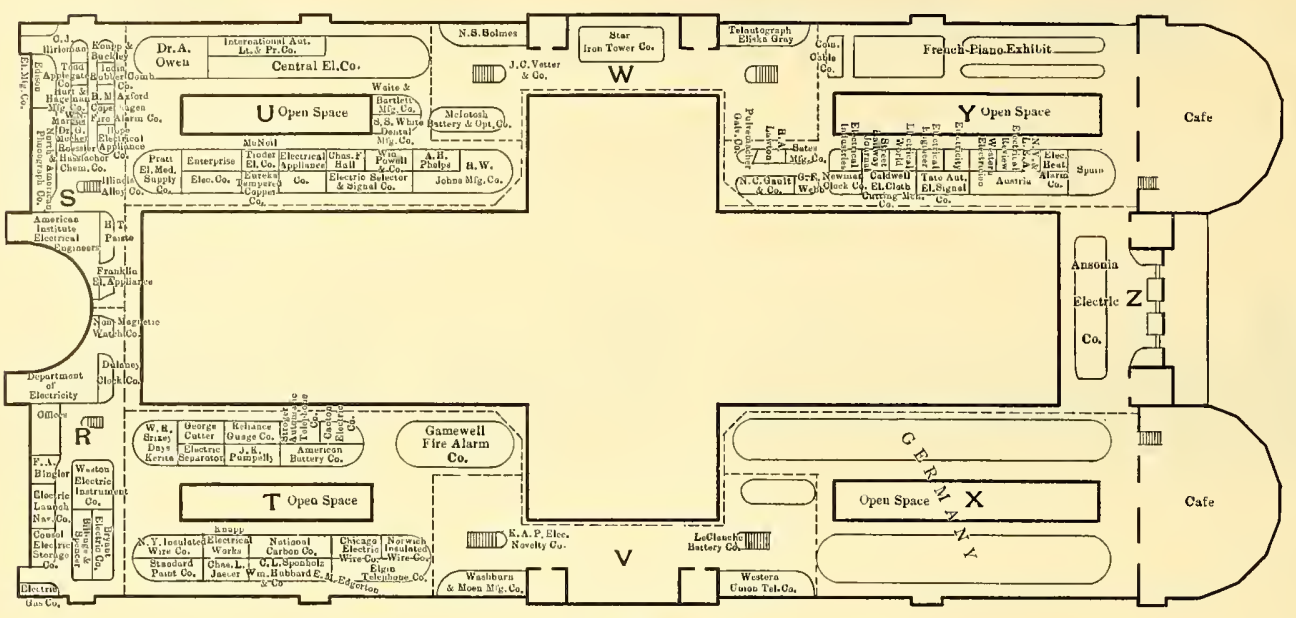

GALLERY.

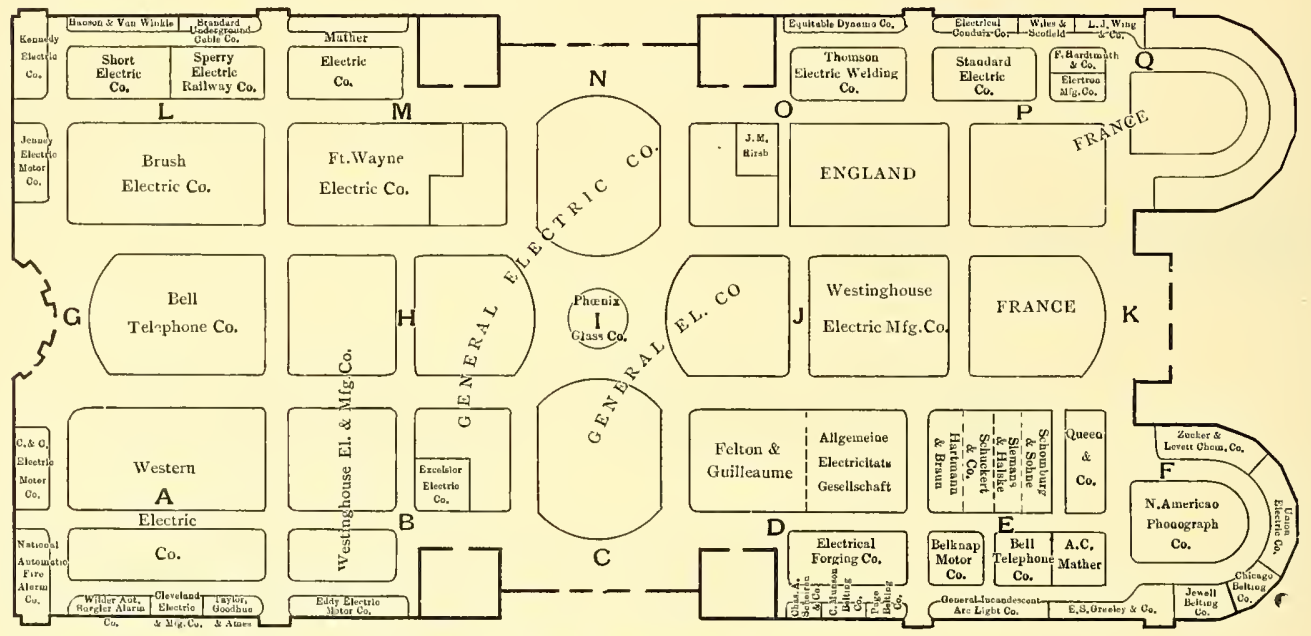

MAIN FLOOR.

Exbibitar.

A ustria.

Ansonia Electric Co..........

American Battery Co

Axford, $H$. $\mathbf{I}$

Allg. Elec. Gesellechaft.

Bryant Electric Co

Billiags \& Spencer

Brixey, $W$.

Bell Telephoue Co

rush Electric Co .......................

Caldwell El. Cloth Cut. Mch. Co

Cutter, George

Chicarn Elec. Wire Co.

Copeshagen k'ire Alarm Co.

Central Electric Co......

Commercial Cable Co.

Clevelaud Eirc. \& Mfg. Co

Chicago Beltiog Co

Dulazey Clock Co

Department of Electricity

ELECTRTCAL INDUSTRIES

Elec. Launch \& Nav.

Electric Seperator.

Elgiu Telephune Co.

Enterprise Elec Co

Eureka Temp. Copper

Electric A ppliance Co.

Elec. Sel. \& Sig'l Co.
Section Exhibitor

Section.

Electricity...

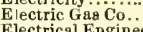

Electrical Engineer

Eddy Electric Motor C

Excelsior Electric Co...

Equitable Dy namo Co.

hlektron Mrg. Co....

England

Worke

.

Felton \& G villeaume.

France ..................

Gault \& Co., N. C....................

Gamewell Fire Alarm Co........... T

General Electric Co ....B-H-N-C-\& J

Greeley, E. S., \& Co

Hobbard, Wm... \& Co

Hart \& Hegemau vifg. Co

Hope Elec. A ppliance $C$

Hall, Chas,

Hartman \& Brain

Haceon \& Vao Wiviki

Hirsh, J.

Hardtmuth, F.. \& Co

Illinois Alloy Co...............

Internat. Aat. L't \& P'r Co.
India Rubber Comb Co...
Section, Exbibitor.

Jaeger, Cbas. L..... Section

Johos, Mfg. Co., ii.

Jewell Belting Co....

J. vney Elec. Motor Co..........

Koapp Electrical Works..

Kuapp \& Bochley

Kennedy Elect

LeClanche Battery Co......

McNeil-Tinder Elec. Co...

Marcus, W. N

MeIntosh Bat. \& opt. Co

Munsoo, C., Belting Co

Mather Electric Co

Newman Clock Co..........

N. Y. Insulated Wire Co.

Natioaal Carbon Co....

Torwich has. Wire Co..................

Nat Ant Fire cion.....

Nat. Engraving Machine

Owen, Or. A

Paiste, H.T

Pulvermacher Galv. Co

Pumpelly, J.

Powell, Wm. Co.

Phelps, A. H

Page Beltiag

Queen \& Co
Exhibitor. Roessler \& Hasslacher Chem. Co....... Street Rail way Journal...... ....... Y Strowger Ant. Telph. Co.......... Standard Paint Co.

Spouholz, C. L....

(n).......

Schier

Schomburg \& Sohne...

Siemene \& Halsh

Schuckert \& Co

.

Stan alec. Railway co...........

Samson Battery Co

Tate Aut. El, Signal Co .............. Y

Todd, Applegate Co ................

Taylor, Goodhue \& Ames ............. A Telantograph, Eligha Gray ..........W

Webb, G.

Weston El. Instrument Cu...........

Washbura \& Moeo Mfg. Co..

Western nion Tel. Co.

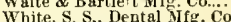

Western.

Wilder Ant Burglsr Ai Co..........

We-teru Electric Co $\ldots$...........

Westinghouse El. \& Mfg.

Wing, L. J., \& Co.....................
Zucker \& Levett Chen.. Co.......... F 


\section{LINE SUPPLIES.}

GONSTRUGTION MATERIAL. INGANDESGENT LAMPS. RUBBER GOVERED WIRES. WEATHER PROOF WIRES. ELECTRIGAL HOUSE GOODS.

\section{TELEPHONE SUPPLIES. \\ TELEGRAPH SUPPLIES.}

ELECTRIC APPLIANCE COMPANY,

CHICACO... 242 Madison Street,

... CHICAGO.

THE MATHER ELECTRIC CO. THE "NOVAK" LAMP.
MANCHESTER, CONN.

Dynamos, Motors, Generators,

Offices, 116 Bedford St., BOSTON.

$$
\text { -AND- }
$$

1002 Chamber of Commerce Bldg,, CHICAGO. 1002 Chamber of Commerce Bldg., CHICAGO.
CLAFLIN \& KIMBALL (Inc.)

\section{Ceneral Selling Agents.}

II6 Bedford Street, BOSTON.

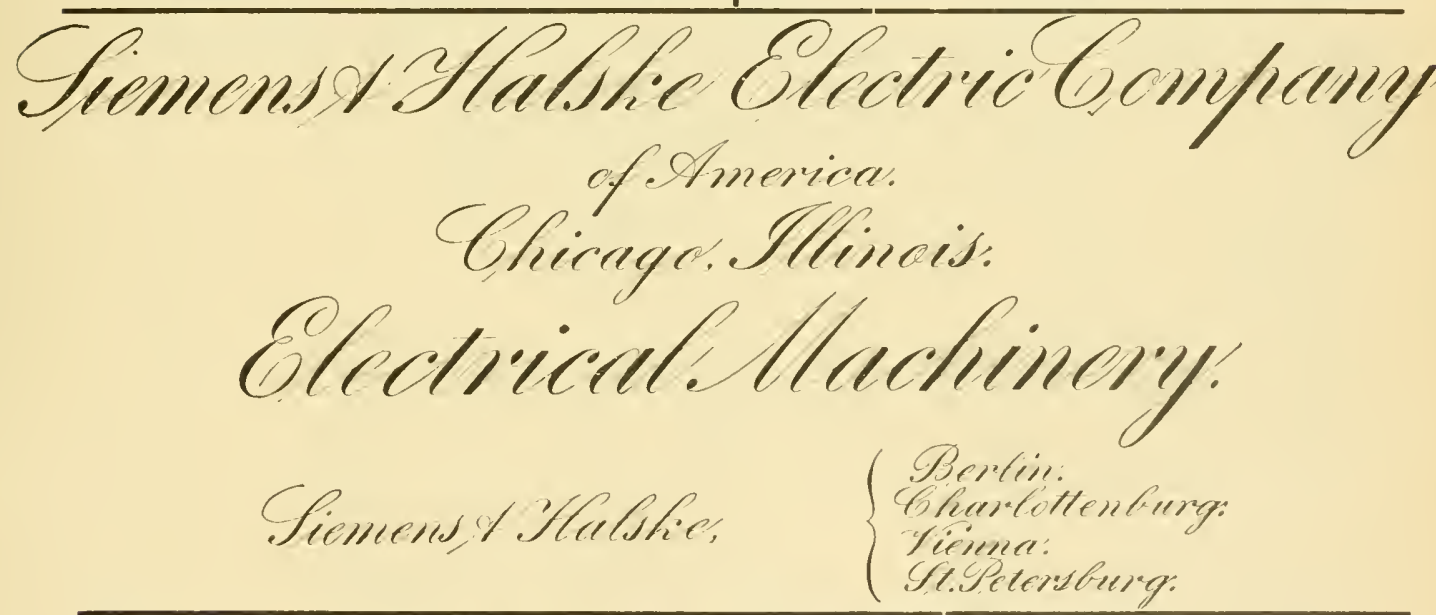

\section{Enterprise}

Electric

Company

207 Dearborn Street, Chicago ....
Manufacturers' Agents and Mill Representatives for

Electric Railway, Telegraph, Telephone and Electric Light SUPPLIES $S_{\substack{\text { of EvEN } \\ \text { ofscriprior }}}$

Cedar Poles,

Cypress Poles, Oak Pins, Locust Pins, Cross Arms, Class -Feeder Wire, Insulatcrs

WIRES, CABLES, TAPE and TUBING 
Map of Chicago.

Showing Location of its Electrical and Allied Business Interests, Principal Hotels, Theatres, Depots and Transportation Lines to the World's Fair Grounds. (Index numbers refer to the black squares.)

45
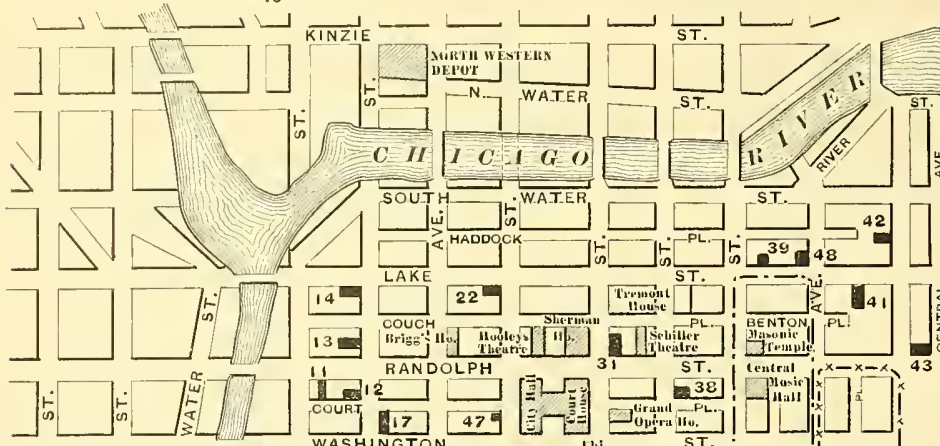

RANDOLPH

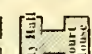

ST. Central

43
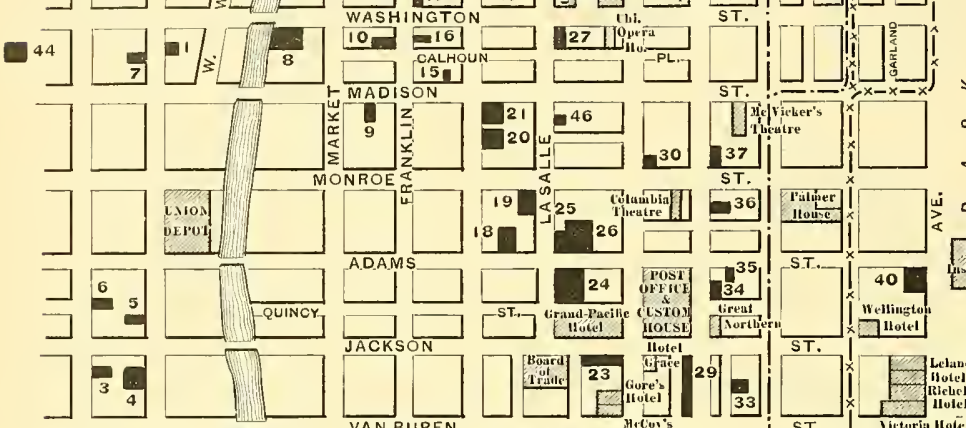

!
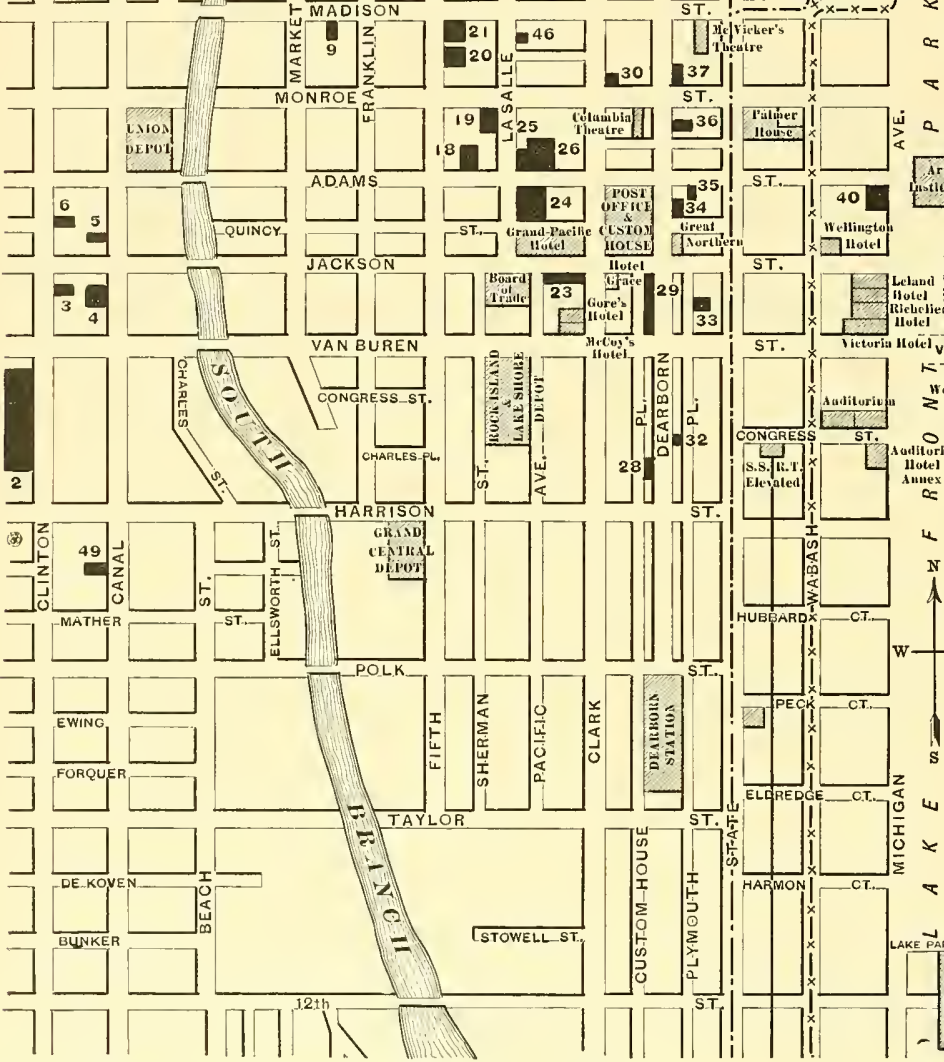
(a)
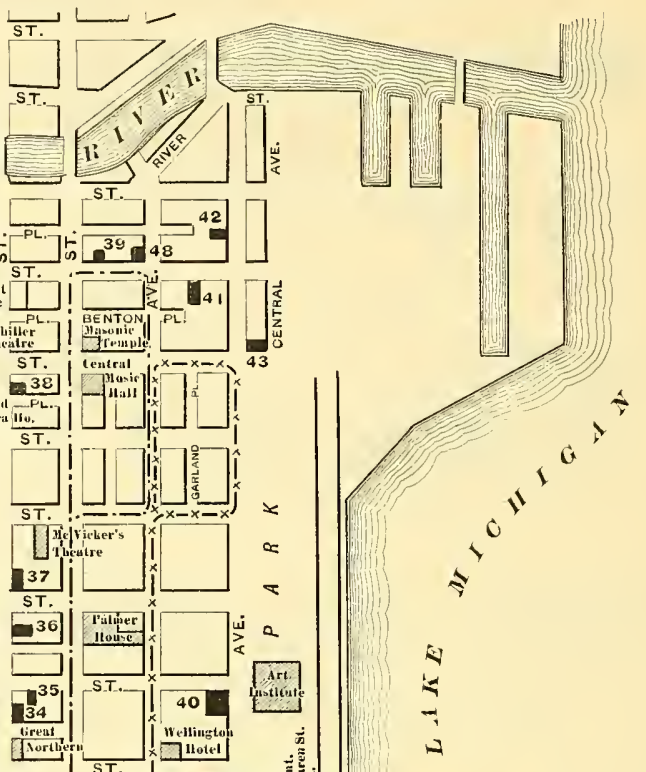

Ansonia Elec Co., Michigan Ave. \& Randolpb St...34 | Cuehing \& Morae, 225 Dearhorn St. merican Battery Co, 188 Madiron St.

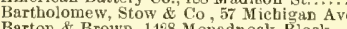
Barton \& Brown, 1428 Monadnock Block Benham, A. D., $200 \mathrm{~S}$. Clinton Bryant Electric to.

Brian Electric Co., Honadnock Block

Buckeye Electric Co $\$ 37$ Rookery Bldo.

Calnmet Electric Mfg, \& Engineering. Co., 174 s

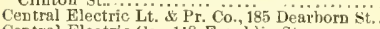
Central Electric Cn., 118 Franklin St. 42 Confolidated Electric Co.

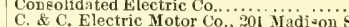
3 D'Unger El. Telephone Co., Stock Exchange B. Detroit Eilectrical Worke, 917 Monadnock Block

Edwrrda, W S Mfg, Co a1 Make

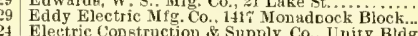
Electic Appliance co supply Co.,

6 k Lectreical Industries Pub Co., Monadock Biock Enterpriae Electric Co., 30; Dearborn St Ft. Wayne Elec. Co., 185 Dearboro st.

Chicago Arc Light \& Power Co, Waghington St., Ply. Gregory, Chat. E., Co., $49 \mathrm{~S}$. Jefferton St 8 \&3 Gregory, Chat, E., Co., 49 S. Jeffertion St... Chicago Telephone Co., 203 W a bington st...........

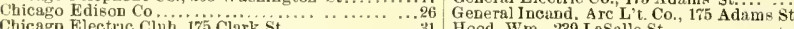
Chicago Electric Club, 175 Clark St.

26 General Incand. Arc L't. Co., 175 Adams S

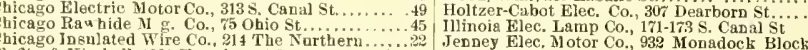

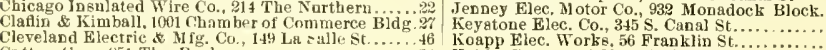
(2) Kohler Bros, 141 i Mlonedock Block...

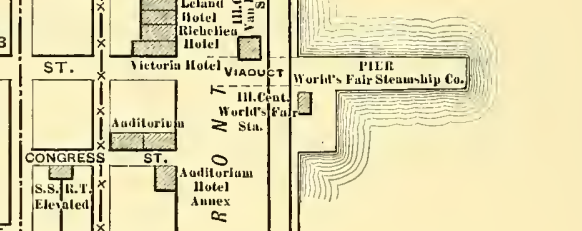



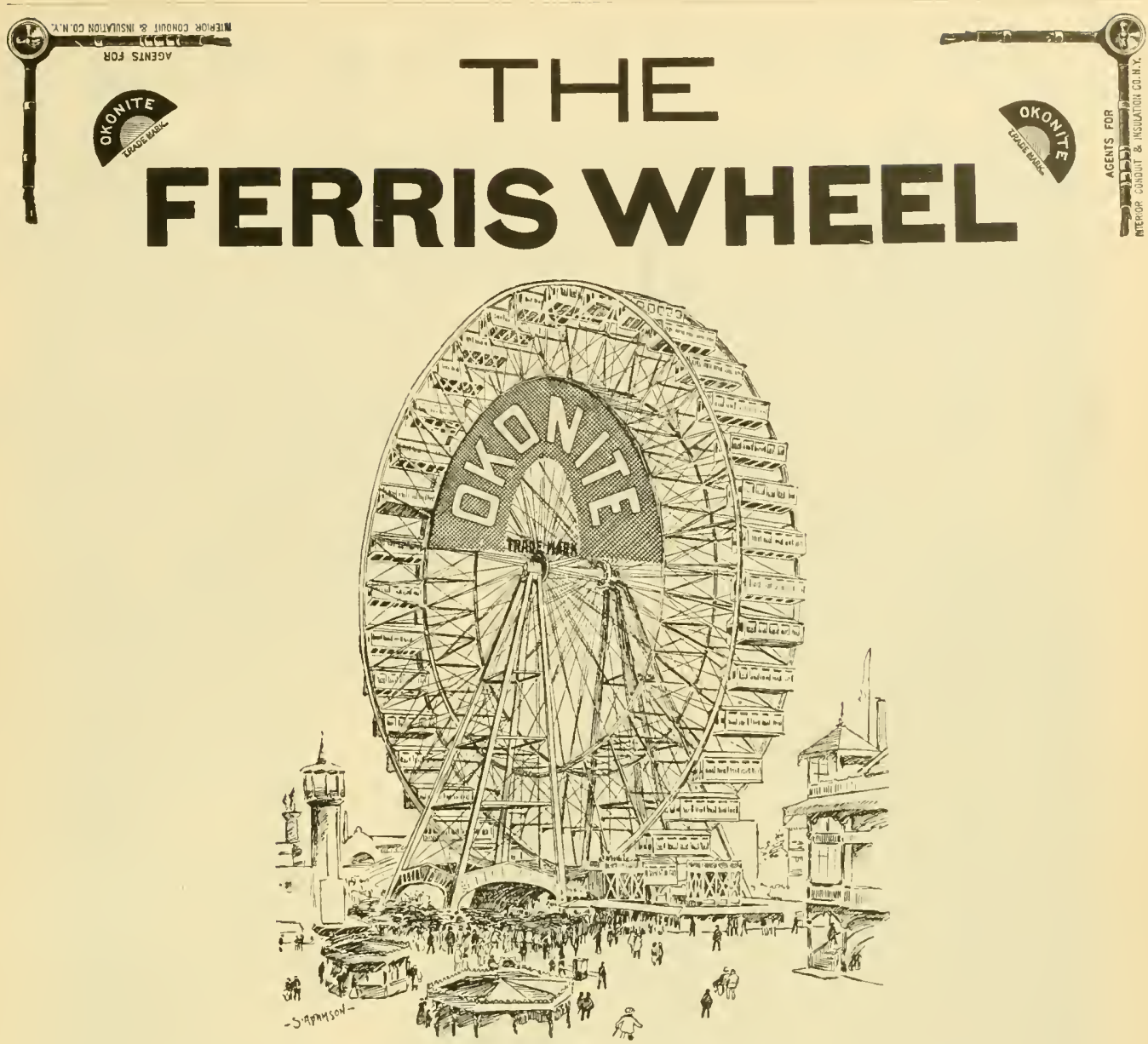

When you visit the World's Fair, you will naturally take a ride on the FERRIS WHEEL and be interested in the ELECTRIC LIGHT INSTALLATION, which is wired throughout with

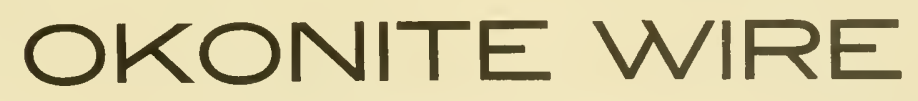

FURNISHED BY THE

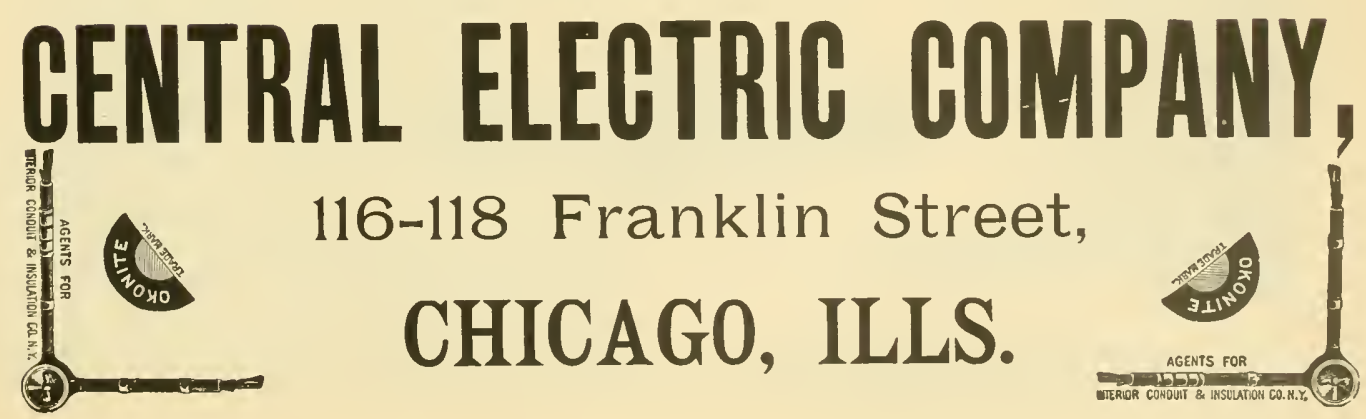




\section{"PENNSYLVANIA"}

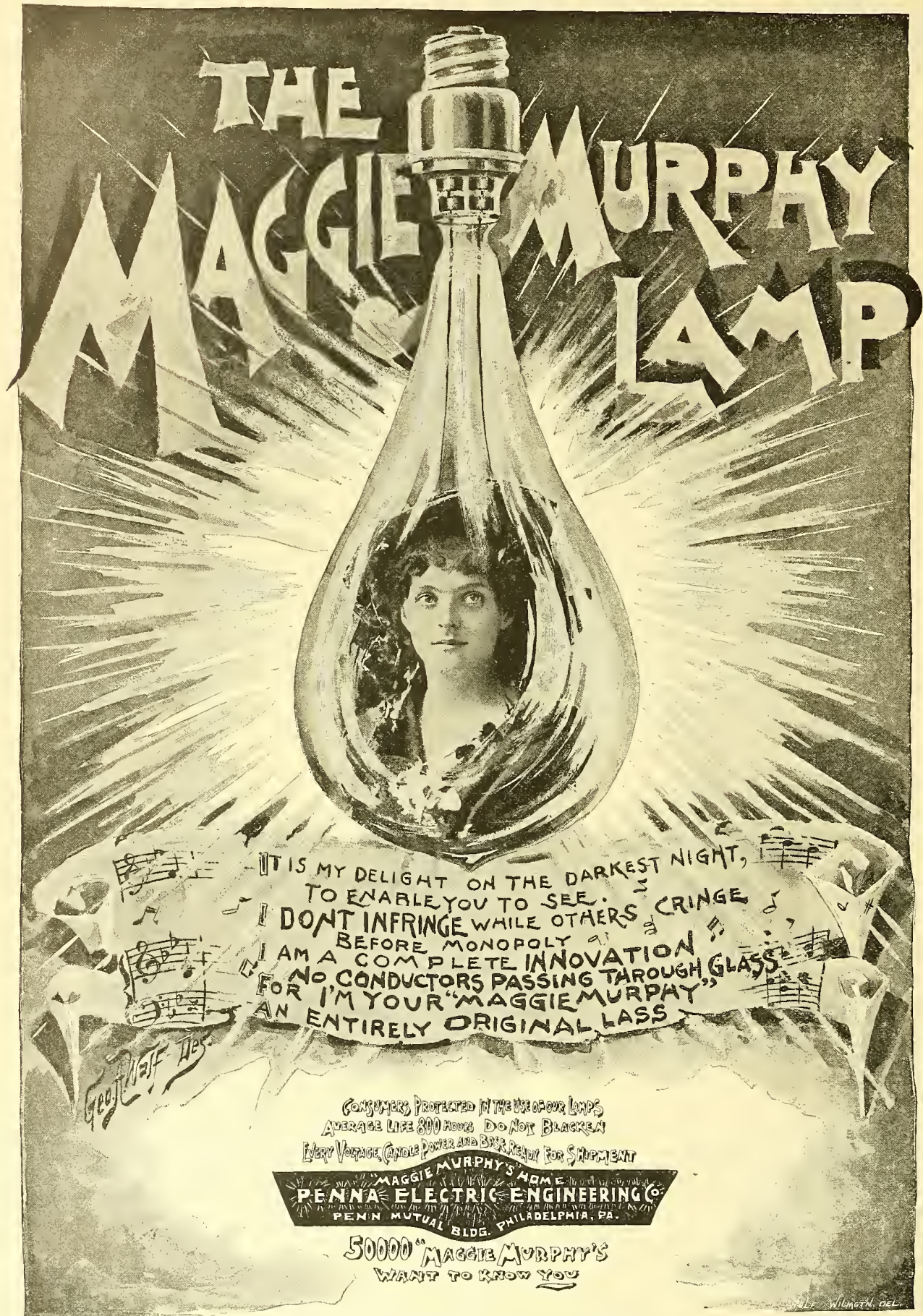

PRICE, 35 CENTS, IN LOTS OF 200.

Dynamos, Power Generators, Motors, Supplies. Railway and Lighting Construction our Specialty. 

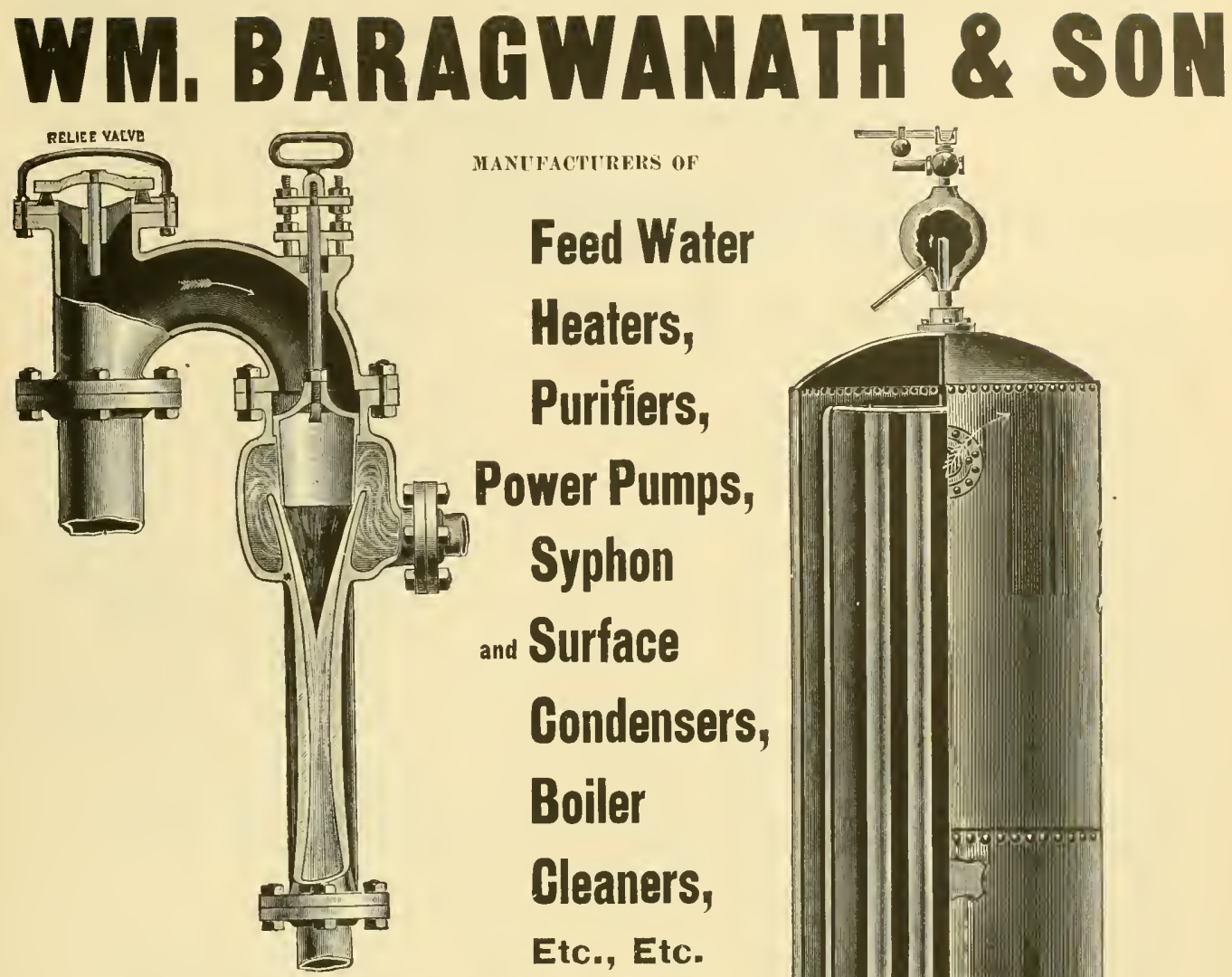

MANUPACTURERS OF

Feed Water

Heaters,

Purifiers,

Power Pumps,

Syphon

and Surface

Condensers,

Boiler

Cleaners,

Etc., Etc.

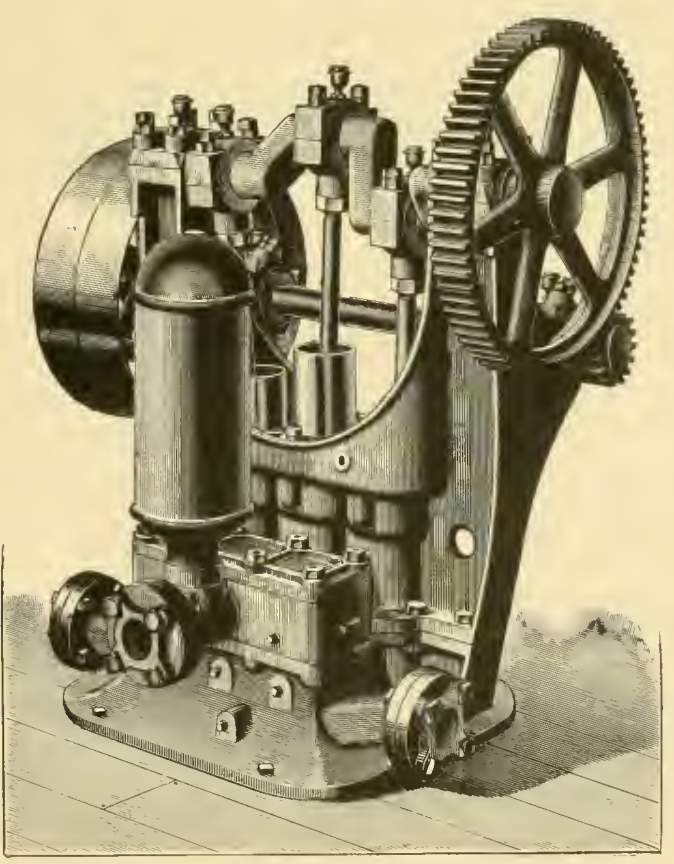

55 West Division St. 


\section{THE MONTHLY ISSUE FOR SEPTEMBER}

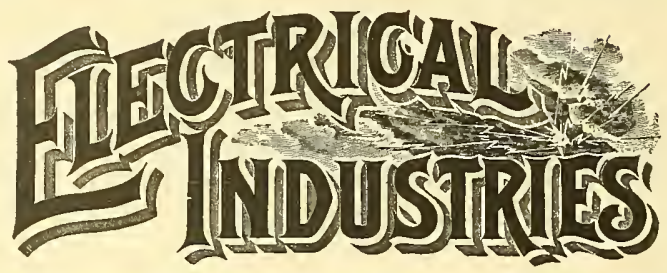

Should be read by everyone interested in electrical matters. In its table of contents is the following:

"World's Congress of Electriciars."

"Nikola Tesla's Lecture.'

"Love Underground Electric System in Washington." By M. D. Law.

"Gas Engines as Applied to Electric Light Work." By Geo. A. Farwell.

"The Underground System at the World's Fair."

"Electric Railway Plant of the Chicago North Shore Railway Company."

"Obitnary-Louis W. Burnham."

"A Brief Review."

"Financial."

Together with illustrations of the recent applications of electricity.

The paper also contains regularly

A Buyer's Directory of Manufacturers and Dealers in Electrical Supplies and Appliances.

A Complete Directory of Electric Light Stations in North America and a Complete Directory of Electric Railways in North America.

These directories are revised each issue to the date of going to press and are to be found in no other electrical journal in the World. Its articles are read carefully and its directories used constantly by all the buyers in the trade. These facts make it without a superior as an advertising mediun. Sample copies and rates sent on application.

Sibscription price $\$ 3$ per year. Six months trial $\$ 1$, if ordered during September.

\section{ELECTRICAL INDUSTRIES PUB. CO., Monadnock Block, CHICAGO.}

NO ONE interested in Electricity at the World's Fair can afford to be without

\section{WEEKLY WORLD'S FAIR}

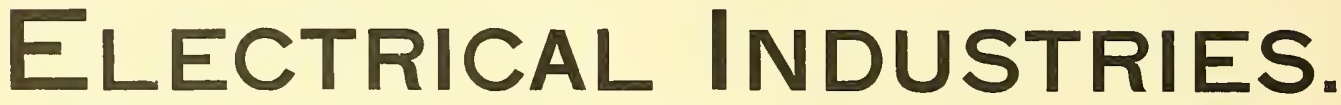

IT is the only Paper Published devoted exclusively to the electrical features of the Fair and containing a complete directory of the Exhibitors in Electricity Building.

IT Publishes more electrical news of what is actually going on at the great Exposition and IT is therefore read and used for reference by more visitors than any other Electrical Journal.

Send for free sample copy. 

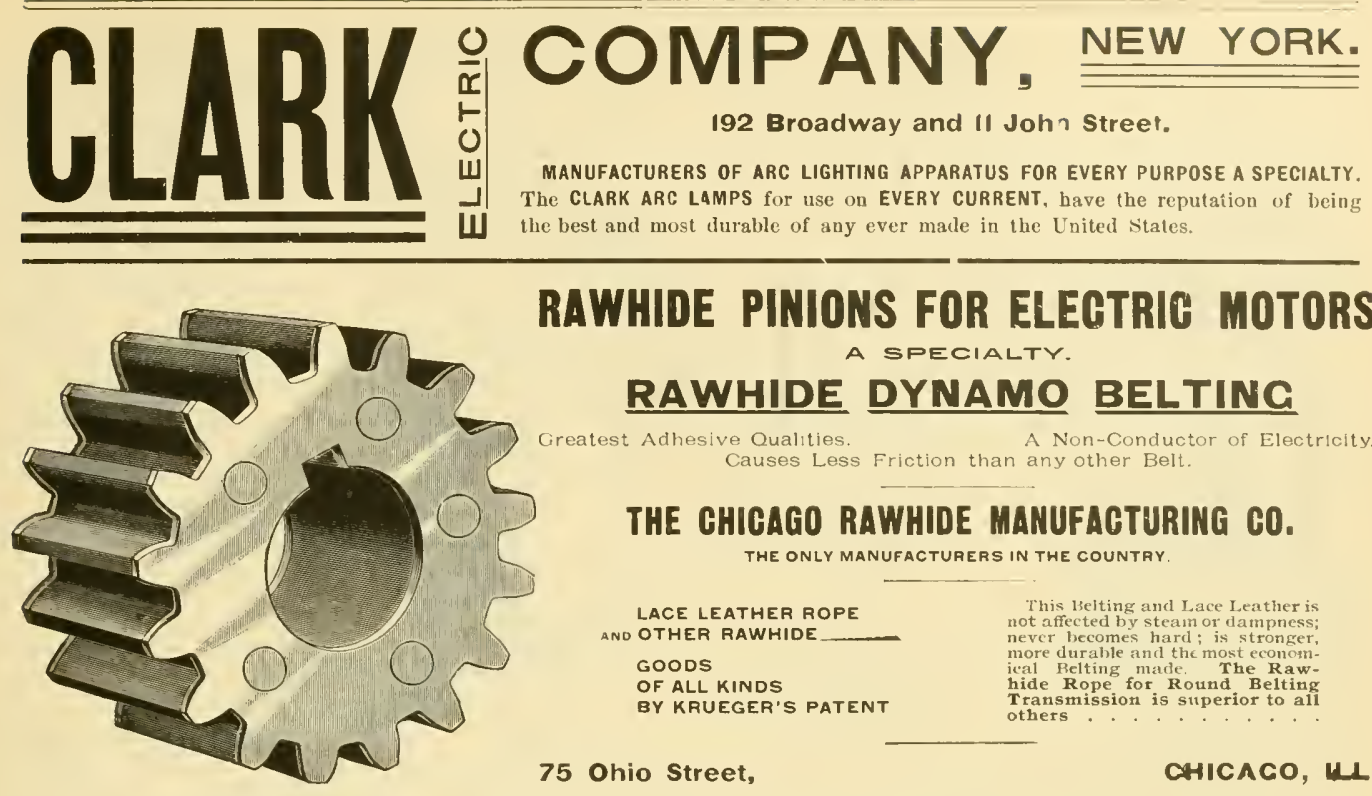

RAWHIDE PINIONS FOR ELEGTRIC MOTORS A SPECIALTY.

RAWHIDE DYNAMO BELTING

Greatest Adhesive Qualities. A Non-Conductor of Electricity. Causes Less Friction than any other Belt.

THE CHICAGO RAWHIDE MANUFACTURING CO.

THE ONLY MANUFACTURERS IN THE COUNTRY.

LACE LEATHER ROPE ANO OTHER RAWHIDE.

GOODS

OF ALL KINDS

BY KRUEGER'S PATENT
This lelting and Lace Leather is not affected by steam or dampnes never becomes hard; is stronger ical Belting made hide Rope for Round Beltin Transmission is superior to all others

\section{Standard Electric Company.}

GENERAL OFFICES: 625 Home Insurance Building. WORKS: So. Ganal Street,

\section{CHICACO.}

\section{STANDARD SYSTEM}

AT THE

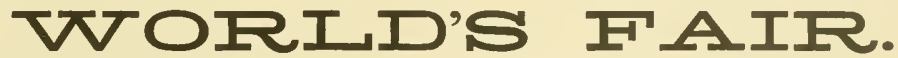

MACHINERY HALL, Sec. Q, 2 Standard Arc Dynamos.

Sec. S, 20 " " "

ELECTRICITY BUILDING. Sec. P, Space 2, Arc Lighting Exhibit.

The Standard Lamps Light the Power Plant, Machinery Hall, Agricultural Hall, Shoe and Leather Building, and Other Buildings and Portions of the Grounds. 


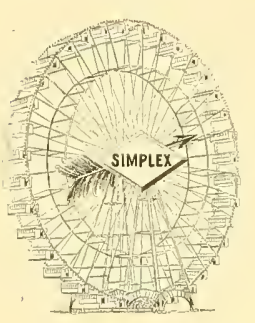

Mile after mile of

SIMPLEX WIRE

Supplied to the

FERRIS WHEEL

$\bullet \bullet \bullet$

By...George Cutter,

The Rookery, chicago.

\section{SIMPLEX WIRES}

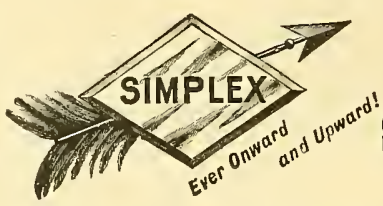

INSURE

HICH

INSULATION

Simplex Elegirical Go. 620 Atlantic Ave.,

George Cutter, Chicago. Boston, Mass.

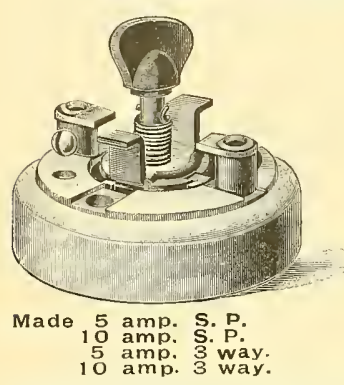

10 amp. 3 way.

\section{XNTRIC}

"That's the Switch"

And we control that movement.

H. T. PAISTE, 10 South I\& th St., PHILADELPHIA, PA.

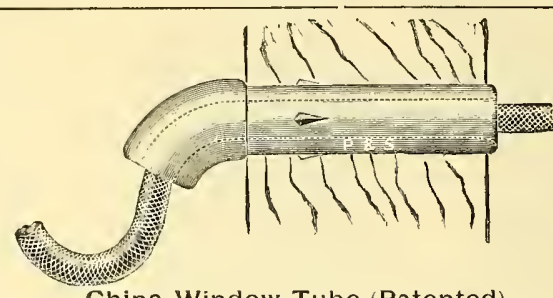

China Window Tube (Patented). Made only by PASS \& SEYMOUR,

George Cutter,
SYRACUSE, N. Y.
Consolidated Elpetric 6. Manufacturers and Dealers in all kinds of

\section{ELECTRICAL . SUPPLIES,}

115 Franklin Street,

\section{chICAGo.}

\section{GFORGF PORTER,}

Contractor for All Kinds of

\section{ELECTRICAL WORK.}

Room 67, I 43 La Salle St., CHICAGo.

Crary Block, BOONE, IOWA.

\section{KOHLER BROTHERS,}

The Edddly Elebtipio Mig. G0.

ELECTRIC MOTORS

DYNAMOS FOR LIGHTING

RAILWAY AND POWER GENERATORS TELEPHONE 5090 .

1417-1418 MONADNOCK BUILDING, CHICAGO.

\section{CALL AND EXAMINE}

\section{Lawton's Call Indicator.}

Indispensable for hotels, railroad offices, school buildings, hospitals, etc.

Section Y, Space 45, Gallery Electricity Building, WORLD'S FAIR.

OFIOAGO, ILI.

WAGNER ELECTRIC FAN MOTORS

For Direct or Altemating Curvents.

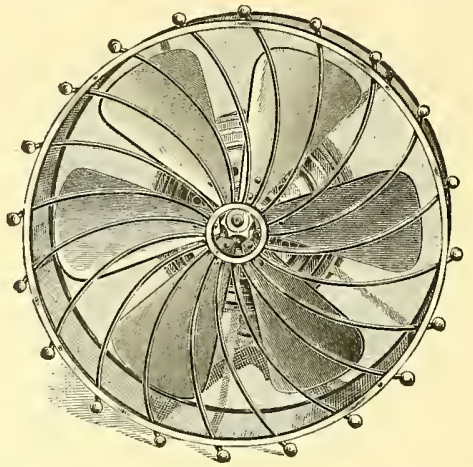

These motors give a stronger breeze with less consumptiou of current thas ather fan motor on the market. They are full 1-8 horse power. Sis bladed Je-1nch fau. Selfoling. Furnished with or without guards.

IT WILL PAY YOU TO SEE THE WAGNER BEFORE BUYING ELSEWHERE.

TAYLOR, GOODHUE \& AMES, 348 Dearborn Street, CHICAGO. 


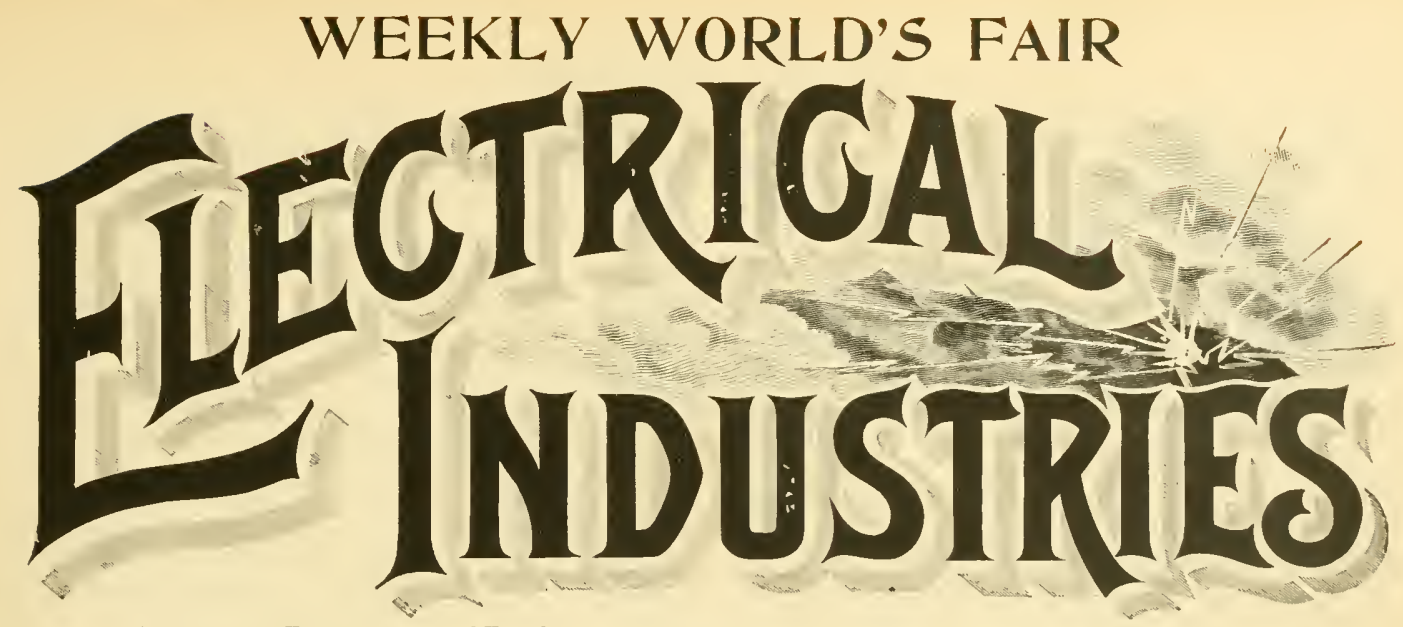

DEVOTED TU THE ELECTRICAL AND ALLIED INTERESTS OF THE WORLD'S FAIR, ITS VISITORS AND EXHIBITORS.

Vol. I, No, 14. CHICAGO, SEPTEMBER 14, 1893.

FIVE MONTHS S1.00

Exhibit of the Electric Appliance Company.

The Electric Appliane. ('omplany hate one of the must intreresting and

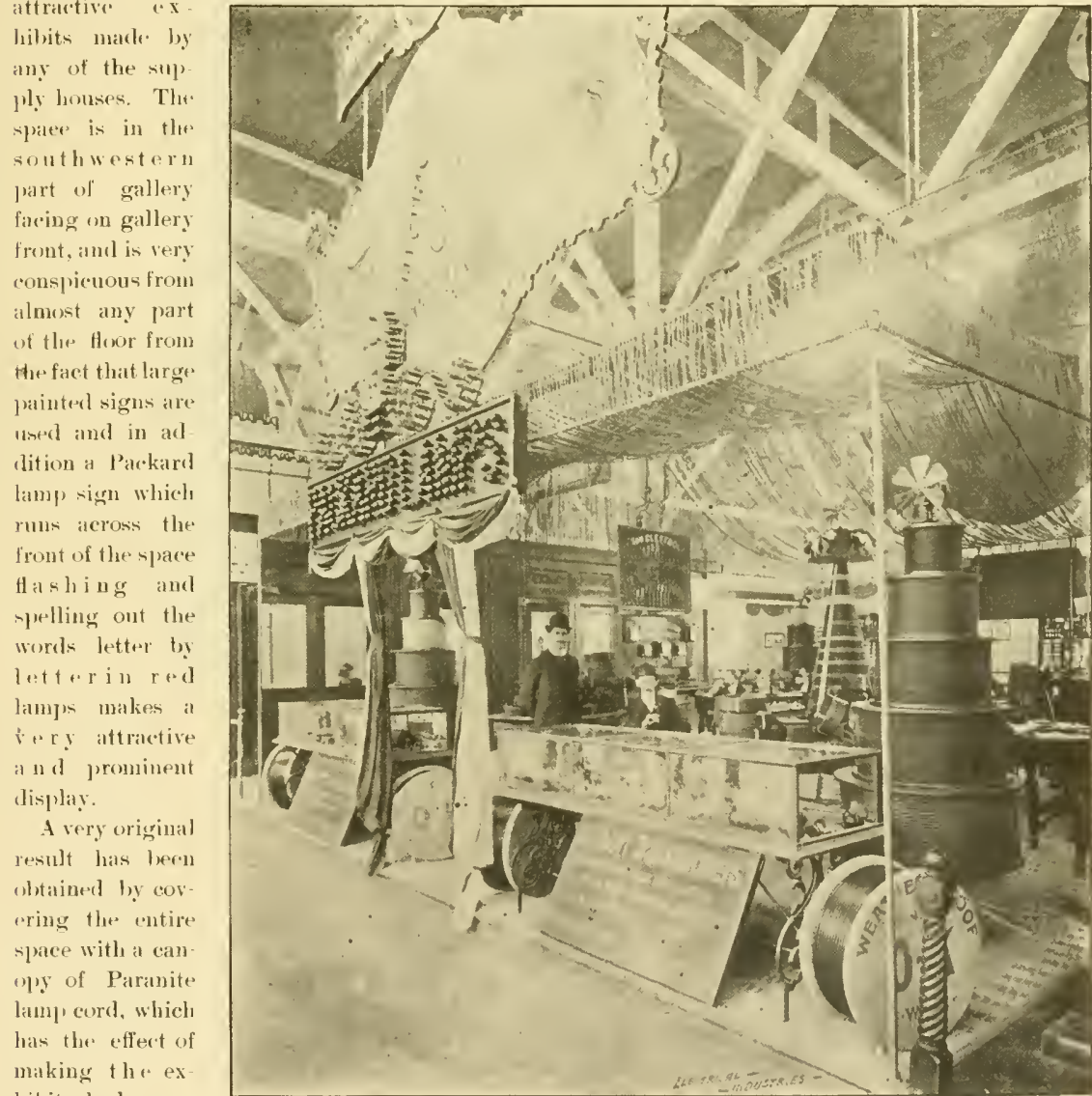

hilit look rely compact and at thing of the kind in the lmilding. This canoly alone con tains about thirty thousurel (30),0moly yards of Paranite lamp cort mate "1p of "1]wards of a million and a half feet of number thirty (")pler wire. The Electric Applianere Com pany lats made. "1) its exhibit prineipally of speecialtites, 11 ot slowing a gen. rat line of sup. plies. The prin cipal sprecialties represented are: the Packarel lamps. P'aranit. wims and cables, (1) K. Waterproof wires, Meston fan motors, Whitney instruments, Elk hart transform r.rs, C. E. II. jack $k$ if if switrhes, It E England sw it ehes and swinginer ball lighlituing arresters

As betore stat ed, the prineipal part of the lamp whibit eonsists of the tlashing sign made in of the new if C. P. Packarl lamps. The sign contains about 5alu lampss of varions colors. The sign the same time

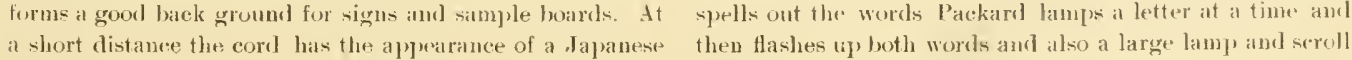
open work curtain and is certainly unipue, being the only alove the sign uade up of alont low small lamps arranged 
to show the shipe of a regular incandescent lamp. In addition to those in the sign there is shown a large assortments of lamps of all candle powers and roltages and a number of special lamps made of various kinds of fancy colored glass making a very original display.

The exhibit of Meston alternating motors is very complete showing the new dental and sewing machine motors and single and duplex power motors in operation doing actud] work, and also a large number of Meston fan motors both stationary and rerolving which are distributed about the exhibit in a way to keep up a stiff breeze in all parts of the space. One of the one eighth horse power motors is used to drive the commutator which operates the lamp' sign.

The exhibit of Paranite wres and eables in addition to the Paranite cord canopy before referred to, is rery complete and extensire. The center of the plat form is occupied
An inte:esting : ample table -howing all sizes and styles of New England switches and the switch parts from the cover to the porcelain base adds to the attractiveness of the display. C. E. M. jack-kuife switches are shown in all finishes, shapes and capacities and the swinging ball lightning arrester is prominently displayed. $U$. K. weatherproof wire is also conspicuously displayed by a mumber of hand. some sample reels.

Another part of the exhibit worthy of mention is the large display board on which is exhibited a line of Von Cleff it Co.'s all steel pliers, connectors and other tools used in electrical work.

The exhibit in detail is rery interesting and the amount of machinery, lamps, ete in operation malies it attractive and what is more desirable the whole arrangement of the display is harmonions and symmetrical and the Electrical Appliance Company is to be congratulated upon having

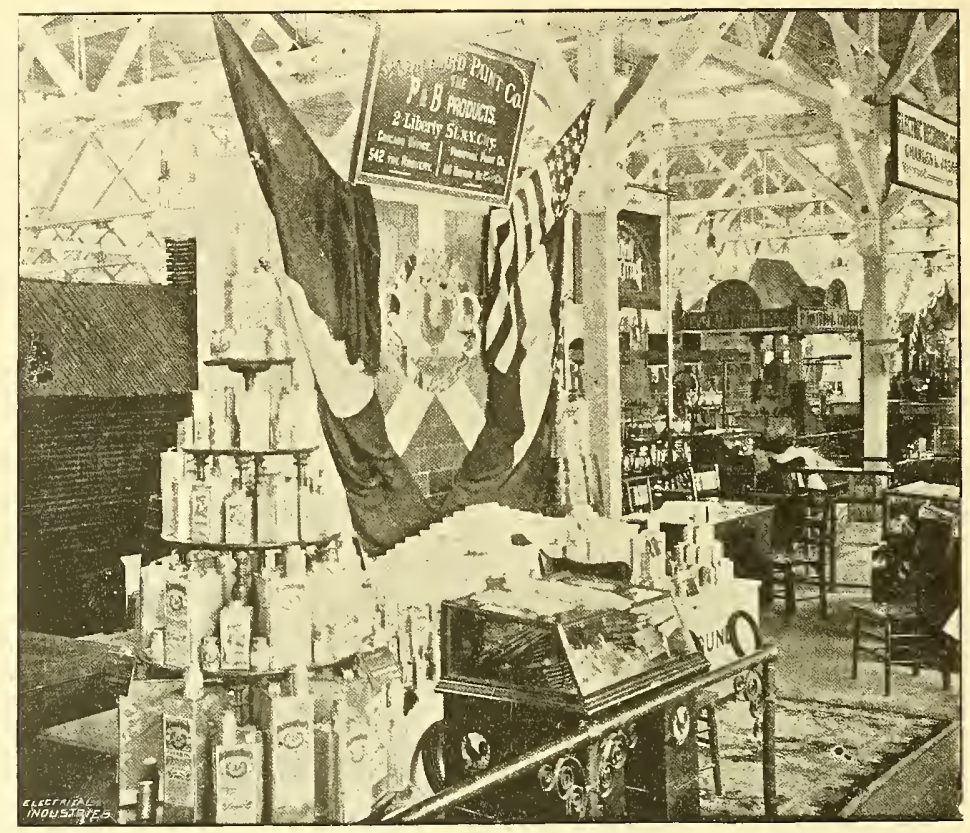

THE EXHIBIT OF THE STAXIALD PAXXT CONPANY

by a large cone about five feet in diameter at the base and eight feet high covered with Paranite wires running from heary submarine cable at the bottom to number eighteen wire at the top. In addition to this the four comers of the space are marlied with pyramids of fancy reels and sereral display tables are covered with handsome coils of Paranite wires and cords.

The Ellihart transformer exhibit consists of the trausformers in actual operation supplying the current used for ilhminating and power furposes in the exhibit. The converters atre so arranged that their close regulation, high efficiency and cool rumning ean he readily shown, and being in actual operation it makes a rery practical converter exhibit.

A rery fine sample bourd of Whitney instruments is shown, also a show anse of the same with immeters and rolt meters connected up to show their operation on direct and alternating currents.
One of the neatest displays in Electricity Builling. Mr. F. S. Cassoway, assisted by C. C. Hilles, is in charys of the exhibit and takes pains to explain to visitors the varions articles shown.

\section{Exhibit of the Standard Paint Co.}

In the manufacture of electrical goods and their installation the matter of insulation plays a most important part. For this purpose special compounds, paints, varnishes, etc, are manufactured and of the manufacturers of this class of goods none are better known than the Standing Paint Company.

In the east gadlery toward the south end of Electricity Building this "ompany has an exhibit made up entirely of electrical insulations. In the center of the space there has been erected a large ntained glass panel in the center of which appears the well known trade mark of the company. 
On each side are drajed thags of different nations making in attractive background to the display of the goods.

Un the base at the bottom of the panel are placerl piles of tape nsed in insulating joints and connections and the smaller products of its factory. Nearly all the larger manu facturers of dynamos, motors and insulated electric wires us. some form of the P. \& B. insulations. In the exhibit are shown samples of different kinds of wires in which the P. A B. componuls are used in the insulations. Small plectric light wires, lead cosered cables painted with the P. \& B. compound, brailed cables with the braid saturated with P.A B. coinpound are shown illustrating some of the uses of the P. A B. comprouml.

Packages of armature rarnish for the protection of the armature and tield coils and enamels for commutators which are extensively usul by retretric street ralways are shown.

\section{The Exhibit of the Chicago Rawhide Manufacturing Company.}

To persons interested in belting, the transmission of power and the various industries in which leather is used. a visit to the exhibit of the Chicago Rawhide Manufacturing Company, of 75-77 E. Ohio St., will be found of great value. It is located in Machinery Hall, section 15. Column J, 25 and 29. The exhibit is composed entirely of the products from the extensive works of the company, treated by the rawhide process.

For many purposes rawhicle leather has been found far superior to leather tanned in the ordinary way. It is said that the process is simpler, requires less time and leaves the leather more in its natural state. No lime or acids are used and when finished the leather retains the natural

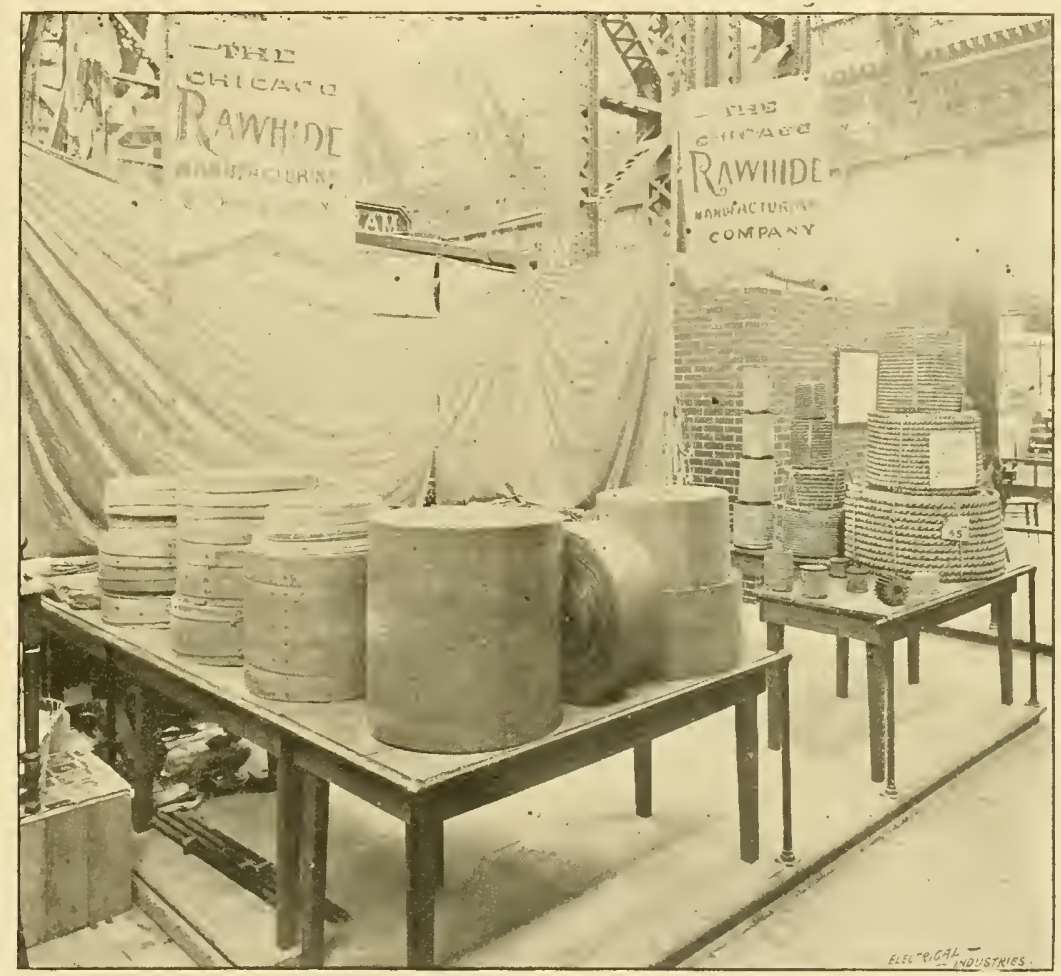

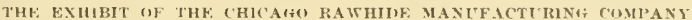

The P. A B. motor cloth for protecting the motors from dust, murl, and water thrown by the wheels, now being used to a large extent by street railways is also shown. There is also displayed samples of the P. \& B. wooden under ground conduit. The methol of putting up, these goorls for the market is shown in the great variety of sizes and shapes of the packages exhibited, from the small half gill can that lin'ms the apex of the pyramids to the harrels that ocempy a comer of the space.

The large works of this cumpany arr locited at Bound Brook, X. J., from which point the goods are distributed through its various agencies over the Enited states. Th. main office of the company is at No. 2 Liberty St.. New York, and branch ottices at 871 The Rookery, Chieago, and at 116 Battery St., San Franeiseo, Cal. Mr. P. H. Hover and Mr. Saml. Cochrane are in charge of the exhibit. strength of the hide. It is especially adapted for belting, ropes, for rope transmission. Jace leather. harness leather and many other purposes.

Arranged on tables about the space, as shown in the accompanying illustration, are displayed the different rawhide products manufactured by the company. On the table at the right are placed a number of sizes of rawhide rope from one quarter of an inch in cliameter to an inch and one-half, also simples of twist belting from one thirty second of an inch in diameter to three eighths of an inch are shown.

Another interesting part of the exhibit is the display of rawhide packing. For jacking, for pumping and hydranlic machinery, it is said to be unsurpassed, and for this purpose the strands are braided into either round or square forms and in size from one quarter inch to as large as is desired. 
For the past 12 years the company has been making rawhide pinions for various purposes, and with the adoption of electric traction on street railways, ic was the first to manufacture rawhide pinions for electric railway motors. With their extended experience as pioneer manufacturers of rawhide goods they have ever since turned out only the best that ean be produced. Sample pinions are shown, together with the blanks from which they are cut. The company also manufactures a trolley rope that is rapidly coming into use, as it fills the place better and is much more durable than the cotton rope.

Rolls of that belting, both single and double, from threequarters of an inch to $2 t$ inches wide are exhibited, in the manufacture of which great pains are taken to make the best that the hide will produce. Special care is taken in the selection of the hides, and in the stretching, trimming and all other important points, the best of materials only being used. The company makes a specialty of dynamo belting, for which they have an extensive trade both in this country and in Europe, and which is rapidly growing. These belts for driving dynamos being a non-conductor of electrieity, users do not experience the heavy static discharge usually found, a point which is recognized as of great importance.

Lace leather is shown in sides and eut in all widths. lumense quantities of this leather is used for this purpose, for which it is specially adapted, being thin and pliable, and yet very strong and durable. These qualities make it valuable for ropes and bridles, for which purpose it is used in the west by the cowboys. The company also furnish large quantities in sides and straps for harness. Samples of these straps and hamess leather are also shown.

For a practical exhibit the company has a 38 -inch belt and an 18-inch belt in daily operation, which connect the Willans engines to the line of shafting in the British section. They run very smoothly. A sample of the rawhide rope can be seen in operation in the neighboring exhibit of the Webster Manufacturing company. It is used to show a particular system of rope transmission for shaftiug and dyumos, and for any work where it is difficult to apply flat belting. Banners about the exhibit call attention to the company and its exhibit.

Schaffer \& Budenberg, of New York, make a very attractive display of engine and boiler appliances on the main aisle of Machinery Hall, just east of the large water tauk. The center of the space contains a large glass case in which is exhibited a full line of pressure gauges, ranging through all capacities and fitted for every class of service. A superior display of speed indicators, recording gauges, tachometers, and pyrometers is made. The Thompson indicator and Prof. Carpenter's calorimeter, instruments made only by this company, are also features to be noticed. Upon raised platforms at the sides of the space are shown samples of the "Acme" steam trap, Holtz's reducing valve, steam jet pumps and both exhanst and live steam injeetors. L pon the rear walls, which are covered with dark felt, are bung plotographs of the company's factory at Brooklyn, N. Y., and a large frame, containing an artistically arranged collection of medals, presented to the company for displays made at various international exhibitions since 1850. An ornamental column, supporting a combination of brewers' gauges, surmounted by a golden eagle marlis the corner of the space. A handsome Brussel's earpet and a fancy railing do much to complete a very tastefully arranged exhibit.

\section{ELECTRICAL INDUSTRIES.}

\section{PTBLISHED EVERY TBURSDAY BY THE \\ ELEGTRICAL INDUSTRIES PUBLISHING COMPANY, INCORPORATED 1809. \\ MONADNOCK BLOCK, CHICAGO. \\ TElephoNe Bartison 159.}

E. L. Powers. Pres. and Treas.

E. E. WOOD, SECRETARY.

E. L. POWERS,
H. A. FOS'TER,
W. A. RENINGTON,
E. E. WOOD,

EDitor.

A ssoc IATE EDitok:

FLOYD T. SHORT,

Eastern Manager.

A DVE RTISING: DEPARTMENT.

EASTERN OFFICE, WORLD BUILDING, NEW YORK. World’s Fair Headquarters, Y 27 Electriciły Building.

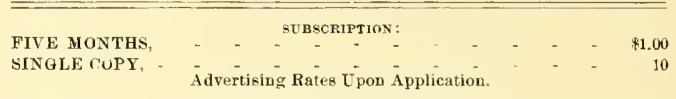

News items. notes or communications of interest to World's Fair Visitors are earnestly desired for publication in these columns and will be heartily appreciated. We especially in ite all visitors to call upon $2 \mathrm{~s}$ or send address at once npon their arrival in city or at the grounds.
ELECTRICAL INDUSTRIES PUBLISHING CO.

MES PUBLISHING CO..,
MOnadnock Block, Chicago

THE present system of distributing the baurls about the grounds of the Exposition and in the galleries of the buildings is a marked improvement. The popular pieces played seem to be better appreciated, and certainly draw as large if not larger crowds.

The present attendance at the Fair is nearly double that of six weeks ago. The railroads are being taxed to nearly their full eapacity in the transportation of the crowds, and accomodations on the regular trains are being engaged a long time in advance. The special excursions on state days have brought large numbers that have greatly increased the attendance on those days.

The dury of Awards has nearly completed its work. Dr. Rowland, Dr. Mendenhall, Dr. Duncan, Prof. Barker and Prof.Dolbear have already returned to their respective homes and duties; many of the other members are away for a few days. A resolution was passed by the Jury recently making five members a quorum for the transaction of business. Tests of lamps and dynamos are still in progress. A report is now being prepared for publication describing the progress made in different branches of the electric art. The awards to competing companies made by the Jury will be announced during the coming week before the Jury disbands.

WE copy from the September number of a London contemporary the following paragraph which we are surprised to see appear after such descriptions and illustrations as have appeared in the various journals. We are sorry that the writer las not seen the electrical exluibits in the Exposition, and that he so foolishly accepted without question the opinion of the alleged expert. But the last parapraph would imply that our contemporary was narrow-minded and lacked the cosmopolitan spirit that has characterized the foreign representatives to the Fair.

"Further reports from the Columbian Exposition go to show that, from a manufacturer's stand-point, the electrical section is practically a failure. The spectacular effects with illuminated columns and screens have, of course, been very 
fine, but, we are informed, on the authority of an expert that there are very few exhibits of new electrical apparatus and that many of the types of machines exhilyited are of patterns which would be considered obsolete here."

"When the scheme of the World's Fair was first mouted we suggested that the British manufacturer need expect to derive but little advantage from sending bis wares to the Exhibition and in view of the high tariff charges the only result could have been that the American manufacturers would have had a good opportunity of availing themselves of English researeh and invention ats exemplified by the types of apparatus exhibited."

\section{WORLD'S FAIR NO'TES.}

The operating force of the Electrieity Building, con sisting of nearly fifty employes, had a group photograph taken last Saturday.

The Electrieity Building now boasts of having the only Irish flag on the grounds, outside of Midway. It is one of the electric Hags deseribed in our last issue, and is hung in honor of the proposed risit of the Lord Mayor of Dublin.

After having given away over 5,000 souvenir horseshoes, the Electrical Forging Company has secured a concession and now sells then at 25 cents each. The number of spectators continually watching the forging process demonstrates the popularity of "working" exhibits.

The west restaurant of the Wellington Catering Company in Electricity Building, which has been closed for sonse weeks past owing to insufficient patronage, was re opened on Tuesday. This is certainly an indication of the popularity of the electrical displays.

Mr. Tesla is expected to return to Chicago the later part of this week and will then conduct in person some of the high frequency experiments which have made him so famous. The Westinghouse dark room will be used for the displays, but no definite time has yet been fixed.

The Hertz retlectors, which have been promised some time, are now shown in operation in the exhibit of Queen \& Co. The reflectors are parabolic in form and when an oscilatory clischarge of a high potential current takes place at the focus of one, the effect is reproduced at the focus of the other,

The Westinghouse company has placed a glass floor in one of the cars exhibited in the railway department so that the operation of the motor ean be easily seen from above. The Columbus egg, which has proven such an attraction to the Westinghouse sprace, is now shown the first fifteren min

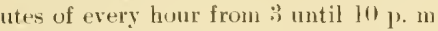

Visitors to the Electricity Building lave foumd a new attraction in the Hoggson time stamp which has recently been placed in the exhibit of the E. S. (ireeley Co. The stamp shows the date and time of day and the machine is electrically comnected with a clock so as to change the tim indicated erery minute. On account of its many commer cial uses the device is attracting considerable attention.

Intw exhibit in the Electricity Buikling is the Meymr: Ballot Machine, which has a space near the exhibit of Eng lish telegraphs. The machine consistis of a metal booth with interlocking entrance and exit dours. On one side of the booth are placed the various party ballots in perpen. dienlar rows and opposite each name a plug, which, when pushed in, registers the vote on an automatic counter and at the same time locks the plugs on the other tickets. thus preventing a voter from roting for two men for the same oftice or voting two ballots. When the polls are closed the back of the machine is remored and the rotecan be immediately taken from the different registers and an nounced. No electricity is used except for lighting pur poses.

The Lniversity of lllinois make a very ereditable display from the department of electrical engineering on the main Hoor of the state building. A direet current dynamo, mounted on a cradle dyanometer and driven by a motor, furnishes current to several are lamps and for the lighting of a number of ineandescent lamps, arranged. to form the college monogram placed above the exhibit. A fully equipped switchboard, a water rheostat, a number of sets of apparatus for typical experiments in electrical measurements and varions styles of storage batteries, some of which were made by students, are also exhibited. A very good idea of the work done at the school may be gained by examining the photographs of students engaged at work in the rooms of the electrical laboratory.

In the southeastern part of the gallery of Electricity Building, The Consolidated Electric Storage Company has an exhibit of storage batteries. It also gives a practical demonstration of the methods of wiring for them when used in connection with an electric lighting plant. A new battery is shown designated as $15 \mathrm{I}$ which is designed especially for electric lighting where heary currents for an uninterrupted period of several hours are required. This battery has a capacity of 350 ampere hours. The great economy of storage batteries in isolated plants has brought many of them into use. In isolated plants. especially in plants for lighting summer residences the storage battery has been found a valuable adjunct. It relieves the maehines of excessive loads and furnishes the necessary lights during the hours when but few lights are required.

The scenic theater of the Western Electric Co. is playing to crowded houses and hundreds are turned away disap. pointed at not obtaining admission. Several new features bave been recently introduced. In the day time the scene is now enlivened by a military procession consisting of a band and several regiments of militia and cavalry. During the rain storm, peasants earrying umbrellas pass across the bridge, while toward dusk a load of hay may be seen hurrying toward the the castle. The booth which was formerly occupied by the theater has been remorleled and is now handsomely fitted up as an office. Separating the two rooms is a screen, consisting of a large stained glass window illuminated by incandescent lamps. The subject of the picture is "The Fairy Queen" and the window is sairl to be the finest stained glass at the Fair. Lpon the walls of the rooms, transparencies of some of the large buildings of Chicago, which are fitted with the Western Electric Company's system of incandescent lighting are shown. In the lighting of the booth some new ideas have been introduced. The walls are delicately tinted and have a figured border, covered with a fine ganze, concealing the incandescent lamps entirely from view, but allowing the light to beevenly dissem inated throngh the rooms, thus producing a softened effect. Two miniature illuminated fountains, changing their colors constantly, add to the general attractireness. These foum tains are a novelty being introduced by the Wester'n Elec tric Co. and are sure to become popular as ornaments for parlors, hotel offices, etc. A model of a new alarm system, which will be of general interest, is now being installed by the company and other additions to the exhibit a re promised 


\section{PERSONAL.}

Mr. R. T. MeDonald, of Ft. Wayne, is among the arrivals this week.

Mr. M. C. Canfield, of the Brush Electric Co., Cleveland, O., is at the Fair.

Mr. D. S. Snyder, of Point Pleasant, W. Va., visited the Fair recently.

Mr. T. F. Dorris, electrician, Newark, N. J., is visiting the Fair this week.

Ir. H. B. Church, of the electrical department, is taking a ten days' vacation.

Mr. David M. Keith and family, of Denver, Colo., registered at the Everette recently.

Mr. Matt. M. Merritt, of the Boston Ine. Lamp Co., paid the Fair a flying visit last week.

Mr. F. R. Wells, representing the Western Electric Co. at Antwerp, Belgium, is visiting the Fair.

Mr. S. Ekstron, Supt. of the alternating department of the General Electric Co., is now in the eity.

Mr. J. G. Biddle, chief of the electrical aepartment of Queen $\&$ Co., spent several days at the Exposition last week.

Mr. Jas. P. Provost, with the K. D. Nuttall Company, Alleghany, Pa., is spending a few days at Jackson Park.

Judge Taylor, of the Et. Wayne Co. has been an interested visitor in the Electricity Building during the past week.

Mr. R. S. Williams, of the mining and power department of the Thomson-Houston factory, is spending some time at the Fair.

Mr. Otto Lemisch, electrical engineer, Klagenburt, Austria. called at the World's Fair office of ELECTRICAL INDUSTRIFs Tuesday.

Mr. F. J. Surth, manager of the electrical department of E. S. Greeley.\& Co., is now at the Fair to attend the operator's conveztion.

Mr. B. B. Ward, the inventor of the Ward Arc Lamp, accompanied by his wife, bas been viewing the sights at the Exposition the past week.

Mr. F. F. Kinney supt. of the Rankin Electric Light \& Power Company of Tarkio, Mo, has been a visitor at the Exposition during the past week.

Mr. J.H. Fedeler, who has been with the operating department since the opening of the Exposition, leaves this week to take up studies at Harvard.

Mr. A. W. Cook, secretary of the Susquehanna Electric Light, Heat \& Power Company, Susquehanna, Pa., paid his respects to ELECTRICAL INDUSTRIES the fore part of this week.

Mr. Geo. W. Brown, mgr, of the Belknap Motor Company, returned to his home in Portland, Me., on Wednesday of this week. Mr. Winters is now in charge of the company's exhibit.

Mr. W. S. Townsend, electrician for the North End street Railway Company, Woreester, Mass, is visiting the Fair this week and called at the office of ELECTRICAL INDUSTRIES.

Mr. Ralph IV. Pope, secretary of the American Institute of Electrical Engineers, left on the 10th for New York to complete arrangements for the meeting of the Institute on the 20th. He will return about the 25 th.

\section{A Correction.}

In our last issue appeared a statement that Mr. Mm. H. MeKinlock had associated himself with the Enterprise Electric Company. We have since been informed that the statement is incorrect. Mr. MeKinlock is located at offices 319 and 3:0 Man hattan building, where he will be pleased to see his old friends.

\section{BUSINESS NOTES.}

The Electrie Appliance Company is showing the trade a new iron box bell that has a number of small improvements over the old form of bell in au automatic set serew on the adjustment an armature spring that is attached to the soft iron armature without rivets; and a frame made entirely of soft stamped iron. They state that the beil is a winner. It is known as the "Acme" iron box bell.

Chief Barrett, of the department of Electricity at the World's Fair, has found the operation of the Reliance Columns on the
World's Fair boilers so satisfactory that he has decided to equip the various boilers in the electric and street railway plants in his charge with Reliance columns manufactured by the Reliance Gauge Co., Cleveland, Ohio, as rapidly as possible, believing that these appliances are sources of economy, as well as a protection to life and property. He has already equipped the boilers in the plant of the Cicero \& Proviso Street Railway Co. with them.

\section{DEPARTMENT OF ELECTRICITY.}

OFFICES: SECTION R, ELECTRICITY BUILDING.

Chief, John P. Barrett,

Assistant Chief, J. Allen HoRnsbi.

General Superintendent, J. W. BLAisnel.l. Assistant, Willis Hawler.

Electrical Engineer, W. W. Рвıм.

\section{A V I:IICAN INSTITUTE OW RLECTRICAL ENOINEERS.

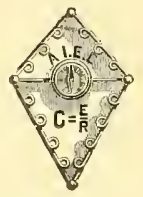 \\ World's Fair Headquartere, \\ SECIION S, ELECTRICITY BUILDING. \\ RALPH W. POPE, Secretary. \\ Open from 9 a.m. to 5 p.m.}

\section{Amusements.}

Hooley's Theater-Mr. E. S. Willard, Mon., Tues., Wed., in "The Professor's Love Story," Thurs. in "Judah." Fri. and Sat. in "Wrealth." 149 Randolph street.

Columbia Theater-Daniel Frohman's Lyceum Theater Co. in "The Charity Ball." 108 Monroe street.

Grand Opera House - Sol Smith Russell, in "A Poor Relation." 87 Clark street.

Auditoriom-Imre Kiralfy's Spectacle "America." Congress street and Wabash avenue.

MoVicker's Theater-Denman Thomson, in "The Old Homestead." 82 Madison street.

Chicago Opera Hovse-American Extravaganza Company, in "Ali Baba, or Morgiana and the Forty Thieres." Washington and Clark streets.

Schlller Theater-Chas. Frohman's Stook Company, in "The Girl I Left Behind Me." Randolph, near Dearborn.

Haverly's Casino-Haverly's United Minstrels. Wabash arenue, near Jackson street.

Trocadero-Vauderille. Michigan avemue near Monroe street.

The Grotto-Vaudeville. Michigan avenue near Monroe street.

Buffalo Bill's "Wild West." 63d street. Daily at 3 and 8.30 p.m.

Everyone who comes to visit Chicago eomes with a desire to see "America" at the Auditorium. Though now in the fifth month of its season its drawing powers are unimpaired. The attractive force of the splendid spectacle is as irresistible as a maelstrom.

Trocadero is having erowded houses. To lovers of vaudeville the Trocadero offers a special list of good attractions. This week Mrs. Alice Shaw, the wondrous whistler, and Jules Levy, the cornetist, both of whom are well known, are delighting the guests of the house. Sandow is introducing new evidences of his strength which are surprising and wonderful.

The crowds at Buffalo Bill's Wild West have been increasing. 'The new scenes, especially Custer's Last Ride, has awakened new interest in these performances. Visitors to the Fa: $r$ consider this show as one of the most interesting sights of the World's Fair season, and set aside an afternoon or evening fol seeing it.

"Ali Babi" began last sunday night the sixteenth week of its World"s Fair run but this engagement cannot be regarded as unusual or due entirely to the presence of the great Exposition, for last summer the same spectacle played an engagement of twenty-three weeks to business that was every bit as large as it is doing now. With the exception of a new song, recently introduced by Eddie Foy, entitled "They All Take After Me," which has made a big hit, there is nothing new in "Ali Baba". The bright and sparkling character of the entertainment, however, the abundance of good music; the attractive scenes, the rich costumes and the general blithe and merry nature of the piece serve to lieep it ever fresh and make it interesting, no matter how many times it is seen. 


\section{OUR IMPROVED SYSTEM}

\section{... of ... \\ Automatic Firs Alarm,}

covered by patents recently issued, is the

embodiment of all factors contributing to the

GREATEST SAFETY,

and the MOST RELLABLE

PROTECTION FROM FIRE.

Western Electric Company, CHICAGO and NEW YORK. 
ELECTRICITY BUILDING-EXHIBITORS AND THEIR LOCATION.

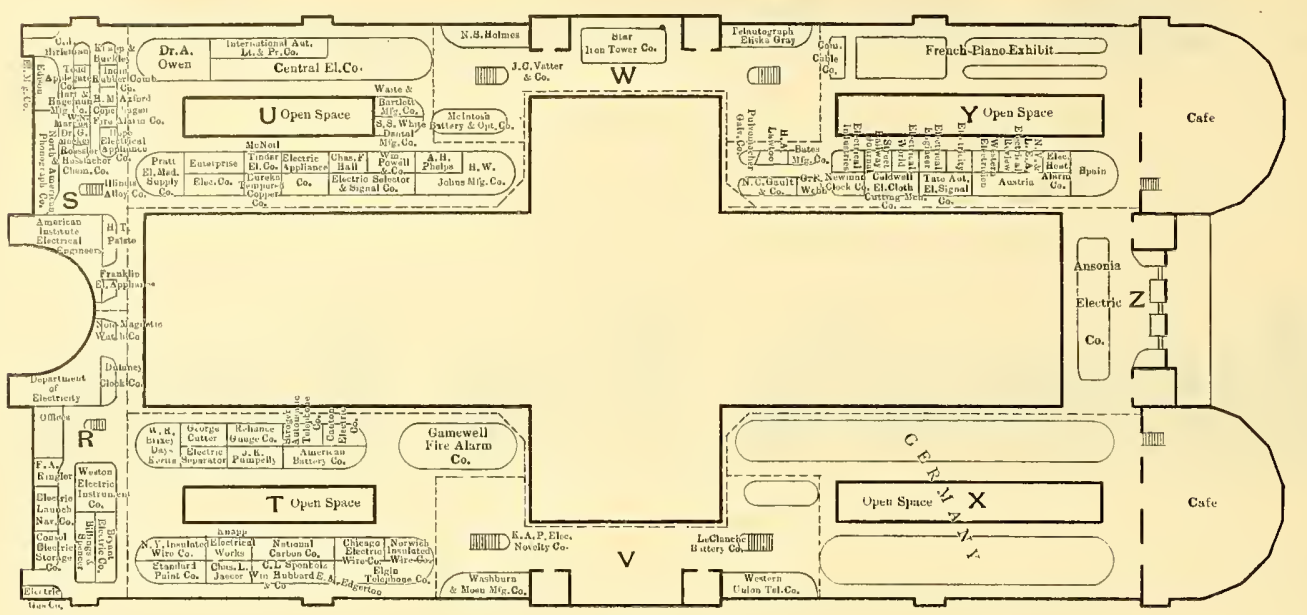

GALLERY.

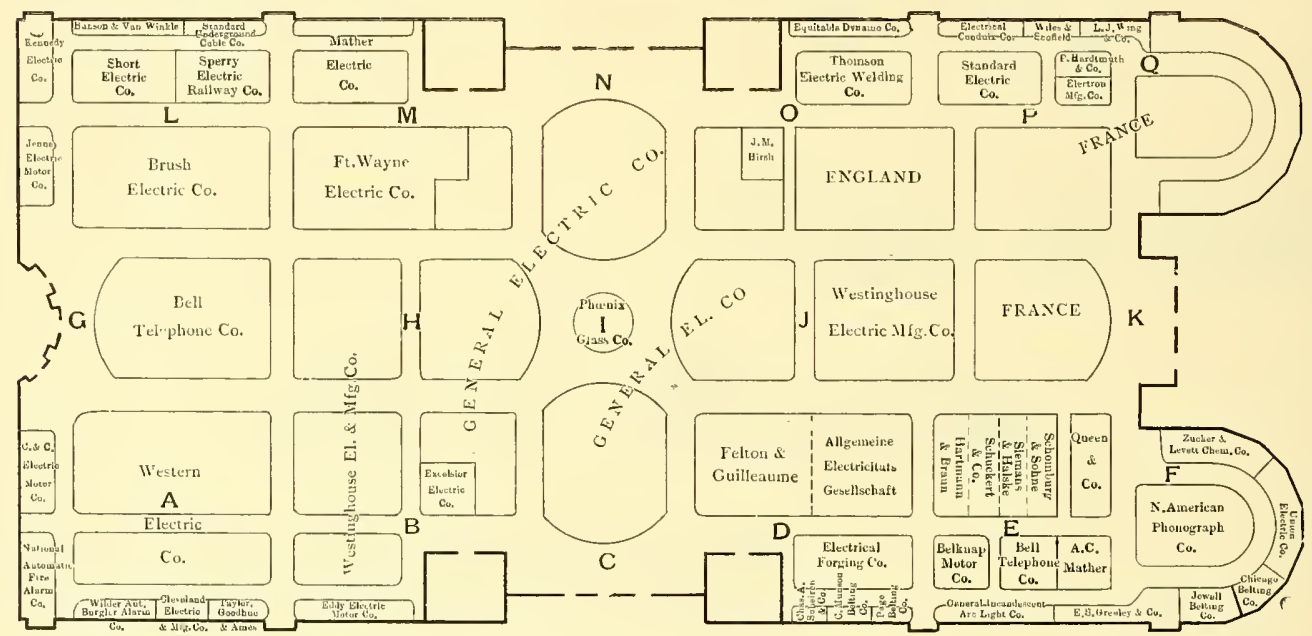

MAIN FLOOR.

\begin{tabular}{|c|c|c|}
\hline Exhibitor. & & Exbibitor. \\
\hline 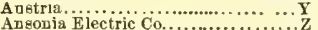 & Electrical Review .................. & Jaeger, Chas. L........... \\
\hline Am. Intt. of Elec. Eng.. ............. & Electric Gas Co & Jewell Belting Co............ \\
\hline American Battery Co ........... & Electrical Engineer. & -F, nuey Elec. Motor Co. \\
\hline Axiford, H. M1............. & $\begin{array}{l}\text { Electrical World..... } \\
\text { Electiol }\end{array}$ & Knapp Electrical Works. \\
\hline Allg. Elec. Gesellschait... & Eddy Ejectric Motor Co............ & K. A.P. Elec. Novelty Co. \\
\hline Bates Mfg, Co................. & Excelsior Electric Co.............. & Kvapp \& Backley.......... \\
\hline Bryant Electric $\mathrm{Co}$ o................. & Electrical Forging Co............... & Kennedy Electric Co. \\
\hline Billings \& Spencer.................. & Equitable Dynamo Co............ & Lawton, H. A........... \\
\hline 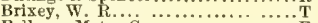 & Elektron Mig. Co.................... & LeClanche Battery Co... \\
\hline 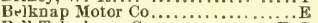 & Electrical Conduit Co................ & McNeil-Tinder Elec. Co \\
\hline Bell Telephode Co.................. E-G & Eugland .................. & Marcos, $\mathrm{W} . \mathrm{N}, \ldots . . . .$. \\
\hline Braeh Electric Co ................. & 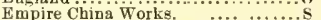 & Yreeker, Dr, G \\
\hline Cald well El. Cloth Cut. Mch, Co.. & Franklin Elec. Appliances. & McIntosh Brt \& Opt Co: \\
\hline Consol. Elec. Storage Co ....... & French Piano Exhibit....... & Munson, C. Belting Co \\
\hline Cutter, George ............. & Felton \& Guilleaume. & Mather, A. C. Belung \\
\hline & & llatber Electric Co. \\
\hline Chicago Elec. Wire co................ & t. Wayne Elec. co... & Newman Clock Co....... \\
\hline Hire Alarm Co.... & Co., N. C ............ & Non-M-gnetic Watch Co. \\
\hline Ceutral Ele & Gamewell Fire Alarm Co.............. & X. Y. Insulated Wire Co \\
\hline Co..... & General Electric Co.... B-H $-\mathrm{N}-\mathrm{C}-\mathrm{d}$ & National Cart \\
\hline or $\mathrm{Co} . . . .$. & General In'and's't Arc L't Co........ & Norwich Ins. Wire Co... \\
\hline$\&$ Mfg, Co......... & Greeley, E. S. \& Co & North Am. Phonograph $\mathrm{Co}$ \\
\hline Co............... & & $\mathrm{N}, \mathrm{Y} \& \mathrm{~L}, \mathrm{E}, \mathrm{A}$ \\
\hline Dutaney Clock Co.......... & Hnbbard, wm $\mathrm{w}$ Co & Nat Aut Fire Alarm $\mathbf{C o}$ \\
\hline Department of Electricity. & IIirleman, C. J........ & Nat. Engraving Machine Co. \\
\hline ELECT & Hegeman ii & \\
\hline \& Nav. Co............... & Elec. Appliance Co... & Phoenix Glase Co. \\
\hline ator.................... & has. F.. & Paiste, H. ' $\mathbf{T}$........ \\
\hline ............ & N. S....... & Pulvermacher Galv. Co. \\
\hline Co.... & \& Braun..... & Pumpelly, J, K ........ \\
\hline Co... & \& Van Winkls. & Pratt El iled sup Co \\
\hline ect. co,........... & Hirsb, J. M ........... & Powell Wm i co. \\
\hline Eureka Temp. Copper vo ........... & Hardtmoth, F.. \& Co... & Phelps, A. H ..... \\
\hline Elec & Hlinois Alloy Co................. & Page Belt ing Co.. \\
\hline Elec & Internat. Aut. L't \& $\mathrm{P}$ r $\mathrm{Co}$ & \\
\hline Electric & India Rnbber Comb Co................. s & Ringler, $\mathrm{F}, \mathrm{A}$............ \\
\hline
\end{tabular}




\section{WE ARE STILL HARD AT WORK ON \\ OUR NEW CATALOGUE}

which we hope to present to our friends in a very few weeks; in the meantime do not fail to make good use of our last edition which we trust you always have convenient for reference

If sou are without

a copy send us
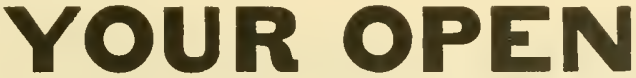

ORDERS

and we will guarantee satisfactory prices and first-class material, and that your order will have

INTELLIGENT-EXECUTION.

ELECTRIC APPLIANCE COMPANY,

Electrical Supplies, 242 Madison Street, CHICACO.

THE MONTHLY ISSUE FOR SEPTEMBER

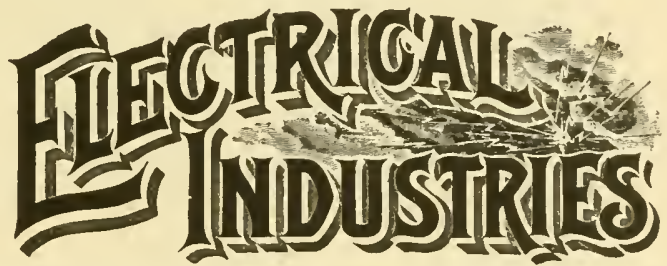

Should be read by everyone interesled in electrical matters, in its lable of contents is the following:

"World's Congress of Electricians."

"Nikola Tesla's Lecture."

"Love Undergronnd Electric System in Washington." By. M. D. Láw.

"Gas Engines as Applied to Electric Lightt Work." By Gieo. A. Farwell.

"Tle Underground System at the World's Fair."

"Electric Railway Plant of the Clicago North Shore Railway Company."

Togetler with illustrations of tle recent applications of electricity.

The paper also contains regularly

A Buyer's Directory of Manufacturers and Dealers in Electrical Supplies and Appliances.

A Complete Directory of Electric Light Stations in North America and a Complete Directory of Electric Railways in North America.

These directories are revised each issue to the date of going to press and are to be found in no other electrical journal in the World. Its articles are read carefully and its directories nsed constantly by all the buyers in the trade. These facts make it withont a superior as an advertising medium. Sample copies and rates sent on application.

Sulbscription price $\$ 3$ per year. Six months trial $\$ 1$, if ordered during September.

\section{ELECTRICAL INDUSTRIES PUB. CO.,} Monadnock Block, CHICAGO.

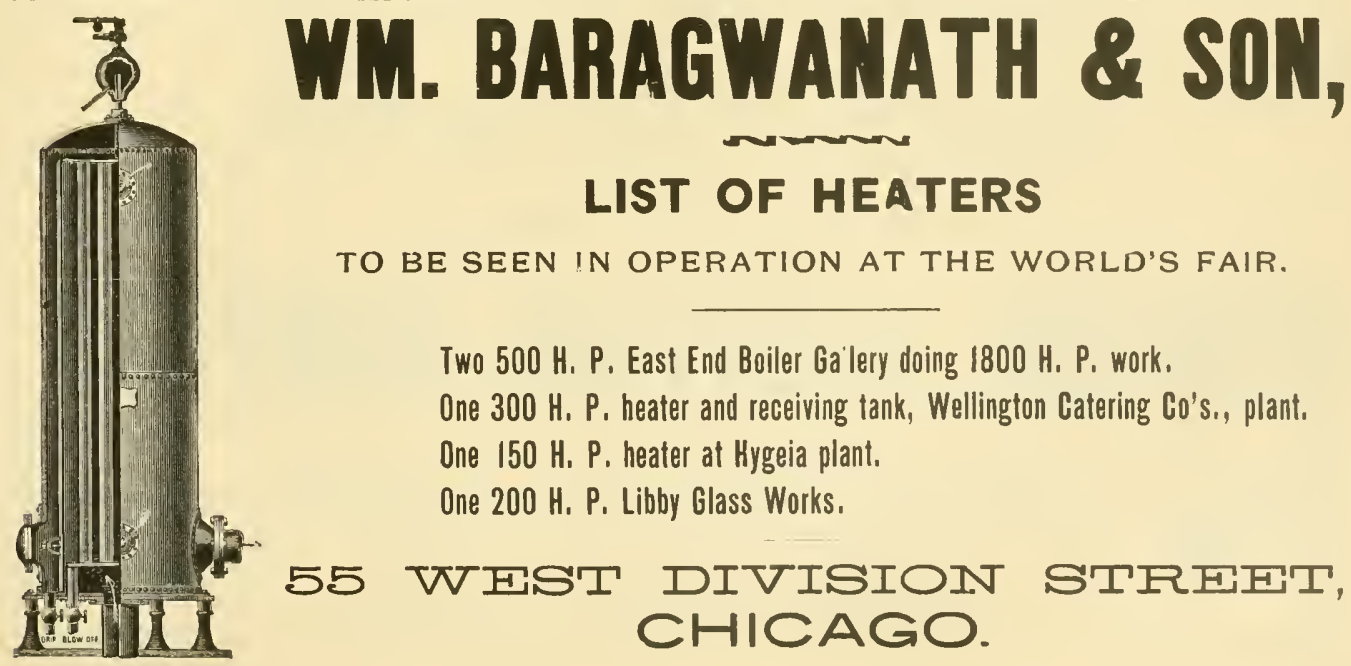


(1)

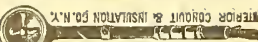

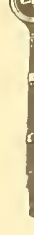

fos
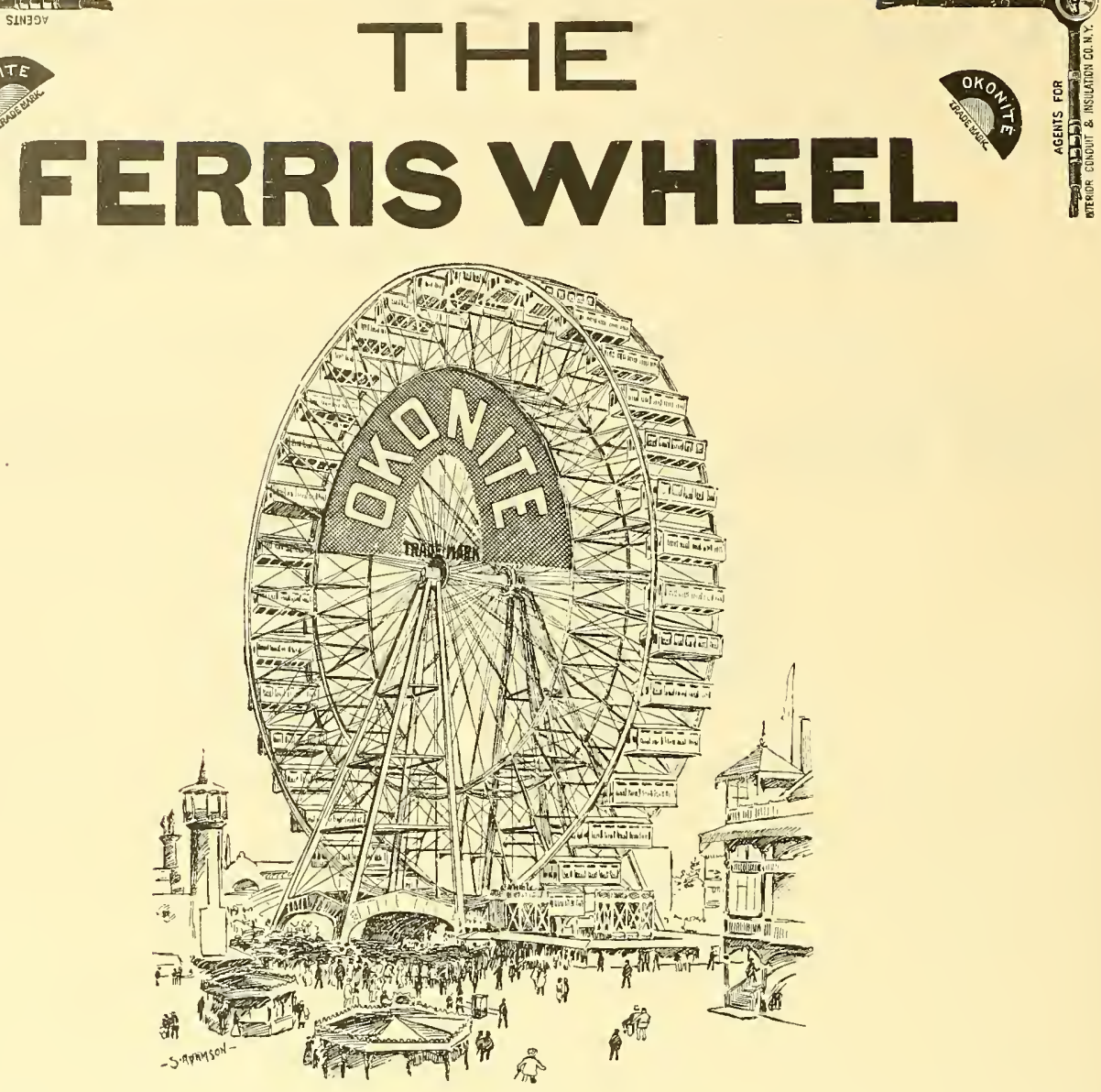

When you visit the World's Fair, you will naturally take a ride on the FERRIS WHEEL and be interested in the ELECTRIC LIGHT INSTALLATION, which is wired throughout with

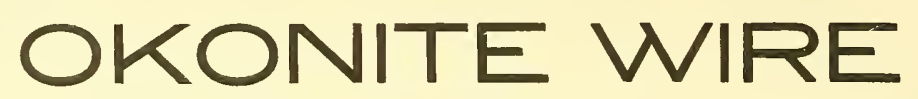

FURNISHED BY THE

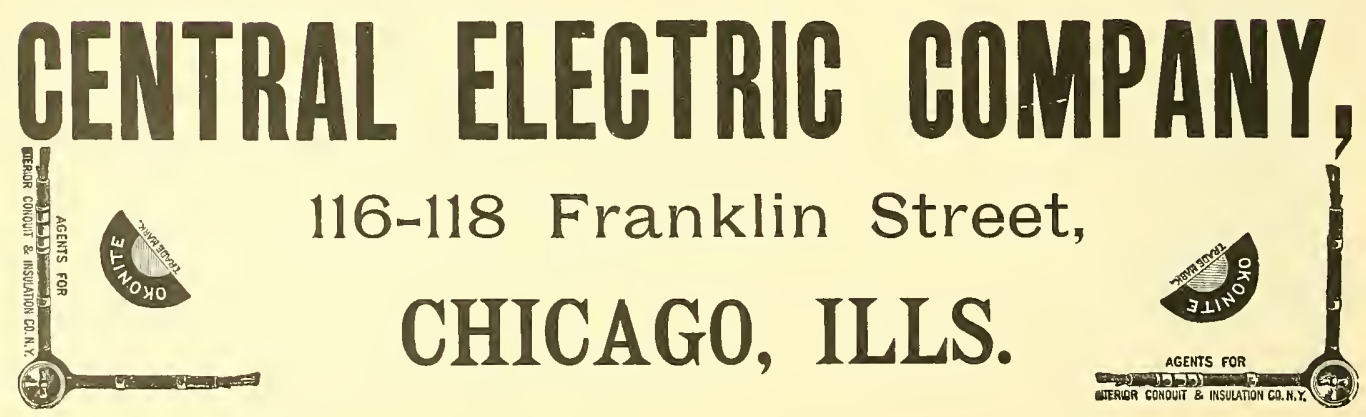


COMPANY, NEW YORK.

192 Broadway and II Joh' Stree".

MANUFACTURERS OF ARC LIGHTING APPARATUS FOR EVERY PURPOSE A SPECIALTY The CLARK ARC LAMPS for use on EVERY CURRENT, have the reputation of being the best and most durable of any ever made in the United States.

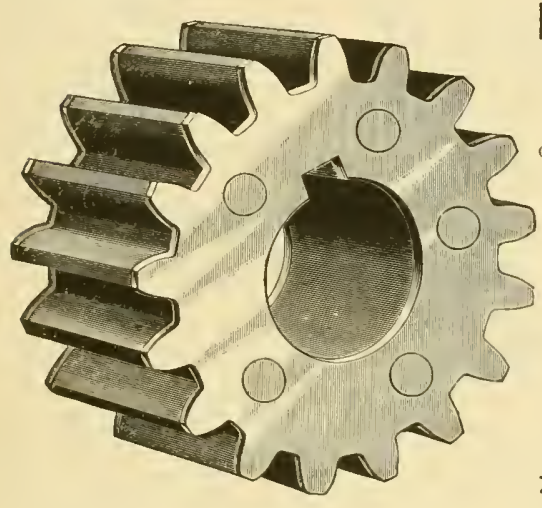

RAWHIDE PINIONS FOR ELECTRIC MOTORS A SPECIALTY.

RAWHIDE DYNAMO BELTING

Greatest Adhesive Qualities. A Non-Conductor of Electricity. Causes Less Friction than any other Belt.

THE CHICAGO RAWHIDE MANUFACTURING CO. THE ONLY MANUFACTURERS IN THE COUNTRY

LACE LEATHER ROPE AND OTHER RAWHIDE

GOODS

OF ALL KINDS

BY KRUEGER'S PATENT

This Belting and Lace Leather is not affected loy steain cr fiampness never becomes hard; is stronger, more durable and the most econm. ical Relting mate. The Raw. Transmission is

75 Ohio Street,

OHICACO, UL

GENERAL OFFICES: 625 Home Insurance Building.

WORKS: So. Canal Street,

CHICACO.

STANDARD SYSTEM

AT THE

WORID'S FAIR.

MACHINERY HALL, Sec. Q, 2 Standard Arc Dynamos.

Sec. S, 20 " " "

ELECTRICITY BUILDING. Sec. P, Space 2, Arc Lighting Exhibit.

The Standard Lamps Light the Power Plant, Machinery Hall, Agricuitural Hall, Shoe and Leather Building, and Other Buildings and Portions of the Grounds. 


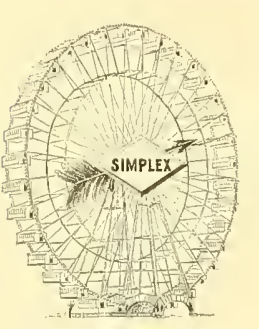

Mile after mile of

\section{SIMPLEX WIRE}

Supplied to the

FERRIS WHEEL

By...George Cutter,

\section{SIMPLEX WIRES}

The Rookery, chicago. George Cutter, Chicago.

INSURE

HIGH

SIMPLEX

INSULATION

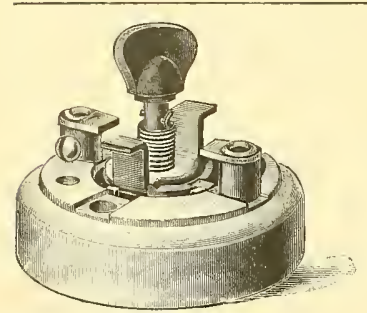

Mad $\rightarrow 5$ amp. S. 5 .

1 a 10 imp. 3 way

\section{XNTRIC}

"That's the Switch"

And we control thal movement.

H. T. PAISTE, 10 South Isth St., PHILADELPHIA, PA.

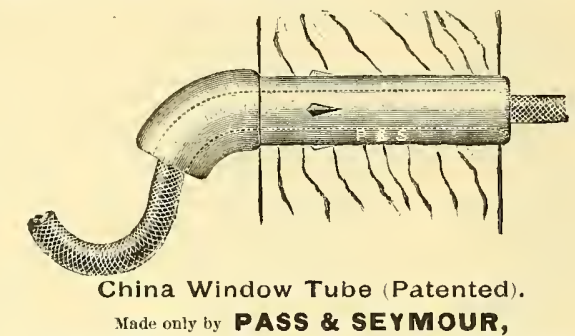

Gsorge Cutter, CHICAGO.

SYRACUSE, N. Y

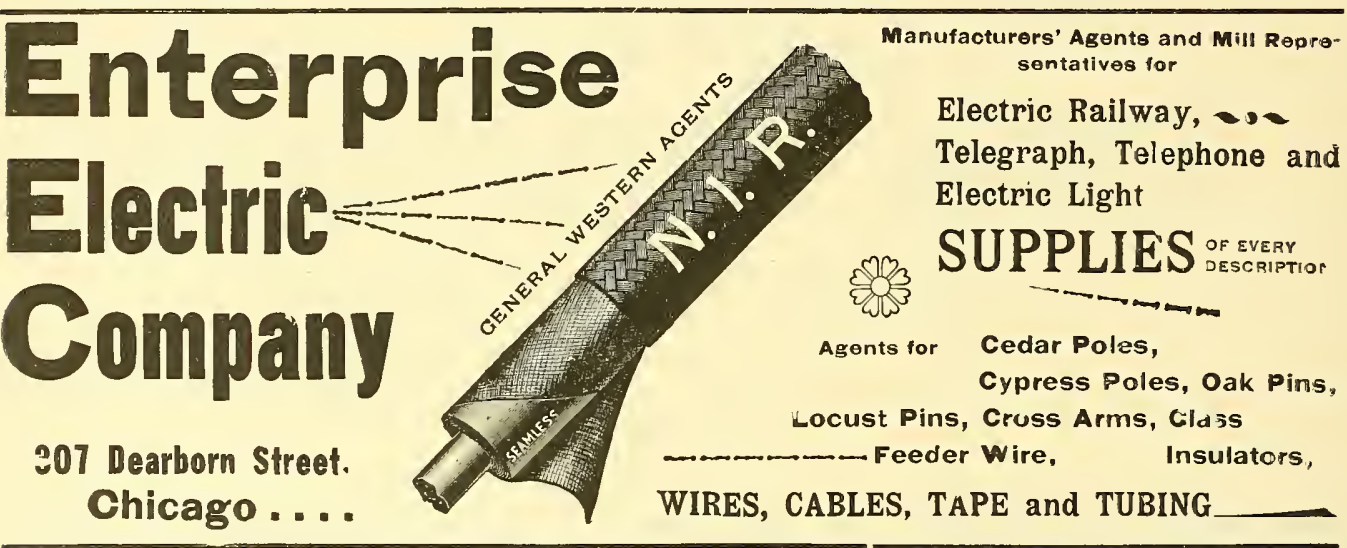

BEAR IN MIND

that the regular monthly issue of ELECTRICAL IN DUSTRIES contains the most cemplete and correct lirectories published of the electric light central stations and tho electric railways in North America.

World's Fair Headquarters Y 27 Elec'ricity Building. CITY OFFICES, Monadnock Block.

Consolidated Elpctric (6. Manufaclurers and Dea'ers in all kinds of

\section{ELECTRICAL . SUPPLIES,}

115 Franklin Street,

\section{WAGNER ELECTRIC FAN MOTORS}

For Inirect or Itternating Currents.

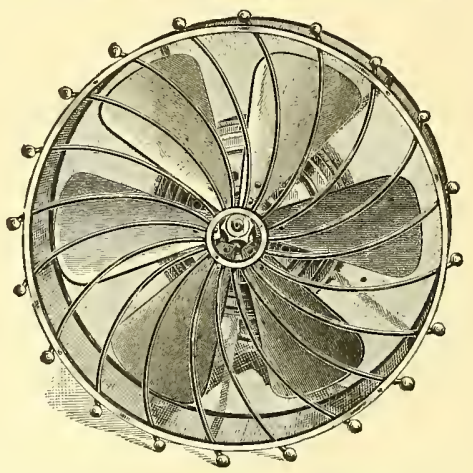

These motors giv a stro: ger breeze with less cousumption of eurrent than

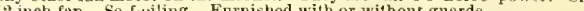

IT WILl PAY YOU tO SEE tHE WAGNER BEFORE BUYING ELSEWHERE

TAYLOR, GOODHUE \& AMES, 348 De arborn Street, CHICAGO. 


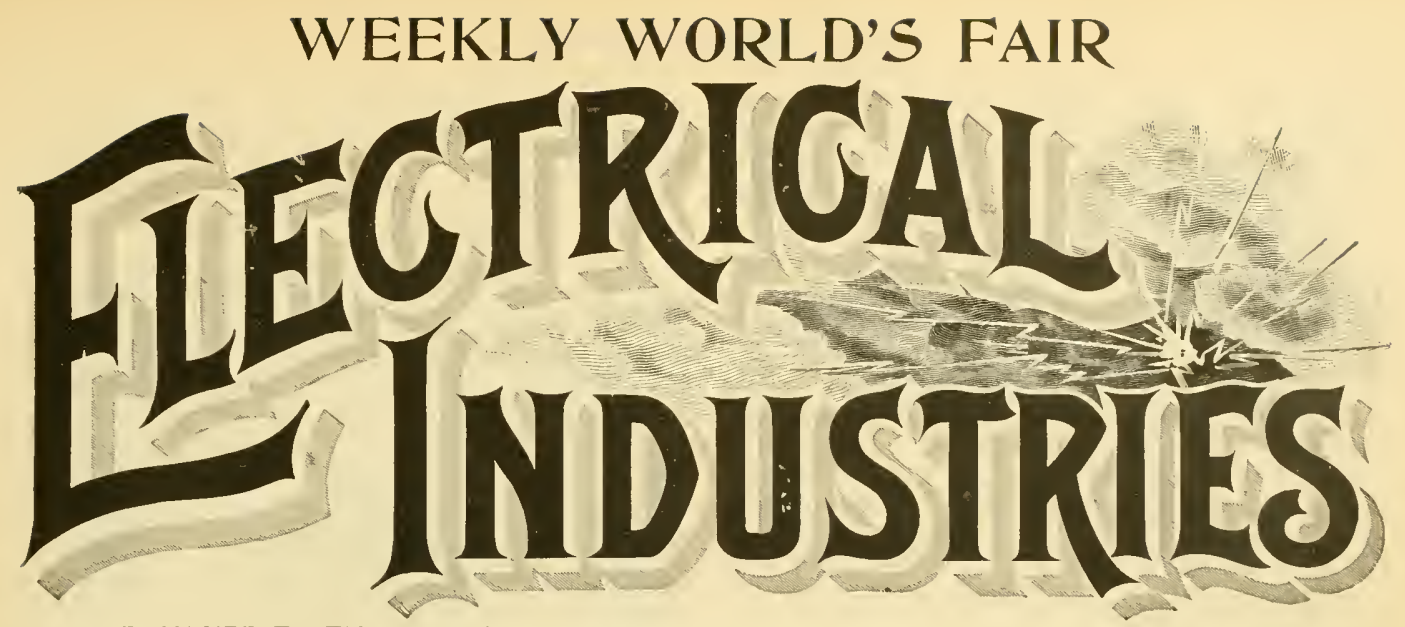

DEVOTED TO THE ELECTRICAL AND ALLIED INTERESTS OF THE WORLD'S FAIR, ITS VISITORS AND EXHIBITORS.

Vol. I, No, 15 ,

CHICAGO, SEPTEMBER 21, 1893.

FIVE MONTHS \$1.00
IEN CENTS A COPY

Exhibit of the Jenney Electric Motor Company.

An exhibit that impresses one with its appearance of comfort and cheerfulness, as well as by the attractiveness of the display, is that of the Jenney Electric Motor Company, of Indianapolis, lnd. Located as it is just at the left of the south entrance to Electrieity Building, few risitors pass through the building with. ont noticing it.

The office erected by the company is neat ly designed. a nd, finisherl without in imitation of hammered copper, it forms an interesting part of the exhilit. The outward appearance is more than equaled by its interior, which has an elaborate wains coting, a handsome ceiling decorated by raised figures, finished in white and lighted by in candes cent lamps. Fan motors keep it cool even on the warmest days. Desk, chairs and an abundance of writing material offer accommodations to the guests of the company.

Above the entrance sparkles in different colors the name
Jenney, an effect prodnced by incandescent lamps shining through the letters formed of eut glass. A't each side are the dates 1878 and 1893 , indicating the period of the company's suceessful existence. The floor of the exhibit is an imitation mosaic, aud is further ormamented by unmerous

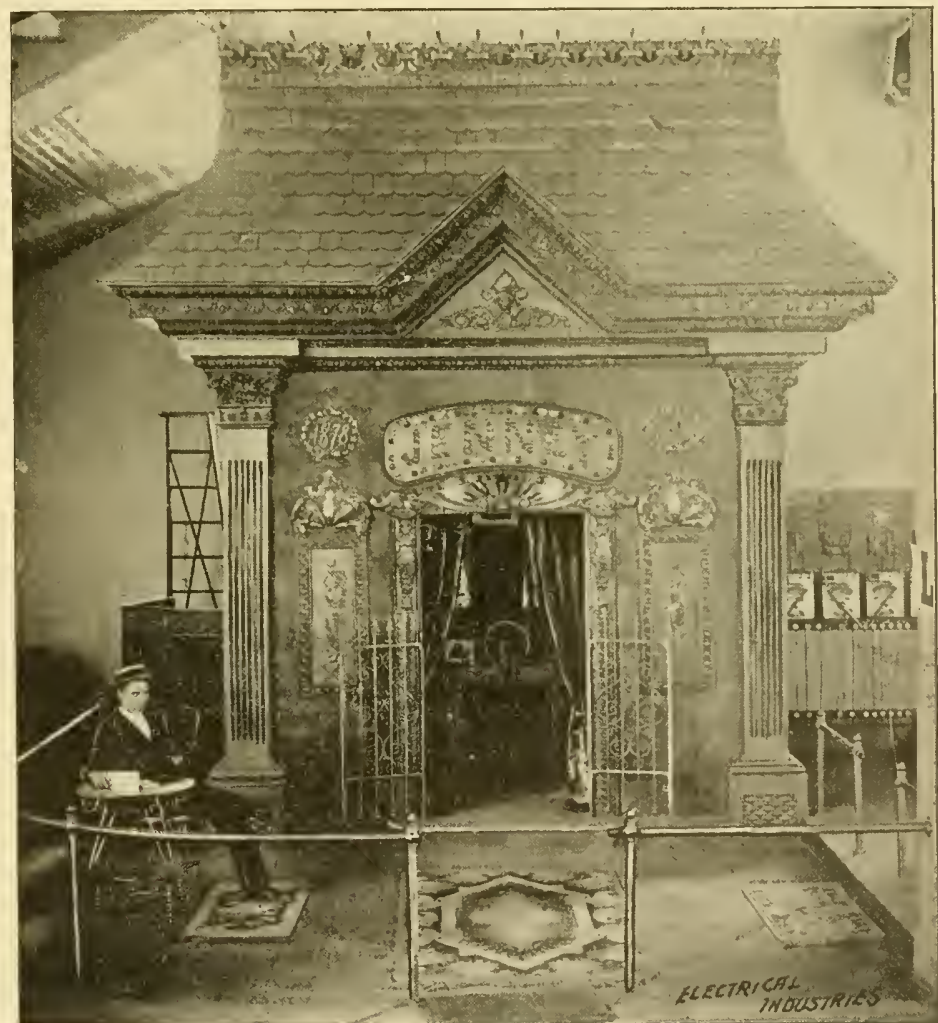

EXHIBIT OF THE , JENAE HLECREL MOTOR COMPAXY. rugs. The exhibit proper consists of elec. tric light and power genera. tors, direct current transformers, automatic motors and starters, and the switeh boarcl which is fitted with the latest improved apparatus for the control of the current and the regulation of the d ifferent ma chines.

The different machines a re shown in prac. tical operation, $t$ he necessary current being sujplien from a $40 \mathrm{k} . \mathrm{w} .5(1)$ volt c o m pound wound generator placed in Machinery Hall. The current from this generator operates a 35-horse power motor directly consected to a 30 kilowatt 110 volt dynamo and a 2\%-horse puwer motor operating a 20 kilowatt 111 volt dynamo. These machines are wired to the switch board, from which point the current is distributerl as de- 
sired. Current for the lights and motors in the exhibit, five horse power to a neighboring exhibit, and current for the beacon light on top of Electricity Building are furnished from this switchboard.

Among the dynamos exhibited are a $40 \mathrm{~K}$, w. 500 volt generator, a 30,20 and 3 K. w. 110 volt dynamos, and a 300 ampere five rolt plating machine. The motors shown are of 35 and 25 -horse power 500 rolt motors and $12,6,1 \frac{1}{2}$ and $\frac{1}{2}$ horse power 110 volt motors. These machines show excellent mechanical skill in their construction and the smoothness with which they run, and their efficiency shows how well they are constructed electrically. The company has given special attention to the construction of directly connected motors and generators and the machines exhibited are the result of extended expe-iments. The six horsepower motor runs a $2 t$ ampere dynamo and to the shaft of the half horse power motor is attached a flexible shaft fitted with a buffer, drill or similar tool to show its advantages in machine shop work.

The switchboard forms an attractive part of the exhibit and among the more prominent objects on it are the automatic motor starters. They are ingeniously constructed and are a valuable protection against a sudden rush of current. Attached to the face of the box is an electro magnet, the coils of which are in series with the fields of the motor. Until the main line switch is closed, or the magnet is magnetized, it is impossible to cnt out the resistance or to start the motor, as the armature of the magnet is dropped in front of the resistance arm. The moment the switch is closed the armature is drawn up, which then allows the resistance to be cut out and the motor started. After the field controllers are operated from the front of the loard by the small hand wheels, the rheostats being back of the board.

The fact that there is always some one at the exhibit is appreciated by visitors, who often wish to know something

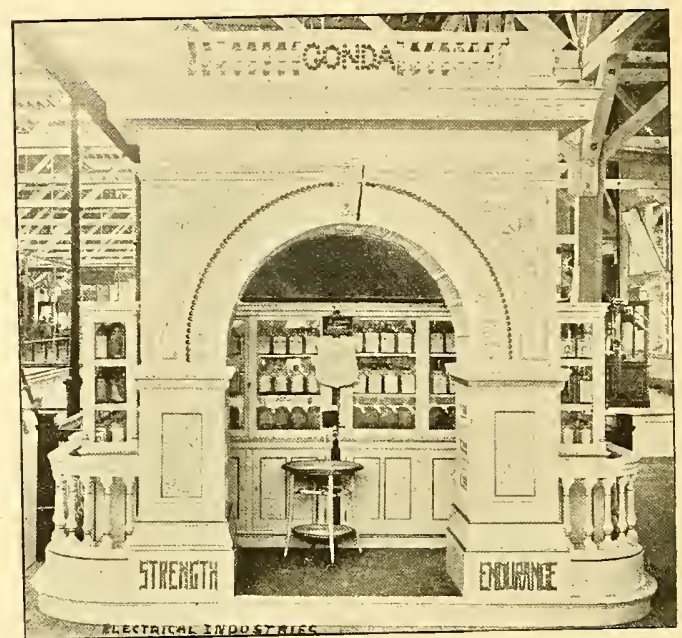

FXUIBIT OF TIE LECLANCHE BATTERY COMPAXY.

more of the exhibits than can be learned from a glance at the array of machines. Mr. Farnsworth, who has charge of the exhibit, has made it a point either to be at the exhibit

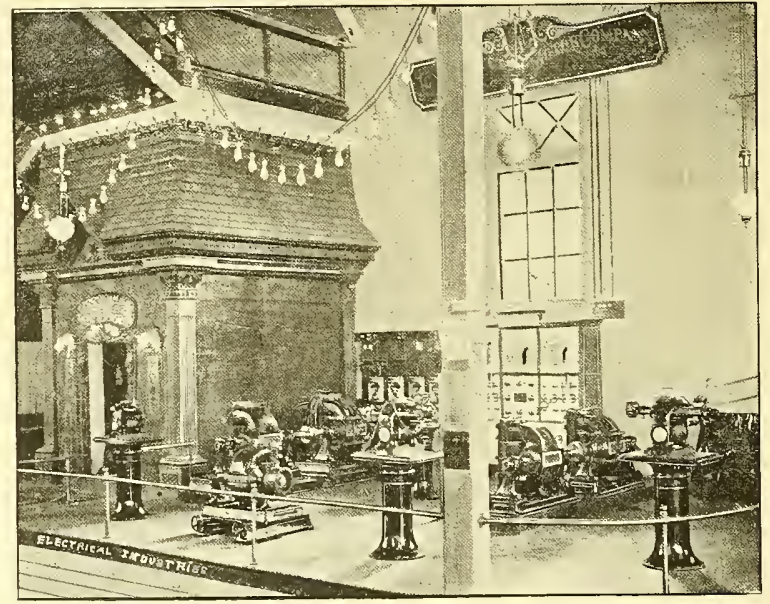

EXHIBT OF THE JENXEX ELECTRIC MOTOR COMPANY.

resistance is out or the motor running at full speed the arm is held in place by a small lever. In case the current is suddenly or accidentally broken the armature of the magnet drops as the motor slows down allowing the arm to return to its starting position, thus protecting the motor when the current is again turned on.

The switchboard, which is of white marble, is supplied with the necessary switches, ammeters, rolt meters, etc., for the regulation of the current. There are two sets of bus bars, one for each dynamo. The light eireuits are run from the smaller bus bars and are eut in and out by the small switches or are all thrown out by the main switch. The or to have an assistant present during the time that the building is open. This method has undoubtedly been beneficial to the interests of his company.

In strong contrast with the large drills used for mining operations is the small dental drill added, this week, to the exhibit of the General Electric Company. The drill is operated by a small motor, the speed of which is easily governed by a switch controlled by the foot, but it is not claimed that this improvement over the foot power formerly used, will make any the less interesting the drilling process preceding the filling of a tooth. 


\section{Exhibit of the Leclanche Battery Co.}

Near the center of the rast gallery of Electricity Build ing is located the exhibit of the Leclanche battery Compray of Sew York. Although the goods exhibited consist entirely of butteries, the mothof of arrangenent, the design of the areh that spans the entranee, and the at propriateness of the details, as well as the taste clisplityed in the eolurs of the decorations alie it the admiration of the visitors

At the top of the areh miniature ineandescent lants sirell ont the word cioncla, the woll known trade mark of

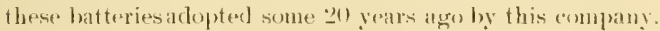
Prominent on the face of the areh aplesare the name of the compang, the natmes of the ditferent colls manufactured by the comprany and wear the bottom of the columms the words. strength, endurance, qualities that these batteries ane sairl to posiass in a marked degree.

Forming three sides of a sefuare of which the arela forms the frent, are the glans cases that rontain the exhibit of is nearly nine inches higrh and four and one-half inches square, and differs greatly in construetion from the other eells. The negative electrole consists of a carbon having sis vertical wings, over which is stretched a bag so as to form poekets between the wings for the lepolarizing rompommls. From its uper end a carbon rox projects through the eorer of the jar, by which it is suspenderl. This cores serewndown on the werek of the jar, and the eell is thus renderend water tight. The zine of the ceell is eirenlar in form, and nearly surrounds the carlon.

(Mne of the motiesable objerts about the exhibit is the shield in white aud gold bearing this inseription: "Thesp are the batteries that wind the clocks that furnish the time for the great Exposition."

\section{Exhibit of the Chicago Electric Wire Company.}

In the mast gillery of Elecetricity Buileling, the Chicago Electric $\mathbb{W}$ ire (ompany has a very attractive exhibit as we-11 as sery complete in representing the line of goods manu

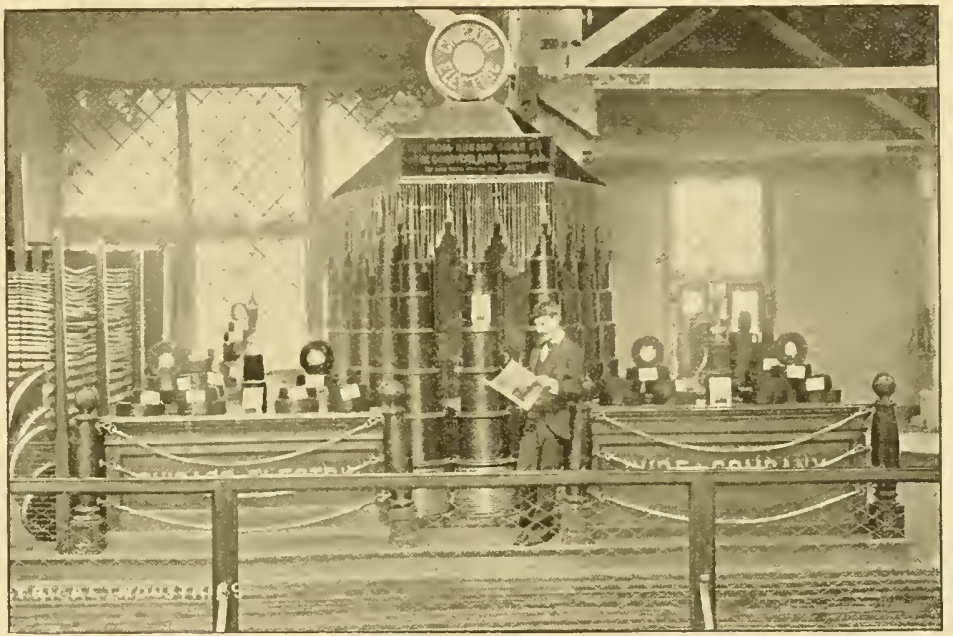

EXIIBIT OF THE ('HICA(i) EIECTRHe WIRE (WMIAXY

Jattries. The glass silles of the cases enable the latteries to besern from both within and withont the space. The latteries shown ar designed for open circuit work, and in all the improved battery comnection is used. The washers used are made of a non oxidizing metal that is always free from rust and corrosion, and no local action can set uj letween the connection and the carbon. Among the batteries shown is the (ionda porons cul cell, which is the originil form of the Leclanche cell. It is about seren inches high and four and one half inches syuare. The Axo cell shown is an improved form of battery in which it proross cuj is used. The special form of cuj, used in this battery hat a flange that fits over the top of the glass jar, making a resod coll. Thus all dust is excluded and Naporation is presenterl. This cell is especially aslapted for physiciats use.

Among the other styles of batteries exhibited are the (ioncla cell. well known to the trade, and the cylinder cell that possesses a large amount of surface and low internal resistince. The Vole cell is the latest battery introduced ly this company. It is constructed for work where a fuantity of enrent and continuous sprvice is rerpuired. It factured by this company. The exhibit has been arranged after a very pretty and artistic design.

In the ceuter of the space is the booth that serves as an otfice of the comprany, reels of wire of various sizes making the columus for the support of the canopy which forms the roof of the booth. The canopy is constructed of insulat ing tubing resembling bamboo, from the edge of which is hung in rope-like fashion a beaded curtain of different colors.

()n the peak of this booth is placed a circular sign bearing the name of the company. Within the booth are clesk and chairs-while the colored curtains enclose the space making it a comfortable retreat. Around the sprace are heavs solid oak tables on which are tisplayed the smaller samples of wire and insulations. On the front of the tables earved in heavy block letters aprear again the well known name of the company

Between the posts that mark the corners of the exhibit are suspended heavy armored cables of the style manufact ured for snlmmarine use. In the exhibit are shown insu lated wires and eables of almost every kind used in the. varions branclues of electrical industry, insulated according 
to the processes used by the company. This exhibit was one of the first arranged in Electricity Building, and it early attracted the attention of visitors. Numerous addi tions have been made to the exhibit from time to time to freshen its appearance.

Mr. A. A. Cobh, representative of the company is in charge of the exhibit, to whom very much eredit is due for the excellenee of the display.

Wonder has been eaused in the past. by the seren great search lights which nightly pieree the darkness with their powerful light, but Fair visitors of the future should prepare themselves for a greater surprise. Arrangements are being completed for the placing of an immense projector on the roof of Mannfactures and Liberal Arts Buikding with which it is intended to throw advertisements on the clouds. The varions attractions along Midway are advised to make early applieations for space.

The gondolier who follows the business of his forefathers on the grand eanals of Venice is liable to be driven to some other form of employment. The practical test of the electric launch on the lagoons of the Exposition grounds has shown their many advantages. According to the Engineering News, from which we take the following paragraph they have made a favorable impression on the commissioners from sunny ltaly. "Electric launches may supersede gondolas on the canals of Venice, as one result of the Columbian Exposition. At least one of the Chicago launches has been sent to Venice by a company which is said to include several members of the Royal Italian Commission. The Electric Lameh d Navigation Co, owning the boats at the Exposition. say this company has an option until Oet. 15 on 30 of the 50 launches of the eompany. Fast steam launches of a considerable size now rum regularly on the Grand Canal in Venice and are well patronized, as the fare is small and the speed great compared with the goudolas. The smoke is said to be objected to, and these larger boats cannot traverse the crooked smaller canals with their low and frequent bridges. It is expected that the electric launches will find favor owing to their small size, lowness and noiseless opera tion, without smoke."

\section{The Actien Gesellschaft fur Chemische Industrie.}

The extensive use of various chemicals in the different branches of the electrical industry, especially sal ammoniac or muriate of ammonia and blue vitrol, or sulphate of copper, makes the exhibit of the above company of interest to the electrical trade. This exhibit is located in the chemical tivision of the German section in Manufactures and Liberal Arts Building.

The exhibit has been arrangect with the aim of not only showing the varied products of the extensive works of the company, but also of presenting an arrangement that will he pleasing to the eye. Paintings form a handsome back ground to the piles of eylinders that contain the exhibits. The painting on the left shows the works of the company at Reinan, while the one on the right shows the works at Bamen

The company is one of the largest exporters to the United States, and it is said that nearly three-quarters of the imports of this character can be traced to the Mannheim company. The exhibit at the Fair was installed under the direction of $\mathrm{Mr}$, C. F. Holland, one of the mandgers of the company.

\section{ELECTRICAL INDUSTRIES.}

\section{ELECTRICAL INDUSTRIES PUBLISHING COMPANY, \\ INCORPORATED 1809. \\ MONADNOCK BLOCK, CHICAGO. \\ TeLEPHONE HABRHON 159.}

E. L. POW ElRs, Plies, and Treas.

E. L. POWFRS,

EDITOR.

H. A. FOSTER,

W, A. REMINGTON,

E. E. WOOD,

FLOYD T. SIIORT

- Eastern manager.

ADVentisnge Departaent

EASTERN OFFICE, WORLD BUILDING, NEW YORK. World's Fair Headquarters, Y 27 Electricity Building.

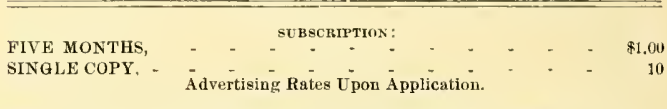

New's itcms. notes or communications of interest to World's Faj isitors are earnestly desired for publication in these columns and will be hearthly appreciated. We especially invite all visitors to call upon us. or send address at once upon their arrival in city or at the grounds. RIES PUBLISHING CO.,

Owing to the report of the Jury of Awards not being complete in certain details the report of the jury will not be made public until after another meeting of the jury, which will be called in the near future.

Throngh the efforts of the Department of Electricity a beacon light has been placed on Electricity Building, at the south end. It is of the type used in the French navy and was placed in position by Barbier et Cie. It has three lenses, red, white and green, which revolve in the frame about the light. A small motor placed just below the light turns the lenses, the shaft of the motor being connected to the frame-shaft through a number of gears. A 64-candle power incandescent lamp, which will soon be replaced by a 150-candle power gires the light. The wiring for the light was done by the Exposition and the current is furnished by The Jenney Electric Motor Company from its exhibit at the south end main floor of Electricity Building.

The committees appointed by the Mayor of Chicago and President Higinbotham, of the Exposition, have adopted a plan for the distribntion of the funds secured by popular contributions for the relief of the injured and those dependent on the killed in the Cold Storage fire at the Exposition grounds. It has required a considerable time to get at the facts in each case and to plan for an equitable distribution of the funds. In general the plan proposes that a certain sum be paid the adnlts in cash; that a certain sum be set aside for the widows and all the money set aside for the children be placed with one or more trust companies to hold in trust, until they become of age and in case of widows until death, or perhaps re-marriage, when it is to revert to the children. The funds will allow each widow $\$ 2,000 \mathrm{in}$ cash and the interest on a second $\$ 2,000$, and the children receive what will be equivalent to $\$ 2,000$ on their coming of age. 


\section{ẄORLD'S FAIR NOTES.}

The large Columbus sign at the south emel of Flectricity Building has been greatly ehanged by the new colored lamps recently put in. The work of ehanging the lamps was watched with interest.

Contracts have been let for the two principal buildings of the California Mid-winter Exposition, the Manufactures and Libural Arts and Mechanieal Arts Buildings, ane? work will begin immediately. The contract price of the two butlling is said to be $\$ 172 .(2)$.

The first meeting of the present season of the American Institute of Electrical Engineers was held last eveniug at 12 West 31st street, New York. President Houstou delivered his inangural address, taking for a sulject the Chi eago International Electrical Congress.

It is now the custom to turn off the lights on the cornice of Electricity Building. Administration Building and Ma. ehinery Hall, on the side of the buildings toward the electric fountains while the fountains are playing. By this arrangements the lights and colors of the fomntains appear to better adrantage.

Chief Allison of the Manufactures and Liberal Arts Building, recently secured from Mr. Geo. B. Clark, of the executive committee of the Gallery Exhibitors C'lub, an outline of the plan followed for increasing the at. tendance in the gallery of the Eleetricity Building, and expects to adopt similar masures for his dejartment.

The goorl natured rivalry which has always existed between the employes of the electrical engineering depart ment and those of the mechanical department has resulted in arrangenents for a foot ball game to be played in the stock parilion in the near future. The elevens hare been chosen, and, judging from the anount of practice being in dulged in, a hard struggle may be expected.

"The oldest telegram in the workl" is the title of an exhibit in the space ocenpied by the l'niversity of the City of New York in the gallery of the Manufactures and Liberal Arts Building. The telegram was sent and reeorded by Prof. Morse in the chapel of the University on Jan. 24th, 15:35. The tape containing the original record in the Morse alplubet and the translation in Prof. Morse's handwriting is shown in a glass aase. The telegram, which was dictated by Prof. Cuminings, reads: "Attention-The Tniverse by kingdomsRight wheel."

The improvised tug of war between the new General Electric Company's electric locomotive and the B. \& $O$. switch engine on last Saturday afternoon did not result in a great victory for the electric locomotive. The event had been well advertised and a large erowd watehed the affair with interest. The wire fence along the terminal sheds kept the crowd back wlite the more eager elimbed upon the exhibition cars stationed on the neighloring tracks much to the detriment of their smmmer clothes and the elegrant tinish of the cars.

The illumination of the Texas state building on the evening of the day celebrated by the Lone Star State was accomplished by using the portable electric Jightiug plant. which has been exhibited hy the Daimler Motor Co., in the south end of Transportation Building. The aplparatus consists of a twelve-horse power oil engine and a ten are light dynamo, mounted compractly on a carriage, so that they ean be quickly moved and easily handled. While intended primarily for use in military operations, the ap paratus is adapted for any serviee where the rapid installation of a temporary plant is called for. Chief Pierce, of the Electrical Engineering Department, speaks in high terms of the accommodation afforded by the plant; anr bopes to make use of it on furture vecasions.

The crowds of visitors these days come to see something and those places where are to be found the most startling displays are the places where the largest crowds assemble. By simply fusing small wires connected across the terminals of a small plating dynamo the Jenney Electric Motor Company attracted crowds of visitors during the evenings of last week. It is the live exhilhits that attract the visitors. The General comprany has a small water wheel operated ly a small motor which stirs un the water in a water tight lox loeated near the center of the building. The water is so agitated that the little propellor is eoncealed from view and it is a mystery to many passing by what is ereating the disturbance.

A good display of small motors may be fond by examining the exhibit of the Western Electric Co. Varions die signs, adapted to special service are shown. Near the north entrance to the Egyptian temple four motors of the multi-polar type are shown ranging from two to fiftern horse power. These motors are especially designed for low speed and high efficiency and show most excellent re sults. There are also two forty-horse power motors directly connected to the two generators which supply the current lor the scenic theater and the cohmm of light. The loads on these motors are comstantly changing, but the shunt and conpound winlings are so arranged to op pose each other and make the motors perlectly self regulating.

Street Railway Association of the State of New York.

The eleventh annual meeting of the Street Railway . 1ssociation of the State of New York is held this werk at Rochester, N. Y, An interesting program has been prepared, which inchdes a number of papers by prominent railway men. Mr. (feo. Wr. MeNulty, engineer of the Broadway d Seventh Av, railroad, presents a paper on "The Recent improvements in Cable Traction," and Mr. Thos. J. MeTighe, electrical engineer of the Atlantic Ave. Ry..Brooklyu, reads a paper on "The Return Circuit of Electric Railways." A large attendance is expected and excellent accommolations have beeu secured at Puwers' Hotel.

The popular route to Milwankee is the Chicago Mil. waukee and St. Paul Railway. Its double track between Chicago and Hilwanke has been completed, and with its block signal system, absolutely preventing accilents from collisions, trains may be run at the highest rate of speerl ob. tainable. The eruipment of the line is perfect.

Trains leave the Lnion Passenger Station. Canal and dedams streets, as per following scherble:

s:30 a. m. daily.

11:30 a. m. daily, except Sunday

[:(x) J. m. tlaily, exeept Sunday.

$3:(14)$ 1. m. laily.

$(5:(x)$ ]. m. haily.

s:tu 1) m. slaily

[0:30 1. 13. daily.

City ticket office, No, 207 Clark street. 


\section{PERSONAL.}

Mr. Wr. E. Jackson, Jr., of Angusta, Ga., was among the arrivals during the past week.

Mr. A. Newman returned the forepart of the week from a somewhat extended trip east.

Mr. Wilder,superintendent of the electric plant at Kalamazoo. was a visitor at the Fair last week.

Mr. F. L. Southack, the well known eleetrical engineer of Boston, Mass., is now at the Fair.

Mr. A. J. Wright, president of the Reliance Gauge Co., of Cleveland; Ohio, is visiting the Fair with his family.

Mr. C. A. Paul, superintendent of the Bridgeport, Conn. Electric Light Co., spent some time at the Fair reently.

Mr. Jerome Penn, of the Electric Light \& Power Co., of Washington Court House, (hio, is in the city attending the Fair.

Mr. Jas. E. Cole, electrical inspector from Boston, Mass., was among the visitors to the electrical features of the Fair this week

Mr. D. L. Davis, superintendent of the Eleetric Light \& Power Co., of Salew, Ohio, was among the visitors of Electricity Building last week.

Mr. Morgan Brooks, general manager of the Electrical Engineering and Supply Co., of St. Paul, Minn., is in the eity visiting the Exposition.

Mr. Herbert M. Price, who is interested in the installation of a power plant at Mt. Morency Falls, seven miles from Quebee. paid the Fair a short visit last week.

Prof. W. J. Herdman, a member of the Jury of Awards, Department of Electricity, was recently elected president of the American Electro-Therapeutic Association.

MIr. H. H. Eustis, of Boston, president and electrician for the Eastern Electrie Cable Co., registered at the headquarters of the American Institute of Electrical Engineers this week.

Herr Prïssman and Herr Otto Arnold, of the main factory of schaffer \& Budenberg, at Magdeburg-Buckan, Germany, accompanied by Mr. L. Portong, the American manager of the company from New York, were interested visitors at the Fair recently, and expressed themselves as highly pleased with the exhibits.

\section{BUSINESS NOTES.}

THe Ansonia Electric Compaxy has been given permission by the court to continue business. The business is carried on under the direction of the assignee, Mr. J. B. Waller. The same line of specialties and standard supplies will be carried as heretofore.

The Cimcago Electric Wire Company is among the few manufacturing companies who have sufficient orders to keep their full force at work. The recent contract received from the U.S. government has kept the New York faetory going night and day.

The eight boilers of the Citizen's Street Railway Co., at Detroit, have recently been equipped with No. 5 Reliance safety water columns, manufactured by the Reliance Gauge Co., Cleveland, Ohio. 'They were specified by Mr. Harry Kinowlton, of the Hartford Steam Boiler Inspectiou \& Insurance Co.

The Electric Appliance Company reports a number of nice orders for the new Hammond porcelain eleat, which they have been introducing to the western trade. Its peculiar merit consists in the fact that it is only one piece of porcelain, but at the same time holds the wire away from the wall or eeiling like an insulating knobinstead of elamping it against the surface. The price is also very reasonable.

\section{DEPARTMENT OF MECHANICAL AND ELECTRICAL ENGINEERING.}

OFFICES SOUTH OF MACHINERT HALL.

Mechanical Engineer, C. F. Foster

Electrical Engineer, R. H. PIERch.

First Asst. Mechanical Engineer, Јонм MEADEx.

First Asst. Electrical Engineer, S. G. Nerner.
DEPARTMEN'T OF ELECTRICITY.

OFFICES: SECTION R, ELECTRICITY BUILDING.

Chief, JohN P. Barrett, Assistant Chief, J. AlLex Horxsby, Creneral Superintendent, J. W. BLAlsnet.

Electrical Engineer, W. IV. Primu.

\section{AMERICAN INSTITUTE OF ELECTRICAL ENGINEERS.

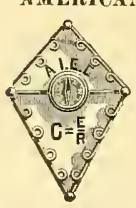 \\ World's Fair Headquarters, \\ SECTION S. ELECTRICITY BUHLDING. \\ RAIPII IV. PoPE, Secretary \\ (1pen from 9 a.m. to 5 p.m.}

\section{Amusements.}

Hooley's Theater-Mr. E. S. Willard, Thurs, and Sat. in "The Professor's Love Story," Fri. in "A Fool": Paradise." 149 Randolph street.

Coldmbia Theater-Daniel Frohman's Lyceum Theater Co. in "The Charity Ball." 108 Monroe street.

Grand Opera Hoose - Sol Smith Russell, in "A Peaceful Valley." 87 Clark street.

Aoditoriur-Imre Kiralfy's Spectacle "smerica." Congress street and Wabash avenue.

McVicker's Theater-Denman Thomson, in "The Old Homestead." 82 Madison street.

Chicago Opera House-American Extravaganza Company, in "Ali Baba, or Morgiana and the Forty Thieres." Washington and Clark streets.

Schiller Theater-Miss Rose and Charles Coghlan, in "Diplomacy." Randolph, near Dearborn.

Haverly's Casino-Haverly's United Minstrels. Wabash avenue, near Jackson street.

Trocadero-Tauderille. Michigan avenue near Monroe street.

The Grotto-Vaudeville. Michigan avenue near Monroe street.

Buffalo Bill's "Wild West." 63d street. Daily at 3 and 8.30 p.m.

The Stoddard Lectures-Central Music Hall, commencing Oct. 2d, Seren courses exactly alike six evenings and matinee each week. Week of October 2, Eastern Japan; week of October \%, Western Japan; week of October 16, China; week of October 23, Farther India; week of October 30 , Nearer India.

On Monday evening, October 2, Mr. Stoddard will commence his fourteenth season of lectures in Chica The lectures this season are on Japan, China and India, the material for which was gained in Mr. Stoddard's tour around the world. 'These lectures will he elaborately illustrated.

The managers of "America" did a wise thing when they decided on an extra Monday matinee. The great Auditorium has been crowded on these oceasions by people who could not secure seats for the regular performances. The spectacle has been freshened up and improved by a new and superior force of ehorus singers. Anotier agreeable change is the engagement of Annie Cameron, a well-known light opera contralto. She takes the part of Bigotry which MIiss Russell has had since the engagement opened. The Schaffer family eontinue to perform their acrobatic feats to delighted and astounded audiences.

Last Sunday night "Ali Baba" began its fortieth week iu Chicago, and on Wednesday evening, September 20, at the Chi eago Opera House, the 600th performance of the extravaganza will be given. Business continues as large as ever. All the west seats for the evening performances are sold away in advance, and the standing room only sign is now put out in the afternoons. The wisdom of the lavish expenditure alrvays made upon the American Extravaganza Company's productions is now shown in the splendid preservation of the seenery, eostumes and properties of "Ali Baba." "The rich satins, velvets and brocades show not a sign of wear, and the beautiful pictures are as bright and charming as when they first eame from the painter's brush. 


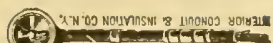

(2) $=0$

年
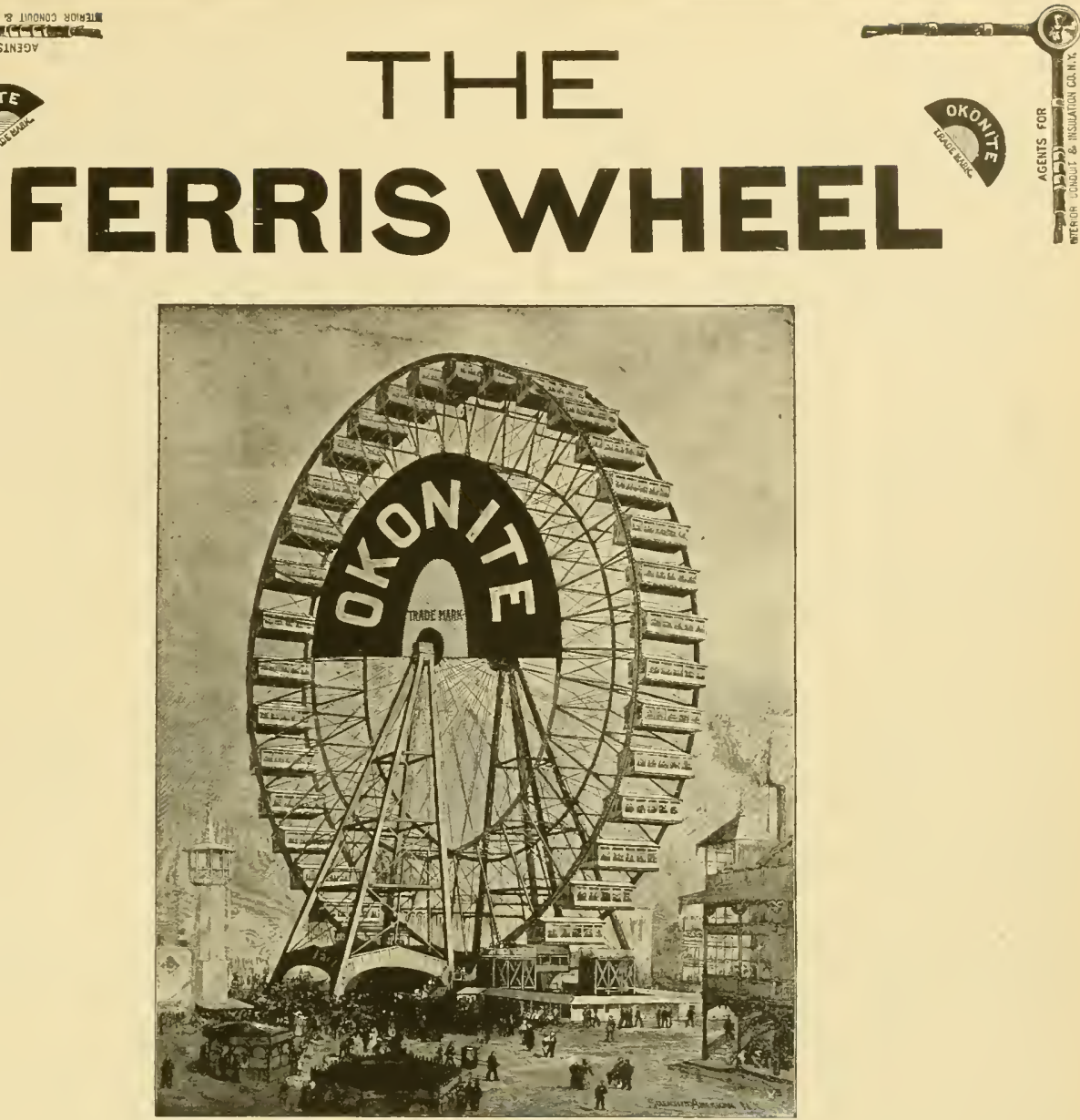

When you visit the World's Fair, you will naturally take a ride on the FERRIS WHEEL and be interested in the ELECTRIC LIGHT INSTALLATION, which is wired throughout with

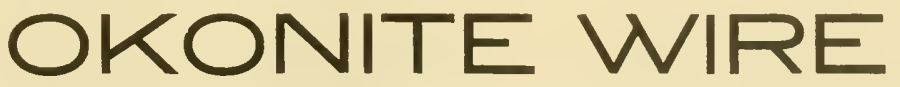

FURNISHED BY THE
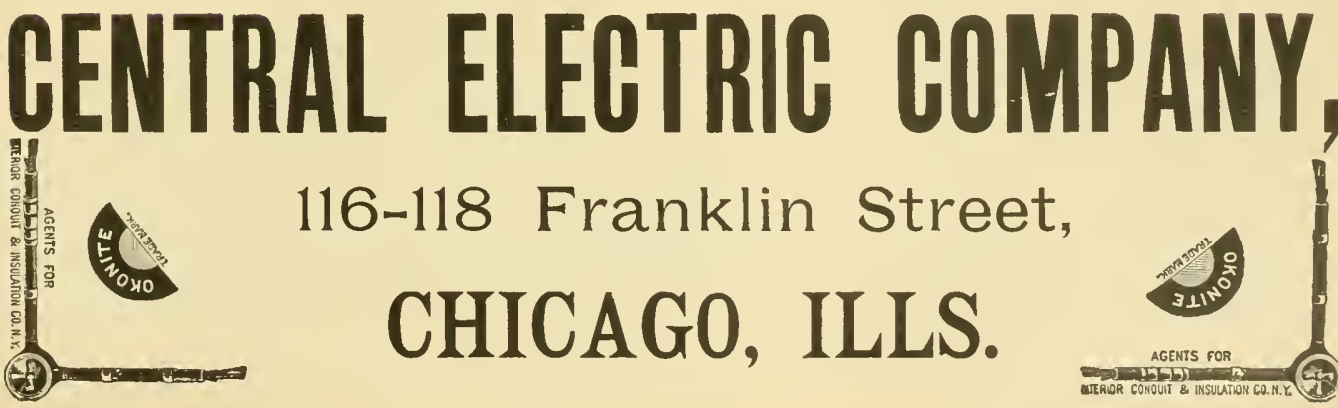

116-118 Franklin Street,

CHICAG0, ILLS.

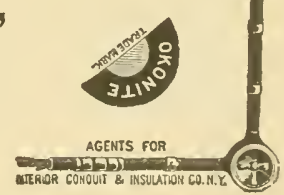


ELECTRICITY BUILDING-EXHIBITORS AND THEIR LOCATION.
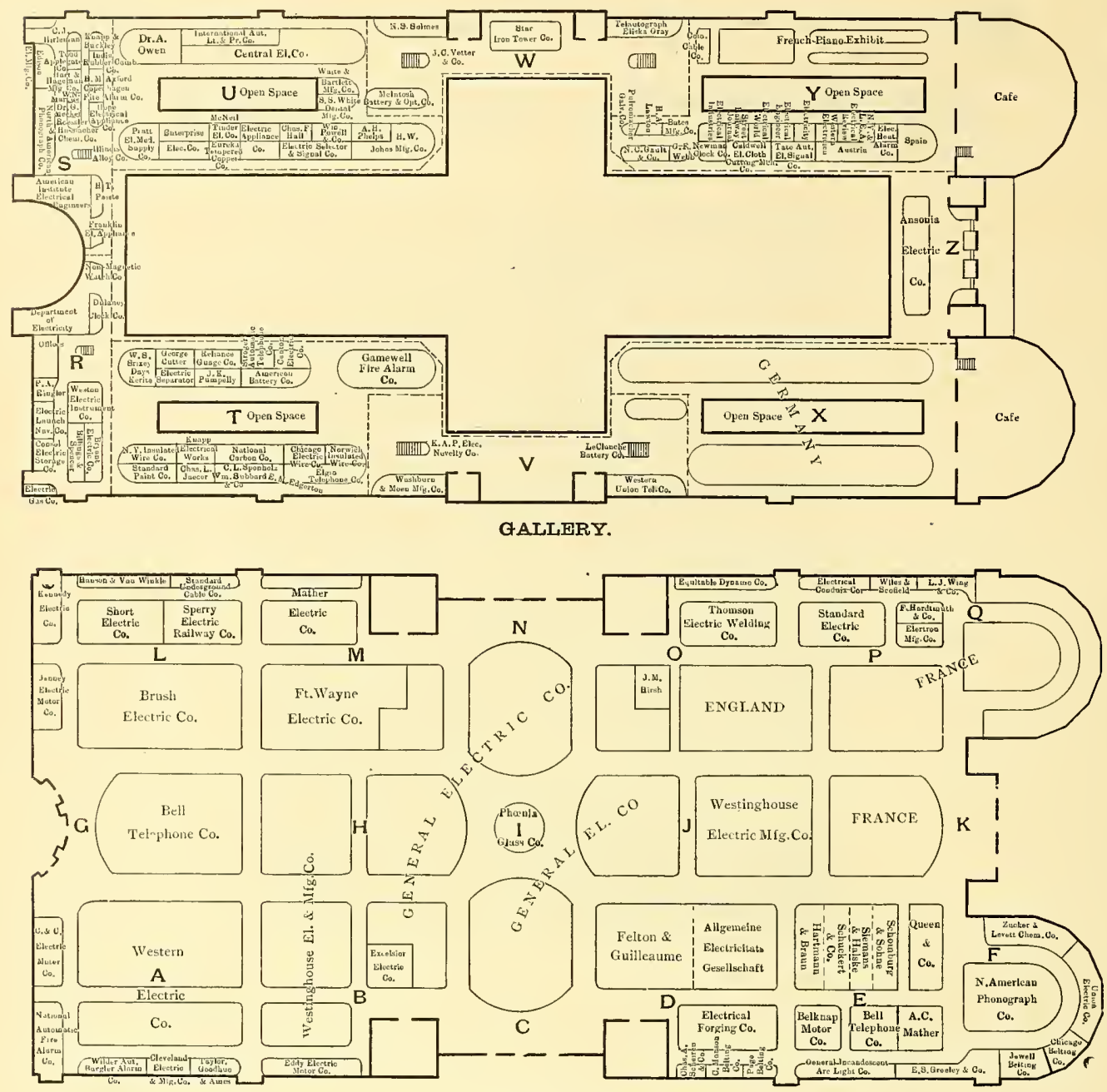

MAIN FLOOR.

Exbibitor.

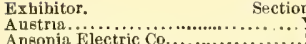

An. Inst. of Elec. Eng.

American Batter

Allg. Elec. Gesellschät.

Bates Mir. Co..........

Bryant Electric Co.

Billings \& Spencer

Belknap Motor Co

Bell Telephone Co.

Brush Electric Co
Cald well El. Cloth Cut. Mich. Co.

Consol. Elec. Storage Co

Cutter, George co.

Chicago Elec, Wire Co...........

Copeshagen H'ire Alarm $\mathrm{Co}$

Central Electric Co

Commercial Cable Co.

C. \& C. Elec. Motor Co

Chicago Belting Co

Chicago belting co.

Department of Electricity

ELECTRICAL INDUSTHIEs

Elec. Launch \& Nav,

Electric Separator.

Edgerton, E. M..........

Igin Telephone $\mathrm{Co}$

ateon

Eureka Temp Copper is.

Electric A ppliance Co.

Elec. Sel. \& Sig'l Co.
Section, Exhibitor.

Exhibitor.

Electricity .......

Electrical Engiveer....

Electrical World

Eddy Electric Motor $\mathrm{C}$

Excelsior Electric Co...

electrical brging $\mathrm{Cn}$

Elektron re. Co

Electrical Couduit Co

England

mpire China Works.

ranklin Elec. Appliance

rench Piano Exhibit

France ...............

Ft. Wayne Elec. Co

Gamewell Fire Alarm Co $-\mathrm{H}-\mathrm{\textrm {N }}-\mathrm{C}-\mathrm{S}$

General Incand's't Arc L't Co.........

Greeley, E. S., \& Co

Germany Inbbard, W..... $\mathrm{Co}$

I art \& Hegeman M I $\mathrm{g}$.

Hope Elec. Appliance Co.

Itall, Chas. I

Hartman \& Braun

Hartman \& Braun.

Hardtmuth, F.. \& $\mathrm{Co}$

Illinois Alloy Co.............

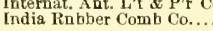

K-P-Q

Section, Exbibitor.

Jaeger, Chas. L..................T

Jewell Belting Co.

-Tr nney Elec. MTotor Co.

Kuapp Eleetrical Works...

K. A. P. Elec, Novelty

Kuapp it Buckley .......

Lawton, H. A .

LeClanche Battery Co.

McNeil-Tíuder Elec. Co...

Marcns, W. N

Meeker, Dr. G..............

Musson, C., Belting Co

Inther, $\mathrm{C}$

Mather Electric Co

Non-Mngnetic Watch Co

V. Y. Insnlated Wire

National Carbon Co...

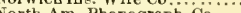

$\mathbf{Y}$ Am. Phonograph Co.......... S-

Aut Fire Alirm Co.....

Nat Engraving Machine Co.

Owen, Dr. A

Phoenix Glas

Paiste, H.

Pratt El. Med. Snp. Co

Powell, Wm, \& Co.

Phelps, A. H.

Queen \& $\mathrm{Co}$
Exhihitor.

Section Roessler \& Hasslacher Chem. Co....... Street Ratlway Journal.............. Y Strowger Ant. Telph. Co.......... 'T Standard Paint co.

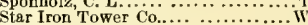
Spain ............................. Y etieren, Chas. A. \& Co ............ D Siemens \& Halske.

schuckert \& $\mathrm{Co}$

Sbort Electric Co..................

Sperry Elec. Railway Co................

Standard Underg. Cahle $\mathrm{C}$

Standard

Tate

Todd, A pplegate Co

Tuion Eleetric Co Gray .........W

Vetter $J$ C \& Co...

Webh, G.

Wenton

Wastburn \& Moen Mfg. Co..... ....V

Western Union Tel. Co $\ldots \ldots \ldots \ldots \ldots$. V

White, S. S., Dental Hirg. Co........... U

Western Electrician
Wilder Aut. Burglar Ai. Co..............
W

Western Electric Co

Westinghouse El. \& Mfg. Co..... B-H-J

Wiles $\&$ Scotield .................. P

Wing, L. J., \& Co C................P 


\section{ELECTRIC APPLIANCE COMPANY, 242 Madison Street, CHICACO.

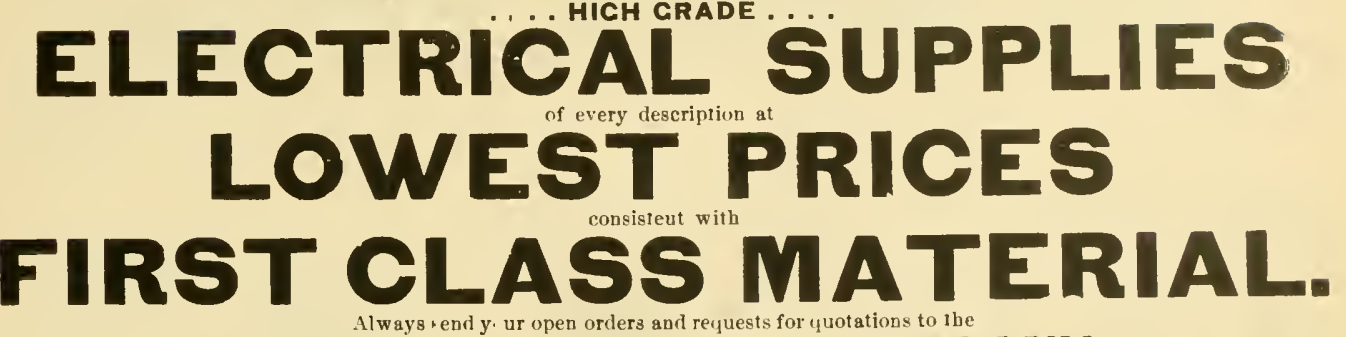 \\ ELECTRIC APPLIANCE COMPANY, 242 Madison Street, CHICACO.

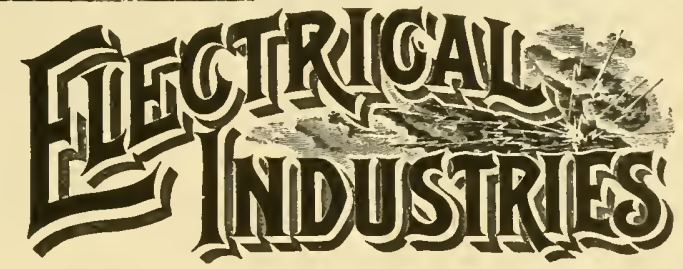 \\ Should be read by everyone interested in electrical matters.}

The paper contains recularly

A Buyer's Directory of Mannfacturers and Dealers in Eleetrical Supplies and Appliances

A Complete Directory of Electric Light Stations in North America and a Conplete Directory of Eilectric Railways in North Anerica.

These direetories are revised each issue to the date of going to press and are to be found in no other electrical journal in the World. Its artieles are read earefully and its directories used constantly by all the buyers in the trade. These facts nuake it withont a superior as an advertising nuediun. Sample copies and rates sent on application.

Subscription price $\$ 3$ per year. Six months trial $\$ 1$, if ordered during Septenber.

ELECTRICAL INDUSTRIES PUBLISHING COMPANY, MONADNOCK BLOCK. CHICACO.
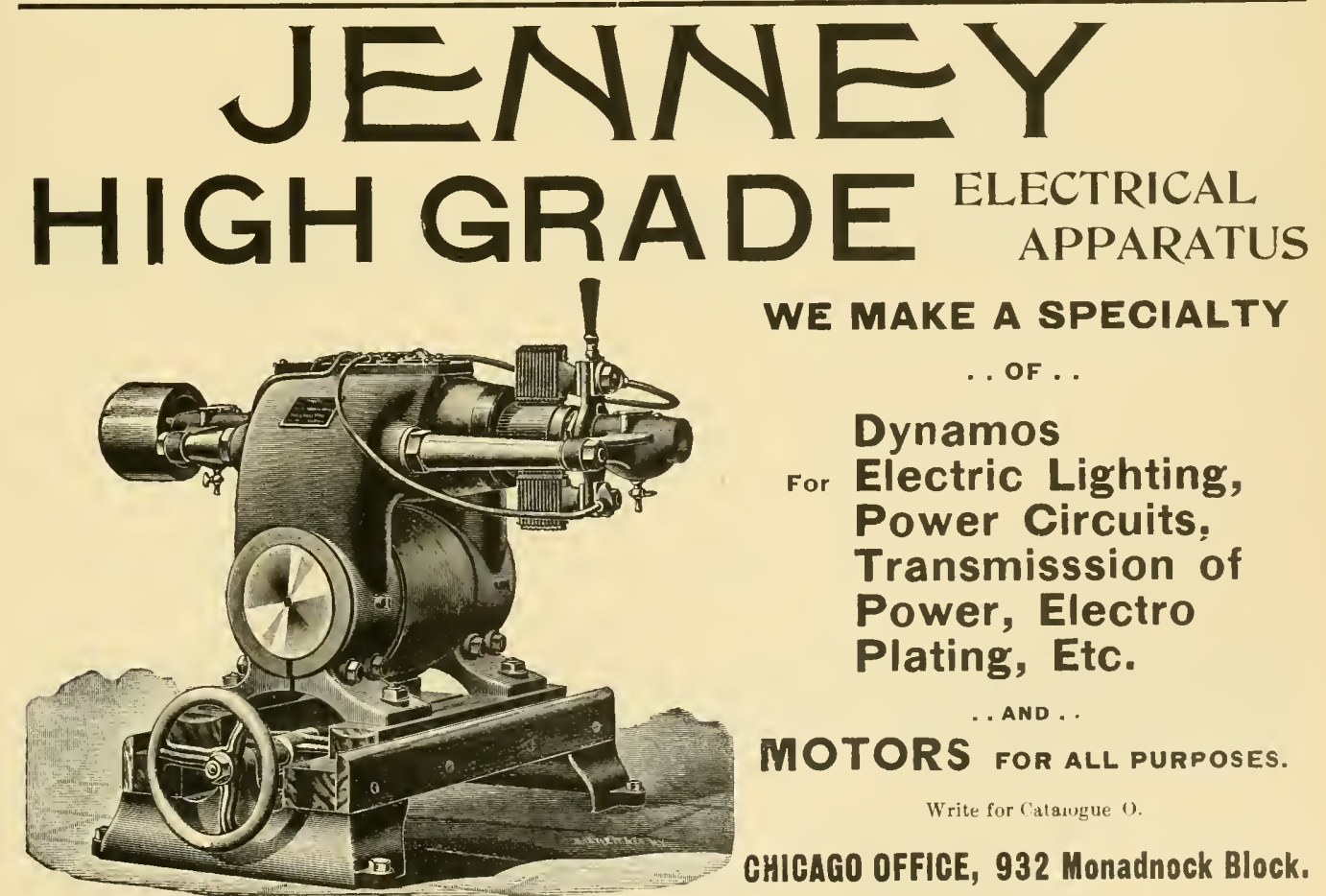

WE MAKE A SPECIALTY

. OF . .

Dynamos

For Electric Lighting,

Power Circuits,

Transmisssion of

Power, Electro

Plating, Etc.

MOTORS for ALl pURposes.

Write for Cataugue 0 .

CHICAGO OFFICE, 932 Monadnock Block.

TYPE OF MOTOR FRUM $1 / 2109 \mathrm{H}$. P.

\section{JENNY ELECTRIC MOTOR CO., . Indianapolis, Ind.}




\section{OUR IMPROVED SYSTEM}

... OF ...

Automatic fire Alarm,

covered by patents recently issued, is the

embodiment of all factors contributing to the

GREATEST SAFETY,

and the MOST RELLABLE

PROTECTION FROM FIRE.

Western Electric Company, CHICAGO and NEW YORK. 
COMPANY, NEW YORK.

192 Broadway and II John Street.

MANUFACTURERS OF ARC LIGHTING APPARATUS FOR EVERY PURPOSE A SPECIALTY. The CLARK ARC LAMPS for use on EVERY CURRENT, have the reputation of being the best and most durable of any ever made in the United States.

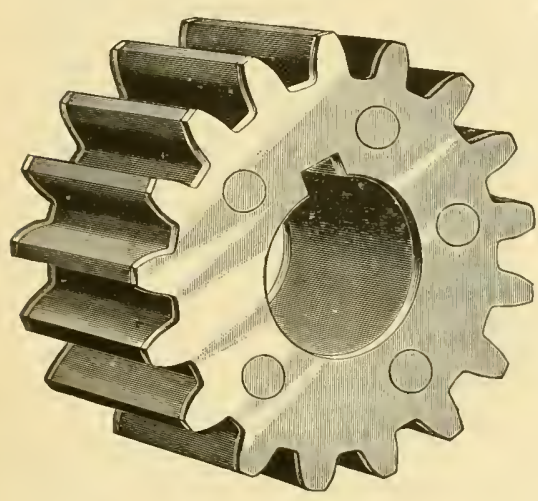

\section{RAWHIDE PINIONS FOR ELECTRIC MOTORS} A SPECIALTY.

RAWHIDE DYNAMO BELTING

Greatest Adhesive Qualities. A Non-Conductor of Electricity. Causes Less Friction than any other Belt.

THE CHICAGO RAWHIDE MANUFACTURING CO. THE ONLY MANUFACTURERS IN THE COUNTRY.

\begin{tabular}{|c|c|}
\hline $\begin{array}{l}\text { LACE LEATHER ROPE } \\
\text { ANO OTHER RAWHIDE }\end{array}$ & $\begin{array}{l}\text { This Belting and Lace Leather is } \\
\text { not affected by steam or dampnes; }\end{array}$ \\
\hline $\begin{array}{l}\text { GOODS } \\
\text { OF ALL KINDS } \\
\text { BY KRUEGER'S PATENT }\end{array}$ & $\begin{array}{l}\text { ical Belting made. The Raw- } \\
\text { hide Rope for Round Belting } \\
\text { Transmission is swperior to all } \\
\text { others. }\end{array}$ \\
\hline
\end{tabular}

\section{Standard Electric Company.}

GENERAL OFFICES: 625 Home Insurance Building.

WORKS: So, Canal Street,

\section{CHICACO.}

\section{STANDARD SYSTEM}

AT THE

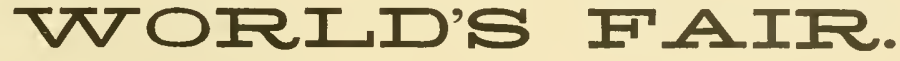

MACHINERY HALL, Sec. Q, 2 Standard Arc Dynamos.

Sec. S, 20 " "

ELECTRICITY BUILDING. Sec. P, Space 2, Arc Lighting Exhibit.

ho Standard Lamps Light the Power Plant, Machinery Hall, Agricultural Hall, Shoe and Leather Building, and Other Buildings and Portions of the Grounds. 


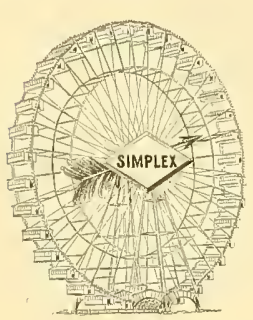

Mile after mile of

SIMPLEX WIRE

Supplied to the

FERRIS WHEEL.

By...George Cutter,

The Rookery, chicago.

\section{SIMPLEX WIRES}

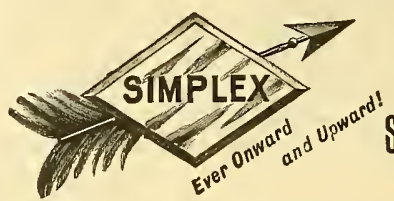

INSURE

HICH

INSULATION

Simplex Electrical Co. 620 Atlantic Ave.

George Cutter, Chicago. BOSTON, MASS.

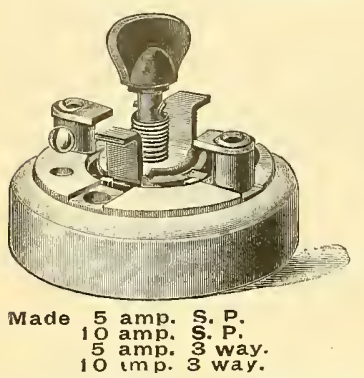

\section{XNTRIC}

"That's the Switch"

And we control that movement.

H. T. PAISTE, IO South I th St., PHILADELPHIA, PA.

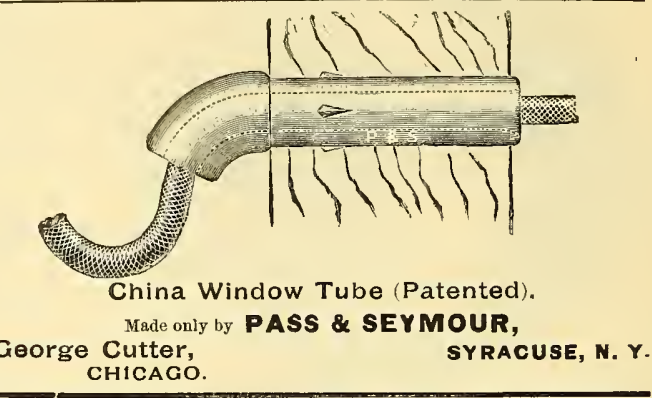

Enterprise Electric

207 Dearborn Street. Chicago ....

Manufacturers' Agents and Mill Representatives for

Electric Railway, $\infty$

Telegraph, Telephone and Electric Light

SUPPLIES

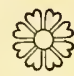

Agents for Cedar Poles,

Cypress Poles, Oak Pins, Locust Pins, Cruss Arms, Class - Feeder Wire, Insulators,

WIRES, CABLES, TAPE and TUBING

\section{BEAR IN MIND}

that the regular monthly issue of ELECTRICAL INDUSTRIES contains the most cemplete and correct directories published of the eleclric light central siations and the electric railways in North America.

Wcrld's Falr Headquarters $Y 27$ Electricity Building. CITY OFFICES, Monadnock Block.

Consolidated Elpctric (6.

Man daclurers and Dea'ers in all kinds of

\section{ELECTRICAL . SUPPLIES,}

1.15 Franklin Street,

\section{WAGNER ELECTRIC FAN MOTORS}

For Direct or Altemating Cureuts.

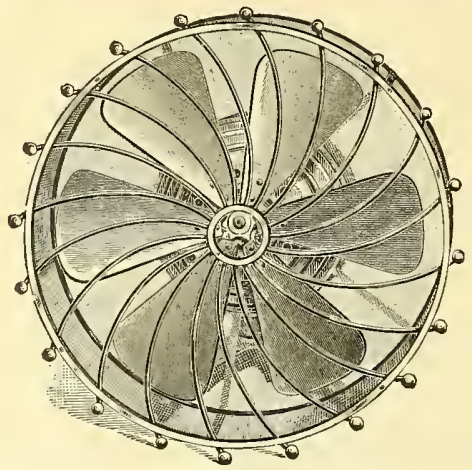

These motors give a stroLger breeze with less consumption of current than ny other fan motor on the market. They are full 1.8 borse power. Six bladed -inch fan. Seli-olling. Furnished with or without guards.

II WILL PAY YOU TO SEE THE WAGNER BEFORE BUYING ELSEWHERE.

TAYLOR, GOODHUE \& AMES, 348 Dearborn Street, CHICACO. 


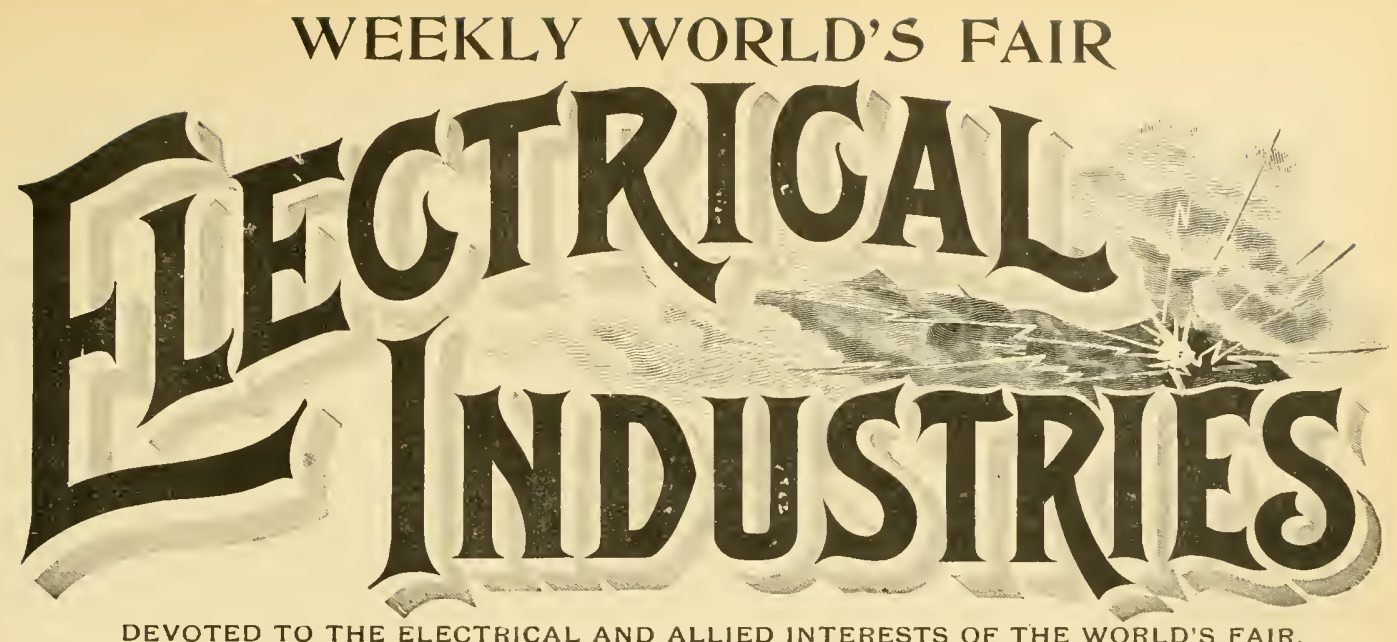

DEVOTED TO THE ELECTRICAL AND ALLIED INTERESTS OF THE WORLD'S FAIR, ITS VISITORS AND EXHIBITORS.

Vol, I, No, 16. CHICAGO, SEPTEMBER 28, 1893.

FIVE MONTHS \$1.00
TEN CENTS A COPY

Exhibit of the E. S. Greeley \& Company.

In the northeastern part of Electricity Building, Section F., E. S. Greeley d Company, of New York, has an exten-

extends the entire length of the exhibit. (Mne of the more prominent figures in the exhibit is the pramil of primary hatteries surmounted by a statue of liberty 31 inches high holding aloft a 16-candle power lamp. This exhibit of sive exhibit containing a large and comprehensive dis- batteries comprises a large number of styles of batteries play of electrical goods. The large floor space has been amongwhich is the Foote Primach battery. This battery is of

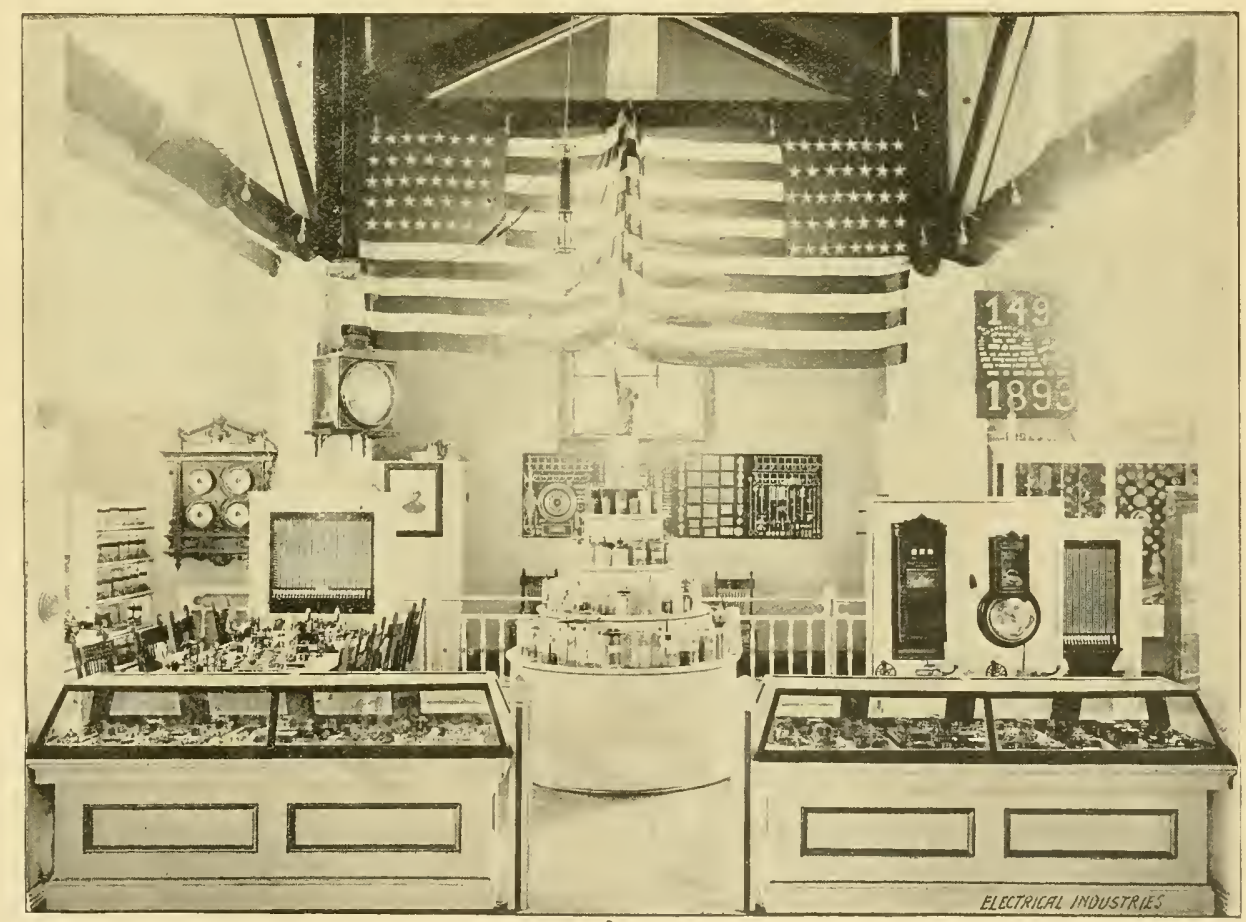

FIG, 1-EXHHBT UF THE E, S, GLEEIEY \& CONPAXY.

nsed to the best advantage by a neat arrangement of show cases and elegant display boards which contain the finely constructed articles and delicate instruments from the fac tories of this firm.

The space is enclosed by neat railings above which is placed a large sign bearing the name of the company that an improved form and construction; to the center of the cojper element is fastened a wooden post covered with as. phaltum that supports the zine element. The zinc is star shape and has a recess on the under sicle into which the post fits. This post keeps the two elements always the sime distance apart, thus preventing the copper working 
up and all short circuits are in this way aroided. A new telephone battery is shown which is a modification of the Fuller cell which is used so extensively in that class of work. Instead of having a bell shaped zinc, it has a peneil zinc which is protected by a rubber tube with an opening at the bottom. The zine feeds down and the lite of the battery is said to be much longer. Its voltage is two and the initial current about three amperes. This exhibit of batteries contains $\$ 6$ varieties of wet and dry batteries.

An extensive line of telegraph instruments are shown, many of new and special designs. The most popular part of this display is the Victor key which the president toucher? when he opened the Exposition. By the simple pressure of this key the current from the battery of Exeter cells operated the starting device that opened the valve of the Allis engine and the great Worthington pump. The Victor key is the only telegraph key that has no trumnions, the fulcrum being a knife edge. This manner of construction presents all side motion and consequent poor contact and also eleminates the so-called jamming motion. A short stout spring near the fulcrum holds the lever in place. This
The main circuit runs through an electro magnet which when the circuit is closed holds the armature up to which there is a lever attached. A pin in this lever catches in a slot of the main lever or the pull of the box. The box cannot be operated except when the pin is held in the slot of the pull so that when another box is being pulled the circuit is closed only momentary but not long enough to magnetize the electro-magnet. The non-interfering magnet is short circuited when the outside door is closed, thus preventing loss of current. The mechanism of the gong is so constructed that when a wire is broken it will not continue to ring.

A large double jack telegraph switch board is so mounted as to show the comnections. It is also of the Western Union standard type and will accomodate 200 loops and 50 circuits. In the cases along the walls are displayed watchmen's time detectors, burglar alarms, annunciators of a variety of forms for hotels, houses, etc. Mounted on handsome hardwood boards are bells of all descriptions and push buttons in a variety of designs.

The Pratt speed indicator is shown which ean be used in

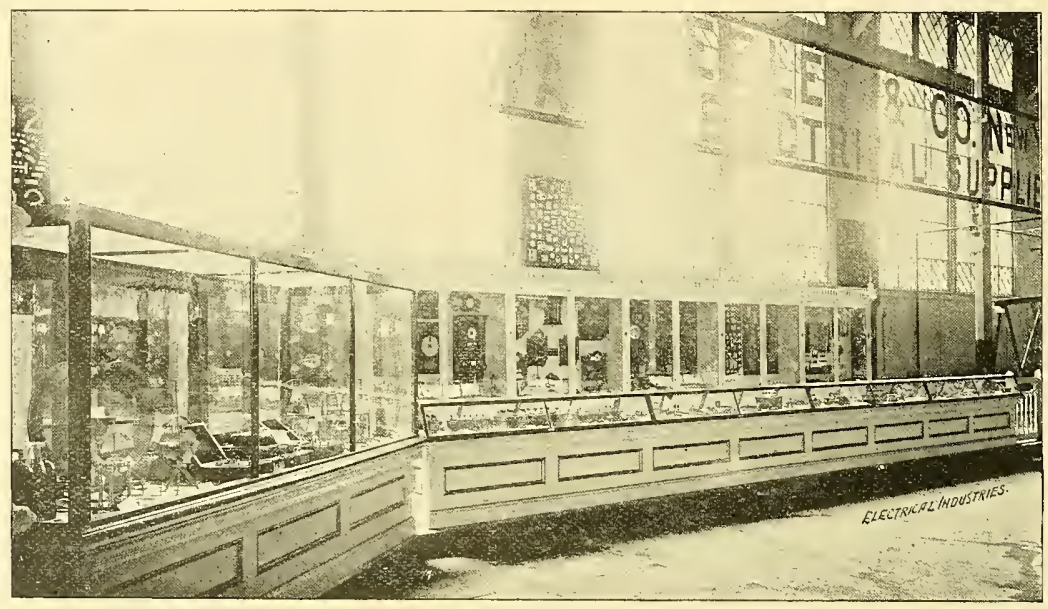

FIG. 2.-EXHIBIT OF E. S. GREELET \& COMPAXY.

key is also modified to meet the requirements of cable transmission.

The Victor relays and sounders shown exhibit the same attention to the details of construction. The relay has a plunger by which the adjustment of the spring is quickly determined. Western Uvion relays and Giant sounders are also mounted with the Victor keys. The Greeley ink writing self starting and stopping register is shown in several modifications, also comnected with the Victor keys and district call boxes. As a fire alarm instrument it is made with either one, two, three or four pens. The four pen register is the first of its kind built and it is able to record four signals of various length of duration at oue time.

These instruments are connected to a single jack switch board of the standard Western Union pattern. Each jack will accommodate four loops and the board is built for 25 lines. The batteries supplying the current for these in struments are the above mentioned Foote Primach type. There are 30 cells used which also operate the Greeley fire alarm system, consisting of four non-interfering boxes, an indicator, an electro-mechanical gong and two registers. both directions and does not register until the handle is pressed.

The W. B. G. protectors which are exceedingly sensitive to any excess of current are mounted in various ways to accommodate different circuits. These protectors are said to fuse at their rated capacity to within one-tenth of an ampere. Its value is readily seen and it is used extensively for protecting telephone, fire alarm and other systems.

At the south end of the space is an octagonal electric light pole on which is mounted a patented electric light crane. It is constructed of $\frac{3}{8}$ inch pipe and of such a form as to be strong and rigicl. Being pivoted in the center the crane may be raised or lowered. Weights are placed on the end opposite the lamp to balance it so that but a slight force is required to raise and lower it. When it is lowered the lamp comes within a foot of the pole enabling the trimmer to trim the lamp from the ground. The Wildt door opener is shown in operation.

An extensive line of testing instruments are shown in the cases among which are the Thompson galvanometers portable testing sets contaiming six chloride of silver cells, a galvanometer sensitive to a variation of one ohm in one 


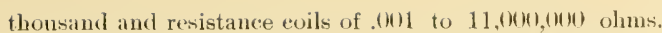
The Frey portable galvanometer for street railway nse is shown in which the galvanometer is suspented by a uni versal joint so that it is always level. It also contains an improved eompensating deviee. Other instruments are displayed for a variety of uses.

Mr. L. J. Anerbacher is in eharge of the exhibit and will be found a valuable assistant in an examination of the display of electrical goots.

\section{Exhibit of the Billings \& Spencer Company.}

The Billings \& Spencer Company has a rery complete exhibit of drop fórgings such as are used in electrical work in the south gallery of Electrieity Building, just baek of the Weston Electrical Instrument Co.'s exhibit. On a six- early Edison mathines were made in two parts, the blade rolled out to the refuired shaje and the shank forged by hand. These two pieces were joined by small dowel pins and then brazed, a long process and one which gave by no means satisfactory results. Mr. Billings, who had watehed the process offered to make them of one piece. His offer was accepted but their confidence in his ability was not perfect until they had seen the bars produeed. From that time until the present the mannfacture of these goods has increased and to one mannfacturer of electrical dynamos and motors this company lads furnished as high as 16 ton 8 a month.

The method of manufacture is so perfect that the fibre or grain of the metal is preserved so that it is everywhere parallel to the axis of the arm. They are used by the principal manufaeturers of eleetrio generators and motors.

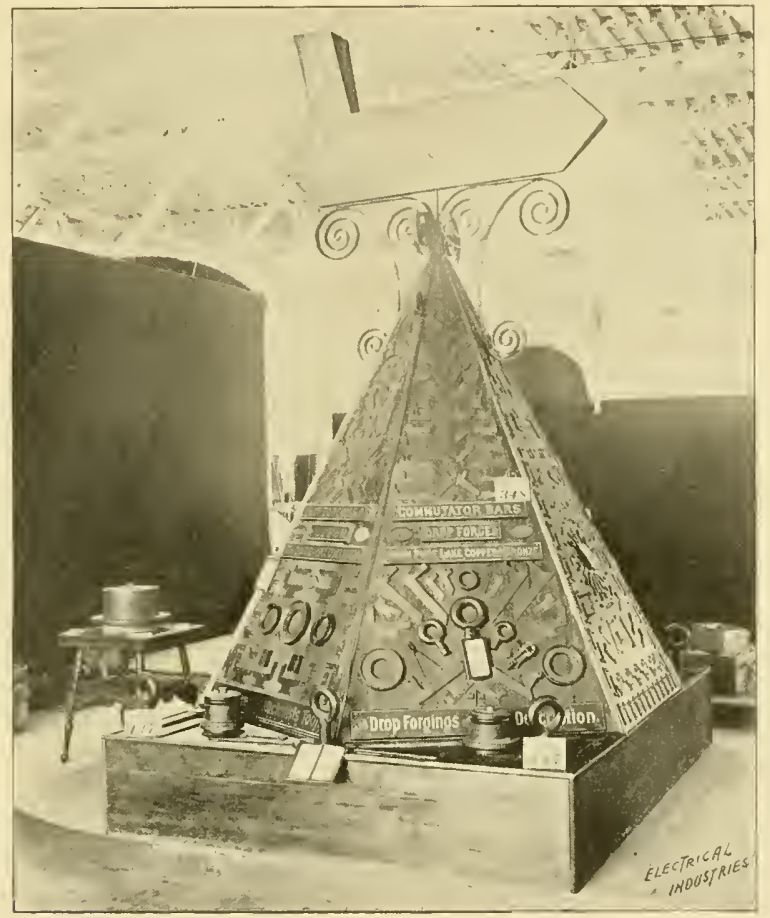

EXHIBIT OF THE BIILINGS \& SIENCER COMPANY.

sided pyramid standing some ten feet high, are arranged samples of forgings in pure lake copper, aluminnm, aluminum bronze, iron and steel in the shape of commutator lyars of various shapes and sizes, name plates for machinery, eye bolts for dynamos and other machines, wrenches, commutators, ete.

This pyramid is surmounted by a sign painted on a large fac simile of a copper commutator bar which is supportecl on four ornamented wronght iron brackets, stemed to the sides of the pyramil. At the four corners of the exhibit are sample commutators in copper and bronze assembled without insulation to show how perfectly each bar fits into its place. Eye bolts of large size up to two inches, drop orged from iron are shown at the corners of the platform. This eompany has been long known for its commutator bars and the origin of this process of manufacture is now an !nteresting piece of history. The commutator bars of the
Besides the exhibit in Electricity Building the company has an extensive exhibit in Machinery Hall Annex, main aisle, in which are foumd many tools manufactured for the use of linemen and wiremen. Billing's hand vise is extensively nsed by linemen in telejhone, telegraph and electric lighting line construction. Each part is interchangeable and can be duplicated at slight expense. There are also shown gas pliers and wire cutters specially adapted for the use of hixture men, earbon tongs whieh are largely used by trimmers, being light and strong and a great variety of machinists' tools and drop forgings among which are various bronze forgings used on the Whitehead torjedves.

A large part of this exhibit shows the capabilities of the company in the line of (Irop forgings, the forgings being shown just as they were forged, no attempt being made to finish the goods. In the show cases are exhibiterl tools, etc., finished with the greatest care. 


\section{ELECTRICAL INDUSTRIES.}

DUBLISHED EVERT THURSDAY BY THE

\section{ELECTRICAL INDUSTRIES PUBLISHING COMPANY, \\ INCORPORATED \\ MONADNOCK BLOCK, CHICAGO. \\ Telephone Harrison 159.}

E. L. POWERS, Pres. AND Treas.

E, E. WOOD, SEcretary.

\author{
E. L. POWERS, \\ H. A. FOSTER \\ W. A. REMINGTON, \\ E. E. WOOD,
}

FLOYD T, SHORT,

Advertising Departaent.

EASTERN OFFICE, WORLD BUILDING, NEW YORK. World's Fair Headquariers, $Y 27$ Electricity Building.

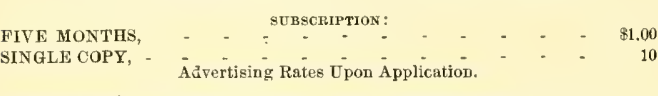

News items, notes or communications of interest to World's Fair isitors are eartiestly desired for publication in these columns and will be heartily appreciated. We especially invite all visitors to call upon u or send address at once upon their arrival in city or at the grounds.

Monadnock Block, Chicago

The List of Awards Department of Electricity.

The following is a list of the awards made at the present time. The tests of incandescent lamps, wires, storage batteries, of some of the transformers and a few others have not been completed. The diplomas will soon be ready and will be placed so that parties interested may inspect them.

$$
\text { UNITED STATES. }
$$

Albert \& J. M. Anderson, Boston, Mass.

1. Trolleys.

2. Railway insulators.

Brush Electric Co., Cleveland, Ohio.

1. Direet eurrent dynamos for series are lighting.

2. Direct current dynamos for series are lighting coupled to engine, $125-2000$ c. p. lamps.

3. Alternating current dynamos constant potential, 36 $-150 \mathrm{~K}$. W.

4. Are eircuit switeh board.

5. Direct current dynamos constant potential 20-100 K. W.

6. Arc lamps all types.

Bryant Electric Co., Bridgeport, Conn.

Snap switches.

W. R. Brixey, New York.

Underground, aerial and submarine telegraph and tel ephone cables.

J. H. Bunnell \& Co., New York.

1. Standard dry batteries.

2. Telegraphic apparatus.

C. C. Electric Motor Co., New York.

1. Direct current motors, constant potential 3-50 H. P.

2. Electric motor, fan and blower combination.

Cutter Mfg. Co., Philadelphia, Pa

Push switches for electric lights.

Commereial Cable Co., New York.

1. Ocean telegraphic apparatus operating through Muribead's artificial resistances.

2. Cuttriss improred eable telegraph apparatus.

Crane Electric Co.. Chicago, Ill.

Electric passenger elevator complete.

Carpenter Enamel Rheostat Co., Bridgeport, Conn.

Rheostats.
Copenhagen Fire Alarm Co., Chicago.

Automatic fire alarm.

Geo. Cutter, Chicago, Ill.

Lamp supporting pulley.

Electrical Forging Co., Boston, Mass.

Electrie heating and welding apparatus.

Electric Heat Alarm Co., Boston, Mass.

Thermostat for automatic fire, hot journal and hot grain alarms.

Electrical Conduit Co., New York.

Underground conduit for electrical wires.

Electric Launch \& Navigation Co., New York. Electric launches.

Eddy Electric Mfg. Co., Windsor, Conn.

Direct current motors constant potential.

Excelsior Electric Co., New York.

1. Are lamps series circuits.

2. Direct current dynamos for series are lighting.

Elektron Mfg. Co., Springfield, Mass.

Direct eurrent motors constant potential multipolar, slow speed.

2. Automatic motor starter.

Electric Selector and Signal Co., New York.

Electrical system for locking and unlocking.

Edison Mfg. Co., New York.

Edison, LeLande primary battery.

Eureka Tempered Copper Co., North East, Pa.

Tempered copper for use in electrical construction.

Fort Wayne Electric Co., Fort Wayne, Ind.

1. Direct current "Wood" dynamo for series are lighting.

2. Alternating current " Wood" dynamo constant potential compound wound $150 \mathrm{~K}$. W.

3. Arc lamps for constant current.

I. P. Fink, New York.

Screen reflectors for incaudescent lamps.

General Electric Co., New York.

1. Electric locomotives for factory and switches services.

2. Electric elevated railway system.

3. Long distance power transmission, plant in operation, tri-phase.

4. Are lamps for direct current series circuits.

5. Search lights and focusing lamps.

6. Transformers 250-125,000 watts.

7. Engine dynamos.

8. Automatic overload switch.

9. Electrically illuminated fountains.

10. Thomson eccentric coil ammeters and rolt meters for alternating currents.

11. Pumping machinery driven by electric motor.

12. Electrically driven rock wroking matchinery.

13. Mine locomotive.

14. Haskins Astatic armeter.

15. Are lamps for constant potential eireuits direct and alternating (Knowles).

16. Jaw switches, fuses, sockets and branch blocks.

17. Direet eurrent dynamos for series are lighting.

18. Alternating current dynamos for series are lighting.

Alternating current dynamos constant potential 30 $300 \mathrm{~K}$. W.

19. System of street railway service.

20. Direct current dynamos constant potential (direct connected excepted) and direct current shunt wound motors, constant potential.

21. Edison feeder system for distribution of electricity.

22. Slate switch board for are light eireuits.

23. Ventilating set, portable, Government standard.

24. Historical apparatus.

25. Edison three-wire system for distribution of electrical energy.

26. Exhibit of incandescent lamps all styles, $\frac{1}{2}$ to 250 c. p.

27. Underground system complete in all details.

28. Hoisting apparatus driven by electric motors.

29. Integrating watt motor. 
The E. S. Greeley \& Co., New York.

1. Testing instruments.

2. Exter dry battery.

3. Telegraph apparatus.

Gamewell Fire Alarm Telegraph Co., New York. Automatic fire alarm telegraph system.

General Ineandescent Are Lamp Co., New York. Are lamps for coustant potential circuits.

Hart \& Hageman Mfg. Co., Hartford, Conn. Snap switches.

Helios Electric Co.

Arc lamp for alternating current.

The Hanson Battery Co., Washington, D. C. Primary batteri's.

Interior Conduit \& Insulation Co., New York.

1. System of interior insulating conduits.

2. Snap switches.

Jenny Electric MIotor Co., Indianapolis, Ind.

Direct current dynamos and motors constant potential.

H. W. Johns Mfg. Co., New York.

$\checkmark$ ulcabeston and molded miea insulating material worked into all kinds of insulations.

LeClanche Battery Co., New York.

LeClanche batteries, especially the "Vole" and "Cylinder" cells.

Nather Electric Co., Nanchester, Conn.

Direct current dynamo, constant potential 500 volts.

McIntosh Battery \& Optical Co., Chicago, III.

Electro medical, dental and surgical apparatus.

National Carbon Co., Cleveland, Ohio.

Carbons for are lamps.

Notting Electric Mfg. Co., Chicago.

Nutting anc lamp.

Otis Bros., New York.

1. Eleetric pump.

2 . Electric motor and controlling derices for elevator and hoisting service.

H. T. Paiste, Philadelphia, Pa. Snap switches.

Police \& Sigual Co, Chieago. System of police patrol telegraph.

Phenix Gilass Co., Chicago.

Electric and gas globes and shade ent, etehed and colored

Queen \& Co., Philadelphia, Pa.

1. Electrometer (Ryan).

2. Galvanometers.

3. Testing sets aud resistances.

4. Portable medical induction apparatus for physician's use.

5. Commercial ammeters and voltmeters.

J. A. Roebling's Sons Co., Trenton, N. J.

Bare copper and trolley wire.

F. A. Ringler \& Co., New York.

Half tone photo-electro type steel faced.

Standard Electric Co., Chicago.

1. Are lamps for direct current series circuits.

2. Direct current dynamos for series are lighting.

Stevenson Hoggson Electric Co, St. Lonis, Mo.

Automatic electric time stamp.

Sperry Electric Railway Co.. Cleveland, Ohio.

Electric raliway system.

Short Eleetric Railway Co., Cleveland, Ohio.

Short Electric Railway system.

Self-Winding Clock Co., New York.

Special application of an iron-elad solonorid magnet.

Thomson Electric: Welding Co., Boston, Mass.

Apparatus for electric welding and forging.

Union Electric Works, Chicago.

Primary battery.

J. C. Vetter \& Co., New York.

1. Incandescent current adapter.

2. Dry LaClanche battery.

Western Electric Co, Chicago.

1. Columbiun street lamp post.

2. Telegrapl apparatus

3. Telephone cables, Paterson.

1. Annunciators and signaling apparatus.

5. Multiple switchboard for telephone service.
6. Direct current dynamos for series are lighting.

7. Application of electric lights for the production of scenic effects in theaters and for the decorations of rooms, etc.

8. Arc lamps various styles for series circuits.

9. Arc lamps for constant potential circuits.

10. Direct current dymamos and motors constant potential.

Waite \& Bartlett Mfg. Co., New York.

1. Holtz induction machines in air tight case with 6 fo inch revolving plates.

2. Special faradic apparatus for varying the teusion and strength of current (Engleman's apparatus).

Waslington Carbon Co., Pittshurgh, Pa.

Carbons for arc lamps, batteries and dynamos, and motor brushes.

Wm. Wallace, Ansonia, Conu.

Historical electric light exhibit.

Walworth Mfg. Co.

Poles for trolleys and are lamps.

S. S. II hite Dental Mfg. Co., Philadelplia, P’a.

Acid gravity batteries "Partz."

Westinghouse Electric \& Mfg. Co., Pittshurg, Pa.

1. Engine dynamos.

2. Transformers, "250-1250() K. II.

3. Direct current dyuamos and motors constant potential bipolar and multipolar (except direct connected dynamos).

4. Alternating current dynamos constant potential 7io K. II.

i. Electric street railway system.

(3. Alternating courrent dynamos for series are lighting.

7. Long distance power trausmission, plant in operation.

s. Two phase altermating current motors (Tesla).

9. Incandescent system of street lighting.

10. Switches.

11. Complete switchboard for controlling 17 tynamos and 40 currents.

12. Lightening arresters.

Weston Electrical Instrument Co., Newark. N. J

1. Alternating current instrument including watt meters.

2. Standard resistance and briclges.

3. Electrical measuring instruments for physicians use.

4. Switchboard instruments.

i. Direct current anmeters and voltmeters, standard and portable.

Western Union Telegraph Co., New York.

Instrmments used in quadruplex telegraph, latest design.

Zucker s Leavett Chemical Co., New Jork.

Collection of chemicals and appliances for electroplating.

GERMAX.

Prof. Aron, Berlin.

Electric meters.

J. Berliner, Hanover.

Iniversal transmitter, long distance.

Geo. Carette \& Co., Nuremburg.

Optical, physical and mechanical instruments and toys.

Dr. Edelmaun, IInich.

Electro medical apparatus.

Felton d Guilleaume, Muhlhansen on Rhine.

1. Electric cables with special armor.

2. Electric cables.

Gehmelzen, Nuremburg.

Carbons for are lights.

Hartmann \& Braın, Frankfort.

1. Differential are lamps.

口. Galvanometers.

3. Electrical measuring instruments including instruments of precision.

4. Platometer, large universal.

5. Apparatus for testing iron and steel with respect to magnetic permeability.

6. Reading telescopes, mirrors and scales.

7. Portable measuringapparatus used in laying vables. 
IV. A. Hirshman, Berlin.

Electro medical apparatus.

Tmperial German Postal Telegraph Dept., Berlin.

1. Maps and drawings showing system of Government telegraph lines using armored underground cables.

2. Telegraphic apparatus of the German telegraph service.

3. Historical telegraphic apparatus.

Korting \& Matthissen, Leipsig.

Arc lamps for constant potential cireuits.

H. Schomburg \& Sons, Berlin.

1. Insulators and insulating material.

2. Dry batteries.

Schuckert \& Co., Nuremburg.

1. Seirch lights with parabolic glass mirrors.

2. Annunciators for ressels.

3. Arc lamps for constant potential circuits.

Siemens \& Halske, Berlin.

1. Arc lamps for constant potential cireuits.

2. Direct current dynamos, constant potential $750 \mathrm{~K}$. IV.

3. Historical apparatus.

Schmidt \& Haench, Berlin.

Limmer-Brodham photometer with accessories.

J. Zacharias, Berlin.

Dry batteries.

TURKET.

Imperial Ottoman Government.

Telegraphic apparatus.

\section{GREAT BRITAIN.}

British Govermment Postal Telegraplı Dept.

1. Modern telegraph apparatus in operation.

2. Historical telegraph apparatus.

Corporation of Birmingham.

Original Woolwich dynamo.

General Electric Co., Ltd., London.

H. I. switches and otler incandescent house fittings.

James White, Glasgow.

Electro magnetic balances, Kelvin.

AUSTRLA.

F. Hardtmuth \& Co., Vienna.

Carbons for are lamps, etc.

$$
\text { RUSSIA. }
$$

Imperial Russian State Paper Manufactory, St. Petersburg. Collection of electrotypes.

Imperial Artillery Arsenal, St. Petersburg.

Electrical registering attachment for testing machine. (Prince Gagarian.)

$$
\text { ITALY. }
$$

Prof. Galeleo Ferraris, Turin.

Historical alternating current motors.

$$
\text { JAPAN. }
$$

Imperial University, Tokio.

1. Seismographs and accessory apparatus.

2. Model of an eartbriuake.

Department of Engineering Imperial Unirersity, Tokio.

Automatic elcetric current recorder.

BRAZIL.

Directoria Geral dos Telegraphos, Rio de Janerio.

Telegraphic apparatus.

Arrangements are being made for a street railway day at the Fair. It is proposed to have the day following the close of the convention at Milwanliee street railway day and have a special program prepared for the delegates on their return from Milwankee.

Irish dily at the Exposition Saturday the 30th, bids fair to be one of the most notable of the red letter days. The Department of Electricity on this oceasion will not be behind in doing honor to Erin. Not only is Chief Barrett the proud possessor of the only Irish Electric flag on the grounds pre- sented him by the Brush Electric Co., the current for which is supplied by the Westinghouse company, but he is also the owner of a very handsome silken flag, presented him by admiring friends. The graceful folds of this flag will float over the Electricity Building in honor of Lord Mayor Shanks, of Dublin, and all other true followers of St. Patrick. Frank D. Nillet, the artist of the Fair, has objected to the hoisting of this flag and a lively fight has been going on between him and Prof. Barrett, but as usual, the Chief has come off victorions and the flag will be unfurled. The electric flag taken with the other banner will certainly do credit to the department on that day.

\section{PERSONAL.}

Mr. J. H. Smith, of Inverness, Ohio, was a visitor at the Fair last week.

Mr. Emile Berliner, of Washington, D. C., is making a visit to the Fair.

Mr. W. E. Shepard, electrical engineer of Lincoln, Neb., is visiting the World's Fair.

Mr. Wm. J. Hammer, of New York, reg istered at Institute headquarters last week.

Mr. Wm. Grosvenor Ely, Jr., of Norwich, Ct., is taking in the electrical features of the Exposition.

Mr. C. E. Billings, president of the Billings \& Spencer Company, of Hartford, Ct., is at the Fair.

Mr. C. E. Clifford, assistant electrical engineer of the Buffalo Street Railway, is in Chicago and the Fair.

Mr. H. F. Parshall, with the Thomson-Houston Company, at Boston, Mass., was among the arrivals last week.

Mr. E. E. Schlosser, manufacturer of electrieal appliances from Denver, Colo., is stopping at the Palmer House.

Mr. W. E. Denning, eity electrician of Minneapolis, Minn. registered at the space of Electrical INDUSTRIES recently.

Mr. Robt. Lundell, engineer for the Interior Conduit \& Insulation Company, of New York, is registered at the Great Northern.

Mr. G. H. S. Young, manager of the C. \& C. Electric Company, at Philatlelphia, spent some time at the Fair during the past week.

Mr. Elias Nusbaum, superintendent of the Pennsylvania Electrical Engineering Company, of Philadelphia, has been at the Fair this week.

Mr. Ed. W. Norton, of Newton, Kan., vice-president of the Armature Electric Union, was an interested visitor in the Electrical Building a short time ago.

Mr. J. Hamblet, manager of the time service of the Western Union Telegraph Company, of New York City, returned this week after a two weeks' visit at the Exposition.

Mr. W.J. Gilmour, district manager of the Bell Telephone Company, at Broekville, Ont, is at the Fair, and is examining with special interest the exhibits of storage batteries.

Mir. L. W. Robinson and Mr. W. B. Cosgrove, of the Westing. house Electric Manufacturing Company, from Pittsburg, while visiting the Fair last week, called upon ELECTRICAL INDUSTRIES.

Among the visitor's to the Electricity Building who have registered during the past week at the booth of ELECTRICAL INDUstries, are the following: Mr. H. K. MeCay, of the MeCayHoward Engineering Company, of Baltimore, Md.; Mr. Elias Nusbaum, superintendent of the Pennsylvania Electrical Engineering Company, Philadelphia, Pa ; Mr. I. M. MeGrath, general sales agent for the Acme Company, of New York; Mr. J. S. Romine, president of the Electric Light \& Power Company, of Chadron, Neb., and Mr. A. M. Hanbrich, of Detroit.

Mr. TV. H. MeKinlock is now husy organizing the Metropolitan Electric Co. Chleago, a corporation of which he will be the head, with ample capital for promoting its business. Mr. MeKinloek has had a wide experience in the electric business extending from the time of the introduction of electricity and is therefore one of the best known men in the trade. With a full knowledge of the wants of the trade, the success of his new enterprise is assured from the start. The new company will do a large manufacturing and supply business comprising the most desira ble specialties of all linds in the line of electric apparatus and a ppliances. 

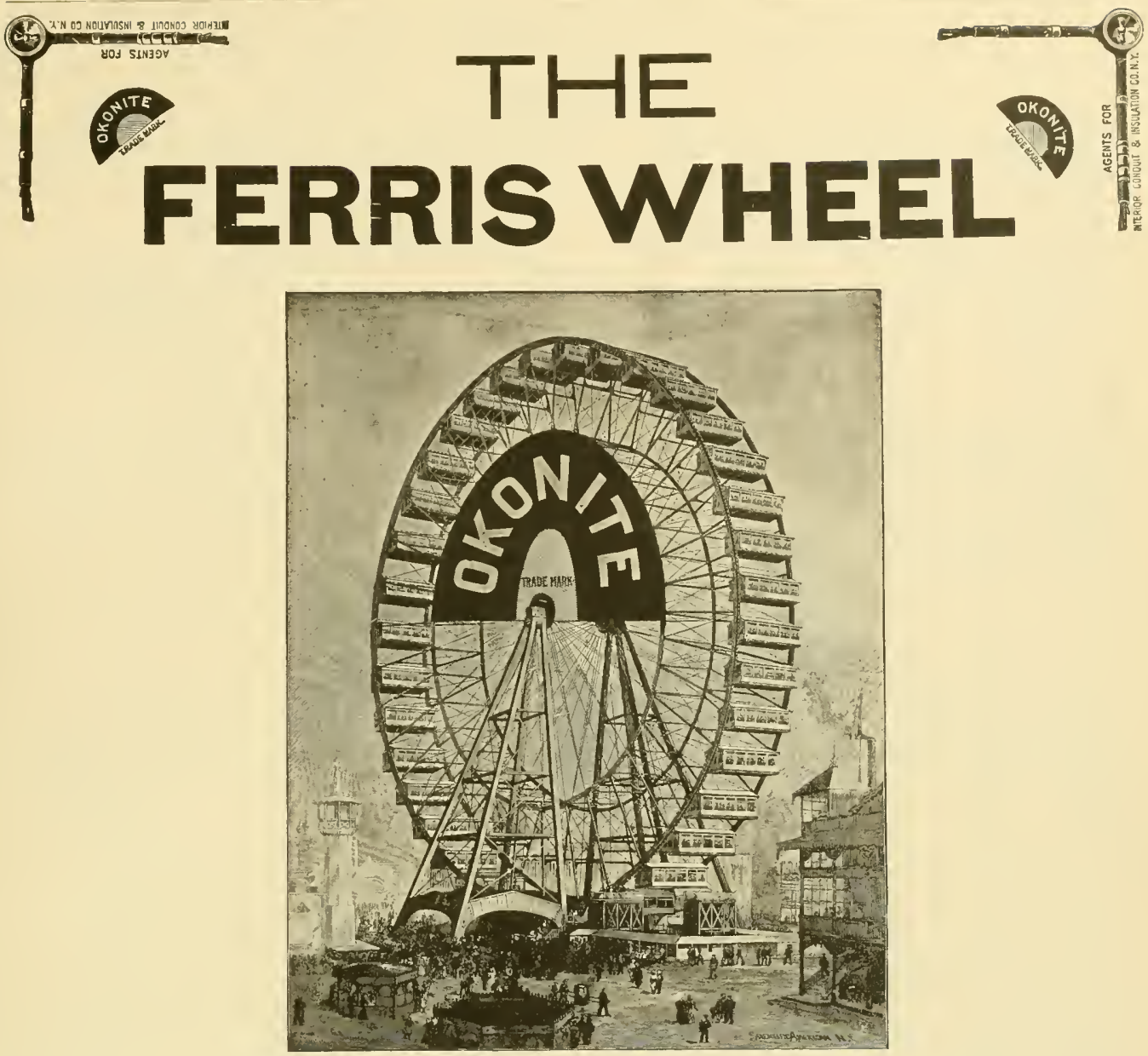

When you visit the World's Fair, you will naturally take a ride on the FERRIS WHEEL and be interested in the ELECTRIC LIGHT INSTALLATION, which is wired throughout with

\section{OKONITE WIRE}

FURNISHED BY THE

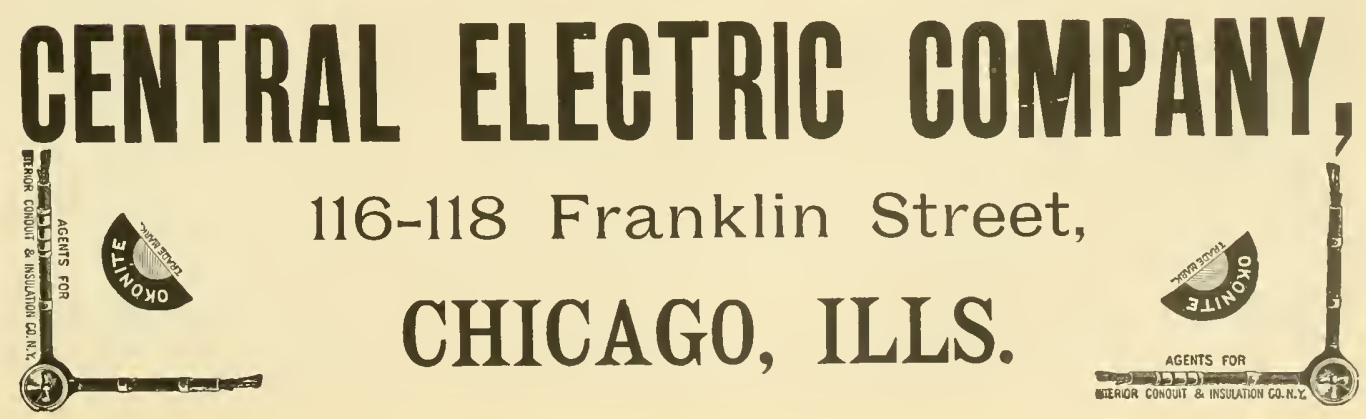




\section{ELECTRICITY BUILDING -EXHIBITORS AND THEIR LOCATION.}

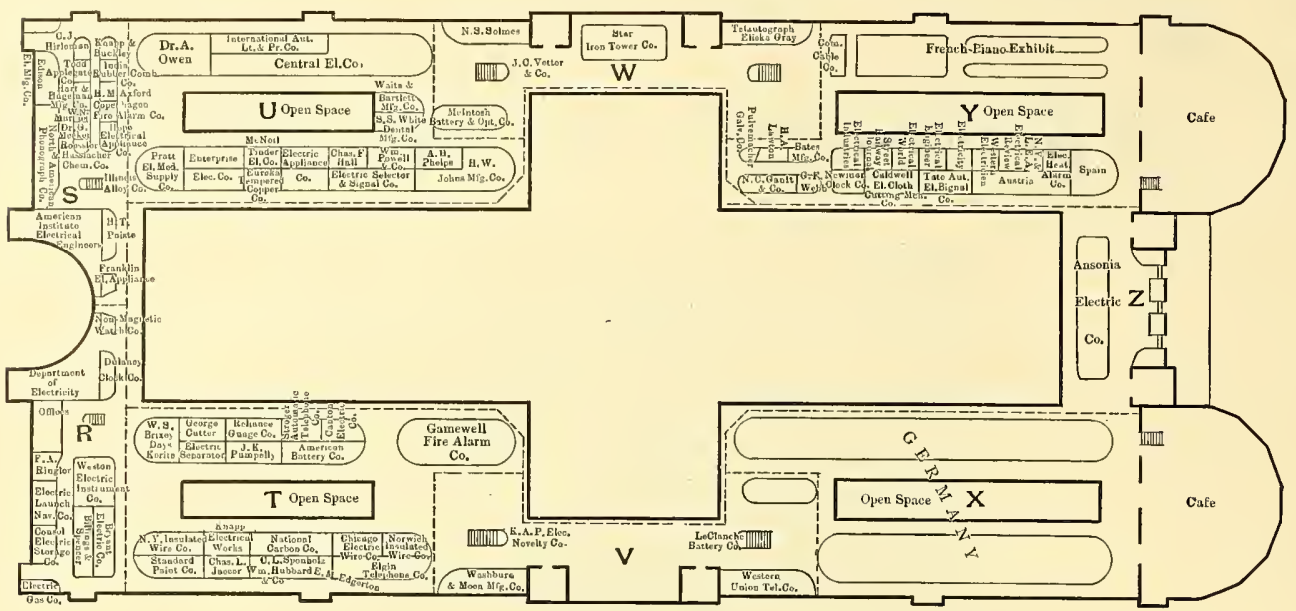

GALLERY.

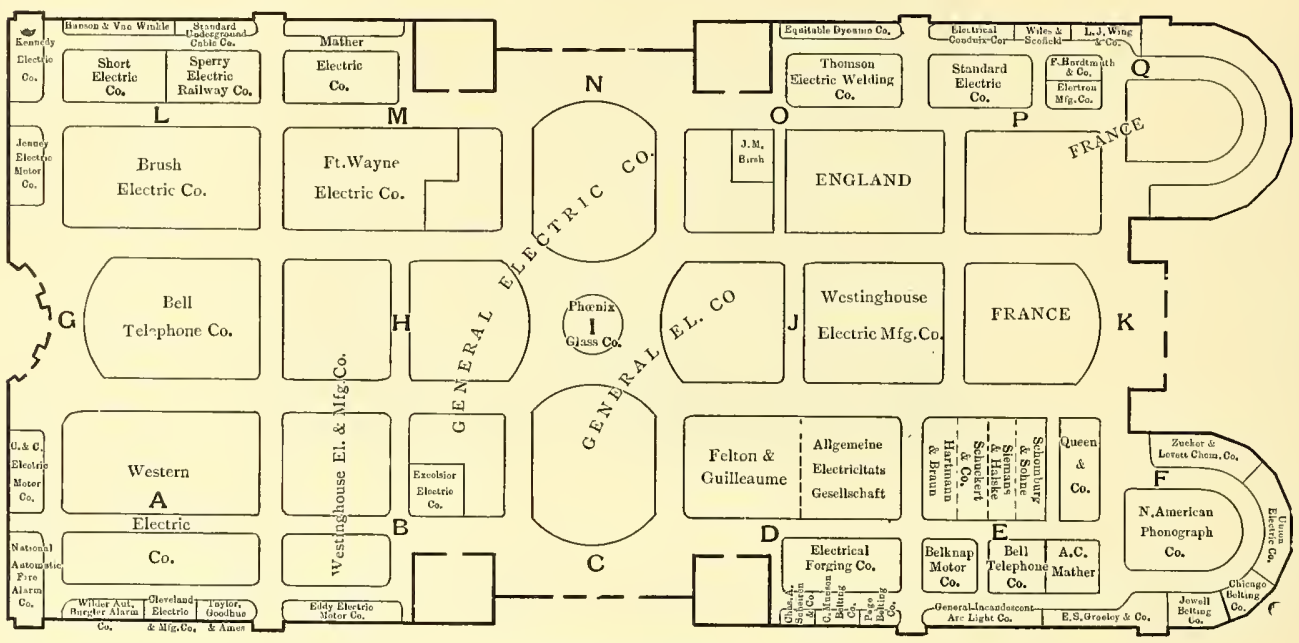

MAIN FLOOR.

\begin{tabular}{|c|c|c|}
\hline Exhibitor. & Exbibitor. & Exbibitor. \\
\hline $\begin{array}{l}\text { Anstria } \\
\text { Ansonia Electric Co....................... }\end{array}$ & 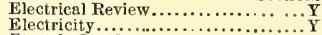 & $\begin{array}{l}\text { Jaeger, Chas, L....... } \\
\text { Johns M fg. Co., H. w. }\end{array}$ \\
\hline Am, Inst. of Elec. Eng.. .............. & Electric Gas Co......................... & $\begin{array}{l}\text { Jonns Arg. Co., H, W. } \\
\text { Jewell Belting Co...... }\end{array}$ \\
\hline American Battery Co............... T & Electrical Enginee & Jonney Elec. Motor Co. \\
\hline Axford, H. $11 \ldots$ Gesellechaft........... & Electrical World ........... & Knapp Electrical Works.... \\
\hline $\begin{array}{l}\text { Allg. Elec. Gesellschaft..... } \\
\text { Bates Mfg, Co }\end{array}$ & Eddy Electric Motor Co.. & K. A.P. Elec. Novelty Co. \\
\hline $\begin{array}{l}\text { Bates Mfg. Co............. } \\
\text { Bryant Electric Co...... }\end{array}$ & $\begin{array}{l}\text { Excelsior Electric Co..... } \\
\text { Electrical Forging }\end{array}$ & Knapp \& Buckley ........... \\
\hline Billinge \& Spencer........ & $\begin{array}{l}\text { Electrical Forging Co.............. } \\
\text { Equitable Dynamo Co......... }\end{array}$ & $\begin{array}{l}\text { Kennedy Electric Co. } \\
\text { Lawton, H. A........ }\end{array}$ \\
\hline Brixey, $w, i \ldots \ldots$ & blektron Mfg. Co.................. & LeClanche Battery Co........ \\
\hline Belknap Motor Co...... & Electrical Conduit Co... & McNeil-Tinder Elec. Co.......... \\
\hline Bell Telephone Co...... & England .................. & Marcus, W. N ................. \\
\hline $\begin{array}{l}\text { Brash Electric Co } \\
\text { Caldwell El. Cloth C̈nt. Mich. Co. }\end{array}$ & Empire China Works. .... & Meeker, Dr. G............... \\
\hline $\begin{array}{l}\text { Caldwell El. Cloth Cnt. Mch. Co.....Y } \\
\text { Consol. Elec. Storage Co .......... }\end{array}$ & $\begin{array}{l}\text { Franklin Elec. Appliances........... S } \\
\text { Frencl Piano Exh }\end{array}$ & McIntosh Bnt. \& Opt. Co. \\
\hline 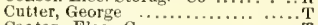 & Felton \& Guilleaume................ D & $\begin{array}{l}\text { Munson, } \mathrm{C} \text {, Belting } \mathrm{Co} \\
\text { Mather, } \mathrm{A}, \mathrm{C}, \ldots \ldots \ldots \ldots . . . .\end{array}$ \\
\hline & France $\ldots \ldots \ldots \ldots \ldots \ldots \ldots \ldots \ldots \ldots \ldots \ldots$ & Mather Electric Co... \\
\hline Chicago Elec. Wire Co.............. & Ft. Wayne Elec. Co & Newman Clock co...... \\
\hline $\begin{array}{l}\text { Copenhagen Fire Alarm Co... } \\
\text { Central Electric Co............ }\end{array}$ & $\begin{array}{l}\text { Gault } \& \text { Co., N. C........... } \\
\text { Gamewell Fire Alarm Co. }\end{array}$ & Non-M rgpetic Wateh Co. \\
\hline Cuble Co.................... & General Electric Co...B-B- $-\mathrm{N}-\mathrm{C}-d \mathbf{J}$ & $\begin{array}{l}\text { N. Y. Insulated Wire Co............ T } \\
\text { National Carbon Co }\end{array}$ \\
\hline Hotor Co ........... & General Incand's't Arc L't Co........ E & 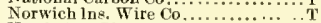 \\
\hline \& Mrg. Co.......... & Greeley, E. S., \& Co ......... & North Am. Phonograph Co........... \\
\hline$\ldots \ldots \ldots \ldots \ldots$ & & 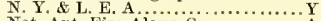 \\
\hline Electricity $\ldots \ldots \ldots$ & Inbbard, Wm, \& Co.... & Nat. Aut. Fire Alarm Co.... \\
\hline $\begin{array}{l}\text { Department of Electricity ............ } \\
\text { ELECTRICAL INDUSTRIEs . ......... }\end{array}$ & Hirleman, C. J........ & Angraving Machine Co... \\
\hline $\begin{array}{l}\text { ELECTRICAL INDUSTRIES ... } \\
\text { Elec. Launch \& Nav. Co..... }\end{array}$ & $\begin{array}{l}\text { llart \& Hege } \\
\text { Hope Elec. A }\end{array}$ & \\
\hline Electric Separator.. & c. Appliance C & 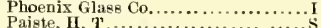 \\
\hline Edgertor & has. F.... & $\begin{array}{l}\text { Paiste, H. T'........... } \\
\text { Pulvermacher Galv, Co. }\end{array}$ \\
\hline $\mathrm{Co} \ldots$. & n \& Braun......... & Pumpelly, J, K ...... \\
\hline Edi & d Van Winkla.... & Pratt El Med Sup. Co \\
\hline & & $\mathrm{H}, \mathrm{Wm}$. $\mathrm{Co}$....... \\
\hline & $\because \mathrm{Co}$... & \& II \\
\hline 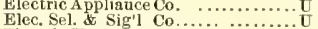 & $\begin{array}{l}\text { llinois Alloy Co } \\
\text { Internat. Ant. L't \& P'r Co.. }\end{array}$ & Page Beltiug Co. ............ \\
\hline Electric Heat Alarm Co............ & 1ndia Rubber Comb Co................. & Ringler, F, A. ............ \\
\hline
\end{tabular}

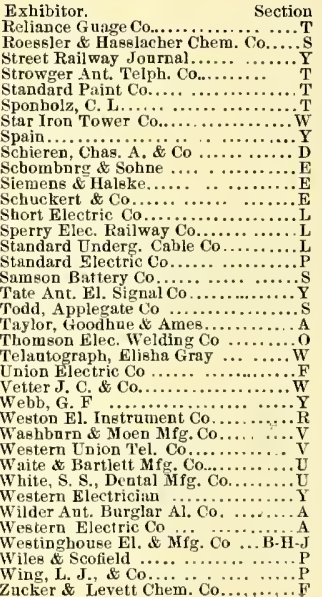




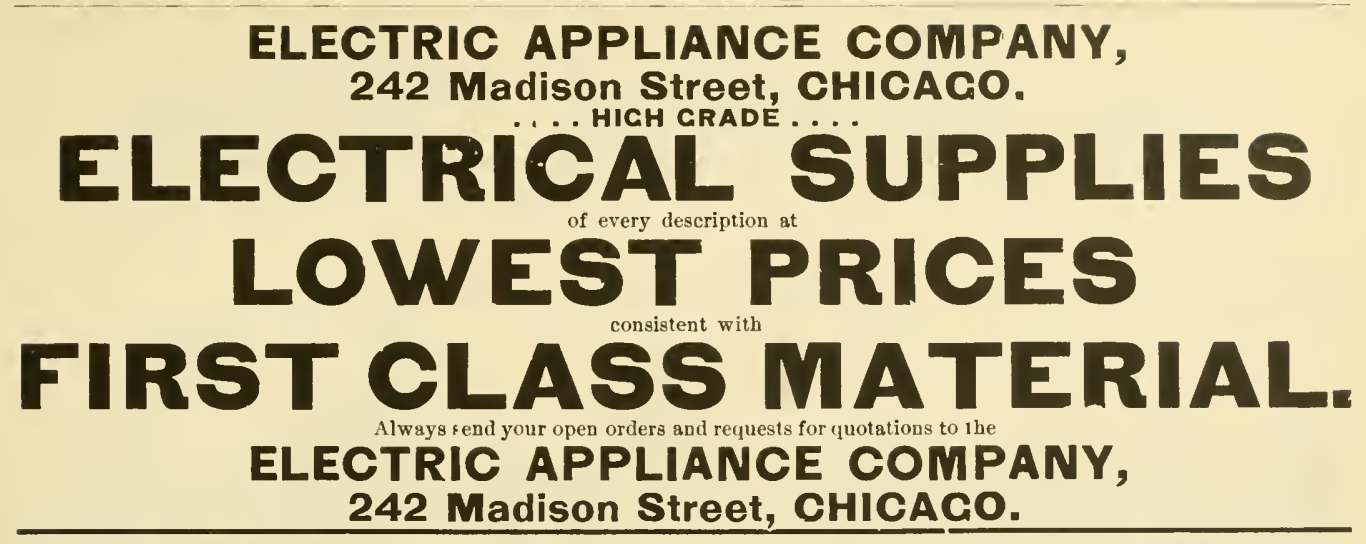

THE MONTHLY ISSUE FOR SEPTEMBER

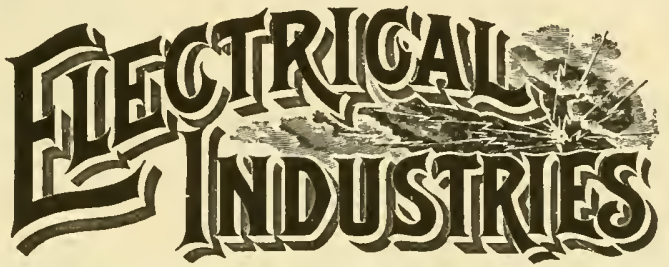

Should be read by everyone interested in electrical matters, In its Table of Contents is the following:

"World's Congress of Electricians."

"Nikola Tesla's Lecture."

"Love Underground Electric System in Washington." By M. D. Law.

"Gas Engines as Applied to Electric Light Work." By Geo. A. Farwell.

"The Underground System at the World's Fair."

"Electric Railway Plant of the Chicago North Shore Railway Company."

Together with illustrations of the recent applications of electricity.

The paper contains regularly

A Buyer's Directory of Manufacturers and Dealers in Electrical Supplies and Appliances.

A Complete Directory of Electric Liglit Stations in North Anerica and a Complete Directory of Electric Railways in North America.

These directories are revised each issue to the date of going to press and are to be found in no other electrical journal in the World. Its articles are read carefully and its directories used constantly by all the buyers in the trade. These facts make it without a superior as an, advertising medium. Sample copies and rates se11t on. application.

Sulsscription price $\$ 3$ per year. Six months trial $\$ 1$, if ordered during September.

\section{ELECTRICAL INDUSTRIES PUB. CO., Monadnock Block, CHICAGO.}

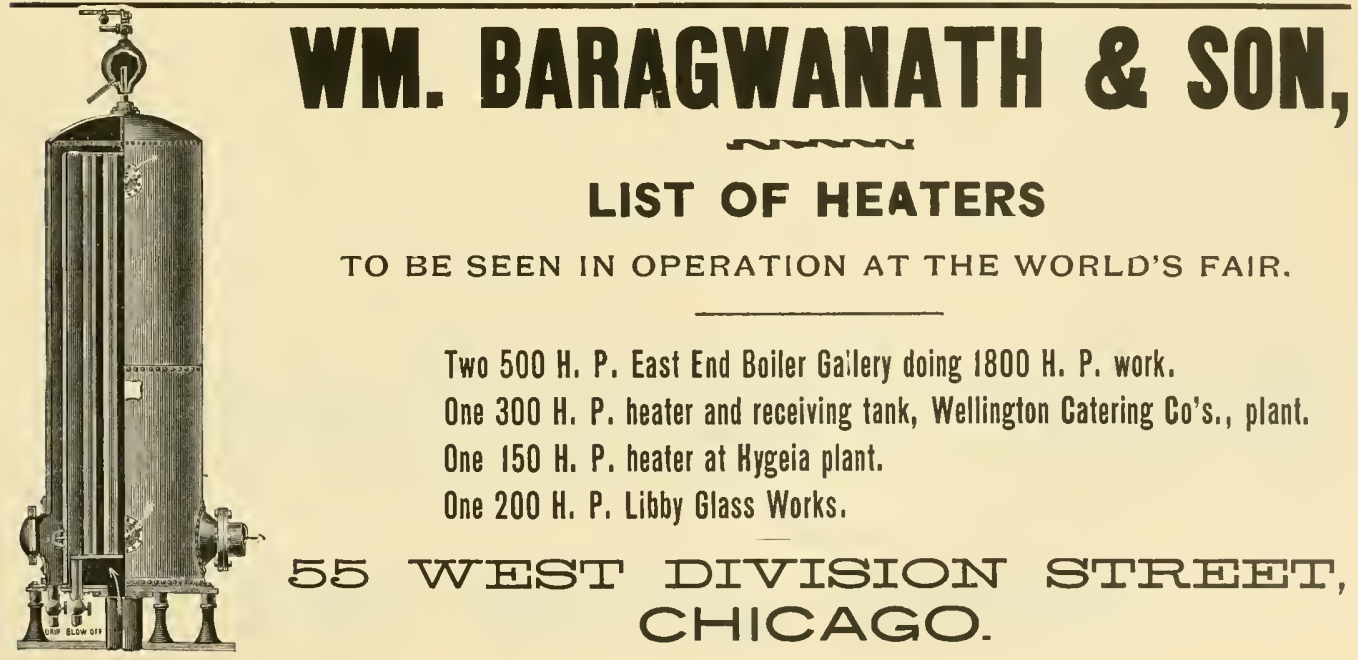




\section{OUR IMPROVED SYSTEM}

\section{... OF ...}

\section{Automatic Fire llarm,}

covered by patents recently issued, is the embodiment of all factors contributing to the

\section{GREATEST SAFETY,}

\section{and the MOST RELLABLE}

PROTECTION FROM FIRE.

\section{Western Electric Company,}


COMPANY, NEW YORK.

192 Broadway and II John Street.

MANUFACTURERS OF ARC LIGHTING APPARATUS FOR EVERY PURPOSE A SPECIALTY. The CLARK ARC LAMPS for use on EVERY CURRENT, have the reputation of being the best and most durable of any ever made in the United states.

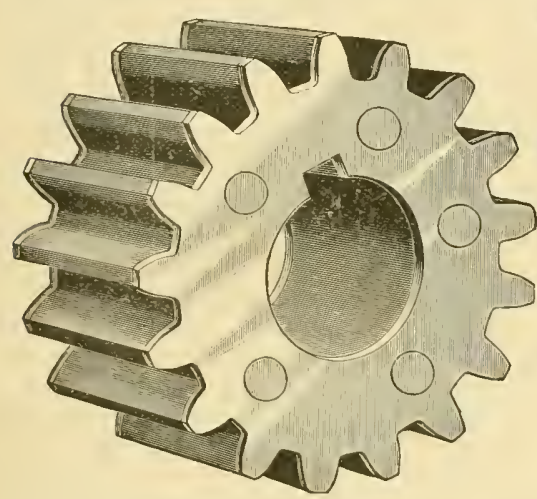

75 Ohio Street,

\section{RAWHIDE PINIONS FOR ELEGTRIC MOTORS} A SPECIALTY.

RAWHIDE DYNAMO BELTING

Greatest Adhesive Qualities. A Non-Conductor of Electriclity. Causes Less Frlction than any other Belt.

\section{THE GHIGAGO RAWHIDE MANUFACTURING CO.}

THE ONLY MANUFACTURERS IN THE COUNTRY

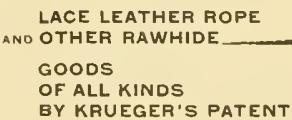

\section{Standard Electric Company.}

GENERAL OFFICES: 625 Home Insurance Building.

WORKS: So, Ganal Street,

\section{CHICAGO.}

\section{STANDARD SYSTEM}

AT THE

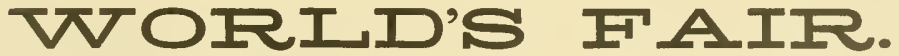

MACHINERY HALL, Sec. Q, 2 Standard Arc Dynamos.

Sec. S, 20 " “ "

ELECTRICIT Y BUILDING, Sec. P, Space 2, Arc Lighting Exhibit.

he Standard Lamps Light the Power Plant, Machinery Hall, Agricultural Hall, Shoe and Leather Building, and Other Buildings and Portions of the Grounds. 


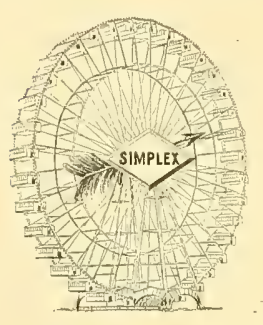

Mile after mile of

SIMPLEX WIRE

Supplied to the

FERRIS WHEEL

By...George Cutter, The Rookery, chicalio. George Cutter, Chicago. Boston, mass.

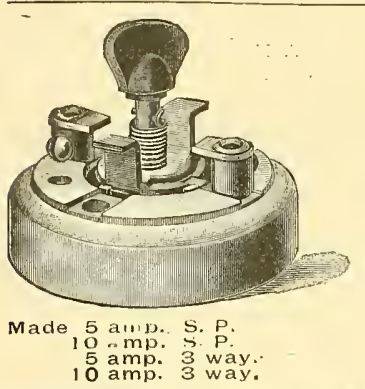

\section{XNTRIC}

"That's the Switch"

And we control that movement.

H. T. PAISTE,

10 South 18 th St.,

PHILADELPHIA, PA.

\section{SIMPLEX WIRES}

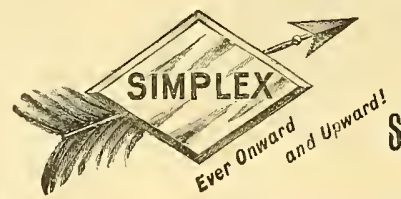

INSURE

HIGH

INSULATION

Simplex Eleglricgl Co.

620 Atlantic Ave.

ב

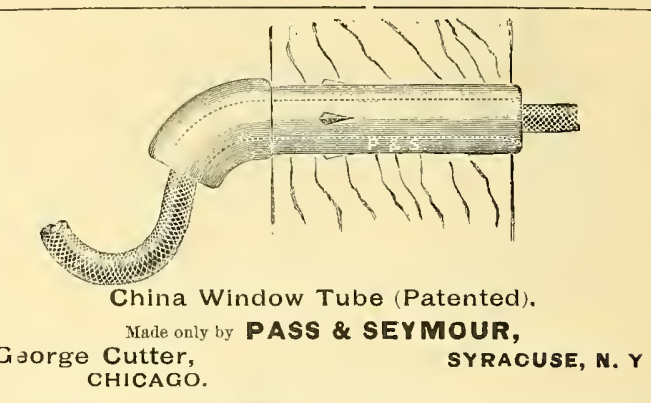

\section{Enterprise}

Electric

Company

207 Dearborn Street. Chicago....
WAGNER ELECTRIC FAN MOTORS

For Direct or Alternating Currents.

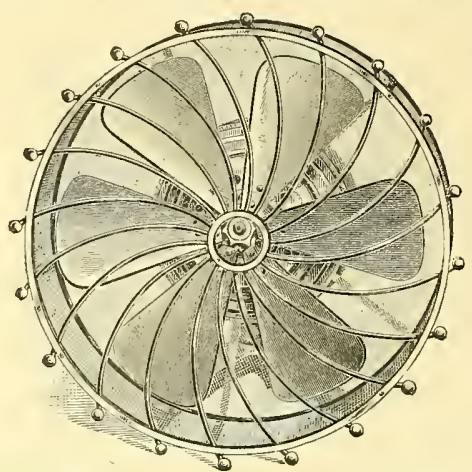

These motors give a stronger breeze with less consumption of eurrent than y other fan motor on the msrket. They are fnll 1-8 horse power. Six bladed IT WILL PAY YOU TO SEE THE WAGNER BEFORE BUYING ELSEWHERE.

TAYLOR, GOODHUE \& AMES, 348 Dearborn Street, CHICAGO. 


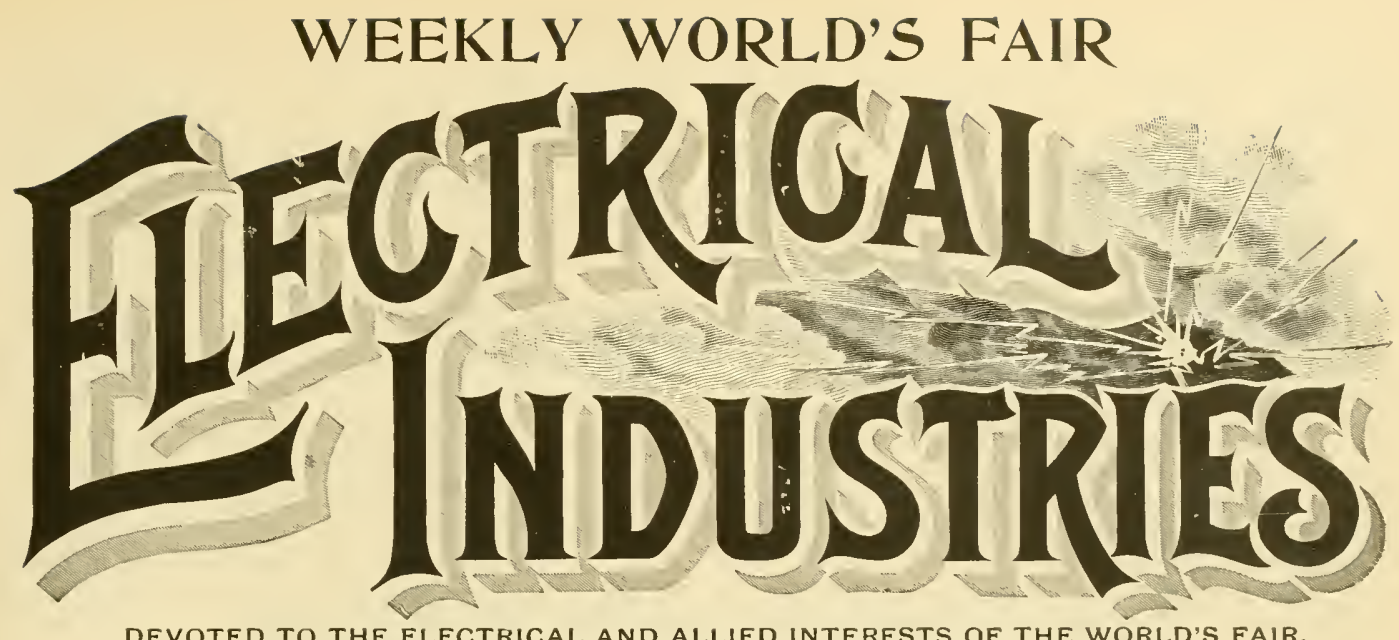

DEVOTED TO THE ELECTRICAL AND ALLIED INTERESTS OF THE WORLD'S FAIR, ITS VISITORS AND EXHIBITORS.

Vol, I, No, 17 . CHICAGO, OCTOBER $5,1893$.

FIVE MONTHS $\$ 1.00$
TEN CENTS A COPY

Exhibit of The Standard Electric Company.

One of the most prominent exhibits of arc lamps and arc apparatus is that made by the Standard Electric Company of Chicago in Electricity Building. The are lamps hung above the borders of the space inclucle a number of styles and a nast arm such as has leen adopted by the city of Cincinuati and which possesses special features adapting it for street use. The lamp is easily drawn into the pole and lowered to a point where it can easily be reached by the trimmer. These devices are shown in such a way as to be easily inspecte: by the visitor. The Standard lamp is also

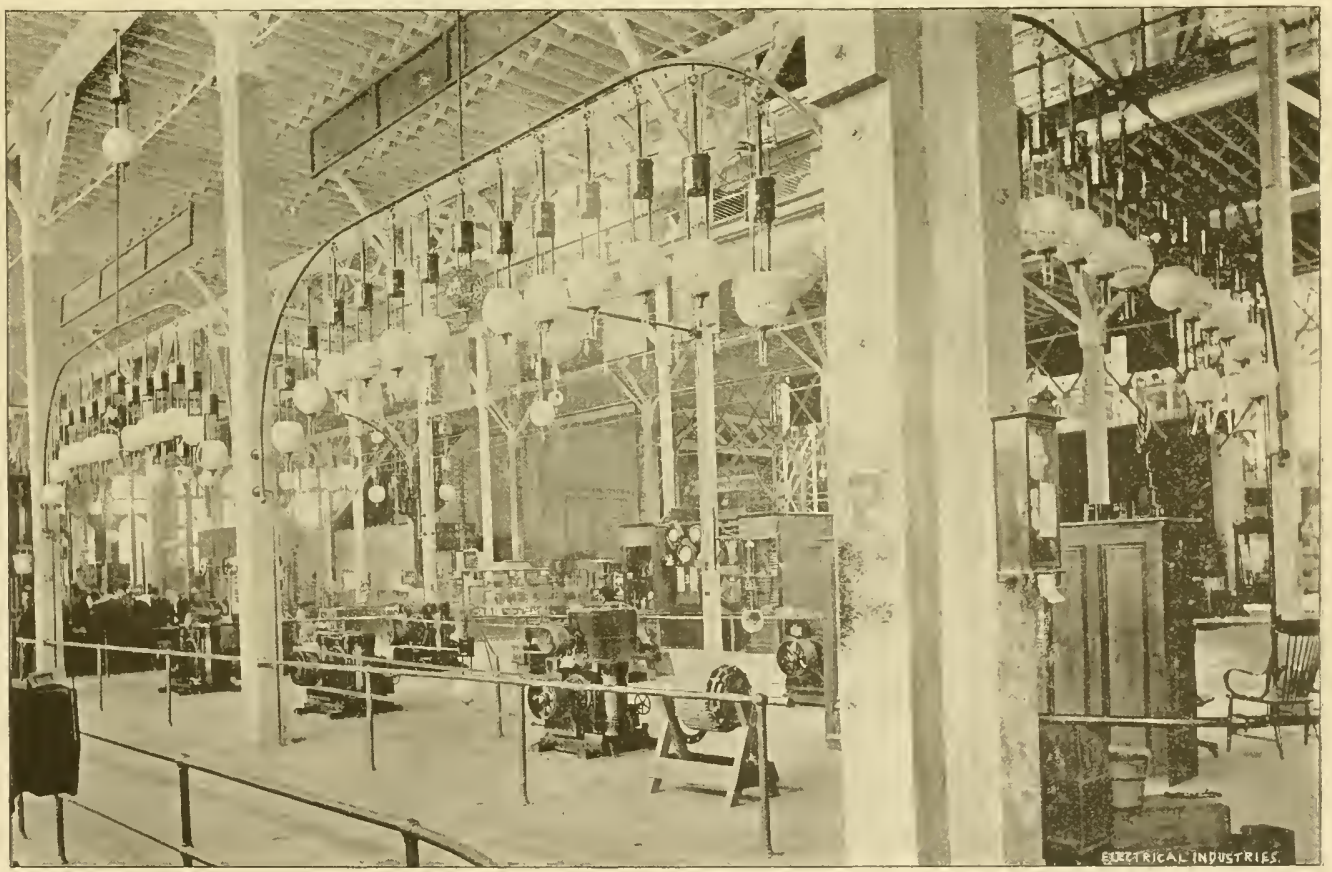

EXHIBIT OF THE STANDARD ELECTRIC COMPAXY.

of are lamps, adapted for the varions places in which are lamps are used.

In connection with the lamps are shown the safety lamp hanger by which the lamp is disconnected from the eircuit as it is lowered to be trimmed thus protecting the lamp and trimmer from any injury from the current while trimming, shown in detail. These lamps although the different styles vary in certain features, which are changed as special uses demand, are all of the independent feed type and are so constructed that under varying loads no difference in light is perceptible. An open circuit is almost impossible, no matter what position the rod may be in. The clntches are 
insulated so that no current ean pass through the frame of the lamp.

The feeding device is sensitive and the automatic cut-out which is one of the most essential features of a lamp, acts sharp and quickly under all conditions and great care has also been taken with its insulation. The same lamp may be changed to a 6,8 or 10 ampere lamp without changing the windings or the adjustments exeept the adjustment of the are spring which is the only change required.

Among the many improvements in the system shown in the exhibit is the double serrice, eliptical carbon, weatherproof lamp using no hood and but one carbon rod. One feeding mechanism is thus required to keep in repair in place of two which with the time saved in trimming and the decrease in the investment a large saving is made in the operation of the system.

An ingenius way of showing this lamp in operation has been devised by the company. In a cabinet placed near the center of the space one of these lamps is burning and by looking through a slide in this cabinet the arc of the lamp is seen projected on a screen greatly magnified. The ning. The heat developed in these machines never exceeds a rise of over 60 degrees above the surrounding atmosphere. The journal boxes are self oiling and self adjusting, thus insuring at all times the perfect alignment of the armature shaft. To remove or put in an armature requires simply the removing of two bolts of the journal stands from either side of the dynamo. The armature is of the Gramme ring type which has long been conceded to be the best adapted for machines of high roltage. It is made of thin laminated rings of Norway iron compressed tightly together under hydraulic pressure, mounted upon a brass spider at one end. Steel rods extend horizontally therefrom, the width of pole pieces and support the armature. The danger of grounding on the core is obviated and under this construction the rentilation of the armature is made perfect. The commutator is simple in construction containing 126 sections made of the best grade of hard drawn copper thoroughly insulated. Power is furnished the exhibit by a 40 -horse power iron clad Rockford motor placed near the center of the space.

The regulations of this dynamo is so perfect that the en-

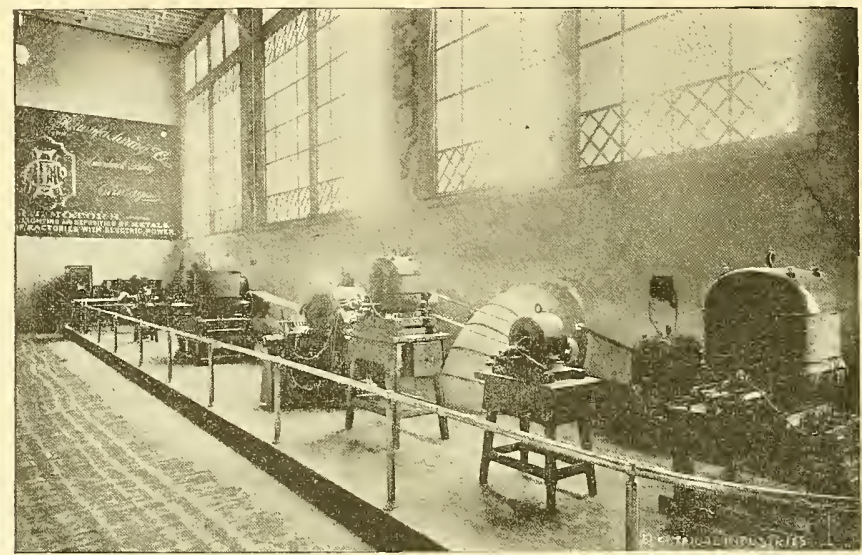

EXHIBIT OF THE EDDY ELECTRIC MANUFACTURIYG COMPANT.

other lamps are also shown burning, eurrent being supplied by one of the dynamos in the exhibit.

About the space are distributed are dynamos of the different sizes manufactnred by this company. One dynamo of 50 2000-candle power lights capacity, a 50 1200-candle power light, a 40 1600.candle power light, a 30 and a 20 2000-candle power light machines are shown. There is also displayed an armature showing the open commutator and its appearance when finished and an armature partly completed showing the armature core and method of wind ing. In design the Standard arc dymamo presents some special features in which the form of the well known Manchester type of field is earried out. The most essential features desired in a dynamo are efficiency, durability, simplicity and ease of operation. In the Standard dynamo these requirements have been as nearly fulfilled as is possible in the present age of $d y$ namo building. The use of wrought iron for the cores of the field magnet coils enables the machine to attain its required amount of magnetism with a much smaller expenditure of electrical energy than if cast iron was used. The wire on the field magnets as well as that on the armature is of unusual size, which means less energy used in the machine; hence cooler run- tire load or any part of it may be thrown on or off without subjecting the machine to an injurious strain. The device is very quick and positive in its action. In the combination of the Standard dynamo and are lamp an efficiency of 92 per cent is said to be secured. It is certainly an efficient combination and worthy of a careful study. This exhibit shows more especially the mechanical features of the various machines and appliances manufactured by the Standard company while a more practical demonstration is made by the large plant in Machinery Hall and the hundreds of arc lamps distributed about the grounds and buildings which the company installed.

\section{Exhibit of the Eddy Electric Manufacturing Com= pany.}

The Eddy Electric Manufacturing Company of Windsor, Conn, has quite an extensive exhibit in the east side of Electricity Building, Section B. It occupies a space over 70 feet long and contains sample machines of the sereral styles manufactured by the company.

A brass railing surrounds the space and desks and chairs furnish accommodations to visitors as well as an office for 
the representatives of the company. The exhibit is confined to motors and generators of which there are a variety shown. A part of the exhibit is located in Machinery Hall, over 1,000-horse power of generators being used for furuishing power about the grounds. These machines were in constant use during the early part of the Fair often carryiug a load much above their rated eapacity until other machines were in order to take part of the load.

Those machines have shown great strength under the continued heavy service. The four $200 \mathrm{~K}$. W. machines composing this plant are of the multipolar type.

The motors in the exhibit are supplied with current and are connected to the different generators so as to show them in operation. A 50 -horse power 500 -volt motor of thestyle designated as type $\mathrm{C}$, operates a 110 -volt, multipolar dynamo rated at 45 kilowatts. It is coupound wound; has self among which are one 20-horse power 220-volt motor, one seven and one-half 22()-volt, a two horse power 500 -volt and a one horse power 500-volt motor. Generators of a number of sizes are shown and of different patterns. These machines show care and skill in their construction. The magnetic circuits are short, the windings well made and their durability and efficiency is said to be of a high order.

The rheostats and other appliances manufactured by the company have met all requirements as to safety and dura bility. The exhibits of the company are in charge of Mr. F. C. Ross, manager and Mr. H. A. Balcom, electrician.

\section{Exhibit of H. T. Paiste Switches.}

In the accompanying cut is shown the exhibit of $\mathrm{H}$. $\mathrm{T}$.

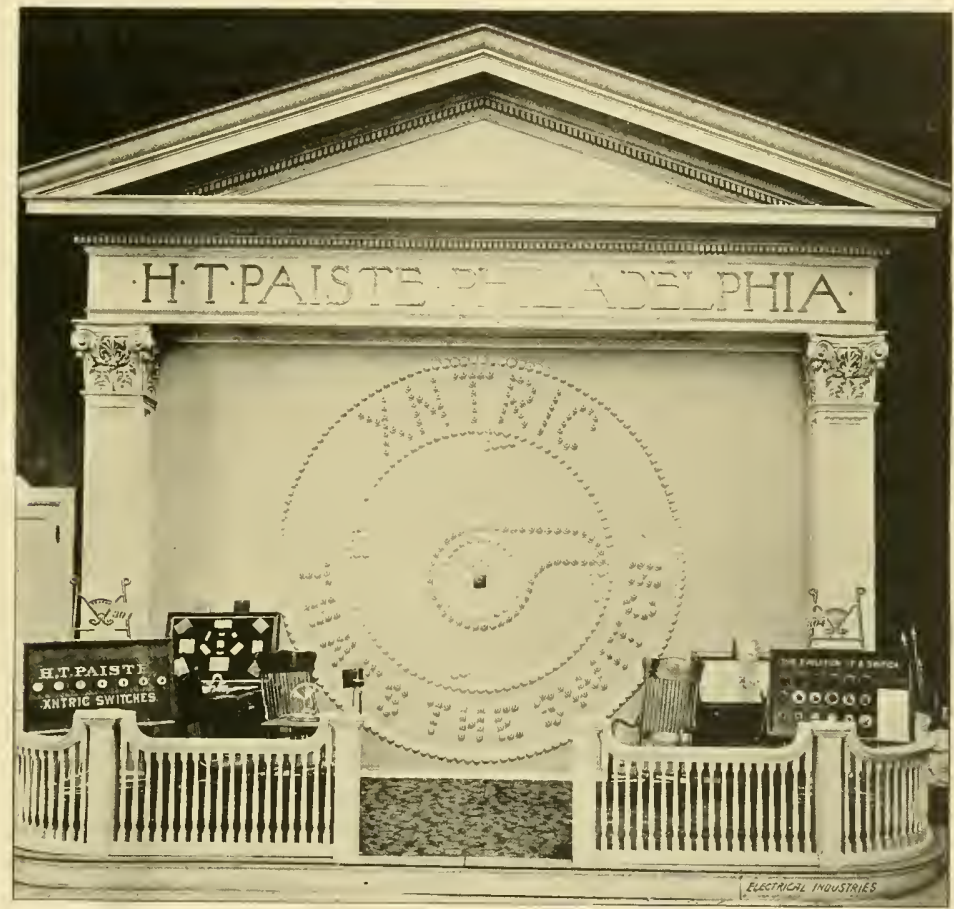

EXIHBIT OF THE H. T, PAISTE SWITCHES.

oiling bearings aud is a very smooth running machine. Another motor of 15-horse power eapacity is supplied with current from the 500 -volt circuit and runs at 600 revolu tions. It is the latest type mauufactured by the company. With two field coils and four poles it suggests the old Wenstrom motor.

This motor operates a 3,000 gallon nickel plater, known as No. '2. It runs 1,200 revolutions and furnishes current at eight volts. For the amusement of visitors a number four copper wire is connected across the terminals of this machine. The wire is soon heated to a bright red aud becomes so soft that it will not support itself. The plating machine does not seem to waver while under this test Other plating machines are slown, numbers 0 and one, which give sufficient range in sizes to supply the wants of any customer.

Various sizes of the regular type of Eddy motor is shown,
Paiste, of $10 \mathrm{~S} .18$ th street, Philadelphia. The ornamental background is finished in pure white touched out with gold. The arrangement of ceiling cut-outs in the center illustrating the "xntric" movement of the switch with the words "xntric that's the switch" is unique.

Within the very neat railing, finished in natural wood, that marks the space, are placed several easels and stands. On the easels, one placed at each end of the space, are panels showing the growth of the "xutric" switch aud the evolutions of the Paiste switch. On the first are placed a number of porcelaiu bases, each succeeding one having one piece more than the preceding one, so that the set shows the growth of the switch, step by step, from the plain porcelain base to the completed switch with its bind. ing posts, its spring, contacts, etc.

On the second are mounted numerous switches showing the gradual developuent of the Paiste switch, the first 
being the oldest form of the Paiste switch and the last the latest and most improved form of the "xntric."

The panels are of polished oak and present a very fine appearance. On another panel are displayed numerous porcelain block cut-outs of a great variety of sizes. Visitors interested in switches will find an attendant at the exhibit who will furnish any desired information in regard to the articles shown.

\section{The Cloud Projector.}

The cloud projector spoken of in a previous issue was given a public trial last Thursday evening and proved to be all that inventors have claimed for it. The apparatus has been temporarily erected upon the southwest corner of Manufactures and Liberal Arts Building and replaces one of the search lights. It consists of a large drum containing a powerful are lamp and fitted with a parabolic mirror for collecting and reflecting the light. In the front aperture a combination lens is placed and four iron arnis extend some distance from the drum to earry another lens. By the use of these lenses it is intended to reproduce on the elouds pietures or words. When nature fails to provide the clouds, vapor, produced by exploding bombs high in the air, will be used. The method of producing the pictures is the result of experiments which have been carried on by Mr. L. H. Rogers, of the Brush Electric Co. The experiments were first made upon Mount Washington and it is said, that in the tests made there, pictures which could be plainly distinguished fifteen miles away were thrown upon the clouds. The present machine is manufactured by The Independent Electric Co, 39th and Stewart Ave., Chicago. At a private exhibition given recently at the factory President Higinbotham and other Fair officials were so satisfied that the scheme was feasible, that permission was given to conduct the experiments upon the grounds of the Exposition. Mr. Elmer E. Sperry, the well known electrician, is in charge of the apparatus, and with the assistance of Mr. E. E. Stark, has been working to simplify the adjustments necessary for the perfect control of the light. The diffieulty that has been experienced has been to properly adjust the are, mirror and lens in their relative positions, a combination very hard to secure. Mr. Sperry regards the invention as a perfect success and calls it a new discovery in optical engineering. It has been found necessary to move the apparatus to an elevated platform constructed above the walk about the roof of the Manufactures Building. When this change has been completed it is promised to give the visitors at the Fair an exhibition during which will be thrown upon the elouds the pictures of Columbus, Cleveland, President Higinbotham and Director General Davis. On Chicago day the picture of Mayor Harrison will be added to the list. Just how much the public may expect of the new derice is not yet certain, but it is said that the development of the invention will lead to the spacing of the heavens and make it possible to rent certain square miles to the proprietors of Hood's soap and Pear's sarsaparilla for the purpose of advertising the merits of their respectire articles. Mr. F. I. Rogers is the business manager of the Cloud Projector Company and is now making arrangements for the placing of the machines in several of the larger cities and also at Niagara Falls, where the spray arising from the falls will be used as a screen for the pictures. Several large contracts are said to have been signed, among which is one with a prominent soap manufacturer of this eity.
ELECTRICAL INDUSTRIES.

\section{PUBLISHED EVERT THURSDAT BY THE \\ ELECTRICAL INDUSTRIES PUBLISHING COMPANY, \\ INCORPORATED 1889. \\ MONADNOCK BLOCK, CHICAGO. \\ TELEPHONE HARRISON 159.}

E. L. POW ERs, Pres, and Treas.

E. E. WOOD, SECrETary.

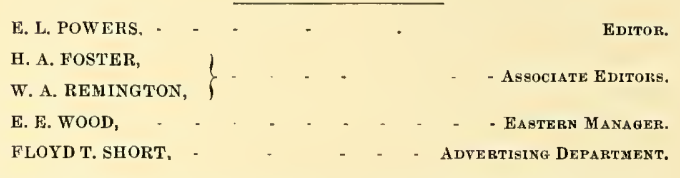

EASTERN OFFICE, WORLD BUILDING, NEW YORK. World's Fair Headquarters, Y 27 Electricity Building,

FIVE MONTHS,
SINGLE COPY, -

For testing the speed of electric cars and locomotives the use of a five mile straight track and the necessary electricity has been offered. To the maunfacturers of electric railway motors an excellent opportunity is thus afforded for comparing the merits of their machines. A similar trial of speed between steam locomotives exhibited at the Fair representing the different countries, England, France, Germany and the United States is being arranged.

In the additional report of the jury of awards published this week, it will be noticed that no award has been made to the Allgemeine Elektricitats Gasellschaft for their excellent exhibit in the electricity building. This is due to the fact that Director General Rathenau is a member of the jury and it was early agreed that no award should be given to a display in which any member of the jury was personally interested. For this same reason the historical exhibit in the offices of the American Institute of Electrical Engineers has received no reeognition from the jury.

Chicago Day, Oct. 9, bids fair to be the greatest of all red letter days at the Exposition. No effort is being spared by the committee in charge to make the day so attractive in special features that the crowd to be seen on that day will be the largest ever gathered together in this country. Guesses on the attendance vary all the way from 400,000 to 700,000 . Everything, however, depends upon the weather. Given a fine day the attendance will be all that could be desired or expected. Among the business houses in the electrical line there is a disposition to close almost without exception and give employes the opportunity to be present. There will be on this day the same electrical features as on every regular day which taken with the other special attractions will make the day one long to be remembered. Our advice to every patriotic Chicago man in whatever line of business is to be present with his friends. 


\section{WORLD'S FAIR NOTES.}

The tests of insulated wires will be continued for six months nnder the direction of Prof. Jackson, consequently it will be some time before these awards will be announced.

With the crowds who come to Electricity Building, both during the day and evening there lrave come hucksters of every kind, class and description who weary the exhibitor, beguile the risitor and grow fat on the profits of their sales. The long days during the early summer and spring when customers were few are now forgotten as they reckon up their profits at the end of the day.

One of the clearest and most comprehensive souvenir guides of the bnildings at the Fair was, until a few days ago, being distributed by the Hale Elevator Co., of Chicago. It contained floor plans of the different buildings and maps of the grounds completely indexed. It was too good to give away, so the eatalogue monopoly thought, and the company has been restrained from distributing them on the grounds.

Irish Day at the Fair last week has the distinction of having been the worst day so far as weather is concerned since the Exposition opened. In spite, however, of the unceasing torrent of rain a large number were present to do honor to Erin. The Irish flag was hoisted over Electricity Building by Chief Barrett as announced in last issue. It is true that it was hauled down once or twice by Mr. Millet's men but the Department of Electricity came out ahead as usual, and the flag was allowed to remain.

A collection of electrical apparatus of historical value is shown in a glass case occupying a prominent position in the exhibit made by Princeton college in the gallery of Manufactures and Liberal Arts Building. The most interesting objects in the collection are a glass rod covered with sealing wax used at one time in experiments made by Franklin, a galvanic trough brought to the United States in 1800, by John Maclean and a number of roughly constructed galvanometers and electro-magnets, made by Henry. A series of induction eoils are also shown with which Prof. Henry first investigated the induction of electric currents and showed the possibility of producing on electric eurrent of high pressure from one of low pressure. Near the case stands a large electro-magnet made by Henry, which has supportel a weight of 3,500 pounds. An electric machine marle under the supervision of Benj. Franklin, and used by Priestly also forms part of the exhibit.

The Western Electric Co. have understood from the beginning of the Exposition, the value of moving effects and by placing on their space a number of startling features, have succeeded in making their exhibit one of the most attractive in the Electricity Building. That the public appreciates the efforts made by the company, one has only to notice the crowd gathered around the writing finger, the groups of visitors watching the bands of light chase each other up the column of incandescent lamps, and the great number always standing in line to be admitted to the scenic theatre. Another addition has been made to the exhibit, last week which is sure to attract its share of attention. A device consisting of a large wheel within a wheel, made of different colored incandescent lamps has been placed near the south entrance of the Electricity Building. The two wheels revolving in opposite directions and with the figures upon them changing constantly in figure and form make a novel and beautifully effect and are the first thing to catch the eye of the visitor upon entering the building.
Awards, Department of Electricity.

In adclition to the list of awards published in the last issue there have been made the following:

$$
\text { UNITED STATES. }
$$

American Battery Co. Storage batteries.

Electrical Engineer.

Historical electric railway mode] (Davenport's),

Elisha Gray.

Telautograph.

General Electric Co.

Incandescent lamps used for decorating rooms ant other strnctures.

A. H. Phelps.

Electro Pyro gravure process.

Westinghouse Electric \& Mfg. Co.

High tension experimental apparatus.

$$
\text { AUSTRIA. }
$$

Schindler \& Jenny.

Electrical cooking apparatns. GERMANY

Casmotern Fabrick "Deutz."

Dynamo, directly connected to gas engine.

Hartmann \& Braun.

Galvanometers of special form.

Chas. Pollack.

Storage batteries.

Reiniger, Gebhardt \& Schall.

Electro medical apparatus. GREAT BRITIAN.

Epstein Aecumulator Co.

Storage batteries.

Awards for Street Railways and Street Railway Ap= pliances. Group 81 .

$$
\text { NEW YORK. }
$$

J. M. Jones' Sons, West Truy.

Body open electric car; Borly closed electric car.

John Stephenson Co., Lt., New York.

"Broadway" cable car; electric motor car.

Peckham Motor Truck \& Wheel Co., Kingston.

Electric motor trueks.

James H. Stedman, Rochester.

Detective transfer.

MASSACHUSETTS,

Lambeth Cotton Rope Co., New Bedford.

Lambeth Cotton Rope.

Bemis Box Car Co., Springfield.

Electric motor truck.

Robinson Electrie Truck \& Supply Cu., Boston.

Electric radial truck.

Coburn Trolley Track Mfg. Co., Holyoke. Overhead Carrying Track.

Washburn \& Moen, Worcester. Cables for street railways.

\section{ILLIXOIS.}

Columbian Intramura] Railway Co., Jackson Park. Electric elevated railway.

Pullman Palace Car Co., Chicago. Single and double deck street car.

Wm. Wharton Jr., \& Co., Chicago. Rails, fittings and special work for street railways.

Street Railway Review, Chicago. Street Railway Review.

International Register Co., Chicago. Conductor's portable register. 


\section{ELECTRICAL INDUSTRIES.}

McGuire Mfg. Co., Chicago.

Trucks.

Gennett Air Brake Co., Chicago.

Air brake equipment for electric and cable railway street cars.

PENNSYLVANIA.

Johnson Company, Johnstown.

Street railway appliances

Robinson Aachine Co., Altoona.

Electric ear truck.

Westinghouse Electric \& Mfg. Co., Pittsburgh.

Street railway electric car equipments.

E. H. Wilson, Philadelphia.

Open and closed restibuled street cars.

CALIFORNIA.

A. S. Hallidie, San Francisco.

Passenger and grip car; ropeway and grip; historical collection of cable systems; pulley.

California Wire Works, San Francisco.

Wire ropes and cables.

NEW JERSEY.

Trenton Iron Co., Trenton.

Aerial tramways and rolling stock; interlocked wire ropes and cables.

Rowell-Potter Safety Stop Co., Trenton.

Automatic block and safety stop system.

GERMANY.

Hoerder Mining \& Steel Co., Hoerde.

Street railway switches; grooved rails; wheel tires, axles, etc.

Phoenix,Actiengesellschaft für Bergbau und Hüttenbetrieb, Laar.

Construction of street R. R. tracks, sections, profiles, etc.

Daimler Motor Co., Cannstatt.

Street car motor.

J. Pohlig, Cologne.

Photographs and plans of cable roads.

George Mary Mining Co., Osnabrück. Rails.

Felton \& Guilleaume, Mülheim.

Ropes for eable roads.

\section{BRAZIL.}

Carrio Urbana Co., Rio de Janerio.

Tramway street horse car.

\section{PERSONAL.}

Dr. J. Allen Hornsby, of the Department of Electricity is in St. Louis, Mo.

Prof. H. S. Carhart, president of the Jury of Awards has returned to Ann Arbor.

Mr. Charles M. Wilkins, of the Partrick \& Carter Co., of Philadelphia, is at the Fair.

Mr. Thorburn Reid, of Lynn, Mass, was noticed upon the Fair grounds last week.

Mr. D. E. Thompson, of the Mt. Vernon Electric Co., paid the Fair a short visit last week.

Mr, J. W. Crowther, of the Quaker City Electric Co., Philadelphia, is among the visitors.

Mr. H. K. MeCay, of the MeCay-Howard Engineering Company, Baltimore, is at the Fair.

Mr. J. L. Cochran, of the Edgewater Electric Light Co. was a visitor at the Fair the other day.

Mr. R. H. Moses, of Cleveland, Ohio, spent some time among the electrical exhibits last week.

Mr. Otto Lemisch, an electrical engineer from Austria, is a visitor in the city and at the Fair.

Mr. R. W. Pinkerton, of the Elgin City Railway Co., Elgin, I11., was among the visitors last week.

Mr. A. L. Daniels, of the Miamisburg, Ohio, Electric Co. was a caller on ELECTRICAL INDUSTRIEs last week.
Mr. J. W. Leech, of the Keystone Electric Co., Erie, Pa., spent a few days in Chicago and at the Fair recently.

Mr. M. Freeman, superintendent of the Mt. Clemens, Mich., Electric Co. has returned home from a visit to the Fair.

Mr. M. C. Austin, secretary of the Light \& Power Co., of Effingham, Ill, was in the city attending the Fair last week.

Mr. M. Kellog, superintendent of the Spencer, Ia., Electric Light Co., was among the recent arrival of visitors to the Fair. Mr. Sydney Smith, general manager of the Hoosac Falls Electric Light \& Power Co., spent part of last week at the Fair. Mr. M. Nippert, Superintendent of the Lake Geneva, Wis., Electric Light Co. spent some time at the World's Fair recently.

Mr. T. H. Bentley, secretary of the Hastings, Mich., Electric Light and Power Co., is now in the eity visiting the Exposition.

Mr. W. C. Gotshall, superintendent of the Citizens' Street Railway Co., Muncie, Ind., spent some time at the Fair last week.

Mr. W. G. Walter, of Pittsburg, Pa., designer of the booth occupied by the Westinghouse $\mathrm{Co}$. has returned to the Fair for a short time.

Mr. Wm. L. Dresser, president of the Electric Light \& Power Co., at Newman, Ga., was an interested visitor last week in Electricity Building.

\section{Amusements.}

Hooley's Theater-M. Coquelin and Mme. Jane Hading, repertoire. 149 Randolph street.

Colombia Theater-Mr. Henry Irving and Miss Ellen Terry, "The Merchant of Venice." Saturday, "Louis XI." 108 Monroe street.

Grand Opera House-Hoyt's "A Trip to China Town." 87 Clark street.

Acditonum-Imre Kiralfy's Spectacle "America." Congress street and Wabash avenue.

MoVicker's Theater- Wrm. H. Crane, in "Brother John," 82 Madison street.

Chicago Opera House-American Extravaganza Company, in "Ali Baba, or Morgiana and the Forty Thieves." Washington and Clark streets.

Schiller Treater-Felix Morris, in "The Old Musician" and "Champagne." Randolph, near Dearborn.

Haverly's Casino-Haverly's United Minstrels. Wabash avenue, near Jackson street.

Trocadero-Vaudeville. Michigan avenue near Monroe street.

The Grotro-Vaudeville. Michigan avenue near Monroe street.

Buffalo Bill's "Wild West." 63d street. Daily at 3 and 8.30 p.m.

The Stondard Lectures--Central Music Hall, commencing Oct. 2d, Seven courses exactly alike six evenings and matinee each week. Week of October 2, Eastern Japan; week of October 9, Western Japan; week of October 16 , China; week of October 23, Farther India; week of October 30 , Nearer India.

This season has brought to Chicago a line of attractions never before equaled, and the appreciation of these eminent player by the people and visitors to Chicago, is shown by the crowded houses at the different theatres. At the Columbia, Mr. Henry Irving appears as Shylock and Miss EIlen Terry as Portia in the "Merchant of Venice" this week except Saturday evening. On Saturday and Monday evenings "Louis Xl"will be presented and the balance of next week "Becket."

At Hooley's M. Coquelin and Mme. Hading have made a very favorable impression on the first evenings of their month's engagement. Although they speak a foreign language their art cannot be hidden, but is apparent in every movement and expression. The repertoire for a week is: Thursday evening, "Tartuffe" and "Les Precienses Redicules;" Friday, "La Dame Aux Camille;" Saturday matinee, "Mlle. de la Seigliere;" Saturday evening, "Nos Intimes;" Monday and Wednesday evenings, "La Megre Apprivoise," and Tuesday evening, "La Joie Fait Peur." 


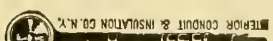

yos S1N39V

㛃
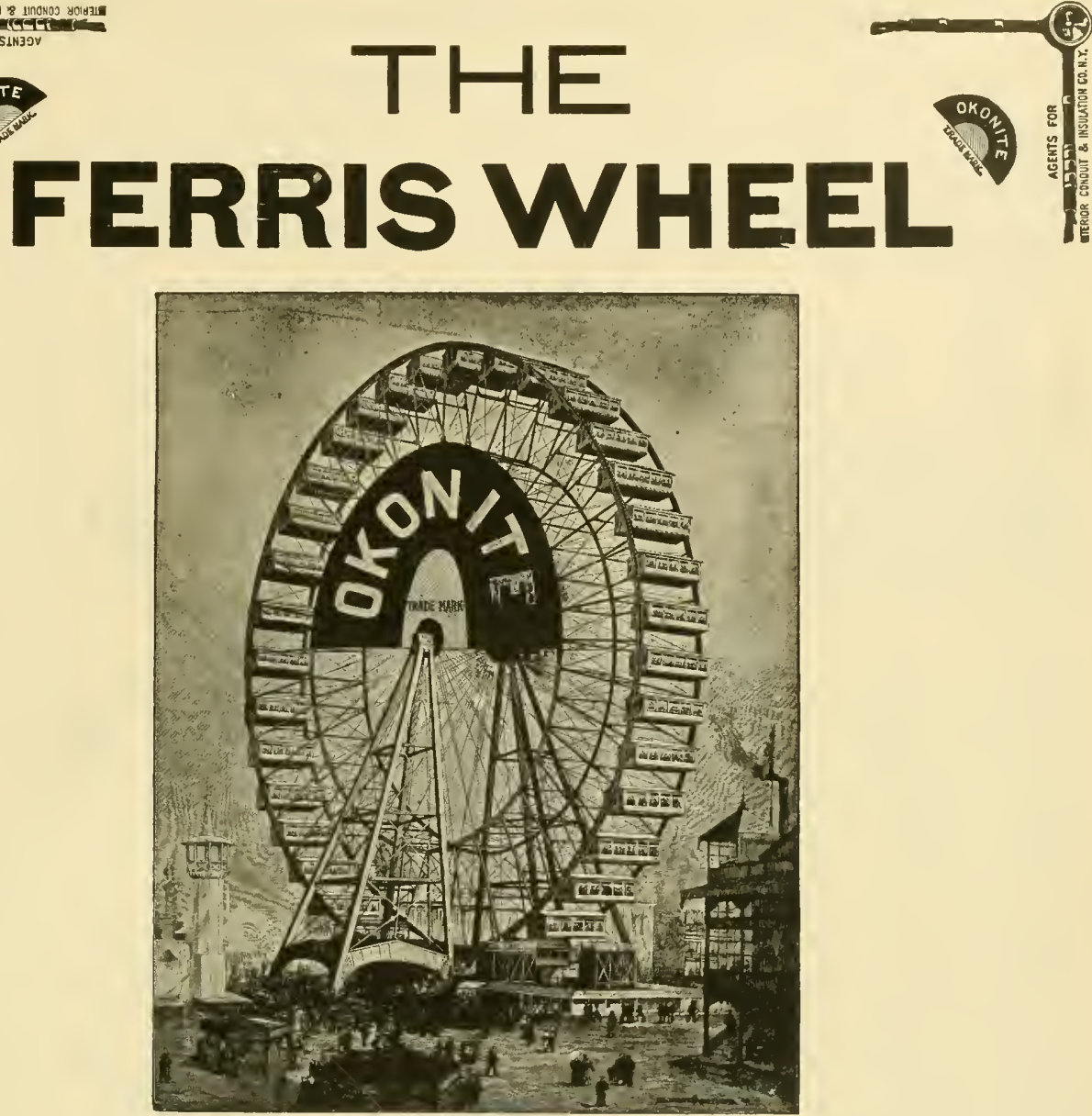

When you visit the World's Fair, you will naturally take a ride on the FERRIS WHEEL and be interested in the ELECTRIC LIGHT INSTALLATION, which is wired throughout with

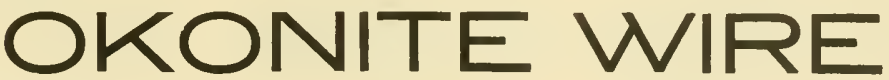

FURNISHED BY THE

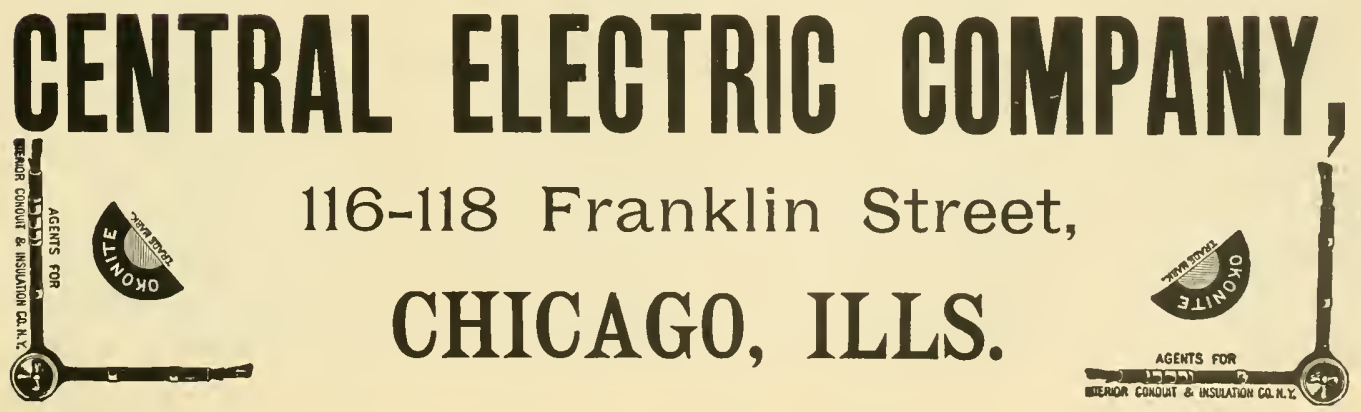




\section{DO NOT BUY SOCKETS}

without first getting a sample of our

\section{ACME SOCKET}

with price. You will agree with us, that it is a very superior article at a low price.

We are prepared to quote exceptionally

\section{LOW PRICES}

on our full line of

General Supplies.

ELECTRIC APPLIANCE COMPANY,

242 Madison Street, CHICACO.

Electrical Supplies.

THE MONTHLY ISSUE FOR OCTOBER

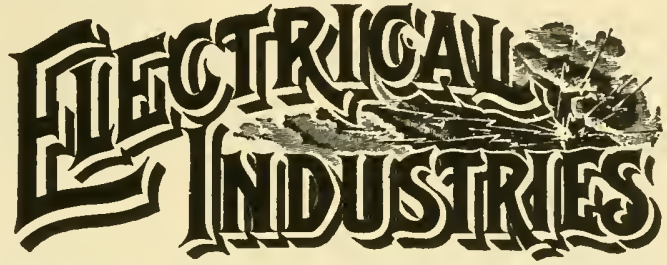

Should be read by everyone interested in electrical matters. In its lable of Contents is the following:

"Electric Railway Exhibit at the Fair."

"American Search Liglits at the Fair."

"Duquesne Lines of Pittsburgh."

"A New Incandescent Arc Lamp." By L. B. Marks.

"The Return Circuit of Electric Railways." By Thos. J. McTighe.

"The Business End of Electricity." By H. C. Thom.

"Three Point Incandescent Switches." By Albert Scheible, M. E.

Together with illustrations of the recent applications of electricity.

The paper contains regularly

A Buyer's Directory of Manufacturers and Dealers in Electrical Supplies and Appliances.

A Complete Directory of Electric Light Stations in North America and a Complete Directory of Electric Railways in North America.

These directories are revised each issue to the date of going to press and are to be found in no ocher electrical jonrnal in the World. Its articles are read carefully and its directories used constantly by all the buyers in the trade. These facts make it without a superior as an advertising medium. Sample copies and rates sent on application.

Subscription price $\$ 3$ per year.

\section{ELECTRICAL INDUSTRIES PUB. CO., Monadnock Block, CHICAGO.}

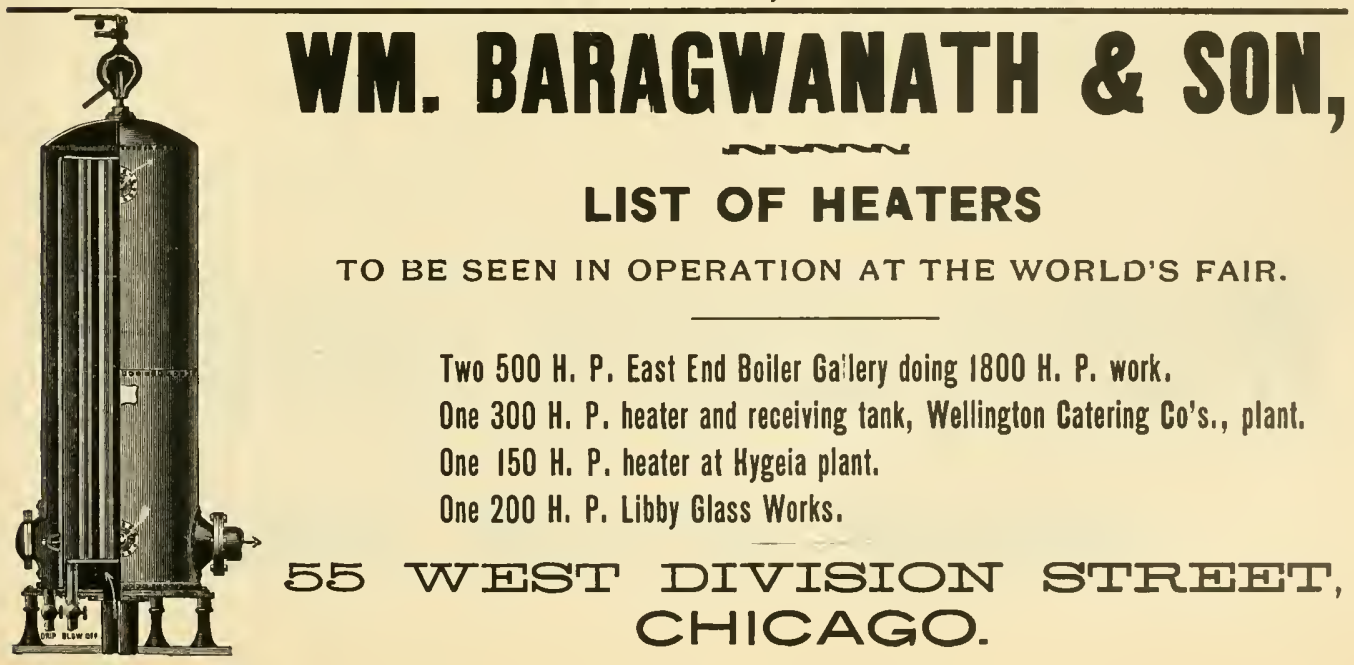




\section{OUR IMPROVED SYSTEM}

$$
\text { ... OF ... }
$$

\section{Automatic fire Alarm,}

covered by patents recently issued, is the embodiment of all factors contributing to the

GREATEST SAFETY,

\section{and the MOST RELLABLE}

PROTECTION FROM FIRE.

\section{Western

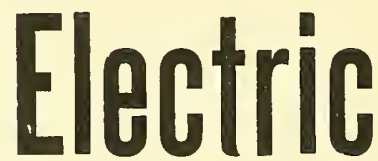 \\ Company,}


COMPANY, NEW YORK.

192 Broadway and II John Street.

MANUFACTURERS OF ARC LIGHTING APPARATUS FOR EVERY PURPOSE A SPECIALTY. The CLARK ARG LAMPS for use on EVERY CURRENT, have the reputation of being the best and most durable of any ever made in the United States.

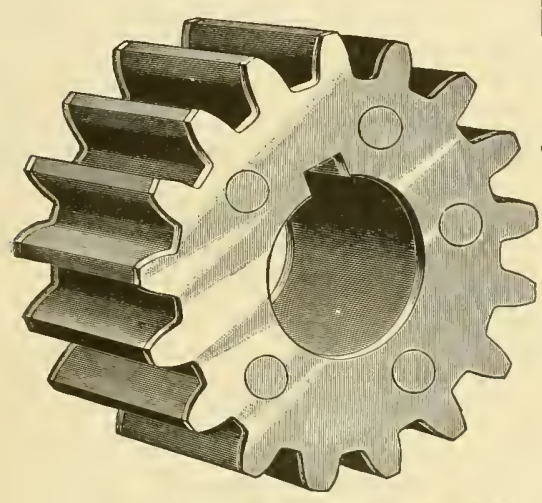

\section{StANDARD}

RAWHIDE PINIONS FOR ELEGTRIC MOTORS A SPECIALTY.

RAWHIDE DYNAMO BELTING

A Non-Conductor of Electrlcity. Causes Less Friction than any other Belt.

\section{THE CHICAGO RaWhIDE MaNUFAGTURING CO.}

THE ONLY MANUFACTURERS IN THE COUNTRY

\begin{tabular}{|c|c|}
\hline $\begin{array}{l}\text { LACE LEATHER ROPE } \\
\text { AND OTHER RAWHIDE. }\end{array}$ & $\begin{array}{l}\text { This Belting and Lace Leather is } \\
\text { not affected by stean or dampness; } \\
\text { never becomes hard; is stronger, }\end{array}$ \\
\hline $\begin{array}{l}\text { GOODS } \\
\text { OF ALL KINDS } \\
\text { BY KRUEGER'S PATENT }\end{array}$ & $\begin{array}{l}\text { ical Belting made. The Raw- } \\
\text { hide Rope for Round Belting } \\
\text { Transmission is superiot to all } \\
\text { others. }\end{array}$ \\
\hline
\end{tabular}

75 Ohio Street,

CHICACO, LL

GENERAL OFFICES: 625 Home Insurance Building.

WORKS: So. Canal Street,

\section{CHICACO.}

\section{STANDARD SYSTEM}

AT THE

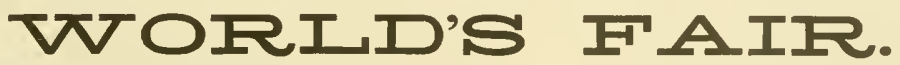

MACHINERY HALL, Sec. Q, 2 Standard Arc Dynamos.

Sec. S, 20 " " "

ELECTRICIT Y BUILDINC, Sec. P, Space 2, Arc Lighting Exhibit.

he Standard Lamps Light the Power Plant, Machinery Hall, Agricultural Hall, Shoe and Leather Building, and Other Buildings and Portions of the Grounds. 


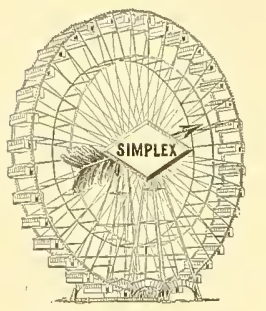

File after mile of

SIMPLEX WIRE

Supplied to the

FERRIS WHEEL

By...George Cutter,

The Rookery, chicago.

\section{SIMPLEX WIRES}

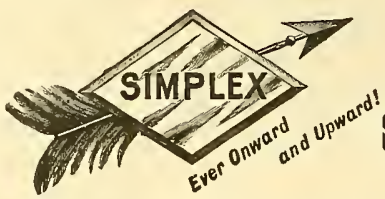

INSURE

HIGH

INSULATION

George Cutter, Chicago. . Boston, MAss.

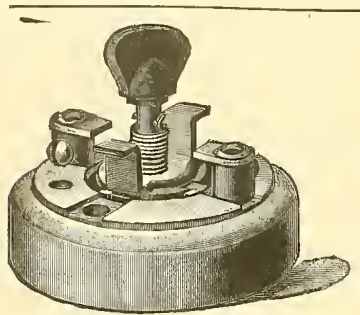

Made 5 amp. S. P.

5 amp. 3 way.

\section{XNTRIC}

"That's the Switch"

And we control that movement.

H. T. PAISTE,

10 South 18 th St., PHILADELPHIA, PA.

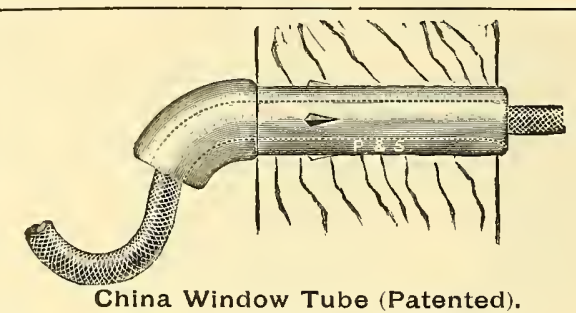

Made only by PASS \& SEYMOUR, George Cutter,

SYRACUSE, N. Y.

BEAR IN MIND

that the regular monthly issue of ELECTRICAL INDUSTRIES contains the most cemplete and correct directories published of the electric light central slations and the electric railways in North America.

Wcrld's Falr Headquarters Y 27 Elec 'riclty Building. CITY OFFICES, Monadnock Block.

Consolidated Elpctric 6. Man klacturers and Dealers in all kinds ol

\section{ELECTRICAL • SUPPLIES,}

115 Franklin Street,
Manufacturers' Agents and Mill Representatives for

Electric Railway, $\infty$

Telegraph, Telephone and Electric Light

SUPPLIES or everv

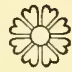

Agents for Cedar Poles,

Cypress Poles, Oak Pins, Locust Pins, Cruss Arms, Class

- Feeder Wire, Insulators,

WIRES, CABLES, TAPE and TUBING
For Direct or Altermating Currents.

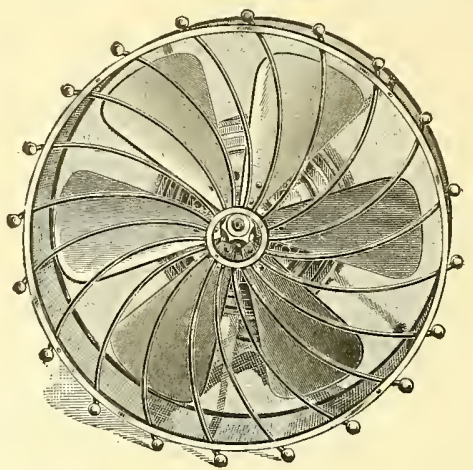

These motors give a stronger breeze with less consnmption of current thar ny other fan motor on the market. They are fnll $1-8$ horse power. Six bladed 2-incb fan. Se'f-oiling. Fnrnished with or without guarde.

IT WILL PAY YOU TO SEE THE WAGNER BEFORE BUYING ELSEWHERE.

TAYLOR, GOODHUE \& AMES, 348 Dearborn Street, CHICACO. 


\section{WEEKLY WORLD'S FAIR}

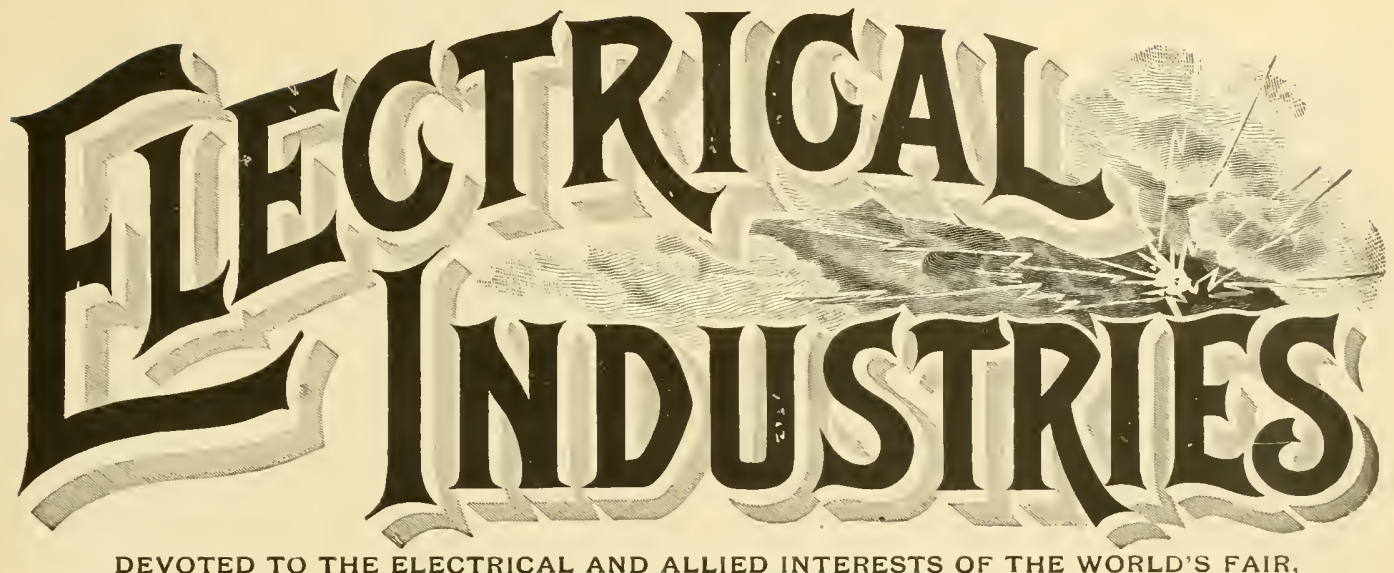

DEVOTED TO THE ELECTRICAL AND ALLIED INTERESTS OF THE WORLD'S FAIR, ITS VISITORS AND EXHIBITORS.

Vol. I, No, 18. CHICAGO, OCTOBER 12,1893.

Exhibit of the Phœnix Glass Company.

The many forms that glass will assume in the skillful hands of the glassblower, as well as the colors and delicate shading it will retain, has made it a most useful article to
The center space in Electricity Building is occupied by the exhibit of the Phonix Glass Company, which gives the company, as it deserves, a very prominent position. The exhibit shows a great variety of designs in glass gocds for gas and electric lights. The parilion, as shown in the

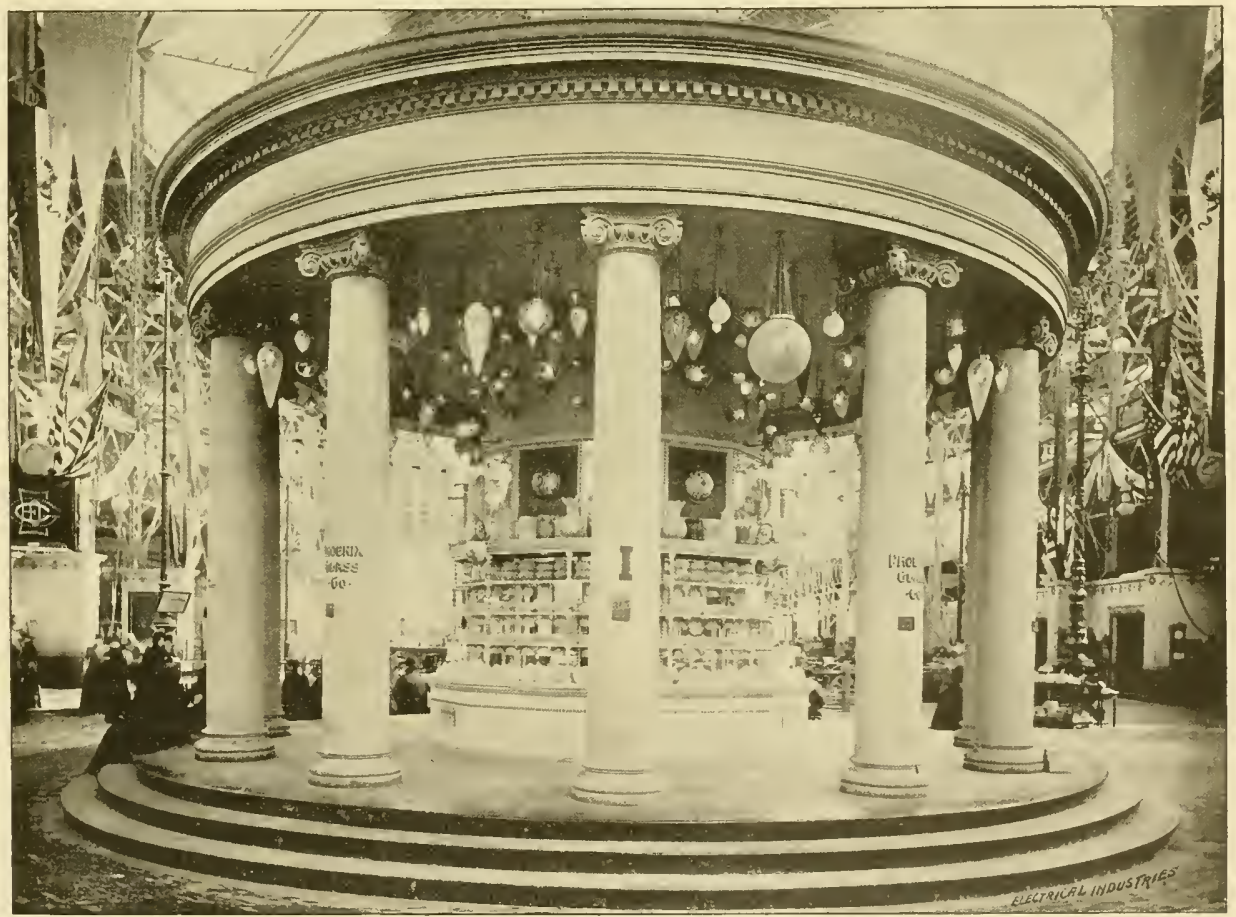

EXHIBIT OF THE PHENIX FLASS COMPANY.

the decorator. Since the introduction of the electric light accompanying illustration, is circular in form, with large glass has ieen used more than ever for decoration, and the columns supporting the roof.

beatiful forms and creations in the line of electroliers, pendant and bracket lights in the morlern house and hotel wonld fill with wonder even the more recent workers in this art that ranks as one of the olclest.
A cylinder of glass mirrors rise to the ceiling in the center of the parilion, forming a background to the shelves on which are displayed many of the glass goods. The shelves and supports are finished in white and gold, pre- 
senting a very handsome appearance. Above the slielves panels of mirrors alternate with panels of plush in the center of which cut-glass bowls of different colors are lighted up by incandescent lights concealed behind them. From the ceiling are suspended globes, stalactites and other forms of pendants enclosing incandescent lamps. The effect is enchanting, reminding one of a crystal care. Some of the pendants are quite valuable, being of cut glass. The designs are quite intricate, requiring great skill in their execution.

On the shelves are displayed a great variety of the standard forms and colors of shades for gas and electric lights and a great many new designs for newel posts and hall lights. A great variety of tints are shown in the spot, wart, fluted and etched styles of glass. Flower-shaped shades for elestroliers in many beautiful and delioate tints are shown. Some very neat bracket globes are displayed, on which the scenes and fig. ures are hand painted and executed with great slill. The coloring of the paint ings is especially interest. ing.

The display has been ar ranged with great care and shows excellent taste. But few cluplicates are shown, the exhibit being made up of separate designs and shows an extensive line of goods. MLost of the new shades and globes are shown on fixtures making the exbibit double attractive. These goods are used about the grounds and buildings. The shades in the decorations about the power plant in Machinery Hall were manufactured by this company, also a great deal of the glass ware in Electricity Build ing and the globes on Wood ed Island.

Great credit is due to $\mathrm{Mr}$ E. H. Fox for the neat arrangement and the excel. ence of the exhibit in many ways. Mr. Fox has been at the exhibit a large part of the summer and has made many new friends and acquaintances among the electrical fraternity

Complaint of the lack of public appreciation has often been heard from firms who have prepared elaborate dis. plays in the electricity and other buildings. There is little doubt but that many visitors simply take an outside view of the Fair and, if they enter the buildings at all, bestow but a passing glance upon exhibits which have been carefully prepared and are full of interest. One reason of this, no cloubt, has been the attractiveness of the grounds and the special efforts made by the Fair management to entertain the crowds with band concerts, swimming contests, Midway processions, etc. But as the cooler days of fall approach it may be expected to find the attendance in the buildings considerably increased and a greater interest taken by visitors in the various exhibits. A great improvement in this direction has been noticed already.

\section{Exhibit of the Eureka Tempered Copper Company.}

In a parilion designed after a Moorish mosque the Eureka Tempered Copper Company of North East, Pa., has arranged an elaborate display of rolled and cast copper goods. This display is located in the southwestern part of the gallery, close to the front, where it can be seen from all parts of the main floor.

The process used by this company was discovered by an operator in the Pennsylvania oil fields. The value of tempered copper was little understood by him at that time, and the success that has attended the company far exceeded the hopes of the capitalists who formed this company. The number of uses found for this metal have gradually increased, and, consequently, the output of the metal, in the various forms. As an anti-friction metal its ralue was first appreciated, and large quantities were early used for journal bearings. With the rapid growth of electric lighting, and the general adoption of electric motors and other electrical machines, its special advantages for commutator bars and other parts of the machines brought it at once into great demand. Being one of the best conductors of electricity, and having a great ralue as an anti-friction metal, it at once filled a place in the new industry for which nothing has been found to take its place.

This company makes a specialty of commutator bars which are east, rolled and hardened without the use of alloys. The metal when finished still has its natural toughness and pliability, which insures its wearing qualities and superior conductivity. The exhibits are artistically arranged about the interior of the mosque and show a great variety in the products of the company's factories. Commutators are shown in sizes ranging from $\frac{1}{8}$ to 750 horse power; commutator bars in a number of styles, trolley wheels gear pinions, bearings to show the extensive use of tempered copper for that purpose, and an extensive line of other goods, in the manufacture of which copper is used to a more or less extent, are shomn.

The commutators of the Westinghouse machines at the Fair are made of Eureka tempered copper, which demonstrates the excellence of the metal more than the most elaborate array of samples. A very neat sourenir of the company and the Fair is given away at their eshibit. On one side it is a fac simile of the John Scott medal given to the company for its improvements in casting and hardening copper by the Franklin Institute. On the other appears 
the name of the company, the World's Fair, and a commutator, brush, trolley wheel, ete., representing the goods exhibited. It is of copper - a most appropriate metal. Mr. IV. H. Grissom, manager of the Chicago office, is looking after the exhibit and the interests of the many visitors.

\section{Power Plant the Mather Electric Company.}

In Machinery Hall, Section C, is located the power plant of the Mather Electric Company. It immediately attracts the attention of the risiter on account of its light color, the machines being linished in white and gold. To the street railway man it possesses many points of interest, as it is especially adapted for furnishing power for that class of work. And for operating moiors for factory purposes, it is also adapted on account of its close regulation and high efficiency.

In this plant are four large generators, of which two are of 2.25 K. W. eapacity, each working at a potential of 5e) volts at 450 revolutions per minute. The other two genera. which is constructed of slate slabs set in steel frame, all of which is enclosed in a neat aud ornamental frame, on the upper panel of which alpears the name of the company. The four generators are connected to one set of bus bars on this switch board, so that all the machines may be operated in multiple if so desired. The switchboard contains four rheostats, four triple pole switches, through which the generators are connected to the bus bars; four ammeters, which reeord the quantity of current geverated by each machine; one rolt meter which is so connected by means of the company's improved switeh that readings may be taken from either generator or from the bus bars by making the proper connection on the switch; one lifferential inclicator which may be connected by means of the company's indieator switch to anyone of the generators when it is desired to throw one or another of the generators into circuit while one or more are in operation, and this instrument indicates exactly when the machine to be thrown into circuit attains the proper potential. There are also on the switchboard four double pole single throw switches, four ammeters,

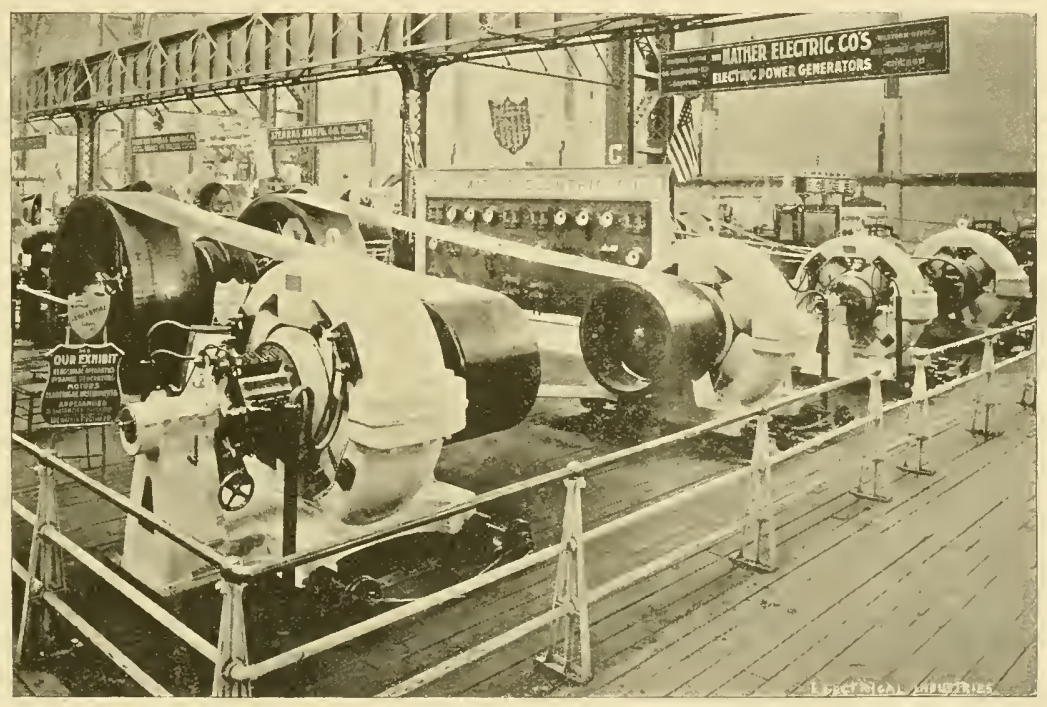

TUE POWER PLANT OF THE MITHER ELECTRIC COMPANY,

tors which are compound wound like the proceeding have a capacity of $120 \mathrm{~K}$. W. and are working at a potential of 550 volts at 525 revolutions per minute. The former generators are sis pole machines, with field magnets and armature supports cast in one piece without joint, except between the upper and lower half of the field.

The winding of the armature is such that there are only two paths for the current through the armature, and yet opposite hars of the commutator are connected and so maintain the same potential. The commutators are cross connecte\}, the opposite hars being maintained always at the same potential, so that it is possible to use either all the sets of brushes or any two sets, as may be clesired. The generators are mounted on sliding iron base's fitted with four screws connected together in pairs by means of a chain, and operated by ratchets, so that the generator can be kept in perfect alignment and the tension of the belt regulated. These base frames are firmly bolted to th foundations.

Near the center of the space is placed the switch board. which show the yuantity of current used on each circuit. These circuits are protected by means of double pole safety cut-outs which are provided with lusible strips of suitable capacity and are also further protected by means of automatic circuit breakers mounted on separate frames behind the switchboard. The bus barsand all the connections hetween the switches and instruments are of finely finished copper symetrieally arranged on the back of switchboard and present a very neat appearance. These generators have been supplying the current for operating the motors in the Hines and Hining Building, Agricultural Building, for the movable sidewalk on the pier and also for the Nather Electric Company's exhibit in Electricity Building. The plant presents a neat and substantial appearance and is worthy of the attention of all power users.

The engines which operate these generators also form an interesting part of the plant. A 600-horse power Woodbury engine, manufactured by the stearns Manufacturing Co. of Erie, Pa., operates the two larger generators and a 37 -horse power the two smaller ones, These engines are 
of the condensing, tanderin compound type and are belted directly to the generators.

The lighting plant of the Libbey Glass Works on Midway Plaisance which is an interesting feature of that exhibit was installed by this company and may well be considered a model lightisig plant. The plant consists of three 55 kilowatt continuous current dynamos, wound for 125 volts and operated by two Russel engines of 125 and 200-horse power respectively.

The current furnished by this station operates about 1,000 incandescent lamps and from 35 to 40 arc lamps. These lights are lavishly arranged about the works both inside and out, and give them a very bright and attractive appearance at night. The continuous service demanded of this plant puts the machines under a severe test that they have stood since they were installed with very creditable results. The dynamos are of the Mather ring type which is as much admired for its neat mechanical appearance as its efficiency in operation.

A machine has recently been devised by Mr. C. S. Bradley by which currents of high potential may be generated without the injurious effects to the commutator on account of the great difference of potential of the neighboring brushes. The Electrical Engineer describes the machine as follows: "The inventor has adopted the ingenious plan of mounting upon the same shaft an armature wound with a number of independent circuits, all of which contribute to the resultant effect through the medium of a number of commutators, the brushes of which are coupled together in such a way that the several windings will be in series relation to oneanother. The dielectric strain upon the wire insulation is reduced by connecting some intermediate point of the internal circuit with the frame of the machine. The windings are highly insulated from each other and so arranged that parts of the windings which lie in close juxtaposition upon the armature will have as low a difference of potential as is compatible wita a symmetrical system of winding. Each commutator has a large number of segments in order that the potential difference between any two adjacent ones may be as small as possible and yet the aggregate difference at the brushes may be high. Each has a pair of brushes. Two brushes of opposite sign are connected together and the remaining two are connected to the terminals of the machine. There will thus be thrown upon the line a current having an $\mathrm{E}$. $\mathrm{M}$. F. behind it equal to the sum of the E. x. F.'s developed by the two windings, and the dielectric strain between the frame of the machine and the windings would be equal to the aggregate $\mathrm{E}$. м. F., a condition which it is very necessary to avoid, inasmuch as the insulation of that portion of the winding where the potential is highest is liable to rupture. In order to avoid this difficulty Mr. Bradley connects the frame of the machine with some portion of the circuit between the line brushes, so as to raise the potential of the machine and thus lower the dielectric strain by connecting the two brushes which interlink the two windings by a good, firm connection with the base of the machine. Thus if each winding develops an E. M. F. of a thousand volts, the frame of the machine will be brought to a potential of 1,000 rolts and the strain upon the insulation will only be the difference between the final E. m. F. or 2,000 volts, and 1,000 volts, or just one-half of what it would be without the base connection. In mounting the machine care is taken to highly insulate it from the earth in order to prevent leakage from the base, which, under the system of connections described, will have a considerable potential."
ELECTRICAL INDUSTRIES.

\section{ELECTRICAL INDUSTRIES PUBLISHING COMPANY, \\ INCORPORATED 1889. \\ MONADNOCK BLOCK, CHICAGO. \\ TELEPHONE HARRISON 159 .}

E. L, POWERS, Pres. and Treas.

E. E. WOOD, SECRETART.

E. L. POWERS.

EDIToR.

W. A. REMINGTON, -

Associate Editor

E. E. WOOD,

- Eastern Manager.

FLOYDT. SHORT,

Advertising Department.

EASTERN OFFICE, WORLD BUILDING, NEW YORK. World's Fair Headquarters, Y 27 Electricity Building.

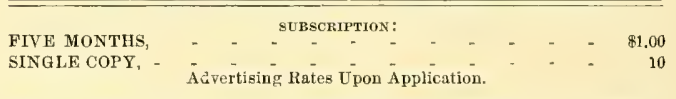

News items. notes or communications of interest to World's Fait Visitors are earnestly desired for publication in these columns and will be heartily appreciated. IVe especially invite all visitors to call upon th be heartily appreciated. IVe especiallv invite all visitors to call upon
or send address at once upon their arrival in city or at the grounds. ELECTRICAL INDUSTRIES PUBLISHING CO.,

Monadnock Block, Chicago

The convention of the American Street Railway Association at Milwaukee next weck should be attended by every one in any way interested in street railways, electric traction or rapid transit. Milwaukee is but a few hours ride from the World's Fair and an excursion, either by train or boat, could be easily made up. The profit derived from such a trip would more than compensate for the expense connected with it.

To mass at one point three-quarters of a million people in a few hours last Monday morning was the unparalleled task which Chicago railways were called upon to perform. That it was accomplished is shown by the fact that that many people went to Jackson Park and back on the long to be remembered Chicago Day. Every piece of rolling stock possessed by the railways was ealled into service, and carried such loads, inside and out, on the roof as rell as on the sides, as are rarely carried. The crowds for blocks aromnd the down-town terminal stations were a remarkable sight. That such crowds were carried with so few accidents speaks well for the railways and their numerous employes. The experience of the preceding months of the Fair was worth a great deal in handling this immense traffic.

At the next meeting of the Jury of Awards, to be held on Saturday next, it is expected that the balance of the awards will be announced except those requiring considerable time for tests. The jury has been very prompt thus far in making the announcements, and has given snfficient time for adjusting any differences that may arise. Although there is dissatisfaction on the part of some at not receiving awards or at not receiving the award desired, in general there has been but little complaint in the Department of Electricity in comparison with some of the other departments. The department should certainly feel pleased with the work so far accomplished. The task is a difficult one although the awards are numerous and broad in the field covered. It would be hard to fix a value to an award, and yet to many exhibitors they will represent some return for the time and expense required to make their exhibit. 


\section{WORLD'S FAIR NOTES.}

The Calumet Electric Street Railway Company has recently erected a large sign, illuminated with incandescent lamps, at the 6.th street entrance to the Fair grounds, to guide the visitor on his homeward way to the proper place to take its lines for South Chicago.

Over a million paid admissions in two days is the re markable record for Monday and Tuesday of this week. This brings the total paid admissions up to $16,>14, \pi 35$, and that we may see the 21 million mark reached before the Fair closes is possible.

The spray from the electric fountilin, south of the Mac Monnies fountain, ent a wider pathway in five minutes in the erowd on Chieago Day than a battalion of Columbian guards was able to make in half an hour. This is not a reflection on the much-abused guards.

Among the visitors at the Eair last week was Miss Sarah J. Farmer, of Eliot, Me., danghter of Prof. Moses G. Farmer a model of whose electric street car, made in 1847 , is part of the exhibit of the Western Elettric Company, a descrip. tion of which was published in WORLD's Fatr ELECTRICAL Indestries No. 1.

An interesting entry in the register of the American Institute of Electrical Engineers at the World's Fair is that of Mr. W. C. Wilkinson, of 5935 Drexel arenue, Chicago. It reads: "I knew Thomas Darenport in Brandon, It. I remember riding, when a boy, in his eircular electrical railway. I camot recall the year-perhaps in 1946 . W. C. W.

If the floats are used again on Manhattan Day, as is now contemplated, it is to be hoped that those in charge will profit by former experience and that everything will move smoothly. It is hardly necessary to say that the electrical lighting of the grounds made possible the night pageant, and the electrical features contributed very materially to its success.

We are pleased to see that the impressions which ou foreign visitors received on their visit to Chicago during the electrical congress were of such a kind that, on their return home, they can speak of the cordiality and hospitality of their American friends. The reports that have appeared in the foreign papers speak of the pleasure, profit and success of the congress.

The Reliance Gange Company, Cleveland, Ohio, receired the only award made by the judges in the Department of Machinery on Reliance safety alarm water columns and pratent solderless floats. The exhibit of this company in the Electricity Building was deseribed in No. 7 of the World's Fair Electrical lndestries. The awards to his company are the bright spots in Mfr. George B. Clarke's life on those days when the other boys come nearer the attendance figures than his own estimate.

One of the daily papers announced last week that a book had been opened in Electricity Building for bets on the attendance on Chicago Day. The paper gave the alleged bookmaker's name, the odds offered, etc., etc. We find there is nothing in it. The Chicago daily papers have become so accustomed to record the bookmaker as part of the attractions which draw crowds that it is hard for them to comprehend the Fair without bookmakers, but neither Electricity Building nor the Fair need bookmakers to bring it visitors.

It is to be regretted thai, owing to a delay in the latter part of the procession of tluats, many of the visitors on
Chicago Day left the gromuls before the Commerce float, lighted by many hundreds of incandescent lights, made its way around the grounds, for it was conceded to be the must beantiful of all the floats. Long after the rest of the already delayed procession had made the tour of the grounds the Edison dragon was got under way, but it was not possible to follow the original line of march, and many who had the patience to wait for it were finally disappointed. Some difficulty was also experienced with the lights on this Hoat.

If one company more than another, of the exhibitors in the Department of Electricity, is remembered by the casual visitor it will be due to the spectacular effects produced by that company. The constant additions made to the display of the Western Electric Company have been mentioned from time to time in this column. The latest novelty in this exhibit is in the shape of a border of red, white and blue incandescent lamps, arranged in consecutive groups of five or six lamps of each color around the large sign on the north side of the Scenic Theater. The effect is produced by two strips of light of about six feet in length, apparently being to chase each other through the lamps around the border. While no display of this sort is needed to attract risitors to the Scenic Theater, the device might be used to advantage by some of the Midway Plaisance or eren down town attractions.

There has been a demand on the part of exhibitors who have been awarded medals for some sort of distinguishing mark to be placed on their exhibits, and to meet this demand the authorities have decided to issue a so-ealled "official ribbon" to those entitled to medals and diplomas. The first ones to make their appearance in Electricity Build. ing adorn W. R. Brixey's exhibit of Day's Kerite. In design the ribbon is neat and at the same time rich. It is of the traditional blue, about three inches wide and twelve inches long, with gold braid at top and tassels at the bottom. Printed in silver on the ribbon is a fac simile of the design of the medal together with the signatures of Gen. Geo. R. Davis, John Boyd Thatcher and the chief of the Department in which the award is made. Then follows the name of the medal wimner and the article or articles on which the award was made.

\section{Awards Department of Electricity.}

The Jury of Awards annomees the following additional awards in the Department of Electricity.

$$
\text { UNITED STATES. }
$$

Brush Electric Co.

1. Carbons for Are Lanjs.

General Electric Co.

1. The Thomson Lightuing Arrester.

Queen i Co.

1. Cable testing set.

2. Conductivity apparatus.

Westinghouse Electric \& Mfg. Co.

1. Automatic carbon shunt eireuit breaker. GERMANT.

Ton Poppenberg.

1. Dry Batteries.

Schuckert \& Co.

Station Ammeters and Voltmeters. RISSIA.

1. N. Wladinioff.

Portalsle Storage Battery. 


\section{PERSONAL.}

Mr. Wm. Hochhausen, E.E., Brooklyn, N.Y., is at the Exposition for a few days.

Mr. Fred W. Royce, E.E., Washington, D.C., is in the city and in attendance at the Fair.

Mr. Wm. S. Lintner, E.E., Gloversville, N.Y., has been doing the Fair for a few days past.

Mr. R. A. Ross, Montreal, Que., registered at the American Institute headquarters Tuesday.

Mr. George Francis Myers, Pittsburgh, Pa., was seen about the Electricity Building recently.

Mr. J. C. Van Buren, Albany, N.Y., has been viewing the electrical exhibits the past few days.

Mr. C. S. Van Nuis, New York, of "Ajax" fame, is visiting the Fair and calling on his many electrical friends.

Mr. Arthur Venning, Brooklyn, was one of the three-quarters of a million people who visited the Fair on October 9 th.

Mr. C. D. Jenney of the Jenney Electric Motor Co., Indianopolis is spending a few days in Chicago and at the Fair.

Prof. H. A. Storrs of the University of Vermont, is registered at the office of the American Institute of Electrical Engineers.

Mr. M. L. Beach, superintendent of the Malone Light, Heat, Power \& Coal Company of Malone, N.Y., is in the eity visiting the Fair.

Mr. H. A. Olmsted, manager of the Monterey Electric Light Co., paid a visit to ELECTRICAL INDUSTRIEs World's Fair headquarters this week.

Mr. Charles Bayliss, supt. Massillon Electric Railway Co., Massillon, Ohio, ealled at the World's Fair office of Electrical INDUSTRIEs this week.

Mr. F. L. Freeman, Washington, D.C., assisted in the celebration of Chicago Day to the extent of getting as far as the office of the American Institute.

Mr. Edward H. Fox; of the Phonix Glass Co, has just returned from a trip to Toledo, Cincinnati, etc., and speaks encouragingly of the outlook for the fall trade.

Mr. Thomas A. Edison, in company with Mr. John I. Beggs, formerly district manager for the Edison Company at this city, now of New York, registered at the World's Fair office of Electrical Industries Tuesday, October $10 \mathrm{th}$.

Mr. W. H. Flemming, E.E., general manager of the International Trading \& Electric Co., New York, called at the World's Fair office of Electrical Industries Tuesday evening, and expressed himself as enjoying the Exposition thoroughly.

\section{BUSINESS NOTES.}

The Centrai Electric Company desires to eall particular attention to the Eichburg Patent Tree Insulator, listed in its new general catalogue. This is a new device which it has recently general catalogue. This is a new device which it has recently trouble brought about by the destruction of the insulation on line wire, caused from constant rubbing against branches of trees. The insulator perfectly insulates the line and gives it plenty of play when attached to a branch, permitting it to move in any direction with the swaying of the limb. This demove in any direction with the swaying of the limb.

The Electric Appliance Compans has just received the order for the wire and cable to be used in wiring the new west side tunnel. It will be wired throughout with celebrated Paranite High Grade Rubber Covered Wire. The selection was made entirely on the merits of the insulation, after a series of very exhaustive tests. It was one of those deals, which are altogether too rare, where quality and not price was made the sine qua non, and the Electric Appliance Company are considerably elated over their success. The conditions in tunnel service of this kind are of course very severe, and satisfactory re. sults can be obtained only with the highest grade of insulation.

Mr. C. R. Huntley of Buffalo, has purchased for the New Tighting $\mathrm{Co}$, at Niagara, N.Y., one of the No. 865 light, 2,000 C.P., arc dynamos comprising the service plant of the Brush company in Machinery Hall, to be delivered at the close of the Exposition. This leaves but one of thesixteen dynamos unsold. There will also accompany the dynamos 60 of the double carbon Brush-Adams lamps which are now doing duty on the "all night" circuit at the Fair. The Indianapolis Light \& Power Co. have placed an additional order for 100 double carbon lamps Co., have placed an additional order for 100 double carbon lamps These, taken in conjunction with the 1565 light dynamos which thay have purchased during the same period shows their appre ciation of the Brush system.
DEPARTMENT OF ELECTRICITY.

OFFTES: SECTION R, ELECTRICITY BUILDING.

Chief, John P. BarRett,

Assistant Chief, J. Allen Horngby.

General Superintendent, J. W. BLAISDEr.t.

Electrical Engineer, W. W. PRIsıs.

\section{DEPARTMENT OF MECHANICAL ANI) ELECTRICAL} ENGINEERIN(

OFFICES SOUTH OF MACHINERY HALL.

Mechanieal Engineer, C. F. FostER

Electrical Engineer, R. H. PIERce.

First Asst. Mechanical Eugineer, JoHn MEAdEN.

First Asst. Electrical Engineer, S. G. Neıler.

AMERICAN INSTITUTE OF ELECTRICAL ENGINEERS.

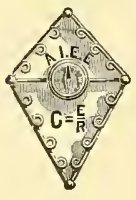

World's Fair Headquarters, SECTION S, ELECTRICITY BUILDING.

RALPH W. PoPE, Secretary

Open from 9 a.m. to 5 p.m.

\section{Amusements.}

Hooley's Theater-M. Coquelin and Mme. Jane Hading, repertoire. 149 Randolph street.

Columbia Theater-Mr. Henry Irving and Miss Ellen Terry, "The Merchant of Venice." Saturday, "The Bells." Monday "Becket." 108 Monroe street.

Grand Opera Hodse-Hoyt's "A Trip to China Town." 87 Clark street.

Audtoridi-Imre Kiralfy's Spectacle “America." Congress street and Wabash avenue.

MeVicker's Theater-Wm. H. Crane, in "Brother John," 82 Madison street.

Chicago Opera House-American Extravaganza Company in "Sinbad." Washington and Clark streets.

Sohiller Theater-Felix Morris, in "Kerry and the Major." Randolph, near Dearborn.

Haverly's Casino-Haverly's United Minstrels. Wabash avenue, near Jackson street.

Trooadero-Vaudeville. Michigan avenue near Monroe street.

The Grotro-Vaudeville. Michigan avenue near Monroe street.

Buffalo Bill's "Wild West." 63d street. Daily at 3 and 8.30 p.m.

The Stoddard Lectures-Central Music Hall, commencing Oct. 2d, Seven courses exactly alike six evenings and matinee each week. Week of October 2, Eastern Japan; week of October 9, Western Japan; week of Octolser 16 , China; week of October 23, Farther India; week of October 30 , Nearer India.

"Sinbad" which had such a remarkable run when presented a few years ago, is revived tonight at the Chicago Opera House. The cast is announced as follows: Sinbad, Louise Royee; Ninetta, Frankie M. Raymond; Maraschina, Ada Deaves; Salamagundi, Lillie Laurel; Cupid, Nellie Lynch; Rafael, Edith Rice; Angelo, Bessie Lynch; Fiametta, Edna Thornton; Zerlina, May Lowrey; Count Maladetto Spaghetti, William Arm strong; Snarleyow, Henry Norman; Old Man of the Sea, Joseph Doner; Nicilo, Jack Guilmette; and Freseo, Edwin Foy. The premiere dancers will be Martha Irmlar, premiere danseuse assoluta, Madeline Morando and Hulda Irmlar, premiere danseuse, and Signor Nicola Guerra, principal male dancer. Gerard Coventry will be the stage manager; W. H. Batchelor, the musical director: Signor Filiberti Marchetti, maitre de ballet, and Martin Frueger, principal electrician. All the scenery will be from the brush of Frederick Dangerfield. The entire force of the American Extravaganza Compauy will be engaged in the production, and the piece on its travels and in Chicago will be under the personal direction of David Henderson, while the business staff will be headed by George Bowles, business manager, and Daniel McCullough, acting manager. 

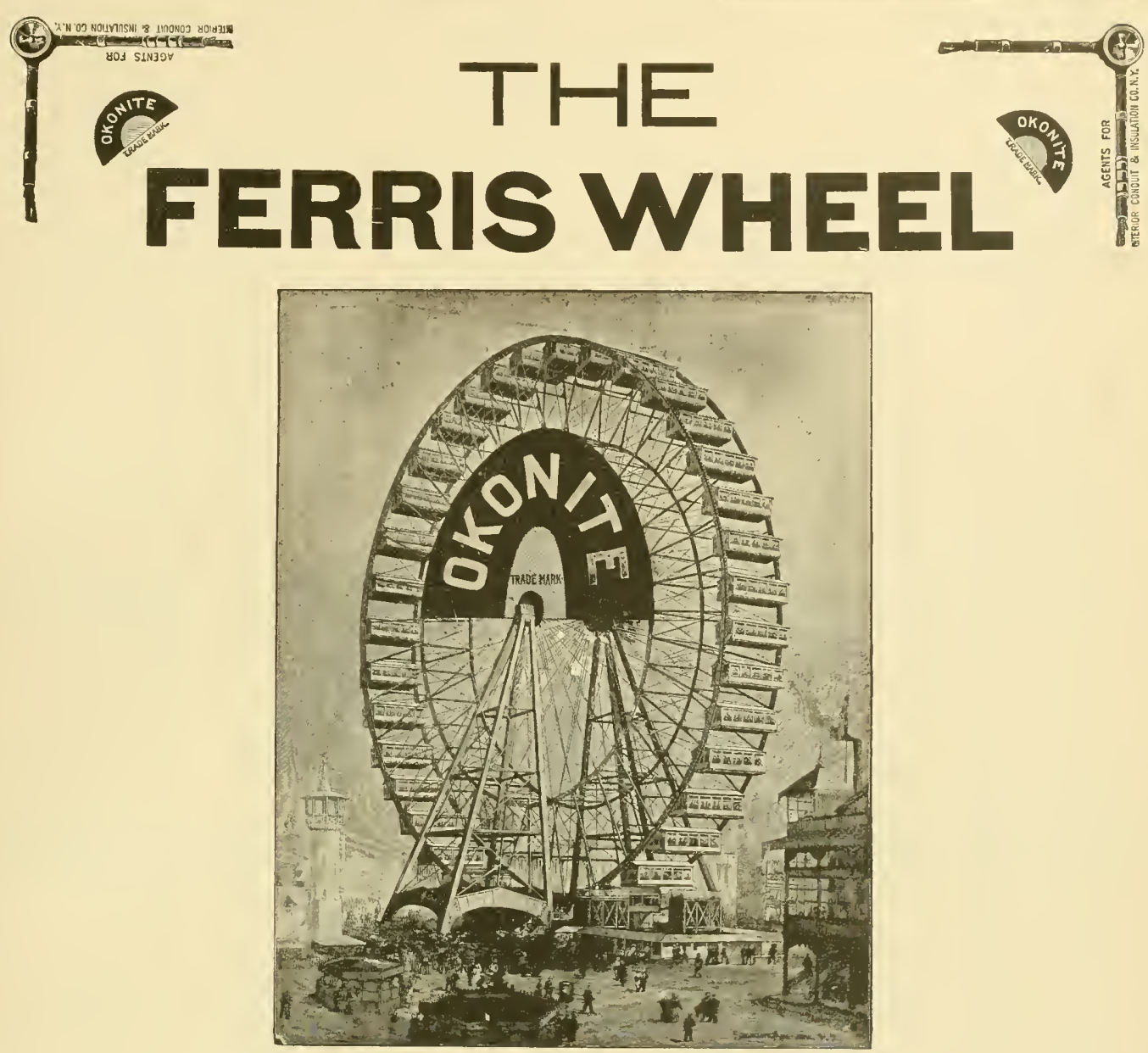

When you visit the World's Fair, you will naturally take a ride on the FERRIS WHEEL and be interested in the ELECTRIC LIGHT INSTALLATION, which is wired throughout with

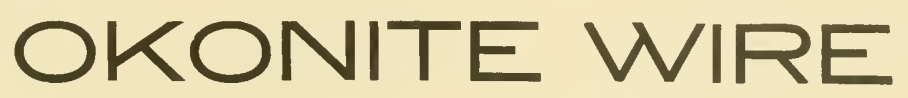

FURNISHED BY THE

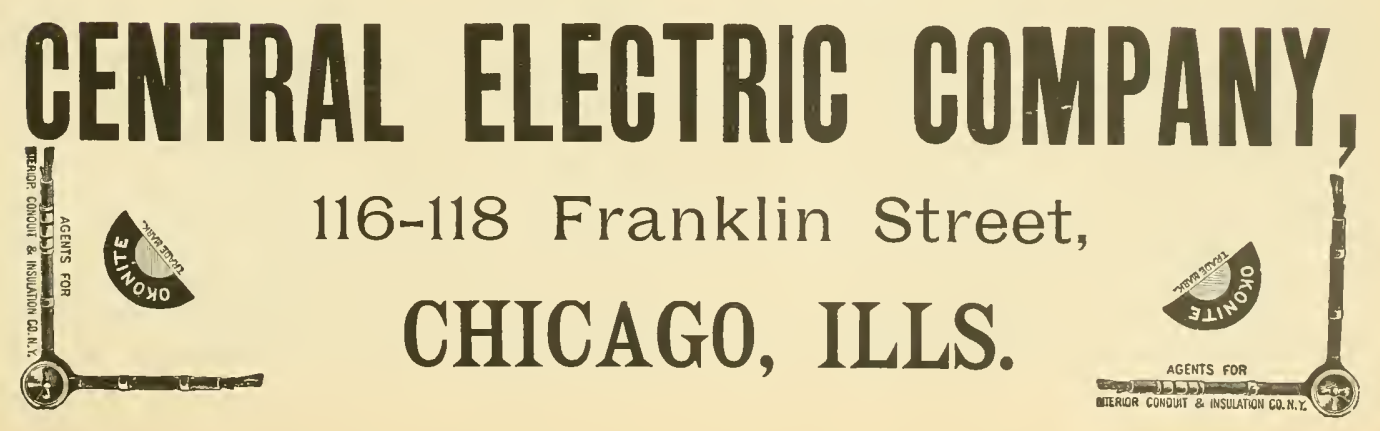


ELECTRICITY BUILDING-EXHIBITORS AND THEIR LOCATION.

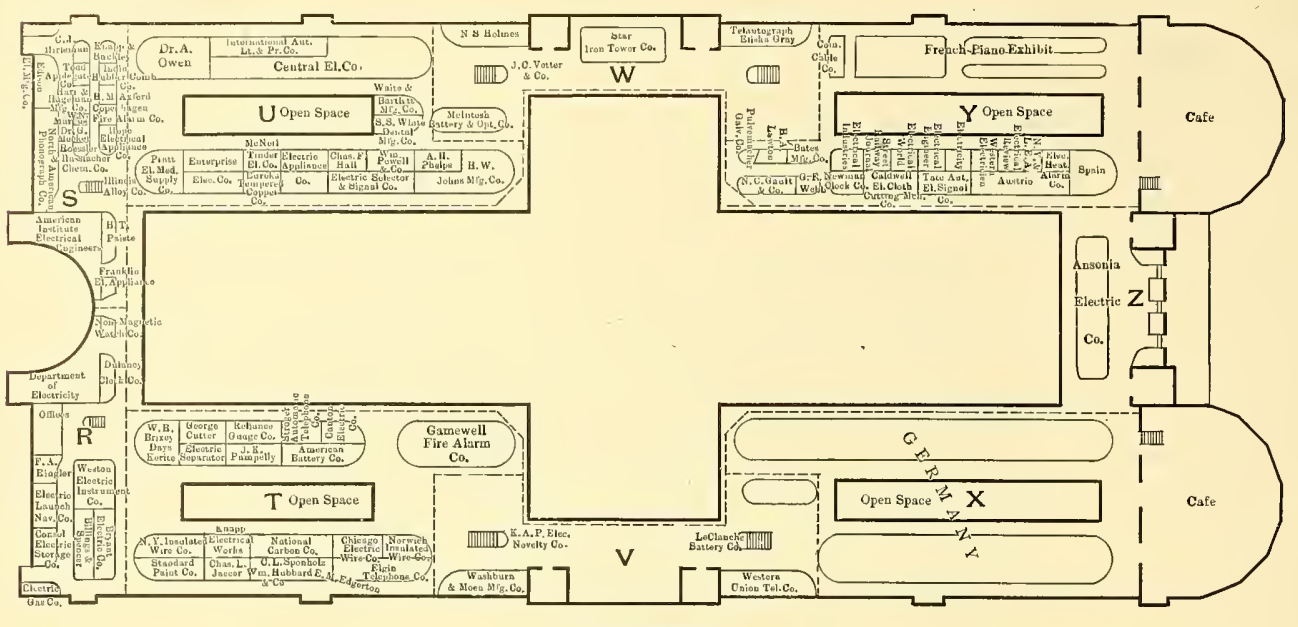

GALLERY.

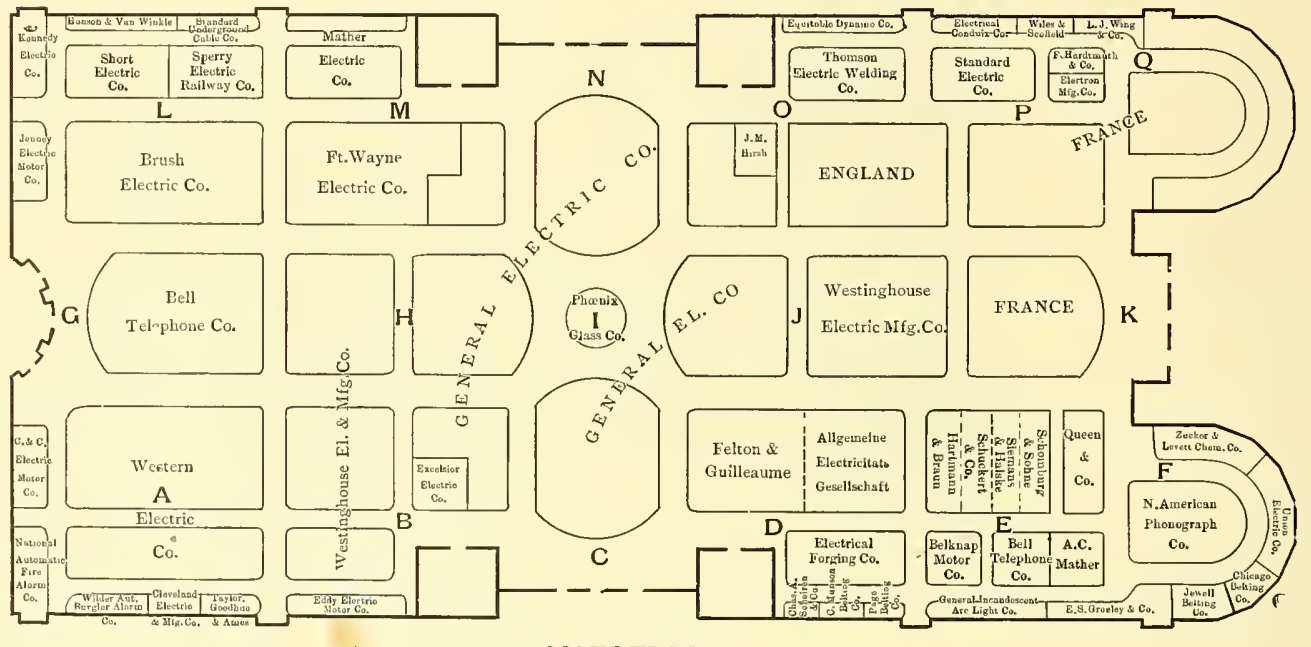

MAIN FLOOR.

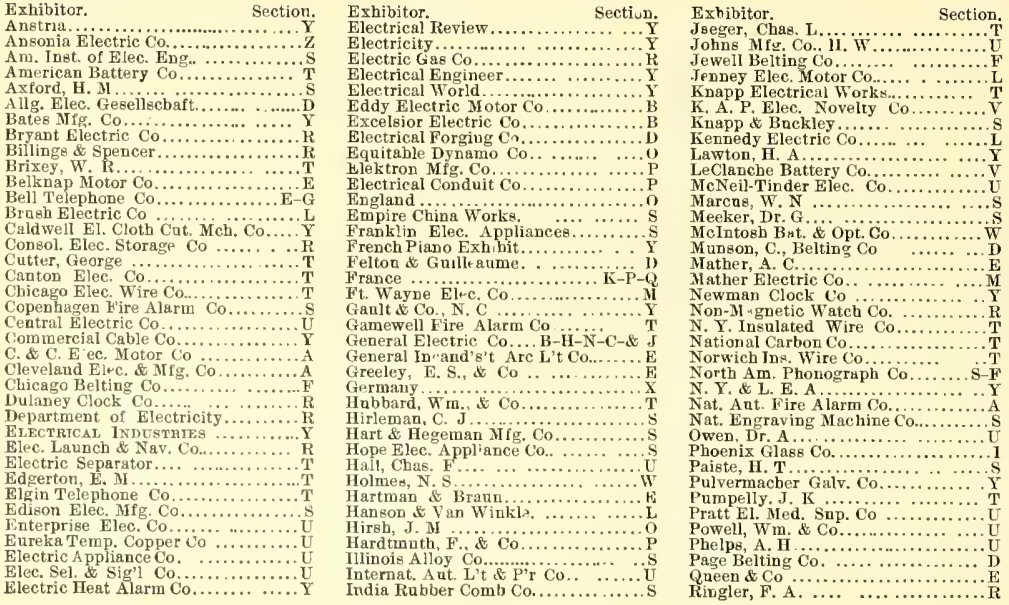
Reliance Guage Co................... Street Railway Jonrnal............. Y Strowger Ant. Telph. Co........... T Standard Paint Co.. sponholz,

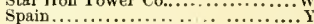
Schieren, Chas. A. \& Co .............. Schomburg \& Sobne .... Siemens \& Halske. . Schuckert \& Co...... hort Electric Co.................. Sperry Elec. Railway Co............. Standard Electric Co.................. P Tate Ant. El. Signal Co............... Todd, Applegate Co ................ Taylor, Goodhne $\mathbb{A}$ Ames............ A Thomson Elec. Welding Co .......... Telantograph, Elisha Gray ........W Vetter J.C. \& Co Webb, G. F Weston El Instrument Co Washbnrn \& Moen Mfg. Co.... ....V Western Union Tel. Co ........... V White, S. S., Dental II fg. Co........... White, S, S., Dental Mfg. Co..........
Western Electrician Wilder Aut. Burglar A. Co............ A Western Electric Co . . .............. Wiles \& Scofield.................... Wing, L. J.. \& Co................. 
LINE-WIRE

PINS

LAMPS

SWITCHES

CARBONS

ARC CUT-OUTS

\section{INSULATORS}

General Construction Material

\section{CUT-OUTS}

Incandescent Lighting Supplies

SPARK-ARRESTERS

Arc Isighting Supplies.
CROSS-ARMS

BRACKETS

SOCKETS

LAMP-CORDS

GLOBES

CARBON HOLDERS

\section{ELECTRIC APPLIANCE COMPANY, 242 Madison Street, CHICACO.}

$\begin{array}{lcc}\text { NEW YORK } & \begin{array}{c}\text { PITTSBURGH } \\ 43 \text { Sixth Avenue. }\end{array} & \begin{array}{c}\text { CHICACO } \\ 42 \text { Murray Street. }\end{array} \\ & 43 \text { \& 2i Wabash Avenue. }\end{array}$

Manufacture the largest line of

\section{ELECTRIC, GAS AND OIL}

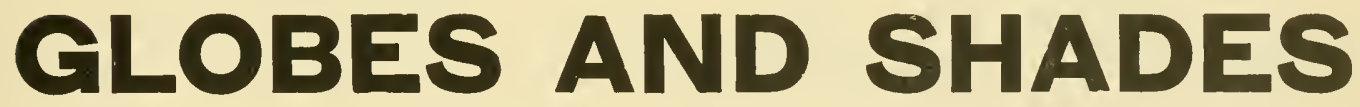

IN THE WORID.

ORIGINAL DESIGNS. NO COPIES.

An inspection will prove our lines to be desirable-and profitable to the dealer purchasing them.

\section{PHCNIX GLASS CO.}

42 Murray Street, NEW YORK, 43 Sixth Ave, PITTSBURGH, PA, I9 \& 21 Wabash Ave, CHICAGO, ILL. Phœnix Glass Co.'s Exhibit can be found in the Center of Electricity Building.

THE REGULAR MONTHLY EDITION OF

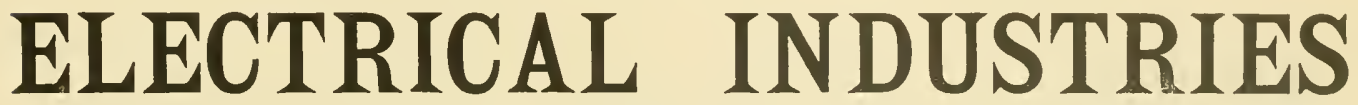

Is the most complete Electrical Journal published,

Every issue containing descriptions of all the ncw applications of clectricity, complete directories of the Manufacturers and Dealers, the Electric Lighting and Railway Companies in North America, revised and corrected to the date of going to press. Thesc special features are found in no other Electrical Jonrnal in the world, and consequently it is read by more actual buyers than any otlser publication, which fact makes it witlont a superior as an advertising medium. 


\section{OUR IMPROVED SYSTEM}

... of . .

\section{Automatic Fire Alarm,}

covered by patents recently issued, is the

embodiment of all factors contributing to the

GREATEST SAFETY,

\section{and the MOST RELLABLE}

PROTECTION FROM FIRE.

\section{Western Electric Company,}


OCOMPANY, NEW YORK.

192 Broadway and II John Street.

MANUFACTURERS OF ARC LIGHTING APPARATUS FOR EVERY PURPOSE A SPECIALTY. The CLARK AR: LAMPS for USE On EVERY CURRENT, have the reputation of being the best and most durable of any ever made in the United States.

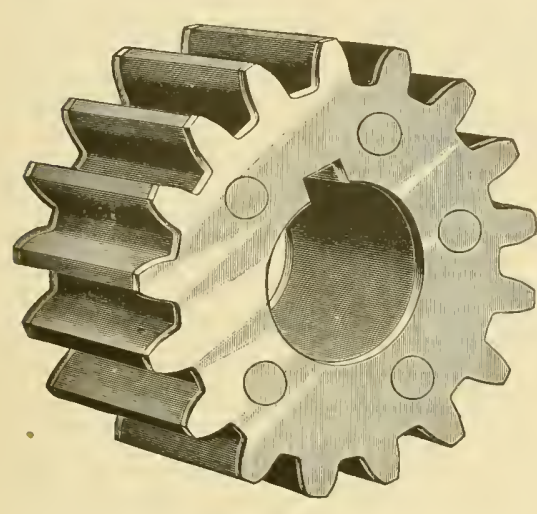

RAWHIDE PINIONS FOR ELECTRIC MOTORS A SPECIALTY.

RAWHIDE DYNAMO BELTING

Greatest Adhesive Qualities. A Non-Conductor of Electriclty. Causes Less Friction than any other Belt.

THE CHICAGO RAWHIDE MANUFACTURING CO.

THE ONLY MANUFACTURERS IN THE COUNTRY.

\begin{tabular}{|c|c|}
\hline $\begin{array}{l}\text { LACE LEATHER ROPE } \\
\text { AND OTHER RAWHIDE. }\end{array}$ & $\begin{array}{l}\text { This Belting and Lace Leather is } \\
\text { not affected by steam or dampness; } \\
\text { never becomes hard: is stronger }\end{array}$ \\
\hline $\begin{array}{l}\text { GOODS } \\
\text { OF ALL KINDS } \\
\text { BY KRUEGER'S PATENT }\end{array}$ & $\begin{array}{l}\text { more durable and the most econom- } \\
\text { ical Belting made. The Raw- } \\
\text { hide Rope for Round Belting } \\
\text { Transmission is stiperior to all } \\
\text { others. }\end{array}$ \\
\hline
\end{tabular}

75 Ohio street.

CHICACO, HL

\section{Standard Electric Company.}

GENERAL OFFICES: 625 Home Insurance Building.

WORKS: So. Canal Street,

CHICAGO.

\section{STANDARD SYSTEM}

AT THE

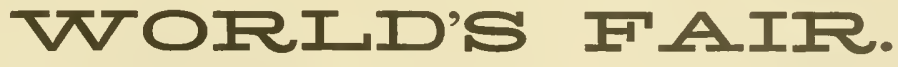

MACHINERY HALL, Sec. Q, 2 Standard Arc Dynamos.

Sec. S, 20 " “ "

ELECTRICIT Y BUILDING, Sec. P, Space 2, Arc Lighting Exhibit.

he Standard Lamps Light the Power Plant, Machinery Hall, Agricultural Hall, Shoe and Leather Building, and Other Buildings and Portions of the Grounds. 


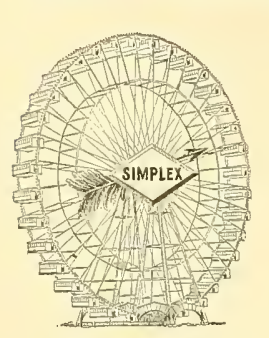

Mile after mile of

\section{SIMPLEX WIRE}

Supplied to the

FERRIS WHEEL

$\bullet$

By...George Cutter,

The Rookery, chicago.

\section{SIMPLEX WIRES}

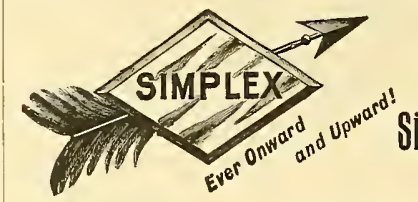

George Cutter, Chicago.
INSURE

HIGH

INSULATION

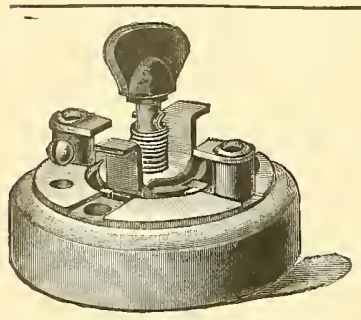

Made 5 amp. S. P. P.

15 amp. 3 way.

\section{XNTRIC}

"That's the Switch"

And we control that movement.

\section{H. T. PAISTE,}

10 South 18 th St., PHILADELPHIA, PA.

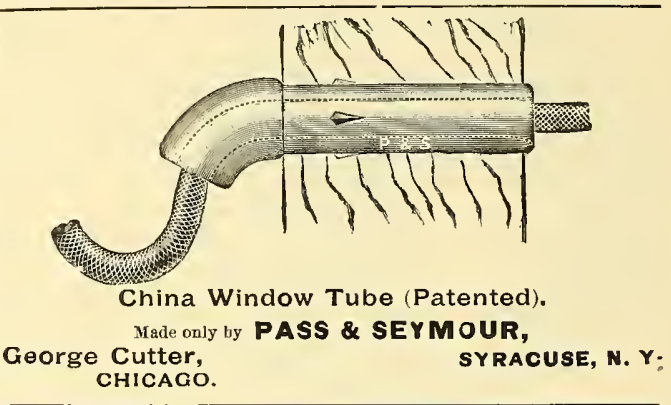

\section{Enterprise}

Electric

307 Dearborn Street, Chicago....

Manufacturers' Agents and Mill Representatives for

Electric Railway, -o

Telegraph, Telephone and Electric Light

SUPPLIES or everv

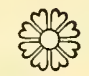

Agents for

Cedar Poles,

Cypress Poles, Oak Pins,

Locust Pins, Cruss Arms, Class

Feeder Wire,

Insulators,

WIRES, CABLES, TAPE and TUBING

\section{BEAR IN MIND}

that the regular monthly issue of ELECTRICAL IN. DUSTRIES contains the most complete and correct directories published of the electric light central stations and the electric railways in North America.

World's Fair Headquarters Y 27 Electricity Building.

CITY OFFICES, Monadnock Block.

Consolidated Elpetric 6.

Mandlacturers and Dealers in all kinds of

\section{ELECTRICAL * SUPPLIES,}

115 Franklin Street,
WAGNER ELEGTRIG FAN MOTORS

For Direct or Alternating Currents.

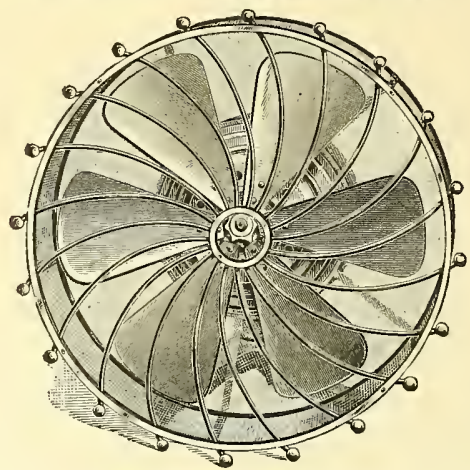

These motors give a stronger hreeze with less consumption of cnrrent that any other fan motor on the market. They are fnll 1-8 horse power. Six bladed

IT WILL PAY YOU TO SEE THE WAGNER BEFORE BUYING ELSEWHERE

TAYLOR, GOODHUE \& AMES, 348 Dearborn Street, CHICACO. 


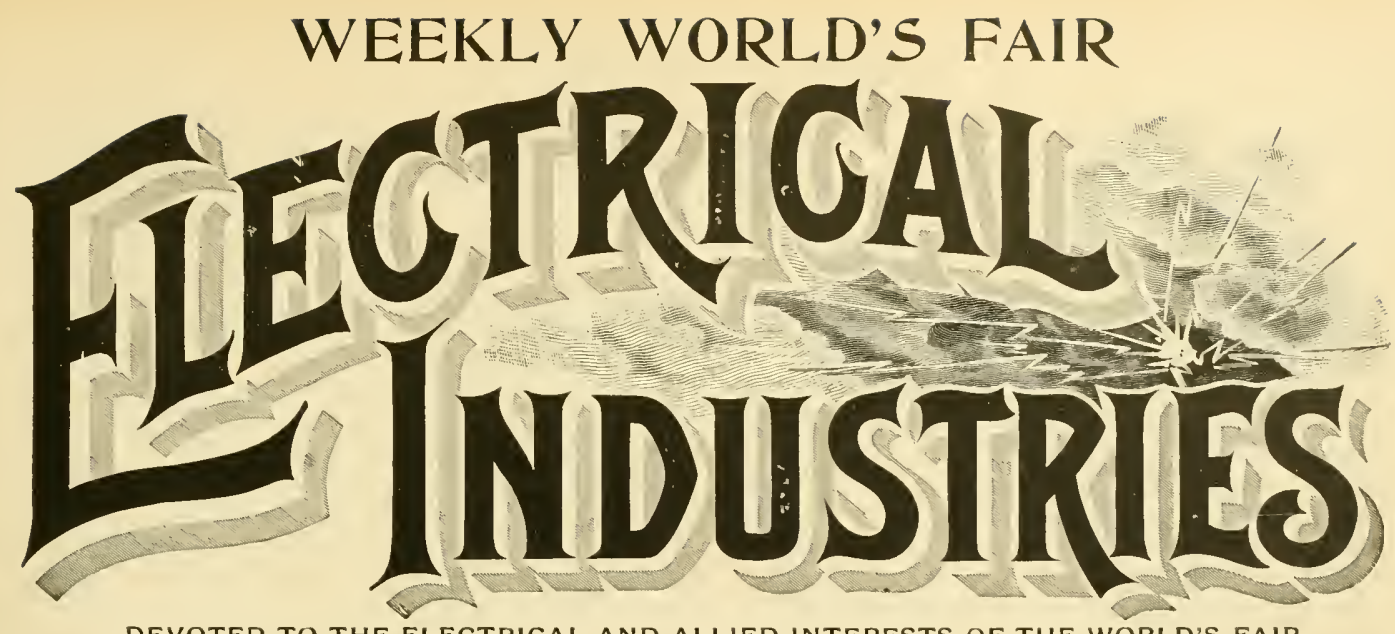

DEVOTED TO THE ELECTRICAL AND ALLIED INTERESTS OF THE WORLD'S FAIR, ITS VISITORS AND EXHIBITORS.

Vol. I, No, 19. CHICAGO, OCTOBER 19, 1893.

Exhibit of Pullman Street Cars.

No department probably shows such exteuded and varied exhibits as are displayed in the department of Transporta tion. These exhibits show a gradual advancement and a points bave been in geueral but a secondary consideration. However in the desigus of the street ears exhibited by the Pullman company at the World's Fair these points have receired special attention.

In connection with the extensive display of passenger

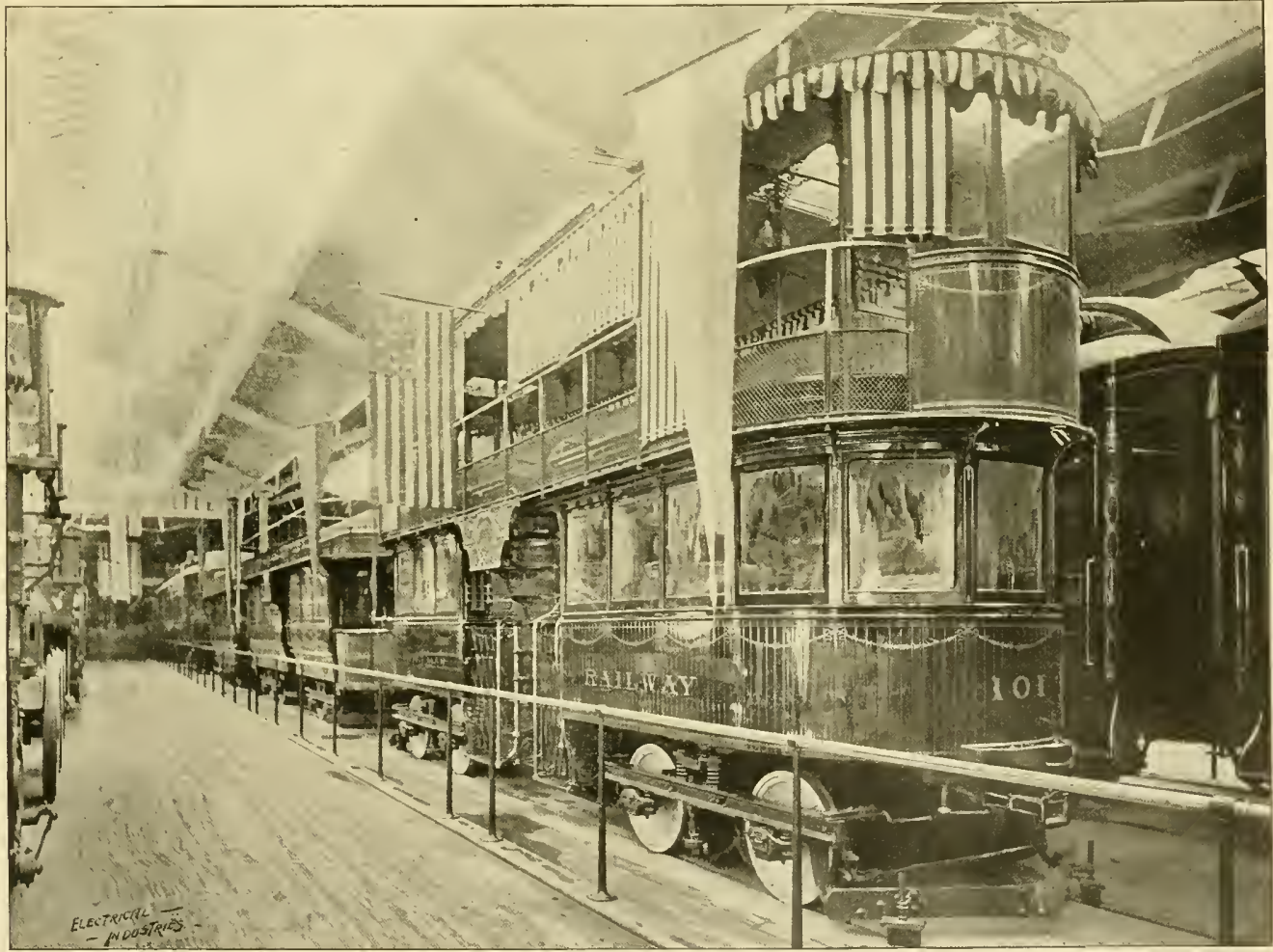

FXHIBIT OF PULIMAN STREET CARS.

complete evolution of ideas in the succeeding stages of the art. Among ear builders the lines followed in the construc. tion of street cars and coaches for steam roads have rapidly diverged since the introduction of the railway. While in cars for"steam roads the eomfort and safety of the passenger has been a special point aimed at, in street ears these cars made by the Pullman's Palace Car Company are a number of street ears embodying the more adranced ideas and improvements in street car construction. The accompanying engraring gives a view of these exhibits looking toward the west. Besirles the features affording comfort and increased safety to the passenger, the double carrying 
capacity and the reduced cost per passenger of operation are worthy of attention. In the foreground is shown a double deck center vestibule motor car. The following dimensions will indicate its size. 1 t is thirty feet eight and seven eights inches long over all; eight feet two inches wide and fifteen feet five inches in height. The center vestibule divides the car below into two compartments and dispenses with the end platform. At each end of the upper derk a pilot house is provided for the motor man.

The outside of the car is sheathed in narrow widths and painted in royal blue with special decorations in gold. The interior is finished in mahogany with decorated ceiling. 'The windows are of Chances' crystal sheet glass and plate glass in the doors. In the upper deck of each compartment are bevelled mirrors also four in the restibule and four at each door. The windows are fitted with fringed curtains hung on Hartshorn rollers. The car is lighted by Hicks \& Smith combination oil and electric lamps, one in each compartment. The seats are of Hale \& Kilburn spring patteru covered with tapestry. The car is provided with eight might these platform seats be given to passengers who wish to smoke.

The stairways going to the upper deck of this carare not of the same design as those in the center vestibule motor car above described there being but a single stairway constructed into each side of the car instead of dividing stairways. The inside finish of the cars is of Mexican mahogany of special design with ceiling handsomely decorated in gold. It is fitted with spring seats upholstered with Wilton plush carpet. The glass in the windows is Chances' crystal plate bevelled and in the doors one-quarter inch polished plate. The curtains at the windows are adjusted by Hartshorn rollers and the floor is fitted with Everett floor matting. The trimmings are all of bronze. The upper deck has slat seats and has an iron handrail and wire sereen guard around the top of the car. The trucks under this car are of Pullman manufacture equipped with iron wheels and steel axles and in addition to the ordinary brakes, with air brakes.

Immediately to the rear of the center vestibule donble

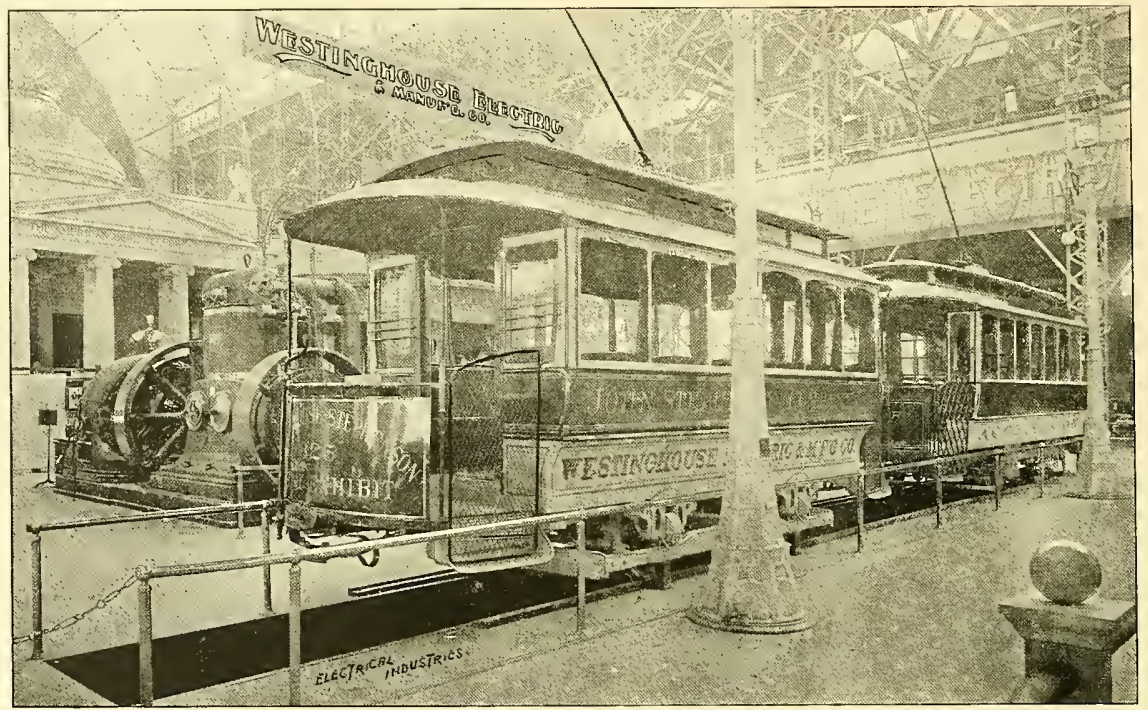

F1G. 1.-EXBIBITS OF ELECTRIC RAILWAY CARS AT THE FAIR-STEPHENSON AND BROWNELL CARS IN ELECTRICITY BUILDING.

electric heaters, electric signal bell and gongs on each pilot house. The trimmings are all of bronze and four folding gates are placed on the platform. The ear is mounted on Pullman trucks which are eqnipped with 30 inch Allen wheels, two 20-horse power Westinghouse electric motors and Sessions' friction brake.

Next to this is a double deck center vestibule trail car. As will be noticed it is but a little higher than the ordinary street car, being eleven feet three and one-half inches high or three and a half inches higher than the ordinary car. The outside is finished similar to the above with gold ornamentation of a special design. There are six large windows and one entrance on each side. There is a platform at each end for the motor man, very much like the platforms on ordinary cars except that they are entirely closed by a wire screen so as not to permit anyone to get on or off ex cept through the entrances at the sides. Seats are provided on each platform to accomuodate several passengers thus further carrying out the idea of utilizing all the available space and giving the greatest comfort possible, especially deck trail car will be seen an ordinary single truck car equipped with the double deck feature, with stairways leading to the upper deck from the platforms at each end; while to the right of the illustration can be sten the new wide vestibules which have attracted so much attention in the Pullman company's exhibit of coaches.

\section{Exhibits of Electric Railway Cars at the Fair.}

The display of street cars at the Fair does not appear as extensive to the casual observer as the importance of the subject would seem to demand. This is in a measure true, but the exhibits of cars are considerably scattered and consequently to the visitor to Transportation Building, the display looks small after following aisle after aisle of steam cars and locomotives. The exhibits display the latest ideas in the industry and are certainly models of their kind.

At the east end of street car row appear two large sketches of the first street car, John Mason, built by the John Stephensou Co., in 1831. These are interesting espe- 
eially when eompared with the molern ears exhibited in the same spaee by that eompany. The stage coaeh style of ear in its clumsiness is but a erude affair when placed by the side of the trim, neat but substantial ears which the John Stephenson Conspany, Ltd., of New York, hare placed on exhibition. These ears are but sample ears and were built as part of reeent orders, one for the Broadway eable line and the other for the electrie line of the Elmira and Horseheads Street Railway of Elmira, N. Y.

The latter is monuted on a Taekaberry truek and is built to aceommodate Westinghouse eleetrie motors and equip. ment. The ear presents a very neat external appearance and is painted a light buff color. The interior is finished in quartered oak, upholstered seats, wide windows with window shades, double doors ete. The floor is eovered with rolling wooden matting; the platforms are wide and the steps low and broad. The ears show excellent workmanship and great skill in the design. The eompany has also a ear on exhibition in the exhibit of the Westinghouse Electric MIfg. Co. in Eleetricity Building which is com. tions are undoubtedly the most elaborate ever attempted and the ear attraets the attention of erery visitor. This eompany also have a car on exhibition in eonnection with the Westinghouse eompany in Electrieity Building.

Both open and elosed cars are exhibited by J. M. Jones Sons Company of West Troy, N.I., near the east end of Street Car Row. The elosed ear is desigued for eleetric traction and is mounted on a Taylor improved eleetric truek. The body of the ear is 18 feet long. There are six windows on each side of Freneh plate glass and two on eaeh end. The platforms are large and designed to earry a large number of passengers. It is fitted with Wilsons improved sand box, foot gongs, Jones ratehet brake hanclle, and the West End trolley. The doors are double at eaeh end so eonstructed that both are opened or closed as the ease may be whenever either is mored. The interior is fuished in mahogany with quartered oak eeiling. Snith eleetrie lamps and shades are provided of a very neat design. The seats and backs are upholstered in blue plush and windows equipped with curtains of blue and gold.

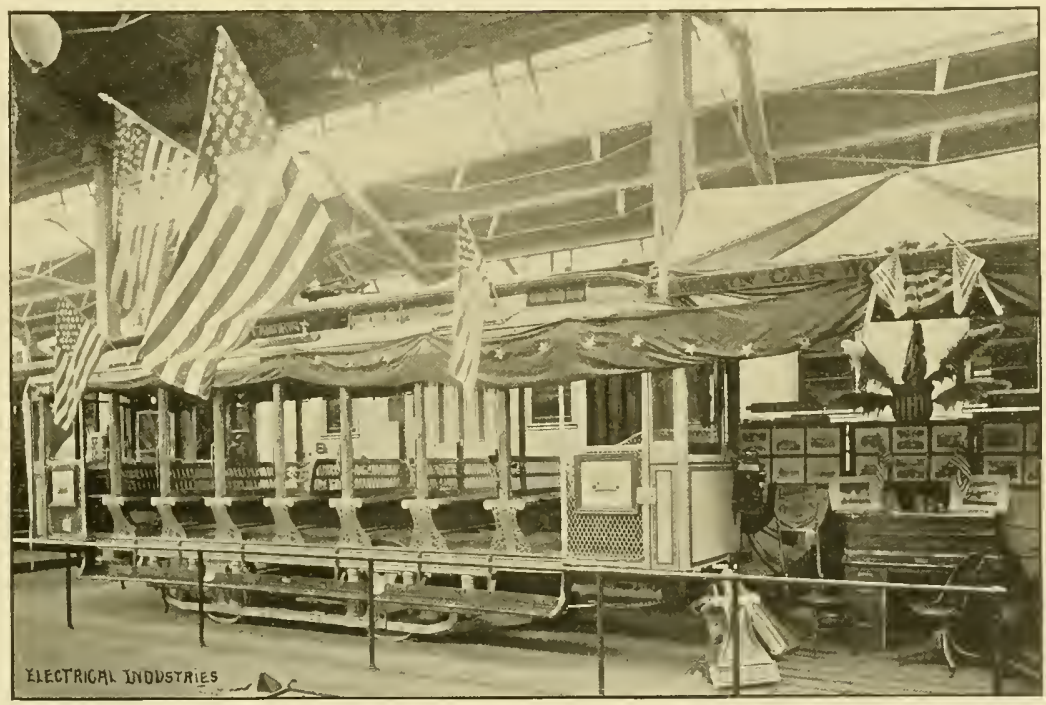

F16. 2.-EXHIBITS OF ELECTRIC RAILWAY CARS AT THE FAIR-LAMOKIN OPEN CAR.

pletely equipped with Westinghouse apparatus and supplied with current showing to exeellent advantage the lighting of the ear, the motive power and controlling apparatus.

The Brownell Car Company has on exhibition a model ear which is certainly haudsome in appearance both inside and out. It is finished in white, yellow and gold. The car is 28 feet orer all and 7 feet 10 inehes wide. It is mounted on a Brownell non-oseillating electrie motor ear truek. The platforms are wide and have solid wrought metal steps fitted with rubber jads. On the eenter panel appear the Latin words "capaeitas, peeunice, dividenda, eommoditas," indicating the things most sought for in a street car, i.e., eapacity and commodiousness, money and diridends. The interior is finished in white and gold and is handsomely deeorated. The seats and backs are old gold silk plush upholstered with eurled hair. In the eenter panels are plate glass mirrors. The doors are of mahogany and are placed two at each encl. The roof is of the improved Brownell truss form, has patented truss trolley bridge and is equipped with trolley eomplete. Thedeeora-
Bronze poles with russet hand straps are also provirled for standing passengers. The trimmings of the car both inside and out are of polished bronze. The main panels on the sides and ends are finished in blue and bronze borders and gold stripes.

The open ear is also eonstrueted for electrie serrice and is mounted on a Bemis truck. It has five reversable seats and four fixed. The reversable seats are maple while the others are paneled in eherry. At each end there are three drop sashes with Freneh plate glass and the sides are prorided with heary eurtains, which are adjustable and run in guides. The eeiling is of white birch deeorated with cherry moulding. The ear is also equipped with solicl bronze trimmings both inside and out. It is also prorided with the Smith lamps, New Haven register, foot gongs, etc.

The Lamokin Car Company, have also an attractive exhibit in Street Car Row consisting of two street ears one open and the other elosed, whieh show great skill in con. struction and design. The closed ear whieh is expuipped with two 25 -horse power Westinghouse motors is mounted 
on a McGuire truck. The car is restibule with large observatory windows. The steps are of the type made by the Stanwood Manufacturing Company, the trimmings are of solid bronze, the seats are of antique oak, the backs are upholstered in plush, and the windows are furnished with curtains of the roller type. The interior of the car is finely car is mounted on an all steel Robinson truck manufactured by the Robinson Machine Company of Altoona, Pa. The fittings are all of bronze and the decorations both inside and out are neat and tasty.

Street car trucks are extensively exhibited. The exhibit made by the Peckham Motor Truck \& Wheel Company, of

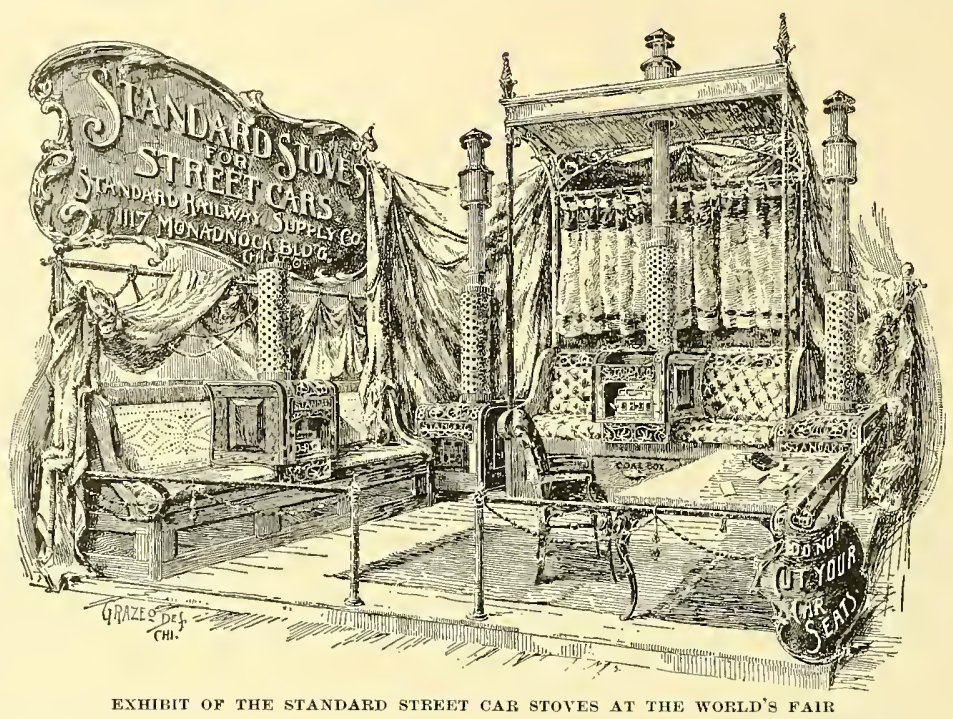

finished and is equipped with the Cochrane electric heaters. The doors are of solid oak and the windows are of French plate double glass.

The open car is of a design that has met with fasor with a great many companies and is especially adapted for heary summer excursion_traffic. It has vestibuled ends with large
Kingston, N.Y., comprises the latest and most improved form of truck which are built for both long and short cars. The excellence of the construction is shown in the individ. ual parts of the truck separately exhibited. In the accompanying illustration is shown truck No. $6 \mathrm{~A}$. design for closed cars up to 20 feet in length. It is of the non

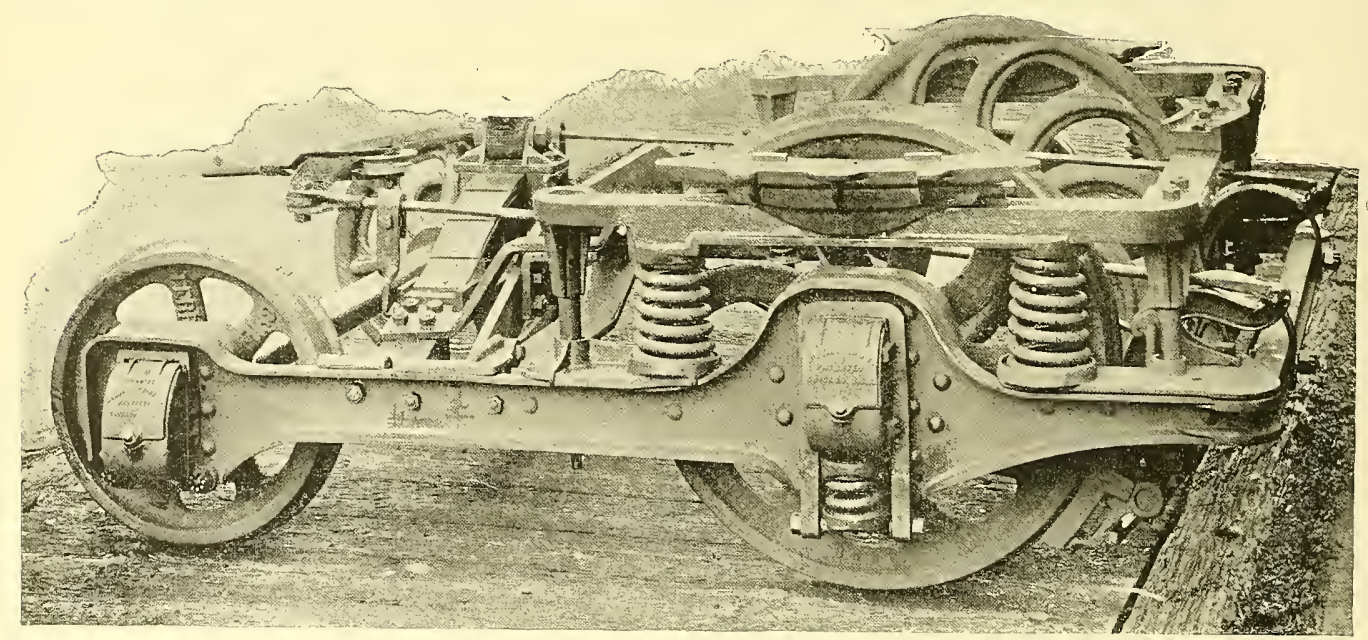

FIG, 3.-EXHIBITS OF ELECTRIC RAILWAT CARS AT THE FAIR-MEGURE BICYCLE TRUCK.

windows. The sides are provided with drop curtains, the ear has seven seats and on each side of the motor man are side seats capable of holding two passengers each. The Stanwood steel step is used and the platforms are also equipped with foot gongs and headlights. It has also Cochrane sand boxes and a Cochrane trolley board. The oscillating type and has spiral springs on the underside of the frame.

The McGuire Manufacturing Company displays a number of styles of trucks in its space in the Transportation Building as well as in connection with other exhibitors in Electricity Building and in other parts of the grounds. 
The new adjustable bicycle truck which possesses many points of excellence has undoubtedly attracterl the most attention. It is the latest improvement made by the com-

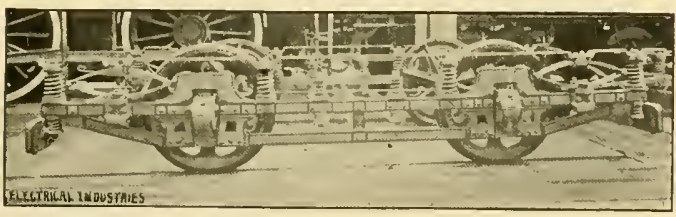

THE PECKHAM TRUCK.

pany in trucks for long cars. It overcomes sereral of the objectionable features of long ears on swivel trucks. The truck has large drive wheels with small guide or auxiliary known Columbian four wheeled truck which is familiar to most street ear men. It is also shown in connection with several exhibitors in Electricity Building and elsewhere.

\section{Exhibit of Stirling Boilers.}

The accompanying ilhustration gives an excellent view of The Stirling Company's exhibit in the main boiler room at the World's Columbian Exposition. It comprises two batteries of $\mathbf{S ( 0 )}$-horse power each of the well known Stirling type of water tube boilers, the construction of which is familiar to most of our readers. A complete description appeared in the June number of Electrical Industries. These boilers have received a good deal of attention since they were installed and the fact that they received a medal and diploma from the jury of awards is sufficient evidence

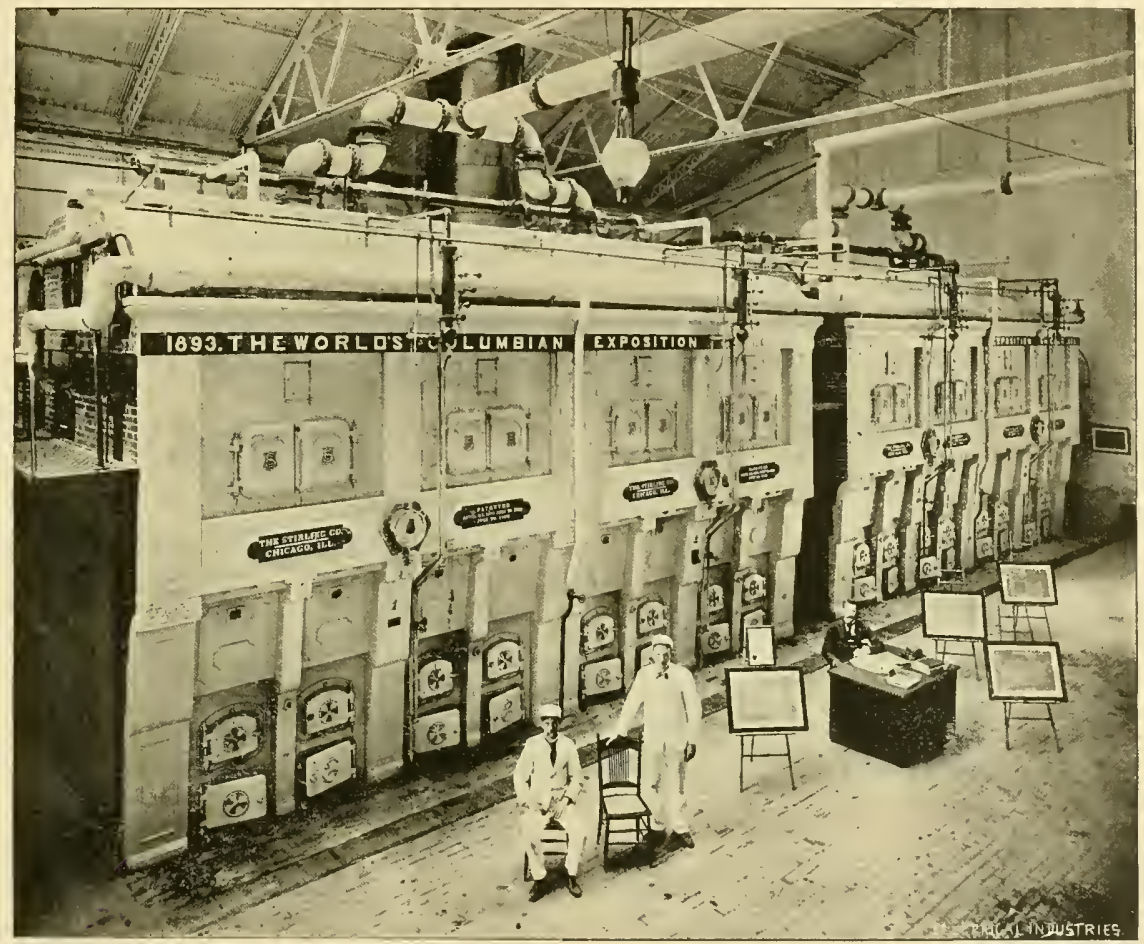

EXHIBIT OF STERLING BOLLERS AT THE FAIR.

wheels. The car may be mounted as low as a four wheel car, the truck being open for the motor. The entire load is carried, it is said, on the eight spiral springs, located over the two driving axles, on a straight track while on curves the proportion transferred to the guide wheels varies, but is always sufficient to prevent derailment.

This is effected by a device consisting of a half eliptical spring located nearly over the drive wheel and a double cam attached to the car body directly over the spring. Iounted on the spring is a roller which fits into a recess in the center of the double cam thereby performing two functions. While on a straight track it serves as a centering device for the truck, at the instant a curve is encomntered the roller acts upon the cam depressing the spring and thereby assuming part of the load and supporting it on the guide wheels. Among the other trucks shown is the well of their excellence. The company has made a good fight for recognition at the Fair and is to be congratulated on the success it has attained.

\section{Exhibit of the Standard Street Car Stoves.}

In the Transportation Annex, street car row, the Standard Railway Supply Company, Monadnock Block, Chicago, has a comprehensive exhibit of the Standard stoves. The general arrangement of the exhibit is shown in the accom panying cut. Car seats are arranged about the space of both the upholstered and reneered pattern with the Standard stove attached showing how it can be placed in any car without cutting the seat, no matter what the finish or the shape of the seat may be.

The old street car manager as he inspects this display of 
neat and compactly designed heaters recalls his varied experience in heating his cars. He remembers the cars where there was no stove and in which the passenger poked his feet in the straw on the bottom to keep them warm; then the introduction of the common house beating stove which was placed at one end of the car, affording some heat and great inconvenience. Then he recalls how some enterprising inventor persuaded him to cut out the seat at the center of the car and install a stove which was protected by heavy boxing. But even this had many objectionable features. As winter approached the car was run into the shop and equipped for the winter and when spring eame it made another trip to the shop to be prepared for the summer traffic.

In the "Standard" stoves here displayed the acme of perfection seems to have been reached. It requires but a few minutes to place it in the car and but a few minutes to remove it when it is no longer required. The cushioned seats are uninjured and the car is neither disfigured nor marred when it is taken out. The stoves are constructed
A two and one-half-horse power motor wound for 50 volts is geared to the back axle of the carriage. The controlling apparatus consists of a contact board and a reversing switch, both fastened to the under side of the carriage floor. A spring plug and foot switch is placed in the floor of the carriage directly in front of the driver, who has only to remove his foot from this spring switch and allow the small contact plug to raise from the cup of mercury. This action breaks the circuit between the battery and motor. One of the most important features of the carriage is the arrangement of the front wheels to facilitate steering. Each of the two front wheels turns upon a bearing that is swivelled to swing horizontally and independently of the axle.

The front axle is rigidly fixed in a position parallel to the back axle. A yoke bar carrying a rack couples the two front wheels and the gears working in this rack and operating through the steering wheel shaft,permits of the two wheels being swung to the right or left so as to guide the carriage.

These batteries are what might be called an improved form of the Plantè cell. No lead oxides or active

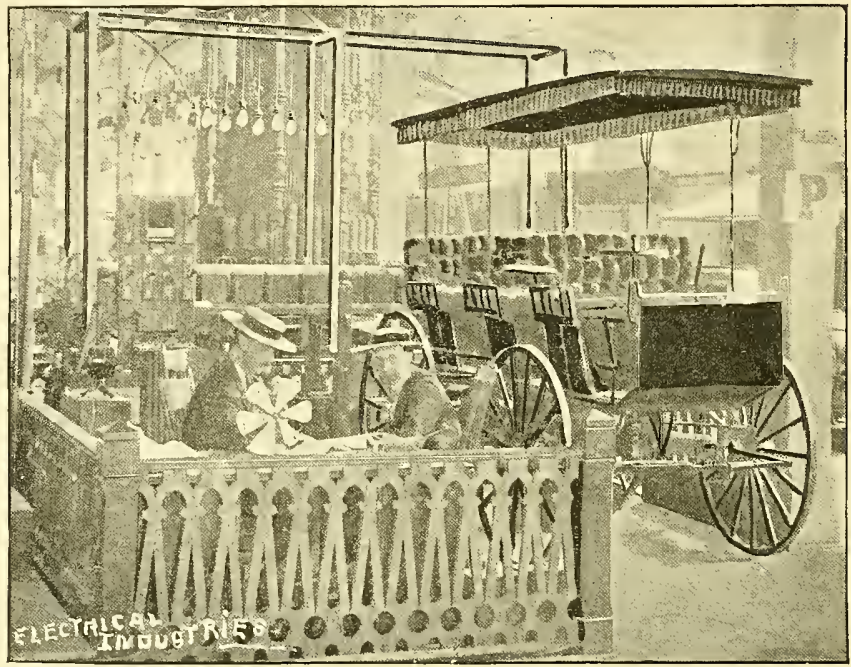

AMERICAN BATTERY COMPANY'S EXMIBIT.

entirely of cast iron in such a manner as to make them durable and efficient.

The boxing or casing of the stove is constructed of hard wood which is finished to match the interior of the car. It is heavily insulated with asbestos, thus protecting the car and shielding passengers sitting next to the stove. The stove bas a large ash pan which, with the opportunity for a coal box beneath the seat, all the necessary adjuncts are conveniently furnished. The neat design and elegant nickel finish of the metal work make it an ornament to the car.

\section{American Battery Company's Exhibit.}

The exhibit of the American Battery Company at the World's Fair shows its storage batteries in operation for lighting and for power. A plant of 52-150 ampere hour cells connected in two series of 26 each is shown, furnishing a current for 3050 -volt 16 candle power lamps. The use of this battery for power is shown in the electric carriage. This carriage bas a seating capacity for six people and is equipped with 24150 -ampere hour cells. material is mechanically applied. The plates are formed by oxidization in an electro chemical bath. The plates consist of a series of horizontal strips of rolled lead crimped on both sides three-eighths and one-half inch wide and of such thickness and separated by such distances as by tests and experiments gives the greatest capacity combined with the longest life. These strips are solidly united at the ends by a process which leaves the sides of the plate a solid bar of metal of special composition, not affected by chemicals. The plate is then supplied with foot and terminal pieces very firmly connected of special composition. The plate is then ready for formation and the plate is submitted to the forming process which oxidizes the surface of the lead strips, but attacking but slightly the surrounding support. The oxide taking more space, expands and the process is continued until the interstices between the strips are filled solidly, thus leaving the alternate strips of lead and active material horizontally across the plate and surrounded by a solid frame of metal. This makes the plate very solid and strong. The lead strips being not

(Continued on page 8.) 


\section{ELECTRICAL INDUSTRIES.}

\section{ELECTRICAL INDUSTRIES PUBLISHING COMPANY, MONADNOCK BLOCK, CHICAGO. \\ TELEPHONE: HARIISON 159.}

E, L. Powers, Preg, and Treas.

E. E. WOOD, SEcretArt.
E. L. POWERS,

W. A. REMINGTON,

E. E. WOOD,

FLOYDT. SHORT.
EDitor.

- Associate Editor.

- Eastern Manager.

ADVERTising Defartment.
EASTERN OFFICE, WORLD BUILDING, NEW YORK. World's Fair Headquarters, Y 27 Electricity Building.

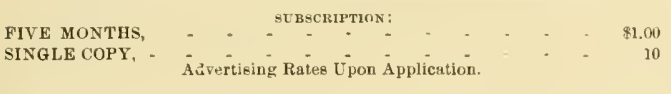

News items. notes or communications of interest to World's Fair lisitors are earnestly desired for publication in these columns and will
be heartilv appreciated. We especially invite all risitors to call upon us be heartily appreciated. We especiallv in vite all risitors to call upon or send address at once upon their arrival in city or at the grounds.
ELECTRICAL INDL'STRIES PIBLISHING CO.

Monadnock Block, Chicago

The fire last Thursday night at the 39th St. barns of the Chicago City Railway resulted in a heary loss to the barns and contents. Nearly four hundred horses were lost, a number of cars, feed, etc. The damage was more severe, occuring as it did just at the time when the traffic was heaviest on account of the World's Fair. The resources of the company, however, were such as to enable it to provide an immediate service. It is the intention of the company to equip the entire system of cross town lines with electric traction, a part of which has already been equipped and the system will gradually be extended notil it is completed.

A most disastrous and probably fatal accident oceurred at the power house of the Atlantic Arenue Railroad Company, of Brooklyn, on last Weduesday, October 11. The power house is located at the corner of Third Ave. and Second St., and supplies power for the extensise Atlantic Ave. system. One of the large fly wheels, 18 feet in diameter and weighing some 20 tons, burst and flew in every direction, badly wrecking the building and seriously injuring the engineer and several persons in adjoining buildings. The accident necessarily stopped the cars, but power was secured from the Brooklyn City Railway's power house, and the cars were again running.

Manhattan Day, for which Uet. 21st has been designated, will undoubtedly be a memorable vccasion. Mayor Gilroy has issued a proclamation full of wise conneil for the citizens of the metropolis and the New York papers urge an attendance on that day of every citizen of New York City who can possibly attend. The World says: "New York owes it to herself to make Oct. 21st an occasion effectively and forever contradicting all ridiculous suggestions of jealousy on our part toward the sister eity which has rendered so notable a service to the whole country in making this the greatest of World's Fairs." Everything is favorable for a large attendance on that day. Railroad rates are extremely low, the railroads are prepared to handle a large traffic, and Chicago is ready to welcome any number of the citizens of the eastern seaport.

The Fair is certainly an educator. Prof. H. B. Smith, of Perdue Lniversity is spending the week with his class in electrical engineering, numbering nearly thirty, inspecting the exhibits in the Department of Electricity. It is to be regretted that other colleges, not located as near to Chicago as the Perdue Iniversity, cannot well follow this most excellent example set by Prof. Smith.

Mr. Willard A. Smith, chief of the Department of Transportation, has expressed his willinguess to co-operate in any arrangements made for the convenience of the railway people who may come from the convention to the World's Fair. Should the convention desire to visit the Transportation Building in a body, be will have the street railway exhibits roped off and the general public excluded during the pleasure of the street railway visitors.

\section{The Milwaukee Convention.}

The conditions are in every way farorable for an unusually large attendance at the street railway convention held in Milwaukee this week. No doult the nearness of the meeting to the World's Fair has prevented many, and especially the larger exhibitors, from making the elaborate display they otherwise would nere it not for their costly exbibits at the Fair, but the street railway men will be present just the same. The number and variety of practical papers that are to be presented and the discussions that will arise will be of great value and will well repay all who hear them. The membership of the American Street Railway Association has steadily grown to large proportions and its importance is fully recognized. The number of members, however, should be larger and we hope to ser a very material increase in the membership during the coming year. Street railway men, as a rule, are progressive as is shown by the rapid adoption of electricity as a method of traction over horse and other motive powers and great benefit to the association will arise from the meeting.

Supply men will of course be present in large numbersand what would a convention be withont them? Their aid in dereloping this new field has been of incalculable value.

The arrangements madle by the committees in charge for the accommodation and pleasure of the delegates and their friends during their stay in the Cream City are all that could be desired. Milwaukee has a well deserved reputation that is known far and wide for hospitality and generous welcome to strangers. We are sure that no one will go away without the best impressions of the city and her street railway men. Much good will come of the meeting. It is to be hoped that all of the delegates will avail themselves of the ofportunity afforded to visit the World's Fair and examine the street railway exhibits in the Electrical and Transportation buildings. The chief of both departments have extended a corclial invitation to them to come and we trust that the exhibits made there by the representative manufacturers will be inspected by every street railway manager. IVe are sure they will be well repaid.

The band stand just south of the Electricity Building was occupied by the Elgin Band last week, whlle this week Innes' 13th Regiment Band of New York City caters to the public ear. 
(Continued from page 6.)

over one-tenth of an inch apart, allow a large as well as intimate connection with all parts of the active material thus enabling them to obtain heavy charge and discharge rates. Corrugations of the lead strips effectively key the active material in place preventing its falling out, while the strips being placed edgewise to the plate solidly filled with active material, gives the plate rigidity sidewise, nearly equal to a solid lead plate of light thickness thereby preventing buckling or bending.

After the plates are formed, they are assembled together, the number of plates being governed by the size of cell desired commencing with the outside plate, and are separated by rubber insulators called combs. Every alternate one is negative while those between form the positive, there being one more negative than positive plates. The plates are then firmly united by fusing a $\mathrm{T}$ shaped piece of rolled lead, positive to positive and negative to negative plates. This piece having a projecting strip for conveniently connecting the cells. The elements are then placed in a containing jar of glass or hard rubber which is then filled with a solution of one part sulphuric acid to five parts water. The cell when charged is ready for work.

\section{WORLD'S FAIR NOTES.}

The display of Christofle et Cie in the French section shows the progress which has been achieved by the aid of electricity in art of galvano plastic and of electro chimic. Many of the reproductions in metal of ancient works of art are more than ordinarily instructing.

"Can you tell me where I will find the exhibit of aereolites," inquired a Vassar girl of a Columbian guard. "In the Electricity Building," calmly answered the blue-coated and tin-sworded dignitary with a graceful movement of his white gloved hand towards the statue of Ben Franklin, and added, "All the lights are over there."

The exhibit of A. C. Mather, so long in an unfinished condition, has at last, during the past week, been put in running order. It shows a proposed solution of the problem occupying the attention of Gov. Flower, of New York, as to utilizing electricity on the Erie canal. An electric railway system is also shown, together with a model of a gigantic water wheel for furnishing power from Niagara.

This is children's week at the Fair, and from 30 to 60 thousand Chicago school children have visited the Fair daily. The Electricity Building has many exhibits which interest them, but none more so than the Electrical Door. Mr. Troy has given up trying to "keep order" in his exhibit, but lets the boys and girls go through as many times as they wish, much to their delight.

\section{CONVENTION NOTES.}

The McGuire Manufacturing Company, Chicago, makes a nice exhibit of trucks. The company is well represented by Messrs. MeGuire, Cooke and Hubbard.

Taylor, Goodhue \& Ames, Chicago, are to be represented at the convention by Messrs. Wm. Taylor and Dee, who have with them a number of their electric railway specialties.

The Electrical Installation Company, Chicago, is represented by its general manager, Mr. L. E. Myers. This company make no exhibit but point with pride to the work that it has accomplished during the past few months in the way of railway and lighting construction. Among other contracts it has just finished 54 miles of overhead electric railway construction in Chicago aud built complete $3 \frac{1}{2}$ miles of road for the Belle City Street Railway Company of Racine, Wis. The company has also recently installed an are and incandescent light plant for the West Chicago Street Railway. It is now installing a large are plant for the Chicago \& West Indiana Railroad for lighting the yards.

The Western Electric Company, Chicago, is making a very fine exhibit of wires and cables at the convention, which is well worth the careful inspection of electric street railway men. The exhibit is in charge of Mr. H. C. Eddy.

Pullman's Palace Car Company, Chicago, is well represented at the convention by Mr. W. S. Louttit, assistant contracting agent, who with just pride points to the 100 handsome new closed and open ears running on the Milwaukee street railway lines manufactured by his company. It is an exhibit worth seeing.

The Siemens \& Halske Electric Company, Chicago, has as a practical exhibit a $750 \mathrm{~K}$. W. Generator in operation connected to a Buckeye engine. This dynamo is sold to the Consolidated Street Railway Company of Cincinnati, where it will be shipped after the convention. Mr. A. W. Wright and other members of the company are in attendance.

The Westinghouse Company is fully represented at the convention. Among those present are Mr. Lemuel Bannister, vice-president and general manager, Messrs. WV. C. Clark, B. F. Stewart (Chicago), W. F. Zimmerman (New York), W. S. Brown (Boston), E. C. Bragg (Phila.), J. A. Rutherford, W. T. E. Gray and several others. The company is distributing large quantities of literature.

The Miamisburg Electric Company, Miamisburg, O., is represented at the Street Railway Convention by Mr. D. H. Allen, general manager of the company, and Mr. A. L. Daniels, salesman of the company, has on exhibition finished street railway commutators and segments of tempered copper in Section A Exposition Building. In the exhibit are also Imperial dry and Burnley cartridge batteries.

'The Western Electric Heating Company, Chicago, is represented at the convention by its manager, Mr. Geo Cutter, who has on exhibition a full line of electric street car heaters besides office heaters for street railway offices. The season is now at hand when managers will be looking after the best means of heating their ears in the coming winter season and they will no doubt examine the exhibit with much interest and profit.

The Railway Equipment Company of Chicago is represented by its manager Mr. W. R. Mason. Its headquarters are in Parlor 92, Plankinton Hotel. Among the specialties there on exhibition is a new rail bond spring bushing which is of special interest in view of the recent discussion of rail bonding. It is simple and effective, and in its use on several roads, it is said, has proved very satisfactory.

The headquarters of the General Electric company are at the Pfister Hotel. The interests of the General Electric company at the convention are under the care of Mr. Theo. P. Bailey, of the Chicago office, assisted by Mr. G. K. Wheeler, Mr. G. Atterbury, and others from the same office. Mr. O. T. Crosby, Mr. Theodore Stebbins and Mr. R. H. Beach, are present from the main office in New York, Mr. W. J. Clerk, from the Cincinnati office, Dr. T. Addison, from the San Francisco office. Mr. W. H. Kinight, Mr. J. B. Blood and Mr. A. K. Baylor represent the engineering department. 
MAP OF ELECTRICITY BUILDING-EXHIBITORS AND THEIR LOCATION.

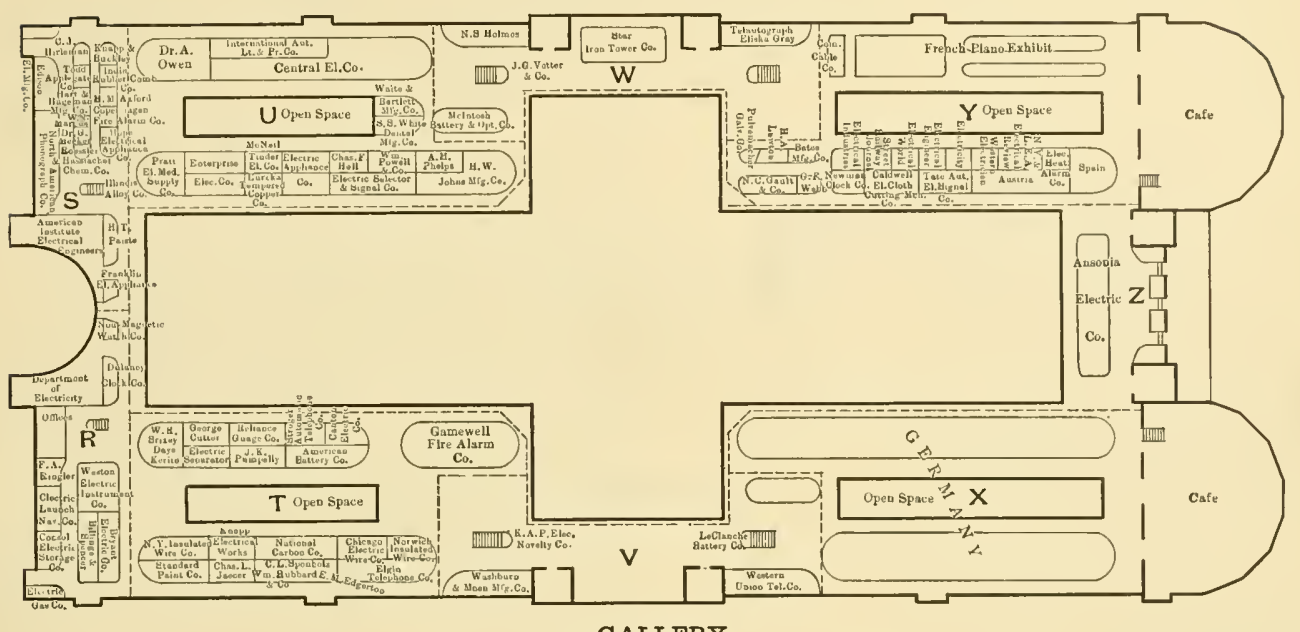

GALLERY.

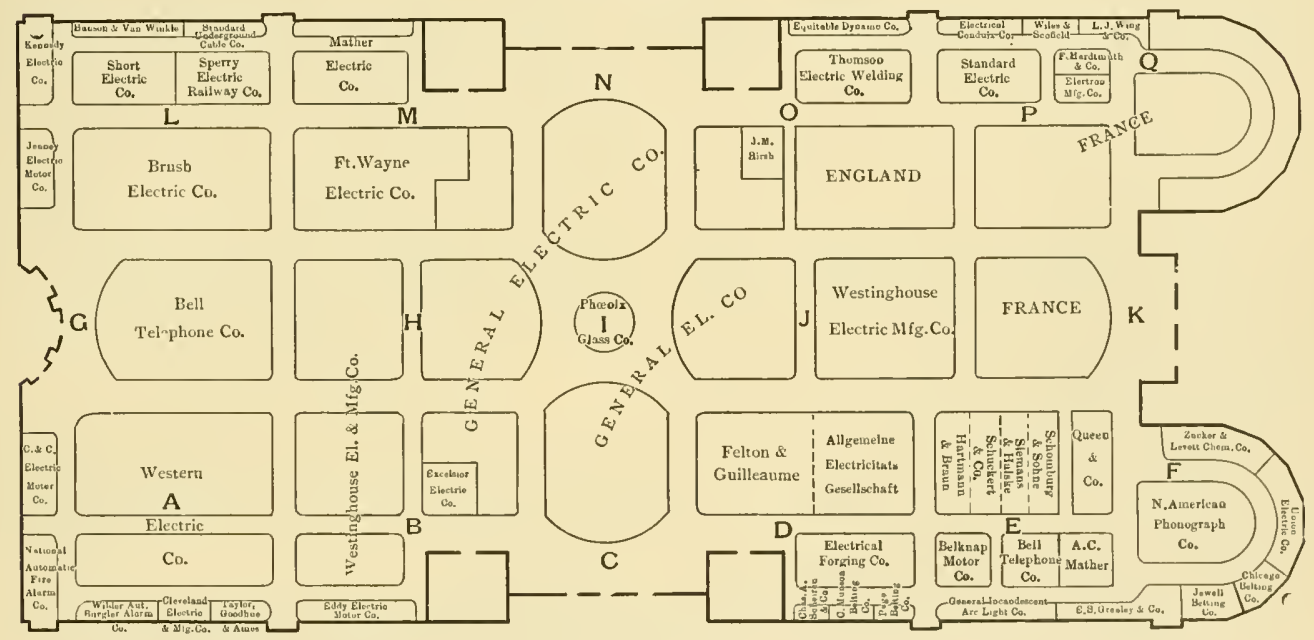

MAIN FLOOR.

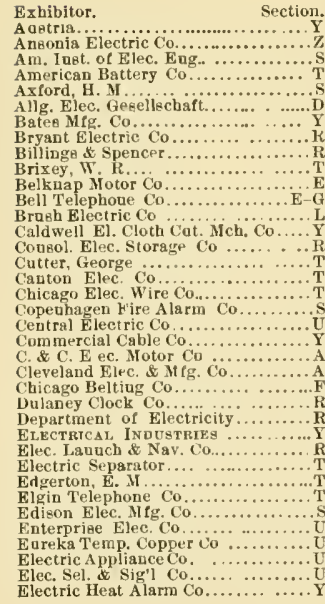

Exhibitor.

Section. Electrical Electricity................. Electrical Engiue Electrical world Eddy Electric Motor Electrical Forging Co. Eqaitable Dynamo hlektron M Ig. Co...... Electrica

Eugland ................. Empire China Works. Franklit Elec. A ppli Eelton Gailleaume.

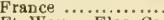
Ft. Wayne Eilec. Co Garmewel........... $-\mathrm{N}-\mathrm{C}-\mathrm{d}$ Greeley, $\mathrm{s}$ \& $\mathrm{Co}$ Germany

Habbard, $1 \mathrm{~m}$. \& $\mathrm{Co}$ Hirleman, C. J.............. Hart \& Hegeman Mfg. Co. Hope Elec. Appliance Co. Hal, Chad.

Holmed, $N$. S ........ Hanom $V$ Bn $W$ inki. Hirsb, J. Hardtmuth, F., \& Co

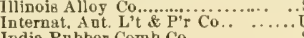

Section. Exbibitor.

Jaeger, Chas, L...... Jewell Belting Ca.......... Knapy Electrical Work'..... Knapp Electrical Work $\mathrm{A}$.... Knupp i Bockley ... Lawton, H. A. LeClanche Battery Co... Marcue, W. Melotosh Bat. d opt. Co Mutos Bal. Iather Mather Electric Co Newman Clock Co....... Non-Mngnetic Watch Co. National Carbod Co.. N. Y. \& L. E. A ............ Nat. Aut. Fire Alarm Co. Nat. Engraving Machine 10 Owen, Dr. $A$. hoenix Glasa Co. Galv. Co Pumpelly. J. K .................. Powell, $\mathrm{Wm}$. \& Co. Phelpe, A. H.......

Page Belting $C$

Queen \& $\mathrm{Co}$.
Section, $\begin{aligned} & \text { Exhibitor. } \\ & \text { Reliance Gunge Co............. Section }\end{aligned}$ Roessler \& Hasslacher Chem, Co....... Street Railway Journal.
Strowger Aut. Telph. Co... Standard Paint Co................. Sponbolz, C. L.

Star Iron, Toor co.

Spaiu.

chiereu, Chas. A. \& Co

Schomburg \& Sohne

Schuckert \& $\mathrm{Co}$

Short Electric Co.

Sperry Elec. Railway Co. Standard 5iectric Co.

Sameon Battery Co......

Tate A at. El. Signal C

Todd, A pplegate Co $\ldots . .$.

Taylor, Goodhne A Ames.....

Telaatograph, Elisha Gray

Union Electric Co

Vetter J. C. \& C

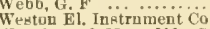

Wasbbarn \& Moen M $\mathrm{fg} . \mathrm{C}$

Write \& Bartlett Mrg Co.

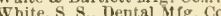

Western Electrician

Wilder Aut, Burglar Ai, Co.

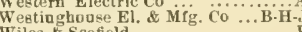

Wiles \& scofield

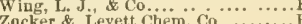




\section{PERSONAL.}

Mr. E. E. Bartlett, New York City, is in the eity and at the Fair this week.

Mr. A. L. Pareelle, E. E., Boston, was viewing the electrical exhibits last week.

Mr. Arthur Churchill, E. E., Schenectady, N. Y., visited the Electricity Building Monday.

Mr. G. Herbert Condict, Germantown, Philadelphia, was in Chicago and at the Fair last week.

Mr. Wm. S. Turner, E. E., New York City, is registered at the A. I. E. E. World's Fair office.

Mr. Wm. C. Cuntz, of the Pennsylvania Steel Co., Steelton, Pa., is visiting the Fair this week.

Mr. George Westinghouse and family are registered at the Hotel Wildemere and are visiting the Fair.

Mr. C. G. Young, New York City, registered last week at the office of the A. I. E. E., Electricity Building.

Mr. Harry Alexander of the Alexander-Chamberlain Electric Co., New York City, is at present in the city.

Mr. E. E. Davis, E. E., Newburn, Tenn., called on ElectricaI INDUSTRIEs during his stay at the Fair last week.

Mr. M. M. Kimble, of Claflin \& Kimble (Ine.), Boston, selling agents of the "Novak" lamp, is spending a few days at the Fair.

Mr. Feliks Rycerski, C. E., Warsaw, Poland, was last week devoting considerable time to the exhibits in the Electricity Building.

Mr. H. Ward Leonard, E. E., New York City, is registered at the World's Fair office of the American Institute of Electrical Engineers.

Mr. J. C. Boyd, supt. of the Jewett Car Co., Jewett, Ohio, is visiting the Fair this week on his way to the convention at Milwaukee.

Mr. J. H. MeGraw of the Street Railway Journal, New York, ealled at the Electrical Industries World's Fair office Monday of this week.

Mr. Geo. Manson who has been spending two weeks at the Fair has just returned east. Mr. Manson expresses himself as much pleased with his visit.

Mr. T. Ahearn, of Ahearn \& Soper, the Canadian agents of the Westinghouse Electric \& Mfg. Co., at Ottawa, Ont., is in the eity and at the Fair this week.

Mr. J. J. Carty of the Metropolitan Telephone Co., New York City, is visiting the Fair and making his headquarters at the Western Electric Company's exhibit.

Mr. B. E. Freene, publisher of Electricity, accompnnied by Mrs. Greene, spent the forepart of the week at the Exposition on his way from New York to the Milwaukee convention.

Mr. W. F. D. Crane, M. E., manager electrical department of the H. W. Johns Mfg. Co., New York, arrived in Chicago the latter part of last week, and is putting in his time sight seeing at the Fair.

Mr. Edward H. Chapin, formerly with the Street Railway Journal, and at present secretary and treasurer of the Shipman Engine Mfg. Co., Rochester, N. Y., ealled at the World's Fair office of Electrical Industries Tuesday.

Mr. Wm. H. MeKinloek, of the Metropolitan Electric Company feels that the outlook for business is encouraging, and sees the promise of liberal support for' a good, strong company conservatively managed. Evidence of this fact is fast multiplying.

Prof. George Forbes, F. R. S., the widely known electrical engineer of 34 Great George St., London, Eng., has opened an American office in the Mills Bldg., eorner of Wall St, and Broadway, New York. Mr. Horatio A. Foster is associated with him as chief assistant.

Mr. J. A. Corby finding that his other business interests require his eloser attention, has resigned the presidency of the Railway Equipment Company, and Mr. W. R, Mason has been elected to that office. The company is doing a large business in electric railway supplies, which will no doubt be greatly inereased in the near future.
Electric Railway Power Plant Equipment.

The transportation lines of Chicago were tested on Chicago Day as no systems of local transit were ever tested before and the companies acquitted themselves in a most satisfactory manner. The Chicago daily papers are the severest eritics when the matter of transportation is brought up, but in this case they are all united in their praises for the magnificent manner in which the crowds were handled by the companies. Although which the crowds were handed by the companies. Although an admirable manner, we believe the cross-town electric lines of the Chicago City Railway are at least entitled to be placed at the head of the entire list. Every possible car and man was placed on this line, and although the equipment is one of the finest in the country, they were utterly unable to meet the requirements of the crowds.

The cars were run as close as it was deemed practical and they were so crowded that every conceivable place was taken up, even so far as the windows and the tops of the cars. These lines moved more passengers per mile of track than any other line, and how they ever ran trains in such a erowd without injuring a person or a breakdown is a mystery. This is without doubt due to the carefulness and thoughtfulness of Supt. Bowen and Chief Engineer Hill in the selection of the equipment and the superintendence of the system.

As in every system of electric traction much depends on the successful operation of the power equipment. The generators and boilers were beavily taxed and the results obtained from the engines were everything that could be desired. These engines are in pair form with eylinders 24 inches in diameter by 48 -inch stroke, running 100 revolutions per minute.

These engines, which are of the improved Wheelock type, are equipped with Hill's patented valve system, which system allows the engine to be operated at a greater speed than the regular Corliss practice and also allows one to take steam to full stroke if necessity demands, thus obtaining a greater maximum out of a certain sized eylinder than is the usual practice. Power is transmitted direct to the driven shaft, on each end of which is a Westinghouse generator, by means of the Hoadley system of a Westinghouse generator, by means of the Hoadley system of is absolutely noiseless, and it was interesting to see how easily they performed their heavy duty on that day.

The above engines were manufactured and installed by the California Engineering Company, Hoadley Bros., engineers, who also installed the system of rope transmission. This company have also the exclusive right for manufacturing the improved Greene engine which embodies the latest patents of Mr. N. G. Greene. A 650-horse power tandem compound engine of this type is being installed hy this company for the Siemens \& Halske Electric Company in this city. The engine is directly connected to the armature shaft. The armature, which is 20 feet in diameter, runs 100 revolutions per minute and acts as a fly wheel.

\section{BUSINESS NOTES.}

The Filer \& Stowell Companx, Milwaukee, has recently gone into the manufacture of the improved Greene engine, improved Wheelock engine and Corliss engine together with a full line of power transmitting machinery. The company also manufactures friction clutches, pulleys, etc. A new catalogue has just been issued.

The Metropolitan Electric Conpany, offices 319-320 Manhattan Building, and salesroom 307 Dearborn St., recently organized,will makean announcement shortly as to the scope and general plan of the company. In the meantime they are receiving orders for general supplies and N. I. R. wire with which they are generously supplied.

The Central Electric Compans, Chicago, has listed among the new specialties recently placed on the market the Hammond cleat. This new device, it is said, is meeting with considerable favor with the trade and this company feels confident that it is a specialty that has come to stay as it is very practical. Special circulars bearing on this subject are sent out on request by the company.

The Electric Apptiance Company report that the opening of the fall season is causing a brisk demand among othes things for their celebrated Acme Expanding wire guard which they first placed on the market about a year ago and which, though comparatively an insignificant specialty, has proven to be a most suecessful seller. Its improvement over other wire guards for the protection of incandescent lamps lies mainly in the fact that it is easily and firmly fastened to a socket without any auxiliary fastenings or clips and is particularly light and symmetrical in appearance.

W. L. Adams \& Company, 84 Adams St., Chicago, have succeeded to the business of W. L. Adams. This change was made in order to secure additional facilities for handling the increased business. The firm is to do a business of manufacturing and selling everything necessary for the equipment, repairs and maintenance of electric railways. Owing to the long and practical experience of the members of the firm in the electric railway field together with every facility for filling orders with dispatch the new concern feel confident that they are able to anticipate the wants of the trade and by supplying goods of the highest character meet the most exacting requirements. 


\section{THE ATTENTION \\ OF THE}
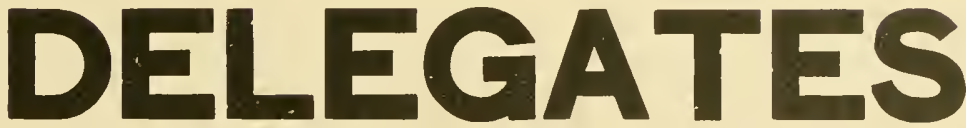

and others who attend the Convention of the American Street Railway Association in Milwaukee this week is called to the

\section{NEW OPEN and CLOSED CARS}

RECENTLY FURNISHED BY THE

\section{PULLMAN COMPANY,}

and now in operation on the Milwaukee Street Railway.

YOUR ATTENTION IS ALSO INVITED TO THE

\section{PULLMAN EXHIBIT}

at the World's Columbian Exposition as illustrated and described in this issue.

Address all correspondence to

\section{CONTRACTING AGENT,}

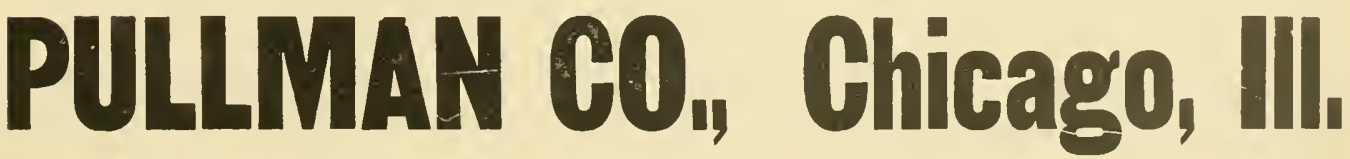




\section{Map of Chicago.}

Showing Location of its Electrical and Allied Business Interests, Principal Hotels, Theatres, Depots and Transportation Lines to the World's Fair Grounds. (Index numbers refer to the black squares.)

Ansonia E] $\mathrm{c}$ Co., Michigan Ave. \& Randoiph St....34 Cnshing \& Morse. 205 Dearborn St.....

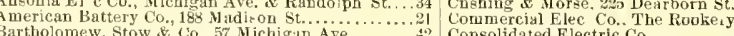
Bartholomew, Stow \& Co, 57 Michigin Ave... Benham, A. D., $200 \mathrm{~S}$. Clinton St. Brill Co., J. G., Phenix Blag....

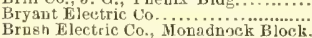
Buckeye Electric Co.. 437 Rookery Bldg. Calumet Electric Mfg. \& Engineering Co., 1 ir. s.

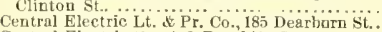
Central Electric Un., 118 Frankl in St.

29 Consolidated Electric Co........................

3 i. Unger El. Telephone Co., Stock Exchange Bid Detroit Electric日l Works, giz Jlonadnock Bl

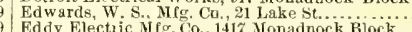

Eddy Electric Mfg. Co. 1417 Monadnock Block... Electric Construction d Sapply Co., Unity Bldg
Electric Appliance Co., 242 Mladiron St.................. ELECTRICAI INDUSTRiES PUB Co., Monadock Block.29

Ft Wayne Elec. Co 185 , Dearborn st.

Glohe Light \& Heat Co 50 Lake St ...

Chicago Arc Light d Power Co, Washington St. Ply- Gregory, Chas, E., Co.. $49 \mathrm{~S}$. Jeffereon S

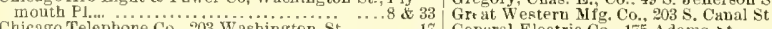

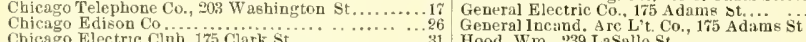

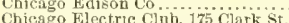

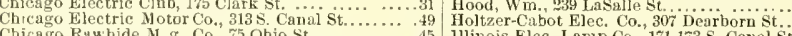

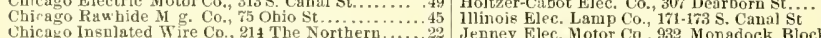
Claflin \& Kimball, 1001 Chamber of Commerce Bldg.27 Keystone Elec. Co., 3.5 S. Canal St

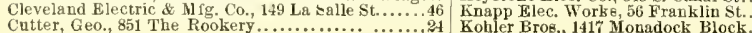

34 McDongall \& Cuumings, Unity Bldg

Co....................

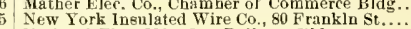
New York lnsulated Wire co, 80 rankln St...

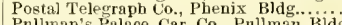
Pullman's Palace Car Co.. Pnllman Bldg..........44 Pumpelly, J. K., 205 S. Canal St................40 Phoenix Glass Cu., Wabash Ave. and Lake St......49 Railway Equipment Co.. Pullman Bldg... ..........48
Rockford Elec. \& $\mathrm{MIf}$. Co., 94 La Salle St........47 Standard Elec. Co.. 625 Home Ins. Bldg...........25 Star Elec. Lamp Co., 805 C̈hamber of Com. Bldg.....2\% Stirling $\mathrm{CO}_{\text {., }} 60^{\circ}$ Pndluno Bldg...................40 Sebieren, Chas, A., \& Co., $46 \mathrm{~S}$. Canal St..... …1 1 Short Elec. Rail way Co., Honadoock Block.......29
I aylor, Goodhne d Ames, 348 Dearborn St......28 Iaylor, Goodhne \& Ames, 348 Dearborn St.........28
Todd. Applegate Co., The, 310 Dearborn St.......28 Waddell-Entz $\mathrm{C}$. 1122 Monadnock Block............29 Westinghonse Electric \& $3 \mathrm{lg}$. Co, Pullman Bldg...40 Western Electric Co., 2,27 S. Clinton St............ 2 Western Union Telegrapb Co., Phenix Bldg..........23

38
4
20
17
42
43
44
40
9
8
47
59
9
7
1
9
8
8
9
40
2
4
33




\section{EXCLUSIVELY HIGH GRADE \\ ELECTRICAL SUPPLIES}

Our stock is complete in every particular. Our prices are as low as consistent with first-class material. Our facilities are unexcelled Our carcful personal attention to all orders is a fact. Our dealings are always satisfactory to our customers.

\section{ELECTRICAL SUPPLIES}

ELECTRIC APPLIANCE COMPANY,

242 Madison Street, CHICAGO.

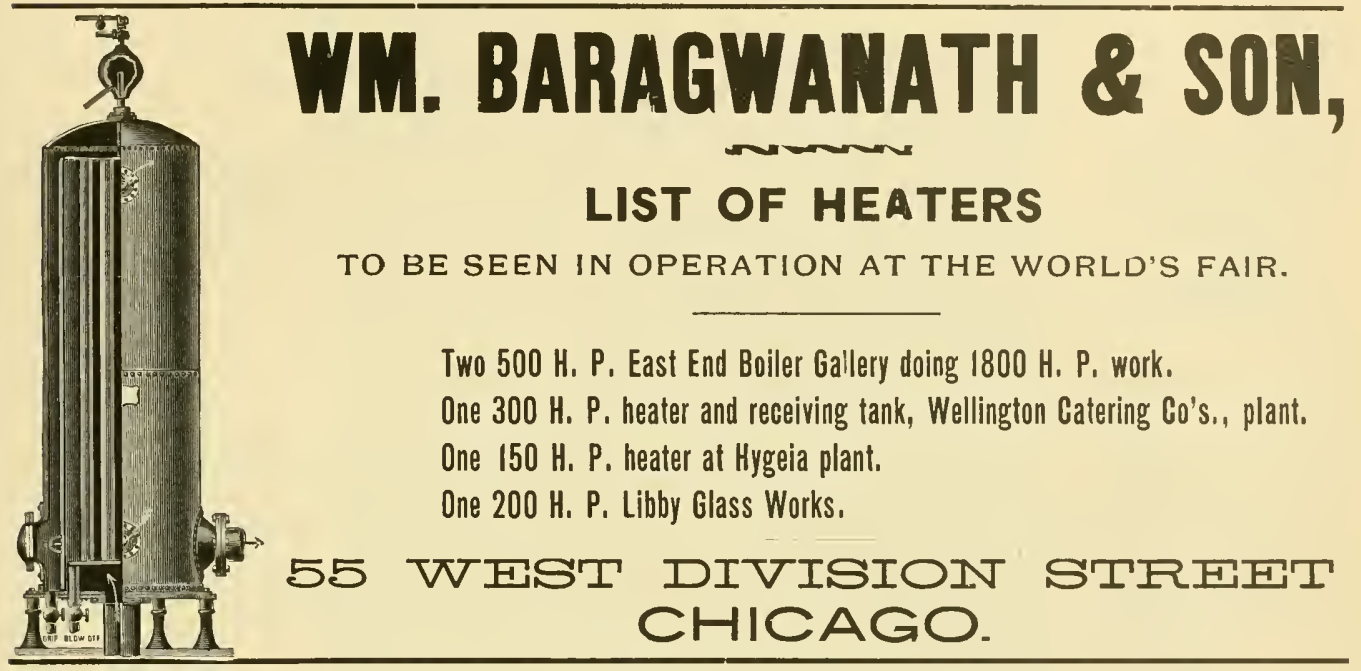

EVERY STREET RAILWAY MANAGER, SUPERINTENDENT AND ELECTRICIAN should read regularly the Monthly Issue of

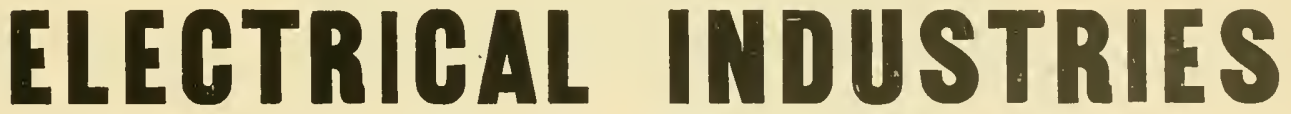

IT WILL GIVE YOU THE NEWS

IT WILL INFORM YOU HOW TO RUN YOUR PLANT ECONOMIGALLY AND THUS INGREASE DIVIDENDS

\section{Subscribe Now}

aND take adVANTAGE OF OUR SPECIAL OFFER to STREET RALLWAY MEN

All Delegates and their Friends are cordially invited to call and register at our Headquarte's. Section $Y 27$, Electricity Building when they visit the World's Fair. 


\section{CENTRAL ELECTRIC COMPANY, CHICACO.}

\section{STREET RAILWAY SUPPLIES.}

Construction Tools, Line Materials, PINS, BRACKETS, INSULATORS, ETC.

OKONITE FEED WIRES,

CAR WIRES, OKONITE and.. MUNSON TAPES,

ARE

THE

LEADERS,

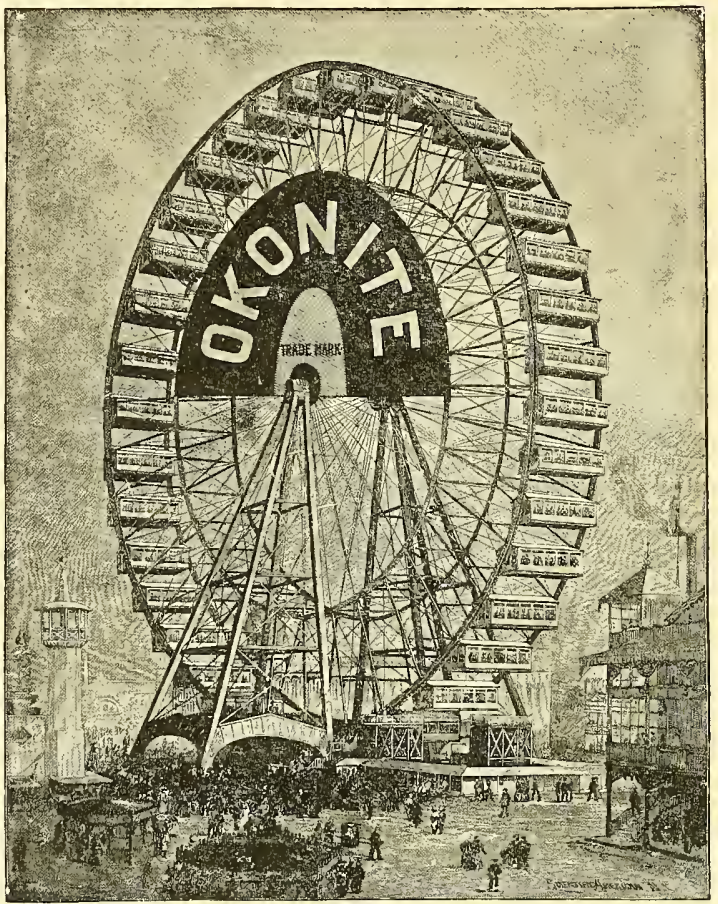

INGANDESGEMT LAMPS,

TIED

AND

FREE FILAMENTS.

LUNDELL MOTORS, FOR STREET RAILWAY CIRCUITS.

THE FERRIS WHEEL...WIRED WITH OKONITE.

Interior Conduit System of Electric Wiring. THE ONLY PFRFECT AND COMPLETE SYSTEM FOR INTERIOR WIRING.

STANDARD PAINT COMPANY'S Celebrated P. \& B. Electrical Paints and Compounds carried in Stock. ELECTRIC LIGHT CARBONS FOR ALL SYSTEMS. .

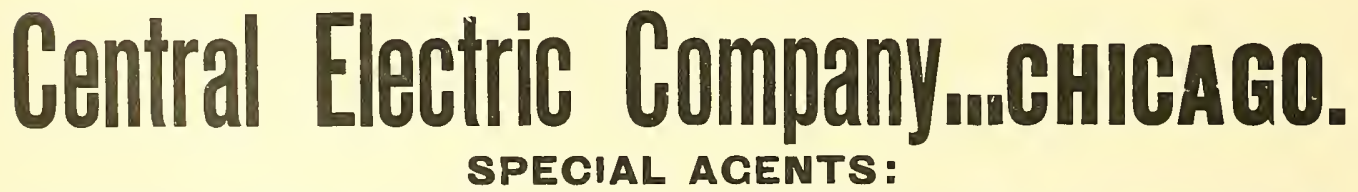

SOUTHERN ELECTRICAL SUPPLY CO., St, Louis, - GATE CITY ELECTRIC CO., Kansas City, Mo, 
THE ONLY STORAGE BATTERY

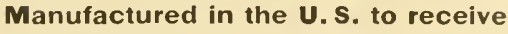

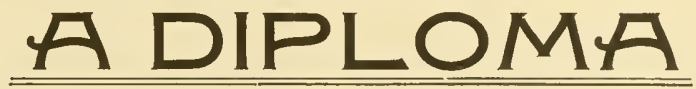

AT THE WORLD'S COLUMBIAN EXPOSITION, CHICAGO.

The following is a copy of the Award given by the Judges of Storage Batteries at the World's Columbian Exposition, Chicago, 1893 , to the only storage battery made in this country deemed worthy of any notice whatever:

"We affirm that the 'American' battery has been examined and tested by us, and found worthy of an award for its excellency of design and construction, and for its efficiency and indications of durability."

(Signed) WILBUR M. STINE. W. LOBACH.

THE “AMERICAN" STORACE BATTERY IS EFFICIENT AND DURABLE.

ITS ACTIVE MATERIAL IS FORMED FROM ITS OWN SUPPORT.

ITS PLATES WILL NOT BUCKLE UNDER ANY CI PCUMSTANCFS.

GUARANTEED TO BE SUPERIOR TO ANY OTHER MADE.

Estimates furnished on application for complete storage battery.

EQUIPMENTS FOR GENTRAL STATIONS, ISOLATED PLANTS, DRAIN LIGHTING, TRACTION AND BOAT WORK,

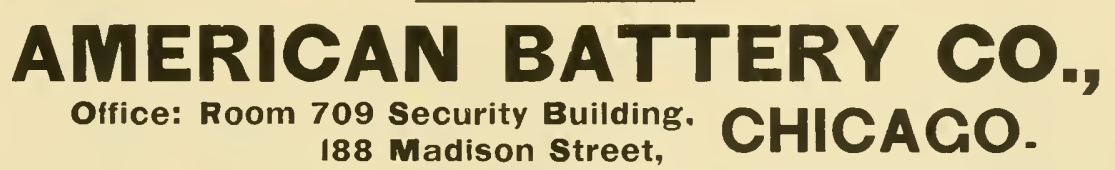

\section{W. \\ ADAMS \\ \& $C$ C.}

Manufacturers and Dealers in

\section{RAILW AY

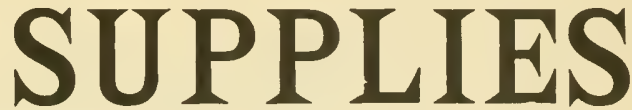

CAN FURNISH YOU WITH ANYTHING FROM A SPIKE, TO THE COMPLETE EQUIPMENT FOR AN

\section{ELECTRIC RAILWAY,}

AT PRICES CONSISTENT with FIRST CLASS MATERIAL.

Let us make you quotations; You will save money.

GENERAL OFFICES, 84 Adams Street, CHICAG0. 


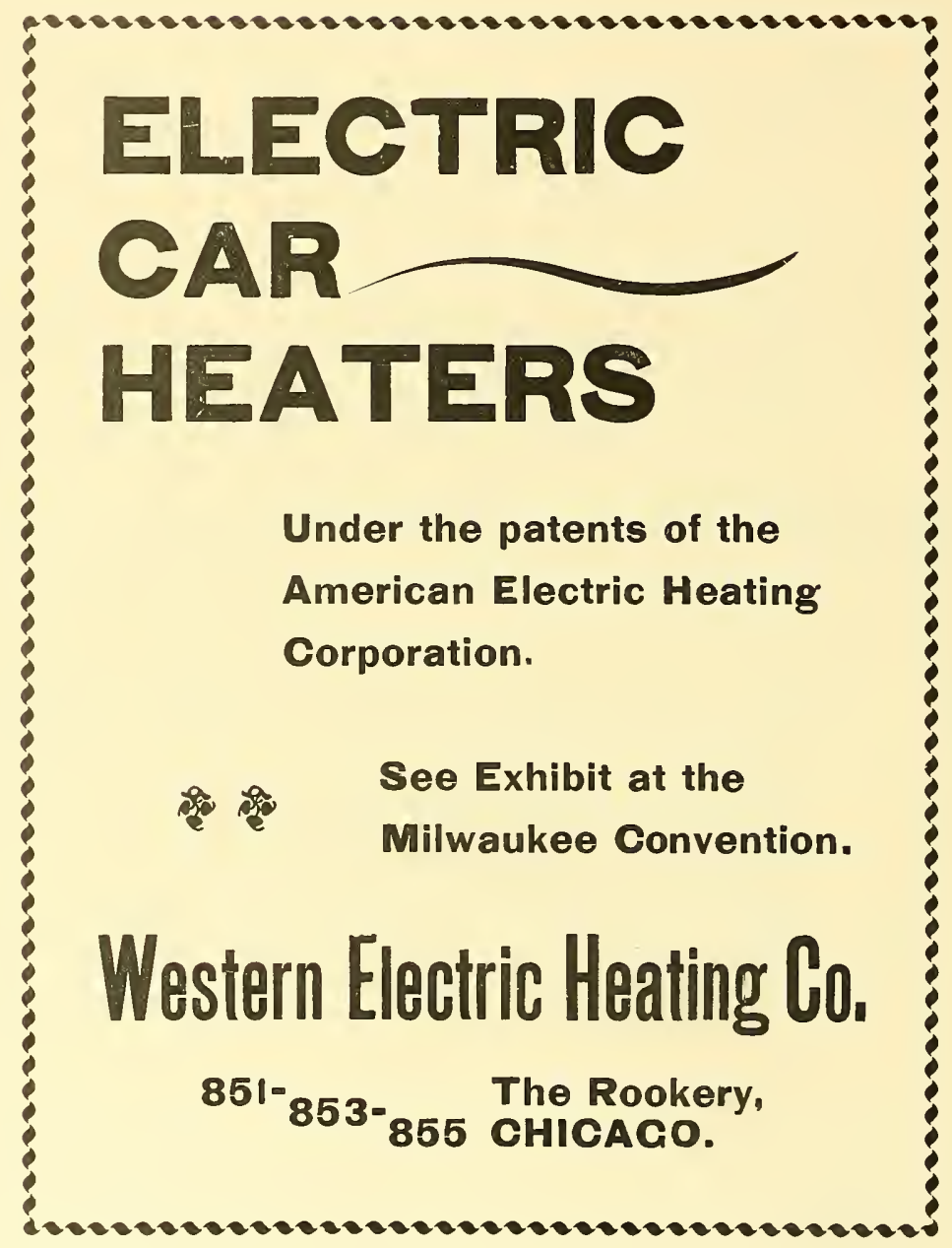




\section{Westinghouse}

Electric ${ }^{\text {and }}$.Manufacturing

$$
\text { Company Pittsburg, Pa. }
$$

USERS OF OUR

Electric Railway Apparatus unanimously attest its

ELECTRICAL and MECHANICAL SUPERIORITY.

Get Our New Pamphlet of Testimonials,

Many statements which fully emphasize the fact, that the

WESTINGHOUSE SINGLE REDUGTION MOTOR, GENERATOR, and all other

\section{Electric Railway Apparatus}

is the BEST in point of

CONSTRUCTION, DURABILITY, EFFICIENCY.

and low cost of maintenance.

Westinghouse Electric an Manufacturing Co. PITTSBURGH, PA. 


\section{THE GREAT VARIETY OF}

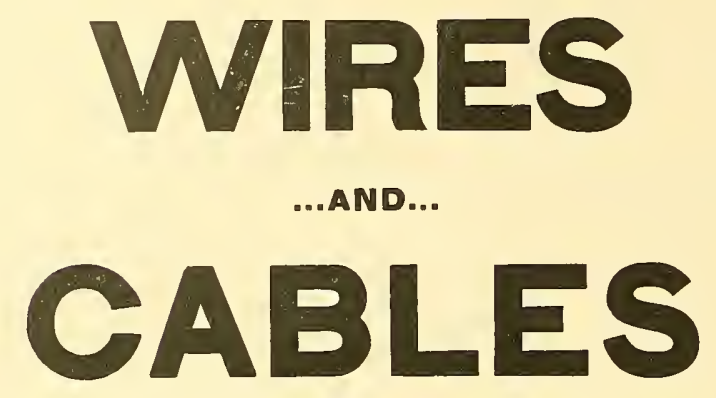

EXHIBITED BY THE

\section{WESTERN ELECTRIC GOMPANY}

AT THE...CONVENTION...OF THE

\section{AMERICAN STREET RAILWAY ASSOCIATION ...AT... \\ Milwaukee}

ARE WORTHY THE CAREFUL INSPECTION OF EVERY

Electric Street Railway Man.

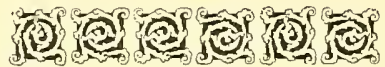

\section{Western Electric Company CHICAG0.........NEW YORK}


COMPANY, NEW YORK.

192 Broadway and II John Street.

MANUFACTURERS OF ARC LIGHTING APPARATUS FOR EVERY PURPOSE A SPECIALTY. The CLARK ARG LAMPS for use on EVERY CURRENT, have the reputation of being the best and most durable of any ever made in the United States.

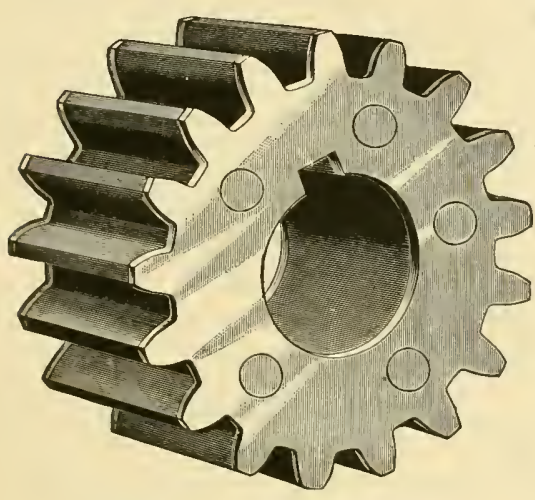

\section{RAWHIDE PINIONS FOR ELEGTRIC MOTORS} A SPECIALTY.

RAWHIDE DYNAMO BELTING

Greatest Adhesive Qualities. A Non-Conductor of Electriclty. Causes Less Friction than any other Belt.

\section{THE GHICAGO RAWHIDE MANUFACTURING GO.} THE ONLY MANUFACTURERS IN THE COUNTRY.

\begin{tabular}{|c|c|}
\hline $\begin{array}{l}\text { LACE LEATHER ROPE } \\
\text { IND OTHER RAWHIDE }\end{array}$ & $\begin{array}{l}\text { This Belting and Lace Leather is } \\
\text { not affected by steam or dampness; } \\
\text { never becomes hard; is stronger, }\end{array}$ \\
\hline $\begin{array}{l}\text { GOODS } \\
\text { OF ALL KINDS } \\
\text { BY KRUEGER'S PATENT }\end{array}$ & $\begin{array}{l}\text { more durable and the most econom- } \\
\text { ical Relting made. The Raw- } \\
\text { hide Rope for Round Belting } \\
\text { Transmission is superior to all } \\
\text { others }\end{array}$ \\
\hline
\end{tabular}

\section{Standard Electric Company.}

GENERAL OFFICES: 625 Home Insurance Building.

WORKS: So. Canal Street,

\section{CHICACO.}

\section{STANDARD SYSTEM AT THE

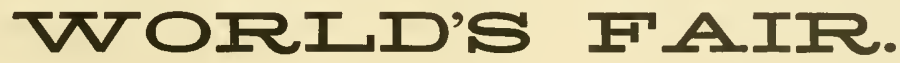

MACHINERY HALL, Sec. Q, 2 Standard Arc Dynamos.

Sec. S, 20 " " “

ELECTRICIT Y BUILDING. Sec. P, Space 2, Arc Lighting Exhibit.

The Standard Lamps Light the Power Plant, Machinery Hall, Agricultural Hall, Shoe and Leather Building, and Other Buildings and Portions of the Grounds. 


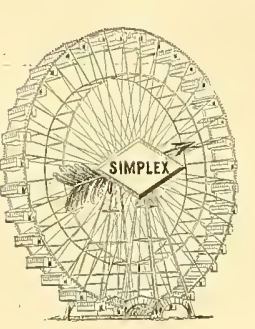

Mile after mile of

SIMPLEX WIRE

Supplied to the

FERRIS WHEEL $\bullet \bullet$

By...George Cutter,

The Rookery, chicago.

\section{SIMPLEX WIRES}

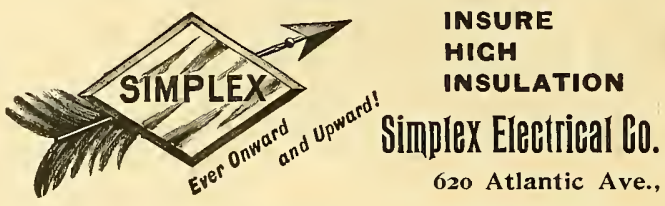

George Cutter, Chicago. BOSTON, MASs.

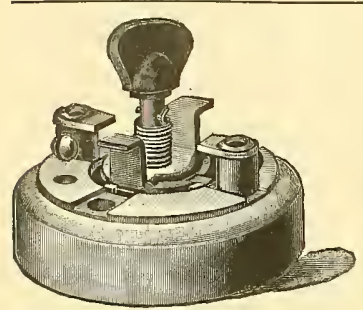

Made 5 amip. S. P 10 amp. 3 way.

\section{XNTRIC}

"That's the Switch"

And we control that movement.

H. T. PAISTE, 10 South 18th St., PHILADELPHIA, PA.

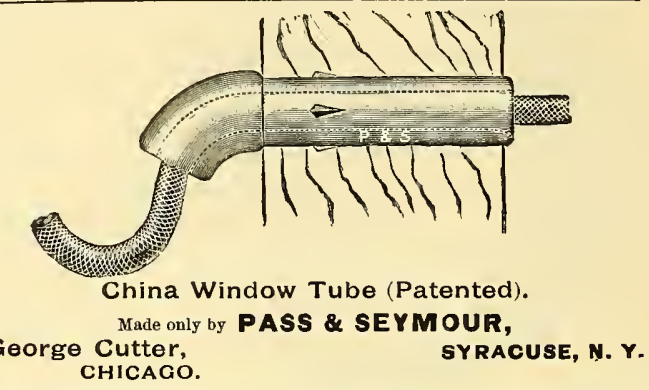

\section{Enterprise} Electric

207 Dearborn Street. Chicago .....
Manufacturers' Agents and MiIl Representatlves for

Electric Railway,

Telegraph, Telephone and Electric Light

SUPPLIES or rever

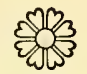

Agents for

Cedar Poles,

Cypress Poles, Oak Pins,

Kocust Pins, Cross Arms, Class

Feeder Wire,

Insulators,

WIRES, CABLES, TAPE and TUBING
Miamisburg Electric Co,

MANUFACTURERS OF

COMMUTATORS

AND

COMMUTATOR SEGMENTS OF TEMPERED COPPER

\section{FOR STREET RAILWAYS}

Also Brushes and Brush Copper, Burnley's Cartridge Batteries and Imperial Diy Batteries.

See our Exhibit at the Street Railway Convention, Milwaukee. Section A, Exposition Building.

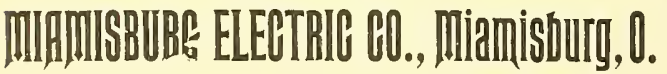

\section{BEAR IN MIND}

that the regular monthly issue of ELECTRICAL IN. DUSTRIES contains the most complete and correct directories published of the electric light central stations and the electric railways in North America.

World's Fair Headquarters Y 27 Electricity Building.

CITY OFFICES, Monadnock Block.

Consolidated Elpctric (6.

Man afacturers and Dealers in all kinds ol

ELECTRICAL . SUPPLIES,

115 Franklin Street, 


\section{WEEKLY WORLD'S FAIR}

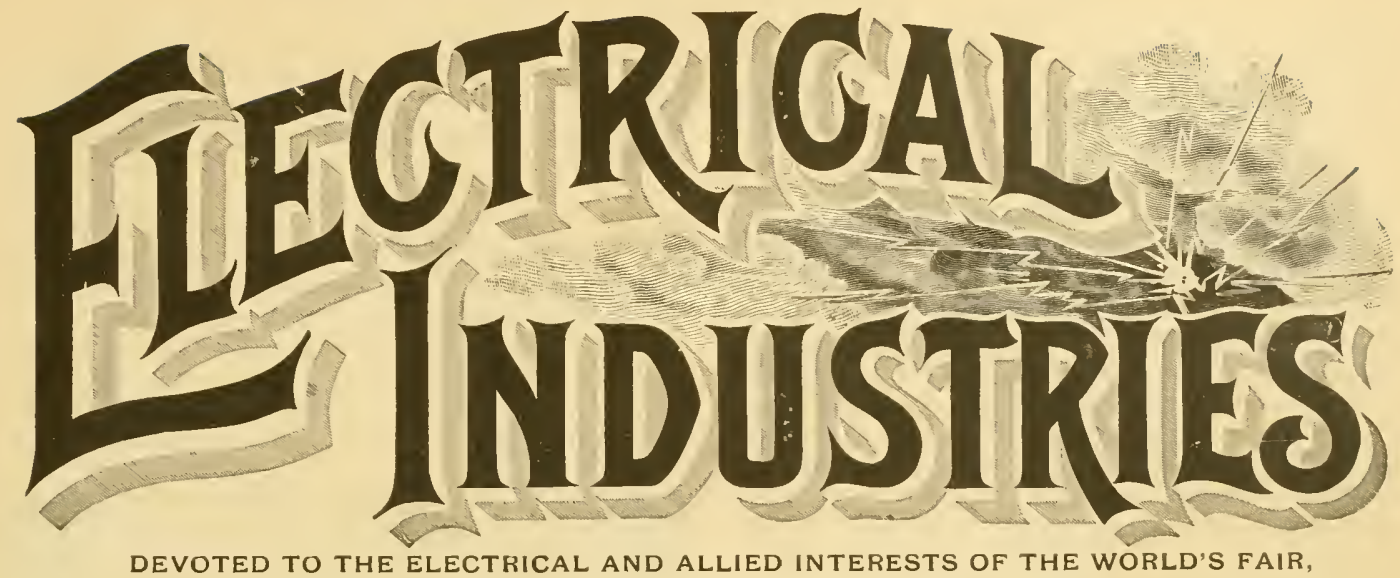

ITS VISITORS AND EXHIBITORS.

Vol. I, No. 20.

CHICAGO, OCTOBER 26, 1893.

FIVE MONTHS \$1.00
TEN CENTS A COPY

The Exhibit of the Mather Electric Company in the Electricity Building.

In the southwestern part of Electricity Building, Section M, is located the exhibit of the Mather Electric Company. It covers nearly 4,000 square feet of floor space which is filled with sample machines and devices from the exten- merous illuminated signs and attractive devices, drawing the attention of the visitor to the company and its products. One of the most conspicuous and ornamental featunes of the exhibit is a large horse-shoe shaped magnet representing the Mather patent ring type field which is a trade mark of the company. The magnet is 12 feet in diameter, mounted on a base 10 feet long. The ring field

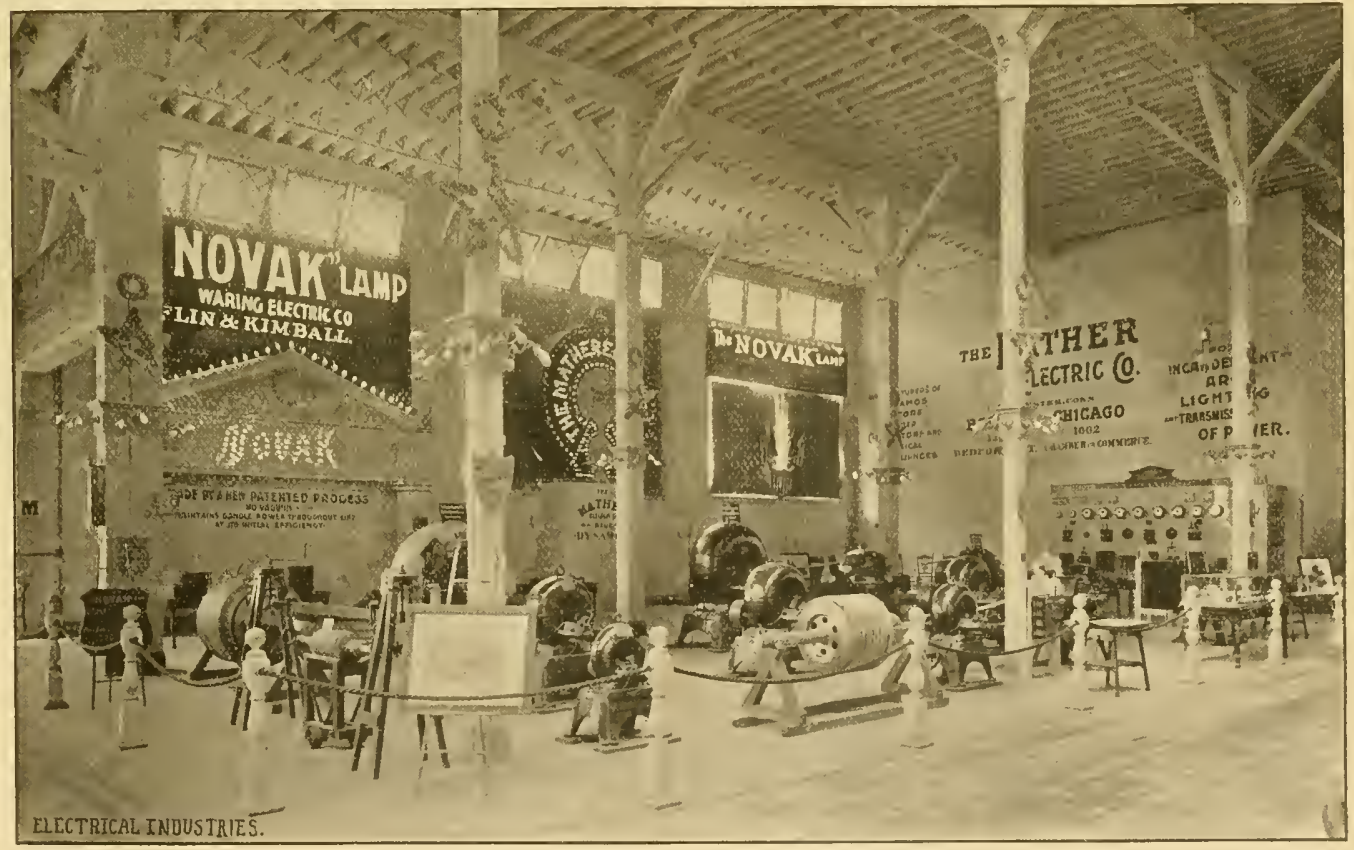

EXHIBIT OF THE MATHER ELECTRIC COMPANY.

sive works at Manchester, Conn. The space is floored with matched pine flooring, a portion of which is raised for an office. The machines and apparatus are symmetrically a rranged about the space. The special fittings and parts of machines showing the construction of commutator journal boxes, journal bearings, self-oiling boxes, etc., are neatly arranged on long polished oak tables.

The walls back of the space have been concealed by nu- and pole pieces are delineated by blue and red lamps, while the words the Mather Electric Company are delineated in white opal lamps. By a special device different colors are shown alternately, then together, producing a pleasing and artistic effect.

On the north wall above the switch board is a large sign covering some 600 square feet, giving the name of the company, its principal offices, the principal products man- 
ufactured, and their applications. Distributed about the space are easels holding views of the works of the company at Manchester, Conn., and also some of the prominent buildings which are using the Mather system. Among the other attractice features of the exhibit is the handsome and interesting display of Novak lamps made by Clatlin \& Kimball, (inc), the general sales agent for the Novak lamp. This display has attracted a great deal of attention and has aroused more than usual interest among the many visitors.

For lighting the exhibit there are 80 incandescent Novak lamps of 16 candle power fed from a 110 volt circuit. The lamps are distributed on brackets and chandeliers of plain but very neat design. The space is marked by a very neat railing made with turned posts, painted in white and gold, through which a worsted cord of Venetian red color is gracefully looped, forming the rail. The dynamos exhibited are of the Mather patent ring type of constant potential, continuous current, compound wound pattern of sizes varying from three and a half to 55 kilowatts. These machines are all wound for a potential of 125 volts and are complete with bases, rheostats, etc.

The 55 and 10 kilowatt machines are in operation, furnishing the current for all the incandescent lights used for lighting and decoration abont the exhibit. The current furnished has a potential of 110 volts from a speed of 750 revolutions. The seven kilowatt machine is also connected so as to be used when a portion of the incandescent lamps are desired for lighting purposes. There is also one multipolar slow speed, compound wound, continuous current, dynamo wound for a potential of 125 volts and having a capacity of 17 kilowatts, shown complete with base and rheostat.

An electric power generator of the multipolar, compound wound, constant potential type with a capacity of 125 kilowatts is shown. It is wound for a potential of 550 volts at a speed of 525 revolutions per minute. These generators are said to have a commercial efficiency of over 90 per cent, and to regulate absolutely from no load to full load. The mechanical part of their construction and equipment is of the latest designs, the generator is set on an iron base, fitted with four screws, connected together in pairs by means of a chain and worked by ratchets so as to control the alignment of the machine and the tension of the belt. These machines have also a rheostat of suitable capacity and a commutator turning device adjustable on the base of the machine.

Electric motors are shown of a variety of sizes and of different types. There are two multipolar self-regulating motors having a capacity of 50 -horse power each and wound for a potential of 250 volts. These motors have been operated in series on the 500 volt circuit supplied by the Mather Electric Company generators in Machinery Hall and are belted to run the 55 kilowatt dynamo mentioned above. The motors are connected through an automatic starting box which is wound for 500 volts. A 10 -horse power motor is also run from this power circuit and is belted to the seven kilowatt dynamo.

There is also shown in the exhibit a six-horse power wound for 220 volts and a one-horse power motor wound for 110 volts. The latter runs a commutator device used for operating the changes in the lighting of the illuminated signs.

Among the other machines exhibited is the company's latest style of armature for electric power generators. This is of the ventilated type and is designed for a 225 kilowatt machine. This armature has a slotted core and is built of copper bars. The winding is such that there are only two paths for the current through the armature which are always maintained at the same potential. The commutator is cross connected, and it is possible to use either all the sets of brushes or any two sets as may be desired. The generators for this armature are built with six poles and carries six sets of brushes. The armature for an electric power generator of 120 kilowatts capacity is shown wound with wire on the same principles as the one above described. There is also shown armatures for smaller generators and a number of field coils.

At the north end of the exhibit is placed a switchboard on which are placed the instruments and devices for

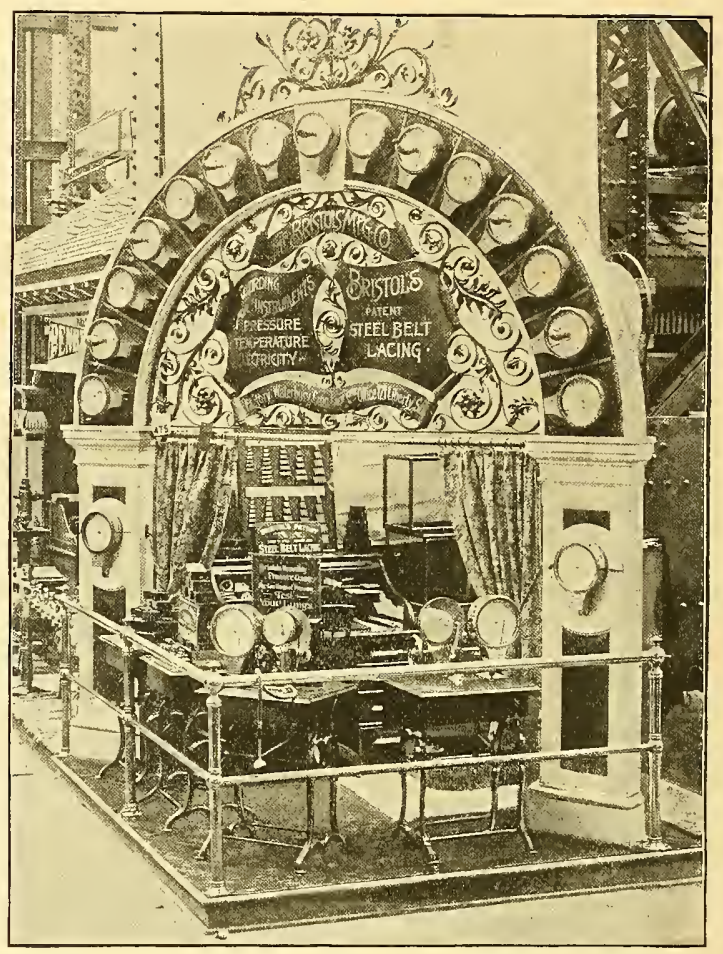

F1G. 1.-RECORDiNg 1XSTRUMENTS EXHIBITED BY THE BRISTOL Co.

controlling the current used in the exhibit. The board is of white Tennessee marble from the marble works of Davidson \& Sons, Chicago. The frame in which it is mounted is neatly ornamented and finished. The instruments, switches and fittings displayed on this board are all of the Mather company's manufacture. There are used on the board a number of magnetic vane ampere meters both large and small, also volt meters, a differential indicator, three volt meter switches, both single and double pole switches and cut outs, etc.

The rheostats for the dynamos are also mounted on the board. For protecting the circuits an automatic circuit breaker is used, adjustable from 100 to 600 amperes and suitable for any voltage up to 600 volts. They are said to act within 10 amperes of the quantity for which they are set, breaking off current absolntely and thus affording complete protection to the circuits. This exhibit which the Mather company has installed shows in a comprehensive way the various electrical machines and appliances which 
the (:)mpany manufacture. The line of goods for power aud lighting stations is completes and are all of a commercial eharacter. The machines show skill in their construction and careful attention to detail and are worthy of the attention of electric light and power users.

\section{Recording Instruments Exhibited by the Bristol Manufacturing co.}

The new recording volt meters exhibited by the Bristol Manufacturing Company are attracting a great deal of attention, notably those used in connection with the incandescent lamp tests made by the Jury of Awards. The main exhibit made by the company is loeated in Machinery Hall Section 25 and contains not only recorling volt meters but also instruments for reeorling the pressure of air, gas, steam, water, and any liquid. The range of pressure runs

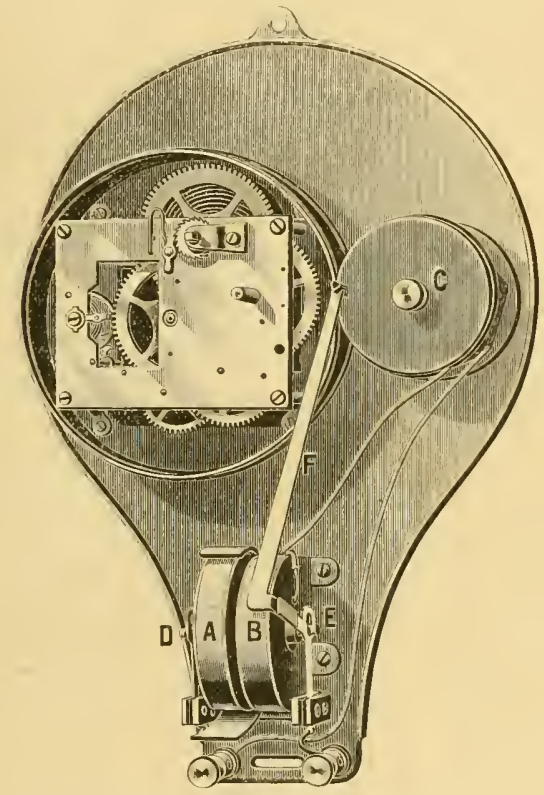

F1G, 2,-IECORDING INSTRUMENTS EXHIBITEU BY THE BRISTOL CO

from zero to fifteen hundred pounds per sifuare inch and adapted to record continuously day and night.

Erected diagonally across the space is an arch in imitation of eut stone; on the face of each is attacheel one of their gold plated recording gauges, every alternate one being provided with an electric light. On one of the pillars supporting the arch is a gauge which records the pressure of the steam used in the building. On the other pillar is phaced one of their new recording volt meters which records the voltage of the current used by the lamps in the exhibit. Within the arch is a semi-eircular grille of wrought iron of an ornamental design which bears the name of the company and its specialties.

About the space there has been arranged on tahles so that visitors may examine them, sample recording instruments among which is shown the new recording volt meter illustrated in the accompanying cuts which show the internal construetion and also the exterior appearance of the instrument. The coil A of Fig. 2 is mounterl on the spring knife edge supports D and $\mathbf{E}$ and is free to move toward the parallel and stationary coil $\mathrm{B}$, when they are mutually attracted to each other by a current passing in series. The current is condineted to the moveable coil A through the supporting springs D and E, which together with the special feature of the moring coil $\mathrm{B}$ mounted on frictionless spring knife edges renders the instrument extremely sensitive to the smallest change of voltage.

The marking arm $\mathrm{F}$ is attached directly to the spring $\mathrm{E}$ and partakes of its motion recording the changes of voltage on a uniformly revolving chart. This chart shown in Fig. 2 is intender for 110 volt circuit and as will be noticerl the divisions on the chart are on an increased scale in the vicinity of the voltage to be maintained. The variation of one volt is possible to be in this way noted. The coil $\mathrm{C}$ is an anxiliary resistance with the alternating current volt meter; the auxiliary resistance is furnished in a separate rheostat which may be adjusted to suit the rate of alternations of the current to be measured. One of the specialties

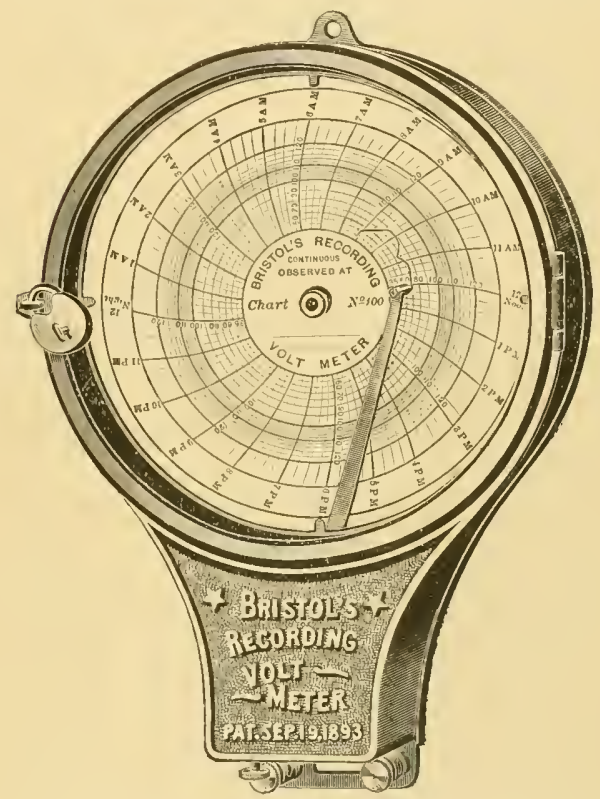

FIf. 3.-TECORDING INSTRUMEXTS EXHIBITED BY THE MKISTOL CO.

shown in this exhibit which is also manufactured by the Bristol Manufacturing Company of Waterbury, Comn, is Bristol's steel belt lacing which is shown in a variety of ways. This company since its establishment in 1859 has developed an extensive business in these lines of goods.

The people of Chicago are getting used to the blockarles incident to the increased number of trains on the street railwas these World's Fair days, but, even to those of us who retain our seats in the cars for ten or fifteen minntes "waiting for them to start," the sight of crowded cars that never will start looks strange. One can see this sight almost any evening in the Westinghouse exhibit in the Electricity Building, where (a Stephenson and a Brownell) cars are filled with tired sightseers glad of a place to rest for a few minutes.

The Jury of Awards met last Saturlay, but as only four members were present, and the rules eall for a quorum of five, no business was transacted. The next meeting will bo held on Saturday of this week. This will probably be the last regular meeting of the jury. 


\title{
ELECTRICAL INDUSTRIES.
}

\section{ELECTRIGAL INDUSTRIES PUBLISHING COMPANY,}

\author{
INCORPORATED 1889 \\ MONADNOCK BLOCK, CHICAGO. \\ TELEPHONY HARMISON 159 \\ E. L. POWERS. PRes. AND TrEAs. \\ E. E. WOOD, SECRETART.
}

\author{
E. L. POWERS, \\ W. A, REMINGTON \\ E. E. WOOD, \\ FLOYD T. SHORT,
}

Assoctate EDitor.

Eastern MaNager.

ADVERTiaino Depamtant

EASTERN OFFICE, WORLD BUILDING, NEW YORK.

World's Fair Headquarters, Y 27 Electricity Building.

FIVE MONTHS, SINGLE COPY,

Äavertising Rāes Ūpon Application.
$\$ 1.00$

10 Visitors are earnestlv desired for publication in these columns and will be heartily appreciated. We especiall $\mathrm{v}$ invite all visitors to call upon u or send addrcss at once upon their arrival in city or at the groumds. ELECTRICAL INDUSTRIES PUBLISHING CO.,

After carefully considering the matter, it has been officially decided that the Fair will close promptly Oct. 30th, the time appointed by Congress. It was thought that the at tendance might be so great that it wonld be necessary to hold open a short time in November, but when it was found that this could not be done legally it was decided to officially close on the day prescribed; consequently the work of taking away exhibits will begin early next week, althongh the public will be admitted to the grounds and buildings during the day for some time yet. In the Department of Electricity exhibitors are beginning to get in a hurry to pack up exhibits at the earliest possible moment. No one can look at the exhibits, the grounds and the buildings without feeling deep regret that within a few days the work of clemolition will begin. The fact, however, that the Fair has been the greatest success of anything attempted in modern times is a thought that brings some consolation.

The California Mid. Winter Fair will receive many exhib. itors and concessioners from the World's Columbian Ex position. Many of the concessioners are preparing to go to San Francisco as soon as Jackson Park is closed. The Fair at San Franciseo will be visited largely by those who have not visited the World's Fair at Chicago. The great distance has allowed but few from that section of the country to visit Chicago and should the winter be favorable their holiday will be spent at Golden Gate Park. The annual meeting of the National Electric Light Association will bring many of those interested in electric lighting together who have not previously attended the meetings of the association. To a large number of manufacturers this is an entirely new field which will become more and more valuable as the country is dereloped. No more favorable opportunity will present itself than the one offered the coming winter. Many manufacturers have exhibits of such a kind as are easily moved and many constructed especially for exhibition purposes which could be transferred at little expense to San Francisco, whilc if they were pre- paring new exhibits the expense would be many times as great.

\section{The Street Railway Convention.}

The 12th annual meeting of the American Street Railway Association, which was held at Milwaukee last week, was well attended. 'The preparations for the convention had been carefully made, and to the Milwaukee Street Railway Company and the citizens of Milwaukee the association is indebted for its $p$ leasant reception and many marks of attention during its stay in the cream eity. The papers read were fully up to the stanclard, and sereral called forth lively and interesting cliscussions. This is specially true of the paper read by Mr. E. G. Connette on Power House Engines. The great attractions of the World's Fair greatly lessened the attendance toward the close, many leaving for Chicago before the convention ended. Owing to the enormous passenger traffic of the railroads, the railroad yards and side tracks are full of freight waiting to be moved, and on this account a great many manufacturers of railway apparatus were unable to exhibit their goods as they had intended. Many although greatly disappointed at not receiving their goors made the most of the situation and established headquarters in the exposition building at their hotel where they could meet their friends. The tendency toward consolidation is noticeable in the report of the executive committee, which shows that 10 roads formerly members of the association have been absorbed by other companies. The consolidation of the roads of a city has its advantages to the roads themselves and to the public in general, still it often has objectionable features. The convention elosed Friclay. The next meeting is to be held at Atlanta, Ga.

The banquet at Milwaukee Thursday evening at the Pfister Hotel was attended by 256 Jadies and gentlemen. At the table of honor sat the newly elected president, $\mathrm{Mr}$. H. C. Payne and the new executive committee of the association. At Mr. Payne"s right sat Mrs. Payne while on his left sat the Rer. Judson Titsworth. The banquet hall was on the serenth floor of the hotel. The floral decorations were elaborate and of handsome and appropriate designs. The banquet was well planned and all roted it a great success.

Ex-president Longstreet acted as toastmaster and to the first toast. "Transportation and Civilization" Mr. J. C. Flanders responded. In his remarks he called attention to the facilities for rajid transit and said that the annual saving to the four billion passengers carried annually, by the introduction of electricity was a million hours. which if calculated in dollars and cents would show a large amount of money which the public owes to street railway managers "Street Railway Employes and the Public," responded to by Mr. Ogden H. Fethers was heartily appreciated and received great applause. Mr. Winfield Snith responded to "The Early Days of Street Railways" and Mr. H. H. Windsor to "The Street Railway Man of the Past, Present ant Future." Mr. Horace Rublee upheld "The Press " and Mr. J. Harrey Stedman read an original poem.

One of the mementoes of the banquet was a souvenir spoon for each guest of sterling silver. In the bowl of the spoon was a representation of President Paynes private car, to whom the delegates were indebted for this further evidence of Milwankee's hospitality.

The tests of incandescent lamps will probably be com pleted on Saturday. The results of the tests will be announced about the first of next year. 


\section{CONVENTION NOTES.}

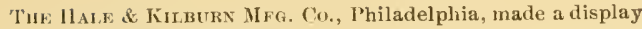
of car seats of several styles.

Hr. 1. H. STromas, Rochester, N. Y., was on hand with several new styles of transfer tickets.

Tur: Garton-Danikus Er.Ectric Co., Keokuk, Jowa, had several of their lightning arresters on exhibition..

Tue Curtis Electric Motor Co., Iersey City, had a truck equipped with the Curtis motors on exhibition.

Tife Graham Eqminent Compans, Boston, Providence and Chicago, were represented by Mr. J. H. Graham.

'TuF, Pawtucke Brass Fonndr, Pawtucket, R. I., showed motor bearings of its manufacture of several sizes.

Tue Daris Car Shade Company, Portland, Me., had a number of shades on model frames showing their operation.

Mir. C. S. VAN Nurs, of New York, was present and distributed a great many fac simile Ajax lightning arresters.

Tue I'inkham CAR-Track Sander Co, of Boston, Mass., displayed in the exposition building its electric sand box.

Tuk EoIson MFg. Co., of New York, had on exbibition a number of Kennelly standard volt meters showing the construction and points of excellence.

Tin Girbs Electric Companr, Milwaukee, had several trolleys complete, trolley wheels and line supplies on exhibition.

Tine Taylok Erectric Truck Co., Troy, N. Y., had on exhibition a Taylor truck and was represented by Mr. Taylor.

The Burnowes Car Shade Co., Portland, Me., was represented by Mr. John II. Baker, who had a number of shades on exhibi. tion.

L. Katzexstein \& Co., New York, had on exhibition a number of journal boxes, showing the use of Katzenstein's metallic packing.

The Walker-Marshali. Automitic świtch Co, Milwaukee, made an exhibit consisting of the Walker-Marshall automatic switches.

The American Arch. Iron and Brass Works, Chicago, displayed Robinson trolley wheels of which this company are the manufacturers.

Mr. W. E. Luduow, Cleveland, Ohio, displayed a new combined step and gate. When not used for a step it acts as a gate and vice versa.

Tine Cutter Electrical \& MFG. Co., Philadelphia, had an exhibition board erected on which were displayed magnetic cutouts, rh eostats, etc.

The R. D. NutTal. Co, Allegheny, made an exhibit of gears, pinions and trolleys of the design which has become well known to street railway men.

The Empje State Radal Truck Compani, Cleveland, Whio, had trucks on exhibition. Mr. Pfetsch of the eompany was present at the convention.

II ARrison \& CAREY, Chicago, agents for the IV. T. C. Macallen Co.. of Boston, had on exhibition circuit breakers, cross overs and general line supplies.

The Tousher Trohler Company, Chicago, had on exhibition its self lubricating trolley which is claimed to possess severa] new features of excellence.

WAshnury \& MoEn MFg. Co., Worcester, Mass, made through its Chicago representative, Mr. H. B. Cragin, quite an elaborate exhibit of trolley and feeder wires.

Tife Link Belt Machineri Compani, Chicago, had on exhibition besides the regular line of goods a new friction cluteh which attracted a good deal of attention.

The: BALTimore SAND BOx Co., Baltimore had sample sand boxes on exhibition, placed on a section of car platform showing their operation both by hand and foot levers.

TIE ST. Lours CAR Co., St. Louis had several cars on exhibition. The two placed opposite the 5th St., entrance of the exposition building attracting considerable attention.

Tile Railway Equpurext Cominr, Chicago, had very pleasant headquarters at the Plankinton Hotel. Mr. W. R. Mason, manager of the company was in attendance.

Tre P. Wall MFo. Surply Co., Alleghaney City, Pd., made an extensive exhibit of street car gongs. Mounted on a display board were arranged gongs in various sizes and kinds.

Tue Hantford Wovex Wire M.tttress Co., lIartford, Conn. had a number of car seats displayed showing the construction of its spring seats. Mr. H. F. Evans western agent with head- quarters at St. Louis was looking after the interests of his com pany.

The Consolidatei Can Heating Co., Albany, N. Y., was rep resented by $\mathrm{Mr}$. MeElroy. The exhibit made of car heaters was of the practical order and received considerable attention.

Faimanks, Moks \& Co., Chicago, displayed railway sup. plies. The exhibit of lifting jacks was quite extensive, show ing jacks of several styles together with a number of models.

Tin National Tine Recorder Co., Milwaukee, had a Bolte automatic time keeper on exbibition showing its operation as used in connection with street railway systems, factories, etc.

ChAs. Munson Beiting Cu., Chicago, was well represented by Mr. W. C. Groetzinger and Mr. J.H. Shay. The display of belting comprised samples of the various kinds manufaetured.

The Superior Machine Conirany, Cleveland, ( hio, had a number of gears and pinions on exhibition which the company manufactures in standard sizes for the different kinds of motors.

The Vose Spring Co., Naw York, was represented by Mr. Gus. Suckow, sales agent, who was on the lookout for new or ders. A number of trucks displayed were fitted with the Vose springs.

The St. Lovis Regrsten Comrany, St. Louis, was represented by Mr. Gardner MeḰnight. The exhibit of registers in the exposition building was attractive and showed to advantage their general use.

IVM. Whapton, J k. \& Co., Baltimore, engineers, founders and machinists, made an exhibit of track material and gave ont neat pamphlets calling attention to their extensive exnibit at the World's Fair.

The New Hivex Cif Regreter Co., New Haven, Conn, was represented by $\mathrm{Mr}$. A. $\mathrm{N}$. Soper who had a display of a number of the New llaven registers which possess several novel and interesting features.

Wadhams Un \& Grase Co., Milwaukee, Wis, ealled the attention of the delegates in many ways to Wadham's graphite curve grease which is particularly intended for use on electric and cable railways.

THe Stirling SUPphy Conpany, New York, had on exhibition car beaters, sand boxes, etc. Mr. John Kennelly, chief engineer of the company and Mr. Howard Wheeler representative were looking after the interests of the company.

II. W. Joнмs MFi Cn., New York, made a display of line materials and supplies. Mr. H. A. Reeves, manager of the electrical department. Chicago, and Mr. W. F. D. Crane general manager of the electrical department, New York, were present.

Mr. F. F. CARLETON, representing the lubricating department of the Standard Oil Co., at Milwaukee, had an exhibit of samples of armature and curve greases, cylinder oils and lubrieants of several kinds, also parafine for insulation.

The Cudahy Lubricatini: Company, Milwaukee, had samples of Kent's motor grease in several forms. Mr. H. W. Kent, the general manager, was looking af ver the interest of his company and the street railway men have undoubtedly become familiar with another kind of lubricant.

Tie Westenn Eiectric Heating Co., Chicago had a number of electric heaters in operation about its booth. Mr. Geo. Cutter the manager was present and the interests of the company were well cared for. 'The exhibit attracted a great deal of attention.

Joxes \& LAUnBfin, Lim., Pittsburgh and Chicago, had on exhibition a number of steel axles of which the company makes a specialty. Many of the axles had been tested in various ways and showed the excellent quality of the material used in their construction.

Tue Peckina Mutor Tru'K \& Whenc Co., New York, was represented by its president, Mr. Edgar Peckham. The extra long $6 \mathrm{D}$ truek exhibited by this company attracted considerable attention. It was equipped with (i. E. silo motors and stood ready for the car body.

The: Eureka Temprein Corper Co., North East, Pa., had a very fine line of copper commutator bars, pinions, etc., on exhibition which showed brth the character and quality of the goods manufactured. Mr. Alfred Short, president of the com pany, was in attendance at the convention.

The Miamingra Elentric Compant, Miamisburg, O., was well represented by Mr. D. 11. Allen, general manager and A. L. Daniels, salesman of the company. The exhibit made at the exposition building was comprehensive, showing to good advantage the specialties made by the company, consisting of 


\section{ELECTRICAL INDUSTRIES.}

pure tempered copper commutator bars and segments, Burnley dry batteries, etc.

The Rochester Car Wheel Works, Rochester, N. Y., made an extensivc exhibit of ear wheels of all kinds. Mr, F. D. Rus sell,general manager of the street railway department, and $\mathrm{Mr}$. Fldridge Packer, general sales agent were present looking after the interests of their company.

BArtiets \& Compant, New York, distributed some very handsome souvenirs in the shape of a little pamphlet entitled a "Modern Triumvirate" containing some very fine engravings. The press work is excellent and the embossed cover handsomely designed. The trumvirate is represented on this cover in the heads, representing the artist, the engraver and the printer.

General Electric Compant, New York, made an extensive exhibit of trolley and line supplies. Mounted on a Peckham truck were exhibited G. E. 800 motors. Representatives from the main office in New York. from the Cincinnati office and also from Chicago and San Francisco offices were present. An illuminated sign was one of the attractive features of its offices in the Pfister Hotel.

The J. G. Brill Compant, Philadelphia. had a number of trucks and sections of cars, showing the construction, on exhibition in the exposition building. The double decked car that made regular trips between the exposition building and Pfister Hotel for the accommodation of delegates undoubtedly attracted the most attention. Mr. J. Randell and Mr. J. C. Brill were present at the convention.

The Siemens \& Haisie Electric Co., Chicago, had one of the most practical exhibits made. In a tent at the side of the exposition building there was operated a complete power plant. A Buckeye engine was directly connected to a Siemens \& Halske generator. The plant was built for Cincinnati and set up temporarily before being shipped to that point. It received a constant stream of visitors.

The Mica Insulator Co., New York, had one of the most complete exhibits in the exposition building. An illuminated sign was one of the attractive features of the display. Micanite was shown in a great variety of forms; in boards, in the required shapes for insulating commutator segments, armature coils, ete. A very neat souvenir was distributed, consisting of a card on which was mounted a piece of Micanite, in the shape of a commutator bar. Mr. Chas. W. Jefferson, manager of the com pany, was in attendance.

The Westinohouse EL. \& MFg. Co, oceupied a very prominent oficice on the main floor of the Pfister Hotel, accessible both from the street and the lobby of the hotel. A display of railway material was made there, consisting of the new series multiple controller for electric railways, lightning arresters, for power stations and various supplies. Representatives from the eastern and Chicago offices were present. A very neat souvenir was given away in the shape of a book of testimonials of its railway apparatus, through which are placed views of many prominent electric roads.

\section{PERSONAL.}

Mr. E. F. Peck, Brooklyn, N. Y., is at the Fair this week. Mr. C. Schlesinger, La Salle, Ill., is in Chicago visiting the Fair.

Mr. W. C. Johnson, Fitchburg, Conn., was in Chicago last week.

Mr. Cary T. Hutchinson, New York City, is visiting the Exposition.

Mr. Chas. K. Wead, Washington, D. C., is in the eity for a few days.

Mr. Joseph Sachs, New York City, was in Chicago last week viewing the Hair.

Mr. Chas. H. Bigelow, E. E., Salem, Mass., is at the Exposition for a few days.

Mr. Joseph Lindsey, Riedsville, N. C., has been at the Exposition the past week.

Mr. T. Fred'k Crawford, Urbana, Obio, called on Electrical INDUSTRIEs Tuesday last.

Mr. M. De Forest Yates, Sehenectady, N. Y., was one of the electrical people at the Fair last week.

Mr. E. Ward Wilkins, of Patriek \& Carter, Co., Philadelphia,
Pa., was seen around the Electricity Building last week, meeting old friends.

Mr. I. Hally Craig, Boston, Mass, , registered at the Exposition oftice of the A. I. E. E. on the 17 th.

Mr. Wm. J. Nieschurtz, with the Electric Light \& Power Co., Canton, Ohio, visited the Fair last week.

Mr. S. H. Brownell, Essex Junction, Vt., was an interested visitor to the Electricity Building this week.

Mr. A. Wickenheiser, Pskor, Russia, called recently at the World's Fair office of ELECTRICAL INDUSTRIES.

Mr. F. B. H. Paine, St. Louis, Mo., is making his headquarters at the office of the A. I. E. E. for a few days.

Mr. D. H. Keeley, of the Government Telegraphs, Ottawa, Canada, is registered at the A. I. E. E. World's Fdir office.

Mr. James Burke, Schenectady, N. Y., registered at the office of the A. I. E. E. in the Electricity Building on the 21 st.

Mr. H. Loewenberg, M. E., of the Metropolitan Telegraph and Telephone Co., New York, visited the Fair last week.

Mr. J. Stanley Thornton, of the Standard Electric Co., 327 Washington St., Buffalo, N. Y., is at the Fair for a few days.

Mr. John A. Seeley, New York City, accompanied by Mrs Seeley, was a visitor to the Department of Electricity last week

Mr. J. D. MeIntyre, of the E. E. S. Co., Syracuse, N. Y. called at the World's Fair office of ELECTRICAL INDUSTRIES recently.

Mr. Geo. F. Porter, New York City, secretary of the National Electric Light Association, ealled at the World's Fair office of Electrical Industries last week.

Mr. O. G. C. Hahn, 136 Liberty St., New York, ealled on Electrical INDUstries while making the round of the electrical exhibit a few days since.

\section{Amusements.}

Hooley's Theater-M. Coquelin and Mme. Jane Hading, repertoire. 149 Randolph street.

Columbia Theater-Mr. Henry Irving and Miss Ellen Terry, "Becket." Saturday, "The Bells." 108 Monroe street.

Grand Opera House-Hoyt's "A Trip to China Town." 87 Clark street.

Audtonium-Imre Kiralfy's Spectacle "America." Congress street and Wabash avenue.

McVicker's Theater-Wm. H. Crane, in "Brother John," 82 Madison street.

Chicago Opera House-American Extravaganza Company in "Sinbad." Washington and Clark streets.

Schiller Theater- “Lady Windermere's Fan” Randolph, near Dearborn.

Haverly's Casino-Haverly's United Minstrels. Wabash avenue, near Jackson street.

Trocadero-Vauderille. Michigan avenue near Monroe street.

The Grotro--Vaudeville. Michigan avenue near Monroe street.

Buffalo Bill's "Wild West." 63d street. Daily at 3 and 8.30 p.m.

At the Auditorium the same crowded houses are seen. Visitors coming to the Fair are securing seats a long time in advance in order to see the spectacle while in Chicago.

Mr Crane and his excellent company are receiving the encouragement of full houses in the presentation of the fourth week of "Brother John" at HeVicker's. The engagement continues until November 4 th.

At the Grand Opera House "A trip to Chinatown" draws crowded houses. This comedy of Hoyt's as presented by the talented company seems to meet with the approval of World's Fair visitors, and as the manager says the only dissatisfied people are those who cannot get admission. The dancing of the pretty Bessie Clayton is a special feature that is admired by all. 
WE HAVE AT THE PRESENT TIME

A STOCK OF ABOUT

\section{4,000 NSULITE SOGKETS OF THE}

SAWYER-MAN or WESTINGHOUSE STYLE.

THESE SOCKETS ARE WELL ADAPTED FOR USE IN

\section{DRY PLACES,}

and we are prepared to offer the entire lot, or part of same, at ten cents each, net cash.

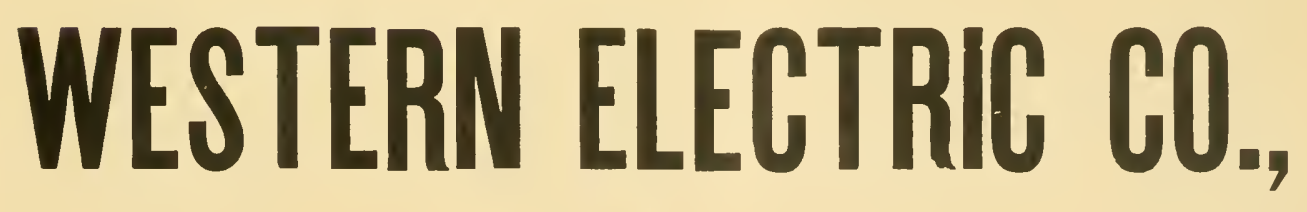

NEW YORI--GHIGAGO, 
MAP OF ELECTRICITY BUILDING-EXHIBITORS AND THEIR LOCATION.

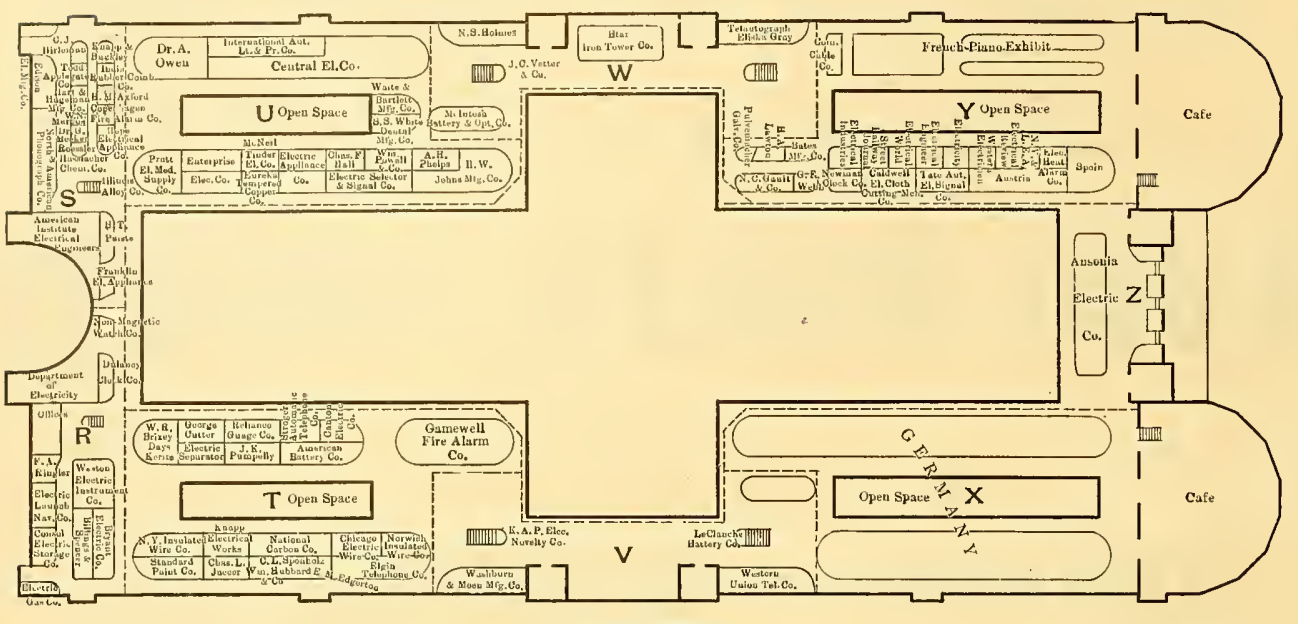

GALLERY.

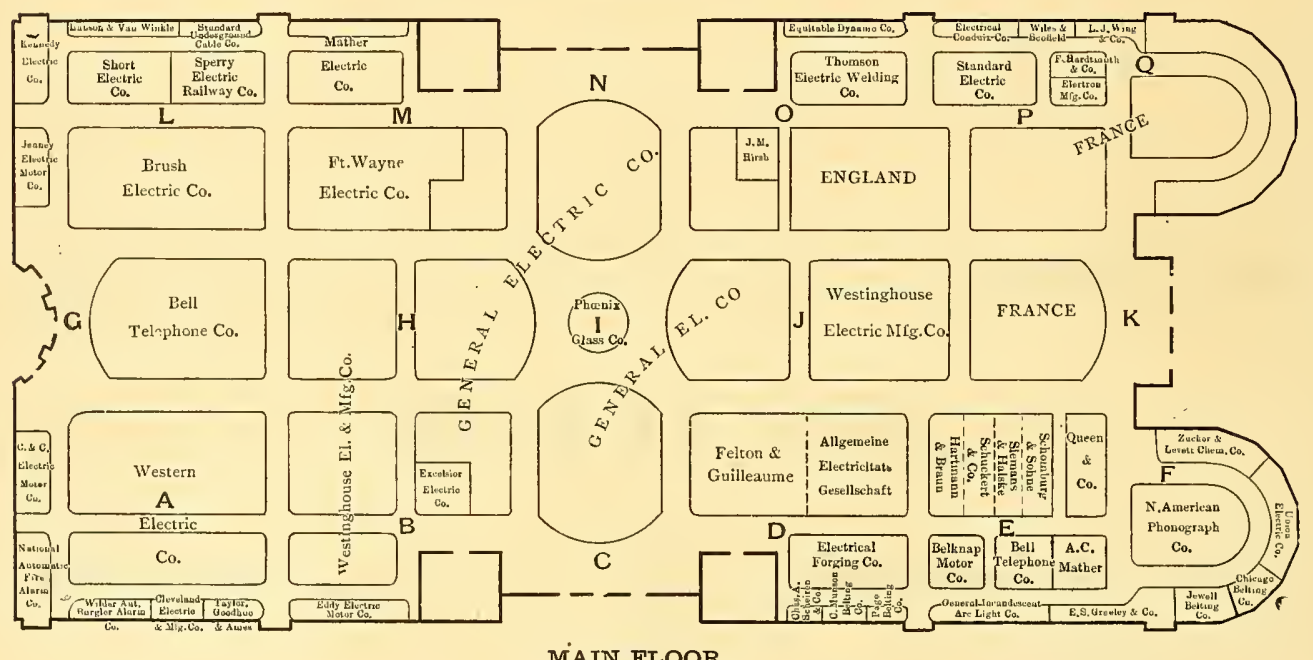

Exhibitor.

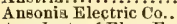

Am. lnst. of Elec: Eng.

American Battery

Allg. Elec. Geseilschaft.

3atee Mig. Co...

Bryant Electric Co.

Brixey, W. $\mathrm{R}$.

elknap Motor

Bell 'T'elephone Co.

rush Electric Co ......................

Caldwell El. Cloth Cut. Mch. Co

Canton George

Chicago Elec. Wire Co.

Copenhagen Fire Alsrm Co.

Central Electric Co.....

coumercial Cable Co.

Cleveland Elec. \& M Ig. Co

chicago Belting Co...

buluney Clock C

Department of Electricit

GLectrical inDUSTrie

klec. Launch \& Nav, Co.

Electric Separator.

Engerton, E. M.........

Edison Telephoue $\mathrm{Co}$

Vinterpribe Elec. Co...

Eureka Temp. Copper

Electric A ppliance Co.

Elec. Sel. \& Sig'l Co.

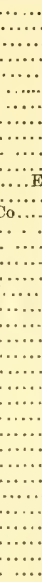

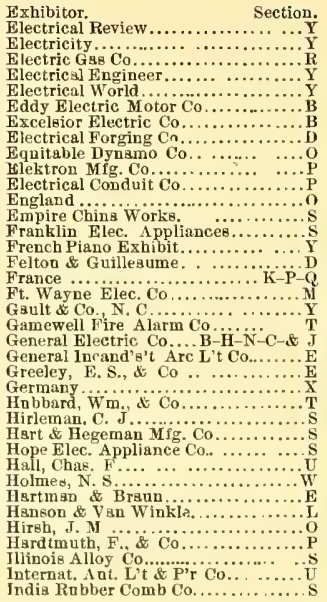
Exbibitor. Section. Johns Mrg. Co., H Jenney belting Co................. F Knapp Electrical Works. K. A.P. Elec. Novelty Co Knspp \& Bnckley..... Kawton, H. A..............

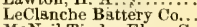
MeNeil-Tinder Elec. C Mlarcas, W. N

Mclntosh Bat. \& Opt.

IJ unson, C., Belting Co

Mather Electric Co.

Newman Clock co.

Non-Magnetic Watch Co.

N. Y. Insnlated Wire Co

Norwich Ins. Wire Co.

North Am. Phonograph co........ is-

N. Y. \& L. E. A.

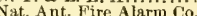

Nat. Engraving Machine C

Owen, Dr. A

Paiste, H.T.

Pulvermacber Galv. Co

Pumpelly.J.

Pratt El. Med. Snp. Co

Phelpe, A. H.

Page Belting $\mathrm{C}$

Ringler, F. A
Exhibitor. Section Roessler \& Hasslacher chem. Co...... Street Railway Jonrnal...... ........ Y Strowger Ant. Telph. Co......... . T Standard Paint Co.

Sponholz, c. L

Spain...

Schuckert \& Co.......

Sperry Elec. Railway Co................

Standsrd Underg. Cable Co..........

Tate Ant. Fl. Signal Co...............

Todd, Applegate $\mathrm{Co}$................

Taylor, Goodhne \& Ames............ A Telanton Elec. Welding Co .......... Union Electric Co $\ldots$.......... Vetter J C \& Co....

Weston El, Instrument Co..... Washburn \& Moen Mfg. Co ... .... Western Union Tel. Co.......... . V White a bartlett Mrg. Co.......... Weste, S., Dental

Wilder Aut. Burglar Äl. Co. ........... A

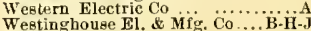
Wiles \& Scofield ............. .... Wing, L. J. \& Co .................
Zucker \& Levett Chem. Co......... k 


\section{AFTER THE FAIR}

It is presumed that the energies of the country will again be devoted more strictly to business interests.

We have fully prepared ourselves to meet the large inerease of business which will naturally result and our stoek is

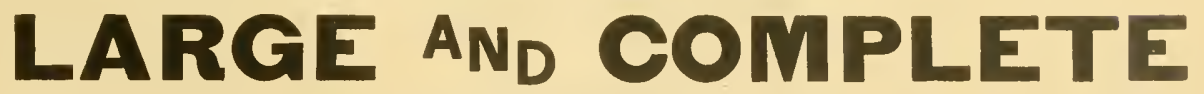

in every line with prices lower than ever before on high-grade specialties and first-class material.

\section{ELECTRIC APPLIANCE COMPANY, 242 Madison St., CHICAGO.}

\section{ELECTRICAL SUPPLIES}

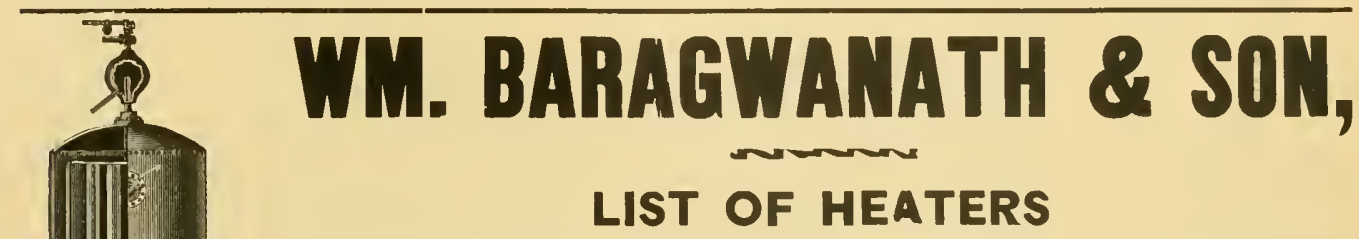

TO BE SEEN IN OPERATION AT THE WORLD'S FAIR.

Two 500 H. P. East End Boiler Gallery doing 1800 H. P. work. One $300 \mathrm{H} . \mathrm{P}$. heater and receiving tank, Wellington Catering Co's., plant, One $150 \mathrm{H}, \mathrm{P}$, heater at Hygeia plant. One 200 H. P. Libby Glass Works.

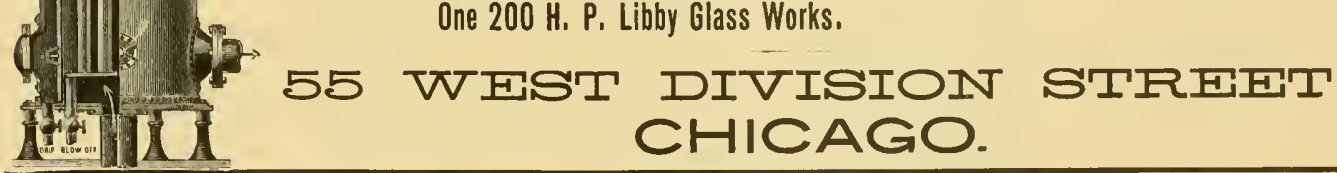

THE MONTHLY ISSUE FOR OCTOBER

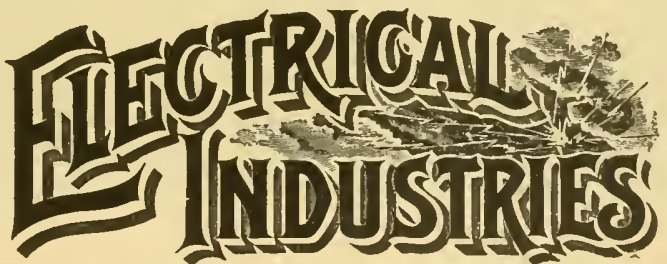

Should be read by everyone interested in electrical matters, In its Table of Contents are the following:

"Electric Railway Exhibit at the Fair."

"American Search Liphts at the Fair."

"Dnquesne Lines of Pittsburgh."

"A New Incandescent Arc Lanip." By L. B. Marks.

"The Return Circuit of Electric Railways." By. Thos. J. McTighe.

"The Business End of Electricity." By H. C. Thom.

"Three Point Incandeseent Switches." By Albert Scheible, Mr. E.

Together with illustrations of the recent applications of electricity

The paper contains regularly

A Buyer's Directory of Manufacturers and Dealers in Electrical Supplies and Appliances.

A Complete Directory of Electric Light Stations in Nortls America and a Complete Dircctury of Eikectric Railways in Nortli Ameriea.

These directories are revised each issue to the date of going to press and are to be found in no other electrical journal in the Workd. Its articles are real earefully and its directories used constantly by all the buyers in the trade. These facts make it withont a superior as an advertising meeliunl. Simple copics and rates sent on application.

subscription price $\$ 3$ per year.

\section{ELECTRICAL INDUSTRIES PUB. CO., Monadnock Block, CHICAGO.}




\section{GENTRAL ELECTRIC GOMPANY, CHICACO.}

\section{STREET RAILWAY SUPPLIES.}

Construction Tools,

PINS, BRACKETS, INSULATORS, ETC.

OKONITE

FEED

WIRES,

CAR WIRES,

OKONITE

and..MANSON

TAPES,

ARE

THE

LEADERS.

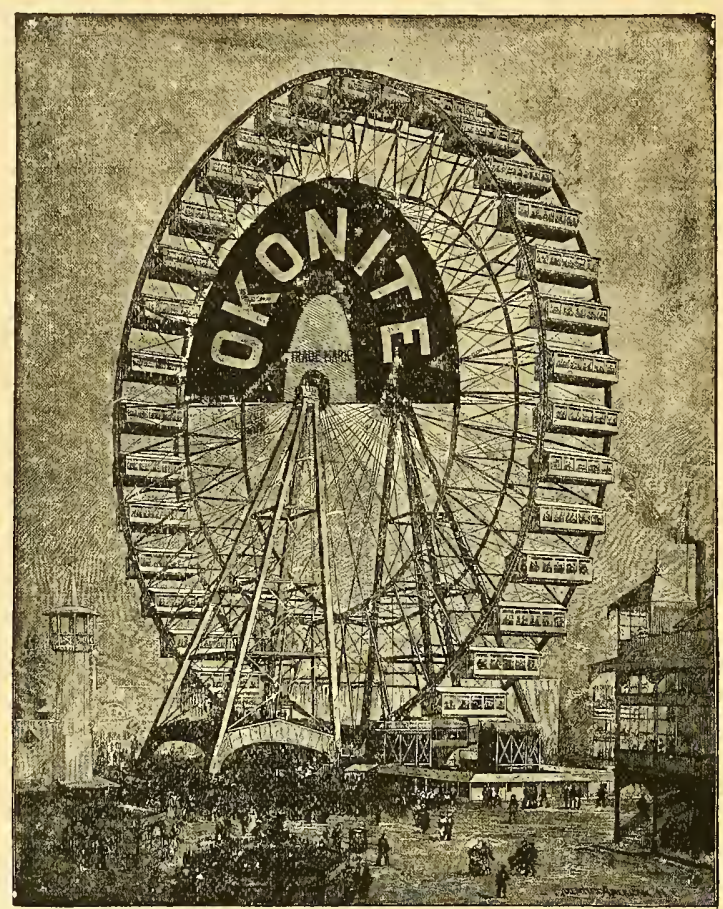

THE FERRIS WHEEL...WIRED WITH OKONITE.

Interior Conduit System of Electric Wiring. THE ONLY PFRFECT AND COMPLETE SYSTEM FOR INTERIOR WIRING.

StaNDARD PAINT COMPANY'S Gelebrated P. \& B. Electrical Paints and Compounds carried in Stock.

ELECTRIC LIGHT CARBONS FOR ALL SYSTEMS. (4)
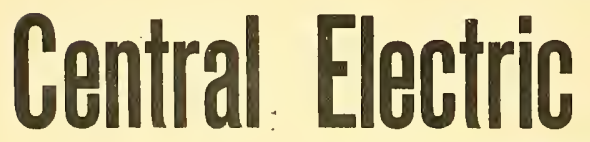

Company....HICAGO. SPECIAL AGENTS:

SOUTHERN ELECTRICAL SUPPLY CO., St, Louis, - GATE GITY ELECTRIC CO., Kansas City, Mo,
INGANDESGENT LAMPS,

TIED

AND

FREE

FILAMENTS.

LUNDELL MOTORS,

FOR

STREET

RAILWAY

CIRCUITS. 


\section{COMPANY, NEW YORK.}

192 Broadway and II John Street.

MANUFACTURERS OF ARC LIGHTING APPARATUS FOR EVERY PURPOSE A SPECIALTY. The CLARK ARC LAMPS for use on EVERY CURRENT, have the reputation of being the best and most durable of any ever made in the United States.

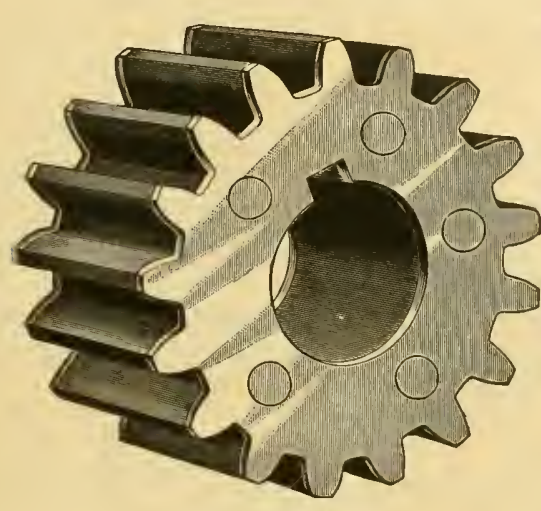

RAWHIDE PINIONS FOR ELEGTRIC MOTORS A SPECIALTY.

RAWHIDE DYNAMO BELTING

Greatest Adhesive Qualities. A Non-Conductor of Electriclty. Causes Less Frlction than any other Belt.

THE CHIGAGO RAWHIDE MANUFACTURING CO. THE ONLY MANUFACTURERS IN THE COUNTRY.

LACE LEATHER ROPE ANO OTHER RAWHIDE

GOODS

OF ALL KINDS

BY KRUEGER'S PATENT
This Belting and Lace Leather is not affected by steam or dampness never becomes hard; is stronger, (n) hide Rope for Round Beltim Transmission is superior to all others

CHICACO, UL

\section{Standard Electric Company.}

GENERAL OFFIGES: 625 Home Insurance Building.

WORKS: So. Canal Street,

\section{CHICACO.}

\section{STANDARD SYSTEM}

AT THE

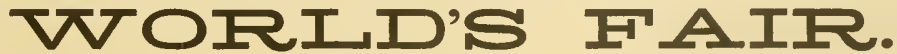

MACHINERY HALL, Sec. Q, 2 Standard Arc Dynamos.

Sec. S, 20 " " "

ELECTRICIT Y BUILDINC. Sec. P, Space 2, Arc Lighting Exhibit.

The Standard Lamps Light the Power Plant, Machinery Hall, Agricultural Hall, Shoe and Leather Building, and Other Buildings and Portions of the Grounds. 


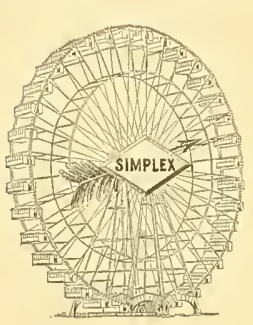

Mile after mile of

SIMPLEX WIRE

Supplied to the

FERRIS WHEEL

$\bullet$

By...George Cutter,

The Rookery, chicago.

\section{SIMPLEX WIRES}

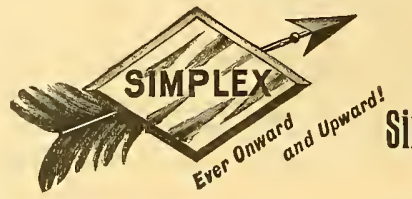

INSURE

HIGH

INSULATION

George Cutter, Chicago. Boston, MAss.

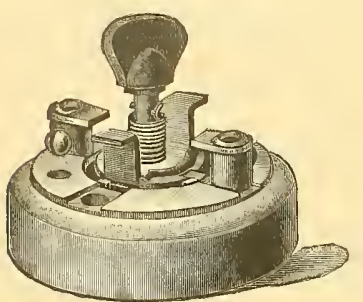

Made 5 amp. S. P.

10 amp. 3 way.

\section{XNTR C}

"That's the Switch"

And we control that movement.

H. T. PAISTE,

10 South 18 th St., PHILADELPHIA, PA.

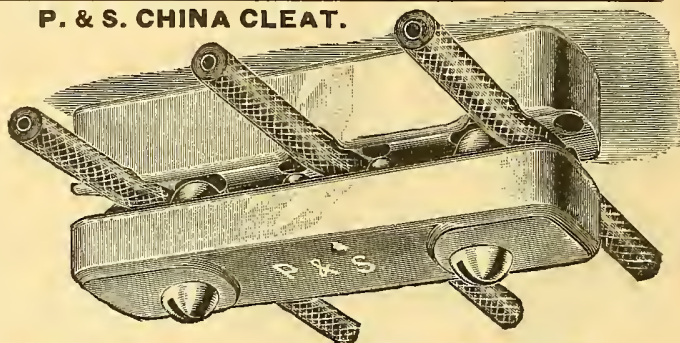

George Cutter, chICAGo. SYRACUSE, N Y.

\section{Enterprise}

\section{Electric \\ Company}

307 Dearborn Street, Chicago .... sentatives for

Electric Railway,

Telegraph, Telephone and Electric Light

SUPPLIES or ever

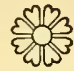

Agents for

Cedar Poles,

Cypress Poles, Oak Pins, Locust Pins, Cruss Arms, Class Feeder Wire, Insulators,

WIRES, CABLES, TAPE and TUBING

\section{Miamisburg Electric Co.}

MANUFACTURERS OF

GOMMUTATORS

AND

COMMUTATOR SEGMENTS OF TEMPERED COPPER

FOR STREET RAILWAYS

Also Brushes and Brush Copper,

BURILEY'S CARTRIDGE BATTERIES and IMPERIAL DRY BATTERIES.

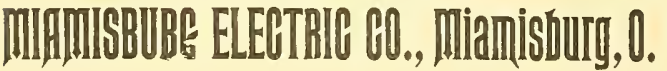

\section{BEAR IN MIND}

that the regular monthly issue of ELECTRICAL INDUSTRIES contains the most complete and correct directories published of the electric light central stations. and the electric railways in North America.

World's Fair Headquarters $Y 27$ Electricity Building.

CITY OFFICES, Monadnock Block.

Consolidated Elpctric 6.

Manafacturers and Dealers in all kinds of

ELECTRICAL . SUPPLIES,

115 Franklin Street,

CHICACO. 


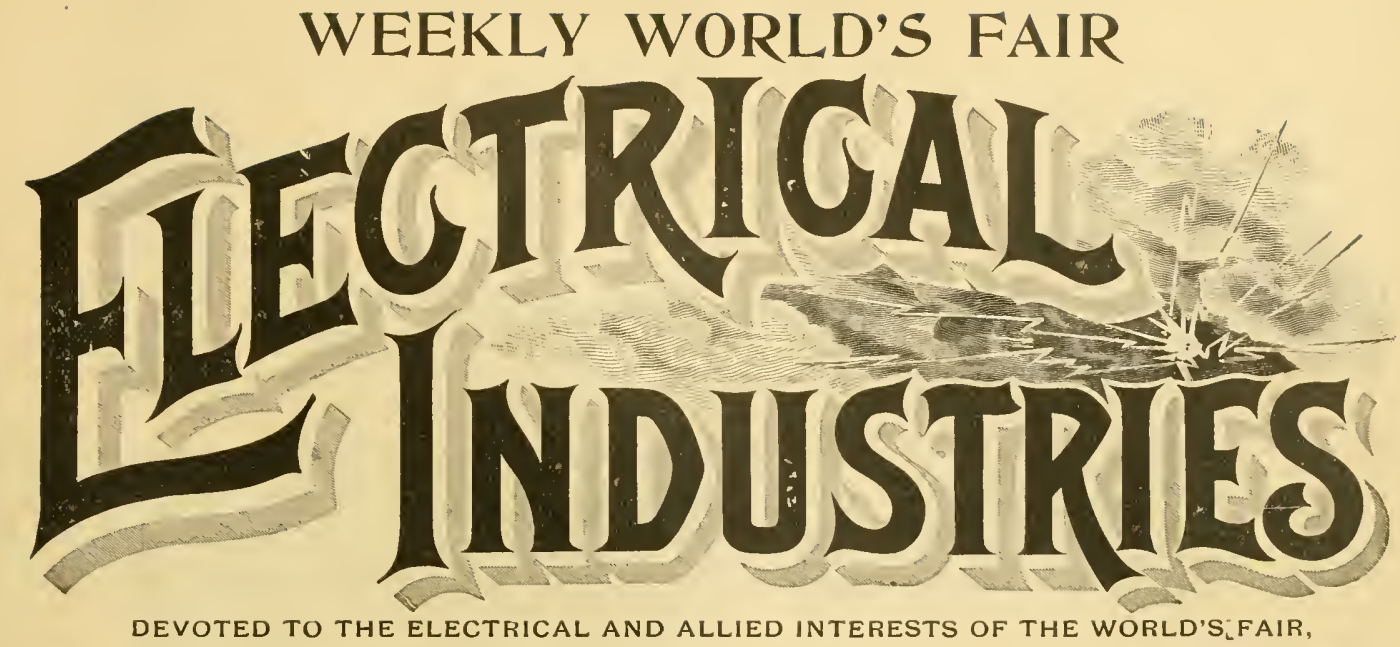

ITS VISITORS AND EXHIBITORS.

Vol. I, No, 21.

CHICAGO, NOVEMBER 2, 1893.

FIVE MONTHS S1.00
TEN CENTS A UOPY

The Department of Electricity.

In January, \$\$ฯ1, Prof. J. P. Barrett was selected ehief of the Department of Electricity, and at once gathered ever apparent. Difficulties were met in the work which at the time seemed almost insurmountable, and which were overcome only by the persistent efforts of the chief and his staff. The formation and construction of an exposition of

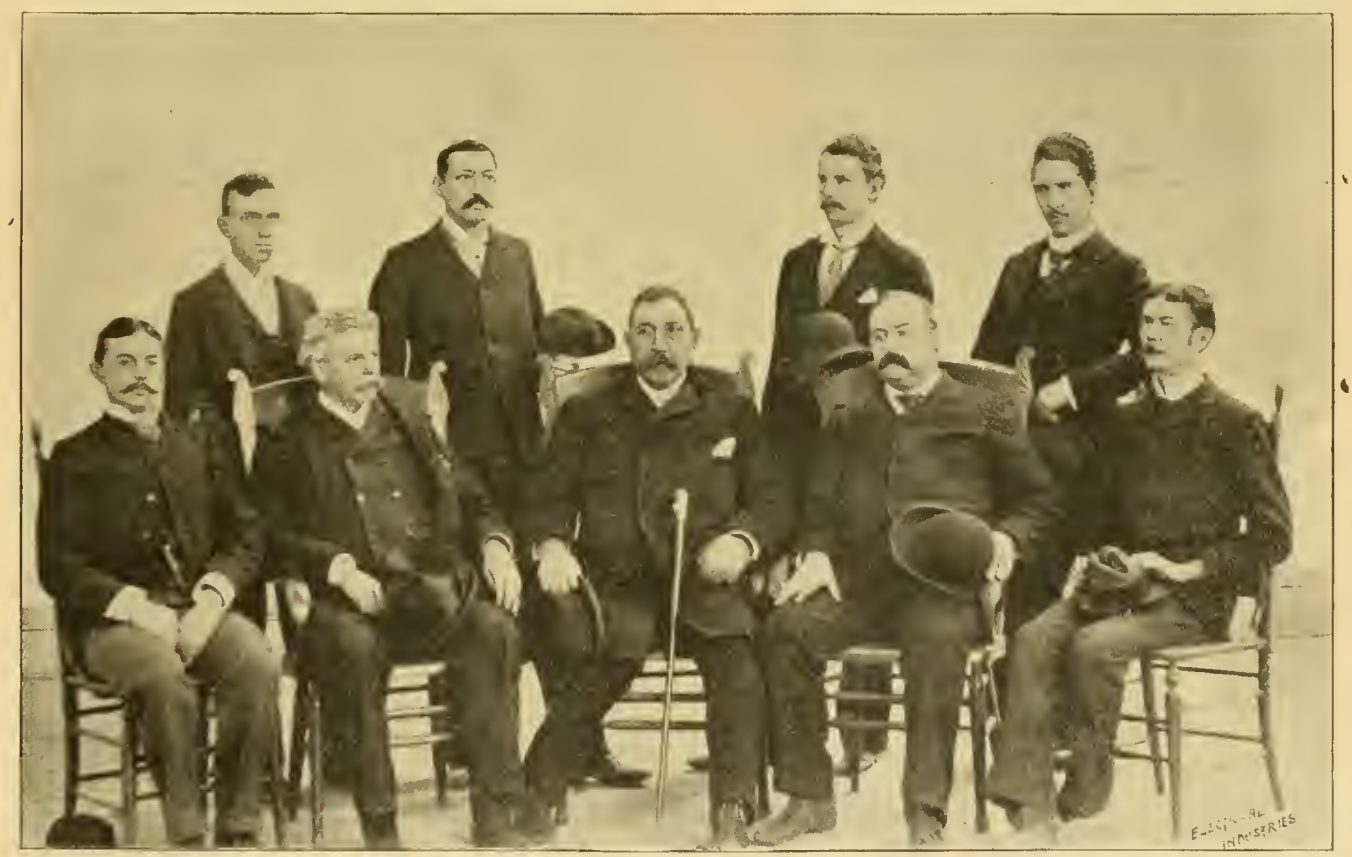

STACEY BUTLER.

ORLANDO SHEPARD.

GEO, W. MOOKE. GEO, J. IIENRY, JR. WILLIS UAWLEY. JOHN W. BLAISDELL. PROF. J. P. BARRETT. DR. J. ALLEN HORNSBY.

about him an efficient corps of assistants. The wisdom with which he selected his staff has never beeu questioned, but in the struggle to create a department that would be representative of the industry his wisdom was this character was something that had never before been accomplished, and consequently experience was out of the question in this department. But in order to profit as much as possible by former expositions, Dr. J. Allen Hornsby, 
who had been selected as first assistant, was dispatched to Europe to visit the Frankfort Exposition and gain as much information as possible from foreign expositions which would be valuable in aiding the department to do the work that was to contribute probably more to the success of the Fair than any other feature. Thus, under the direction of the chief, to whom Dr. Hornsby, the acting head of the department, submitted his plans, the Department of Electricity gradually came to maturity. In the accompanying engraving, taken from a photograph by our photographer, we present to our many readers the chief of the department and his assistants. In the February nnmber, 1891, of Electrical Industries, appeared a sketch with portrait of Prof. Barrett, and in the April number of the present year appeared a portrait and sketch of Dr. Hornsby, so that our readers are in a measure familiar with their history. Mr. John W. Blaisdell, general superintendent, has occupied a position which to a less competent person would have been extremely difficult, but his genial manner, especially in handling the allotment of passes, has preserved most friendly feelings. To Mr. Wr. W. Primm, who, for the past two years has been with the department, occupying the position of electrical engineer, wuch credit is due to the perfection of the details of the work. Mr. Willis

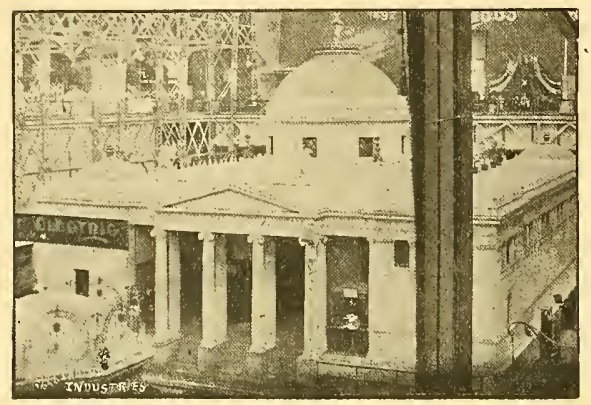

EXHIBIT OF THE BELL TELEPHONE COMPANY.

Hawley, the assistant, had previous to his connection with the department an extended experience in electrical work. Commencing with the Western Electric Company, he became familiar with different branches of electrical construction, installation and maintenance.

The inspectors of the department are Mr. Geo. J. Henry and Mr. Orlando Shepard, and to their efforts and watchfulness was due the magnificent fire protection of the building. Mr. Frank J. Sullivan and Mr. Stacy Butler have attended to the receipt of the exhibits, and have kept a record of every piece of apparatus installed. Between them they have divided the twenty-four hours of the day so that one of them has been in constant attendance. Mr. Geo. E. Moore has fulfilled the duties of stenographer, which has by no means been a light task. As the department disbands and the members return to their former occupations the goodwill and best wishes of the many friends and acquaintances which they have made in connection with the discharge of their duties will go with them.

\section{Exhibit of the Bell Telephone Company.}

In the pavilion of the American Bell Telephone Company which occupies a prominent place at the south end the visitor to the Fair could gain a very good idea of the telephone system now so extensicely used. In the west peristyle is located a switchboard of the latest pattern to which are connected all the telephone subscribers at the World's Fair and which forms what is called the World's Fair station. An iron railing separates the visitors from the space occupied by the operators. An attendant is nearly always present to explain the details in the operation.

To the south of the board through the grating in the floor the visitor can see the cables as they emerge from the conduit and rise to the frames where the wires of the cable are separated and run to the different places on the switchboard. In the east peristyle are a number of cases which contain the historical exhibits of the company and which show the first telephone in practical use and the succeeding ones up to the latest pattern of the long distance telephone. There is also shown a telephone adapted

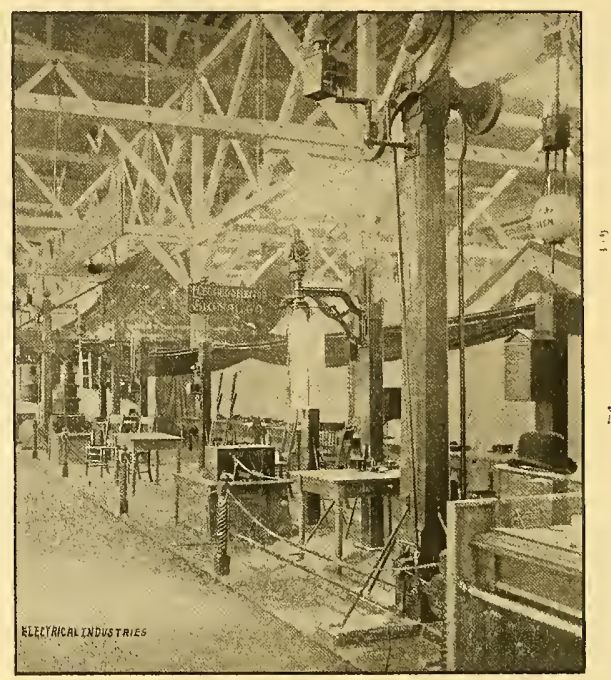

EXHIBIT OF THE ELECTRIC SELECTOR AND SIGNAL COMPANY.

to the requirements of a diver and shown attached to a divers suit.

In the center of this parilion are maps showing the extent to which the telephone. system has been introduced in the United States, the amount of territory covered by the line and statistics giving the number of subscribers and stations at the present time.

\section{Exhibit of the Electric Selector \& Signal Company.}

The exhibit of the Electric Selector \& Signal Company of 45 Broadway, New York, comprises a practical demonstration of its system of electric selection and signals. Its block system is fully shown in its method of transmitting and operating its signals. Along the back part of the space are arranged 10 tables representing 10 railroad stations. At the end is another table representing the train despatchers office. Each table is supplied with the necessary instruments and equipment for an office such as it represents.

But one line is used for this work and over this one line any signal may be transmitted to any station or operated at any one station without disturbing the others, from the train dispatchers office. The system involves the use of the same batteries, relays and keys used in the ordinary telegraph system. By the use of small discs, notched on their edges forming the different combinations, the train dispatehers office communicates with the signals having the same com- 
bination as that of the dise which the train dispatcher uses. This same method of selection is used for cutting out or in lights, motors, or any kind of machinery or apparatus operated by the electric current. A number of arc and incandescent lights, motors, etc., are shown in the exlibit illustrating the operation of the company's system. This exhibit was one of the earlier installed and at the exhibit some one has always been in attendance to explain the apparatus shown. Mr. J. H. Raymond who has been at the exhibit most of the summer has been very diligent in arrangement of strain insulators made of moulded mica, of which it required nearly 1,000 to complete the figure. Just beyond this are some large panels on which are displayed trolley appliances and line appliances in which moulderl mica is used as an insulator.

In the case at the end of the exhibit is shown ashestos in the form of gaskets, washers, various forms of packing, etc. In another case are displayed incandescent lamp sockets, rosettes, etc, of moulded mica. These different appliances are shown in another case cut in two, so that the relative

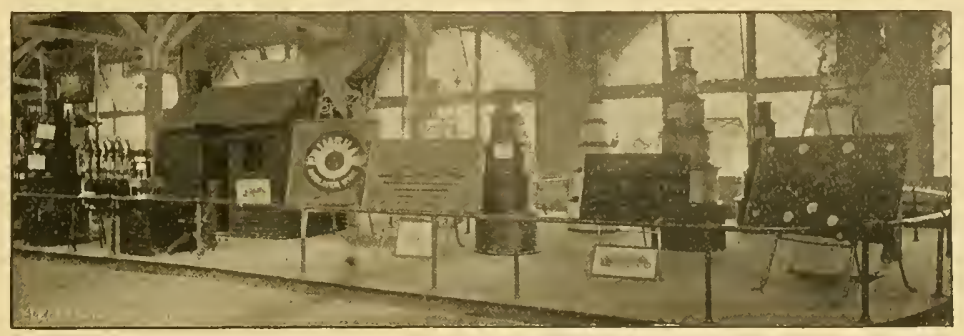

EXHIHIT OF THE NEW YORK INSULATEN WHE COMPANY.

extending the knowledge of this system and its various applications.

\section{The Exhibit of the H. W. Johns Manufacturing Company.}

One of the most important parts of every electrical machine and apparatus is its insulation and consequently to electrical manufacturers and users of manufactured articles the exhibit of the H. W. Johus Mfg. Company has been very interesting. It is located in the west gallery of the Elec- position of the insulation and metal is shown. Armature rings and a great variet yof forms and shapes of valeabeston are shown as it is used in conncetion with numerous electrical devices. Near the center of the exhibit are shown insulations for armature and field coils, magnet spools, etc

Exhibit of the New York Insulated Wire Company.

Among the exhibits of insulated wire in Electricity Building that of the New York Insulated Wire Company occupies a prominent place. About the space, which is near the

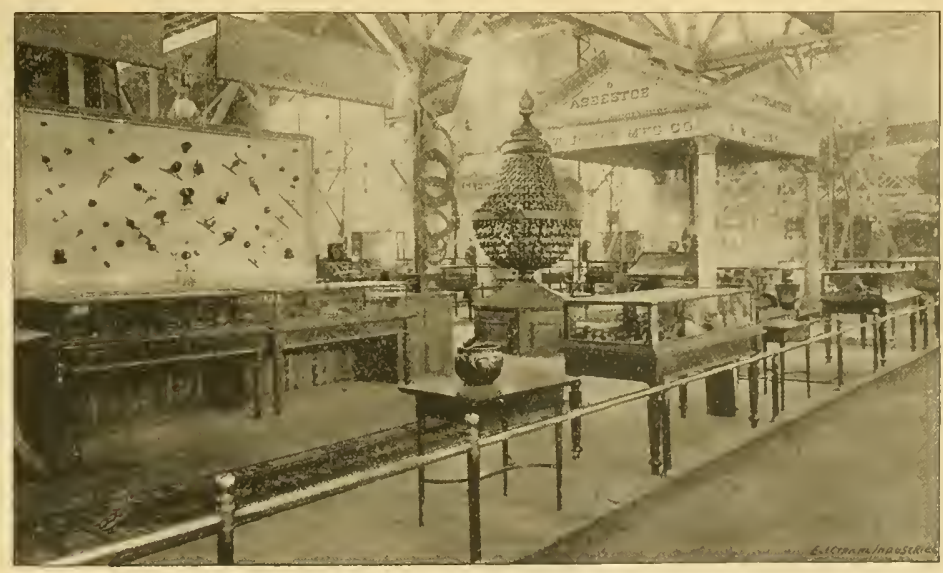

THE EXHIBIT OF THE H. W. JOHNS MANIFACTURING COMIPNY.

tricity Building and is quite conspicuous on uecount of the large white balls mounted ou posts and placed at the corners of the space and also the large pavilion finished in white and gold in the center of the space.

The illuminated sign which flashes out the name of the company and then the word "insulation" in red lamps attracts the attention of visitors on the ground floor. Placed about the exhibit are a number of unique objects constructed of various pieces of apparatus manufactured by the company. On an oak stand just south of the pavilion is an urn-shaped south end of the east gallery, are arranged a number of pyramids composed of reels of wire of different sizes. The $\log$ cabin built of vulca duct has probably attracted the most attention as it was designed after a primitive log cabin. The method of construction, and the chimney that rises a foot or two above the ridge are each suggestive of the old-time cabin. A number of easels supporting signs are prominent objects about the exhibit. These signs, which are of neat and attractive design, call attention to the Grimshaw wire, tapes and compounds, 


\section{Exhibit of $J$. Lang \& Co.}

In the west end of the long pavilion erected under the direction of the Ansonia Electric Co., between the exhibit of Stanley transformers and the dynamo built by Mr. Wm. Wallace, in 1875, is located a handsome display of switehes made by J. Lang \& Co. of 44 Michigan St. The switches, which comprise single, double and a very neat design as is also the bronze railing that surrounds the exhibit. Current is supplied to the space by the 500-volt power circuit from Machinery Hall. A 50 kilowatt motor drives an 800 light dynamo which is of the standard 110 rolt type. Small motors are shown in operation illustrating some of the different uses to which these motors are applied. A five-horse power motor is connected to a Sturdevant blower; a 10 -horse power motor to a mine

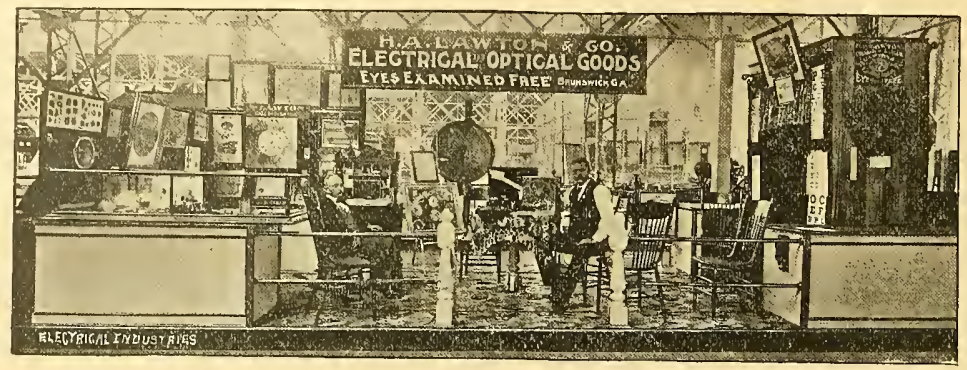

EXHIBIT OF H. A. LAWTON \& Ce.

triple pole switches, are all finely polished and skillfully made.

They are nearly all of the knife pattern, which closes between substantial contact pieces. The double pole clipper switch and the single pole quarter throw switch which have more recently been introduced are shown. In all these switches the current passes through the blade of the switch and in no case through the arm.

\section{Exhibit of the C. \& C. Electric Motor Co}

At the south end of Electricity Building near the scenic hoist and another 10-horse power motor to a 60 inch exhaust fan.

On the switch board which is of white marble are shown an excellent display of instruments, switches and connections. This board is placed immediately beneath the illuminated sign. The exhibit has been in charge of $\mathrm{Mr}$. Arthur Capen who has been painstaking in explaining to the many visitors the machines and appliances on exhibition.

\section{Exhibit of the Jewell Belting Company.}

The space occupied by the Jewell Belting Co., of

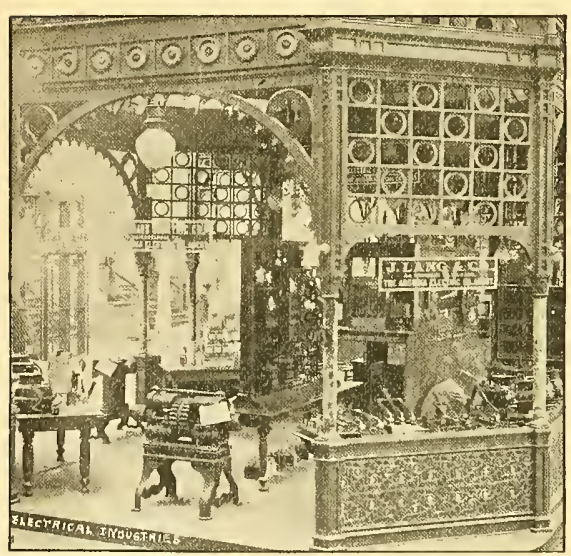

EXHABT OF J. LANG \& COMPANY.

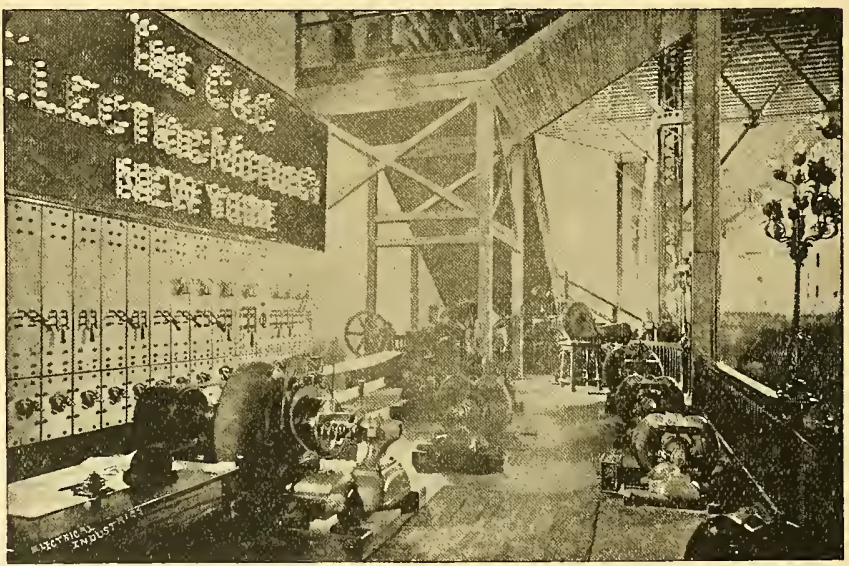

EXHIBIT OF THE C. \& C. EIECTRIC MOTOL COMPANY.

Hartford, Conn., in the north-eastern part of Electricity Building is filled with a variety of belt goods of interest to power users. Probably the most prominent feature of the display is the immense star suspended above the exhibit. It can be seen from the distant parts of the building, and draws the visitors in that direction as they make their way through the building.

The frame work of this star is made up of Jewell belting and shows in the method of joining the different pieces the different methods of joining the lengths of leather in the

The standard that supports these clusters are bronze of 
manufacture of belts. The surface of the star points is made of oak bark, while around the large cut glass jewell that forms the center is the name of the company.

Belts of different widths from four inches to 52 inches are shown. The latter represents the width of a steer hide.

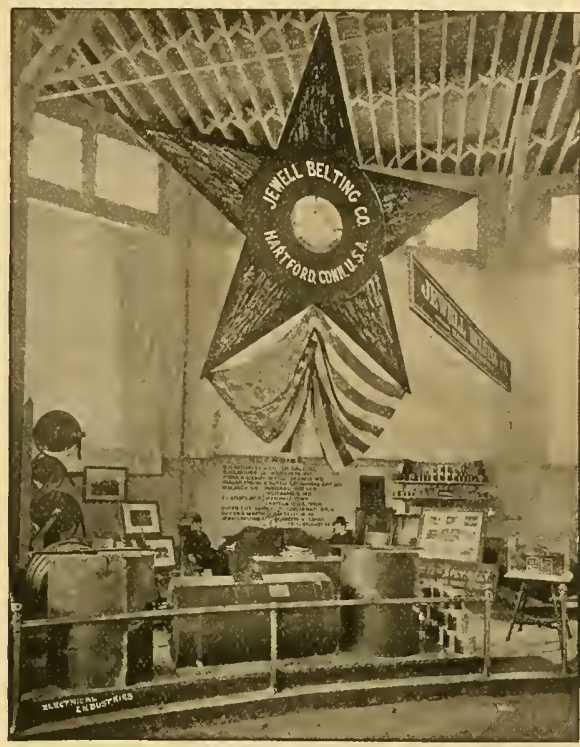

EXHIBIT OF THE JEWELL BELTING COMPANY.

A brand of ielting known as the diamond is shown, which is used extensively for driving electrical machinery. It is short lapped and tanned by the oak process, making an exceedingly durable belt. In a case at the right is shown a belt that has seen continual service for 36 years, piece of belting represents a considerable, the practical use of a belt will indicate more exactly its value for transmit ting power. In Machinery Hall there may be seen in use Jewell belts of several sizes; for driving the Eddy generators in Machinery Hall four 2t.inch Jewell helts have heen in constant use; for transmitting the porrer from the Atlas engine to the larger Westinghouse generator, a 72 -inch three-ply Jewell belt is used. These belts demonstrate in the only practical way the efficiency of these belts. Numerous views about the space in Electricity Building

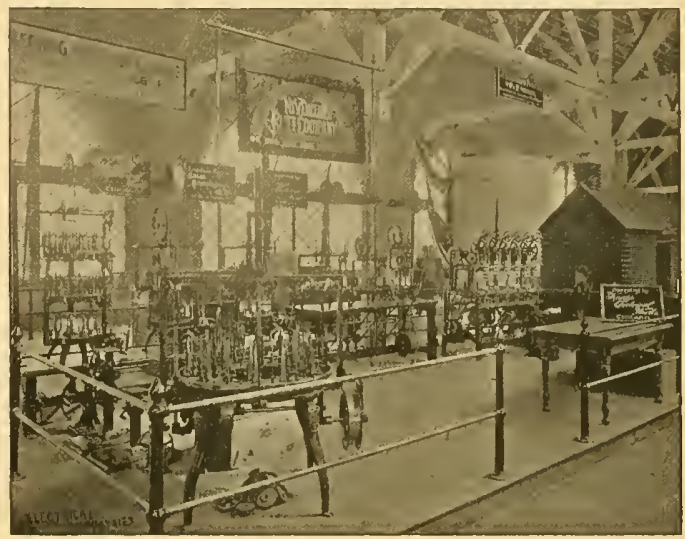

EXIIBIT OF THE NEW ENELAND BUTT CO.

show belts manufactured by this company in use for driving different kinds of machinery.

Exhibit of the Hope Electric Appliance Co.

In the south end of the west gallery is located the ex.

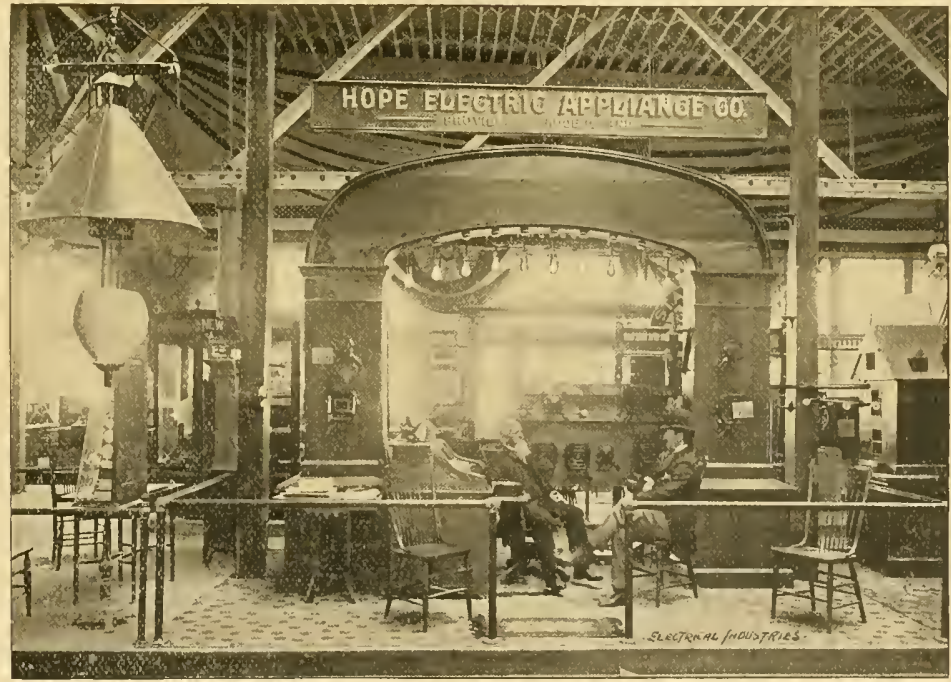

EXHIHI' OF THE HOPE ELECTRIC APPIIANCE COMPANY.

having been taken off the pulleys and brought direct to the World's Fair. There is also shown in this space belt dressing and cement, bearing the well-known Jewell trade mark.

Although to the experienced eye the appearance of a hibit of the Hope Electric Appliance Co. of Providence, $\mathrm{R}$ I. The appliances displayed are all practical and useful. They are so arranged as to sliow their operation, current being supplied to the space.

On posts at each side of the large arch that spans the 
space are shown mast arms and cut-out boxes for both arc and incandescent circuits. To one of the posts Wright's automatic mast arm is shown, which is of great value for use in crowded streets where it is dangerous to lower a lamp in the center of the street. This arm consists of one large piece of wrought iron pipe securely attached and braced to the post. Beneath this pipe is a swinging arm hinged at the post. To the outer end of this swinging arm an are lamp is attached. A thin tape of strong bronze metal, $\frac{5}{8}$ of an inch wide, is attached to the lamp, runs over a pulley at the end of the stationary arm and through it to post, where it passes over another pulley and down the post to a windlass. By turning the handle attached to the windlass the tape is unwound and the lamp lowered until it hangs at the end of the swinging arm beside the post, at the side of the street out of the way of passing teams.

The wires are carried to a series cut-out on the post from whence they are carried through the movable arm to the lamp. When the lamp is lowered the lamp is cut out of the circuit, thus protecting the trimmer while handling the lamp. The windlass is covered and the tape entirely concealed in a cleat on the pole and within the fixed arm so that it is entirely protected from injury from the weather.

The other mast arm shown is designed for use on streets where trolley lines prevent the lamp being lowered from the center of the street. In this case the lamp is drawn into the pole. From the arch are suspended numerous incandescent lamps which are fed from a transformer, which shows the operation of the double pole primary switch which opens the primary circuit. The cut-out boxes shown are perfectly weather proof and are durable in construction. The special feature of these cut-outs is the quick break. The construction is such that the instant the lever reaches a certain point the spring is released and the circuit is instantly opened or closed. A number of styles of line insulator brackets are shown. Mr. Wright, of the company, has been at the exhibit most of the season.

\section{Exhibit of the New England Butt Co.}

Under the direction of the Knapp Electrical Works of Chicago, the western agent of the New England Butt Co., a number of braiding machines have been shown in operaation in Electricity Building. The machines are located in the east gallery, and power is furnished by an electric motor. Single, double and triple braiding machines are shown in operation. The exhibit has been surrounded by many interested visitors who were unfamiliar with the process of manufacturing insulating wire.

The incandescent lamp tests were brought to a close on the 30th ult. The preparation of the report of the judges, which will be very exhaustive, will be begun immediately. This report will not only show the exact cost of maintaining a 110 , as well as 50 volt lamp, for a given time, but will give the cost of the candle power of the different makes of lamps tested, including the first cost of the lamp. In other words, the report will show which of the lamps tested is the cheapest for the public to use.

The Western Electric Co., shut off all current from their Machinery Hall plant, except that used to light and heat their offices at midnight on the 30 th.
ELECTRICAL INDUSTRIES.

PUBLISHED EVERY THURSDAY BY THE

\section{ELECTRICAL INDUSTRIES PUBLISHING COMPANY,}

MONADNOCK BLOCK, CHICAGO.

Telephone Barkigon 159.

E. L. POWers, Pres, and Treas.

E. E. WOOD, SEcretary.

E. L. POWERS, -

EDTToR.

W. A. REMINGTON,

- Associate Editor.

E. E. TOOD,

- Eastern manager.

FLOYDT. SHORT,

ADVERTISING DEPARTMENT.

EASTERN OFFICE, WORLD BUILDING, NEW YORK. World's Fair Headquarters, Y 27 Electricity Building.

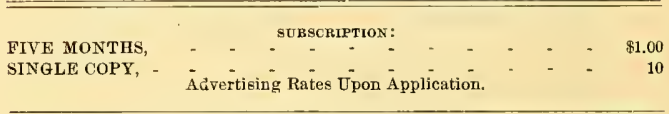
News items. notes or communications of interest to World's Fair
Visitors are earnestly desired for publication in these columns and will be heartily appreciated. We especiallv invite all visitors to call upon us or send address at once upon their arrival in city or at the grounds. ELECTRICAL INDUSTRIES PUBLISHING CO.' Monadnock Block, Chicago

The World's Columbian Exposition having closed, the publication of the Weekly World's Fair Electrical INDUstries will be discontinued with this issue. From the assurances received we believe that our readers will regret that this is the last number they will receive, but the time having expired that it was to run, and its field having been taken arvay, we must bid our friends adieu. When the Exposition opened it was apparent that there was an important and useful field for a weekly paper devoted exclusively to the electrical and allied interests of the World's Fair, and Electrical Industries with its characteristic enterprise promptly undertook to corer this field. The enterprise met with favor from the start, and the great success of the paper has been due to the support accorded it by both subscribers and advertisers, for which we are grateful. The many original illustrations that have appeared in these columns have cost much labor, time and expense, but we have the satisfaction of knowing that our efforts to give our readers the fullest descriptions of exhibits, the freshest and most timely notes on current events of interest at the Fair have been fully appreciated. We have endeavored to give our subscribers and every visitor, so far as possible, desirous of seeing the different features of the electrical exhibits, information not otherwise available, and the demand for copies assures us that the maps published for their information have been used very extensively. Our efforts in fact, we feel have been fully rewarded. We again thank you and make our final bow.

The World's Columbian Exposition is now at an end. Its close was marked by no great demonstration, but in sorrow over the death of Chicago's Mayor, the flags were 
lowered, a salute fired and the Fair was officially at an end. Festival Hall that was to have witnessed a scene of joy over the success of the Fair, witnessed instead, memorial exercises over the death of Nayor Carter H. Harrison. Thus closed the greatest exposition ever held. The whole world united in producing this Exposition, but to Chicago's wonderful enterprise we are indebted for the magnitude and success of the undertaking. When the success is considered in connection with this year of business depression what the success would have been in an ordinary year can only be conjectured. As a civilizing agency the Fair has been far reaching in its influence and effects. Nations but little acpuainted with the United States have become famil. iar with its people, its country and products. Countries in all quarters of the globe have through their exhibits and representatives made the people of the United States and other countries acquainted with their manufactures and products. But to the electrical industry it has been a triumph. Of but recent growth, its displays at former ex positions have been small and have attracted but little at tention. Electricity was wisely adopted as the means of transmitting power from the central station throughout the grounds. It made it possible to operate in any building in any part of the grounds machinery without disfiguring in any way the light colored interior or exterior of the buildings. It furnished the power for different forms of intramural transportation both on land and on the canals and lagoons. It carried the risitor to the roof of the highest building. It made trips to the galleries of the different buildings easy. It illuminated the grounds and turned night into day. By different combinations and devices, as a means of clecoration, places otherwise unattractive were made points of interest and amusement. The power plant and system of distribution together with the displays made by the different manufacturers of electrical goods familiarized the general public with this new indus. try. Under the able direction of the Department of Electricity, the Electricity Building was made one of the most attractive buildings on the grounds, and in it both day and night there was always a crowd. The displays made by the larger companies were certainly a credit to them and the manner in which they placed attendants in charge and the pains with which they explainer the exhibits and systems is commendable. Aided by the information and ideas gathered from the machines, plans and literature of foreign and domestic manufacturers which have been thoroughly discussed during the past months the American manufacturers will be able to produce even better machines and the public to purchase and use them more intelligently. After the exhibits are removed and the buildings demolished, there will still remain vivid recollections of the White City, its buildings, grounds, the displays and festive occasions, and the friendships and acquaintances that have arisen from the close relations which have existed during the six months of the city's life.

The Antwerp Exposition which is to open at Antwerp, Belgium, May 5th, 1894 has brought into existence the American Propaganda which has for its object, the presentation of American industry at foreign expositions. It also acts as commercial agent for exhibitors and will collect and install exhibits and statistics such as will present the coun. try's resources and products in a creditable manner. A building is to be erected called the American Propaganda Building for these exhibits and statistics, and which will also afford a headquarters for American visitors.

\section{WORLD'S FAIR NOTES.}

From October 31st, the Electricity Building will be open to the public only from S A.M. till \& P.M. All current, whether for lighting or power was cut off at midnight on October 30th.

There was such a crowd of people demauding admittance to the Scenic Theater of the Western Electric Co., Monday, that at one time it was thought the theater would bave to be closed before the day was over, not to be opened in the erening, for fear of a disturbance on the part of those who were not fortunate enough to gain admission.

The E. S. Greeley \& Co., exhibit was the first to be torn down in the Electricity Building, Mr. Anerbacher having had his packing cases delivered at his exhibit Monday. The teariug down and packing of the exhibit was begun early Tuesclay morning, and Mr. Auerbacher hopes to have the space entirely cleared and the goods shipped to New York by Saturday of this week.

It is rumored that some of the manufacturers of insulated wire are not desirous of having a "soak" test, as was originally contemplated by the jury, and this part of the test may be abandoned. This is to be regretted, for a wire which may show excellently in a "break-down" test may be the first to show defects when subjected to the "soak" test. The sooner the faults in a particular brand of wire are known, the sooner does the manufacturer set abont remedying them.

\section{Additional Awards in the Department of Electricity.}

UNITED GTATES.

Brush Electric Co.

Historical exhibit.

General Electric Co.

Ornamental lamp posts.

Greves Arc Lamp Co.

Are Damps.

N. S. Keith.

Constant current motors.

The Mather Electric Co.

Automatic adjustable circuit breakers.

National Engraving Machine Co.

Jewelers engraving machine.

Standard Paint Co.

Insulating compound, liquid.

S. S. White Dental Co.

Application of electricity as a motive power for electric drills.

Western Electric Co.

Automatie fire alarm apparatus.

Westinghouse Electric \& Mfg. Co.

Electric Meter, "Shallenberger."

Constant potential, alternating current arc lamps.

Ft. Wayne Electric Co.

Constant potential dynamos and motors.

Mather Electric Co.

Constant potential dynamos and motors latest "ring" type.

Queen \& Co.

Hot wire voltmeter.

Washburn \& Moen.

Bare copper wire.

Westinghouse Electric \& Mfg. Co,

(1) Regnlator, Stillwell.

(2) Continuous current, constant E.M.F. "Letter" type dynamos and motors.

Siemens Bros \& Co.

GERMANY.

Cored carbons.

Schuckert \& Co.

Registering watt meters. 
General Electric Co., Ltd.

ENGLAND.

Carbons.

ITALY.

Societa Ceramina Richard, Milan.

Insulators.

JAPAN,

Eizaomon Tukagawa, Saga.

China insulator.

\section{PERSONAL.}

Mr. S. Dana Green, of the General Electric Co., left for New York on Thursday last.

Mr. E. E. Winters, general manager of the Consolidated Street Railway, Macon, Ga., was a visitor at the Fair last week.

Mr. Edw. H. Chapin, secretary and treasurer of the Shipman Engine Company, Rochester, N. Y., was a recent visitor to the Fair.

Mr. W. R. Scott, of the Buffalo Street Railway, was a visitor at the World's Fair headquarters of ELECTRICAL INDUSTRIEs recently.

Mr. C. C. Benson, electrical engineer of Atlanta, Ga., was one of the interested exhibitors in the Department of Electricity last week.

Mr. J. T. Myhan, supt. of the Macon \& Indian River Railroad, Macon, Ga., spent several days at the Fair and in Chicago last week.

Mr. C. J. Purdy, general superintendent of the Canandaigua Electric Light \& Railway Co., made an extended visit to Chicago and the Fair recently.

Mr. W. Worth Bean, president of the St. Joseph \& Benton Harbor Eleetric Railway \& Light Co., has been in Chicago and at the Fair for several days.

Mr. J. C. Liggett has been appointed to the position of electrical engineer of the Citizen's Street Railway Company, Detroit, and is too enter upon his duties at once.

Mr. P. E. Elevier, electrical superintendent for the Superior Water, Light \& Power Co., of West Superior, Wis., has spent several days at the Exposition and returns home this week.

Mr. G. W. Johnson, treasurer of the Western Electrical Supply Company, of Omaha, Neb., has been in the city for several days visiting the Fair and looking after the business interests of his company.

Mr. Chas. A Schieren, of Chas. A. Schieren \& Company, New York, has received the nonination for mayor of the eity of Brooklyn on the republican ticket. His many friends and business acquaintances will unite with us in hoping that he may be elected.

Mr. W. D. Packard, secretary and treasurer of the New York \& Ohio Company, Warren, O., has been in the eity for several days past doing the Fair and looking after certain business interests. Mr. Packard is very enthusiastic over the new lamps which he has just brought out.

Mr. Ra]ph W. Pope, secretary of the American Institute of Electrical Engineers, is at the Fair for a few days closing up the World's Fair headquarters of the institute. The headquarters of the institute has been a most convenient meeting place during the Fair and the information and curiosities to be had there have been greatly appreciated by thousands of visitors. Under Mr. Pope's skillful management to members of the institute it has been a means of extending their acquaintance and of great benefit to the institute in extending its field of usefulness.

\section{BUSINESS NOTES.}

The Laclede Carbox \& Electric Company has recently re moved its plant to Kokomo, lnd., where it will continue the manufacture of electrie supplies and apparatus, including glass and porcelain insulators, cut-outs, sivitches, sockets and Laclede and Hercules batteries.

The Western Electric Company, Chicago, has recently closed several large contracts for nearly everything in the electrical line. The business done by this representative company during the dull times has as a whole been very satisfactory Among the recent contracts closed is one for three dynamo for lighting the Columbia Building at Louisville, $K y$.

The Reliafce GUage Company of Cleveland, Ohio, supplied the safety water columns for the Washington street plant of the Chicago Edison Company. These goods have become recognized as important parts of every first class boiler plant and the awards recently received by this company for its safety alarm water colnmns and patent solderless floats were but a just appreciation of their worth.

The Chicago Rawhide Manufacturing Company, 75 \& 77 Ohio St, Chicago, is to be congratulated upon having worked its factory to its full capacity all the time during the late financial stringency with no reduction in the number of hands. At the stringency with no reduction in the number of hands. At the
present time the factory is exceptionally busy in all departments. Among recent shipments made was a 40 -inch main driving bel to John Wanamaker, Philadelphia, which is to be used for operating an electric light plant. Mr. Wanamaker has used the goods of this company's manufacture for the past 10 years, a fact which speaks well for the quality of the product. The company has also recently shipped several other large dynamo belts to various points in this country. Its foreign trade is constantly increasing. Awards of the highest character were given the company on its rawhide belting, lace leather and other products.

The Charles E. Gregory Co., Chicago, is in receipt of the following letter from the Ferris Wheel $\mathrm{Co}$, which speaks well for the apparatus furnished by them.

CHicago, Oct. 14th, 1893.

Charles E. Gregory Co., 47-49 S. Jefferson St., City.

Gentleuen:-We have the pleasure to say that the two 500 light Edison dynamos, which your company furnished us, have given us most excellent service up to the present time, and that we are very much pleased with the installation of these dynamos. We have the pleasure to remain very truly yours,

The Ferris WheEL Co.

"Geo. W. F. Ferris, General Manager.

The company also reports business excedingly brisk having sold 22 dynamos and motors during Oetober.

\section{Amusements.}

Hooley's Theater-A. M. Palmer's Stock Company in "A Pair of Spectacles" and "Mercedes." 149 Randolph street.

Columbia Theater-Mr. Henry Irving and Miss Ellen street.

Terry, "Becket." Saturday, "The Bells." 108 Monroe

Grand Opera House-Hoyt's "A Trip to China Town." 87 Clark street.

Additorium-Inre Kiralfy's Spectacle "America." Congress street and Wabash avenue.

MoVicker's Theater-Wm. H. Crane, in "Brother John," 82 Madison street.

Chioago Opera House-American Extravaganza Company in "Sinbad." Washington and Clark streets.

Schiller Theater- "Lady Windermere's Fan" Randolph, near Dearborn.

Haverly's Casino-Haverly's United Minstrels. Wabash avenue, near Jackson street.

Trocadero-Vauderille. Michigan avenue near Monroe street.

The Grotro-Vaudeville. Michigan avenue near Monroe street.

The excitement attending the recent revival of "Sinbad" at the Chicago Opera House has about snbsided, and the big production, which is undoubtedly the superior of any of its predecessors, is moving with the briskness and smoothness of an old timer. The houses of course have been erowded, and a noticeable change has taken place in the clientele. Musically the piece is full of bright hits, and the comedy incidents follow one another thick and fast. Dangerfield's new scenes are revelations of stage art, and the hundreds of beautiful costumes have never been surpassed in cleverness of design or richness of material. From a spectacular point of view, the new Sinbad is much better than any of its predecessors. The great ballet scene, with its gorgeous dresses, brilliant scenic environment scene, with its gorgeous dresses, brilliant scenic environment immense procession in the last act, through the corridors and over the terraces of a palace of ivory and gold, is stupendous in conception and kaleidoscopic in its wealth of color and everchanging movement. 


\section{GENTRAL ELECTRIC COMPANY, CHICACO.}

\section{STREET RAILWAY SUPPLIES.}

\section{Construction Tools, \\ Line Materials,} PINS, BRACKETS, INSULATODS, ETC.

OKONITE

FEED

WIRES,

CAR WIRES,

OKONITE

and..MANSON

TAPES,

ARE

THE

LEADERS.

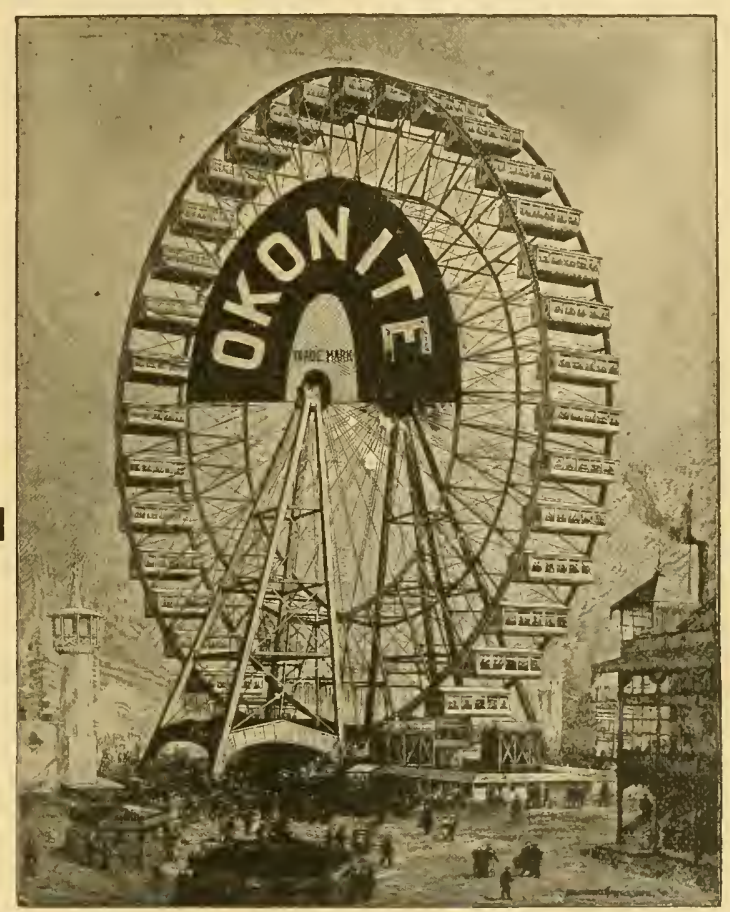

INGANDESGENT LAMPS,

TIED

AND

FREE

FILAMENTS.

LUNDELL MOTORS,

FOR

STREET

RAILWAY

CIRCUITS.

THE FERRIS WHEEL...WIRED WITH OKONITE.

Interior Conduit System of Electric Wiring. THE ONLY PFRFECT AND COMPLETE SYSTEM FOR INTERIOR WIRING.

STANDARD PAINT COMPANY'S Celebrated P. \& B. Electrical Paints and Compounds carried in Stock.

ELECTRIC LIGHT CARBONS FOR ALL SYSTEMS. .

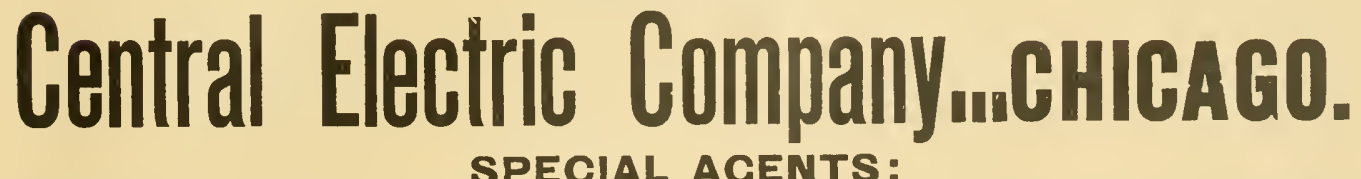
SPECIAL AGENTS:

SOUtherN EleCtRIGal SUPPLY CO., St, Louis. - GaTE GITY ELECTRIC CO., Kansas City, Mo. 
MAP OF ELECTRICITY BUILDING-EXHIBITORS AND THEIR LOCATION.

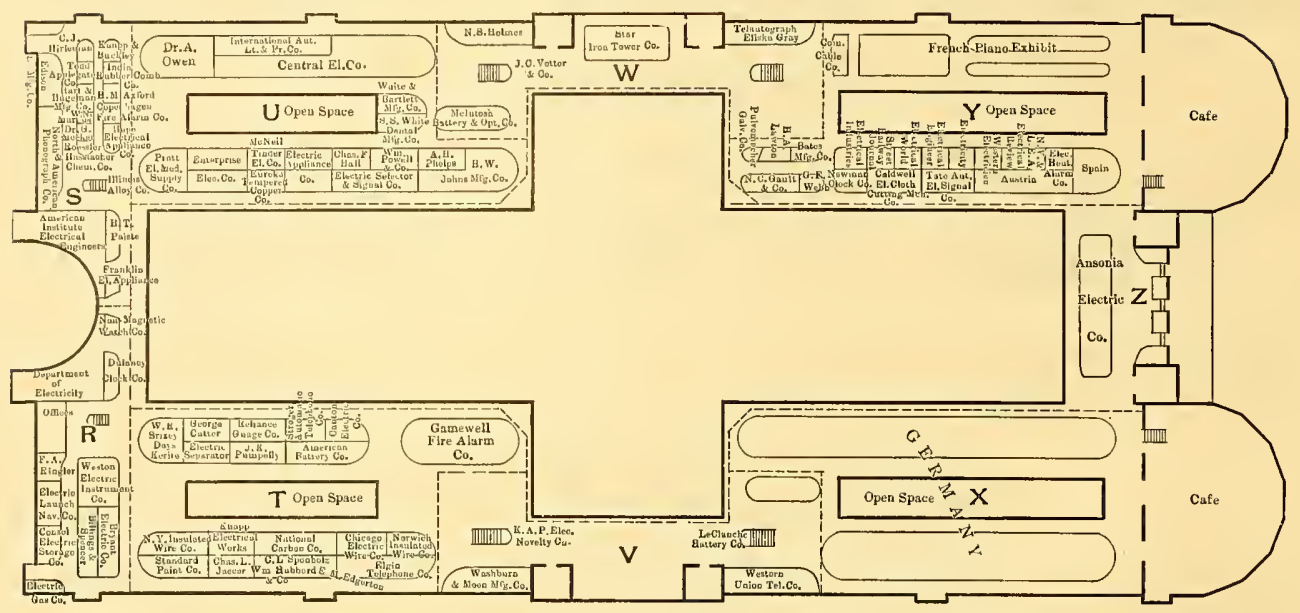

GALLERY.

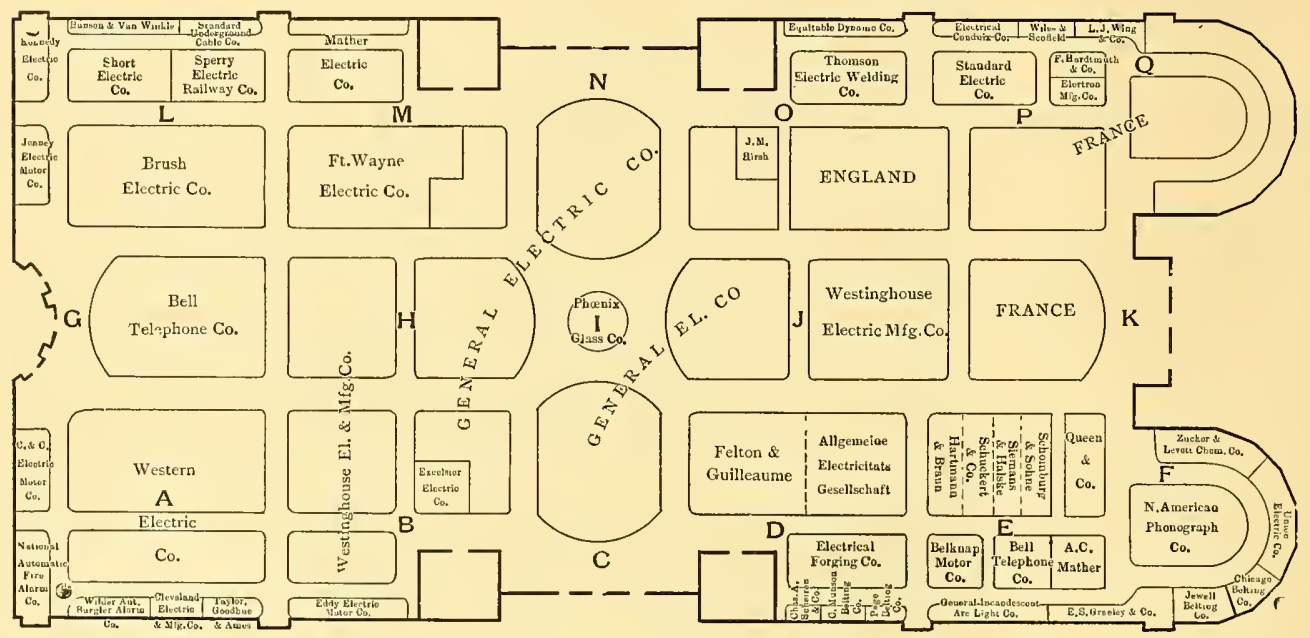

MAIN FLOOR.

\begin{tabular}{|c|c|c|}
\hline & & \\
\hline $\begin{array}{l}\text { Exhibitor. } \\
\text { A ustria }\end{array}$ & $\begin{array}{l}\text { Exhibitor. } \\
\text { Electrical Review...................Y Sectiun }\end{array}$ & $\begin{array}{l}\text { Exhihitor. } \\
\text { Jaeger, Chas. L........... }\end{array}$ \\
\hline & & \\
\hline Am. Inst. of Elec. Eng.. ............. & Electric Gas Co. & Jewell Belting Co... \\
\hline American Buttery Co............... T & Electrical Engineer & J. nuey Elec. Motor C \\
\hline Axford, $\mathrm{H}, \mathrm{M} \ldots$.......... & Electrical World ......... & Kuapp Eleotr \\
\hline illg. Elec. Gesellschaft.............. D & Eddy Electric Motor Co ... & K. A.P. Elec. Novelty Co \\
\hline Bates Mfg. Co.................... $\bar{Y}$ & Excelsior Electric Co...... & \& Bnckley ........... \\
\hline Bryant Electrie Co $\ldots \ldots \ldots \ldots \ldots \ldots$. & trical Forging $\mathbf{C}$............ & $\mathrm{El}$ \\
\hline Spencer.................. & Dynamo Co.......... & \\
\hline W. R................... & Elektron Mfg. Co.......... & loeche Battery Co... \\
\hline $\begin{array}{l}\text { Brlknap Motor Co............ } \\
\text { Bell Telephone Co........ }\end{array}$ & 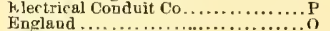 & Neil-Tinder Elec. Co. \\
\hline Co $\ldots . . . . .$. & $\begin{array}{l}\text { Englaud ....................... } \\
\text { Empire China Works. }\end{array}$ & r, Dr. G... \\
\hline Caldwell El. Cloth Cot. Mch. Co..... Y & anklin Elec. Appliances... & sh Bot. \& \\
\hline rage Co ........ & iano & \\
\hline Eut & pilleaume & \\
\hline Cag & Fr & Electric Co.. \\
\hline Co.......... & yoe Elec. Co & \\
\hline $\mathrm{a}$ Co. & , N. C.... & Watc \\
\hline 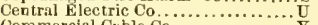 & larm Co & d Wi \\
\hline & $\mathrm{B}-\mathrm{H}-\mathrm{N}-\mathrm{C}-\mathrm{c}$ & $\mathrm{CO}$. \\
\hline & $y^{\prime} t$ Arc & ire co. \\
\hline g. Co & S., $\& \mathrm{Co}$ & Phonog \\
\hline & G & L. E. A... \\
\hline & $w \mathrm{~m}, \mathrm{~s}$ & Fire Alar \\
\hline city..... & & \\
\hline EL & $\mathrm{Ha}$ & \\
\hline & & \\
\hline & $\mathrm{F} .$. & H. T... \\
\hline & s... & nacher Gal \\
\hline Elg & $\&$ Br & \\
\hline Edi & Vinkle & d. Sup. \\
\hline & & n. 4 Co. \\
\hline Lo & H & \\
\hline & & Beltiog Co. \\
\hline $\begin{array}{l}\text { Elec, Sel. \& Sig'l Co } \\
\text { Electric Heat Alarm }\end{array}$ & $\&$ Pir Co........U & \\
\hline & & \\
\hline
\end{tabular}

Exhibitor. Section Roessler \& Hasslacher chem. Co....... Street Railway Journal.............. Standard Paint Co................... T Star Iron Tower Co................ schieren, Chas. A. \& Co .............. D schomburg \& sohue ..... . ........... She Short Electric Co... Elec Pgilway C............... Stavdard Uaderg. Cable Co.............. Standard Slectric Co... Samson Battery Co ..........

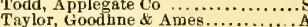
Thomson Elec. Welding Co .......... Teluatograph, Elisha Gray .........W Union Elestric Co ................. Webh, G. C. \& Co.................. Weston El. Jestrument Co............... Waebburn \& Moen Mfg. Co............ Western Union Tel, Co........... Waite \& Bartlett Mfg. Co............ Western Electrician ................. Wilder Ant. Burglar Al. Co. ......... A Westinghouse El. \& Mpg. Co ..... B. Ḧ-J Wiles \& Scofield ................... Zucker \& Levett Chem. Co............ 


\section{THE PACKARD LAMP AGAIN}

We are again supplying the celebrated Packard High Grade Lamp at a price below that ever quoted before on strictly high grade incandescent lamp. We are also

\section{GUARANTEEING AGAINST INFRINGEMENT}

suits, and furnishing a lamp, which for efticiency, long life, and non-discoloration has

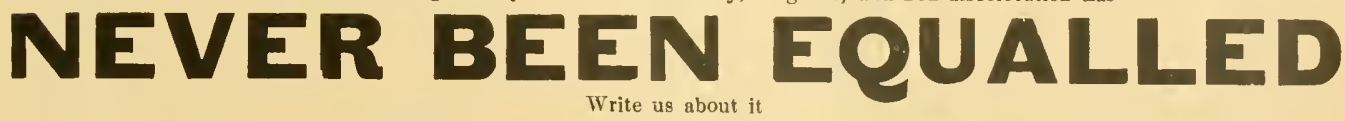

ELECTRIC APPLIANCE COMPANY, 242 Madison St., CHICAGO

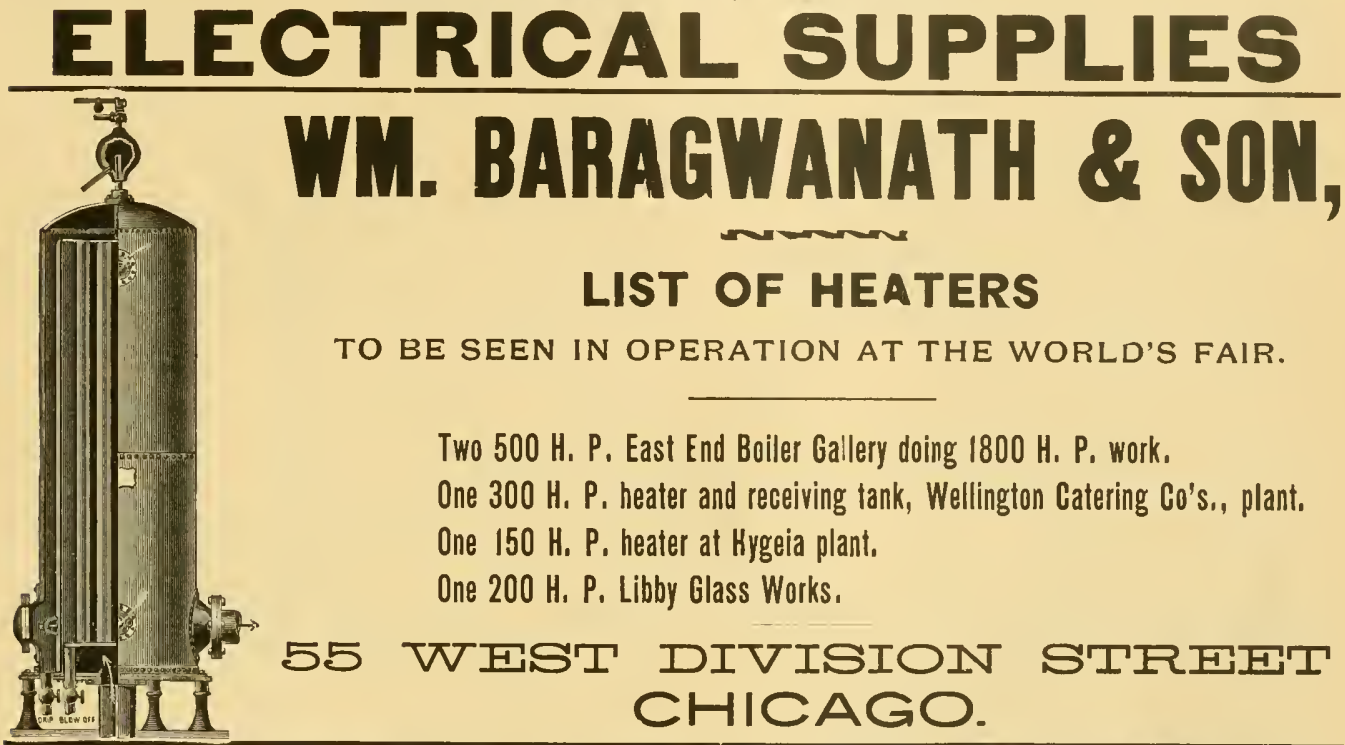

THE MONTHLY ISSUE FOR NOVEMBER

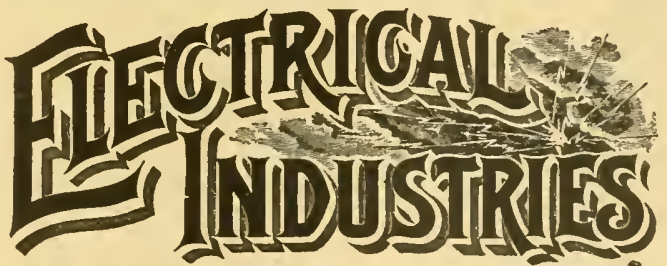

Should be read by everyone interested in electrical matters. In its Table of "Contents are the following:

"The Department of Electricity."

"The Convention of the American Street Railway Association."

"Power House Engines" by E. G. Connette.

"Use of Storage Batteries in Electric Generating Stations for Utilizing and Regnlating Power," by C. O. Mailloux.

"Street Car Magnetic Cut-Outs," by W. S. Harrington.

"Accident at Atlantic Avenue Power House."

"The St. Pancras Electric Lighting Station."

Together with illustrations of the recent applications of electricity.

The paper contains regularly

A Buver's Directory of Manufacturers and Dealers in Electrical Supplies and Appliances.

A Complete Directory of Electric Light Stations in North America and a Complete Directory of Electric Railways in North America.

These directories are revised each issue to the date of going to press and are to be found in no other electrical journal in the World. Its articles are read carefully and its directories used constantly by all the buyers in the trade. These facts make it without a superior as an advertising medium. Sample copies and rates sent on application

Subscription price $\$ 3$ per year.

\section{ELECTRICAL INDUSTRIES PUB. CO., Monadnock Block, CHICAGO.}


Map of Chicago.

Showing Location of its Electrical and Allied Business Interests, Principal Hotels, Theatres, Depots and Transportation Lines to the World's Fair Grounds. (Index numbers refer to the black squares.)
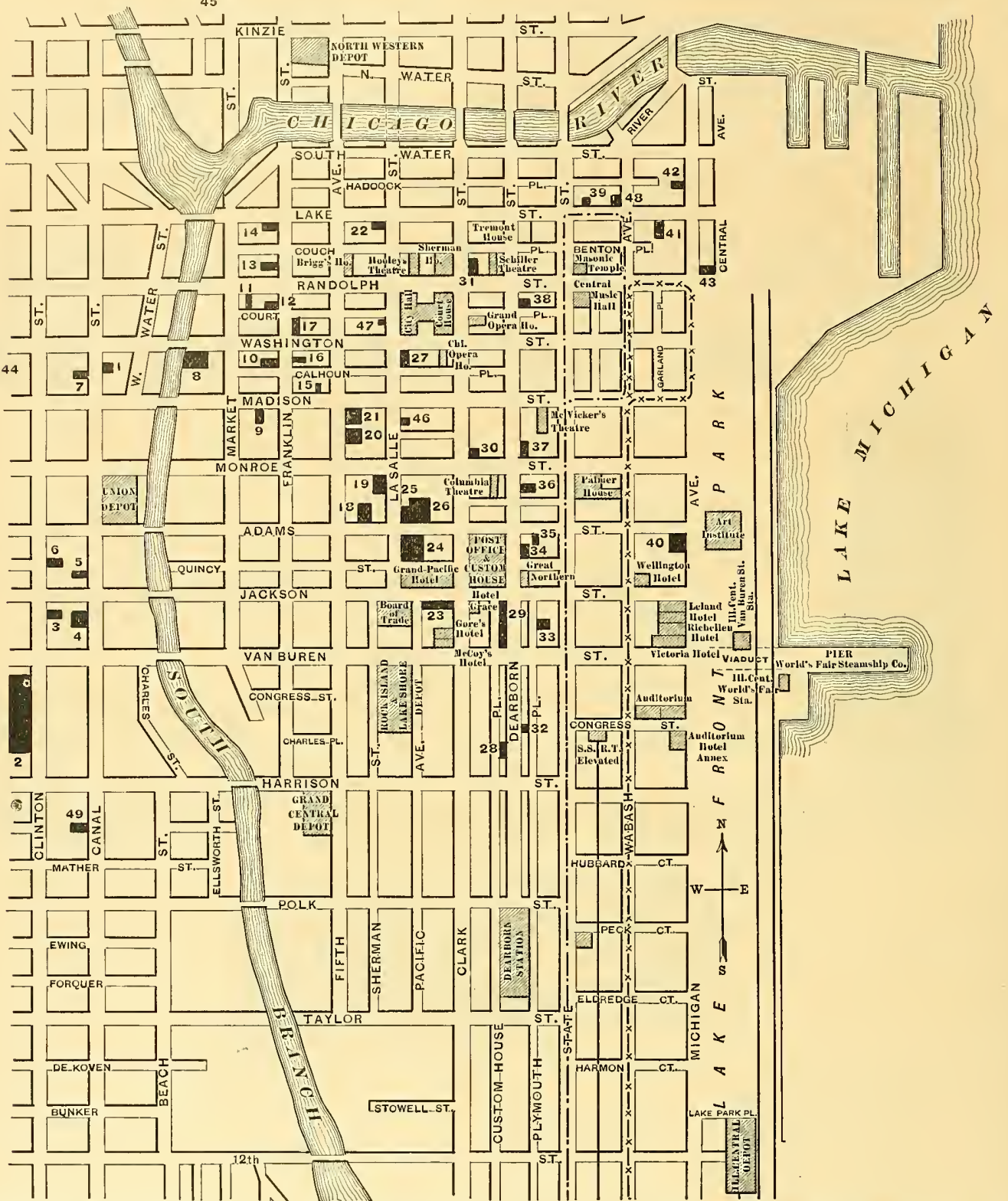

A nsouia El. e Co., Mlichigan Ave. \& Randoiph St....34 Cusbing \& Moree. 225 Dearborn St....

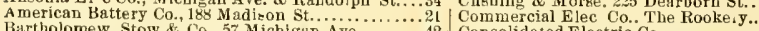

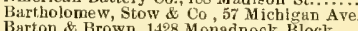
Barton \& Brown, 1428 Monadnock Block. Benham, A. D., 200 S. Clinton St Brill Co, J. G., Phenix Bldg.

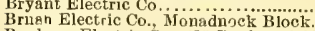

Bnckeye Electric Co. 43 \% Rookery Bldg.

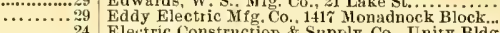

Electric Appliance Co., 242 Madifon St.

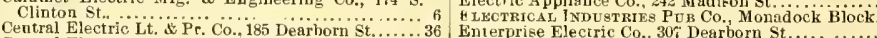

Central Electric Cn., 118 Frazklin St..................

Central Telephone Co..........................31 31 Globe ligbt \& Heat Co., 52 Lake St.....

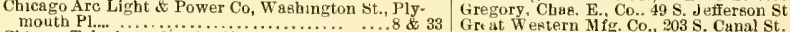

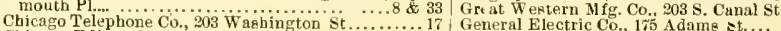

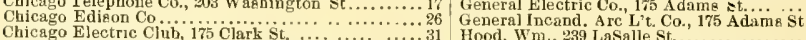

Chicago Electric Cluh, 175 Clark st.

Chicago Electrio Motor Co., $313 \mathrm{~s}$. Canal St.

49 Holtzer-Cabot Elec, Co., 307 Dearborn St.

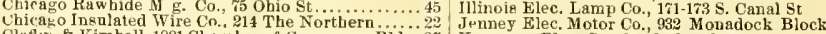

Claflin \& Kimball, 1001 Chamber of Commerce Bldg. 27 Keyatone Elec. Co., 345'S. Canal St

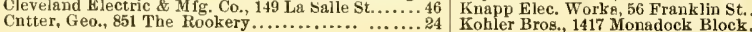

34. McDongall \& Cumminge, Tnity Bldg............ 38 \begin{tabular}{l|l} 
24 & McLean \& Schmitt, 195 S. Canal St............... 4 \\
16 & Matber Elec. Co., Chamber of Commerce Bldg.......20
\end{tabular} 15 New York Inenlated Wire Co., 80 Frankln St.......... it 9 (Postal Telegraph Co., Phenix Bldg....................... 1 Pullmnn's Palace Car Co.. Pullman Bldg..............4 Pumpelly, J. K., 205 S. Canal St..................40 Railway Equipment Co.. Pullman Bldg............48 Rockford Elec, \& IIfg. Co., 94 La Salle St...........47 Standard Elec. Co.. 625 Home Ins. B]dg..........25 Star Elec, Lamp Co., 805 Chamber of Com. Bldg.....27

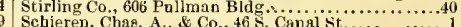
Scbieren, Chas. A., \& Co., $46 \mathrm{~S}$. Canal st ........... 1 Taylor, Goodhne \& Ames, 348 Dearhorn St.........28 Todd. Applegate Co., The, 340 Dearhorn St...........28

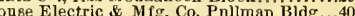
Western Electric Co, 227 S Clinton St..... Wolleneak, J. F., Lake and Franklin Ste............... 14 (13) 


\section{WE HAVE AT THE PRESENT TIME}

A STOCK OF ABOUT

\section{4,000 INSULITE SOCKETS OF THE}

SAWYER-MAN or WESTINGHOUSE STYLE.

THESE SOCKETS ARE WELL ADAPTED FOR USE IN

\section{DRY PLACES,}

a d we are prepared to offer the entire lot, or part of same, at ten cents each, net cash.

\section{WESTERN ELECTRIC CO.,}



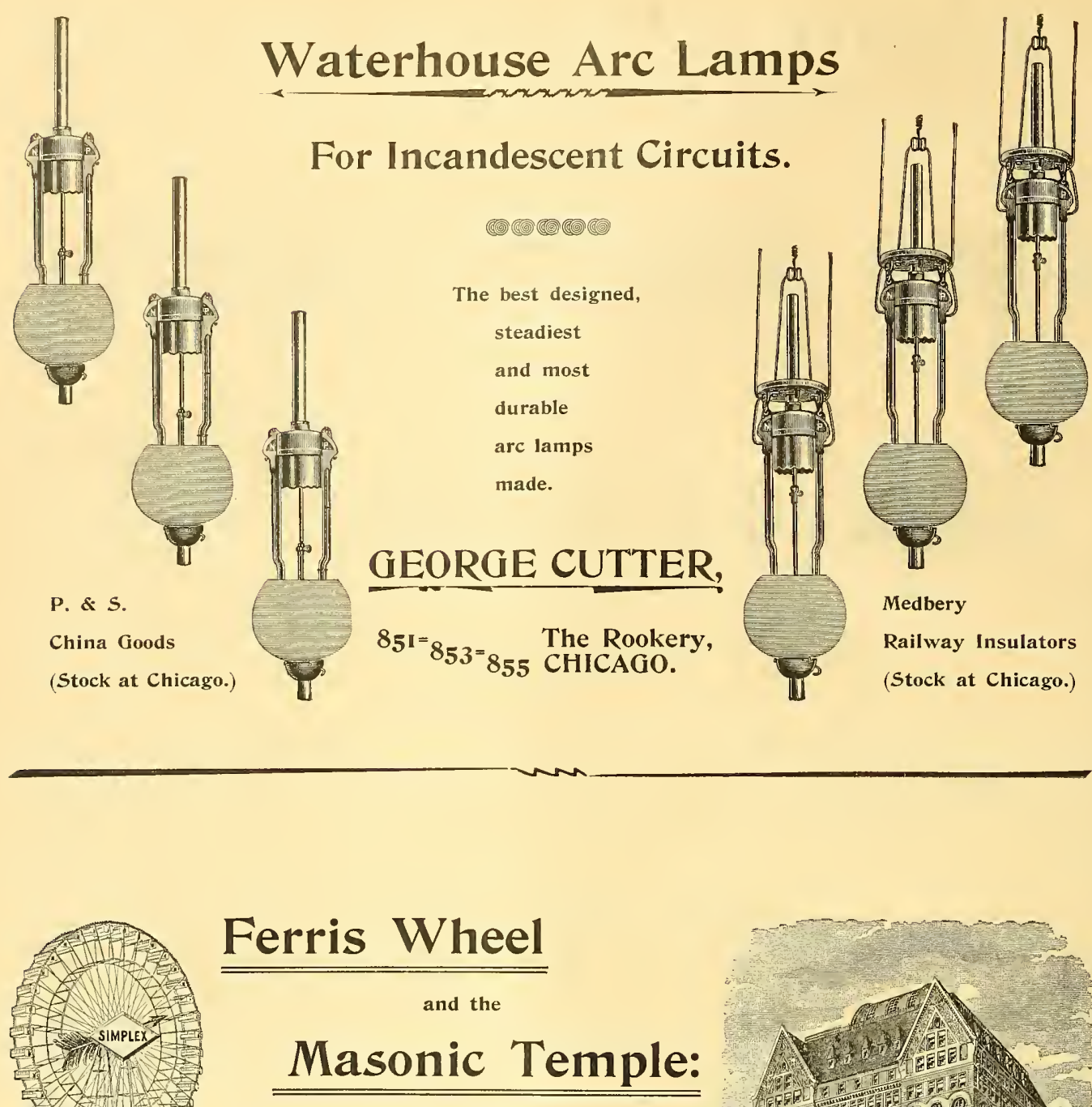

The tallest structures

of Chicago

of the World's Fair

Both wired with SIMPLEX

Simplex Electrical Co., 620 ATLANTIC AVENUE, BOSTON, MASS.

GEORGE CUTTER, 851-855 The Rookery, CHICAGO.

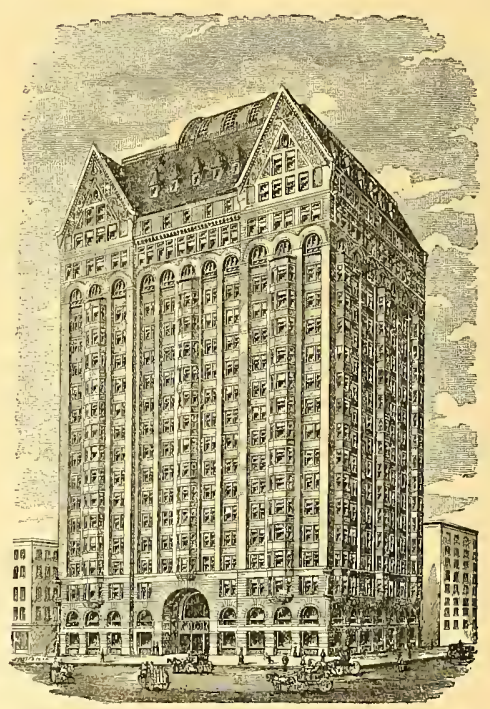


COMPANY, NEW YORK.

192 Broadway and II John Street.

MANUFACTURERS OF ARC LIGHTING APPARATUS FOR EVERY PURPOSE A SPECIALTY. The CLARK ARC LAMPS for use on EVERY CURRENT, have the reputation of being the best and most durable of any ever made in the United States.

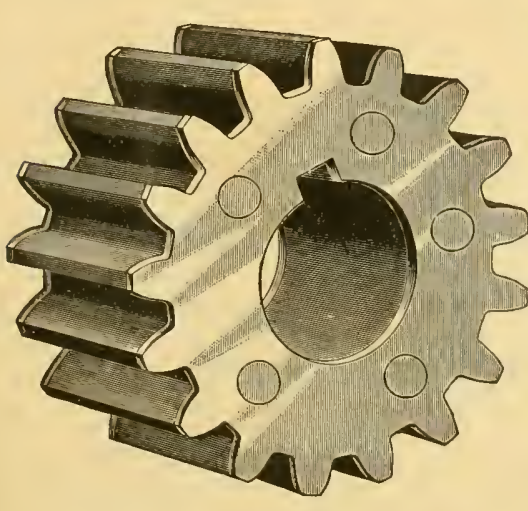

RAWHIDE PINIONS FOR ELEGTRIC MOTORS A SPECIALTY.

RAWHIDE DYNAMO BELTING

Greatest Adhesive Qualities. A Non-Conductor of Electricity Causes Less Friction than any other Belt.

THE CHICAGO RAWHIDE MANUFACTURING CO. THE ONLY MANUFACTURERS IN THE, COUNTRY.

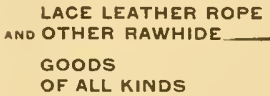

75 Ohio Street,
This Belting and Lace Leather is not affected by steam or dampness: never becomes hard; is stronger, ical Belting ande mo hide Rope for Round Beltin Transmission is siperior to all others

\section{Standard Electric Company.}

GENERAL OFFICES: 625 Home Insurance Building.

WORKS: So. Ganal Street,

\section{CHICAGo.}

\section{STANDARD SYSTEM}

AT THE

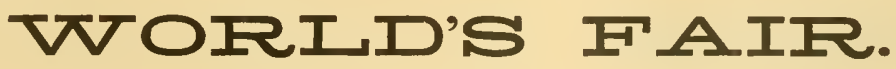

MACHINERY HALL, Sec. Q, 2 Standard Arc Dynamos.

Sec. S, 20 " " "

ELECTRICIT Y BUILDING. Sec. P, Space 2, Arc Lighting Exhibit.

The Standard Lamps Light the Power Plant, Machinery Hall, Agricultural Hall, Shoe and Leather Building, ard Other Buildings and Portions of the Grounds. 


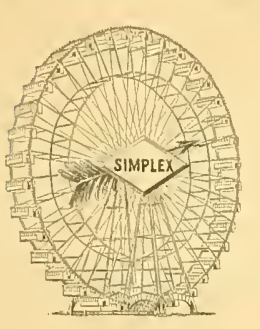

Mile after mile of

\section{SIMPLEX WIRE}

Supplied to the

FERRIS WHEEL.

By...George Cutter,

ori The Rookery, CHICAGio.

\section{SIMPLEX WIRES}

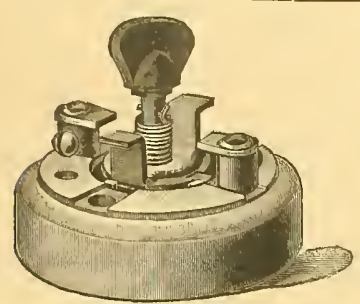

Made 5 amp. S. P.

15 amp. 3 way.

\section{XNTRIC}

"That's the Switch"

And we control that movement.

H. T. PAISTE.

10 South I- th St., PHILADELPHIA, PA.

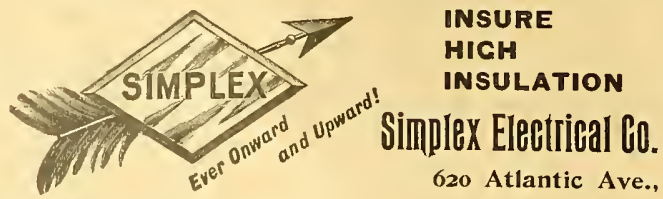

George Cutter, Chicago. Boston, MAss.

\section{Enterprise Electric \\ Company \\ 207 Dearborn Street. Chicago ..... \\ Manufaoturers' Agents and Mill Repre. sentatives for \\ Electric Railway, -o \\ Telegraph, Telephone and Electric Light \\ SUPPLIES $S_{\text {or evear }}$

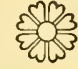 \\ Agents for Cedar Poles, \\ Cypress Poles, Oak Pins, Locust Pins, Cruss Arms, Class Insulators, \\ WIRES, CABLES, TAPE and TUBING}

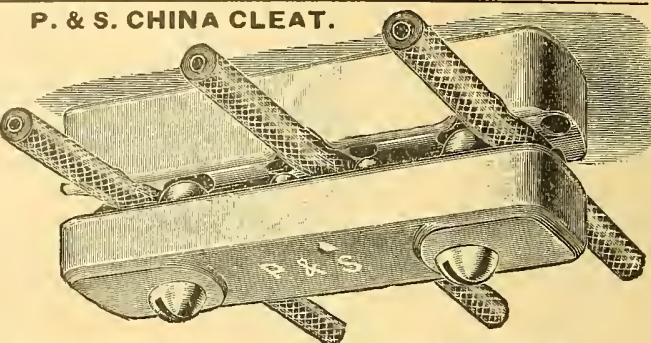

George Cutter, CHICAGO.

SYRACUSE, $N$ Y

\section{Miamisburg Electric Co.}

MANUFACTURERS OF

COMMUTATORS

\author{
AND
}

COMMUTATOR SEGMENTS OF TEMPERED COPPER FOR STREET RAILWAYS

Also Brushes and Brush Copper, BURNLEY'S GARTRIDGE BATTERIES and IMPERIAL DRY BATTERIES.

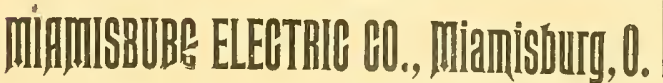

\section{BEAR IN MIND}

that the regular monthly issue of ELECTRICAL IN. DUSTRIES contains the most complete and correct directories published of the electric light central siations and the electric railways in North America.

World's Fair Hadquarters Y 27 Elec ricity Building.

CITY OFFICES, Monadnock Block.

Consolidated Elpctric 6.

Mandfacturers and Deaters in all kinds of

\section{ELECTRICAL . SUPPLIES,}

115 Franklin Street,

CHICACO. 



SMTHSONIAN INSTTUUTION LIBRARIES
SWH 